\title{
EL PROYECTO DE \\ LA CASA DE LUDWIG WITTGENSTEIN EN SKJOLDEN, NORUEGA
}

TESIS DOCTORAL

Autor: Enrique Clemente Quintana

Arquitecto

Director: Dr. Jorge Torres Cueco

Catedrático de Proyectos Arquitectónicos · ETSAV · UPV

Valencia, 7 de septiembre de 2015

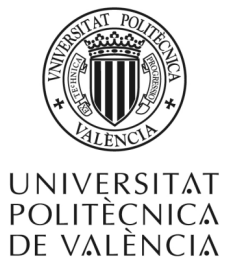

DEPARTAMENTO DE PROYECTOS ARQUITECTÓNICOS · ESCUELA TÉCNICA SUPERIOR DE ARQUITECTURA DE VALENCIA • UPV 
Universidad Politécnica de Valencia

Escuela Técnica Superior de Arquitectura

Departamento de Proyectos Arquitectónicos | Programa: Proyectar desde el territorio una mirada moderna | R.D. 778/1998

TESIS DOCTORAL_ID 9158 Enrique Clemente Quintana_fecha depósito 11/09/2015 


\section{Tribunal y lectura de la tesis doctoral}

El acto de lectura de la presente Tesis Doctoral se ha producido a las 11:00 del día 6 de octubre de 2015, en el Salón de Grados de la Escuela Técnica Superior de Arquitectura de Valencia, ante el Tribunal nombrado por el Magfco. Y Excmo. Sr. Rector de la Universidad Politécnica de Valencia previo depósito en la Escuela de Doctorado de la Universidad Politécnica de Valencia:

Presidente: D. Juan Calatrava Escobar, Catedrático de Composición Arquitectónica e Historia de la Arquitectura, Universidad de Granada.

Secretario: D. Juan Deltell Pastor, Profesor Titular de Universidad, Departamento de Proyectos Arquitectónicos, Universidad Politécnica de Valencia.

Vocal: D. Julián Marrades Millet, Catedrático de Filosofía, Departamento de Metafísica y Teoría del Conocimiento, Universidad de Valencia.

Calificación: Sobresaliente Cum Laude. 

En 1914, el filósofo Ludwig Wittgenstein (1889-1951) proyectó e inició la construcción de una casa de madera en la escarpada ladera del lago Eidsvatnet en Skjolden, Noruega. En esa pequeña villa, Wittgenstein había encontrado la tranquilidad necesaria para trabajar en lógica. Sin embargo sus planes de instalarse en Noruega se vieron truncados por el estallido de la Primera Guerra Mundial y sólo ocupó la casa en algunas visitas a lo largo de su vida, la última de ellas cinco meses antes de morir en Cambridge. Pese a ello, la casa de Skjolden fue central en el desarrollo del pensamiento de Wittgenstein y el único lugar en el que de verdad se sintió capaz de trabajar. Hasta hoy, la relación entre Wittgenstein y la arquitectura se había limitado a la casa de Viena que construyó para su hermana Margaret en 1929 en colaboración con el arquitecto Paul Engelmann. Esta tesis desarrolla por primera vez el proyecto de la única casa que el filósofo pensó y construyó para sí mismo, certifica su compromiso ético con la arquitectura, recalifica como hiciera Loos, la arquitectura vernácula y plantea elementos que anticipan soluciones que aplicaría años más tarde en la casa de Viena.

In 1914, the philosopher Ludwig Wittgenstein (1889-1951) designed and started to build a timber house on the steep hillside of Lake Eidsvatnet in Skjolden, Norway. In this small village, Wittgenstein had found the peace that he considered essential to his work on logic. But his plans to settle in Norway were cut short by the outbreak of World War I and he only occupied the house during visits at various but important stages of his life, the last of them only five months before his death in Cambridge. Nevertheless, the Skjolden house was central to the development of Wittgenstein's philosophical thought and represented the only place he really felt capable of working. To date, understanding of the relationship between Wittgenstein and architecture has been determined by research on the 1929 house in Vienna, which was built for his sister Margaret, in collaboration with the architects Paul Engelmann and Jacques Groag. My work details, for the first time, the project of the single house that the philosopher conceived and built for himself. The Skjolden house certifies Wittgenstein's ethical commitment to architecture, which is independently reclassified as vernacular architecture to that espoused by Adolf Loos and anticipates solutions that Wittgenstein applied later to the house in Vienna.

En 1914, el filòsof Ludwig Wittgenstein (1889-1951) va projectar i va iniciar la construcció d'una casa de fusta a l'escarpada vessant del Ilac Eidsvatnet a Skjolden, Noruega. En aquest xicotet poble, Wittgenstein havia trobat la tranquil.litat necessària per treballar en lògica. No obstant això, els seus plans d'instal.lar-se a Noruega es van veure truncats per l'esclat de la Primera Guerra Mundial i només va ocupar la casa en algunes visites al llarg de la seva vida, l'última només cinc mesos abans de morir a Cambridge. Malgrat això, la casa de Skjolden va ser central en el desenvolupament del pensament de Wittgenstein i l'únic lloc en què de veritat es va sentir capaç de treballar. Fins avui, la relació entre Wittgenstein i l'arquitectura s'havia limitat a la casa de Viena que va construir el 1929 junt a l'arquitecte Paul Engelmann per a la seua germana Margaret. Aquesta tesi desenvolupa per primera vegada el projecte de l'única casa que el filòsof va pensar i va construir per a si mateix, certifica el seu compromís ètic amb l'arquitectura, requalifica, com va fer Loos, I'arquitectura vernacla i planteja elements que anticipen solucions que aplicaria més endavant a la casa de Viena. 

A Eva y mis hijos, sin duda 
Las palabras que siguen, en su brevedad, no hacen justicia al sincero agradecimiento que siento hacia las personas que nombraré y también, sin excepción, a las que no. Sin todas y cada una de ellas este trabajo no habría podido existir:

A mi director de tesis Jorge Torres Cueco por su paciencia infinita y los sabios consejos dados, que debía haber seguido mucho antes.

A Enok Kippersund, porque contestó a un completo desconocido y me permitió dar con las personas adecuadas, nada menos.

A Knut Olav Åmås por su amabilidad y colaboración en las primeras fases de la investigación.

A Paul Wijdeveld por su comprensión y enorme generosidad compartiendo conocimiento.

A David Connearn por su pasión en esta investigación, por todo lo dado, que es muchísimo y por lo que todavía esté por venir. Tanto es, que no ha cabido en una única tesis.

A Dawn Wilson por su capacidad para encontrar el detalle y el matiz adecuado y saber ver la profundidad de las cosas con claridad.

A Harald Vatne, porque aunque no haya sido consciente de ello, el misterio me ha estimulado a seguir adelante.

A Michael Nedo, por los imprescindibles comentarios, por abrirme su hermosa casa y por la inesperada y plena confianza hacia un incompetente en lo que él es un maestro.

A Alois Pichler por atender mis consultas con cariño pese a ser siempre excesivas.

A Andrea Lamas Domingo por su ayuda en la emocionante fase terminal de la tesis, por su derroche de energía y competencia como arquitecta.

A mi amigo y compañero en este viaje, Francisco J. Nieto, por presentarme a Wittgenstein y por tanto ser responsable de que esta tesis haya terminado por ocurrir. Por su constante apoyo y comprensión incondicional mucho más allá de lo que la amistad obliga.

A mi familia de nuevo y sobre todo, por consentir que siguiera adelante, pese a que el único beneficiado haya sido yo mismo.

$Y$ a todo aquel que, sin estar expresamente nombrado y sepa que le debo un agradecimiento, porque seguro que es así. 


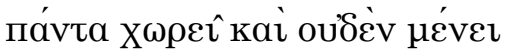

Nada permanece fijo ni estable. Todo fluye.

(Platón, Crátilo 402a) 


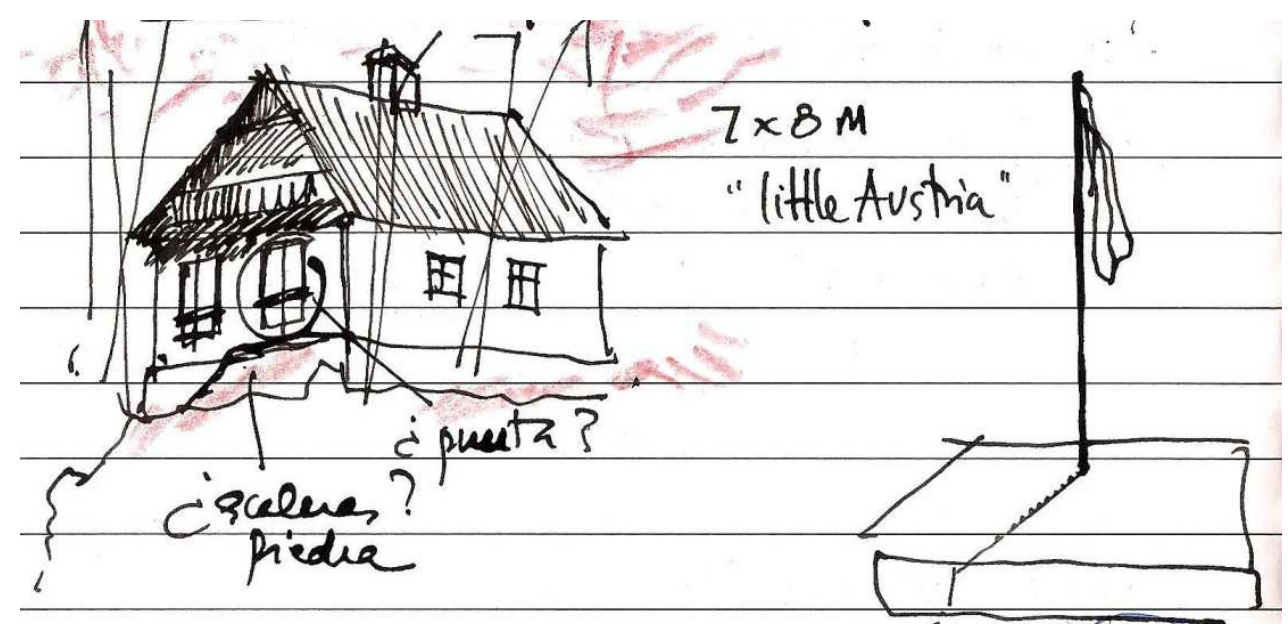

1. Primer dibujo en el cuaderno «proyecto Wittgenstein en Skjolden», 2010 
01. INTRODUCCIÓN

Una casa para una tesis 13

Motivación $\quad 21$

$\begin{array}{ll}\text { Estado de la cuestión } & 27\end{array}$

Fuentes de la investigación $\quad 39$

Metodología y estructura de la investigación 47

02. CONTEXTUALIZACIÓN

Ludwig Wittgenstein en Noruega $\quad 65$

Skjolden. Espacio y tiempo 105

Referentes. Arquitectura vernácula y ética 113

03. PROYECTO DE LA CASA DE WITTGENSTEIN EN SKJOLDEN

$\begin{array}{ll}\text { Paisaje } & 137\end{array}$

$\begin{array}{ll}\text { Investigación gráfica } & 147\end{array}$

$\begin{array}{ll}\text { Habitar la soledad } & 179\end{array}$

Elementos de composición 193

$\begin{array}{ll}\text { Elementos de construcción } & 217\end{array}$

04. EPÍLOGO

A modo de cierre 299

$\begin{array}{ll}\text { Reconstruyendo Østerrike } & 309\end{array}$

05. ANEXOS

Documentación gráfica adicional. Planos y material inédito 321

Bibliografía $\quad 345$

Listado de imágenes, planos y esquemas 357

Textos traducidos 369 

01 INTRODUCCIÓN 

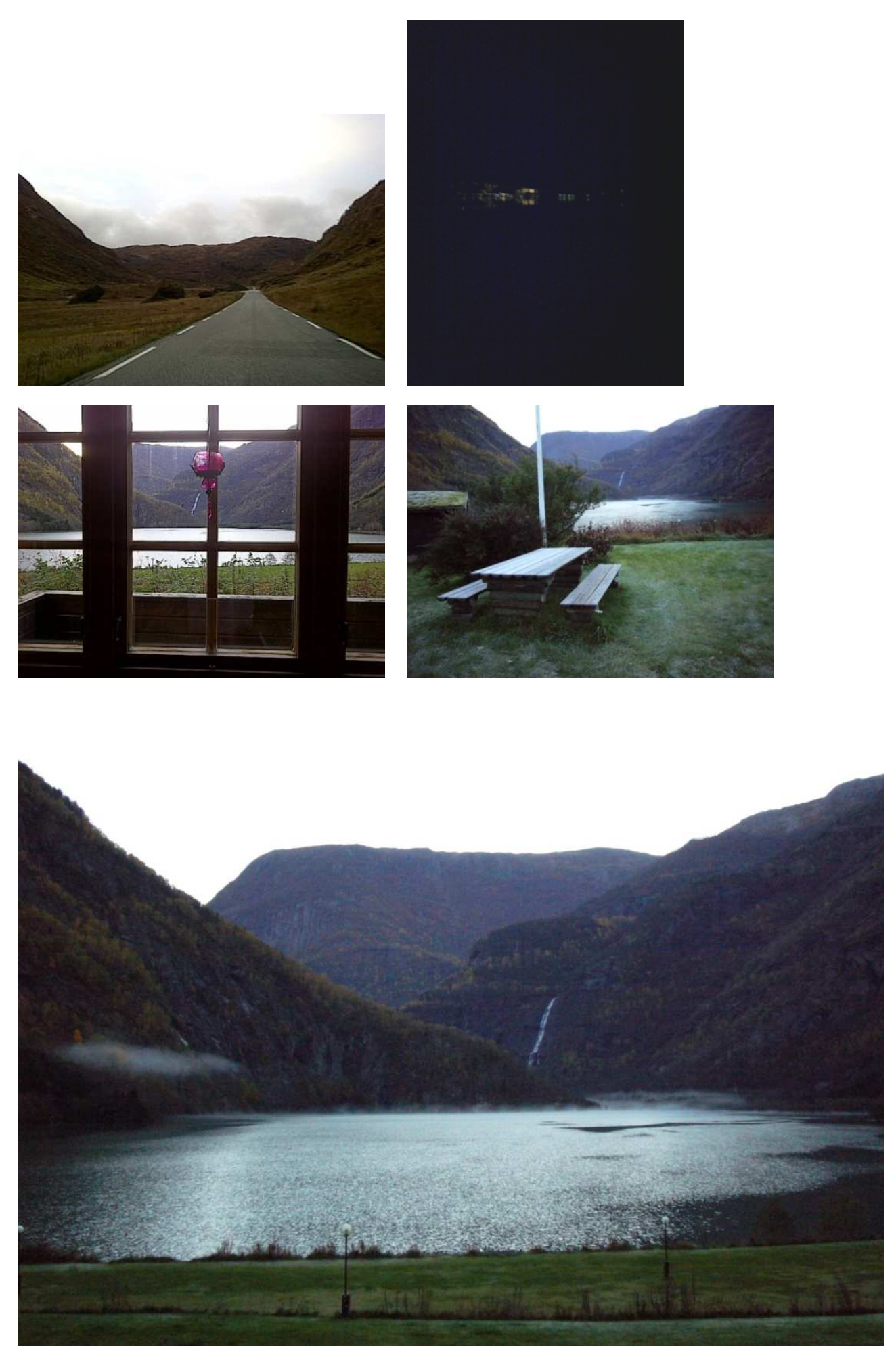

2. Voss 18:14, 09.10.2013 | 3. Skjolden 21:51, 09.10.2013

4. Skjolden 07:48, 10.10.2013 | 5. Skjolden 08:12, 10.10.2013

6. Skjolden, lago Eidsvatnet 08:41, 10.10.2013 


\section{Una casa para una tesis}

«Jueves, 10.10.2013

Skjolden. Nymoen Leirplass. Cabaña no 11. Up 7:30 am.

Anoche llegué a Skjolden en coche sobre las 22:00h, tras casi seis horas de viaje por carreteras de montaña, durante las cuales apenas encontré tráfico. Es curioso que en Noruega las carreteras físicas se interrumpan en los fiordos pero aparezcan dibujadas en los mapas sobre el agua; un servicio de ferry transborda los coches de una orilla a la otra, así que la carretera realmente no termina, cambia de medio. De las dos rutas posibles desde Bergen tomé la de Vik que era algo más corta. Crucé el fiordo entre Vangsnes y Hella. Aquí la tarde cae rápidamente y de repente era de noche, no se veía casi nada, sólo siluetas de montañas por todas partes recortadas sobre un fondo azul oscuro. Extraña sensación la de estar dentro de un coche que a su vez está dentro de un ferry. Hoy me he despertado un poco desorientado, anoche encontré el camping de milagro a la primera, no era difícil, pero ya me costaba gran esfuerzo seguir conduciendo. Tal y como Barbra me había indicado, sólo mi cabaña tenía la luz encendida -también la calefacción, por suerte- y las llaves puestas. Como había poca iluminación exterior aparqué junto a la cabaña y cargué con la maleta casi a tientas por lo que parecía una pradera. Estaba todo muy húmedo, lo notaba en los pies. Me acosté enseguida, sin deshacer el equipaje. Sólo di un vistazo rápido a la cabaña, salón con cocina, dormitorio, baño. Quería posponer el momento de verlo todo hasta hoy. Estaba tan cansado que evité que la primera imagen de mi llegada se viera alterada por ello. Al despertar y salir a la sala, me he encontrado frente al lago y tengo unas vistas impresionantes sobre él, las montañas que lo rodean y sobre el plinto de la casa de Wittgenstein que veo, no sin dificultad, al fondo, sobre el escarpe de la orilla. Hay niebla a ras del agua, precisamente en el fondo del lago, donde asoma el río y estaba la casa. Hace frío fuera, puedo respirar el frío. Está todo escarchado.

Ayer seguí leyendo a Thoreau en el avión y subrayé lo siguiente que anoto ahora aquí: "Por mi parte, le pido a todo escritor, que antes o después, nos cuente su propia vida, y no simplemente lo que haya podido oír de las vidas de otros; como si tuviera que contarlo a sus seres queridos desde alguna tierra lejana; porque si ha vivido de forma sincera lo ha hecho desde allí."

Hoy es la primera jornada hábil en Noruega. Puedo sentir esa lejanía de lo cotidiano, en el paisaje, el frío y el silencio. No es sólo sensorial, puedo percibir de alguna manera la distancia geográfica, como una agradable euforia, creo. Estoy deseando ir a ver los restos de la casa pero antes voy a llamar a Vatne y ver si podemos quedar. Necesito ir a comprar algo de comer al pueblo. Ahora debo salir a presentarme a Barbra y de paso preguntar dónde puedo desayunar.[...]»1

\footnotetext{
${ }^{1}$ Diario personal de viaje. Entrada (parcial) del 10.10.2013: Primer paseo por Skjolden para componer mentalmente el lugar; adquisición de provisiones (pan de centeno, queso, pasta, salsa pesto, manzanas, té y cerveza); entrevista con Harald Vatne 11:30-13:45; primera visita a los restos de la casa en el lago 14:15-18:00. N.B. Escribir un diario es un ejercicio de disciplina que requiere un esfuerzo mayor del proyectado, y no sólo físico.
} 
The Wittrenstein's site

Latitud $=61.48740$

Longitud $=7.63137$
Alt $=(105 \mathrm{~m} !)$

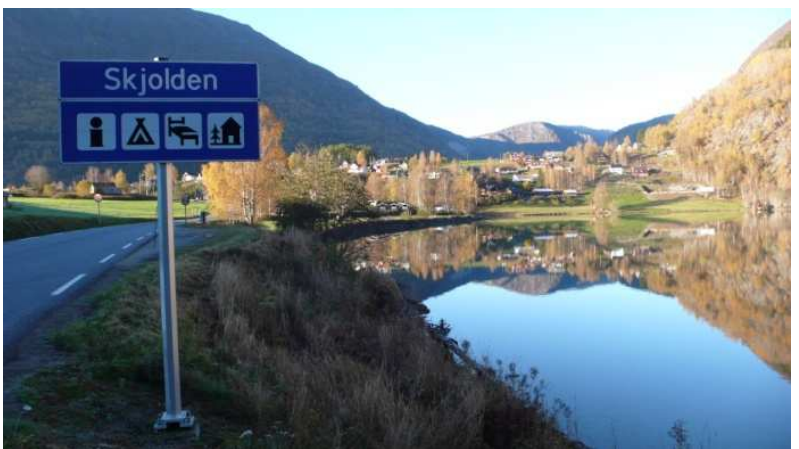

$\frac{\log _{3}}{3^{2}}$
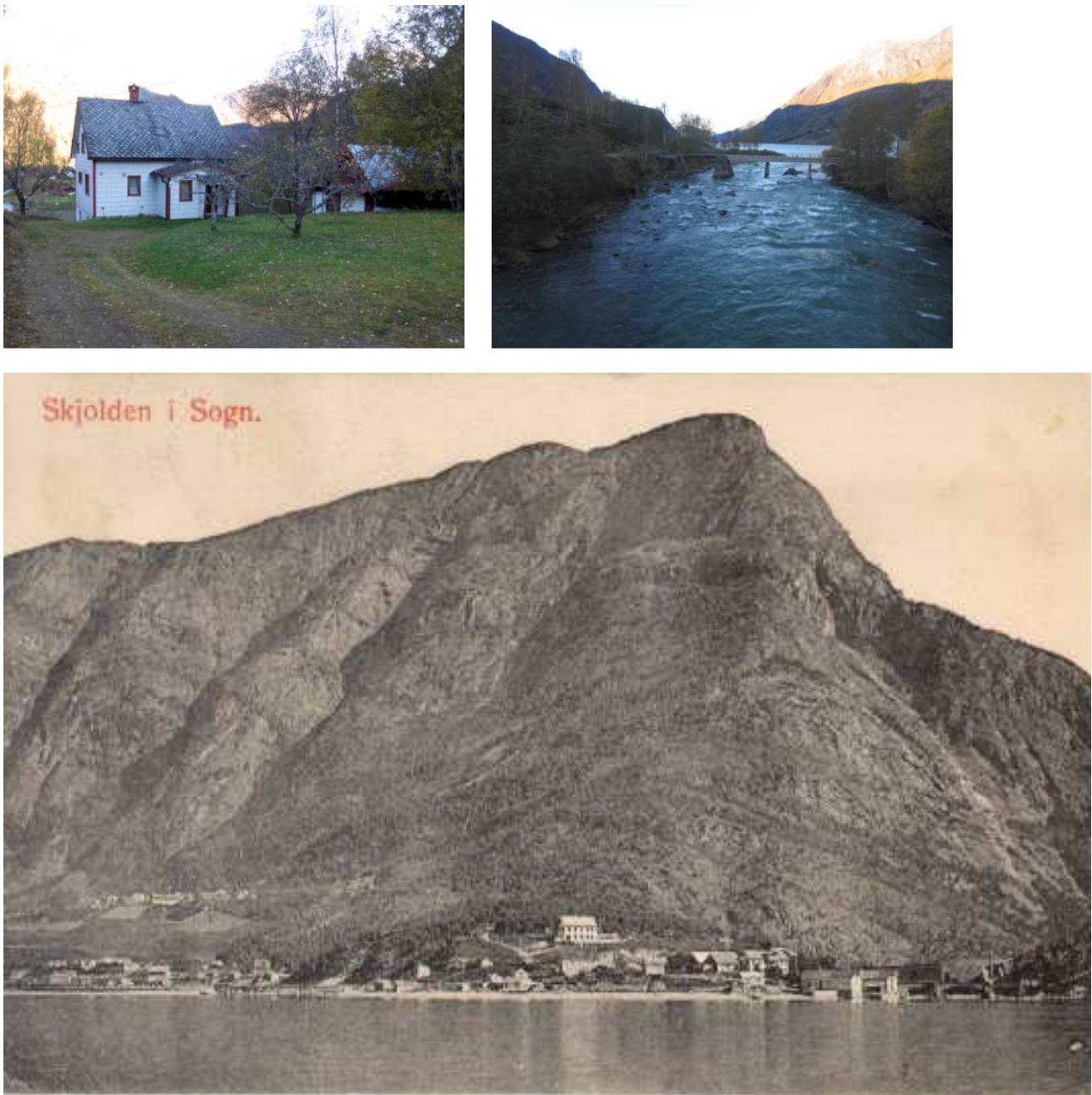

7. Skjolden, Rv55 a Lom | 8. Coordenadas Casa de Wittgenstein en Skjolden

9. Casa de Gunnar Bolstad | 10. Puente sobre río Eidselvi

11. Tarjeta postal de Halvard Drægni y la familia Klingenberg a Wittgenstein, 21.12.1914 
Arranca así, un viaje ${ }^{2}$ con el objetivo de documentar la casa de Ludwig Wittgenstein en el pueblo noruego de Skjolden.

Viajar, a veces geográficamente y casi siempre antes, sin escapar del escritorio propio, a través de los libros o de las redes virtuales, es el material que estructura la urdimbre de esta investigación y lo que ha permitido que se haya alcanzado alguna conclusión. No representa por tanto un trabajo compilatorio sino proyectual, un periplo que establece unas reglas, un discurso y un deseo.

El necesario camino recorrido por los distintos escenarios del mundo Wittgenstein, ha permitido conocer lugares y personas pero nunca recrear sensaciones. El ingenuo peregrino filosófico ${ }^{3}$ que se acerca a Skjolden en busca de Wittgenstein, no lo encuentra. Tampoco este autor ha tratado aquí de lograrlo. Se presenta este trabajo como una investigación arquitectónica, en el que sin embargo el texto tendrá tanto peso como lo dibujado. Wittgenstein fue una persona de carácter y obra poliédrica, y cualquier aproximación a su intelecto no se puede abordar de otro modo.

Es reconocida la impericia de los arquitectos, cuando menos la del que escribe estas líneas, por pretender trasuntos de otras actividades intelectuales a la disciplina que les es propia, incluida la escritura. Se tratará aquí de no centrar el discurso en el esbozo biográfico, tampoco en el estudio meramente historiográfico y menos aún dilucidar cuestiones pertenecientes a la escurridiza lógica, a la metafísica o a la filosofía del lenguaje. Ha habido un intento consciente de soslayar la tentación de abordar este proyecto a través del atractivo aforístico de la obra y la mítica personalidad de Wittgenstein. ${ }^{4}$ A pesar

\footnotetext{
2 Vamos a considerar esta fase de la investigación como un segundo plan de viaje. El primero, como se explicará en breve queda determinado por lo investigado antes de julio de 2012.

${ }^{3}$ La red está preñada de bitácoras que relatan visitas a los restos de la casa de Wittgenstein. En el Seminario Internacional Wittgenstein que cada mes de abril o mayo (en 2015 ha tenido lugar la quinta edición) se realiza en el Walaker Hotell de Solvorn, organizado por Knut Olav Åmås se gira una visita-excursión (opcional) hasta el lugar. Con anterioridad el profesor Johannessen de la Universidad de Bergen organizaba un seminario de similares características en Skjolden desde los años noventa. En el lugar de la casa, protegida bajo una piedra, cerca de la esquina noreste del plinto de piedra, encontramos una caja hermética con una libreta de firmas. Durante la visita de octubre de 2013, quedaban restos de una instalación artística realizada por un estudiante de la universidad de Oslo.

${ }^{4}$ El profesor Eduardo De Bustos advierte al estudiante de filosofía: «Tampoco es recomendable leer previamente sobre la figura de L. Wittgenstein, pues es muy corriente que la fascinación que ejerce el personaje constituya un obstáculo para la comprensión y valoración de su obra.» Eduardo De Bustos Guadaño, "Teoría general del simbolismo en el Tractatus de L. Wittgenstein", en Filosofía del lenguaje, (Madrid: UNED, 1999), p. 331.
} 

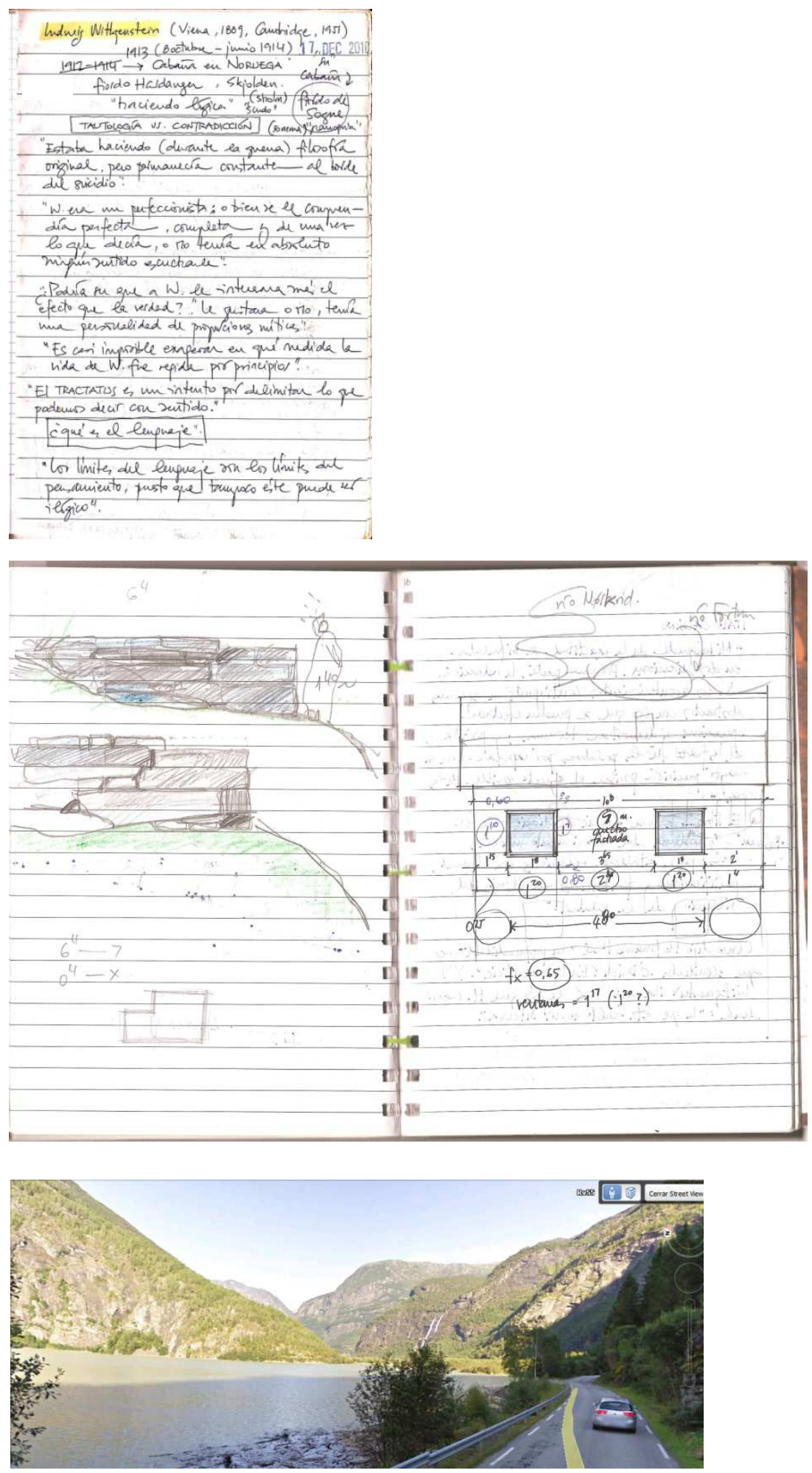

12. Cuaderno notas, 17.12.2010

13. Cuaderno notas, sin fecha

14. Visita virtual al lago Eidsvatnet con google earth, 2010 
de ello conviene advertir que en alguna sección puedan quizá filtrarse elementos extra-arquitectónicos, sin otra intención que el aclaramiento ${ }^{5}$ de algún pasaje o como respaldo de alguna sección del discurso. Y es que en definitiva separar al Wittgenstein filósofo del Wittgenstein intelectual es tarea ímproba, pues todo en su vida, como él mismo describía su labor en 1931, aparece como una única amalgama: «[...]Cuando yo have done with the world, habré creado una masa amorfa (transparente), y el mundo, con toda su complejidad, se quedará a un lado, como un cuarto trastero nada interesante. $»^{6}$

La presente tesis se ha titulado pragmáticamente ${ }^{7}$ «El proyecto de la casa de Ludwig Wittgenstein en Skjolden, Noruega». Este trabajo desarrolla -corrige y modifica profundamente- un trabajo de investigación previo realizado con el mismo título, para la obtención del Diploma de Estudios Avanzados ${ }^{8}$. Precisamente por el marco en el que se inscribe, en una escuela de arquitectura, debe considerarse un proyecto. Además el objeto del mismo es la necesidad primigenia del refugio, es el proyecto de una casa.

La casa de Ludwig Wittgenstein en Skjolden, es la única que poseyó en su vida. Hasta ahora, los intentos por entender las lecturas que el filósofo hizo de la arquitectura se habían focalizado en la casa que construyó entre 1926-1929 para su hermana Margaret en Viena, la conocida como Kundmanngasse 19 o Casa Wittgenstein. Esta tesis pretende responder a un objetivo único: la definición completa de un proyecto constructivo de la casa de Wittgenstein en Skjolden. Pero esta senda aparentemente lineal se verá ampliada en un paisaje de significados. Veremos que Wittgenstein anticipa planteamientos de arquitectura ética, que Loos definiría en sus escritos como vernácula, quedarán ya aquí establecidas líneas teóricas del pensamiento arquitectónico de Wittgenstein que hasta ahora se habían analizado únicamente en la casa de Viena de su hermana,

\footnotetext{
5 «Acción y efecto de aclarar.» DRAE (22a Ed.), voz «aclaramiento». Traído aquí inevitablemente por ser el principal y único objetivo de toda la obra de Wittgenstein: «Todo lo que, en suma, puede pensarse, puede pensarse claramente. Todo lo que puede formularse en palabras, puede formularse claramente.» (Tractatus, §4.116)

${ }^{6}$ Ludwig Wittgenstein, Observaciones diversas. Cultura y valor, §42; en Wittgenstein, vol.2, (Madrid: Gredos, 2009), p.571-572

${ }^{7}$ Pragmático en su sentido literal de «basado en la utilidad, para caracterizar la verdad o el significado de las cosas».

8 Trabajo de Investigación, realizado entre 2010-2011, Departamento de Proyectos Arquitectónicos, UPV. Director Dr. Jorge Torres Cueco. Defensa y obtención del DEA en julio 2012.
} 

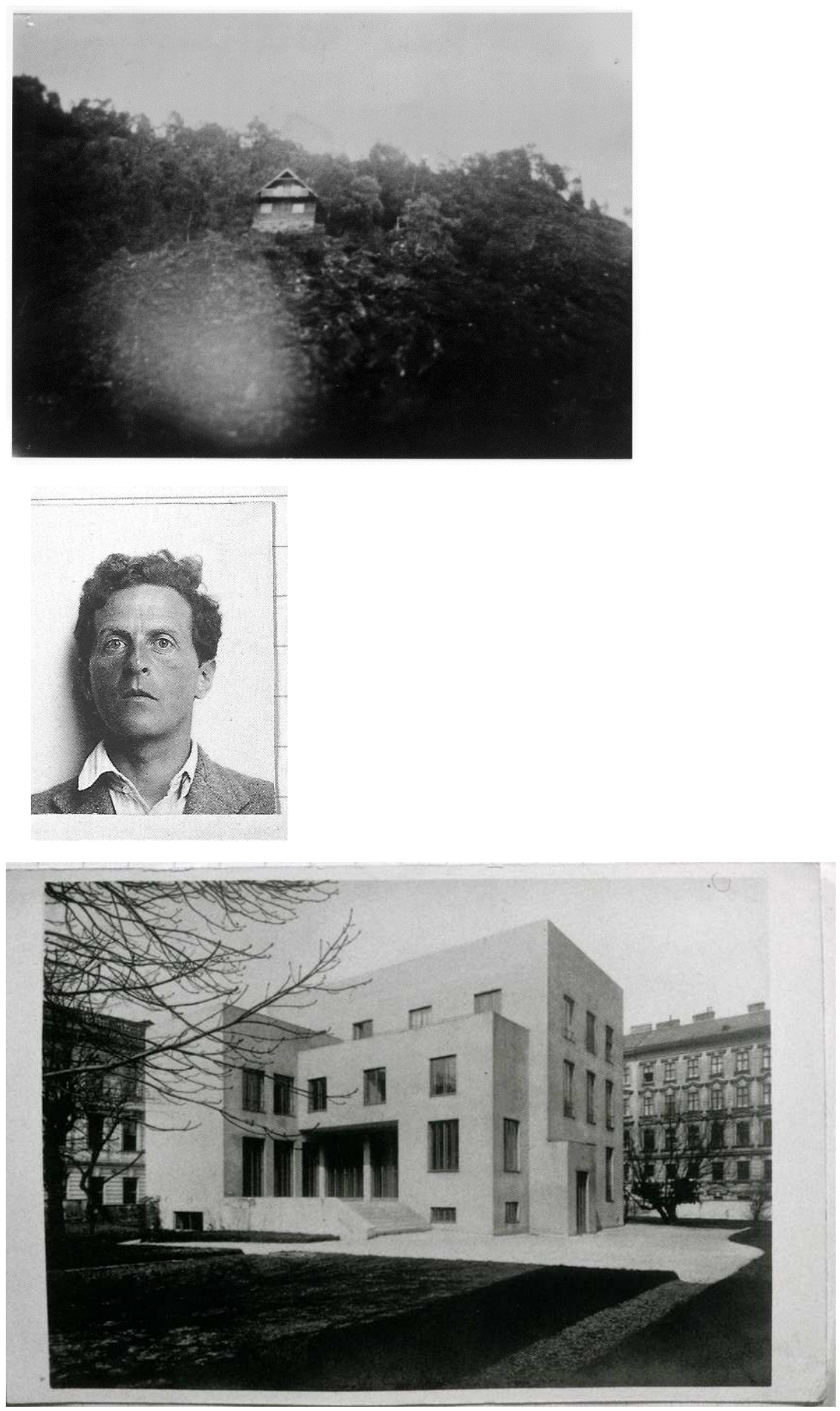

15. Casa de Ludwig Wittgenstein en Skjolden, fotografía de 1950. Álbum de Ben Richards

16. Wittgenstein en 1926-1928. Álbum personal de Wittgenstein

17. Kundmanngasse 19, fotografía de 1928. Álbum personal de Wittgenstein 
y destilaremos conceptos referidos al paisaje, la escala, la calidad material e incluso la sostenibilidad, en relación directa con el entorno.

El planteamiento de la tesis es objetivo, volver a proyectar una casa para el retiro intelectual de uno de los principales filósofos del s. XX, que realizó estudios de ingeniería aeronáutica y que quiso ser arquitecto.

Exilio deriva del latín arcaico exul, esto es, «el que deambula, el que vaga». La soledad se puede encontrar cerca o muy lejos, pero el denominador común es la búsqueda de uno mismo. Alejarse del mundo cotidiano es necesario para encontrarse con el yo olvidado. El que se exilia sólo lo hace de los demás. Porque si hay algo que contar y si vale la pena hacerlo sólo puede ser un ejercicio de intimidad. La soledad se logra en el ámbito propio, en el lugar de cada uno. La arquitectura es, en ese sentido, el medio por el que nos aislamos del mundo, es un refugio premeditado. Carles Martí dice que la arquitectura está hecha de obras y proyectos, y no de textos ni arquitectos.

De la comprensión de esa intensa ausencia del mundo de Wittgenstein «tal como lo encontré» ${ }^{9}$, tantas veces violenta, y del espacio -la arquitectura- que la cobijó durante casi dos años, tratan las siguientes páginas.

${ }^{9}$ Ludwig Wittgenstein, Tractatus logico-philosophicus, $\$ 5.631$ (Madrid: Tecnos, 2003) p. 237 
LUDWIG WITTGENSTEIN

Tractatus

logico-philosophicus

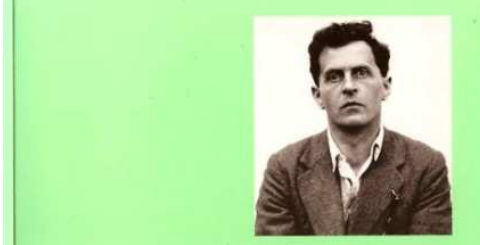

Traducción, introducción y notas de Luis M. Valdés Villanueva

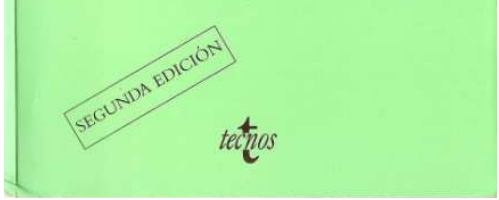

penitz con el Elda; 55 uUu nav. Inaustrias textiles; construcciones mecánicas; fundiciones; material ferroviario; papel.

WITTGENSTEIN (Ludwig), filósofo austríaco (Viena 1889-Cambridge 1951), nacionalizado británico en 1938. Fue discípulo de B. Russell en Cambridge, de donde posteriormente seria profesor (1929-1947, con inter(1921-1922) marcó un punto de partida del (1921-1922) * ló un purivado del círculo de neopositivismo logico, derivado del circulo de Viena, á que propia, derivado del irculo de incorporo a ese movimiento: el lenguaje refleja la estructura de la realidad; en el análisis del lenguaje se descubren las tautologías y sus límites; la filosofia sólo tiene como funcion aclarar los problemas (primer Wittgenstein). Poco despues inicio una reflexion rectificativa del Tractatus, que culminaria en la publicación postuma de las Investigaciones filosoficas (1953): los juegos del lenguaje engendran perplejidades; no hay nada oculto en el lenguaje sino sólo diversos usos de él. Dentro de estas perplejidades están los problemas filosóficos, que consisten en mostrar las raices de la perplejidad en los límites del lenguaje, con raíces en la realidad (último Wittgenstein). Entre otras obras póstumas fundamentales figuran: Observaciones filosóficas sobre los principios de la matemática (1956), las notas sobre las Investigaciones conocidas como Cuadernos azul y marón (1958) y Lecciones y conversaciones sobre estética, sicología y fe religiosa (1966). [ $\rightarrow$ Biblio.]

WITTICHENITA n. f. (de Wittichen, localidad de Alemania). Miner. Sulfuro de bis-
LUDWIG WITTGENSTEIN

Fenomenología

Secciones 94-100 del Big Typescript

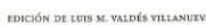

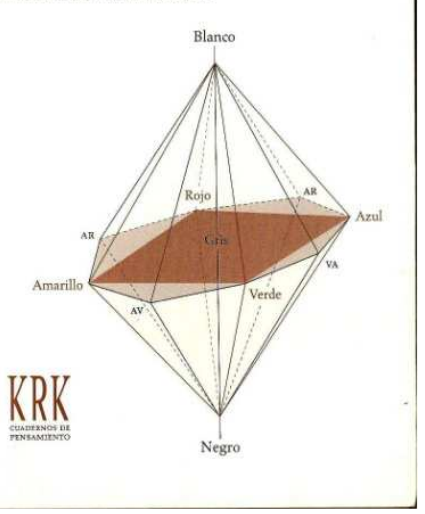

Stanley Cavell

PRE-TEXTOS

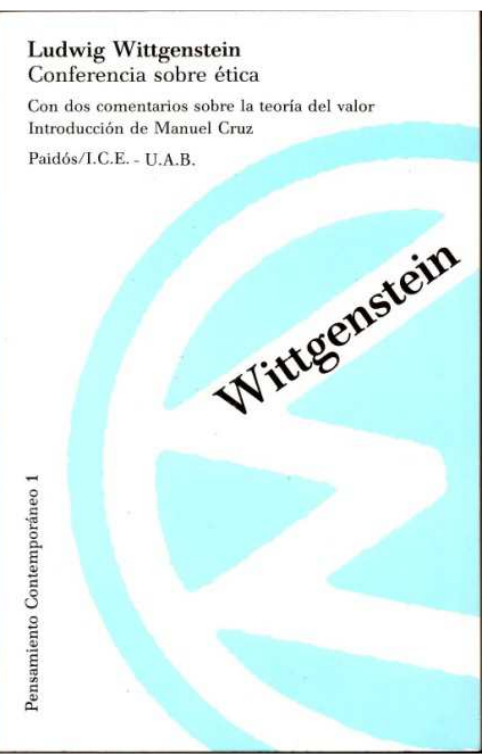

18. Wittgenstein, Tractatus logico-philosophicus ｜ 19. Wittgenstein, Secciones 94-100 del Big Typescript | 20. S. Cavell, Los sentidos de Walden

21. Entrada «Wittgenstein», Nueva Enciclopedia Larousse

22. Wittgenstein, Conferencia sobre ética 
En octubre de 2003, el profesor Francisco J. Nieto Edo presenta una lección magistral ${ }^{10}$ en la que cita al filósofo Ludwig Wittgenstein y la convergencia de sus ideas con las de Adolf Loos: «lo que se puede pensar es lo que se puede decir y por tanto lo que puede existir.» Dice Nieto que el lenguaje permite «cartografiar la realidad» y de ello se colige que cuanto mejor describa un nombre aquello que nombra, mayor será su valor cognitivo. ${ }^{11}$

Aquella motivación por descubrir algo más sobre la figura de Wittgenstein, la curiosidad $^{12}$ por uno de los filósofos del s. XX con mayor número de referencias bibliográficas, dio con el descubrimiento de un personaje de proporciones míticas y la imposibilidad de abandonar el estudio -de límite impropio, infinito- de tan compleja existencia ${ }^{13}$. En palabras de David Connearn:

«Dear Enrique,

They were right, catching Wittgenstein is worse than a dose of Kant, it's viral.»14

En ese proceso de iniciación, una de las primeras lecturas fue la obra de Paul Wijdeveld Ludwig Wittgenstein Architetto, en la edición italiana de Electa, publicada en Milán en 200015. Entre los contactos con la literatura secundaria de Wittgenstein, fue crucial, por la ampliación que ofrecía del contexto sociocultural

\footnotetext{
${ }^{10}$ Se refiere a la lección magistral presentada en el concurso de acceso a profesor Titular de Escuela Universitaria de Proyectos Arquitectónicos en la U.P.V. bajo el título: «Palabras extraviadas que nombran y figuran espacios de la casa», Valencia, octubre 2003.

${ }^{11}$ Tal discusión sobre la capacidad para nombrar se remonta a las disquisiciones de los filósofos presocráticos, si bien fue Platón el primero que explicitó la cuestión en su diálogo Crátilo (aprox. 390 a.C.). «La principal preocupación de los griegos acerca del lenguaje era saber si es un instrumento 0 aún más el medio fundamental para la comprensión de la realidad. Como indica Martínez Marzoa al comienzo de su

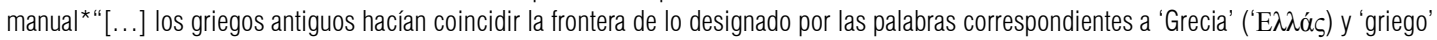

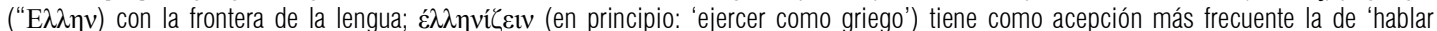
griego')". Por tanto, el griego equipara en gran medida el lenguaje y la razón puesto que es el lenguaje, el 'hablar del mundo' lo que le permite conocerlo, puesto que el mundo se expresa a través de las palabras. Es la 'realidad hablante', como aspecto de la realidad, tal como colige Ferrater Mora de Heráclito y Parménides. Si el griego nombra la "verdad" como negación o rechazo referida al "permanecer oculto" (cf. Martínez Marzoa, p. 23) ${ }^{\star}$, la verdad es por tanto ruptura con lo desconocido y transmitida por el lenguaje, la justeza con que este describe a aquella debe permitirnos saber ( $\delta$ ó $\xi \alpha$ ) acerca de la realidad y vincula necesariamente uno con otra.» (Reflexión en torno al Crátilo de Platón, extraído de documento personal). ${ }^{*}$ Felipe Martínez Marzoa, Historia de la filosofía I (Madrid: Akal, 1994)

12 Entendida incluso según la definición del DRAE (22 $2^{\mathrm{a}} \mathrm{Ed}$.) como «el deseo de saber 0 averiguar alguien lo que no le concierne» pero también la voluntad de dar cuenta de una segunda acepción que reza «cuidado de hacer algo con primor».

${ }^{13}$ He aquí el inicio del primer plan de viaje, otoño 2003-verano 2012. (cfr. Nota 2)

${ }^{14}$ Correspondencia electrónica de David Connearn, 4.08.2012

${ }^{15}$ La edición original es Ludwig Wittgenstein Architect, (Amsterdam: The Pepin Press, 1993)
} 


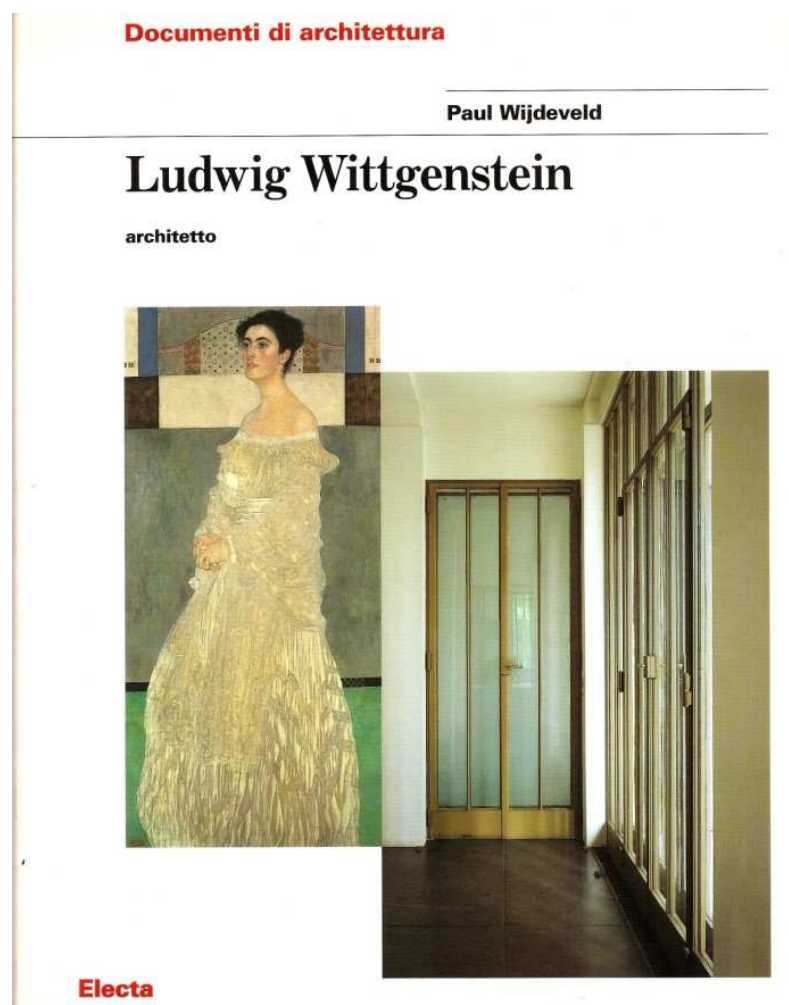

Electa

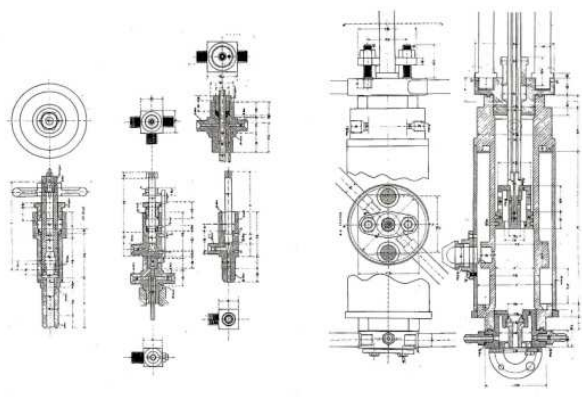

Nel gennaio del 1913 Karl Wittgenstein mori, e Ludwig ereditò la sua parte del patrimonio paterno, che era ancora immenso. Nel 1914 costrui la sua prima e unica casa vicino al villaggio norvegese di Skiolden, sulle sponde
del Sognefford, dove aveva trovato la pace necessaria per dedicarsi agl studi di logica. La casa costrnita in legrno secondo l'uso loce ese con un seminterrato, un piano terreno con qualche stanza e una soffit simili a quelli della casa che in seguito avrebbe costruito per sua sore Poiché la casa sorgeva su una nipia scarpata a picco su un lago (dove

argano $\mathrm{e}$ un cavo per issare secchir d acqua

$\grave{b}$ in Austria per riscuoter

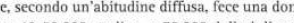
(circa 40-50.000 sterline, o 75.000 dollari d ogg re della rivista culturale "Der Brenner", osli chiese di suldividere la somma fra artisti di sua scelta senza rivelare il nome del donatore. Fra i beneficiari vi furono i poeti Georg Trakl e Rainer Maria Rilke, il pittore Oskar Kokoschka, la pittrice e poetessa Else Lasker-Schuler e l'architetto Adolf Loos, che Wittgenstein ammirava molto e che gli venne presentato da von Ficker quello stesso mese

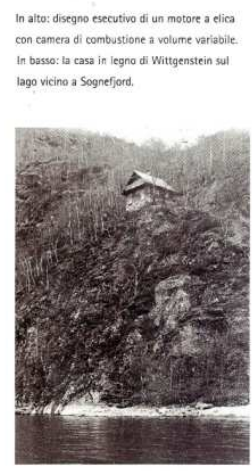

La Viena de Wittgenstein

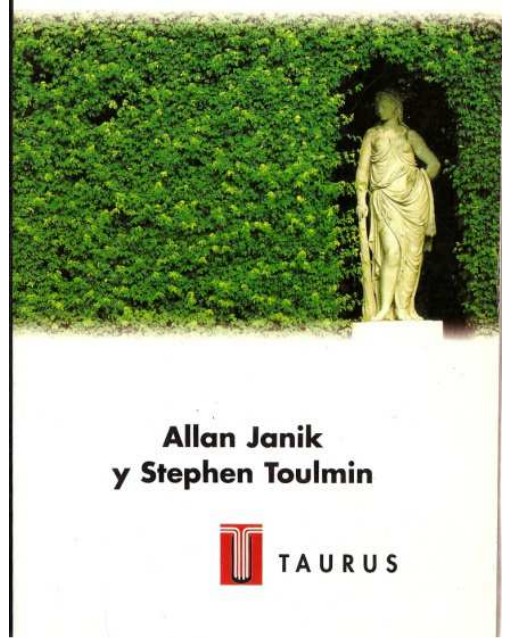

23-24. Paul Wijdeveld, Ludwig Wittgenstein architetto. Portada y página 27 25. A. Janik \& S.Toulmin, La Viena de Wittgenstein 
en el que creció el filósofo, el libro de Allan Janik y Stephen Toulmin La Viena de Wittgenstein. ${ }^{16}$

Otras lecturas sobre la vida y obra de Wittgenstein, que motivaban un interés creciente sobre la casa de Margaret Stonborough-Wittgenstein que había construido el filósofo en Viena junto a Paul Engelmann y Jacques Groag alumnos ambos de Adolf Loos- se demoraron durante años.

No fue hasta otoño de 2010 cuando se tomó la decisión de avanzar definitivamente en una investigación sobre la Kundmanngasse 19 como motivo principal. Sin embargo, una relectura del libro de Wijdeveld modificaría definitivamente el objeto estudio. En la página 27 de la edición italiana (Electa) se refería la existencia de una cabaña que Wittgenstein había construido en Noruega y que había utilizado, en distintos periodos, para trabajar.

Todo intento posterior de conseguir información concreta de la casa de Wittgenstein fue inútil. Los datos accesibles en la bibliografía fundamental se reducían a unas pocas fotografías en blanco y negro realizadas en octubre de 1950 y a alguna referencia biográfica de las estancias en Noruega de Wittgenstein en distintos periodos de su vida.

Resultaba sorprendente, incluso en la fase inicial de aproximación al tema de investigación, la ausencia absoluta de estudios sobre el asunto. Las referencias bibliográficas que estudian aspectos del filósofo vienés se cuentan por miles. Sin embargo reiteradas búsquedas por medios electrónicos no arrojaban luz sobre el asunto o lo trataban de manera tangencial, anecdótica. Este fue el acicate principal para desarrollar esta investigación. La elección del tema pudo ser determinada por el azar, como quizá le ocurrió a Wittgenstein al elegir ese apartado lugar noruego entre cualquier otro posible. Cuestionarlo en este momento carece de sentido.

Baste decir por ahora, que no es gratuito insistir en que el proyecto se ha realizado desde la visión de un arquitecto. El componente gráfico de la presente tesis es primordial para transmitir la información en imágenes, bocetos, planos y

\footnotetext{
${ }^{16}$ La edición original del libro en inglés se remonta a 1973, en castellano en 1974. Edición consultada (Madrid: Taurus, 2001)
} 


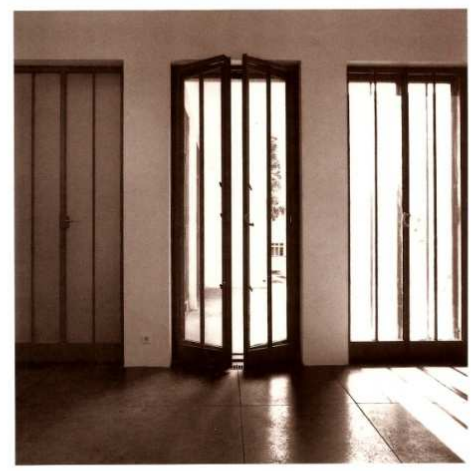

THE WITTGENSTEIN HOUSE

BERNHARD LEITNER
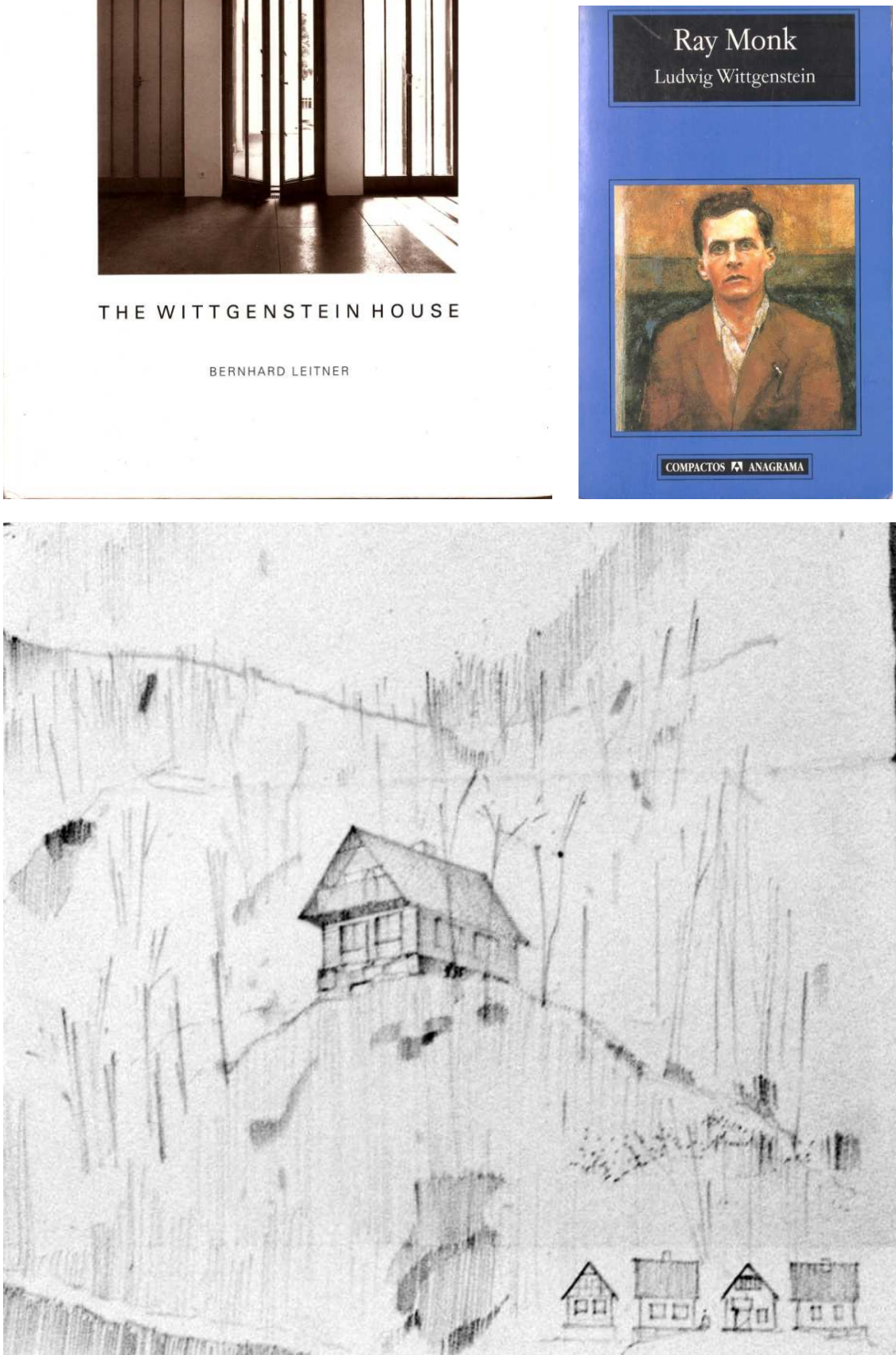

26. Libro de Bernhard Leitner sobre la casa de Wittgenstein en Viena | 27. Biografía de Wittgenstein por Ray Monk, 1990 28. Dibujo de asimilación de la casa, agosto 2011 
esquemas. Las soluciones planteadas en ellos son altamente precisas pero no necesariamente exactas. Así, la reiterada visita sobre los escasos datos disponibles, el análisis de las imágenes históricas y el intercambio de información con otros investigadores ha permitido concretar determinados elementos de forma inequívoca. Pero muchos otros, forman parte de la indagación, de la imaginación -invención o proyecto- de posibilidades plausibles, constructivas, técnicas o históricas. Se ha dicho al principio que también el texto es muy importante y esto es así pese a ser una tesis de arquitectura. La tarea exploratoria durante la investigación ha generado una considerable cantidad de escritos, reflexiones y apuntes, meditaciones y alguna que otra iluminación. Puesto que el trabajo académico de la tesis debe estar respaldado por la evidencia, este autor ha encontrado necesario extenderse en muchas secciones del trabajo con la palabra escrita, sobre todo allí donde las posibilidades objetivas del dibujo o la fotografía no alcanzaran a explicar los matices o simplemente el proceso.

La única casa proyectada por Wittgenstein para su propio uso, nunca antes había sido analizada. Esta tesis da respuesta inédita y extensamente a ello. Se plantea aquí un proyecto que recoge el resultado de una investigación minuciosa, de la casa que el filósofo hizo construir en 1914 en Skjolden, sobre la orilla del lago Eidsvatnet y que fue desmantelada en 1957, sin más. 

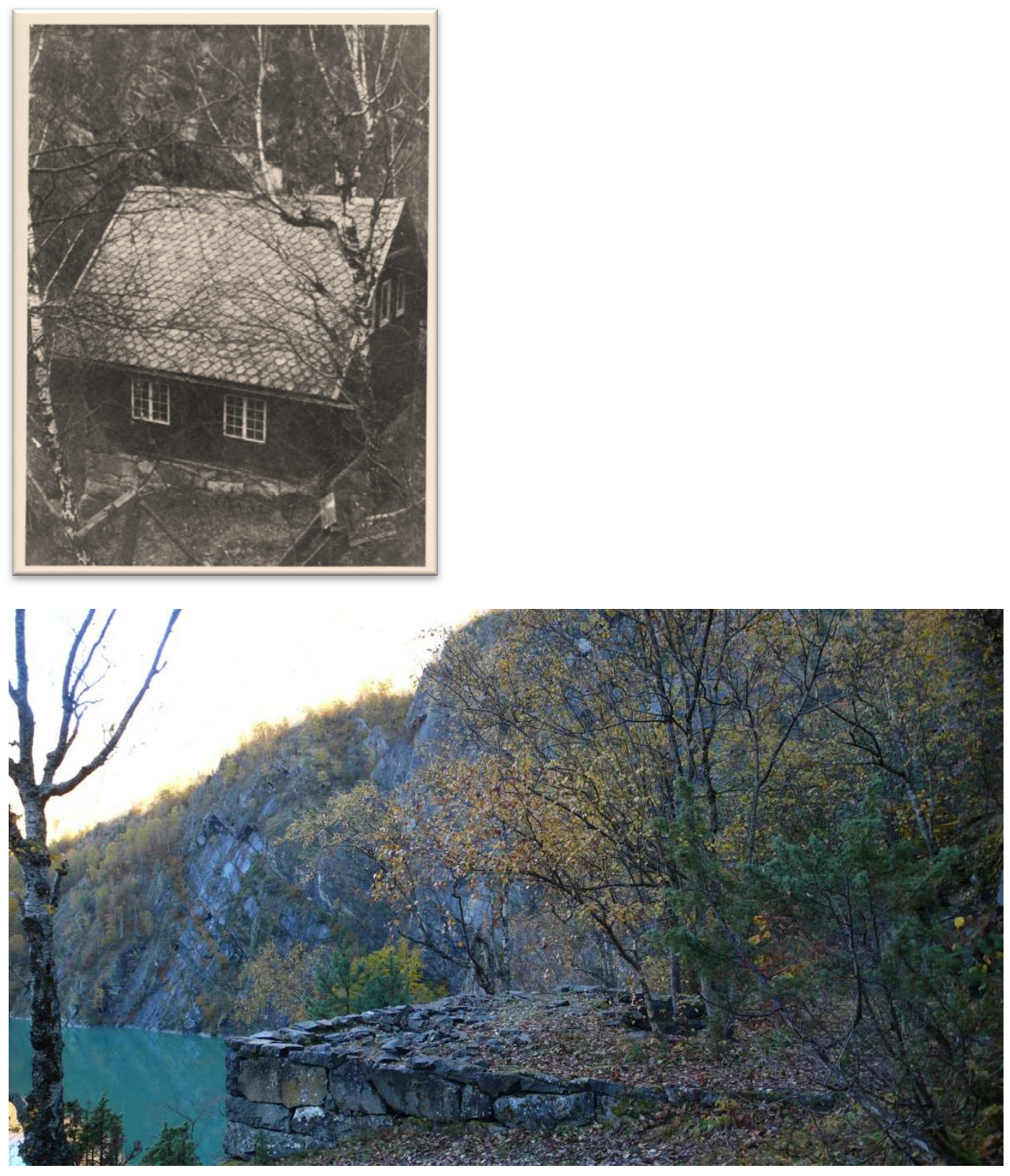

De: $\quad$ "Paul Wijdeveld"

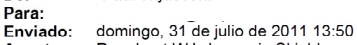

Asunto: Re: about W.'s house in Skjolden

Dear Mr. Clemente,

I am afraid I am not such a specialist anymore, for it has been 17 years now since my book was published... ;-). During my research the 'hut' in Skjolden mostly kept its secrets as I couldn't find much on it. Digging deeper into it would cost a lot of time and I decided that that would be a separate project for someone else - I did only use the facts at hand at the time of my research. As far as I know untill 1993 there hasn't been any throrough systematic research into the history and architecture of the hut. The contacts you made in Norway and in Cambridge suggest that afterwards there has been a renewed interest which is very interesting; their information is certainly much more up to date than I provided in my
book.

So I wish you succes, and if you find anything new I am very interested (my main interests presently center around formulating a "geometry of consciousness and creativity" based on findings of present day neuroscience; in that Wittgenstein's later philosophy plays a certain - small - role which is what is left of my interest in his life and work) Best regards,

Paul Wijdeveld

29. La casa en octubre de 1950

30. La casa en octubre de 2013

31. Primer mensaje de P. Wijdeveld, 31.07.2011 


\section{Estado de la cuestión}

El punto de partida principal que va a articular el estado de la cuestión de esta investigación es el hecho evidente de que la casa original ya no existe. Este hecho representa un inicio, pero no un estadio congelado en el tiempo.

La investigación de la casa de Wittgenstein es una secuencia temporal y debe entenderse como una franja de cierta anchura en el calendario y no como una línea de sucesiones. La evolución del estado de la cuestión ha formado parte del devenir, no siempre sistemático, del presente proyecto, nombre con el que nombramos habitualmente la investigación que realiza un arquitecto. Tal como se ha referido, la primera noticia de la existencia de la casa noruega de Wittgenstein se produce en 2004, pero no es hasta finales de 2010 cuando se orienta una verdadera investigación focalizada en el proyecto de la casa ${ }^{17}$, recurriendo en primer lugar a la fuente que la había motivado:

«De Paul Wijdeveld, 31.07.2011

Dear Mr. Clemente,

I am afraid I am not such a specialist anymore, for it has been 17 years now since my book was published...;-). During my research, the 'hut' in Skjolden mostly kept its secrets as I couldn't find much on it. Digging deeper into it would cost a lot of time and I decided that that would be a separate project for someone else -I did only use the facts at hand at the time of my research. As far as I know untill 1993 there hasn't been any throrough systematic research into the history and architecture of the hut. The contacts you made in Norway and in Cambridge suggest that afterwards there has been a renewed interest which is very interesting; their information is certainly much more up to date than I provided in my book.

So I wish you success, and if you find anything new I am very interested (my main interests presently center around formulating a "geometry of consciousness and creativity" based on findings of present day neuroscience; in that Wittgenstein's later philosophy plays a certain -small- role which is what is left of my interest in his life and work).

Best regards,

Paul Wijdeveld.»18

\footnotetext{
${ }^{17}$ En correspondencia electrónica con F. Nieto de 15.12.2010 en referencia al objeto del proyecto de investigación: «[...] creo que podría ser bonito hablar de la cabaña de troncos a la que se retiró en Noruega para "poder" escribir y la casa burguesa de su hermana en Viena, [...]». El mencionado proyecto de investigación fue presentado en el Departamento de Proyectos Arquitectónicos para su evaluación el 29.09.2011.

18 Primer contacto a través de correspondencia electrónica con Paul Wijdeveld, como respuesta a la petición de información adicional a la que Wijdeveld había publicado en 1993 respecto de la casa en Noruega. Pese a que el profesor Wijdeveld no ha podido aportar datos propios adicionales a los conocidos en otras fuentes en cuanto a la casa, ha comentado amablemente y con generosidad los progresos de la investigación, aportando opiniones que en algunos casos han colaborado como respaldo teórico e historiográfico a todo el proceso.
} 

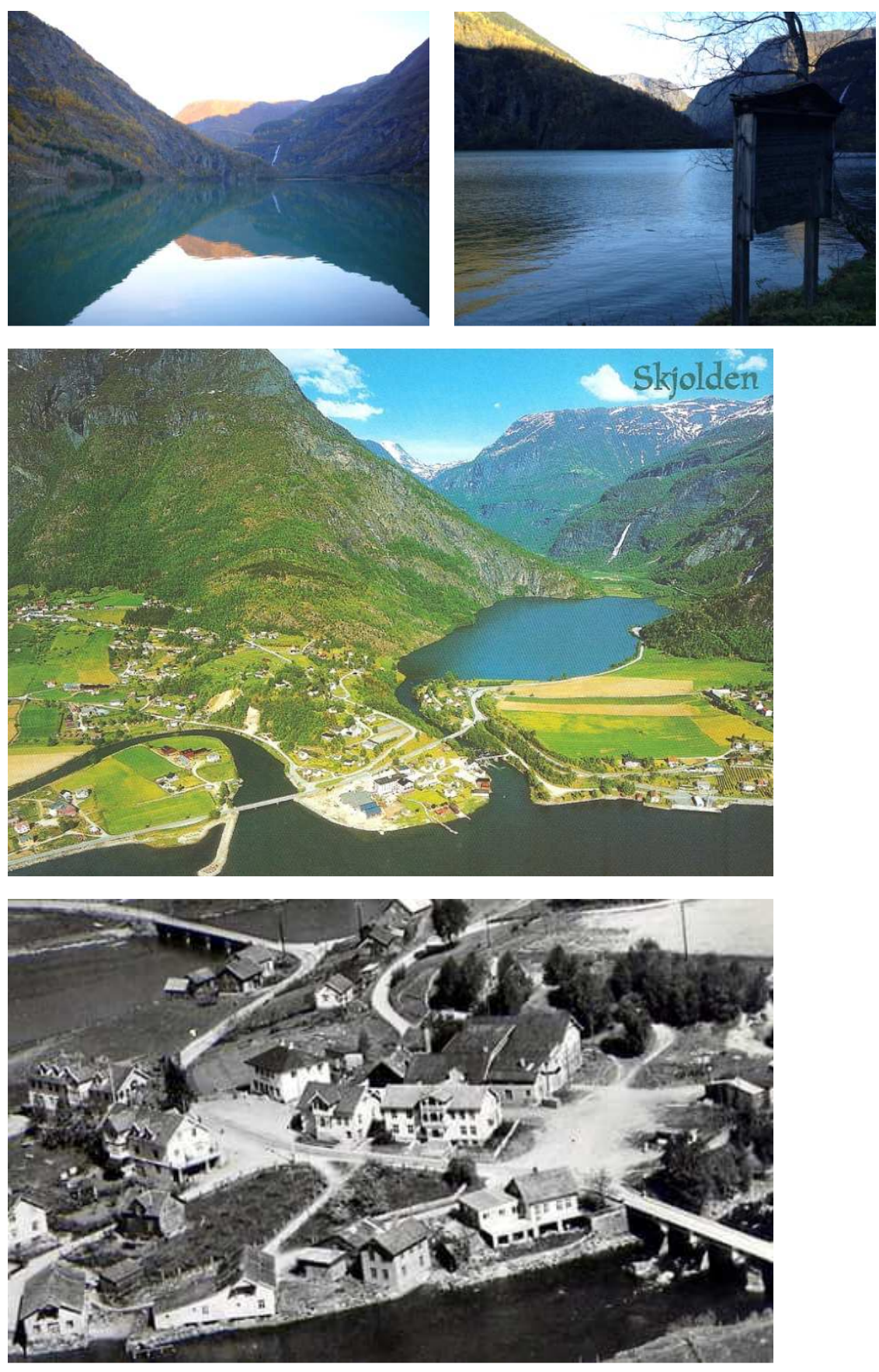

32. Lago Eidsvatnet, 18:15, 11.10.2013 | 33. Lago Eidsvatnet, cartel conmemorativo en Rv55, 14:10, 10.10.2013

34. Tarjeta postal Skjolden, innerst i Lusterfjorden, Sogn

35. Skjolden, 1950 
En 2011, Paul Wijdeveld se expresaba en esos términos respecto a la inexistencia de investigaciones realizadas sobre la casa de Wittgenstein en Skjolden. La situación a la que hacía referencia el profesor Wijdeveld era la conocida en 1993: «Durante mi investigación, la "cabaña"19 en Skjolden guardó sus secretos. [...] Hasta 1993 que yo sepa, no ha habido ninguna investigación minuciosa y sistemática de la arquitectura e historia de la cabaña.». Ese año Wijdeveld había publicado su obra Ludwig Wittgenstein Architect. En su libro se mostraba una pequeña fotografía - más tarde sabríamos que se trataba de una de las realizadas por Ben Richards en 1950- de la casa, cuyo pie de foto rezaba «la casa de madera de Wittgenstein sobre un lago cerca del fiordo de Sogn» y una breve descripción de la misma:

«En 1914 construyó su primera y única casa cerca del pueblo noruego de Skjolden, a las orillas del fiordo de Sogn, donde había encontrado la paz necesaria para dedicarse a sus estudios sobre Lógica. La casa, construida en madera según el uso local, era pequeña, con un semisótano, una planta baja con alguna habitación y un altillo. Aunque ya no existe y todos los dibujos y documentos hayan desaparecido, sabemos por testimonios de sus amigos que contaba con detalles ingeniosos, parecidos a los de la casa que, más adelante construiría para su hermana. Puesto que la casa se asomaba a una empinada ladera sobre el lago (a la que se podía llegar únicamente en barca), realizó por ejemplo un mecanismo con una polea y un cable para subir cubos de agua. $\aleph^{20}$

La descripción de Wijdeveld parece basada en la lectura de un proyecto, puesto que describe su escala, los materiales, las soluciones constructivas e incluso las distribuciones de la casa, todo ello de forma genérica pero posible.

Sobre ello volveremos más adelante, pero conviene retroceder en el tiempo cinco años atrás respecto a la publicación de Wijdeveld. En 1988, el primer biógrafo autorizado por los albaceas del legado literario de Wittgenstein ${ }^{21}$, el profesor Brian F. McGuinness había publicado Wittgenstein A Life. Young Ludwig 1889-1921. En él leemos ${ }^{22}$ :

\footnotetext{
${ }^{19}$ El entrecomillado de "cabaña" del propio Wijdeveld en el mensaje original, no es gratuito, como se verá a lo largo del texto.

${ }^{20}$ Wijdeveld, op.cit. p. 27 (Milano: Electa, 2000. En italiano en el original)

${ }^{21}$ En sus últimos años de vida, Wittgenstein depositó el legado de su obra en sus discípulos Gertrude Elisabeth Margareth Anscombe (19192001), Rush Rhees (1905-1989) y George Henrik von Wright (1916-2003).

${ }^{22}$ McGuinness, op. cit. p. 202 (en inglés en el original)
} 

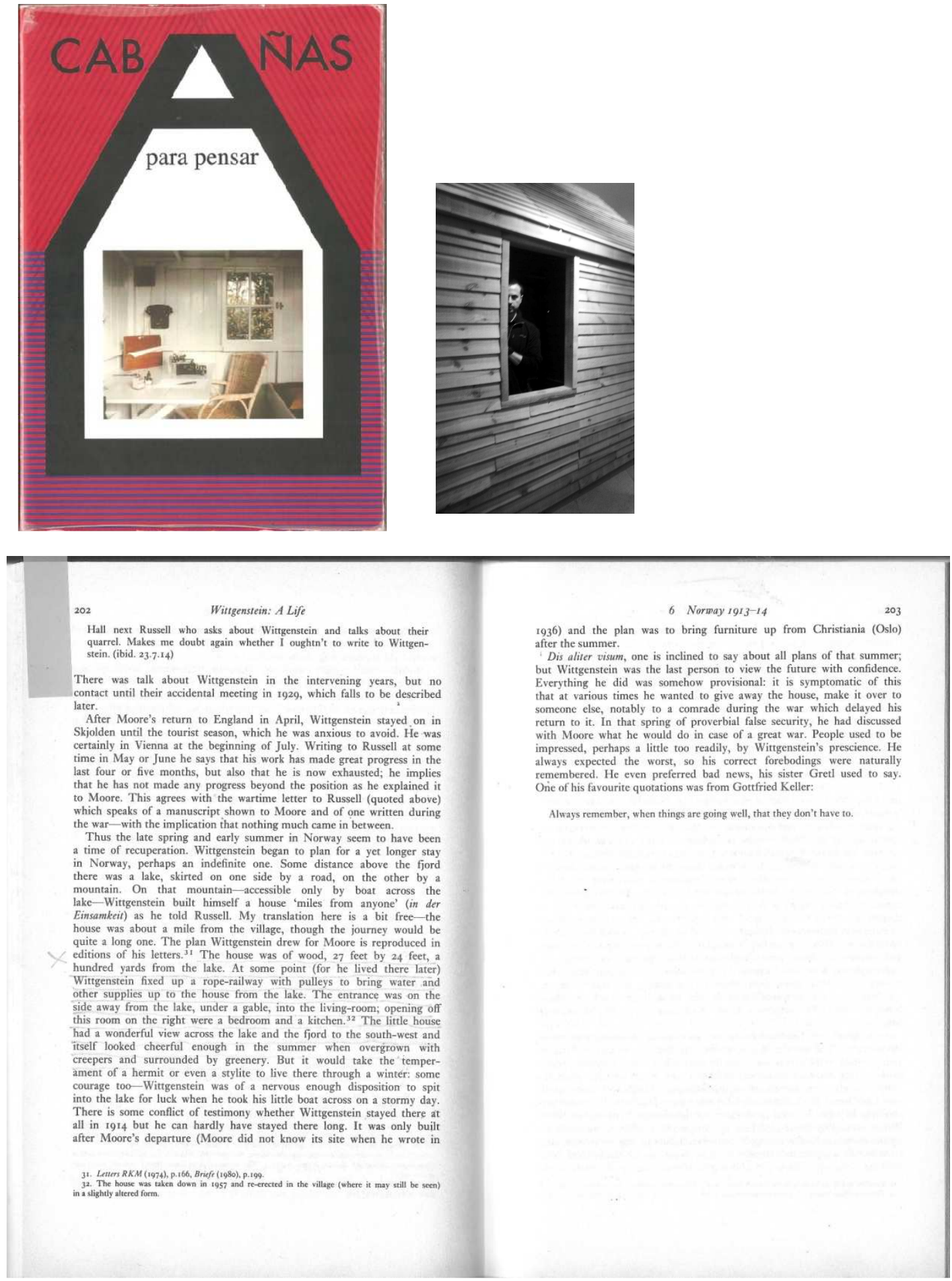

36. Eduardo Outeiro, Cabañas para pensar, 2011

37. Walden en la exposición Cabañas para pensar, Granada, noviembre 2011

38. McGuinness, Young Wittgenstein, 1988, párrafo descriptivo de la casa 
«[...] La casa era de madera, de 27 pies por 24 pies, a unas 100 yardas del lago. En algún momento (puesto que vivió allí más tarde) Wittgenstein fijó un cable con poleas para poder subir agua y otras cosas hasta la casa, desde el lago. La entrada estaba en el lado opuesto al lago, bajo un aguilón, a la sala; dando a esta, a la derecha, había un dormitorio y una cocina. La pequeña casa tenía una vista maravillosa a través del lago $\mathrm{y}$ del fiordo hacia el suroeste y la casa misma era preciosa en verano cubierta de enredaderas y rodeada de verdor [...].»

Una nota a pie de página de este párrafo añade:

«La casa fue demolida en 1957 y reconstruida en el pueblo (donde todavía se puede ver) con alguna pequeña variación.»

No vamos a agostar aquí las fuentes bibliográficas que sí se recogen en otras secciones del presente documento, sino que queremos enfatizar que dos de los más minuciosos y elaborados trabajos sobre determinados aspectos de la vida y obra de Wittgenstein -Wijdeveld en términos cercanos a la arquitectura y McGuinness con una presentación erudita de datos biográficos del filósofo (y parcialmente de pedagogía del pensamiento wittgensteiniano) - se refieren a la casa del lago de manera absolutamente genérica y difusa ${ }^{23}$. Muy pocos adicionales se han podido localizar acerca de la casa, en la exhaustiva revisión bibliográfica realizada hasta la preparación de este documento.

Avanzando ahora hasta el año 2011, se publicó el catálogo de la exposición Cabañas para pensar, proyecto de Eduardo Outeiro y comisariado por Alfredo Olmedo y Alberto Ruiz de Samaniego. Esta es la primera y única referencia gráfica $^{24}$ publicada hasta la fecha de la casa de Wittgenstein en Skjolden. Sin embargo y aunque el proyecto de Outeiro en su conjunto es ambicioso, interesante y atractivo, la información allí plasmada en cuanto a la representación gráfica de los planos de la casa del lago son una invención, basada sin duda en el aspecto de la casa reconstruida en el pueblo por los Bolstad y que difiere sensiblemente de la original. Es notorio además por simple

\footnotetext{
${ }^{23}$ Y en ninguno de los dos casos se citan las fuentes de tales descripciones, fueran documentales o testimonios de personas. El origen de muchos datos de esta investigación explicitará la relevancia de esta acotación.

${ }^{24}$ Eduardo Outeiro, Cabañas para pensar, (Madrid: Maia, 2011), p. 214
} 

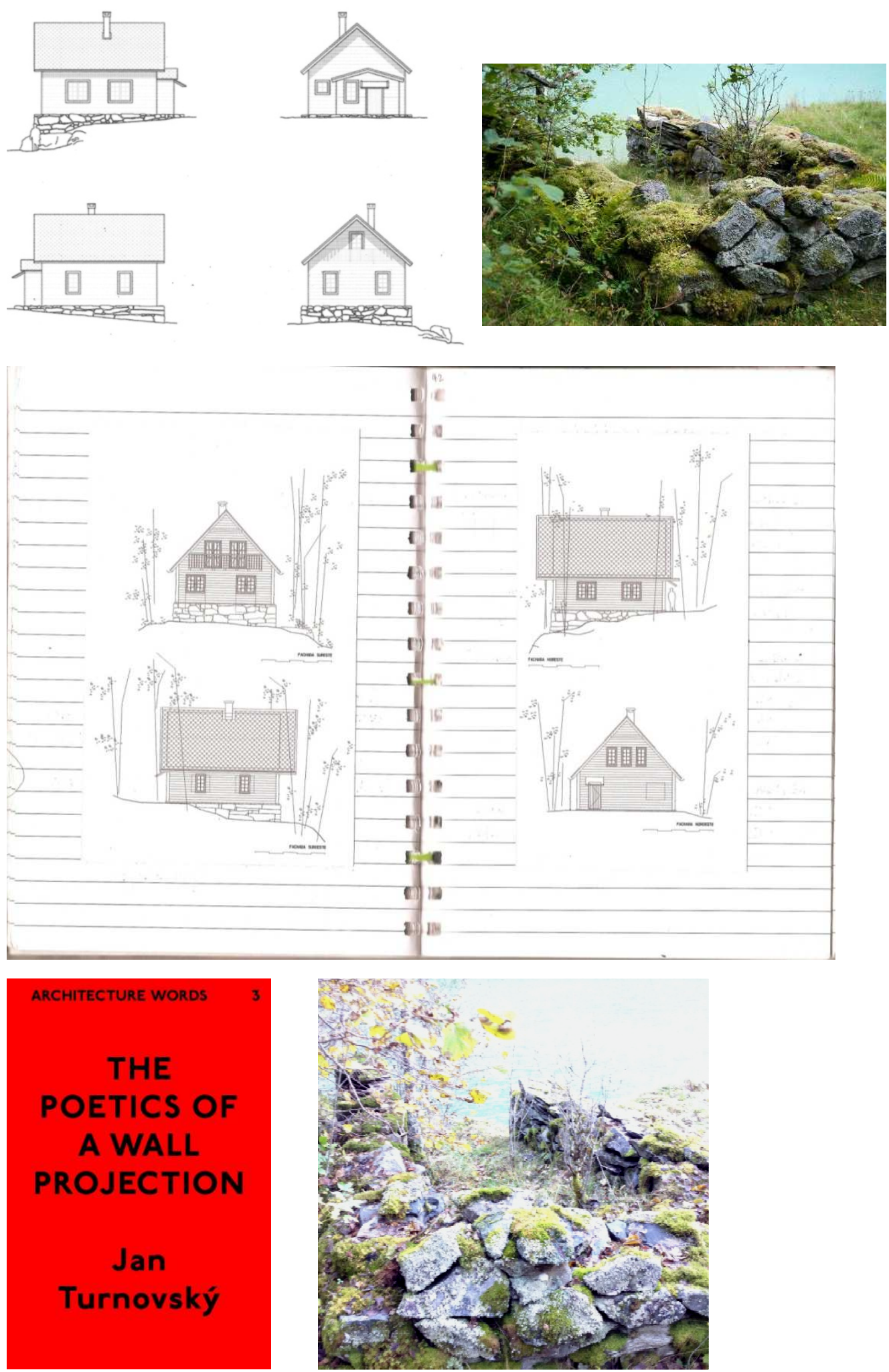

39. Eduardo Outeiro, Cabañas para pensar, «planos de la casa y embarcadero de Wittgenstein» en 2011

40. Versión preliminar del presente proyecto de investigación, 2011. Abajo: el embarcadero, 14:42, 10.10.2013 de un granjero de Hjerseggi (testimonio de Vatne) 41. Jan Turnovsky, The Poetics of a Wall Projection 
observación, que los planos y descripciones de Outeiro ${ }^{25}$ no recogen siquiera la información que sí es visible en las fotografías de Ben Richards de 1950. Incluso el embarcadero que Outeiro y más tarde Ruiz de Samaniego asignan a Wittgenstein para su bote, pertenecía en realidad, según refirió Vatne con total seguridad, a un granjero de más allá de las colinas del Hjerseggi.

«Estimado Enrique:

En primer lugar quisiera darte las gracias por tan alentadoras palabras. Siempre es una alegría que el trabajo llegue y estimule a otras personas. En lo que respecta a la restitución de alzado y planta, conté con dos breves textos del propio Wittgenstein sobre la cabaña, las fotografías que tú mismo has citado, la imagen de la cabaña reconstruida en el pueblo y la inestimable ayuda de David Connearn, que ha sabido indicarme los cambios sufridos por la cabaña en dicha reconstrucción. Por lo demás los planos son lo más ajustado que hemos logrado con los datos de los que disponíamos. Estoy seguro de que las investigaciones de David son mucho más exactas. Te escribo ahora con un poco de prisa, pero este domingo intentaré poner al día mi correspondencia y enviarte todos los datos de los que dispongo en este momento.

Hasta entonces, un abrazo.

Eduardo Outeiro.»26

El análisis de la obra arquitectónica de Ludwig Wittgenstein se ha centrado, hasta la fecha, en la casa que proyectó entre 1926-1929 para su hermana Margaret junto a los arquitectos Paul Engelmann y Jacques Groag27. La conocida como Kundmanngasse 19, en Viena. Existen monografías específicas como la de Paul Wijdeveld o la de Bernhard Leitner The Wittgenstein House (2000) o The Architecture of Ludwig Wittgenstein (1973). Jan Turnovský publicó en 1985 un pequeño y delicioso libro The Poetics of a Wall Projection, del que vale la pena al menos traer aquí lo siguiente:

\footnotetext{
${ }^{25}$ Los créditos, tal como constan en el catálogo de la exposición son: "Fotografías y herbario: Eduardo Outeiro, 2010; Planos: Lorena González García, Yago Mafé Astray, Daniel Estévez Cachafeiro"; op.cit. p. 208 y Alberto Ruiz de Samaniego, «Ludwig Wittgenstein en su cabaña. El engaño y el estilo», FronteraD, revista digital, 23.04.2015

${ }^{26}$ Correspondencia electrónica, 22.07.2011. Primera y última comunicación -dicho sea esto sin acrimonia- con Eduardo Outeiro.

${ }^{27}$ Paul Engelmann (Olomouc, 1891-Tel-Aviv, 1965) amigo personal de Wittgenstein y de su familia. Fue un confidente también de sus quebrantos filosóficos durante tres décadas. Las cartas que ambos intercambiaron entre 1916-1937 se recogen en Wittgenstein-Engelmann, Cartas, encuentros, recuerdos, IIse Somavilla (ed.), Valencia, 2009. Fue una persona de extrema sensibilidad, siempre a caballo entre la arquitectura, la poesía y el sionismo. Wittgenstein, para quien la amistad era un concepto muy valioso y de elevadas expectativas, siempre mostró -a su manera- su estima por Engelmann. Por su parte Jacques Groag (Olomouc, 1892-Londres, 1962) aunque pertenecía al círculo de amistades de Engelmann en Olomouc, no mantuvo una relación de estrecha amistad con el filósofo. Su labor en la construcción de la casa se orientó a los cálculos estructurales y de costes y en más de una ocasión estuvo a punto de abandonar la obra. Engelmann y Groag fueron alumnos y asistentes de Loos en su Escuela de Arquitectura.
} 

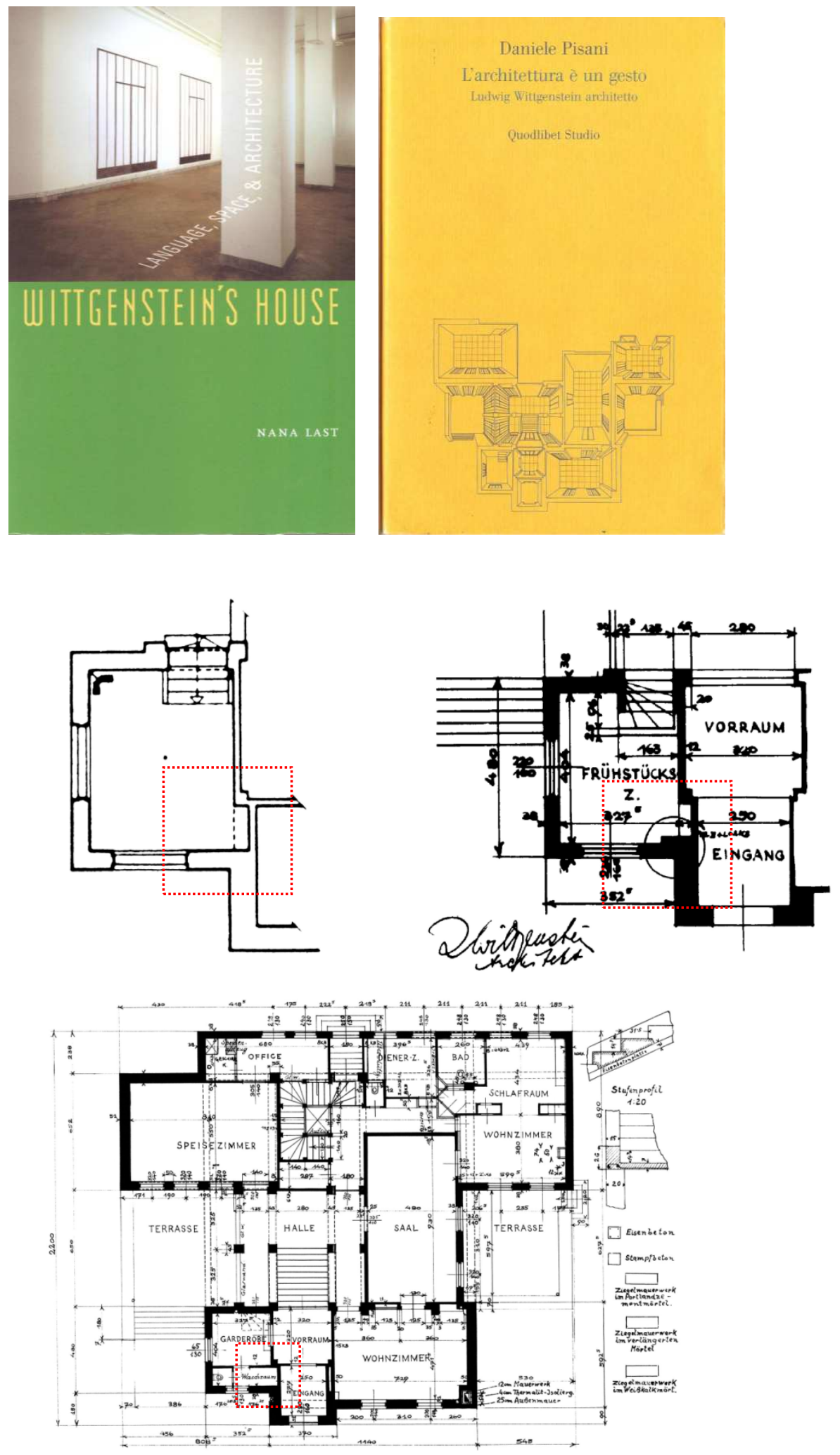

42. Nana Last, Wittgenstein's House, 2008 | 43. Daniele Pisani, L'architettura è un gesto. Ludwig Wittgenstein architetto, 2011 44. Dibujos de la Wall Projection en la Kundmanngasse 19, Jan Turnovsky 
«There are beautiful houses,

and there are ugly houses.

There are banal houses,

and there are spiritual houses.

But in every house

the systematic spirit fails.

That is beautiful to observe.» ${ }^{28}$

En fechas recientes han aparecido otros estudios monográficos, como Wittgenstein's House. Language, Space, \& Architecture de Nana Last, 2008. En él, Last presenta la casa de Viena como un elemento independiente del desarrollo filosófico de Wittgenstein pero relacionado transversalmente con el mismo, puesto que postula que ambas disciplinas comparten planteamientos lingüísticos y espaciales. Así, Last se aleja de las tradicionales convenciones interpretativas acerca de si la casa representa o fija materialmente un pensamiento filosófico, fuera el de Tractatus o el que podría estar evolucionando hacia sus Investigaciones Filosóficas.

En la literatura acerca de la Kundmanngasse de los últimos años se percibe un intento de discernir entre las obligadas -por clásicasinterpretaciones en clave de neopositivismo construido de la casa hacia análisis independientemente arquitectónicos del hecho construido aunque destinados a entenderse con el planteamiento del sistema de pensamiento de Wittgenstein. En 2011, Daniele Pisani publica L'architettura è un gesto. Ludwig Wittgenstein architetto. En él se analiza de nuevo la casa de Viena desde una perspectiva quizá más cercana al pensamiento arquitectónico, a la búsqueda de la trasposición entre el proyecto como ente teórico y la obra física construida. Por último cabe citar aquí la Tesis Doctoral Proyectar la verdad. La Casa Wittgenstein, de Juan Diego López-Arquillo, leída en 2013, en la Escuela Técnica Superior de Arquitectura de Madrid. López-Arquillo desarrolla secuencialmente una superposición de capas de significado en las que se solapan

\footnotetext{
28 Jan Turnovský, The Poetics of a Wall Projection (London: Architectural Association, 2008), p. 25. Edición original: Die Poetik eines
} Mauervorsprung (Wien, 1985) 

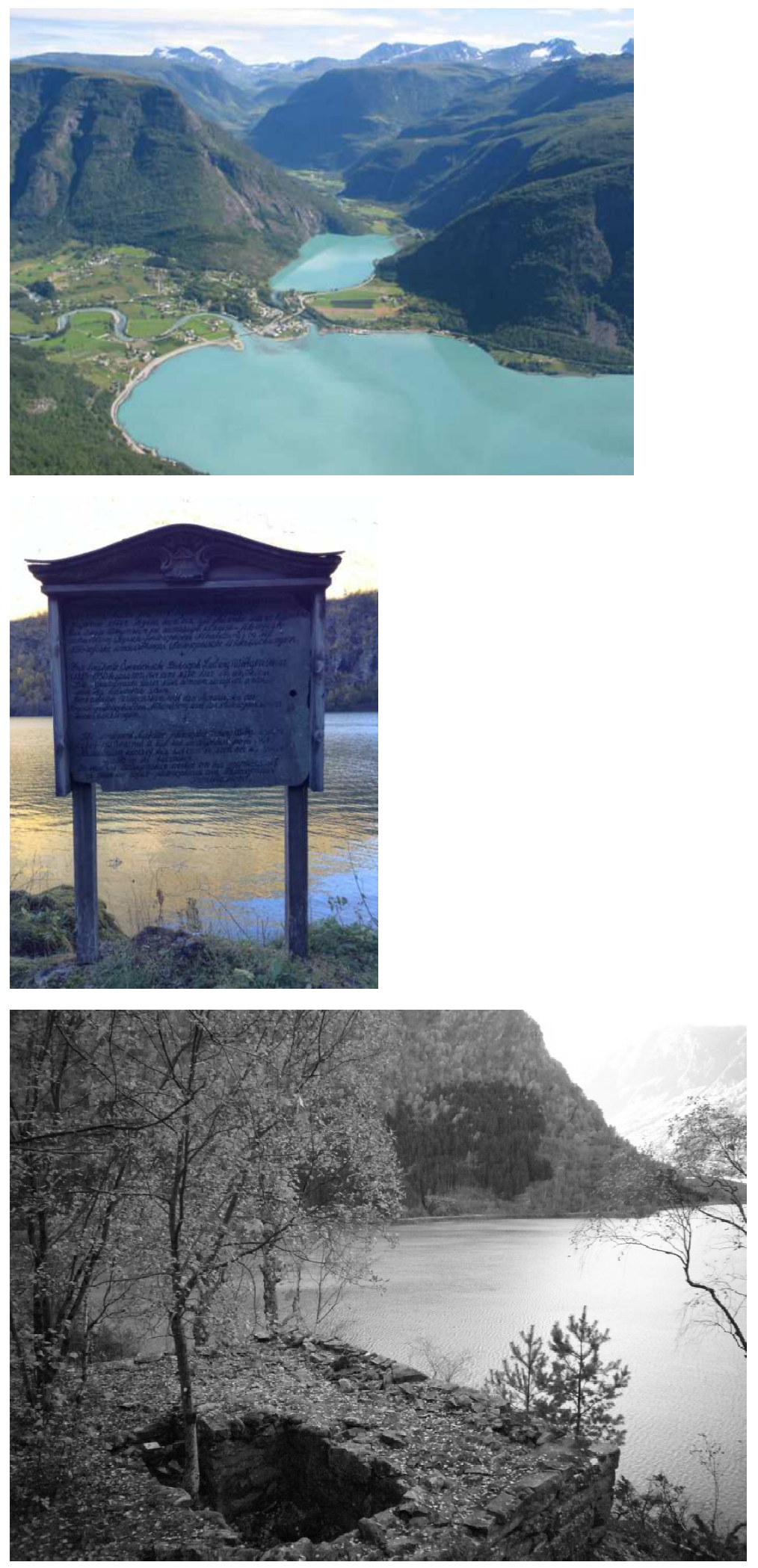

45. Skjolden, Sognefjord, lago Eidsvatnet y los ríos Mørkridselvi y Eidselvi

46. Cartel conmemorativo de la casa de Wittgenstein, 14:10, 10.10.2013

47. Plinto de la casa, octubre 2013 
la construcción de la casa como objeto material, su situación en el contexto de la modernidad -no pretendido o inconsciente por el propio Wittgenstein-, la reivindicación de la figura del arquitecto, la imposibilidad de la idea construida, el valor de la experiencia dinámica de la casa y la relación de la misma con la ciudad.

Vemos que Wittgenstein, tanto en su producción filosófica como extrafilosófica ha despertado no poco interés y su presentación aquí no es gratuita. Porque siendo así, no deja de ser paradójico que la casa del filósofo en Skjolden no haya sido nunca investigada en profundidad y aún menos desde su concepción arquitectónica. No existen referencias gráficas ni escritas de la construcción de la casa en Skjolden y no se conocen testimonios directos que permitan su descripción detallada.

La arquitectura de la casa de Ludwig Wittgenstein sobre el lago Eidsvatnet en Skjolden ha permanecido oculta hasta la fecha. 

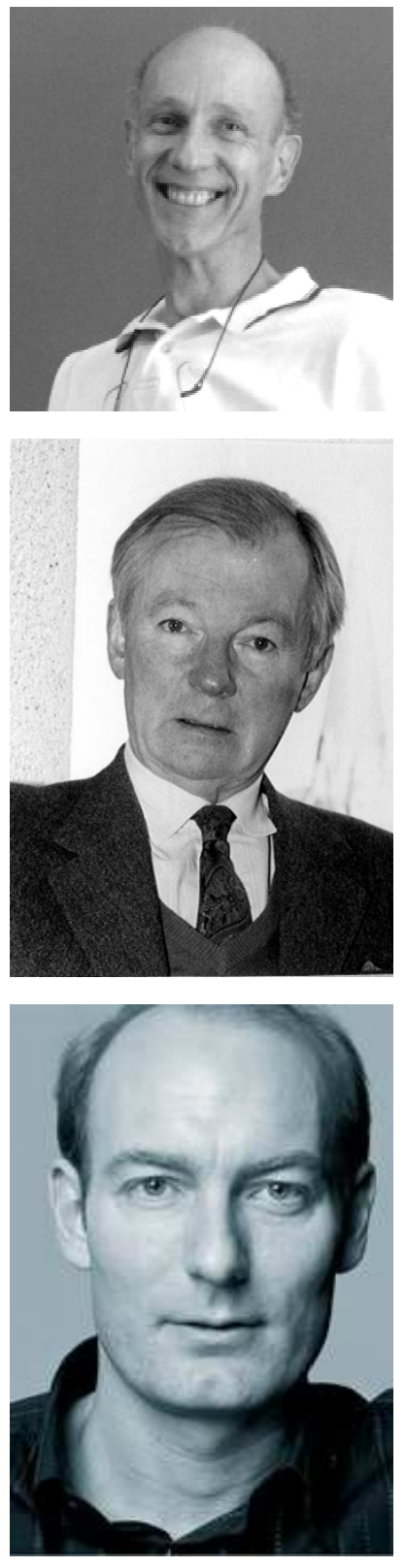

48. Paul Wijdeveld

49. Brian McGuinness

50. Knut Olav Åmås 


\section{Fuentes de la investigación}

El conocimiento contextual del entorno vital y filosófico y otras lecturas transversales necesarias tanto de Wittgenstein como de otros protagonistas y temas tratados, no siempre explícitamente en esta investigación, se ha podido solventar con relativa sencillez. Sin embargo, ya se ha dicho anteriormente que la información -pública-29 existente hasta la fecha, sobre la casa de Ludwig Wittgenstein en Skjolden es muy limitada. Se recogen aquí, única y exhaustivamente -en orden cronológico ${ }^{30}$ - las fuentes primarias de información relacionadas con el tema de la tesis:

1. Paul Wijdeveld (1953). Profesor de Psicología Neurocognitiva en la Universiteit Leiden. Autor de una de las primeras y más exhaustivas monografías sobre la Casa Wittgenstein en Viena. El profesor Wijdeveld ha aportado detalles y matizado conocimientos en lo referente a la teoría arquitectónica de Wittgenstein en correspondencia personal.

2. Brian Francis McGuinness (1927). Profesor y filósofo, es una eminencia en el ámbito de la vida y obra de Wittgenstein. Su inmensa labor ofrece una perspectiva completa de la figura del filósofo. Fue el primer biógrafo autorizado por los albaceas literarios de Wittgenstein. En nuestra investigación ha contribuido con una de las pocas referencias escritas descriptivas de la casa de Wittgenstein en Skjolden.

3. Knut Olav Åmås (1968). Filósofo, escritor, periodista y político noruego. En 2013-2014 fue Secretario de Estado del Ministerio de Cultura noruego. Actualmente dirige la fundación Fritt Ord para la libertad de expresión y de prensa. En 1994, Åmås publicó las dos únicas monografías existentes sobre Wittgenstein y Noruega, incluyendo un capítulo dedicado a la casa de Skjolden y

\footnotetext{
${ }^{29}$ En el transcurso de la investigación para aclarar determinados aspectos de la casa, se han ido descubriendo datos que obraban en poder de particulares. Gran parte de esa información se recoge ahora también y se integra como parte de este proyecto. Sabemos también que muchos otros elementos que quizá hubieran arrojado luz sobre detalles todavía desconocidos o hubieran confirmado los propuestos seguirán sin conocerse, quizá ya nunca.

${ }^{30}$ La secuencia de acceso a la información ha sido determinante en esta investigación. Se explicita esto mejor en el apartado de la metodología de la investigación.
} 

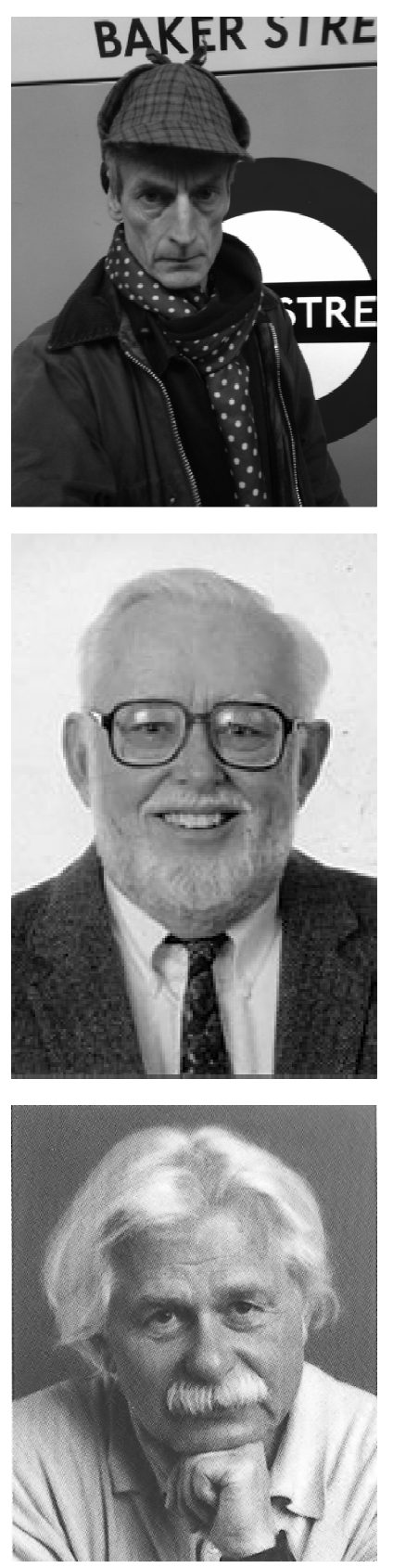

51. David Connearn

52. Ivar Oxaal

53. Michael Nedo 
una recopilación de la correspondencia que mantuvo durante años el filósofo con sus amigos noruegos, Det stille alvoret, en noruego y Wittgenstein and Norway, en inglés.

4. David Connearn (1952). Artista británico no figurativo. Se graduó en Cambridge y fue asistente de Sol LeWitt entre 1980-1990. Su obra gráfica se centra en el proceso del dibujo más que en el propio dibujo en sí mismo. Ha desarrollado proyectos relacionados con la arquitectura. Desde 1998 se interesó por la casa de Skjolden. En 2009 inició, junto a Dawn M. Wilson una iniciativa internacional por la conservación del legado de Wittgenstein en Skjolden. Desde 2011, Connearn puso a nuestra disposición su archivo personal y su propia labor activa en el proceso de investigación.

5. Ivar Oxaal (1931). Antropólogo, sociólogo y profesor emérito de la Universidad de Hull. En 2011 publicó On the Trail to Wittgenstein's Hut. De ella se toman testimonios de primera mano de su visita en 1984 a Skjolden. El profesor Oxaal ha aportado para la presente investigación algunas imágenes inéditas de aquella visita y ha permitido generosamente su reproducción aquí.

6. Michael Nedo (1940). Matemático, físico y zoólogo alemán. Director del Wittgenstein Cambridge Archive desde 1992. Custodia gran parte del legado personal de Wittgenstein. Su archivo contiene correspondencia, fotografías y manuscritos originales. Ha publicado innumerables trabajos sobre Wittgenstein, entre ellos Wittgenstein: Sein Leben in Bildern und Texten y su reciente reedición parcialmente modificada Ludwig Wittgenstein: Ein biographisches Album. Nedo, sus publicaciones y su archivo han sido fuente primaria al permitir acceder al único material gráfico original existente de la casa de Skjolden. Desde hace veinte años Nedo se encarga de la edición del Wittgenstein Wiener Ausgabe.

7. Skjolden. En el lugar se ha tenido acceso a los restos del plinto de la casa en la orilla del lago Eidsvatnet. También se ha podido acceder al exterior y parcialmente al interior de la casa de la familia Bolstad construida en 1957 con el material proveniente de la casa original de Wittgenstein. 

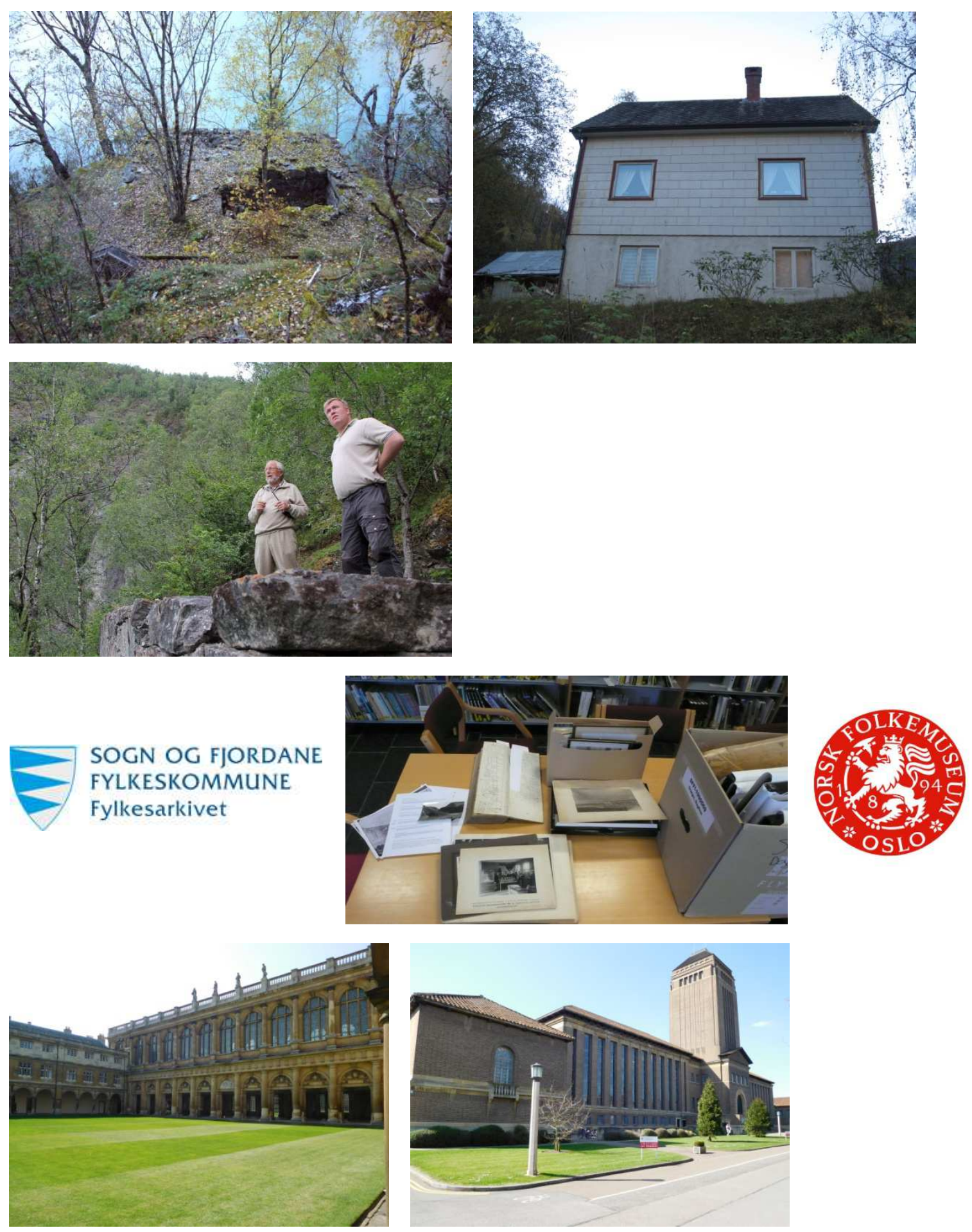

54. Skjolden, Wittgenstein's site, octubre 2013 | 55. Gunnar's Bolstad House, Skjolden, octubre 2013 56. Harald Vatne (izq) y el alcalde del municipio de Luster Ivar Kvalen

57-58. Fylkesarkivet Sogn og Fjordane, Leikanger, octubre 2013 | 59. Norsk Folkemuseum

60. Wren Library del Trinity College, Cambridge, abril 2015 | 61. Cambridge University Library, abril 2015 
8. Harald Vatne (1941). Profesor de escuela, ya jubilado. Natural de Skjolden, es la persona que más información -inédita todavía hoy-atesora sobre las vivencias de Wittgenstein en Skjolden. Ha recopilado durante treinta años testimonios, datos y materiales originales de la casa de Wittgenstein.

9. Fylkesarkivet. El archivo regional de Sogn og Fjordane en Leikanger posee una amplia colección de archivos familiares, de fotografías y documentos originales de Skjolden vinculadas con la biografía de Wittgenstein: Klingenberg, Drægni y Bolstad. Cuenta con una colección de fotografías de escenas populares, ambientes y paisajes de la zona.

10. Norks Folkemuseum. En el archivo fotográfico del Museo Nacional del Pueblo Noruego se han localizado algunas fotografías históricas del área de estudio.

11. Wren Library del Trinity College, Cambridge. Conserva un buen número de cuadernos manuscritos de Wittgenstein. Se ha podido tener acceso a los documentos escritos en Noruega, con la esperanza de encontrar alguna referencia a su casa. Gran cantidad de esos documentos son todavía inéditos. En esta biblioteca se guarda una copia mecanografiada de los diarios de David Pinsent, compañero de Wittgenstein durante sus primeros años en Cambridge y en los viajes de Islandia y primer viaje a Noruega en 1912 y 1913.

12. Cambridge University Library. En la inmensa sala de manuscritos de la CUB se han consultado los cuadernos de diarios de George E. Moore, por la relación personal y académica que le vinculó a Wittgenstein y por haber realizado una visita a Noruega en 1914 que quizá arrojara luz sobre las intenciones de Wittgenstein de construir su casa en Skjolden.

13. Wittgenstein Archives at The University of Bergen, Noruega. Alois Pichler, director del archivo electrónico del WAB, ha colaborado amablemente en la interpretación de algunos fragmentos de los diarios de Wittgenstein.

14. Bibliografía y referencias web. Se ha hecho un vaciado exhaustivo de todas las referencias bibliográficas accesibles publicadas, trabajos inéditos a los que se ha podido tener acceso e innumerables páginas web, blogs y publicaciones 

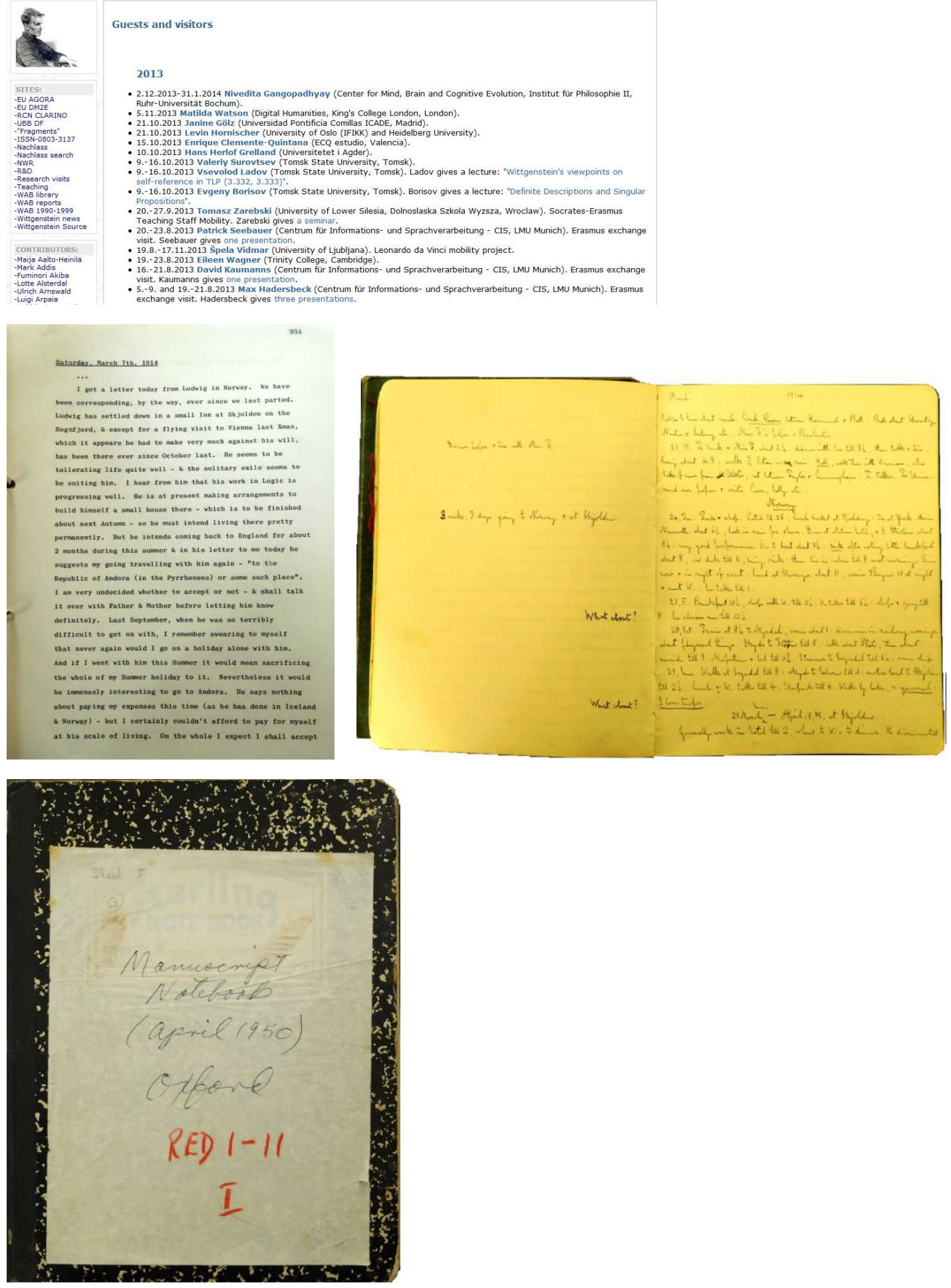

62. Registro visitantes Wittgenstein Archives Bergen, 15.10.2013

63. Diario de David Pinsent, 07.03.1913, Wren Library ～６4. Diario de G.M. Moore, Cambridge University Library

65. Manuscrito de Wittgenstein, Wren Library 
(trabajos monográficos, revistas y periódicos) en línea con información sobre Wittgenstein, cuyo número sin embargo no deja de incrementarse.

El principal responsable de la multiplicidad de fuentes fue Wittgenstein. $\mathrm{Su}$ existencia y su producción responden, de alguna manera ${ }^{31}$, al esquema de las Zettel, «papeletas», colección de reflexiones fragmentarias y dispersas que Wittgenstein recopiló desde 1929 hasta 1948. Su vida, su obra y la continuidad en el trabajo de sus discípulos ${ }^{32}$ amplificaron tal deriva geográfica.

\footnotetext{
${ }^{31}$ La obra de Wittgenstein, planteada como si de pensamientos independientes se tratara, es incluso coherente con su estar en el mundo, sus continuos viajes, sus variables intereses en las lecturas y su pertinaz discontinuidad con las amistades y los sentimientos. Transpira su vida entera una sensación ingenieril, atomista, mecánica, de compartimentación estanca. Sin embargo y a la vez, nada le interesaba sólo superficialmente: «La curiosidad de Wittgenstein en amplia, le entusiasma ver de todo» y «Me asombra lo apasionado y también lo voraz, lo ferozmente voraz que debe ser Wittgenstein cuando lee», en Oets Kolk Bouwsma, Ultimas conversaciones (Salamanca: Ediciones Sígueme, 2004) p. 45 у p. 82

${ }^{32}$ En muchos aspectos, el trabajo de los albaceas literarios de Wittgenstein, Elisabeth Anscombe, Georg Henrik von Wright y Rush Rhees, se ha tildado durante décadas de sectaria (cfr. Wilhelm Baum, 1988 y 1991), recreando un concepto Wittgenstein manipulado y censurado en muchos aspectos, como el remilgado intento por ocultar determinados manuscritos que consideraron alimentaban la especulación sobre comportamientos poco adecuados de la biografía de Wittgenstein o sencillamente su homosexualidad. Muchos años después de la muerte del filósofo sus biógrafos oficiales, McGuinness (1988) y Monk (1990) aun han conservado esa veladura innecesaria, en sintonía con los administradores del legado.
} 

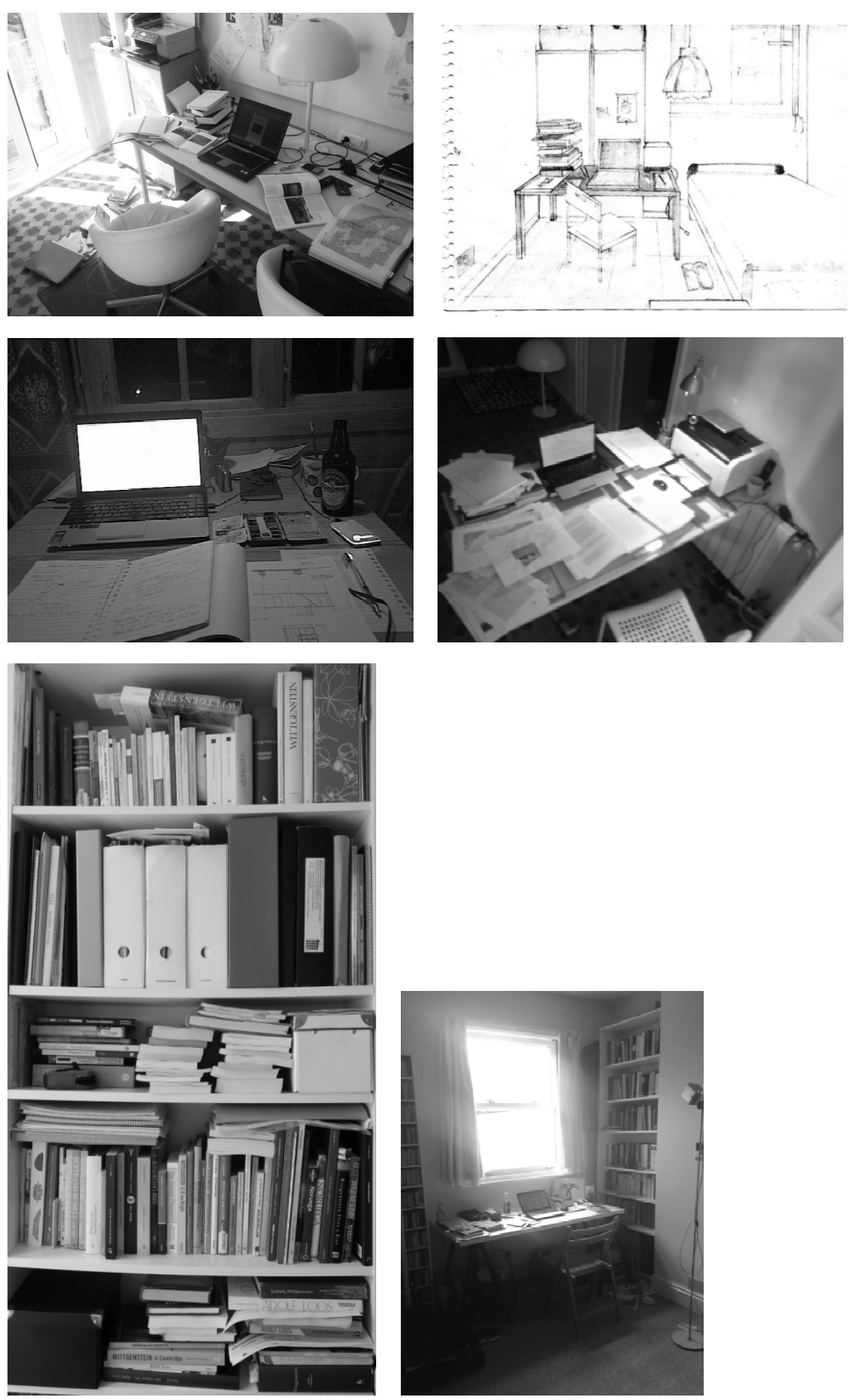


\section{Metodología y estructura de la investigación}

Toda investigación, y por supuesto esta tesis, se desarrolla en el tiempo y en el espacio. Pero el matiz que nos interesa traer a colación en cuanto a la metodología es que el propio sistema, el proceso, ha conformado -moldeado- su ruta. Evidentemente no es nuevo contar con que las líneas de trabajo y hasta las hipótesis varíen conforme el trabajo avance. Así que digámoslo de otra manera: sin el uso de determinadas herramientas empleadas en esta investigación, no hubiera podido darse esta tesis. Quizá otra sí, incluso con el mismo objetivo, pero no esta.

El primer viaje ${ }^{33}$ referido unas líneas más arriba se puede datar en otoño de 2003, y darse por terminado en verano de 2012. Ese desarrollo temporal se produjo sin embargo en un único espacio físico: la propia mesa de trabajo por un lado y múltiples espacios virtuales, Internet, por otro. La investigación llevada a cabo en ese periodo supuso un vaciado de la bibliografía primaria y secundaria referida a Wittgenstein, tarea en sí misma inmensa. Una vez clasificada y jerarquizada se redujo considerablemente el número de fuentes bibliográficas que refirieran información del objeto investigado. Concretamente, la literatura primaria quedó restringida a McGuinness y Wijdeveld. Un año más tarde conseguimos añadir dos nuevas referencias, Åmås y Oxaal. La caracterización de la bibliografía secundaria se redujo algo menos, con un número cercano al centenar de obras. Por el contrario, el análisis de las referencias web supuso un trabajo de selección considerable. ${ }^{34}$

En paralelo se dibujó ${ }^{35}$ un proyecto, a partir de las fotografías históricas existentes, confrontándolo con la información obtenida de las fuentes literarias y

\footnotetext{
${ }^{33}$ En 2003 se produce una inicial curiosidad por la obra de Wittgenstein que rápidamente devino en interés por su producción extra-filosófica. En julio de 2012 se presentó el trabajo de investigación con el que se obtuvo la suficiencia investigadora. En ese momento se explicitó ya el deseo de que la tesis doctoral bien pudiera ser el proyecto de la casa de Wittgenstein en Skjolden.

34 Una sucinta búsqueda en la red de la palabra «Wittgenstein» nos muestra más de 12.500 .000 resultados; concretando algo más «Wittgenstein +architecture» 412.000; «Wittgenstein +Norway» 340.000; «Wittgenstein +architecture+Norway» 50.000; «Wittgenstein + architecture + Norway +Skjolden» 40.000 y «Wittgenstein+Skjolden» unos 8.600 resultados. (Accedido en mayo 2015).

${ }^{35}$ El dibujo es la palabra del arquitecto. Pero el acto de dibujar es imaginar y por tanto modificar la realidad. Al no existir tal realidad de confrontación, como era el caso, sino unas borrosas imágenes en blanco y negro, la obsesión de recrear lo percibido en ellas, a través de un dibujo arquitectónico ha condicionado todo el trabajo gráfico (y generado muchas discusiones con Connearn).
} 


\section{facebook}
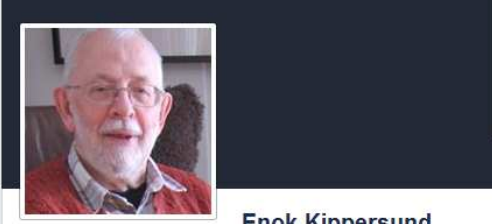

Enok Kippersund

Reisa The expedition

\begin{tabular}{|c|c|c|c|}
\hline Bilde og kommentarar $\sim$ Pitures and comments & & Ludwig Wittgenstein - brikeripieces & \\
\hline Vi er klar $\sim$ We are ready & start & Den niande reisefellen $\sim$ The ninth travelmate & LW01 \\
\hline Nordkapp North Cape & nordkapp & Om "Det stille alvoret" About "Wittgenstein and Norway" & LW02 \\
\hline Tromsø Tromsoe (1) & tromsoe & Wörterbuch für Volksschulen & $\lfloor$ LW03 \\
\hline I skipsleia In the fairway & leia & Dei to bøkene $\sim$ The two books & $\lfloor$ LW04 \\
\hline Svartisen Svartisen Glacier & svartisen & W. in Norway - back cover text & $\lfloor$ LW05 \\
\hline Langs Skjomenfjorden Along the Skjomen Fjord & skjomen & Wittgensteinarkivet $\sim$ The Wittgenstein Archives & LW06 \\
\hline Finmarkskysten $\sim$ The Finmark Coast & finmark & The Duty Of Genius & $\underline{L W 07}$ \\
\hline Regine Normann. Krabvåg (Norwegian) & krabvág & $\begin{array}{l}\text { A quote from: Kjell S. Johannessen: Philosophy, Art and Intransitive } \\
\text { Understanding }\end{array}$ & $\underline{L W 08}$ \\
\hline Lofoten fisheries and fishery stations (English) & fishery & $\begin{array}{l}\text { Frå "Undersokelser" Vil bli lagt inn så snart som mogleg - Will be installed } \\
\text { as soon as possible. }\end{array}$ & \\
\hline $\begin{array}{l}\text { Namnet Nord-Norge under lupa - Utdrag frả artikkel av Einar Niemi + } \\
\text { bildeserie av Enok Kippersund (Norwegian) }\end{array}$ & identitet & Wittgenstein for nybegynnere $\sim$ Wittgenstein for beginners & $\underline{L W 10}$ \\
\hline
\end{tabular}

enokekippersund.ne

Heim til Hugen Hugen Home

Det stille alvoret

Ludwig Wittgenstein blir rekna som "ein av dei mest innverknadsrike tenkarane i det fjuande hundreáret (DSA). Han gjekk sine eigne vegar og

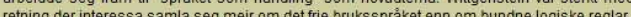

I visse periodar søkte Wittgenstein til Noreg, til bygda Skjolden inst I Lustrafjorden I Sogn. Her fekk han sett opp si eiga hytte. På denne staden fann han ro til a samie seg om vikige deler av aroeidet sitt

Eg etlar meg altsả til ả gjere ei "lesereise" i livssoga og tankeverda til Ludwig Wittgenstein. Den første boka er "Det stille alvoret". Sitat frả denne boka merkjer eg med bokstavane DSA. Eg set hit omtalen pá omslaget av boka

$$
\begin{aligned}
& \text { Det } \\
& \text { stille } \\
& \text { alvoret }
\end{aligned}
$$
'Eg kan ikkje forestella meg at eg kunne ha arbeidd noen stader slik eg gjer her. Det er roa og kanskje det vedunderlece landskapet, eg
meiner det stille alvoret i landskapet. (Ludwig Wittenstein i eit brevi 1936)

Dette skreiv filos ofen i Skjolden, inst i Lustrafiorden. Det var her delar av hovudverka til Wittgenstein blei til, og dette er utgangspunktet for denne biografien av Knut Olav Amås og Rolf Larsen.

Ludwig Wittgenstein (1889 - 1951) er ein av dei mest sentral flios ofane i dette hundreåret. Etter Wittenstein er all filos ofi sprâkfilosofi. Denn

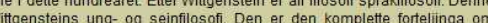
ent kieldemateriale. mellom anna ukjende brev og dagboksnotat.

Kjartan Fløgstad teki etterordet lesarane med pả ei reise i Ludwig Wittgensteins komplekse landskap: Den unge Ludwig Wittgenstein søker seg bort frả sitt storborgare opphav. Han søker ein stad à arbeida i fred og ro. Men han søker seg kanskje ogsả bort frà seg sjolv som modern

M> wittoenstein 03 
La obtenida de los propios autores de las mismas. Se llegó en ese momento 2011- a una propuesta de proyecto con coherencia interna, trasunto de la información con que se contaba a tal fecha. El trazado entonces era plausible. Conviene aclarar que el estudio planteado debía ser sincrónico, y esto era determinante, puesto que un proyecto verdadero debía considerar los conocimientos y los medios de la época y el lugar y desde luego el pensamiento y escenario vital previos de Wittgenstein. Era imperativo recurrir a los archivos históricos no sólo en la búsqueda de material inédito sobre la casa sino para analizar datos sobre la época en que se construyó la casa y sobre el propio Wittgenstein.

Pero el escaso número y profundidad de las fuentes escritas y la inmensidad de referencias electrónicas impulsaron otro tipo de estrategia en la búsqueda de información. Tal fue la de contactar con los principales autores sobre Wittgenstein e indagar si tras las publicaciones podía haber ulteriores informaciones todavía inéditas. La «campaña» de cartas y mensajes de correo electrónico ${ }^{36}$ se inició de la siguiente manera:

«Dear Enok Kippersund,

I've found your website looking for information about the cabin in Skjolden built by Wittgenstein in 1913-14.

I'm a Spanish architect and I'm working on "great thinkers" houses, like now Wittgenstein, Jung, Woolf,...I'm really interested in the bibliography you introduce on your website about 'Wittgenstein in Norway', because I have not heard before about these authors: Åmås and Larsen.

You say in your blog that there's probably an English version of these books. I've found the second one, called "Wittgenstein and Norway" although it's not possible to buy it (out of print). But I can't find "Det Stille Alvoret: Ludwig Wittgenstein i Norge 19131950" in English. Do you know if there's any English version of this book? Do you know how/where could I find them? I'll be really glad if you can tell me any information about the books or the Wittgenstein's hut in Skjolden, I'm trying to draw it but I have too many doubts of being in the right way. I'm not sure if there's actually any graphic information about the Wittgenstein's cabin in Skjolden, it's too difficult for me here in Spain to find anything about it...

Thanks in advance,

Enrique» ${ }^{37}$

\footnotetext{
${ }^{36}$ Tal como se ha desarrollado esta investigación, hubiera sido altamente improbable haberla podido llevar a cabo sin medios electrónicos. A eso nos referíamos en cuanto a la particularidad de la metodología seguida aquí.

${ }^{37}$ Correspondencia electrónica a Enok Kippersund, 29.06.2011
} 
Dear Olav Ámås,

I appreciate the information about your book "Wittgenstein and Norway". I've tried to find it in Spain but it's definitely impossible for me, and so far I have not either found it on internet. I hope to succeed

because I'm really interested in everything that refers to Wittgenstein's relationship with Norway, in order to understand the quiet gravity he needed to work, and the parallelism between this requirement and other great thinkers of the history to produce their work...but always from my point of view as an architect (reflexion as a refuge and a refuge for reflexion)

I also thank you a lot for informing David Connearn about my interest about Wittgenstein's hut. Hopefully

Mr. Connearn could give me some information about the hut's reconstruction project.

Best regards,

Enrique Clemente

[I include in cc Enok Kippersund]

$\mathrm{ECQ}$

panta rhei - everything flows
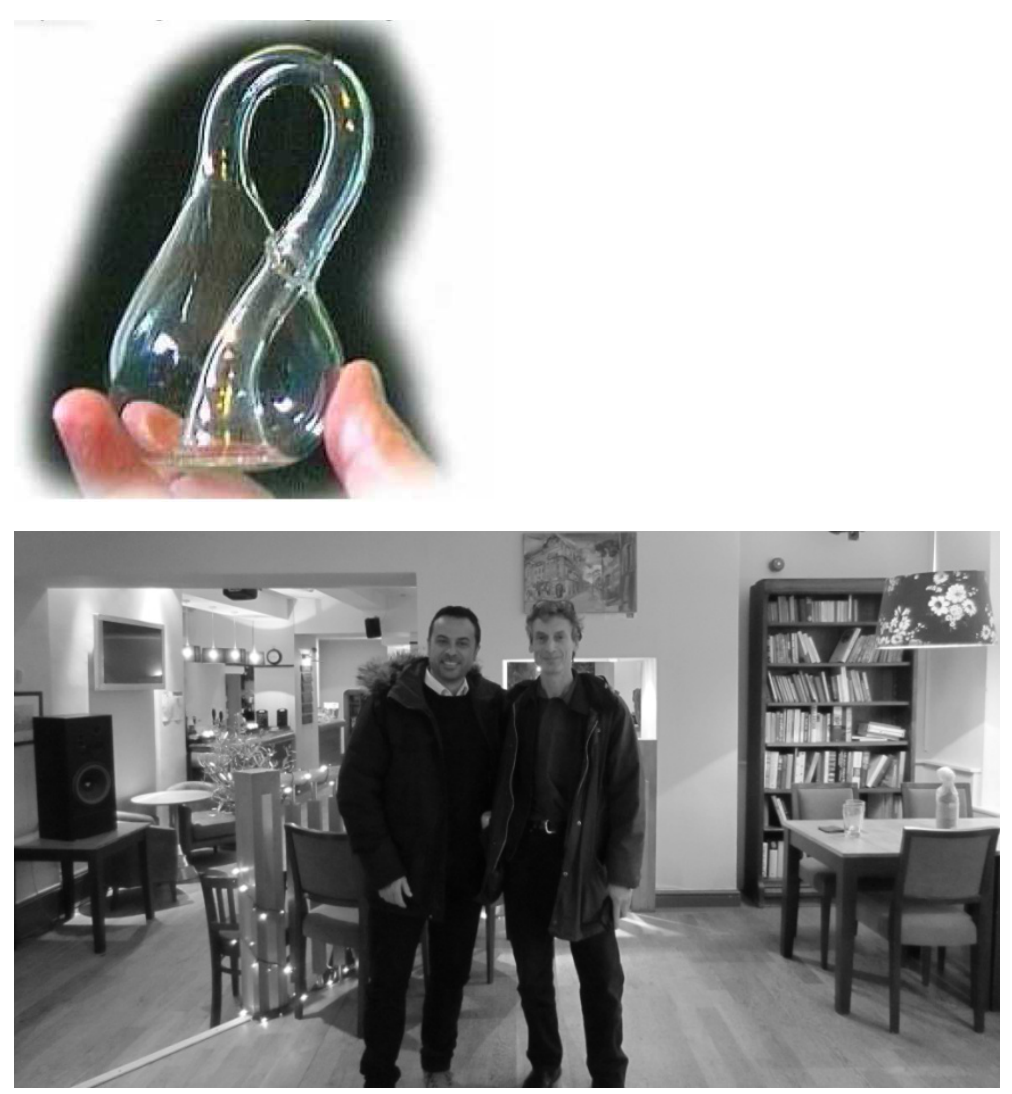

75. Correspondencia electrónica a Knut Olav Åmås, 04.07.2011

76. Imagen de «la mosca en la botella», metáfora de la filosofía para Wittgenstein en correspondencia electrónica de D. Connearn, 04.08.2012

77. Con David Connearn, Cambridge, 31.12.2013 
Y la amable y rápida contestación de Kippersund:

29.06.2011 To Enrique Clemente

«Dear Enrique!

Your mail was quite a surprise, -a nice surprise.

I will try to get in contact with Olav Åmås, who is in front for a rebuilding of the Wittgenstein's cabin. If I succeed I will submit Åmås' adress to you, -I hope tomorrow. Most friendly regards,

Enok»

A partir de esta primera prometedora contestación, la metodología de la investigación se modificó profundamente, pasando de la revisión bibliográfica secuencial y de futuribles visitas al lugar, al contacto directo con los principales investigadores europeos en el asunto, y la sorprendente constatación de que parecía existir una propuesta de reconstrucción de la casa de Wittgenstein. Este será el segundo aspecto que modificará ya para siempre el propósito de la investigación, como se explicará más adelante.

En un primer contacto con Knut Olav Åmås, este redirigía mi petición de información a David Connearn:

\subsubsection{To Enrique Clemente}

«I have forwarded your request to David Connearn, who heads this work. Det stille alvoret is the complete story of Wittgenstein's years in Norway. Only pars of it are translated to English in Wittgenstein and Norway.

Knut Olav Åmås

Kultur-og debattredaktør, Aftenposten»

David Connearn se puso en contacto el 20 de julio de 2011:

\subsubsection{To Enrique Clemente}

«[...] We have the same desire I think. I have been working towards the comprehensive conservation of the site and house since 1999, and one problem is that there is no other documentation in public domain other than that which you list. Of course this is a deplorable state of affairs, and it is absolutely necessary that a complete documentation of the building should be provided in order to establish a complete and perspicuous record of Wittgenstein's architectural endeavours. 

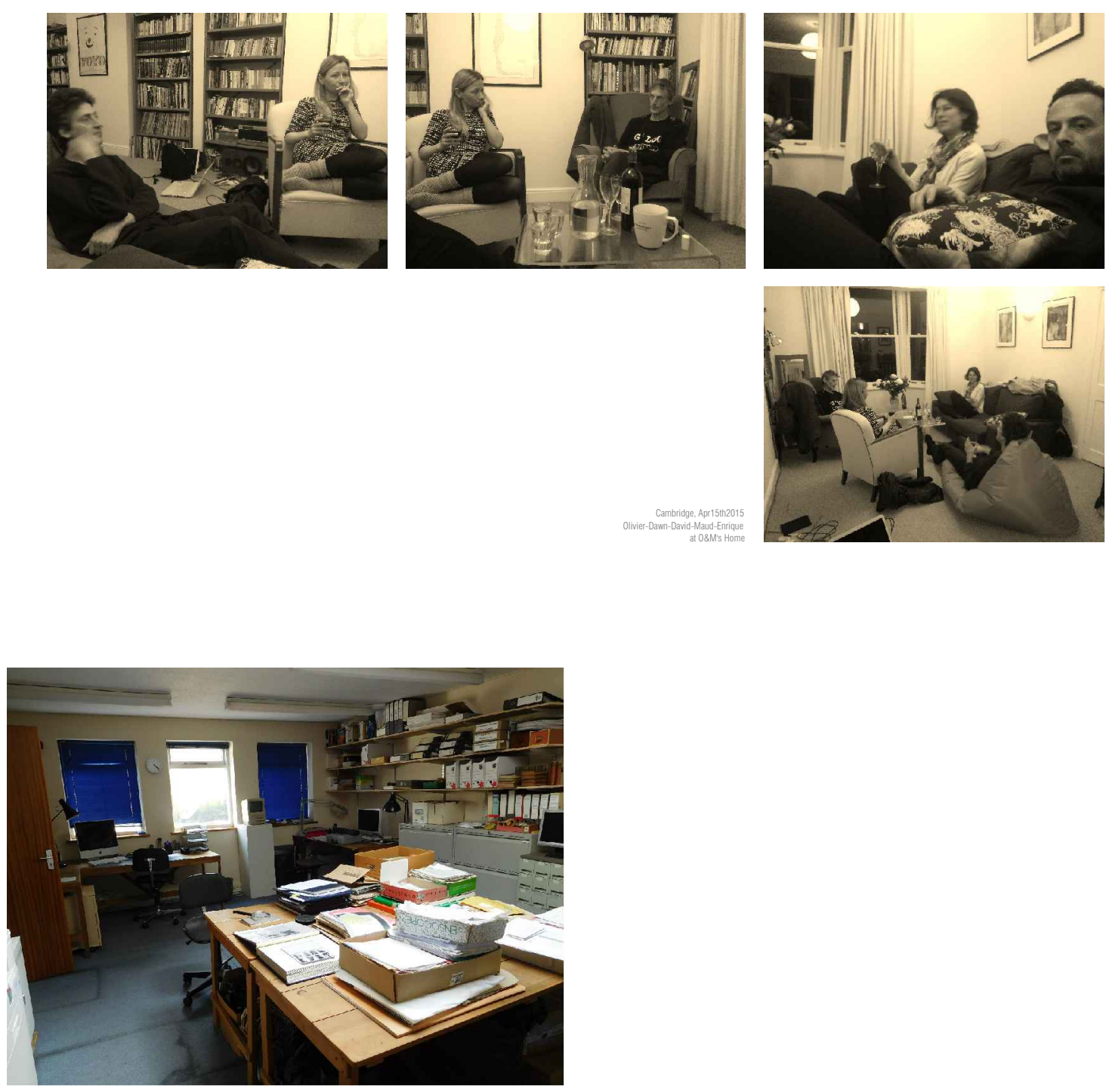
It may be necessary to gather International support requesting a documentation of the house as a necessary preliminary stage of a conservation assessment. Should this become the case, I hope to be able to call upon your support.

Keep in touch,

David»

Más de un centenar de mensajes de correo electrónico y dos viajes a Cambridge separan aquel momento de este. El intercambio de reflexiones con Connearn y un tiempo después con Dawn M. Wilson ${ }^{38}$ ha sido intenso y productivo. El trabajo previo desarrollado hasta 2012 (pese a haber conocido a Connearn en 2011, no es hasta 2012 cuando se presenta el resultado del trabajo de investigación) se vio cuestionado hasta el punto de ser necesario reiniciar el proyecto de la casa por completo.

En el transcurso de 2012 se mantuvo correspondencia con otros autores, Ivar Oxaal (Hull, UK), cuya referencia bibliográfica ha sido muy importante ${ }^{39}$ :

\subsubsection{To Enrique Clemente}

«Dear Enrique,

Many thanks for your interest in my book about Wittgenstein. I would be happy to help to give you as much information as I can. However, I can't do so immediately as I am expecting relatives visiting me from the US tomorrow to spend a week, but I will email you in a few days.

Best wishes,

Ivar»

\section{Harald Vatne (Skjolden, Noruega):}

\subsubsection{To Enrique Clemente}

«Thank you for your letter.

I am part of a group that plans to move Wittgensteins house back to its original settting. I will send you more information as the work goes on.

Harald Vatne»

\footnotetext{
${ }^{38}$ Dawn M. Wilson (Phillips de soltera) es profesora titular de filosofía en la Universidad de Hull. Es miembro de la British Society of Aesthetics, la British Wittgenstein Society y la Nordic Wittgenstein Society. Sus investigaciones arrancan en la «Picture-Theory» de Wittgenstein.

${ }^{39}$ Ivar Oxaal, On the Trail to Wittgenstein's Hut. The Historical Background of the Tractatus logico-philosophicus, (New Brunswick, New Jersey: Transaction Publishers, 2011)
} 

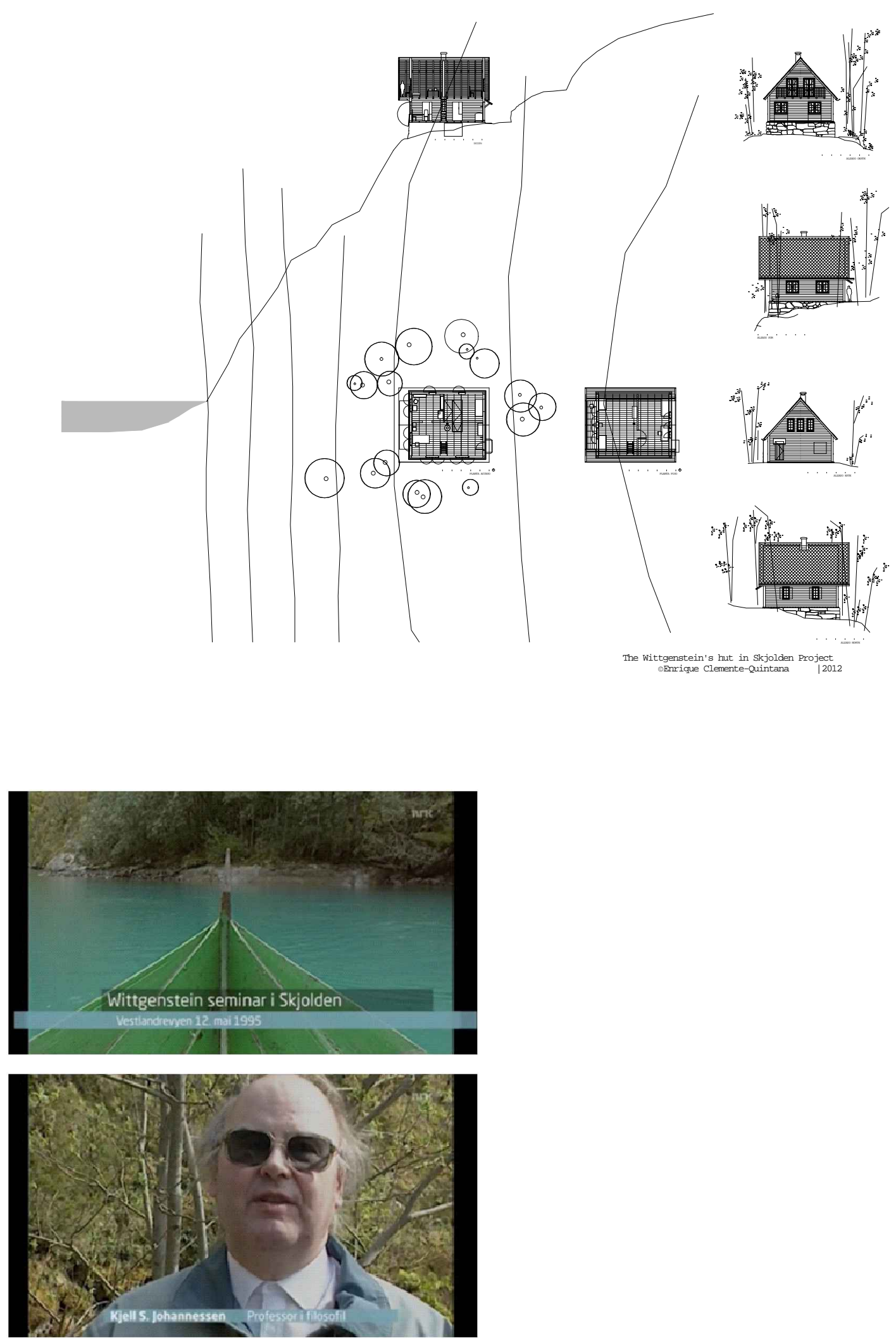

80. Proyecto de la Casa de Ludwig Wittgenstein, versión julio 2012

81. Lago Eidsvatnet, Skjolden, 12.05.1995

82. Kjell S. Johannessen entrevistado en el plinto de la casa de Wittgenstein, 12-05.1995 
Se inicia aquí, como se ha adelantado en la sección anterior el segundo plan de viaje. Tras descartar el proyecto previo desarrollado hasta 2012 se hace imperativo viajar ${ }^{40}$ a Noruega y a Cambridge. En Skjolden -octubre 2013- se realizó una toma de datos exhaustiva de los restos de la casa en el lago; entrevistas a Harald Vatne; visitas y toma de datos de la casa Bolstad; visitas al archivo regional -Fylkesarkivet i Sogn og Fjordane; análisis de construcciones en madera de principios del s.XX. En Bergen se realizó visita al Wittgenstein Archive en el que se desarrolló la edición en versión electrónica del Nachlass ${ }^{41}$ íntegro de Wittgenstein, The Bergen Electronic Edition, y en la que consta la correspondencia de Wittgenstein escrita desde Noruega en los periodos que pasó en su casa del lago. Además se tuvo oportunidad de contrastar opiniones y escuchar sugerencias de Alois Pichler (1966), director del archivo y con Kjell S. Johannessen (1936), coautor con Åmås y Larsen de una de las referencias bibliográficas principales para esta investigación Wittgenstein and Norway:

«A. Pichler:-Creo que no tiene sentido reconstruir la casa de Wittgenstein.»

«K. Johannessen: -Hace veinte años ya lo intentamos pero los Bolstad no querían saber nada del asunto.»

«A. Pichler: -Bien, pero aunque se hiciera, ¿con qué propósito? ¿Quién iría allí? No parece un sitio cómodo.»

«K. Johannessen: -Yo sí que hubiera ido de joven. Ahora ya no podría subir hasta la casa.»

En Cambridge -diciembre y enero de 2013 y abril de 2015- se ha tenido la oportunidad de investigar entre los manuscritos de Wittgenstein y George E. Moore y tener acceso al único material gráfico existente de la casa de Skjolden, las fotografías tomadas por Wittgenstein y Ben Richards en octubre de 1950 y poder consultar multitud de documentos originales en el Wittgenstein Archive

\footnotetext{
${ }^{40}$ Toda la investigación ha sido realizada con fondos propios. Voluntad, capacidad y oportunidad no siempre se alinean.

${ }^{41}$ Nachlass en alemán, se traduce como «legado» 0 «herencia». Es la forma como se conoce entre los investigadores la obra de Wittgenstein en su conjunto.
} 

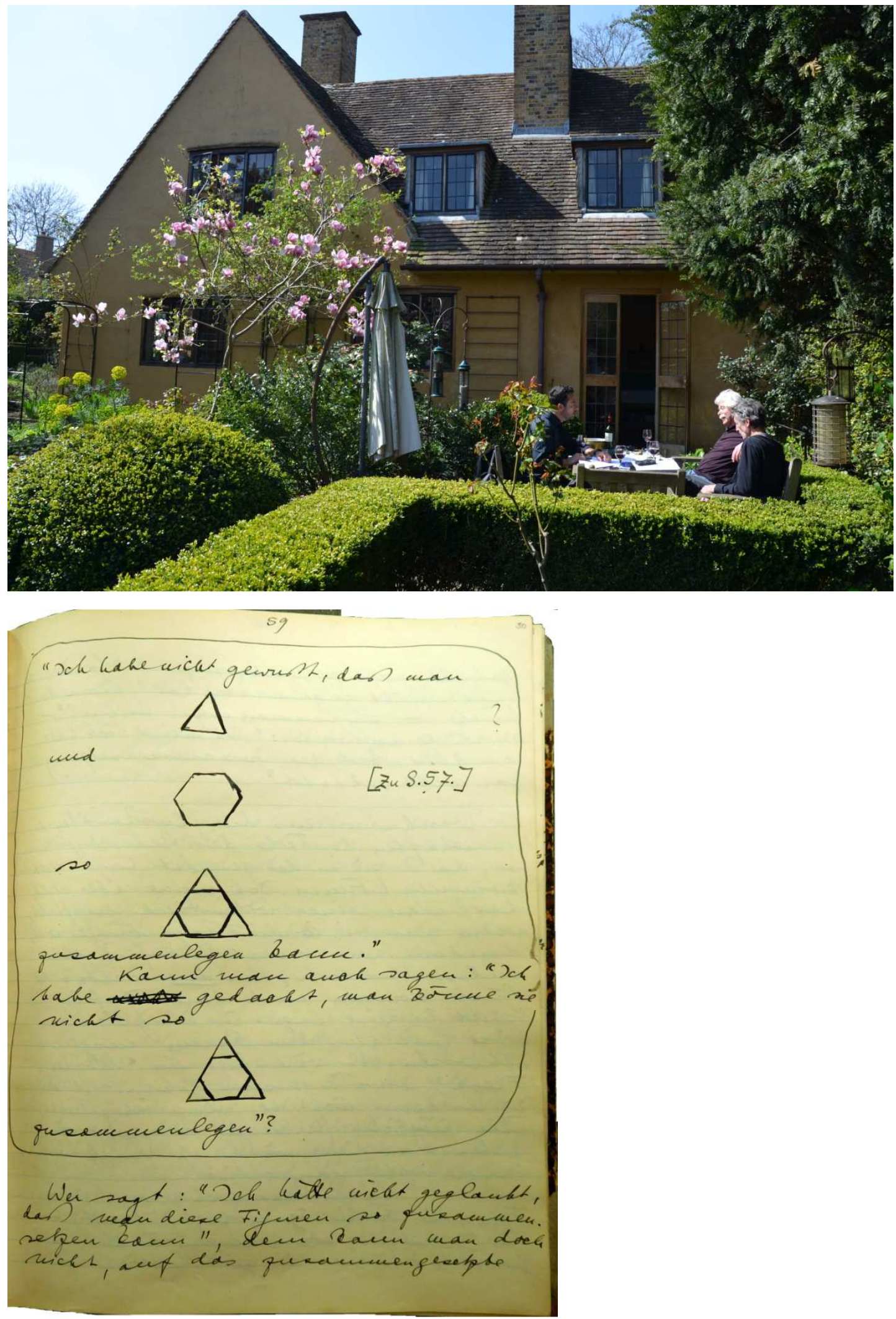

83. Conversación con Michael Nedo y David Connearn en casa de Nedo, Cambridge, 15.04.2015 84. Manuscrito de Wittgenstein, Wren Library, Cambridge, abril 2015 
Cambridge, tutelado por Michael Nedo. Las reuniones mantenidas con Nedo, Connearn y Wilson en esa ciudad, han sido clave en esta investigación.

El contenido de la tesis se ha podido ordenar secuencialmente con el objetivo de crear un marco de referencia e interpretativo de la casa de Wittgenstein en Skjolden y de la propia investigación, que nos permitiera entender el proyecto propuesto en este documento, porqué se llega al mismo y bajo qué premisas, cuestión esta mucho más compleja de lo que pudiera parecer al inicio. Además se plantea un capítulo importante de conclusiones, a modo de epílogo abierto, en el que se presenta la situación actual del proyecto de reconstrucción de la casa y de las diferentes líneas de investigación que se han ido abriendo paso durante todo este proceso.

La estructura del documento se organiza con una introducción y los siguientes bloques generales:

\section{Contextualización.}

¿Por qué un filósofo austríaco, estudiante y más tarde profesor en Cambridge, decide trabajar en completo aislamiento en Noruega? Trazaremos los escenarios mentales posibles que llevaron a Wittgenstein a Noruega. Contextualizaremos el lugar, pero también el espacio y la persona. La vida y la obra de Wittgenstein son un «estar en el mundo», por lo que no podremos soslayar el contexto de su pensamiento, de su intelecto en general, incluyendo sus planteamientos respecto a la arquitectura. Es común encontrar, en la literatura sobre Wittgenstein, el componente mítico, heroico, de no haber tenido compañeros de viaje intelectuales. Veremos que Wittgenstein se refirió a ellos en numerosas ocasiones y suponen la entretela que da cuerpo, parcialmente, a su pensamiento. 
IIH. $\overline{\text { WAC }}$

MICHAEL NEDO

DAVID CONNEARN

ONL

DAWN WILSON

W. lacer cim!

INT. INTEREST

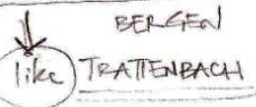

Wittzentein

severius

xARTS no la filloofre

nú la eurrión

piodercide

Sol Lamí

"life of $w "$

fiem?

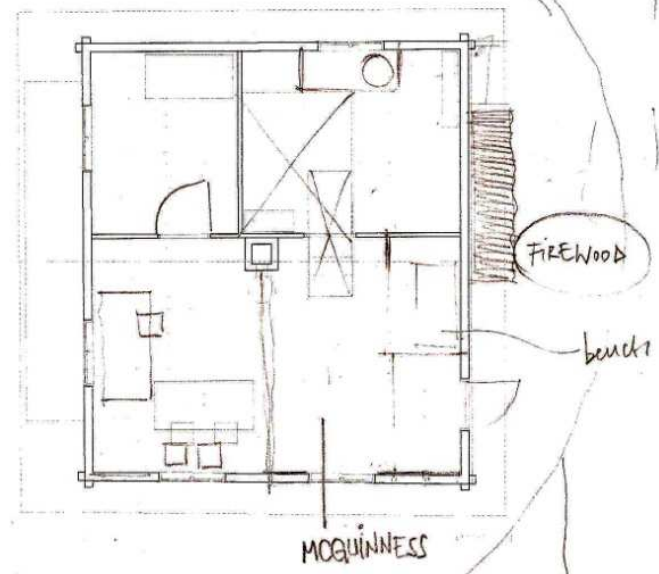

He's neding Goethe

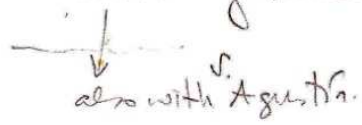

ARGOMEATTO SOBRE

( $\quad \angle A M U S I C A \rightarrow T L P$

$\rightarrow$ QNOTING WHO?

(Prefare)

FAIRY TILE fisherman

PUsikin (Catctia gold firth)

$$
\begin{gathered}
\text { The tale of the } \\
\text { Fisheman } x \text { the firt" } \\
\text { change the } \\
\text { object, if you chauge } \\
\text { the point of view. }
\end{gathered}
$$

kaut $\rightarrow 4$ lo que no puede sel dictio<smiles>[TeH2]</smiles>

\section{PAESILEY}

Bider between aght and

Realided no $x$ juede defwir.

clenk is the plan we an

alvagn worng.

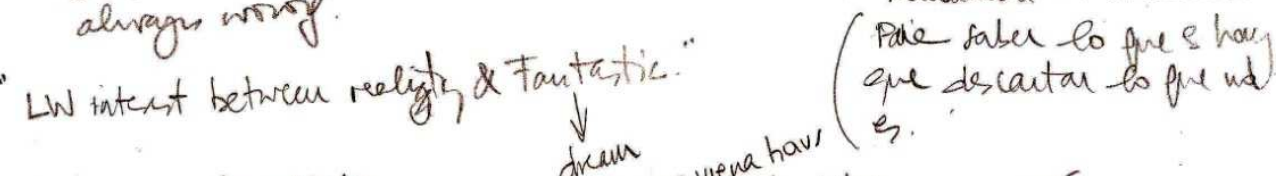

"Remarkable $\rightarrow$ to Duntet

1910 rameniton peldids draur for viena havl

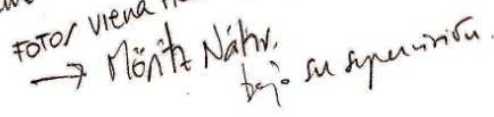




\section{Proyecto de la casa de Wittgenstein en Skjolden}

En 1914 Skjolden es un lugar tranquilo, cien años después también lo es. Está metafóricamente lejos de todo, pero no es inaccesible. Es suficientemente calmo para cualquier persona pero la situación de la casa abunda en el aislamiento. ¿Por qué allí? ¿Significa arquitectónicamente algo la soledad para Wittgenstein? ¿Sabemos cómo utilizó la casa?

Contamos con escasísima documentación gráfica, aún menos testimonios de personas que la conocieron y la casa ya no se eleva en la orilla del lago. ¿Cómo la hemos proyectado? Se plantea aquí el trabajo iterativo de dibujo a partir de las imágenes. El sistema de propuesta y revisión, con el objetivo de alcanzar la coherencia de composición y construcción, de la técnica y de los anhelos del proyecto.

\section{Epílogo}

La tesis ha abierto nuevas posibilidades de conocimiento de la casa de Wittgenstein en Skjolden. Pone énfasis en la revisión del pensamiento de Wittgenstein y la arquitectura. Redefine los estudios históricos que centraban el foco de interés de la producción extrafilosófica de Wittgenstein en la Kundmanngasse, no sólo eso sino que se abren nuevas líneas de investigación, como el tratamiento de las teorías de la planta espacial, entre Loos y Wittgenstein, o el análisis de qué hay de arquitectura vernácula en ello, ¿es el campo el origen del Raumplan?

Pero sobre todo plantea por primera vez un proyecto de arquitectura de la casa, a partir del análisis exhaustivo de la información histórica disponible y que ha llevado a que esta tesis pueda formar parte del estudio internacional que plantea la reconstrucción de la casa de Wittgenstein en su situación original. Queda mucho camino por recorrer pero conseguir establecer un vínculo directo entre el trabajo académico de una tesis y el proyecto real verifica por sí mismo lo que se decía al principio, una investigación de arquitectura es un proyecto de arquitectura. 
« FUTILE ATTEMPT AT ORGANISING MY THESIS "

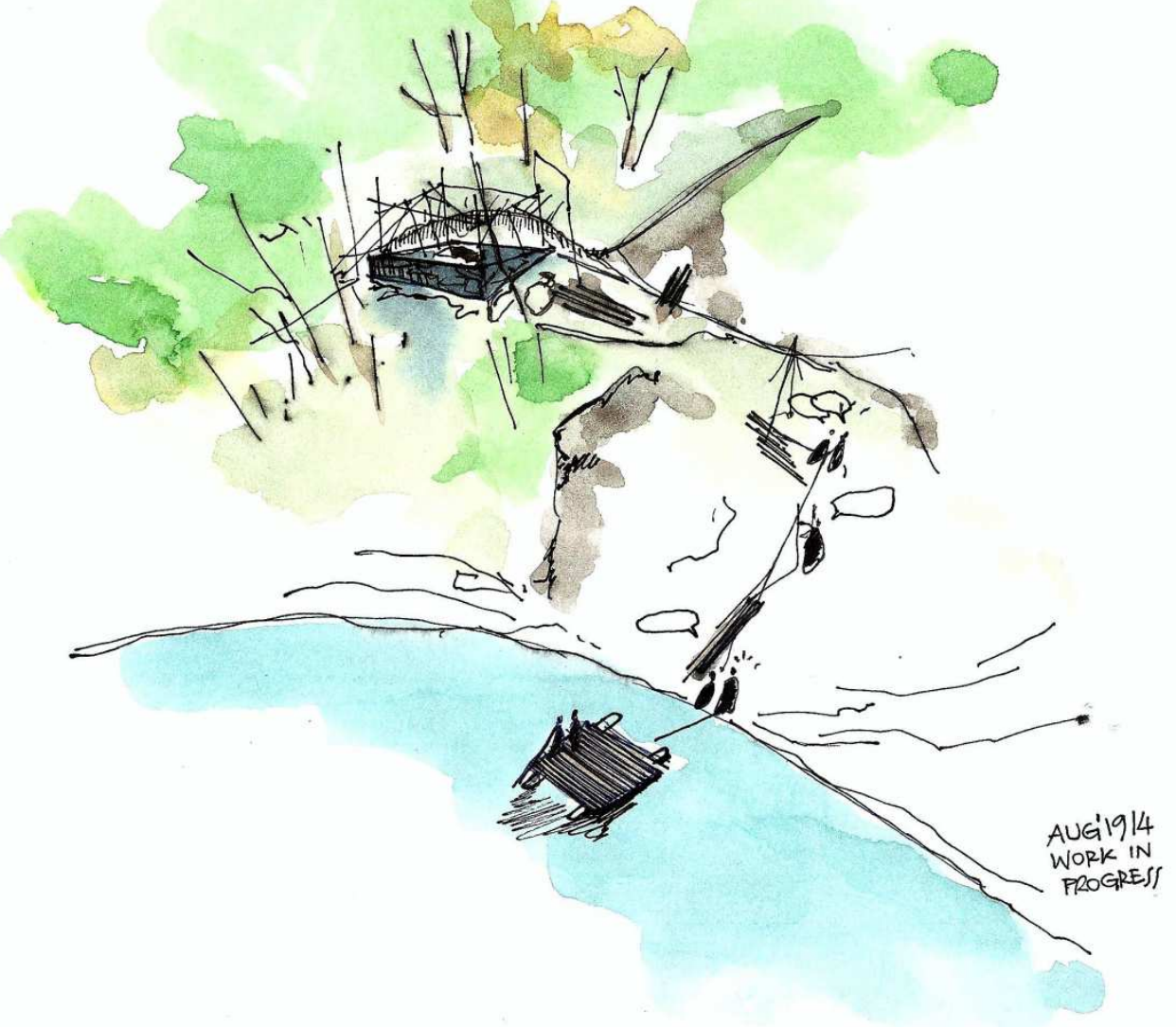


Empezamos enseguida a desgranar el proyecto, los libros rebosantes de señaladores, la libreta abierta, el correo electrónico siempre actualizado y la maleta a medio deshacer. Estamos listos para proyectar Austria. ${ }^{42}$

${ }^{42}$ Los lugareños conocían a Wittgenstein como el Østerriker y al lugar donde construyó su casa Østerrike. A unos metros de la casa hacia el sur, sobre la ladera, se instaló hace años un mástil con una bandera austríaca. 

02 CONTEXTUALIZACIÓN 

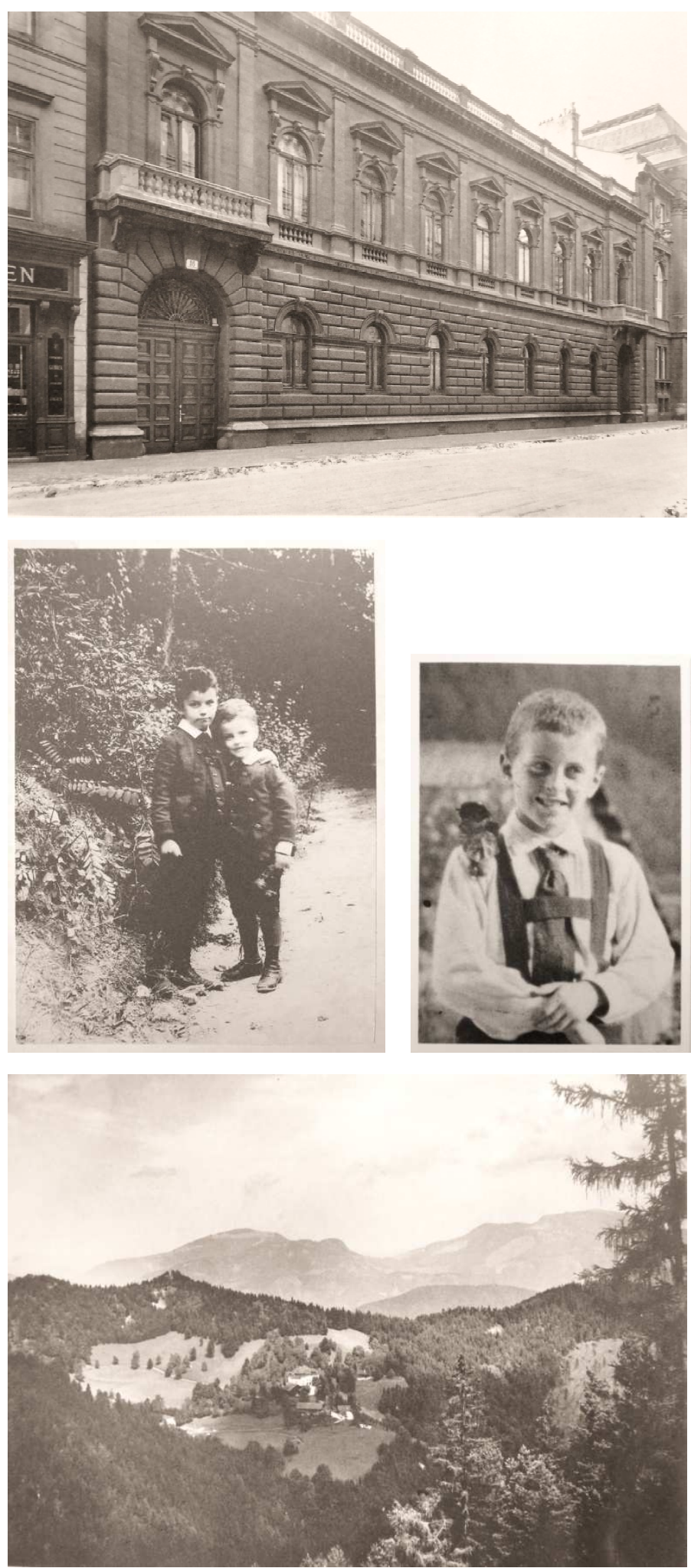

1. Palais Wittgenstein, Alleegasse 16, Viena

2. Paul y Ludwig Wittgenstein | 3. Ludwig jugando con un pájaro. Uno de sus intereses adultos fue la observación de estos animales 4. Residencia estival de la familia Wittgenstein, Hochreith (Austria) 


\section{Ludwig Wittgenstein en Noruega}

«I think he talked for quite a while and certainly said many things I do not know remember. At one stage I cried out: "What is it? You want to be perfect?" And he pulled himself up proudly, saying: "Of course I want to be perfect!".»"

Ludwig Josef Johann Wittgenstein nació en la residencia familiar, el Palais de invierno, que la familia Wittgenstein poseía en la Alleegasse, a las 20:30 del 26 de abril de 1889, en Viena, Austria. Murió en la casa del Dr. Bevan en Storeys End, Cambridge, Inglaterra, la mañana del 29 de abril de 1951. La víspera de su muerte, antes de quedar inconsciente, pidió a la señora Bevan que dijera a sus amigos:

«Tell them I've had a wonderful life!».2

Norman Malcolm, amigo de Wittgenstein desde 1938, comentaba en la semblanza que hizo de este en 1958:

«Por "ellos" se refería sin duda a sus amigos más íntimos. Cuando pienso en su profundo pesimismo, la intensidad de su sufrimiento moral y mental, el camino implacable que guió su intelecto, su necesidad de amor junto a la aspereza con la que lo rechazaba, me inclino a pensar que su vida fue ferozmente infeliz. iY justo al final él mismo exclamó que había sido "maravillosa"! Esto me parece un comportamiento misterioso y extraño.» ${ }^{3}$

Ludwig fue el menor de ocho hermanos, cinco hombres y tres mujeres. De los cinco, tres cometieron suicidio, Hans, Rudolf y Konrad ${ }^{4}$. El padre, Karl Otto Clemens Wittgenstein (1847-1913), industrial del acero de éxito ${ }^{5}$ y generoso mecenas del arte vienés tuvo una personalidad dominante. La madre Leopoldine

\footnotetext{
${ }^{1}$ Fania Pascal, en Rhees, op. cit. p. 50. Rememora una conversación con Wittgenstein en enero de 1937.

${ }^{2}$ Monk, op. cit. p. 521

${ }^{3}$ Norman Malcolm, Ludwig Wittgenstein A Memoir, (New York: Oxford University Press, 1977), p. 100.

${ }^{4}$ A Hans, niño prodigio musical, le dieron por desaparecido en 1902 en una embarcación en Chesapeake Bay (o en Everglades, Florida, o en La Habana porque no hubo acuerdo sobre ello). Rudolf, en 1904 entró en un bar y tras pedir al músico que interpretara Estoy perdido, bebió de un frasco de cianuro. Kurt, en 1918 se disparó tras la negativa de sus hombres a acatar sus órdenes durante la retirada de las tropas en la Primera Guerra Mundial. Ludwig también mostró durante toda su vida tendencia a la autodestrucción.

${ }^{5} \mathrm{~A}$ la fortuna en los negocios sumó la riqueza familiar de su esposa Leopoldine. Cuando se retiró a los cincuenta y un años era inmensamente rico. Karl rechazó el ofrecimiento de formar parte de la nobleza, prefería seguir siendo considerado un «hombre hecho a sí mismo».
} 

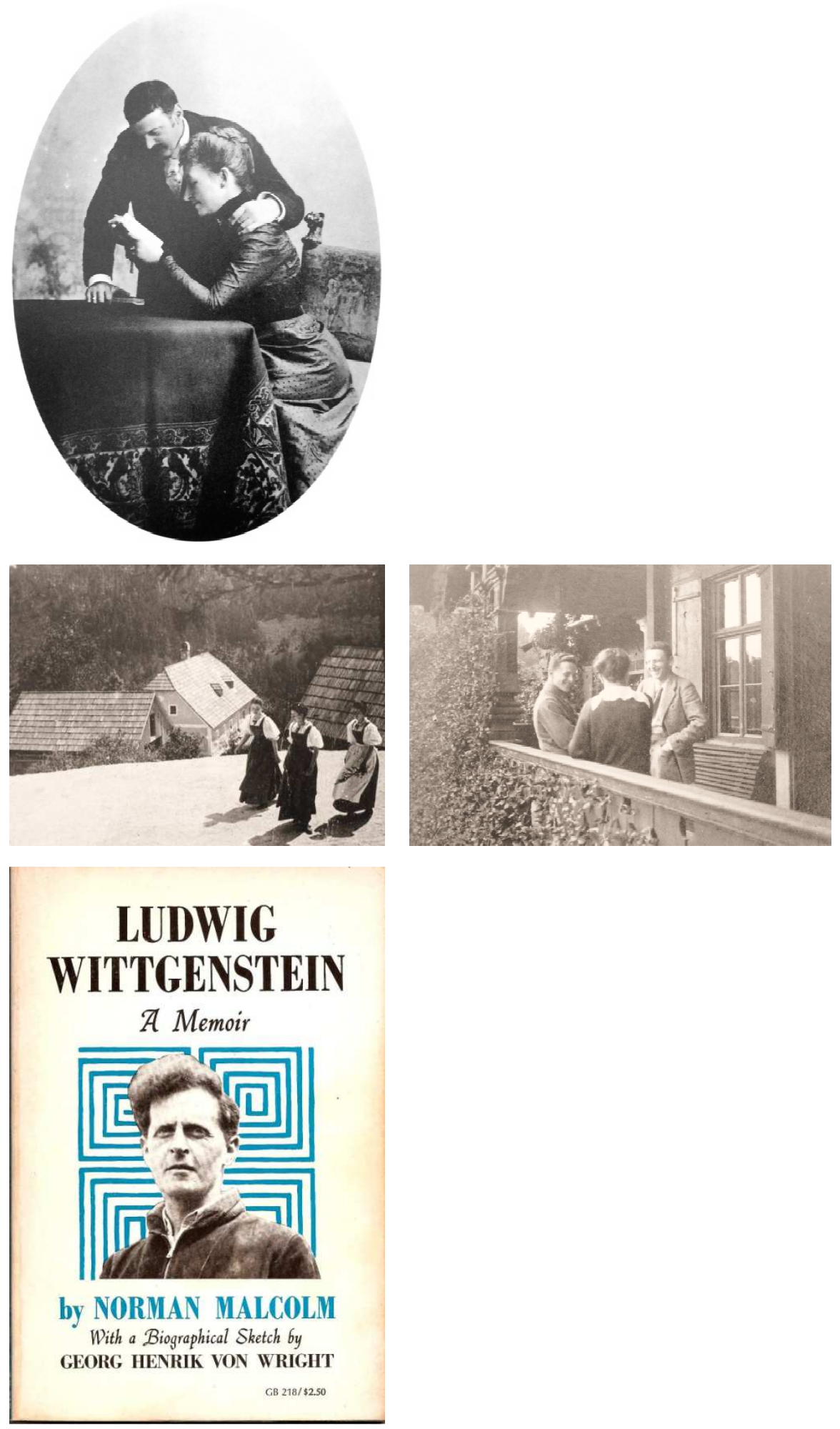

5. Karl Wittgenstein y Leopoldine Kalmus-Wittgenstein

6. Helene, Margaret y Hermine Wittgenstein en Hochreith ～7. Ludwig, Helene y Paul Wittgenstein en Hochreith, 1914 8. Biografía de Wittgenstein por N. Malcolm, 1958 
Maria Josefa Kalmus (1850-1926), fue una devota cónyuge y una figura ausente cuando no extraña para sus hijos. El único nexo entre el mundo y ella era la música y los hijos fueron educados en el respeto a los grandes compositores clásicos. Ludwig siempre se mantuvo firme, inamovible, en sus juicios musicales, sólo valía la pena escuchar a los seis grandes: Haydn, Mozart, Beethoven, Schubert, Brahms y Labor.

Ludwig fue considerado el menos talentoso de los hermanos. Su carácter sumiso -él consideró esa etapa de su vida indeseablemente deshonesta ${ }^{6}$ - hizo que su padre encontrara por fin, un vástago al que dirigir hacia la ingeniería y por ende los negocios familiares en la siderurgia.

«When I was about 8 or $9 \mathrm{I}$ had an experience which if not decisive for my future way of life was at any rate characteristic of my nature at that time. How it happened, I do not know: I only see myself standing in a doorway in our house and thinking: 'Why should one tell the truth if it's to one's advantage to tell a lie? I could see nothing against it.». ${ }^{7}$

En un contexto de exquisitez cultural y de elevados ideales morales y patrióticos se crió el joven Wittgenstein.

Hasta los catorce años la educación académica de Ludwig se dejó en manos de instructores privados -de igual manera que al resto de hermanos-, pero en 1903 fue enviado a Linz a estudiar en la K.u.k. Realschule ${ }^{8}$, en la rama científico-técnica $^{9}$. Paul estaba convencido que a Ludwig le iría muy bien sobre todo en física, en línea con las preferencias que mostraba desde pequeño. Sin embargo sus calificaciones fueron mediocres, destacando sólo en Religión y algo en Comportamiento e Inglés. Sus peores resultados se dieron en Alemán,

\footnotetext{
${ }^{6}$ Su carácter se modificó a partir de 1908, cuando ya en Manchester empezó a desviar su interés por la aeronáutica hacia los fundamentos de la matemática. La sumisión a su padre empezó a flaquear y en 1912 Karl dio por perdida toda esperanza de tener un sucesor en los negocios familiares entre sus hijos. En cualquier caso, para entonces ya estaba siendo tratado del cáncer que acabaría con él en enero de 1913.

${ }^{7}$ En McGuinness, 1988, op. cit. p.48. Wittgenstein fue un crítico temible pero un autocrítico no menos feroz.

${ }^{8}$ La referencia a que coincidió en la escuela de Linz con Adolf Hitler parece obligada en toda biografía escrita sobre Ludwig Wittgenstein, aunque carece de sentido aportar tal dato sin indicar al menos que Wittgenstein se sintió de alguna manera corresponsable de la tragedia judía perpetrada por el III Reich. Sobre ello el controvertido libro de Kimberley Cornish The Jew of Linz, 1998. Los principales estudiosos de Wittgenstein, como Monk o McGuinness tildan tal teoría de pura fantasía malintencionada. El propio Wittgenstein tuvo episodios autodestructivos constantes durante los años treinta y cuarenta respecto a su origen judío. Trató de depurar su propia conciencia con una serie de confesiones en conversaciones y cartas a su familia y amigos. Ver por ejemplo el sufrimiento que supuso tal situación a Fania Pascal en Drury, 1981, op. cit. p. 48 y ss.

${ }_{9}^{9}$ Paul fue enviado al instituto público el gymnasium Wiener Neustadt, de formación más clásica. Parece que en Linz, aparte de ofrecer materias
} de la rama técnica, las pruebas de acceso eran más ligeras que en el gymnasium. Tal era la confianza de Karl en su pequeño Luki. 

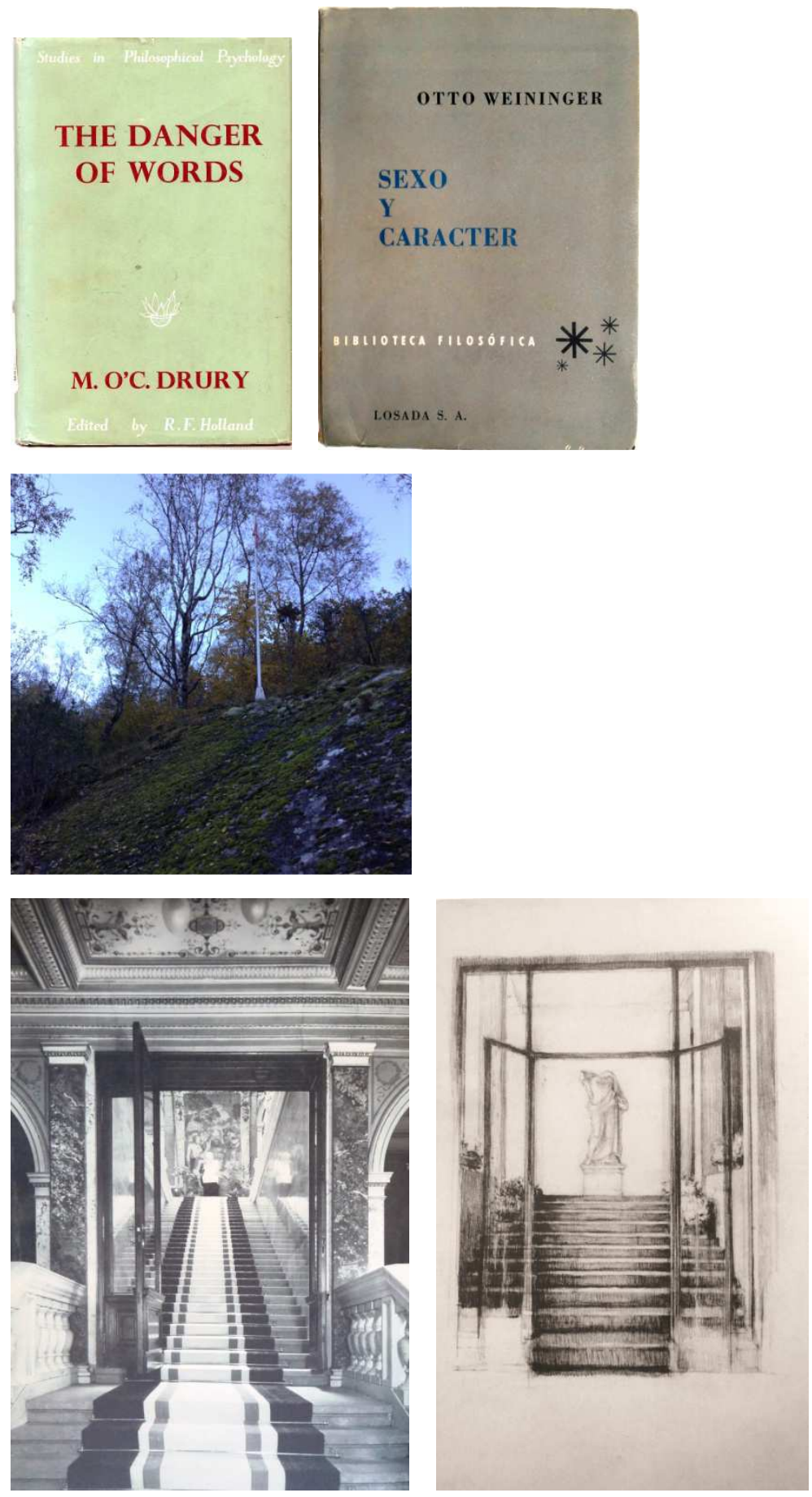

9. Maurice O'Connor Drury, The Danger of Words $\mid$ 10. Otto Weininger, Sexo y carácter

11. Skjolden, bandera de Austria junto al plinto de la casa de Wittgenstein

12. Escalera de acceso Alleegasse 16, Viena | 13. Escalera acceso Kundmanngasse 19, Viena 
Química, Geometría Descriptiva y Dibujo Artístico ${ }^{10}$. En 1906 accede a la Technische Hochschule de Berlín-Charlottenburg y desde esa fecha hasta finales de 1912, Wittgenstein sufre un periodo de constante infelicidad, puesto que no conseguía encontrar una ocupación en la que él creyera destacar. Es este un rasgo muy importante de su carácter puesto que lo que obsesionaba a Wittgenstein era sencillamente ser un genio. El exigente temperamento familiar transmitido a través de la excelencia artística y las tempranas lecturas de Weininger determinaron la necesidad en el joven Wittgenstein de buscar la perfección. Ninguna situación intermedia tendría ya sentido en su vida. La influencia de Otto Weininger, autor moralista cuya principal obra fue Geschlecht und Charakter, ${ }^{11}$ fue decisiva en la conformación del carácter de Wittgenstein. Así lo recoge su conversación con M. O’C. Drury²:

«He did advise me to read Sex and Character saying it was the work of a remarkable genius.» ${ }^{13}$

Weininger distingue en su libro entre talento y genio. Wittgenstein podía reconocer el talento, por ejemplo el musical, de su familia y la aparente falta de cualquier otro en sí mismo. Optó por buscarlo y aún más, ser un genio. Ser perfecto. Su vida sería en adelante y en todo caso, regida por la rectitud, la honestidad y la búsqueda de la objetividad. «El genio no es heredable, es siempre individual», decía Weininger y «el hombre genial es pues, más complicado, más complejo, más rico».

Esta actitud frente a la vida de uno mismo, forjó el comportamiento de Wittgenstein a partir de su salida de Linz, primero en sus estudios en Berlín y su talento para la aeronáutica -quería haber estudiado con Boltzmann ${ }^{14}$ pero

\footnotetext{
${ }^{10}$ En McGuinness, 1988, op. cit. p.51 y Nedo, 1983, op. cit. p. 58

${ }^{11}$ Sexo y Carácter, en castellano. Aquí se ha consultado la $4^{a}$ edición de Editorial Losada, Buenos Aires, 1959. Sobre la influencia de Weininger en Wittgenstein es imprescindible consultar Allan Janik, Assembling Reminders, 2006, Stockholm, p. 183 y ss.

12 Maurice O'Connor Drury (1907-1976), amigo de Wittgenstein -y también acólito- desde 1929. Se dedicó a la psiquiatría en Dublín en el St Patrick's Hospital, claramente influenciado por el filósofo. En una apartada casa de piedra del hermano de Drury, en Rosro Pier en Connemara, pasó Wittgenstein algunas semanas, en similares circunstancias a las de Noruega, en 1934 y 1948.

${ }^{13}$ Rush Rhees, op. cit. p.106

${ }^{14}$ Ludwig Boltzmann (1850-1906) fue un eminente físico y estableció las leyes de la termodinámica, pero lo que Wittgenstein retuvo de sus lecturas (Monk, 1990; Janik, 2006, entre otros) fue la noción de que llegamos a conocer la naturaleza de las cosas sobre la base de una imagen que nos hacemos de ellas. El concepto de «imagen-significado» sería un pilar fundamental de la filosofía de Wittgenstein.
} 

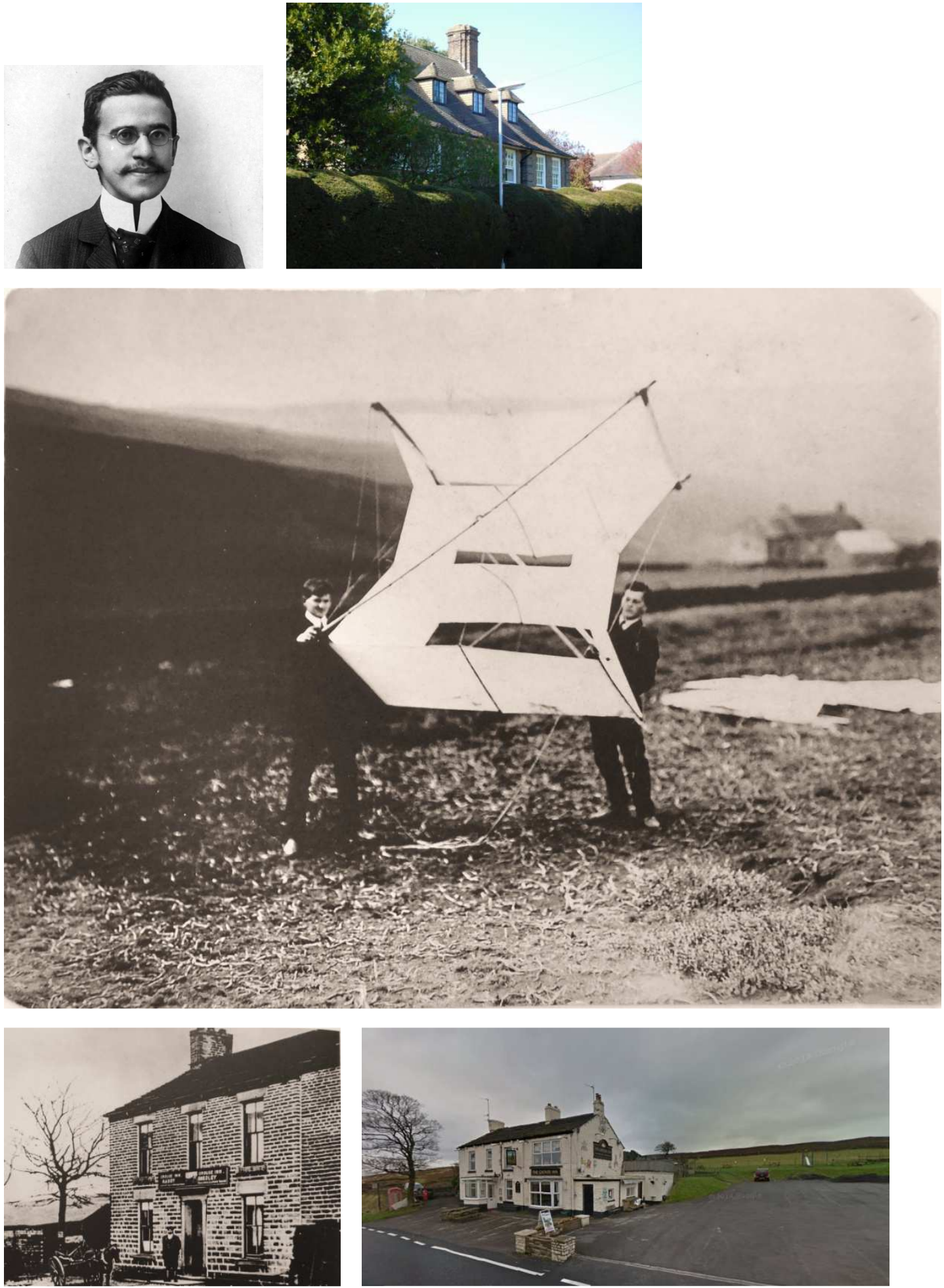

14. Otto Weininger | 15. Casa del Dr. Bevan, Storey's End 76, Cambridge, abril 2015

16. William Eccles y Ludwig Wittgenstein en Glossop

17. Grouse Inn, Glossop, Manchester, 1910 ～18. Grouse Inn, Glossop, Manchester, 2012 
este se había quitado la vida en 1906. En todo caso parece que la Matura de la escuela de Linz no le hubiera permitido el acceso directo a la universidad-para más tarde desarrollar estudios en Manchester sobre motores de propulsión y hélices, entre 1908-19115, dice Monk «ahogando su creciente preocupación por las cuestiones filosóficas».

Durante su estancia en Manchester y en el centro de observación meteorológica cerca de Glossop, dirigido por el físico Joseph Ernest Petavel (1873-1936) ${ }^{16}$ se interesó por las matemáticas puras. Tras un seminario con el matemático Horace Lamb (1849-1934) asistió a clases de análisis con John Edensor Littlewood (1885-1977). Allí tuvo conocimiento de la obra Principia Mathematica ${ }^{17}$ de Whitehead y Russell.

A partir de tal descubrimiento de los fundamentos lógicos de la matemática, Wittgenstein dirigió toda su energía e interés -más bien obsesión, en palabras de su hermana Hermine ${ }^{18}$ - a cuestiones filosóficas. Una visita en Jena a Gottlob Frege, a finales del verano de 1911 encaminó a Wittgenstein a presentarse ante Bertrand Russell en Cambridge. Wittgenstein estaba dispuesto a quedarse en el Trinity College al menos hasta haber comprendido y solucionado los problemas de la lógica, planteados por Russell:

«Mi amigo alemán amenaza con convertirse en un castigo, vino conmigo después de la clase y discutió hasta la hora de cenar...obstinado y contumaz, pero creo que no es estúpido. [19.11.1911]»19

Fue admitido en el Trinity a comienzos de 1912 y estudió allí durante tres trimestres. En Cambridge conoció al estudiante de matemáticas David Hume Pinsent (1891-1918).

David Pinsent representó para Wittgenstein la figuración del amor y la fraternidad. Era un hombre de gran sensibilidad. Su presencia le proporcionaba

\footnotetext{
${ }^{15}$ Contextualizando a Wittgenstein, digamos que por aquel entonces el desarrollo de la aviación estaba en sus inicios. En 1905 los hermanos Wright habían patentado el aeroplano y hasta 1909 no se realizó el primer vuelo tripulado de cierta duración.

16 «Trabajar con Petavel en aquellos años sería como hacerlo hoy en día en la NASA.» D. Connearn en correspondencia electrónica, 21.03.2015.

17 Sobre esta obra la entrada de la Stanford Encyclopedia of Philosophy (www.plato.stanford.edu/entries/principia-mathematica/)

${ }^{18}$ Hermine Wittgenstein, en Rhees, 1981, op. cit.

${ }^{19}$ Entrada del diario de B. Russell, en Monk, 1990, op. cit., p.53
} 

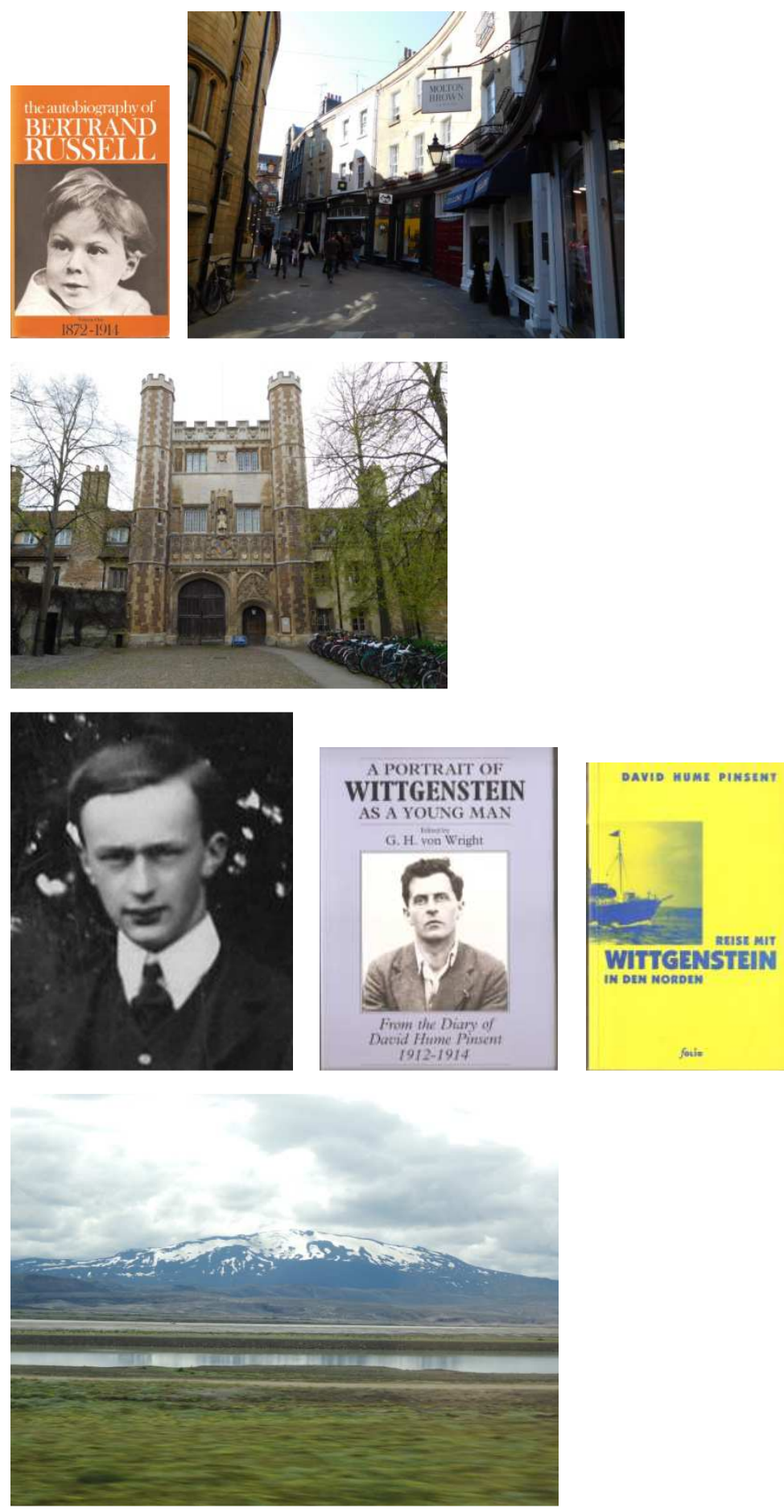

19. Bertrand Russell, Autobiography 1872-1914 | 20. Rose Crescent, Cambridge, abril 2015

21. Trinity College, Cambridge, abril 2015

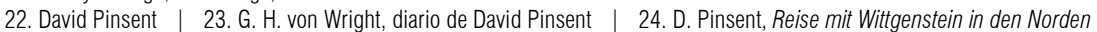

25. Monte Hekla, Islandia 
la ansiada calma interior tantas veces desbordada por su temperamento nervioso. Con Pinsent inició en 1912, sus viajes hacia el norte ${ }^{20}$, en ese proyecto de vagar obstinado, éxodo premeditado que le permitiera encontrar un espacio de soledad concentrada, la intimidad innovadora.

En agosto de 1913, Wittgenstein escribe a su amigo David Pinsent desde Austria, para organizar un nuevo viaje por vacaciones. Wittgenstein proponía hacer algo parecido al que habían realizado un año antes por Islandia ${ }^{21}$ :

«Viernes. 22.08.1913

Me comentó Wittgenstein hace más o menos un mes, que nos encontraríamos en Inglaterra, para ir a España, entre el 25 y el 30 de agosto. Pero no me ha escrito nada desde entonces y no sé dónde hemos de quedar. Le he escrito a Viena, a Londres y Cambridge, pero no he obtenido respuesta.. ${ }^{22}$

Lunes 25 de agosto, los dos amigos se encuentran en Londres, en el Grand Hotel de Trafalgar Square -tanto este viaje como el de 1912 serían costeados íntegramente por Wittgenstein- para decidir finalmente adónde viajar. Wittgenstein propone alternativas al viaje a España: Andorra, las islas Azores o quizá Bergen, en Noruega y desde allí hacer alguna excursión. Pinsent escribe en su diario que Wittgenstein se esfuerza por no mostrar preferencia por Noruega, pero le parecía tan obvio que decide elegir ese destino.

En esos momentos, Wittgenstein está trabajando intensamente en Lógica y así lo valoraban sus mentores Russell y Whitehead:

\footnotetext{
${ }^{20}$ Oxaal, 2011, op. cit, propone una intencionada búsqueda de Wittgenstein de un cierto heroísmo interior en los viajes a Islandia y Noruega. 1912 fue el año del hundimiento del Titanic y las noticias de las aventuras árticas eran recientes: «lce was associated with heroism, danger, and perhaps purity.», p. 9.

${ }^{21}$ Durante las vacaciones de verano de 1912, Wittgenstein y Pinsent hicieron un recorrido a lomos de ponis por Islandia. Partieron de Londres en 5 de septiembre con destino a Edimburgo, para tomar un barco el día 7 desde Leith. El día 10 tomaron tierra en las Islas Feroe, en Thorshavn y llegaron al puerto de Reikiavik el 12 de septiembre. Desde allí recorrieron una ruta circular por el lago Thingvellir, Geysir, Gullfoss, Thjorsabrun, Ölfusa, Hlitharendi y Krisuvik, regresando a Reikiavik en la tarde del 24 de septiembre. En la capital dedicaron dos días a hacer algo de turismo y regresaron en barco a Inglaterra, zarpando el día 27 hasta el puerto de Aberdeen, donde llegan el 3 de octubre. Pinsent y Wittgenstein terminan su periplo en Birmingham, en casa de los padres de Pinsent. El 5 de octubre ambos amigos se despiden y Wittgenstein toma un tren a Londres. (Recorrido extraído del diario personal de David Pinsent, citado en nota sucesiva)

22 David Pinsent, A Portrait of Wittgenstein As a Young Man, G.H.von Wright (Ed.), Oxford, 1990
} 

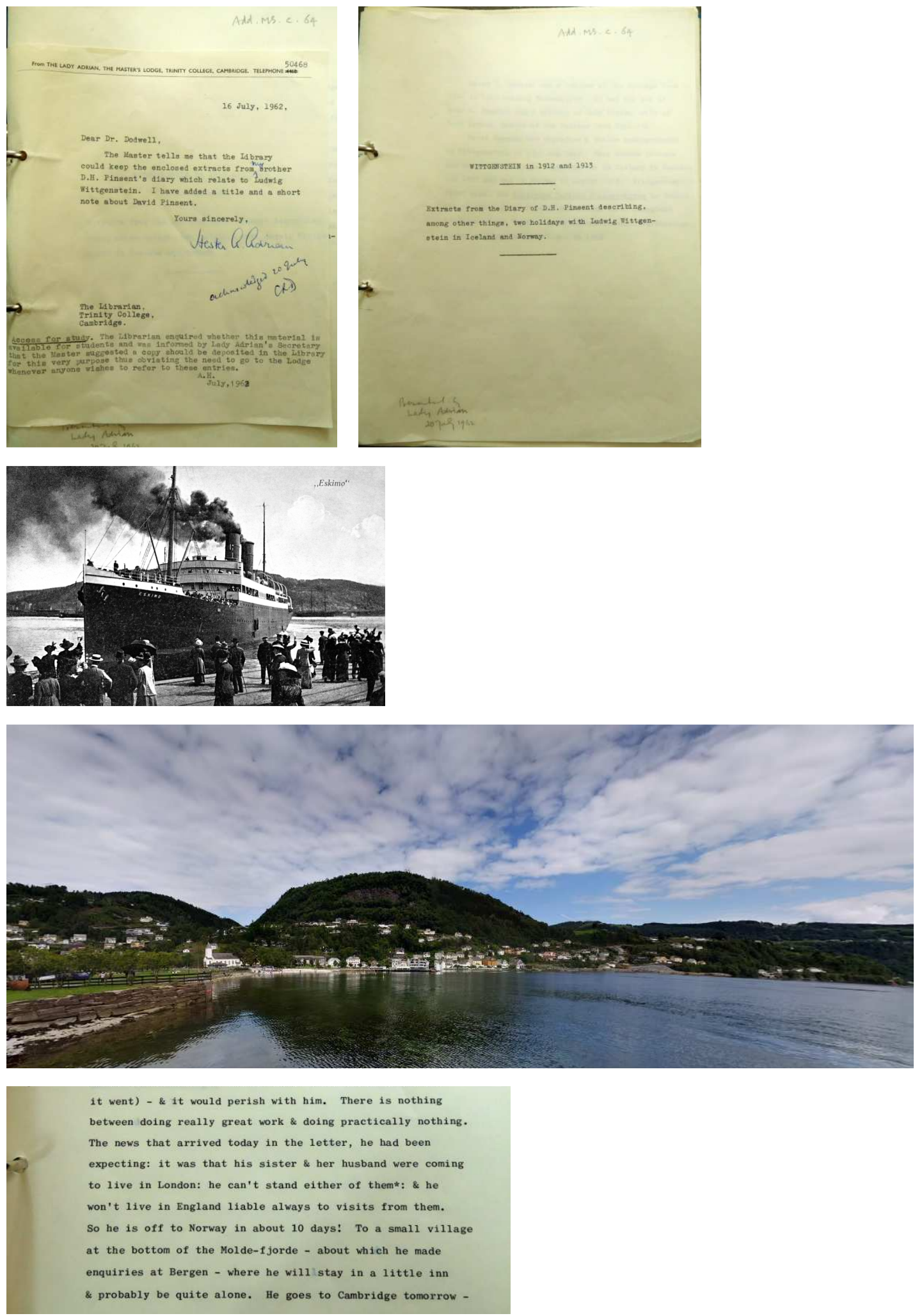

26-27. Diario de David Pinsent, 1912-1913 Wren Library

28. Eskimo, barco en que viajaron a Noruega en 1913 Wittgenstein y Pinsent

29. Øystese, Noruega

30. Entrada diario Pinsent 02.10.1913, Wittgenstein decide ir a vivir a Noruega 
«Viernes. 29.08.1913

[...]Parece que tanto Russell como el viejo Whitehead se muestran muy entusiastas acerca de sus recientes progresos en Lógica. Es probable que el primer volumen de los "Principia" deba ser reescrito y que Wittgenstein tenga que escribir él mismo los once primeros capítulos. ¡Es un estupendo triunfo para él!»»23

Wittgenstein no fue del todo sincero con su amigo en cuanto a la intención de su viaje. Sin duda, necesitaba un compañero en el que encontrar comprensión y diálogo frente a su cada vez mayor tensión por la responsabilidad y complejidad de los problemas que trataba de elucidar. Un estado de ánimo tan variable durante la mayor parte del viaje hizo que Pinsent, pese a su innata contención británica, escribiera que Wittgenstein, en ese estado de neurosis, resultaba agotador. En su diario, Pinsent recoge las partidas de dominó, los paseos en barca y las conversaciones de toda índole con Wittgenstein, pero sobre todo da cuenta del tiempo que Wittgenstein dedicaba a trabajar y del suyo propio en tratar de tranquilizar al nervioso austríaco. Se divirtiera más o menos, Pinsent parece que se prometió a sí mismo no volver a viajar con Wittgenstein jamás.

En su viaje por Noruega, habían partido de Oslo el 1 de septiembre, en tren hasta Bergen. Puesto que no disponían de información acerca de posibles destinos, el 3 de septiembre se dirigieron a la oficina de turismo. Pinsent escribe en su diario:

«Miércoles. 03.09.1913

Hemos desayunado a las 9:30 am. Después hemos ido a la Oficina de Turismo Beyer para hacer indagaciones. Queremos un lugar tranquilo, donde haya un pequeño hotel, en algún lugar del fiordo, de gente amable y que no sea demasiado turístico (sobre esto Ludwig se muestra inflexible). Queremos un lugar así para poder quedarnos unas tres semanas y trabajar (yo en Leyes y Ludwig en Lógica) y donde podamos hacer algún paseo y navegar por el fiordo si es posible.. ${ }^{24}$

En la oficina de turismo les sugieren entre otros destinos, el pueblo de Øystese, en el fiordo de Hardanger. Durante la estancia en Noruega, maduró la

\footnotetext{
${ }^{23}$ Pinsent, 1990. op. cit.

24 Pinsent, 1990. op. cit.
} 

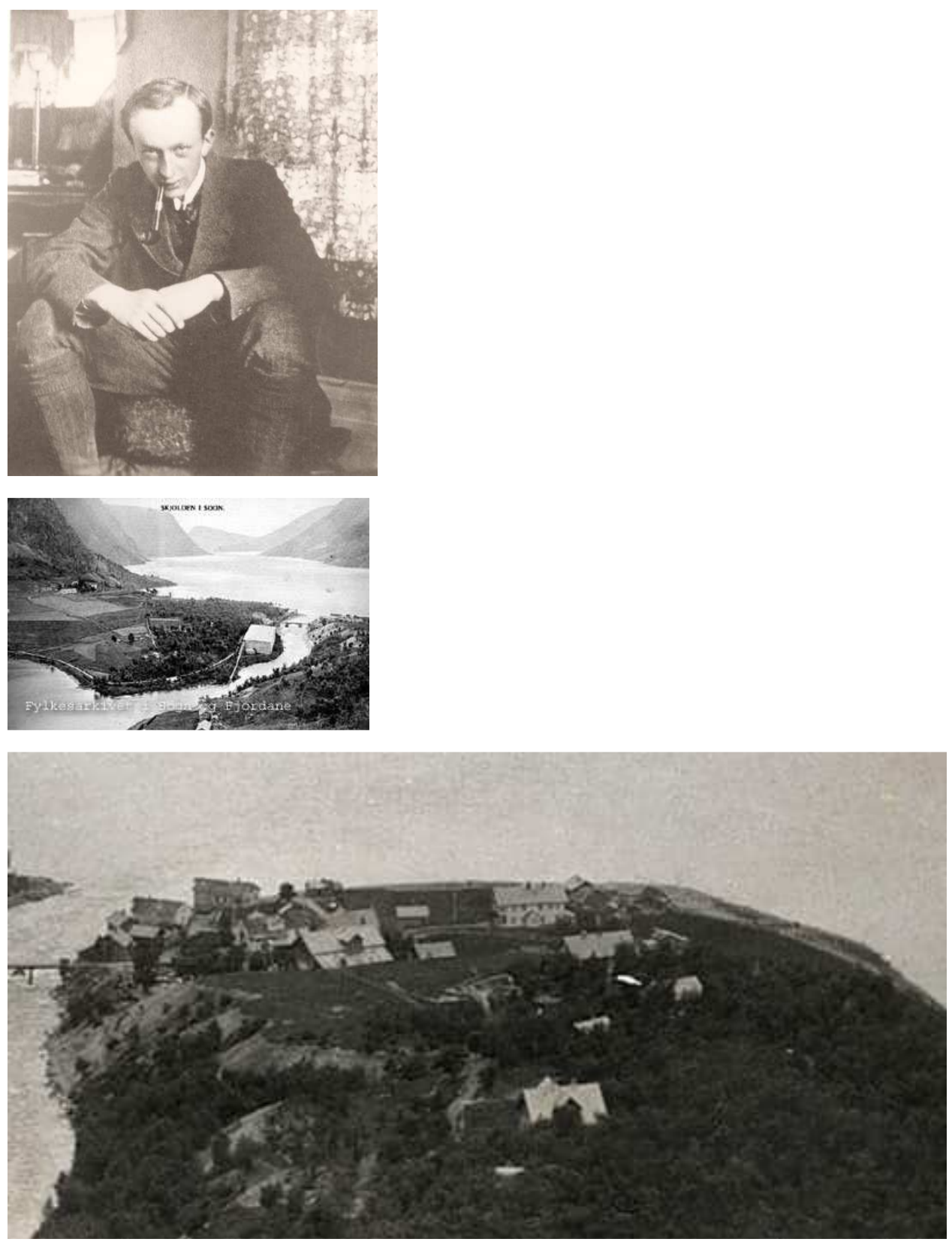
idea en Wittgenstein de trabajar en soledad. Quizá fuera un sentimiento indefinido que arrostrara desde tiempo atrás, en la necesidad física de encontrar menos estímulos y obligaciones -sobre todo sociales- a su alrededor, para alcanzar el suficiente nivel de concentración.

«Miércoles. 24.09.1913

[...] Wittgenstein estaba muy contento esta mañana, cuando de repente hizo una reflexión de lo más alarmante, eso es, que debería exiliarse y vivir durante unos años lejos de todas las personas que conoce, por ejemplo en Noruega. Que debería vivir a solas - una vida de eremita- y no hacer otra cosa sino trabajar en Lógica.[...]» ${ }^{25}$

A Pinsent las razones le resultaban extrañas pero Wittgenstein se mostraba convencido de no ser capaz de trabajar correctamente con el tipo de vida que le ofrecía Cambridge, lleno de actividades, personas que conocía y distracciones. Además se sentía extraño al mundo, a la gente en general, de manera recíproca. Podemos ver en su planteamiento la búsqueda weiningeriana del genio, trabajando por sí mismo en condiciones extremas, hasta encontrar un resultado que valiera la pena el esfuerzo. Cualquier otra opción le resultaba insatisfactoria. Su estado neurótico en esas semanas define tales sentimientos, un pánico a morir prematuramente, al menos antes de haber resuelto los problemas de la lógica o hacerlo sin haber conseguido un trabajo decente.

Todo quedó decidido al regresar a Inglaterra. El día 2 de octubre Wittgenstein fue a hablar con Russell de sus planes:

«Entonces se presentó Wittgenstein, recién llegado de Noruega, completamente resuelto a vivir en completa soledad hasta haber solucionado todos los problemas de la Lógica.»

Wittgenstein, se ha dicho ya, fue una personalidad compleja, por lo que no podríamos encontrar un único motivo directamente relacionado con su imperativo deseo de alejarse de todo, aparte de los expuestos por él mismo. En el diario de David Pinsent, el 1 de octubre, encontramos un motivo adicional, y tal es que la hermana mediana de Ludwig, Margaret -Gretl, a la que entre 1926-29 iba a construir una casa de la Kundmanngasse en Viena- iba a instalarse con su

${ }^{25}$ Pinsent, 1990. op. cit. 

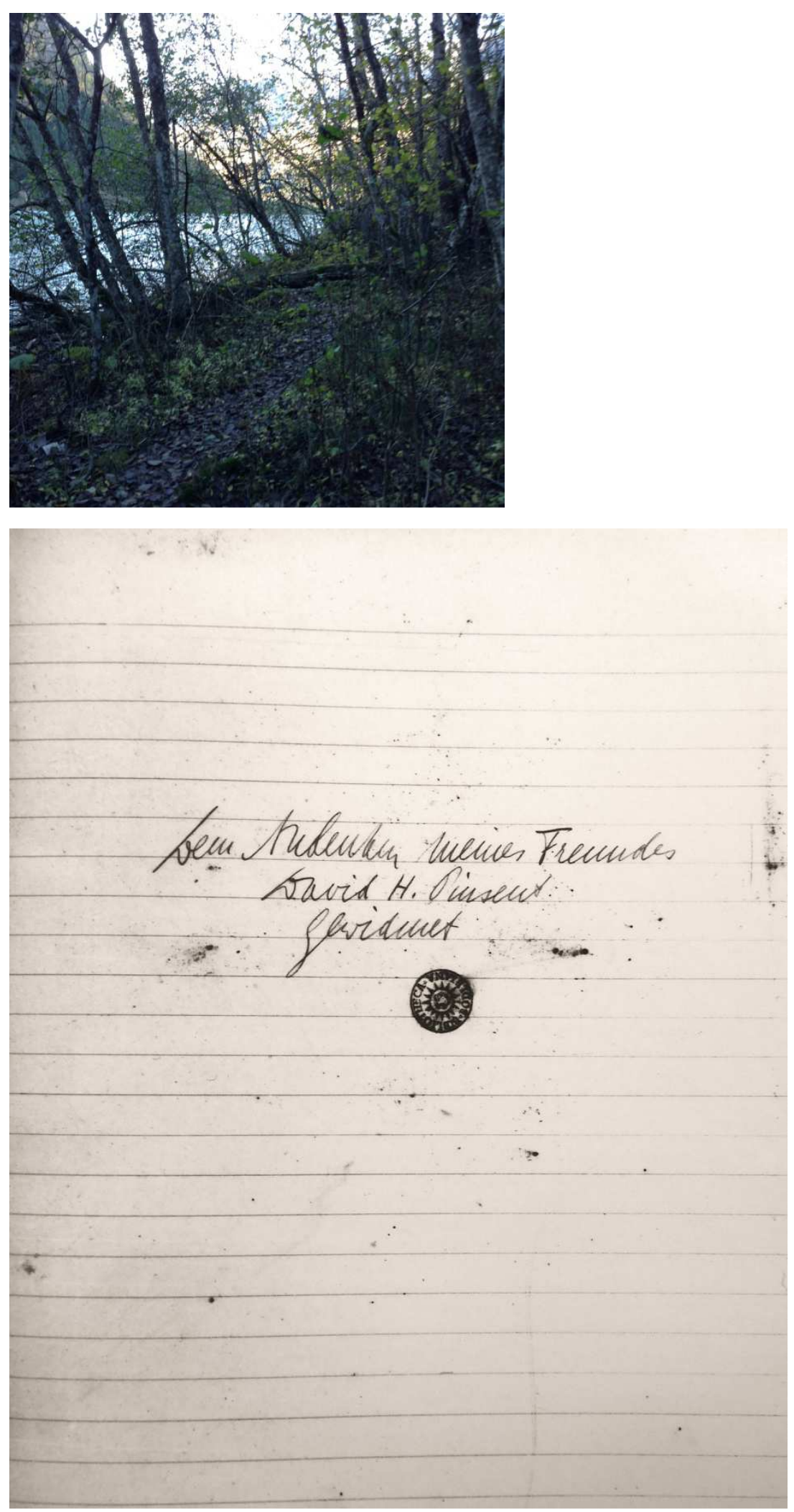

34. Inmediaciones de la casa de Wittgenstein en Skjolden

35. Dedicatoria del Tractatus logico-philosophicus: «Dedicado a la memoria de mi amigo David H. Pinsent» 
marido Jerome Stonborough cerca de Oxford. Wittgenstein no soportaba a su cuñado. Quizá el autocastigo de reprimir o idealizar el amor que Wittgenstein sentía por su compañero, reinterpretado a través del filtro de Weininger fuera un motivo no menor en todo el asunto de la necesidad de huir en soledad. Fueran unos, otros o una amalgama de anhelos imperativos, Wittgenstein partió hacia Noruega el 11 de octubre de 1913. Pinsent escribe que en esta ocasión el destino de Ludwig iba a ser una pequeña localidad en el fiordo de Molde, de la que sabía por informaciones que obtuvo en Bergen antes de partir hacia Inglaterra.

«Miércoles, 08.10.1913

Me he levantado a las 6.15 para ver partir a Ludwig. Debe marcharse muy pronto vuelve a Cambridge- porque tiene un montón de cosas que hacer allí. Le vi marchar de casa en un taxi a las 7.0 - para coger el tren de las 7.30 am desde New St station. Fue triste despedirse de él -pero es probable que haga una visita corta a Inglaterra el próximo verano (permaneciendo hasta entonces en Noruega, donde volvería después) y entonces podré verle. Nuestra relación ha sido caótica, pero estoy muy agradecido: estoy seguro que también él lo está. En conjunto disfruté mucho de nuestras vacaciones en Noruega y sé que él también -como él dice son las mejores que ha tenido. [...]»26

Los dos amigos no volverían a encontrarse. El diario de Pinsent y algunas cartas que se conservan de 1914, nos muestran que planearon pasar las vacaciones de verano de 1914 juntos, pero el estallido de la Primera Guerra Mundial los separó para siempre. David Pinsent murió en un accidente aéreo, mientras realizaba un vuelo de pruebas, el 8 de mayo de 1918. Para Wittgenstein, Pinsent fue su único amigo y a su memoria dedicó el único libro que publicó en vida, el Tractatus logico-philosophicus, en 1921.

${ }^{26}$ Pinsent, 1990. op. cit. 

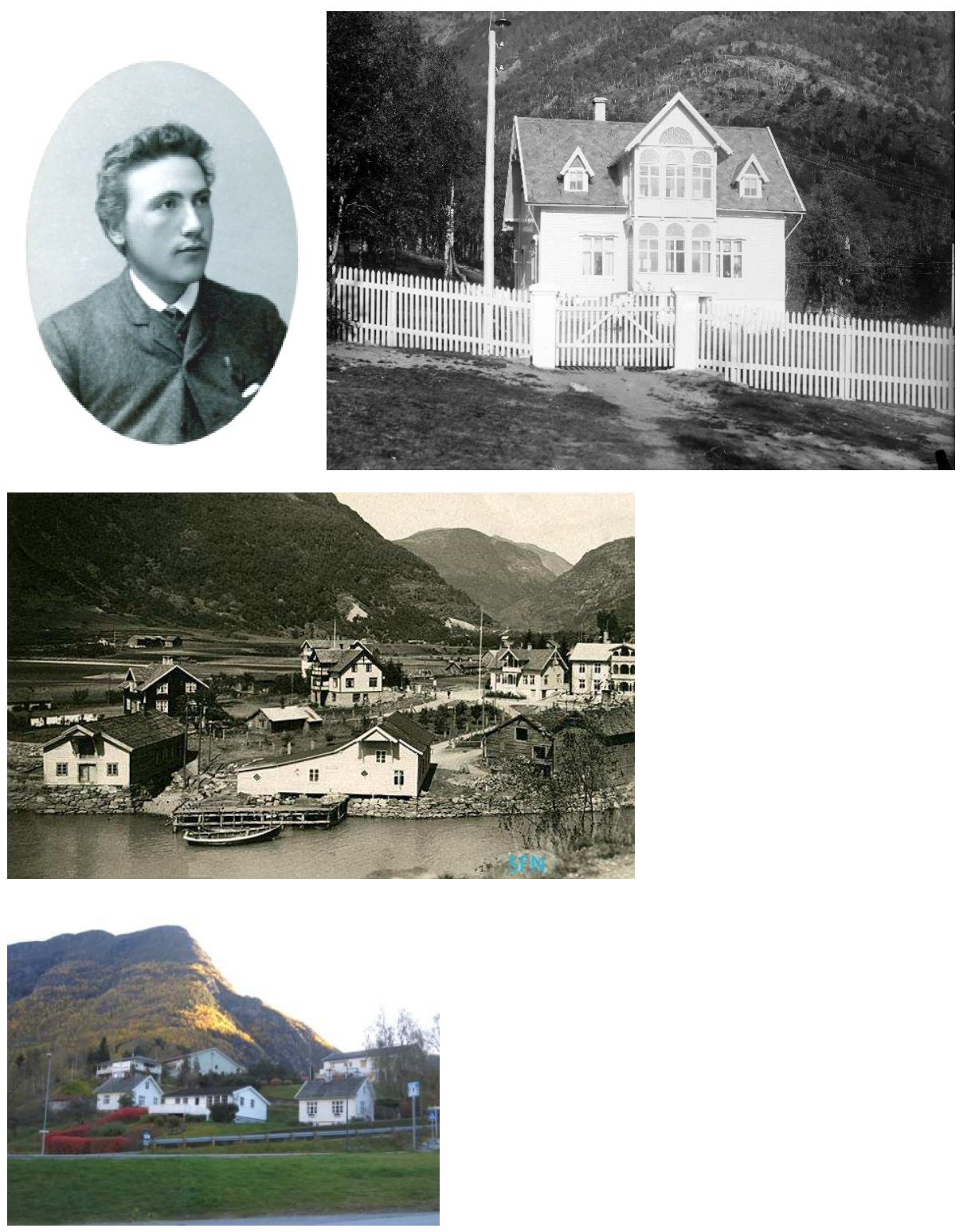

36. Halvard Drægni (1879-1950) | 37. Casa Drægni, Skjolden, 1919

38. Skjolden, 1930

39. Skjolden, 2013 
Finalmente, Wittgenstein no fue a Molde, tal como había comentado a Pinsent ni aún más al norte a las Islas Lofoten ${ }^{27}$ como interpreta McGuinness (1988) de la carta que Ludwig envió a Russell ${ }^{28}$ desde Noruega el 17 de octubre de 1913:

«Querido Russell,

Mi dirección va a ser: L.W. c/o Halvard Drægni, Skjolden, Sogn, Norway. Todavía no estoy allí. [...]

P.S. No estoy tan al norte como había pensado que estaría puesto que la posada en la que me quería alojar está cerrada durante el invierno.» ${ }^{29}$

¿Por qué Wittgenstein eligió finalmente Skjolden? Cuando McGuinness escribe su libro en 1988 dice que fue el azar el que llevó a Wittgenstein a tal destino en lo más profundo del fiordo de Sogn. Sin embargo Johannessen, Larsen y Åmås (en adelante Åmås) proponen una explicación plausible. El 14 de octubre Wittgenstein se encontraba ya en Bergen, y el día 17, como se ha dicho, envió una carta a Russell con sus nuevas señas en Skjolden. Parece natural, que si en la oficina de turismo de Bergen le dijeran que la posada de Molde iba a estar cerrada durante el invierno y dadas las importantes conexiones familiares y políticas de la familia de Wittgenstein en Austria, que el joven Ludwig se dirigiera al consulado autro-húngaro de Bergen, con la intención de obtener información sobre lugares a los que poder viajar en las condiciones que él necesitaba. Allí se debió reunir con el cónsul Jacob Valentin Kroepelien (18361926), quien le puso en contacto con un vivaz empresario conocido suyo de Skjolden, Halvard Drægni (1869-1950), dedicado a las conservas de frutas y zumos desde Luster con cierta proyección internacional, también era el alcalde de Luster (1911-1916) y repetiría el cargo en los periodos de 1920-1921 y 19261927. Todo indica que el cónsul Kroepelien se puso en contacto con Drægni para que este consiguiera un alojamiento adecuado a su joven compatriota. Lo único

\footnotetext{
${ }^{27}$ Brian McGuinness, Wittgenstein in Cambridge. Letters and Documents 1911-1951, (London: Wiley-Blackwell, 2012), p. 47

${ }^{28}$ No sólo Wittgenstein parecía necesitar aislamiento. En una carta de Russell a su amante Lady Ottoline Morrell de 8.10.13 dice: «He is more intellectually intimate to me than anyone I have ever met, and yet I shall be thankful to see him go.» (En McGuinness,1988, op. cit. p. 186)

${ }^{29}$ McGuinness, 2012, op. cit. p. 47.
} 

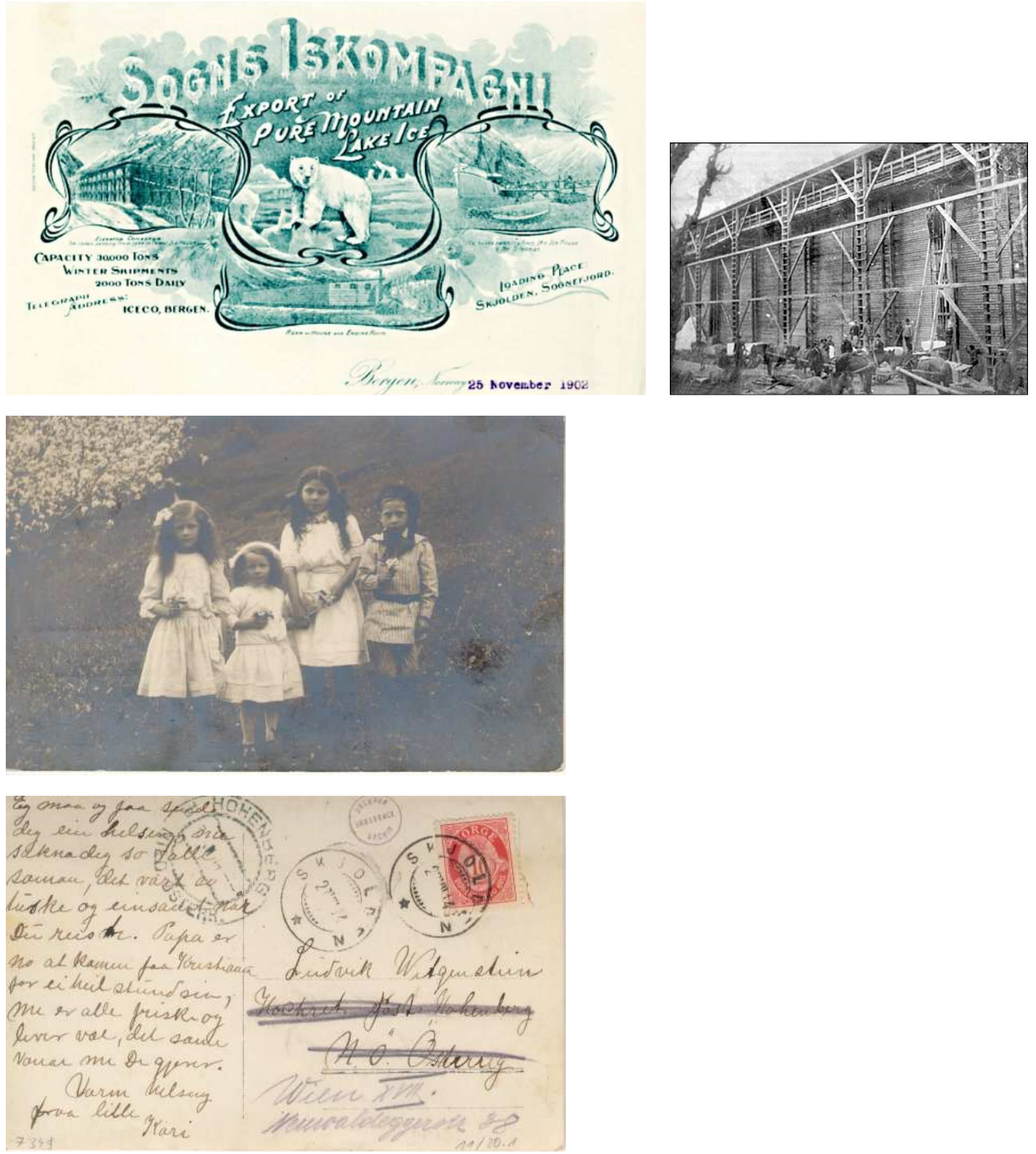
que exigía el joven austríaco era un lugar tranquilo y sin distracciones para trabajar. ${ }^{30}$

Drægni acordó con Hans Klingenberg, el jefe de la oficina de correos local y director de la fábrica de hielo del pueblo, la llamada «Ishuset»31, que le alquilaría unas habitaciones en su casa. El 23 de octubre, Wittgenstein parece que se había ya instalado en casa de la familia Klingenberg, aunque curiosamente sigue escribiendo durante su estancia la dirección postal de Drægni. Ludwig se encuentra a su gusto en Skjolden desde el primer día:

«To G. E. Moore, [23.10.1913]

Querido Moore,

[...] El lugar es muy agradable y tengo un montón de tiempo para trabajar.[...]»32

«To B. Russell, [29.10.1913]

Querido Russell,

[...] Este es un lugar ideal para trabajar. -En cuanto llegué tuve una violenta gripe que no me ha dejado trabajar hasta ahora.[...]. -Tengo aquí dos estupendas habitaciones en la casa del cartero y me encuentro instalado realmente bien.[...]Como no me encuentro prácticamente ni un alma por aquí, mis progresos con el noruego son excesivamente lentos; tanto que no aprendido todavía ninguna palabrota. [...]»33

No nos vamos a extender en la relación de Wittgenstein con los lugareños en Skjolden ni de sus progresos en Lógica, de lo segundo, dan cuenta ampliamente los textos de McGuinness ${ }^{34}$ y Monk y de lo primero los dos libros de 1994 de Åmås.

Sin embargo por el asunto que estamos tratando aquí, es muy importante referir cuándo creemos que Wittgenstein decidió proyectar y construir una casa para sí mismo en Skjolden.

\footnotetext{
${ }^{30}$ En entrevista a Bjarne Drægni, hijo de Halvard, en 1991, en Åmås, 1994, p. 22.

${ }^{31}$ La fábrica de hielo de Skjolden, producido en Fortun y transportado en barcos hasta Bergen desde donde se distribuía a Inglaterra y el continente, se encontraba junto a la desembocadura del río Eidselvi. Estuvo en funcionamiento entre 1893 y 1919 aunque a partir de 1915 el comercio de hielo era ya mínimo. Fuente: Fylkesarkivet Sogn og Fjordane.

${ }^{32}$ McGuinness, 2012, op. cit. p. 48

${ }^{33}$ McGuinness, 2012, op. cit. p. 49

${ }^{34}$ McGuinness, 1988 y sobre todo McGuinness, 2012.
} 

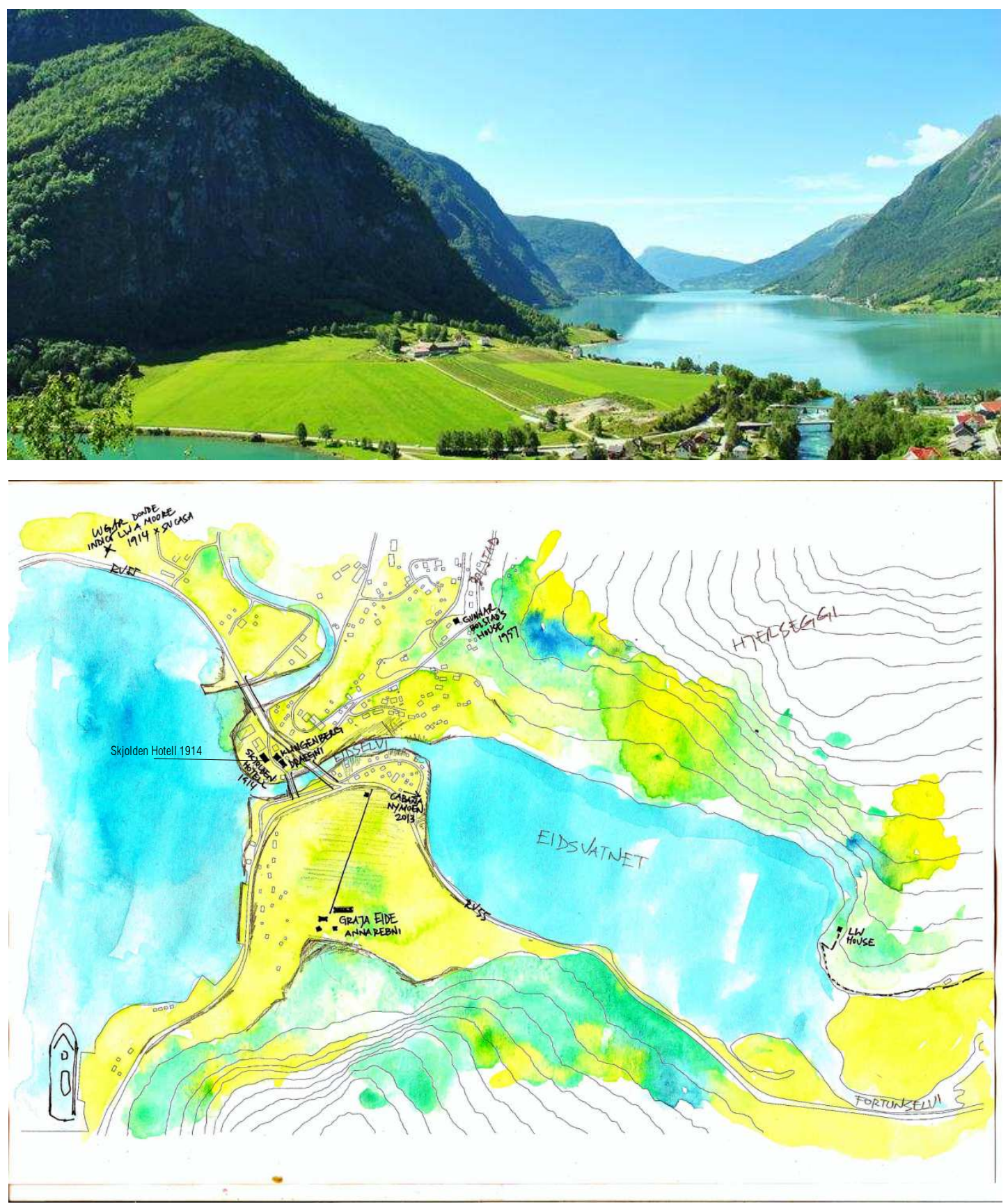

44. Granja Eide, Anna Rebni 45. Referencias en Skjolden 
La primera referencia escrita, de la futura casa en noruega la encontramos en el diario de David Pinsent:

«Sábado, 07.03.1914

Hoy he recibido carta de Ludwig desde Noruega. Nos hemos estado escribiendo, por cierto, desde que nos despedimos. Ludwig se ha instalado en una pequeña posada en Skjolden en el fiordo de Sogn, y a excepción de una visita fugaz a Viena la pasada Navidad, que parece haber hecho muy en contra de sus deseos, ha estado allí desde el pasado octubre. Parece tolerar bastante bien la vida -y su solitario exilio parece que le viene bien. Sé por él que su trabajo en Lógica está progresando. Ahora está haciendo planes para construirse una pequeña casa allí -que debería estar acabada para el próximo otoño- por lo que debe pretender vivir allí de manera más o menos permanente.[...]» ${ }^{35}$

No sabemos qué quiere decir Pinsent en su diario con «está haciendo planes» en la versión original transcrita ${ }^{36}$ de su diario dice «He is at present making arrangements to build himself a small house there» y puesto que no se ha conservado, no podemos confrontar la anotación de Pinsent con la carta de Wittgenstein. Por «arrangements» entendemos preparativos, esto es, probablemente estaba ya proyectando la casa o hablando con Drægni de ello. La entrada del diario está fechada a primeros de marzo. Por la correspondencia conservada, podemos estimar que Wittgenstein escribió a Pinsent comentando su intención de construirse una casa durante la segunda quincena de febrero.

Podemos elucubrar acerca del tiempo que podía estar preparando Wittgenstein los planos de su casa en febrero de 1914. Las cartas que intercambia con Russell y G.E. Moore durante el invierno de 1913 y 1914 versan únicamente de su trabajo en Lógica y de sus propios sentimientos, de la amistad hacia Russell, etc., pero no hay mención alguna al proyecto de su casa.

G. E. Moore visitó a Wittgenstein, prácticamente obligado por este -estaba convencido de que le quedaban pocos meses de vida- en Skjolden.

«To G. E. Moore, 18.02.1914

[...] You must come as soon as Term ends and I shall meet you in Bergen. I am looking forward to your coming more than I can say! I am bothered to death with Logik and

\footnotetext{
${ }^{35}$ Pinsent, 1990, op. cit. p. 89.

${ }^{36}$ La versión entregada por Lady Adrian a la Biblioteca Wren del Trinity College en 1962 a la que se añadió una addenda en 1978, mecanografiada por McGuinness. Ver imágenes 26-17, p. 74.
} 

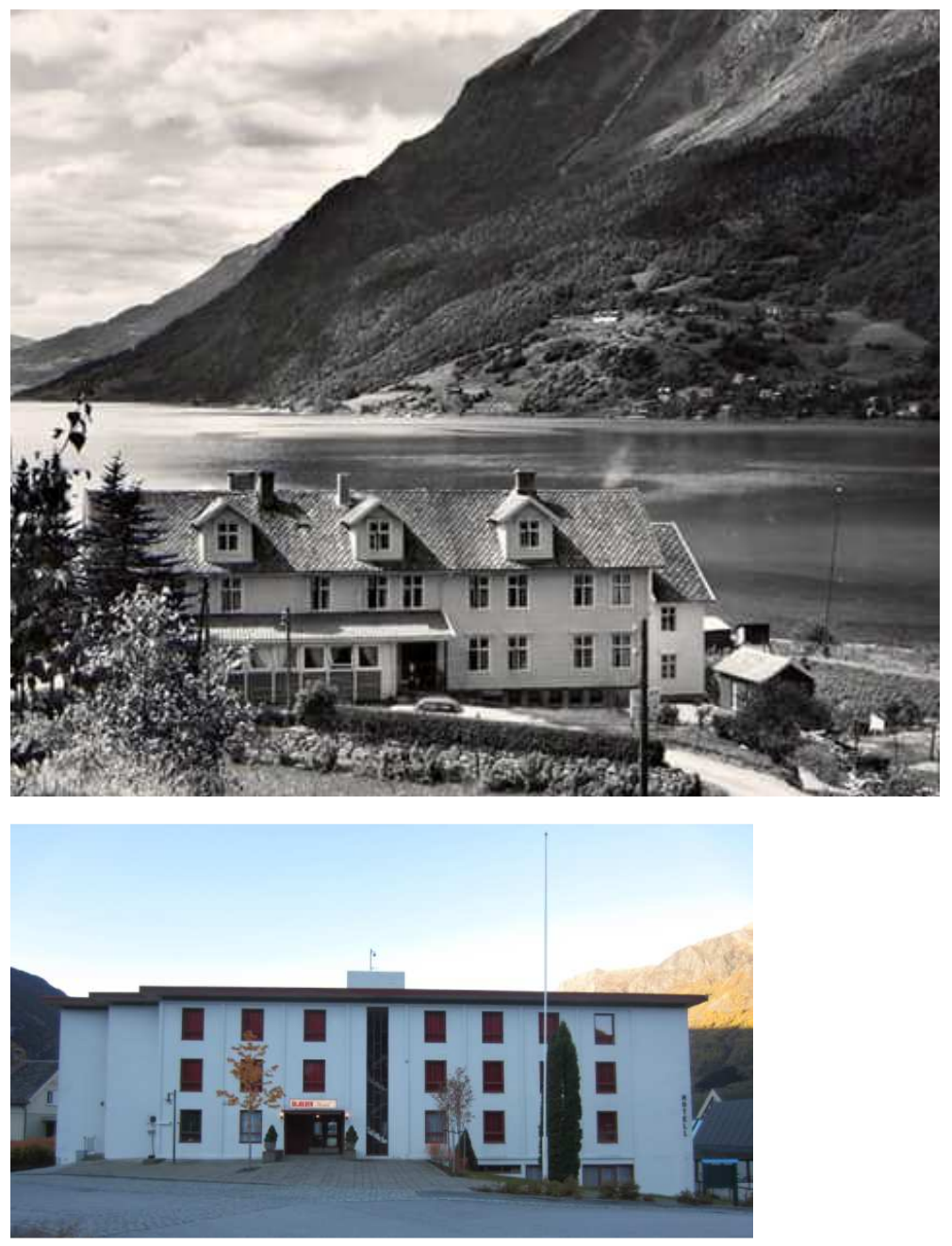

46. Skjolden Hotell, donde se alojó G.E. Moore en 1914. Fotografía de 1950 47. Nuevo Skjolden Hotell, octubre 2013 
other things. But I hope I shan't die before you come for in that case we couldn't discuss much.»

Más allá del humor negro e ironía destilados por su supuesta muerte inminente y el estado de ansiedad en que se encontraba Wittgenstein, conviene recordar que Moore era un reconocido profesor de Cambridge y Ludwig en ese momento un estudiante no graduado. De hecho la insistencia de Wittgenstein se debía a que quería discutir y dictar a Moore un trabajo de Lógica ${ }^{37}$ que le sirviera como tesis de licenciatura en filosofía. Hemos tenido oportunidad de leer los diarios de Moore que escribió en Noruega y, aparte de las contenidísimas referencias al comportamiento de Wittgenstein hacia su persona, no hay ningún comentario sobre la casa del lago que pretendía construir. Quizá Wittgenstein dejó a un lado por unos días cualquier otra materia que no fuera la Lógica para poder expresar a Moore todas sus ideas, o quizá Moore simplemente no lo tomara en cuenta como para escribirlo en su preciosista diario ${ }^{38}$. Moore partió hacia Bergen el 24 de marzo de 1914. Las anotaciones de su diario definen su carácter y el de Wittgenstein con muy pocas palabras:

«Tierra en Stavanger a las 11 y en Bergen a las 10 de la noche. Encuentro con W.: él habla hasta la 1.»

«Desayuno 101/2. Compras con W hasta las 21/2. Él habla hasta las 61/2: paseo hasta las 8: él abusa de mí hasta las $12^{1 / 4 . »}$

Moore permaneció en Skjolden -en el hotel- desde el 29 de marzo al 13 de abril, según indica su diario. Apunta en él la manera peculiar en que se relaciona Wittgenstein con él: paseos, piano en casa de Drægni, dictado de las notas de Lógica, etc. Ningún comentario del proyecto de su casa.

No podemos contrastar el dato, pero Åmås (1994:a) dice que, durante la residencia del filósofo con los Klingenberg, la hija Kari (1907-1991) se encargaba de llevar el té vespertino al inquilino mientras este se dedicaba a trabajar en los

\footnotetext{
${ }^{37}$ Se conocen como Notas dictadas a G. E. Moore en Noruega. Fueron publicadas en Notebooks (1914-1916), en 1961 por G. H. von Wright y G. E. M. Anscombe. Suponen un avance parcial de lo recogido posteriormente en su Tractatus.

${ }^{38}$ Moore seguía un sistema de notas simples en las hojas pares de los cuadernos que utilizaba como diario, a modo de recordatorio y posteriormente redactaba de manera concisa pero con precisión de cirujano las entradas completas en las páginas impares.
} 


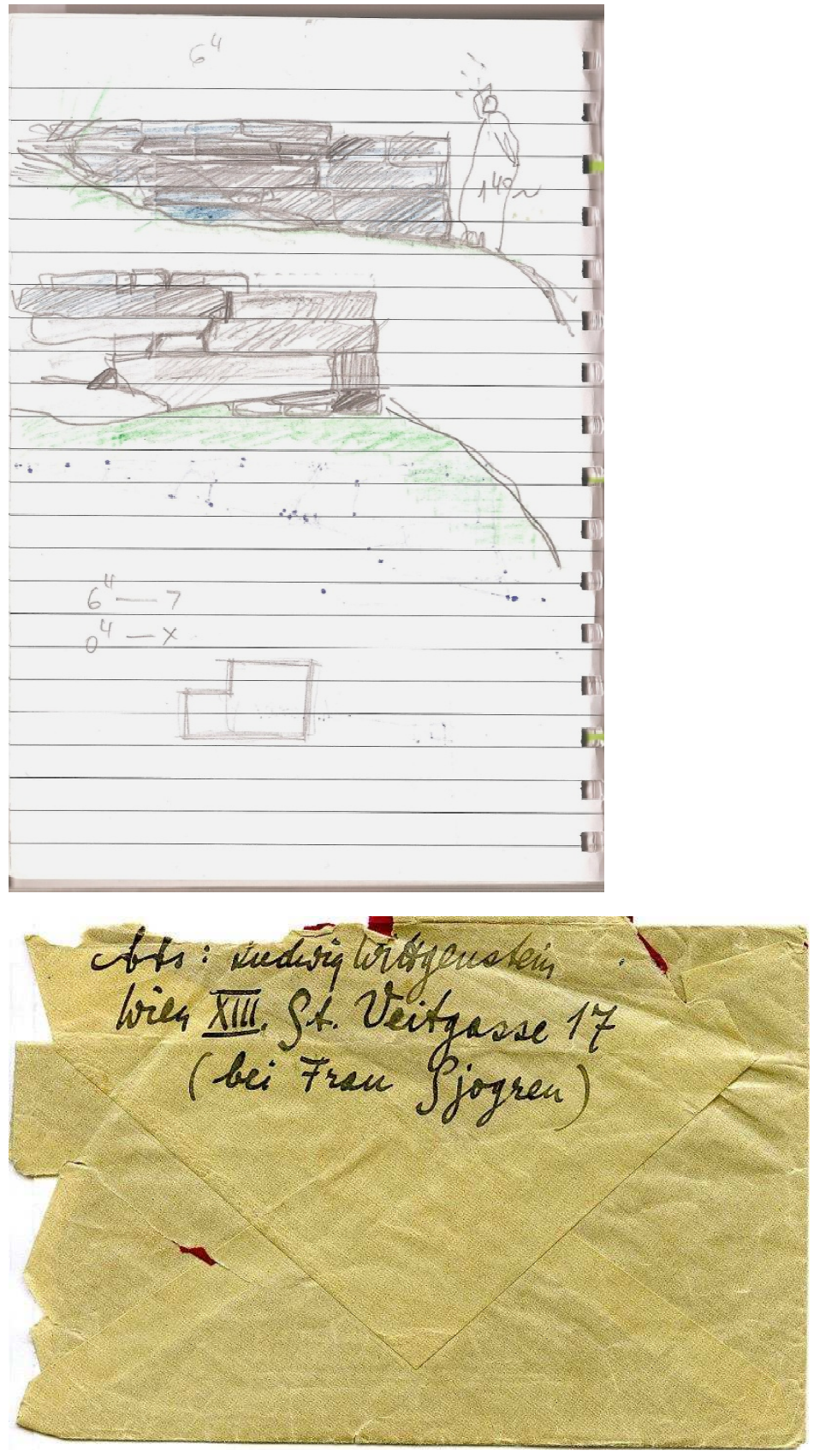

48. «Estoy construyéndome aquí una pequeña casa», cuaderno

49. Carta de Wittgenstein a Halvard Drægni, 1921 
planos -en inglés la palabra plans significa planes y planos- para construir una casa en el lago Eidsvatnet. En la edición en noruego de Åmås (1994:b) utiliza la palabra planane que significa indistintamente planes y planos:

«Vesle Kari var den som bar inn ettermiddagsteen til Wittgenstein medan planane om å bygga seg eit hus i bergskorta ved Eidsvatnet.» ${ }^{39}$

No encontramos nuevas referencias escritas de la casa desde la carta de Pinsent de febrero-marzo (no consta fecha en la misiva) hasta una nueva misiva a Russell en junio de 1914:

«Querido Russell,

Sólo unas líneas para decirte que recibí tu amable carta y que mi trabajo ha progresado considerablemente en los últimos cinco meses. Pero he entrado en un estado de cansancio extremo y no puedo avanzar en el trabajo ni explicar lo que ya he hecho. En cualquier caso se lo expuse en detalle a Moore cuando estuvo conmigo y tomó diversas anotaciones. Así que puedes saberlo por ti mismo de él. Muchas cosas en ese trabajo son nuevas. -La mejor manera de entenderlo todo sería leer por ti mismo las notas de Moore. Probablemente pase algún tiempo antes de que produzca algo más. Hasta entonces-

Tuyo

L.W.

P.S. Estoy construyéndome una pequeña casa aquí, a millas de todo el mundo. Espero que tu viaje sea un éxito.»

A finales de junio de 1914 Wittgenstein abandonó Skjolden, huyendo de la temporada turística. Los primeros días de julio ${ }^{40}$ lo encontramos ya en la midseason house de la familia a las afueras de Viena, en Neuwaldeggergasse ${ }^{38 .}$

Wittgenstein pensaba dedicar las vacaciones estivales a estar con su familia en Austria y viajar a finales de agosto y primeros de septiembre de nuevo con David Pinsent con destino por decidir, entre los que había barajado Andorra, España o Escocia.

\footnotetext{
${ }^{39}$ Knut Olav Åmås, Det stille alvoret, Oslo, 1994, p. 102. No son los dos libros de Åmås de 1994 el mismo texto traducido del noruego al inglés. Son ediciones distintas aunque gran parte del material de la edición noruega sí se recoge en la edición en inglés, pero este último contiene más información, recopilación de correspondencia, ensayos sobre Wittgenstein, etc.

${ }^{40}$ Carta de Wittgenstein a Moore, de 03.07.1914: «Mientras recogía papeles antes de partir de Skjolden me encontré con tu carta [...]»
} 
W A L D E N ;

L IFE IN THE W0ODS.

BY HENRY D. THOREAU,
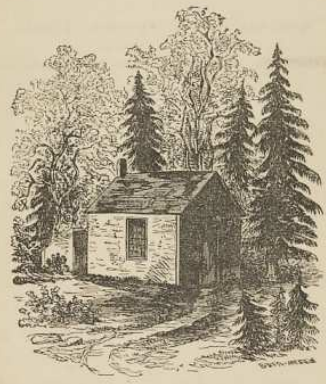

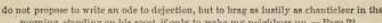

BOSTON:

ICKNOR AND FIELDS

N Deco anv.

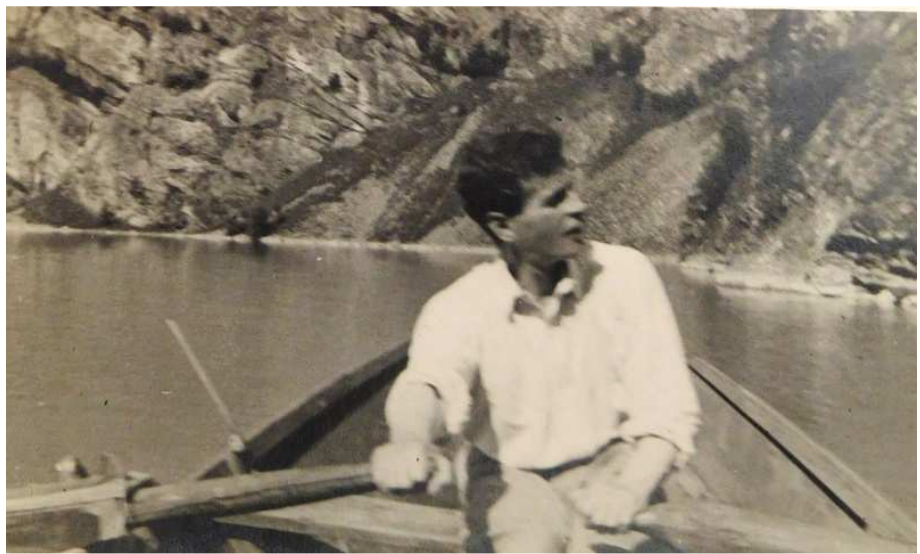

50. Walden, que leía Wittgenstein con Arvid Sjögren y otros amigos en Hochreith

51. Wittgenstein remando en el lago Eidsvatnet, 1921 
El 28 de julio Austria declaró la guerra a Serbia. Wittgenstein se alistó voluntario. No volvió a Skjolden hasta siete años más tarde. Tampoco volvió a ver a su amigo David Pinsent.

«Viena XIII, St. Veitgasse 17 (att Frau Sjögren)

¡Querido Sr. Drægni!

Hace dos meses regresé de mi cautiverio en Italia, y ahora tengo que decirles a usted y al resto de mis amigos noruegos que no volveré a Noruega. Me siento muy triste porque no vaya a volver a verlos. Me acuerdo a menudo de ustedes, y les escribiré en el futuro. Por favor envíenme todas mis cosas lo antes posible: ropa, libros, etc., a la dirección que indico arriba. Bolstad puede quedarse mi casa. Dele recuerdos a Sofia Klingenberg y a su marido, y también a su querida esposa, al viejo Galde y a Arne Bolstad. ¡Nunca les olvidaré! ¡Acuérdese de mí y escríbame alguna vez!

Sinceramente suyo,

Ludwig Wittgenstein.» ${ }^{41}$

Wittgenstein decidió no volver a Noruega tras la guerra. Los motivos son complicados de explicar, puesto que no los expuso nunca, probablemente una mezcla de sentimientos por las vivencias de la guerra y probablemente Wittgenstein era un fervoroso patriota- porque Noruega no fue absolutamente neutral durante la contienda. No había visto siquiera su casa terminada, al haber partido de Noruega a finales de junio de 1914. Se alistó en agosto como voluntario en el ejército austríaco con el firme deseo de morir decentemente como un héroe. La casa, que había construido para él mismo decidió cederla a su amigo Arne Bolstad, un joven diez años más joven y al que insistió en tal cesión por carta, unos meses más tarde. El 21 de marzo de 1920, Wittgenstein insiste a Arne: «My house belongs to you.»42

\footnotetext{
${ }^{41}$ Carta de Wittgenstein a Halvard Drægni, 30.10.1919. En Åmås, op. cit. p. 114

${ }^{42}$ Carta de Wittgenstein a Arne Bolstad, 01.03.1920. En Åmås, op. cit. p. 130
} 

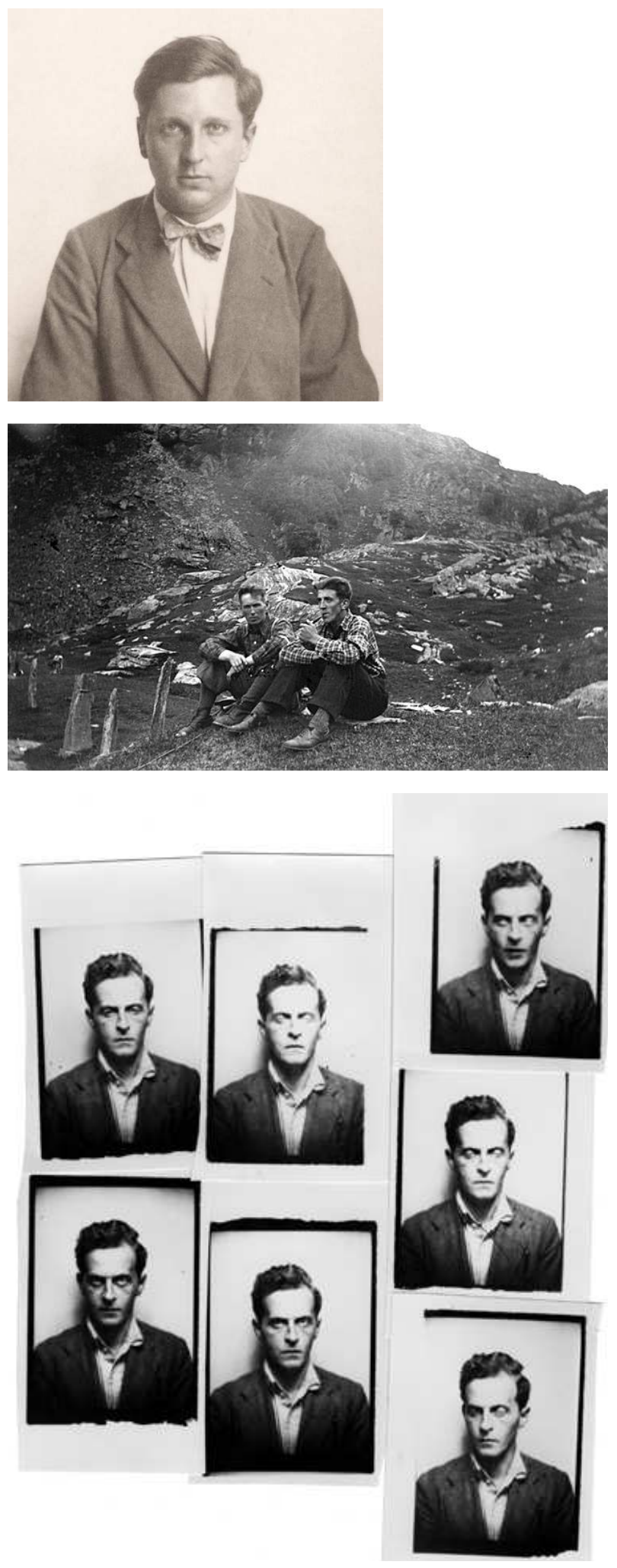

52. Arvid Sjögren, 1930. Fotografía de Moritz Nähr

53. Arne Bolstad (izqda) con Hans Kristian Tomasson Mørkrid, en Knivabakkli, cerca de Skjolden 54. Wittgenstein, autofotografías, 1922 
En octubre de 1920, Wittgenstein se incorporó como maestro de escuela elemental en Trattenbach, en una zona rural de la Baja Austria:

«[...]Ya soy, por fin, maestro de escuela, y además, en un nido muy hermoso \& pequeño, que se llama Trattenbach (cerca de Kirchberg am Wechsel B.A.) El trabajo en la escuela me produce alegría y la necesito de verdad; si no, se me desatan inmediatamente todos los demonios. [...]» ${ }^{43}$

La actividad como maestro no le deparó, sin embargo, demasiadas alegrías, su entusiasmo inicial se fue transformando en aversión hacia los niños pero sobre todo hacia los padres. Durante las vacaciones de verano de 1921 y pese a lo dicho a sus amigos noruegos, decidió ir a Skjolden en compañía de un amigo de la familia, Arvid Sjögren.

Wittgenstein era, por propia decisión, un hombre pobre ${ }^{44}$. No pudieron viajar directamente desde Austria a Noruega e incluso pidieron a Drægni dinero para poder alcanzar el país, puesto que en Holanda no tenían ya dinero para continuar hacia el norte ni para volver a Austria. Drægni los encontró en el muelle de Bergen y los invitó a cenar durante el trayecto en barco a Skjolden.

Pasaron dos meses en Noruega, trabajando para pagarse la manutención y el viaje de vuelta en el taller del carpintero que fabricaba las cajas y barriles para la fruta de la empresa de Drægni.

El 5 de agosto escribe a Paul Engelmann desde Skjolden: «Estoy en Noruega, donde ya pasé un año entero antes de la guerra.» El 9 de septiembre escribe a Engelmann de nuevo, ya desde Viena.

No nos ha llegado referencia escrita alguna sobre la casa. Este hecho resulta especialmente sorprendente siendo la primera visita de Wittgenstein a su casa en el lago.

\footnotetext{
${ }^{43}$ Carta de Wittgenstein a Paul Engelmann, 11.10.1920. En Wittgenstein-Engelmann, 2009, op. cit. p. 82

${ }^{44}$ Cedió la parte de la herencia que le correspondía de su padre a diferentes obras benéficas pero en su mayor parte a sus hermanos. No a todos, a Gretl la consideraba ya suficientemente rica, tras unir su fortuna personal a la de su marido americano Jerome Stonborough.
} 

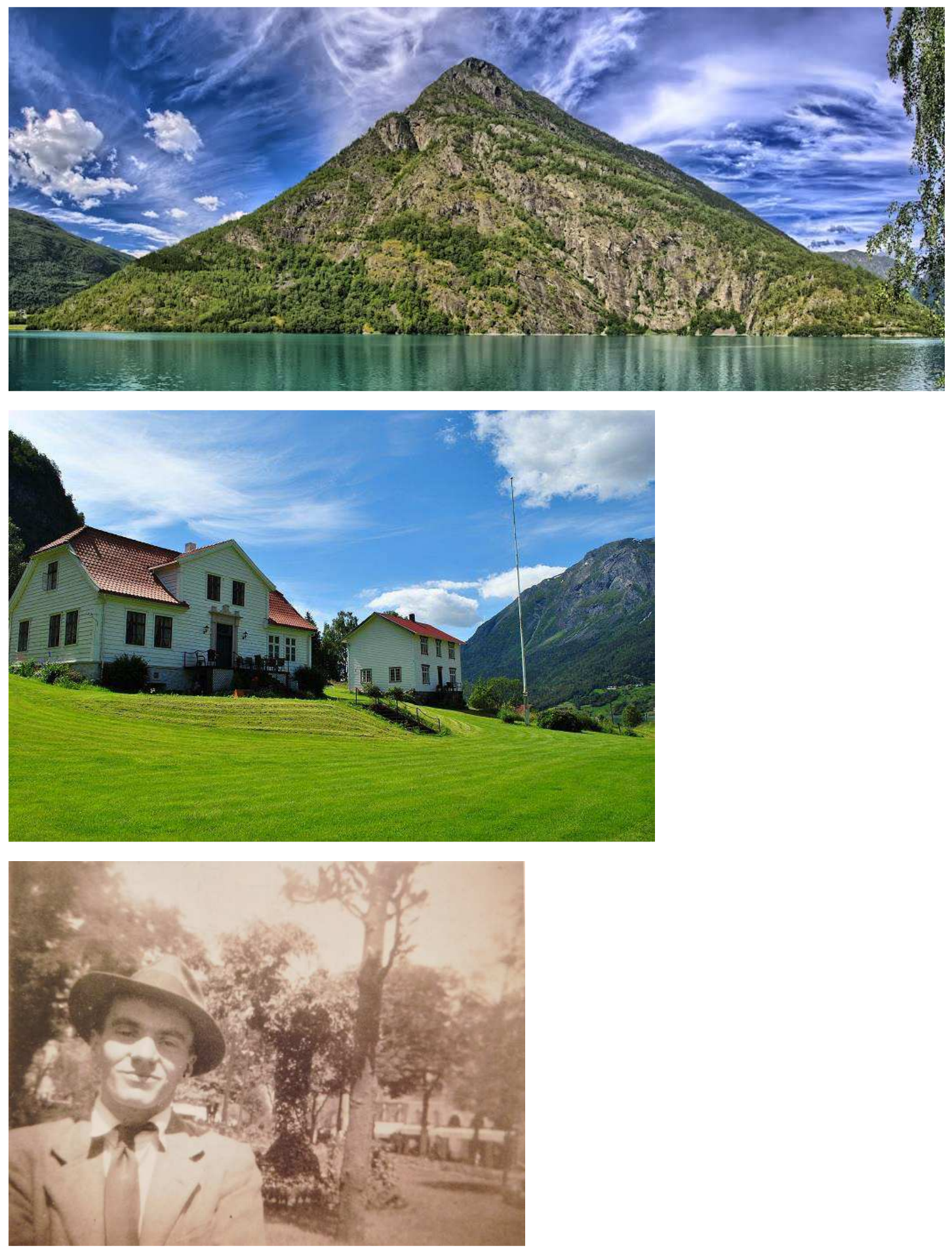

55. Hierseggi sobre el lago Eidsvatnet: «Nature is wonderful in all her moods.»

56. Granja Eide

57. Gilbert Pattison 
«Nature is wonderful in all her moods.» ${ }^{45}$

En una situación personal totalmente distinta a la de 1921. Wittgenstein, había sido contratado en 1930 como fellow en el Trinity College por un periodo de cinco años. Era ya un consagrado filósofo, muy a su pesar, y había completado sólo un año antes la construcción de la residencia de su hermana Gretl de Viena, en la Kundmanngasse 19. Dice Monk que, para Wittgenstein, todo dependía del espíritu. Son tiempos en los que se dedicaba a leer a Frazer, a recomendar a sus alumnos y compañeros Sexo y carácter de Weininger, a comentar la visión de occidente de Spengler y a planear su propia autobiografía, a modo de confesión. $\mathrm{Su}$ visión del judío interior empieza a mostrarse en sus escritos como una manera de ver la vida trágicamente. En este escenario psicológico, propone a Marguerite Respinger, amiga de la familia en Viena, que se case con él. Para ayudarle en la reflexión y en el tipo de relación que le estaba proponiendo, Wittgenstein invita a Marguerite a Noruega. Allí, él se instala en su casa del lago y ella debe permanecer en la granja de Anna Rebni, cerca del pueblo. En la maleta de Marguerite, Wittgenstein ha dejado una biblia y una carta en la que le propone una vida en común platónica. La estancia en Skjolden ayuda a Marguerite a decidir con absoluta claridad que nunca se casaría con Ludwig, pero tuvo ocasión de entender qué había encontrado el filósofo en Skjolden: «allí había paz y simplicidad en su más alto grado.»46

Durante las dos semanas que estuvo Marguerite en Skjolden apenas vio a Wittgenstein. A mediados de agosto este ya ha vuelto a Austria, a su casa en el Hochreith (cfr. carta al físico en Cambridge William Heriot Watson, 19.08.1931, en McGuinness, 2012). Durante unas tres semanas, Wittgenstein compartió su estancia en Noruega con un amigo de Cambridge, Gilbert Pattison, aunque este no coincidiera con Marguerite, que había viajado a Roma por la boda de su hermana.

\footnotetext{
${ }^{45}$ Tarjeta postal de Wittgenstein a Drury desde Skjolden en 1931. En Rhees, 1981, op. cit. p.135

${ }^{46}$ Testimonio de M. Respinger de 1991, en Åmås, op. cit. p. 44
} 


\section{CARTAS, ENCUENTROS, RECUERDOS}

\section{Wittgenstein-Engelmann}

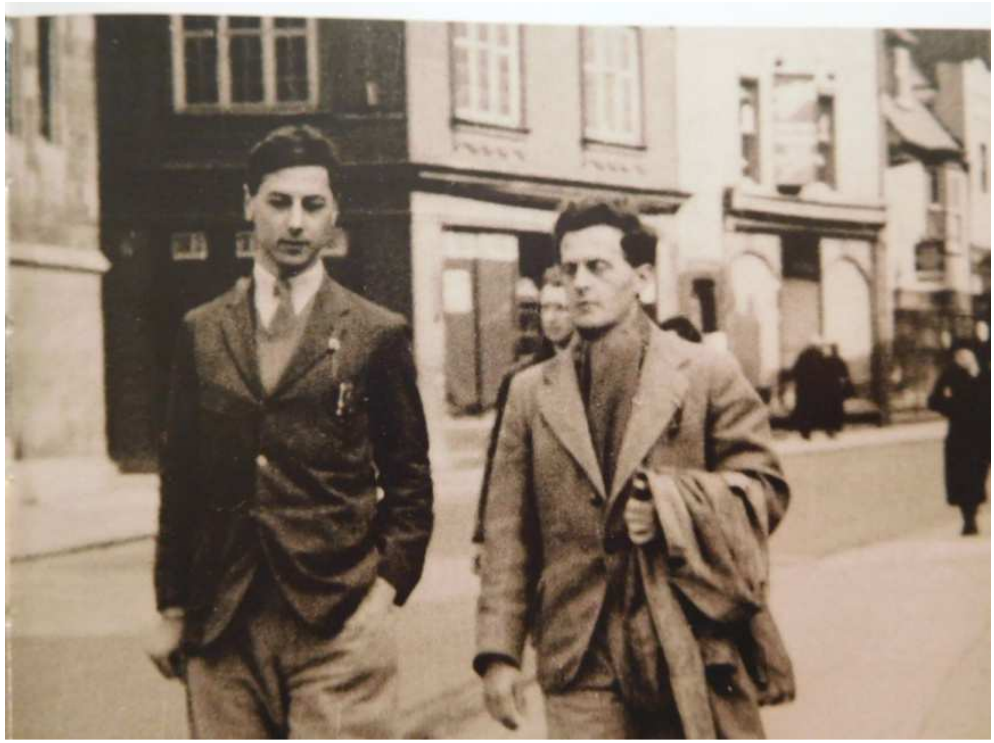


La visita no ha quedado recogida en sus diarios; Wittgenstein se dedicó a rezar en lugar de escribir y a pensar en sus pecados, según le dijo a Drury ${ }^{47}$. No sabemos nada de su estancia en la cabaña.

Wittgenstein concluyó su periodo como fellow en Cambridge en el Trinity College en verano de 1936 y decidió escapar a Skjolden para trabajar en sus observaciones filosóficas. No se ha podido localizar correspondencia alguna entre Wittgenstein y Drægni o Bolstad entre 1921 y 1938, pero es seguro que Wittgenstein debió preparar la casa y contactar con sus amigos en Noruega con la intención de pasar una larga temporada allí. Llegó a Skjolden a primeros de agosto de 1936 según las anotaciones de su diario, y estuvo viviendo en su casa del lago hasta el 11 de diciembre de 1937, con dos periodos de interrupción durante esos dieciséis meses, una en la Navidad de 1936 para pasarla como era tradición, con su familia en Viena -también se encontró con Paul Engelmann. En enero fue a Cambridge pero reinició el viaje de vuelta a Noruega el 23 de enero. Su primera carta desde Skjolden está fechada en «viernes», sin duda el 29 de enero de 1936.

Durante esa larga temporada en su casa de Skjolden, Wittgenstein trabajó en la preparación de lo que formaría parte de las Investigaciones Filosóficas (parece que según sus cuadernos en las secciones §1-188). Fue un año en el que Wittgenstein volvió a sentirse profundamente abatido, su diario está repleto de referencias a sus sentimientos, emociones y necesidades. También vicios y flaquezas. En diciembre a su familia y en enero a sus amigos de Cambridge, realizó una serie de confesiones que para Wittgenstein eran una manera de devolverse la valentía ante la vida, siempre necesitando revelarse a la pobreza de espíritu que le atenazaba y le impedía -sobre todo- concentrarse en su trabajo. En una carta a Moore del 4 de marzo de 1937 dice: «Mi trabajo no ha ido

\footnotetext{
${ }^{47}$ A su vuelta de Noruega, expuso a Moore y a Drury a sus confesiones. Lo haría en otras ocasiones, como en la Navidad de 1937 con su familia, en Viena y con sus amigos de Cambridge. Wittgenstein tenía necesidad de sentirse honesto, no sólo de serlo.
} 

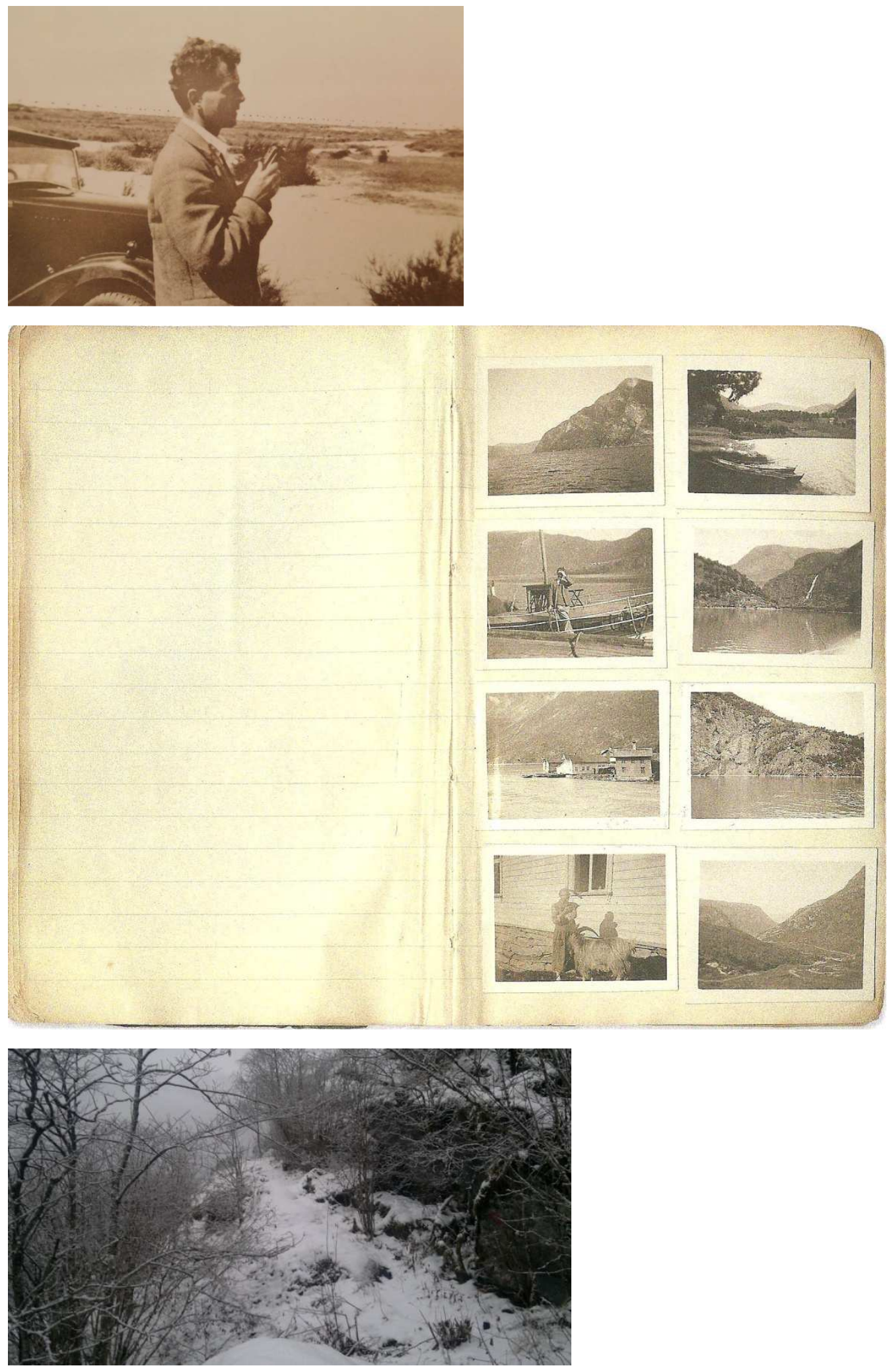

60. Viaje con Gilbert Pattisson por Francia, 1936

61. Viaje de Skinner a Skjolden, septiembre 1937

62. Acceso a la casa de Wittgenstein en invierno, 07.11.2012 
bien desde que volví [a Skjolden]. Parcialmente porque he estado muy preocupado por mí mismo.» ${ }^{48}$

Entre mayo y agosto de 1937, Wittgenstein estuvo con su familia en Viena y con Francis Skinner ${ }^{49}$ en casa de este, en Cambridge. A su vuelta a Skjolden el 16 de agosto, la angustia ante el miedo a su incapacidad para trabajar lo mantenían en un estado de neurosis que recuerda a sus tiempos de juventud en que pensaba sistemáticamente en quitarse la vida, por no verle sentido de la decencia, por mediocridad. En Cambridge «podía enseñar, pero no escribir» y en Noruega se sentía «atrapado en la mezquindad.»

No soportaba vivir a solas en su casa y rogó a Anna Rebni que le alojara en su granja. Su diario está lleno de reflexiones acerca de su cobardía, aunque probablemente su estado físico tampoco era bueno. El 21 de agosto $^{50}$ decide mudarse a su casa, pero el malestar no cede demasiado. Francis Skinner visitó a Wittgenstein en septiembre. Tan esperada visita, sin embargo motivó en Ludwig sentimientos de culpa y la ausencia posterior de su compañero reavivó su estado neurótico. En otoño las entradas de su diario muestran un Wittgenstein lleno de pesar, que no entiende si su trabajo y sus esfuerzos por estar solo han valido la pena. Hace frío, la casa tiembla en medio de las tormentas y se siente un perturbado. Se veía incapaz de trabajar en Noruega pero seguro de no poder hacerlo fuera de allí. El tiempo ha cambiado, frío, nieve, hielo. La oscuridad y el cansancio hacen que todo sea difícil. El miedo le impide trabajar. El 29 de noviembre escribe: «Cuento los días que me quedan aquí. Sólo Dios podría ayudarme a descansar.» ${ }^{51}$

El 12 de diciembre, en el barco por el fiordo, camino ya de Bergen escribe Wittgenstein en su diario:

\footnotetext{
${ }^{48}$ En McGuinness, 2012, op. cit. p. 263

${ }^{49}$ Skinner fue compañero sentimental y partner intelectual del filósofo entre 1932 y 1941, fecha en que murió, a los 29 años, de poliomielitis. Francis visitó a Wittgenstein en la casa del lago entre el 19 de septiembre y el 1 de octubre de 1937. A partir de 1939 la relación se había deteriorado entre ellos, probablemente por el propio Wittgenstein. La familia de Skinner culpó siempre a Wittgenstein de haber destruido la prometedora carrera y la personalidad de Skinner.

${ }^{50}$ Anotación en su diario MS118, 8r [2] et 8v [1]. Wren Library, abril 2015.

${ }^{51}$ Anotación en su diario MS120, 16r [2] et 16v [1]. Wren Library, abril 2015.
} 

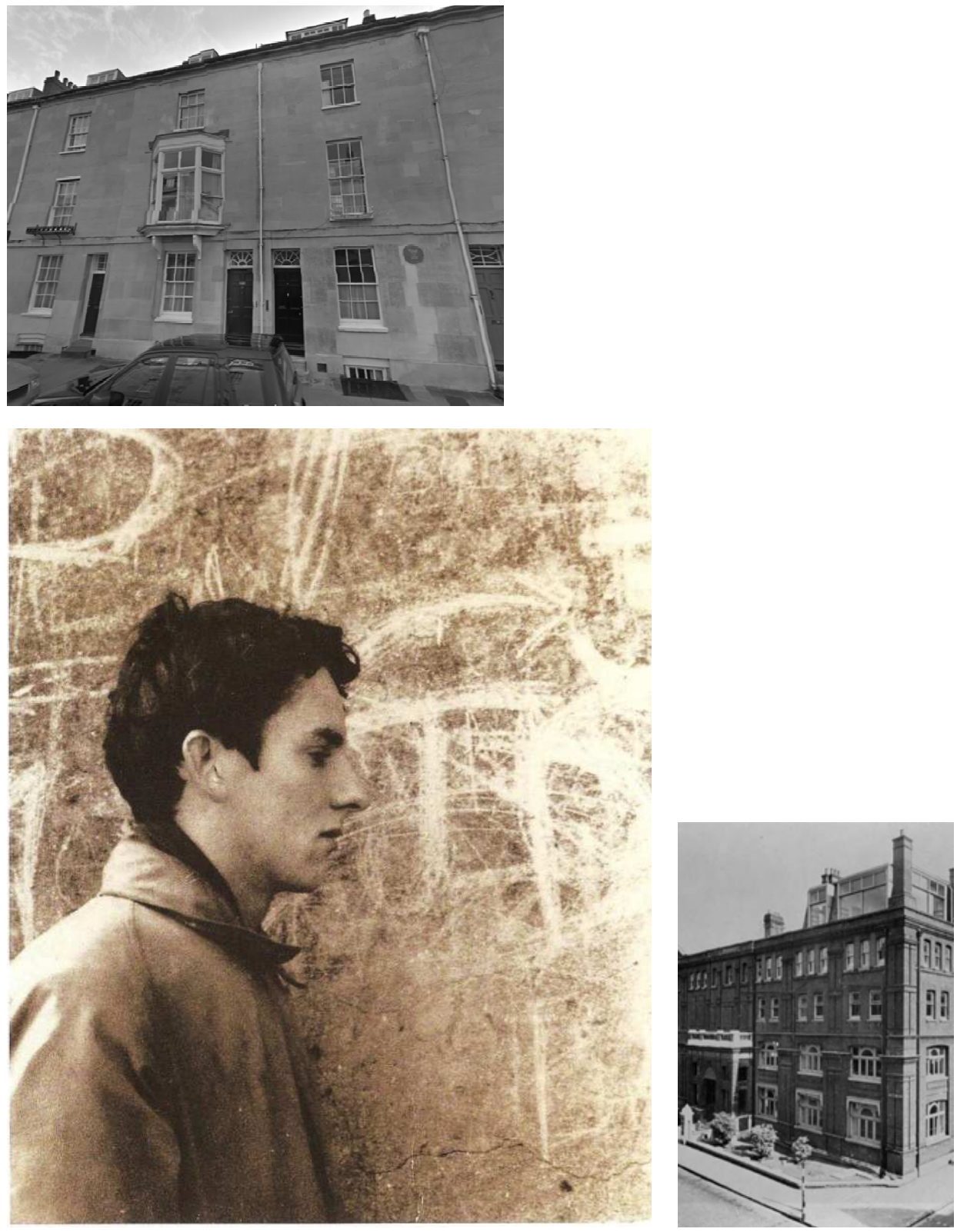
«En el barco a Bergen. Mucho frío y estoy bastante incómodo. Ayer pasé mi último día en mi casa, luego fui a Skjolden y me despedí de todo el mundo. No me han entendido. No hay nada más difícil que escribir con sinceridad sobre uno mismo.» ${ }^{52}$

Wittgenstein acababa así una estancia en su casa de Skjolden de casi año y medio. Durante ese tiempo recibió correspondencia y amigos -Francis Skinner ${ }^{53}$ y Hermann Hänsel-, mantuvo una relación cordial con los lugareños y tempestuosa con Anna Rebni, viajó a Austria e Inglaterra. Nos habló del sol en su casa, del frío, de la lluvia y el lago helado, pero nunca de su casa.

El 25 de abril de 1950, Wittgenstein se traslada a Oxford. Allí ocupa la segunda planta del 17 St. John St, en la casa de Elisabeth Anscombe. Wittgenstein tenía previsto viajar a Noruega y pasar el verano en su casa en Skjolden, junto a su compañero Ben Richards ${ }^{54}$. Sin embargo este suspendió su último examen y Wittgenstein pasó el verano en Oxford. La casa era tranquila, al menos más que la de los von Wright en Cambridge. Pero tampoco demasiado. Durante ese verano, Wittgenstein siguió trabajando en sus notas para Observaciones sobre los colores.

Cuando Richards aprobó por fin su última asignatura en medicina en el Bart's College ${ }^{55}$ partieron hacia Noruega a mediados de octubre y permanecieron allí hasta el 20-21 de noviembre.

La visita no fue bien. Wittgenstein había sido diagnosticado de cáncer de próstata en octubre de 1949. Sin embargo fue Richards quien contrajo una bronquitis en Skjolden y no pudieron residir en la casa del lago. Tuvieron que trasladar al joven Ben con urgencia a una clínica en Luster y unos días después

\footnotetext{
${ }^{52}$ Anotación en su diario MS120, 48r [2] et 51v [2]. Wren Library, abril 2015.

${ }^{53}$ De la visita de Francis Skinner se guardan algunas fotografías del álbum personal de Wittgenstein (WAC y Michael Nedo, Cambridge). En alguna de ellas aparece la casa del lago, al fondo. Ninguna tiene como objeto a fotografiar la propia casa. Siempre forma parte del paisaje. Sobre esto nos extenderemos más adelante.

${ }^{54}$ Wittgenstein era treinta y cinco años mayor que Ben cuando se enamoró de él en 1945. Encontró en su nuevo compañero las cualidades que egoístamente necesitaba para refugiarse de sí mismo, como las tuvieran Pinsent o Skinner: inteligencia, sensibilidad, cierta timidez y seguramente docilidad.

${ }^{55}$ St Bartholomew's and the Royal London School of Medicine and Dentistry.
} 


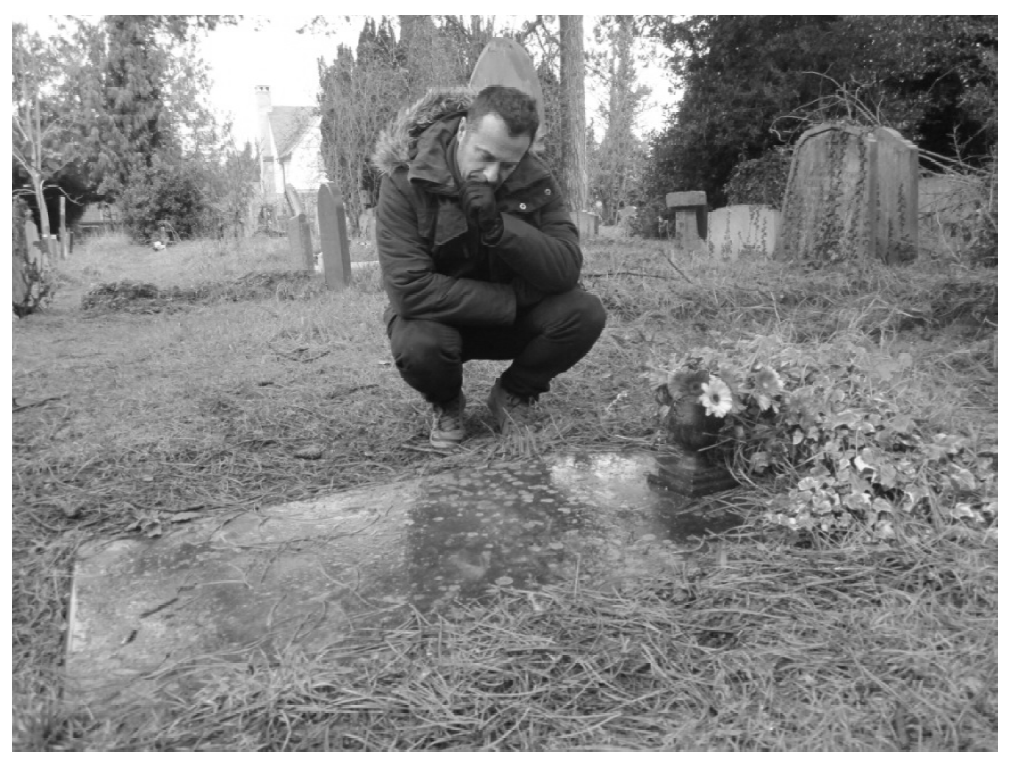

66. Tumba de Ludwig Wittgenstein en el Ascension Parish Burial Ground, St. Giles Church, Cambridge, diciembre 2013 
se alojaron en la granja Eide de Rebni, en la que Wittgenstein hallaba refugio y compañía. De esta visita conservamos las únicas imágenes premeditadamente enfocadas hacia la casa de Skjolden, que conservaba Ben Richards en un álbum bajo el título de Ludwig Wittgenstein's House:

«Nos quedamos en Bergen poco tiempo -dos o tres días- tras zarpar desde Newcastle. Navegamos durante la noche por el fiordo de Sogn hasta Skjolden e hicimos una noche en el pueblo. Wittgenstein hacía años que había regalado la casa a un jardinero llamado Arne Bolstad. Tras remar y escalar hasta la cabaña, la primera cosa que hicimos fue quitar las banderas y otras cosas que Bolstad había colgado en las paredes de madera desnuda y barrer y limpiar el lugar. Trajimos provisiones. Había una polea para izar cubos desde el lago. Traer agua era, evidentemente, mucho más fácil entre dos personas - una para llenar los cubos y otra para enviarlos arriba y devolverlos abajo- que una a solas. Remamos por el río para dar paseos y hacer visitas. Había llevado conmigo la reciente traducción de Austin de Fundamentos de Aritmética de Frege, y lo leíamos y comentábamos.» ${ }^{56}$

\section{A su regreso, Wittgenstein escribió a Malcolm:}

«Gracias por tu carta del 3 de noviembre. La encontré a mi regreso de Noruega hace unos diez días. [...]Tuvimos un tiempo estupendo. Intenté trabajar algo pero no pude. Probablemente vuelva a Noruega pronto e intente trabajar; es el único lugar que conozco en el que estoy realmente tranquilo.[...]»57

\section{Y a von Wright:}

«[...]Si todo va bien zarparé el 30 de diciembre hacia Skjolden de nuevo. No creo que pueda quedarme en mi casa porque el esfuerzo físico que hay que hacer allí es demasiado pesado para mí, pero una vieja amiga me dijo que podría quedarme en su granja.[...]Si no puedo trabajar allí, no puedo trabajar en ninguna parte.[...]»58

Sin embargo, poco antes de Navidad, Anna Rebni informó a Wittgenstein que no podría alojarlo en su granja. Ludwig aún intentó contactar con Arne Bolstad para arreglar un alojamiento en el pueblo pero no obtuvo respuesta. La salud de Wittgenstein iba empeorando. Tras una revisión tuvo que pasar la Navidad en casa del Dr. Bevan. De vuelta a Oxford, en enero se sintió muy débil y a principios de febrero se instaló en Cambridge, en casa de su doctor, hasta su fallecimiento a finales del mes de abril.

\footnotetext{
${ }^{56}$ Testimonio de B. Richards de 1993, en Åmås, op. cit. p. 55

${ }^{57}$ Carta de 01.12.1950, en McGuinness, 2012, op. cit. p. 469

${ }^{58}$ Carta de 07.12.1950, en McGuinness, 2012, op. cit. p. 470
} 


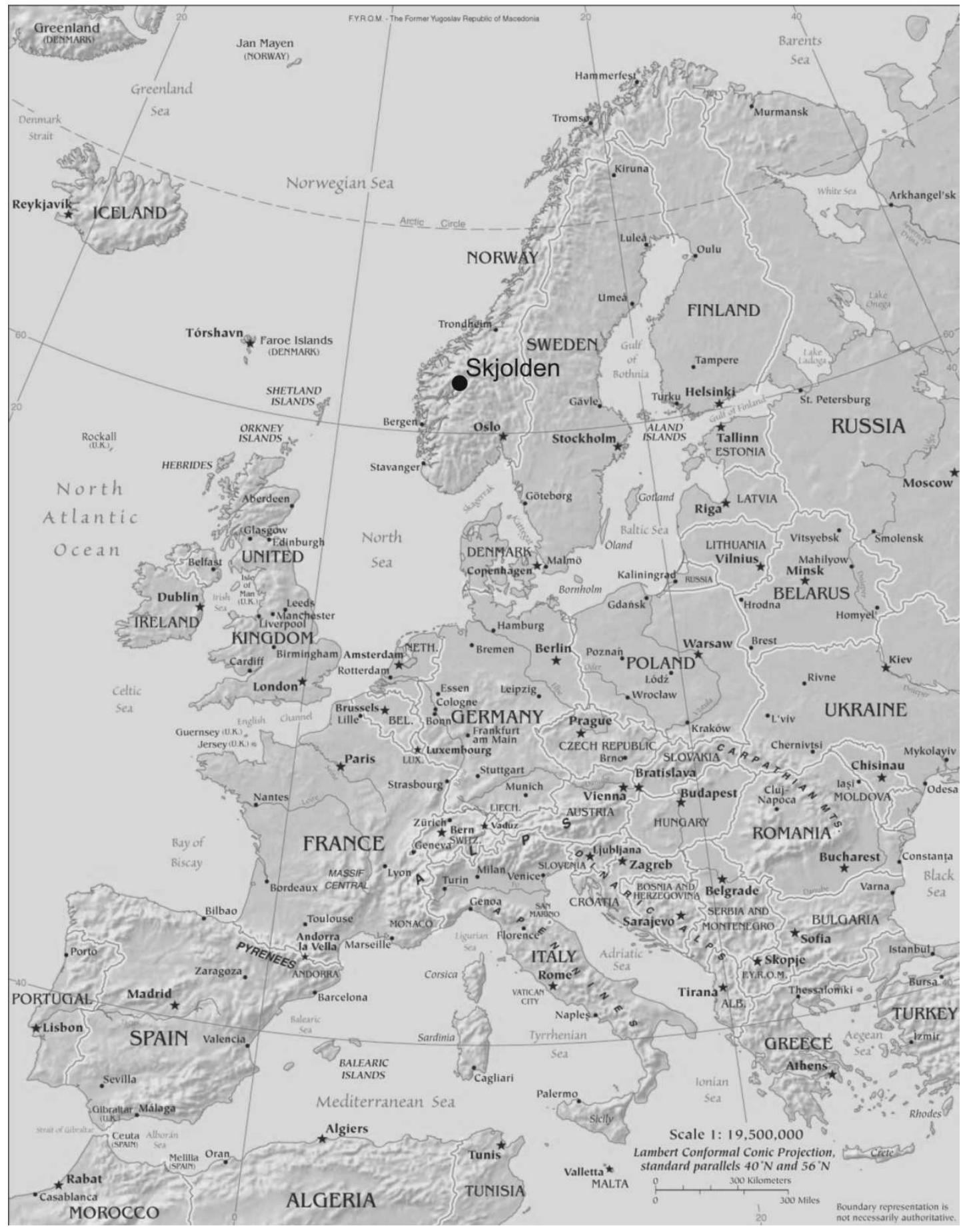

67. Skjolden y su localización respecto a Europa 


\section{Skjolden. Espacio y tiempo}

Durante estos cinco años de investigación para la preparación de la presente tesis, he podido comprobar repetidamente que la literatura, en general, considera necesario definir Skjolden como una población prácticamente inaccesible. Somos conscientes -se ha dicho ya aquí- que Wittgenstein ha sido mitificado de tal manera que cualquier aspecto de su vida se considera extremo en grado sumo. Cierto es que su vida y su obra fueron intensas, coherentes, neuróticamente honestas y premeditadamente difíciles. En palabras de Kanterian, «Wittgenstein nació, trabajó, amó, buscó a Dios, sufrió y murió.» ${ }^{59}$

Wittgenstein es considerado por la sociedad filosófica como un héroe. ¿Y no sería propio del héroe exiliarse a un lugar remoto, inauditamente inaccesible?

Y sin embargo, Skjolden no es ese lugar. No lo era en 1914 y menos si cabe cien años después. Pero tampoco lo era siquiera en el s. XIX. No son meros matices los que aquí se expresan sino que nuestra aproximación es, como se destila de entre las líneas, pragmática. Vayamos pues leyendo el mapa topológico del lugar.

Skjolden es una pequeña población situada a unos 280 kilómetros por carretera al noreste de Bergen. Se encuentra en la región de Vestlandet, pertenece al municipio de Luster, en la provincia de Sogn og Fjordane.

Skjolden se localiza en la misma cabecera del fiordo de Sogne (Sognefjord), rama oriental del Lustrafjord, a 205 kilómetros de la $\operatorname{costa}^{60}$ sobre un talud de derrubios procedente de la erosión de las laderas de las montañas circundantes y por los aportes sedimentarios de los ríos Fortun y Mørkridselvi que vierten sus aguas al fiordo. La población, de unas 300 personas, vive en casas y granjas dispersas con una relativa concentración en el entorno de la desembocadura de los ríos en el fiordo.

\footnotetext{
${ }^{59}$ Edward Kanterian, Ludwig Wittgenstein, London, 2007, p. 8. Aquí el profesor Kanterian parafrasea a su vez a Martin Heidegger que comenzó una clase sobre Aristóteles diciendo: «Aristóteles nació, trabajó y murió. Vayamos ahora a estudiar sus ideas.»

${ }^{60}$ La medición se considera hasta el límite oficial de mar abierto, en la isla de Ytre Sula. En nuestro planeta, sólo el fiordo Scoresby Sund en Groenlandia tiene mayor longitud.
} 

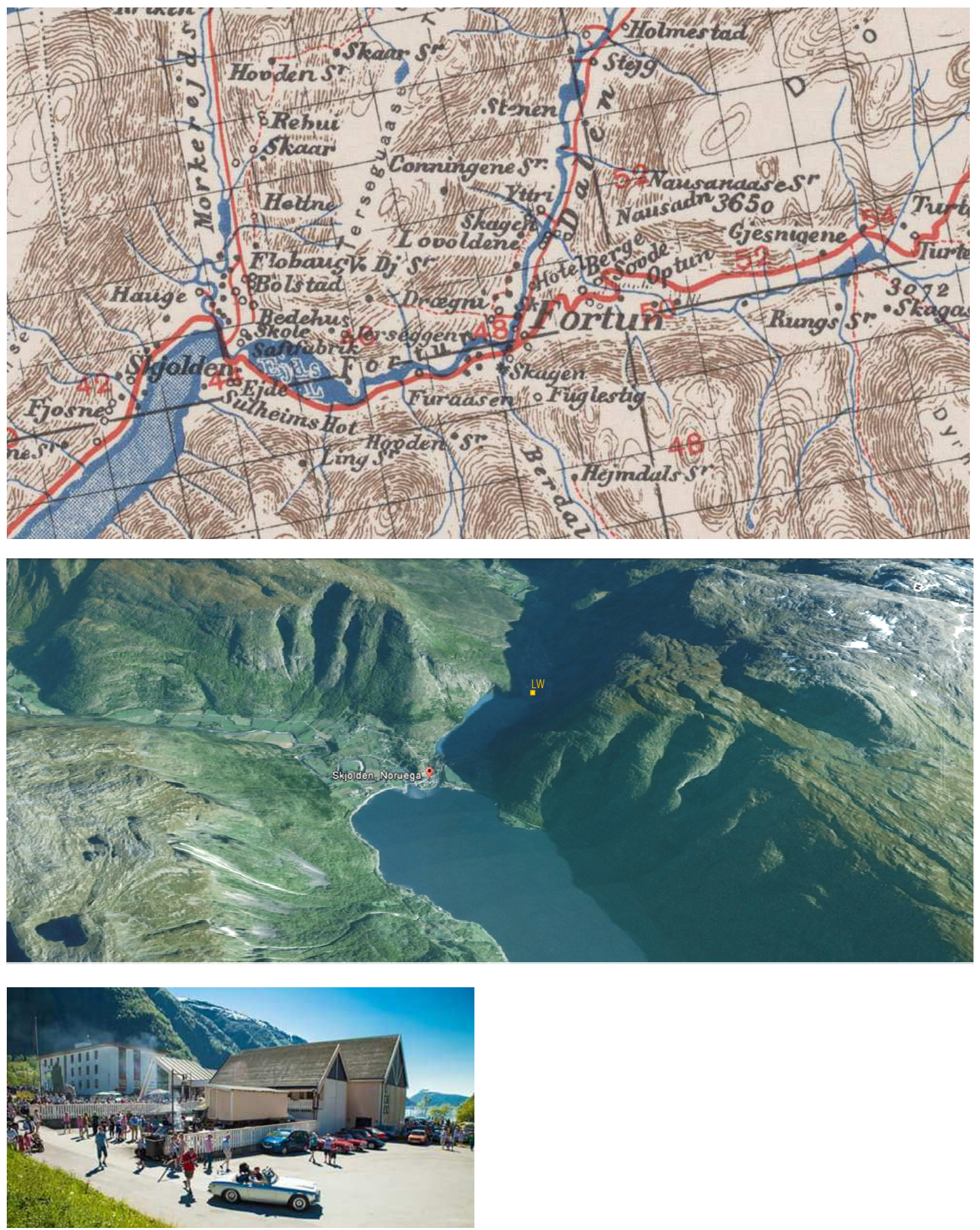

68. Mapa topográfico de Skjolden. Se aprecia el encajonamiento de los valles glaciares y la violencia de la topografía

69. Imagen aérea del Sognefjord, Skjolden y el lago Eidsvatnet, este aparece prácticamente en sombra a mediodía por su orientación este-oeste

70. Actividades culturales en la fiesta del verano de Skjolden, «Kulturdagane Skjolden 2010» 
En la plaza encontramos un edificio multifuncional, llamado Fjordstova, que hace las veces de edificio comunitario, cafetería, piscina cubierta, rocódromo y biblioteca, con una pequeña estantería dedicada a Wittgenstein. En otro lado de la plaza, un colmado, que nos permite aprovisionarnos, es a su vez la oficina de correos. Las montañas que rodean el pueblo alcanzan más de mil metros. El agua es omnipresente, torrentes caen en cascada desde las cimas. El fiordo, dos ríos y un lago glaciar.

La presencia del lago Eidsvatnet es importante en el pueblo. Hace años, cuando en invierno la superficie del agua se congelaba con mayor asiduidad ${ }^{61}$, los lugareños gustaban de patinar sobre el hielo. A finales del invierno de 1915, los Klingenberg escriben a Wittgenstein, «Todavía hay hielo en el lago. Este invierno el tiempo ha sido muy malo para esquiar. La mayor parte del tiempo no nevaba o estaba todo tan resbaladizo que se podían usar patines para ir a cualquier parte. Estuvimos patinando sobre el lago helado, Kari fue muchas veces.» ${ }^{62}$

El fiordo fue, durante décadas, el canal de transporte principal desde Skjolden hacia Bergen y el continente. Una fábrica de hielo y producción de frutas y zumos, como las factorías de Drægni ${ }^{63}$ demuestran que el aislamiento de la población al fondo del fiordo no era tal.

Abundando en esta circunstancia, Skjolden representa desde el s. XIX la puerta de acceso a algunos de los parques naturales más importantes del oeste de Noruega. El tráfico de barcos de mercancías y personas por el fiordo era muy elevado. Vatne editó en 1991 un folleto ${ }^{64}$ con una recopilación de datos históricos

\footnotetext{
${ }^{61}$ En conversación con H. Vatne, octubre 2013 explica que desde que se hiciera la central hidroeléctrica de Fortun en los años 50-60, a unos 5 $\mathrm{km}$ aguas arriba de Skjolden, las variaciones de volumen del río al lago han incidido en los ciclos de congelación de la superficie del Eidsvatnet. (Más información de Fortun: http://www.fortunsdalen.no/)

62 Åmås, 1994:a, op. cit. p. 105

63 Drægni producía unos 100000 I de fruta al año y exportaba a todo el continente. La Ishuset de Skjolden produjo en 1909 unas 8000 toneladas de hielo. (Fuente: Fylkesarkivet)

${ }^{64}$ El folleto de Vatne, editado con el Kulturkontor de Luster en 1991 no se publicó, sino que parece se distribuyó localmente. Hemos tratado de conseguir una copia directamente del delegado de cultura de Luster. La respuesta siempre amable y positiva no ha sido seguida del envío del material. Desconocemos el motivo pero alrededor del interés local sobre Wittgenstein hay cierta inexplicable opacidad. En correspondencia electrónica del 27.04.2015, nuestro enésimo intento y su correspondiente aserción: «Hallo! This article can be sent to you as a written copy. However, the text will be in Norwegian only. The author Mr. Harald Vatne is also finishing a new book about L.W. in Skjolden in which he also tells the story about the house (or the cabin as many local names it). Please send me your mailing address. Thank you for your interest in the history of L.W. in Skjolden, Norway. Med venleg helsing. Erling Bjørnetun, kultursjef.»
} 

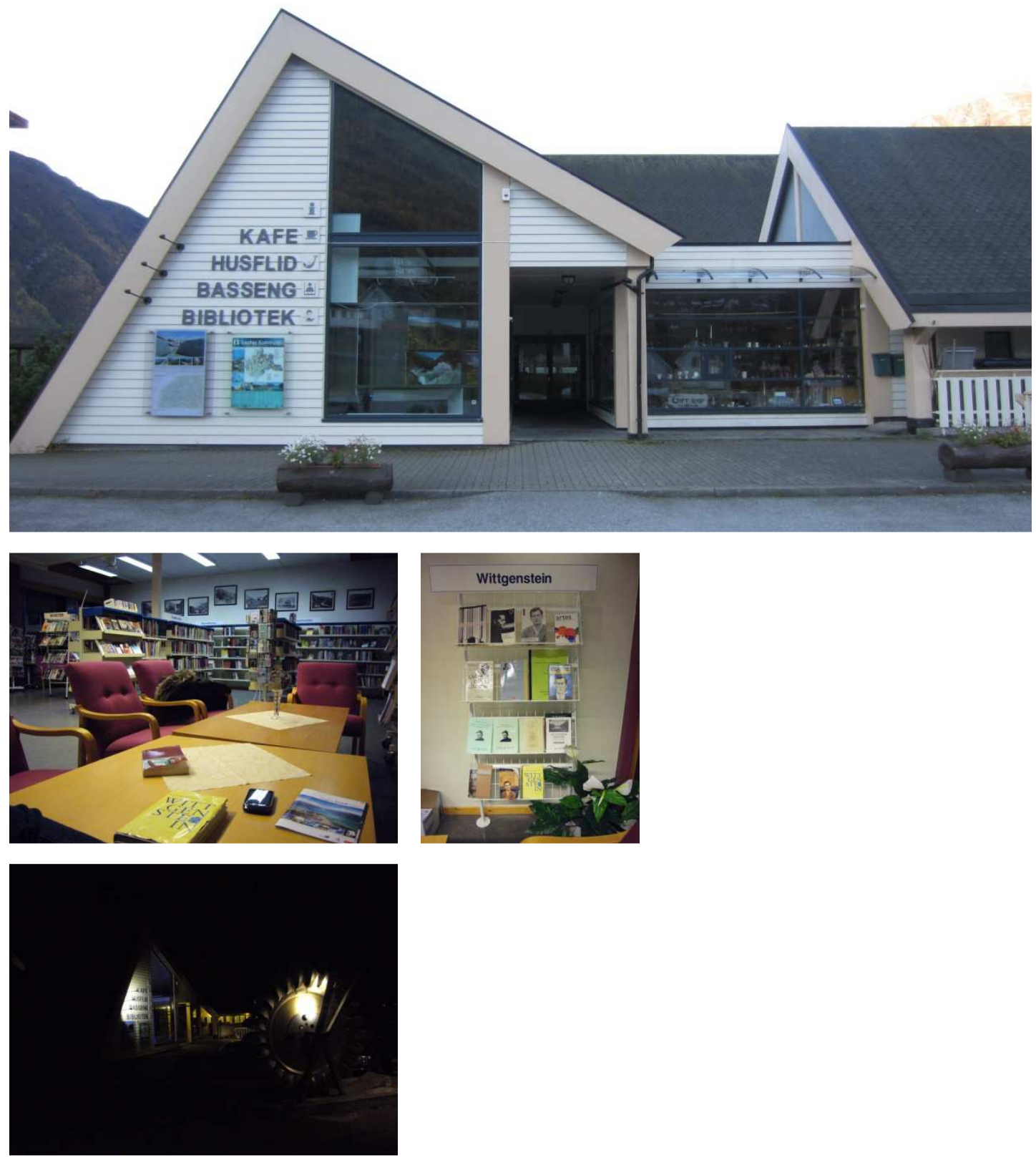

71. Edificio comunitario, Fjordstova, octubre 2013

72. Biblioteca en el Fjorstova | 73. Estantería (en noruego) dedicada a Wittgenstein en la biblioteca

74. Fuera de la temporada de verano (mayo-septiembre) el Fjordstova sólo abre una tarde a la semana durante unas horas 
que nos permite recrear el intenso trasiego de personas en Skjolden. Así, en 1878 se registró el paso de 16000 personas y 2500 caballos siguiendo la ruta hacia las montañas del valle Gudbrandsdalen. Los parques nacionales de Jostedalsbreen y Jotunheimen son de los más visitados del país y se accede de manera natural en Skjolden. A sólo 15 km, se encuentra la estación de Turtagrø, que desde 1888 es cuna del montañismo noruego y desde 2000 cuenta con una biblioteca cedida por el filósofo de la ecología Arne Naess ${ }^{65}$ y por el himalayista David Durkan.

Wittgenstein empleaba unos dos o tres días para trasladarse desde Inglaterra hasta Skjolden y en el mismo plazo podía llegar desde su casa en Noruega hasta la residencia de verano en Austria o la casa familiar en Viena. Con los medios de la época, tren, barco de vapor, etc., resultan viajes en apariencia sencillos.

Por tanto, quizá no era la distancia lo que hacía de Skjolden un lugar lejano para Wittgenstein. En 1914 escribe a Russell en alemán que está construyéndose una casa «In der Eissamkeit», "en soledad». Fue McGuinness quien lo tradujo como «a millas de cualquier lugar», advirtiendo que lo hace con cierta libertad 66 .

Monk (1990)67 dice que allí encontró la tranquilidad necesaria para trabajar. Quizá sea esa la clave. El lugar no es inaccesible pero sí estaba -y está- fuera del círculo académico y burgués que a Wittgenstein le impedía trabajar. En la correspondencia que intercambia con los lugareños entre 1914 y 1946 -la edición de Åmås de 1994 cuenta con 51 cartas- se transmite una cierta quietud, el ir y venir constante de las estaciones en el paisaje y los trabajos de un ámbito rural. Pocas cosas pasaban en Skjolden, más allá de la propia vida. Wittgenstein valoró especialmente esa autenticidad, sencillez y elegante rudeza tolstoiana.

\footnotetext{
${ }^{65}$ A. Naess (1912-2009). Filósofo noruego, padre del movimiento de la Deep Ecology. Pasó largos periodos de su vida en una cabaña en Tvergastein. Una selección de textos de Naess es The Ecology of Wisdom, Berkeley, 2010.

${ }^{66}$ op. cit. p. 202

${ }^{67}$ op. cit. p. 101
} 

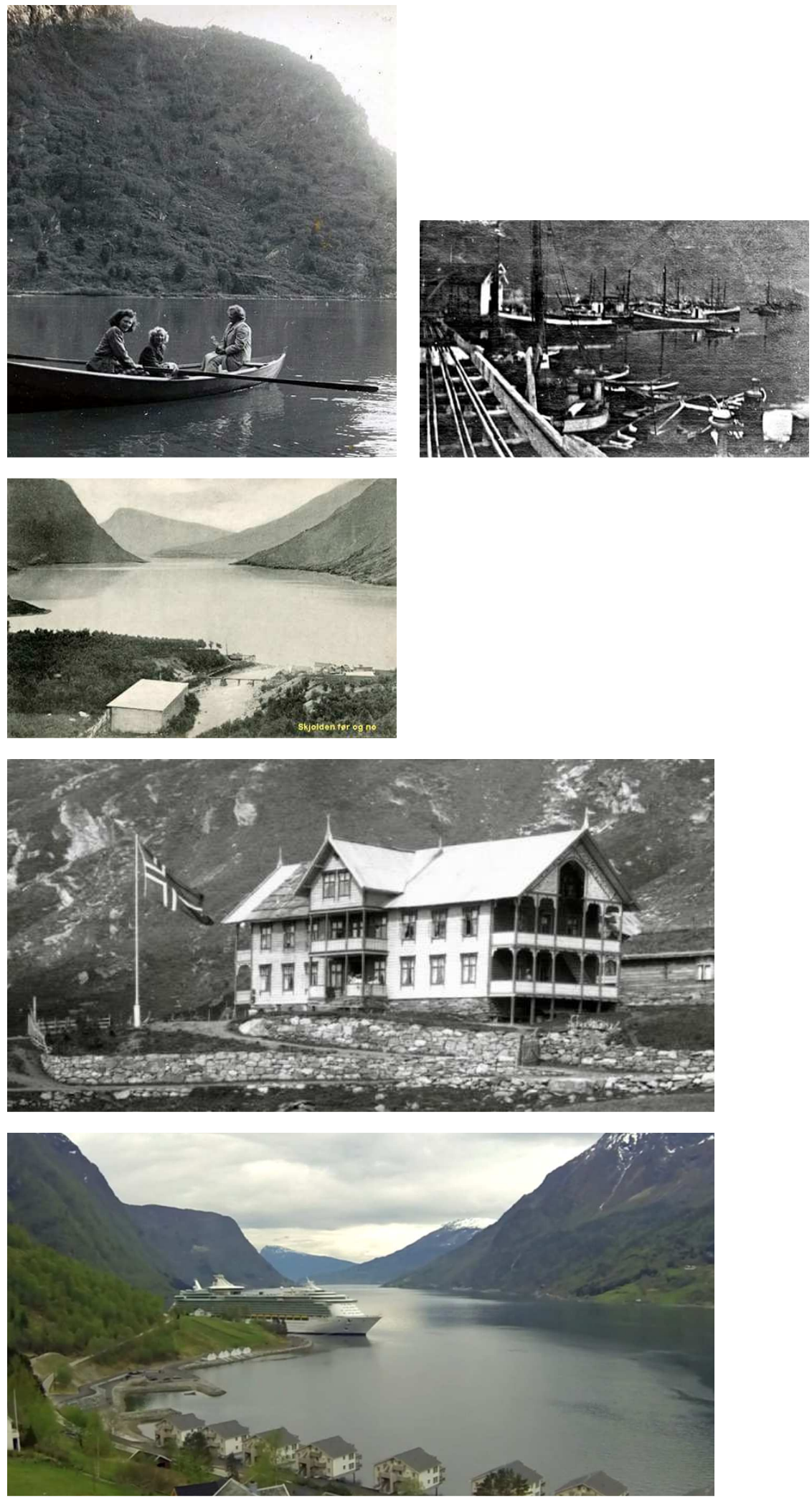

75. Excursión por el lago Eidsvatnet, 1950 | 76. Actividad portuaria de transporte de hielo y otras mercancías en Skjolden, 1910 77. Ishuset junto al Sognefjord, 1900

78. Hotel Turtagrø, 1920

79. Crucero Independence of the Seas, Skjolden, 21.05.2013 
Recientemente la cuestión del espacio-tiempo en Skjolden ha variado. Tras décadas sin servicio habitual de pasajeros en grandes naves, aunque sí en barcos más pequeños, puesto que el transporte por el fiordo ha seguido siendo importante, el 20 de mayo de 2010 llegó al pequeño muelle cercano al pueblo el crucero Marco Polo, con capacidad para 800 pasajeros. Otros 11 barcos amarraron en 2011 y 22 en 2012. El 21 de mayo de 2013 atracó en Skjolden el crucero Independence of The Seas de 4370 pasajeros y también lo hicieron otros 27 cruceros. En 2014, entre abril y septiembre han alcanzado la pequeña localidad de Skjolden 21 naves, con una capacidad conjunta de 19486 pasajeros. ${ }^{68}$ La población de la región de Luster es de 5089 personas en 2014, en un área de $2700 \mathrm{~km}^{2}$.

En julio de 1914, Wittgenstein abandonó Skjolden y la obra recién iniciada de su casa en el lago Eidsvatnet huyendo de la temporada turística. Skjolden sigue como hace un siglo, sigue siendo un refugio posible sólo en invierno.

\footnotetext{
${ }^{68}$ www.sognefjordcruise.no/; «From the coastline cruise 66 miles inland up the fjord to the village of Skjolden, population 300. We cruised up this beautiful fjord in the Emerald Princess with 3000 passengers, and tied up to a small wharf. There is not a lot to do in Skjolden, except to stroll into the village and just enjoy the beauty that surrounds you....» opinión de un turista en septiembre de 2014. No hay mucho que hacer en Skjolden. Pero siempre nos queda el paisaje.
} 

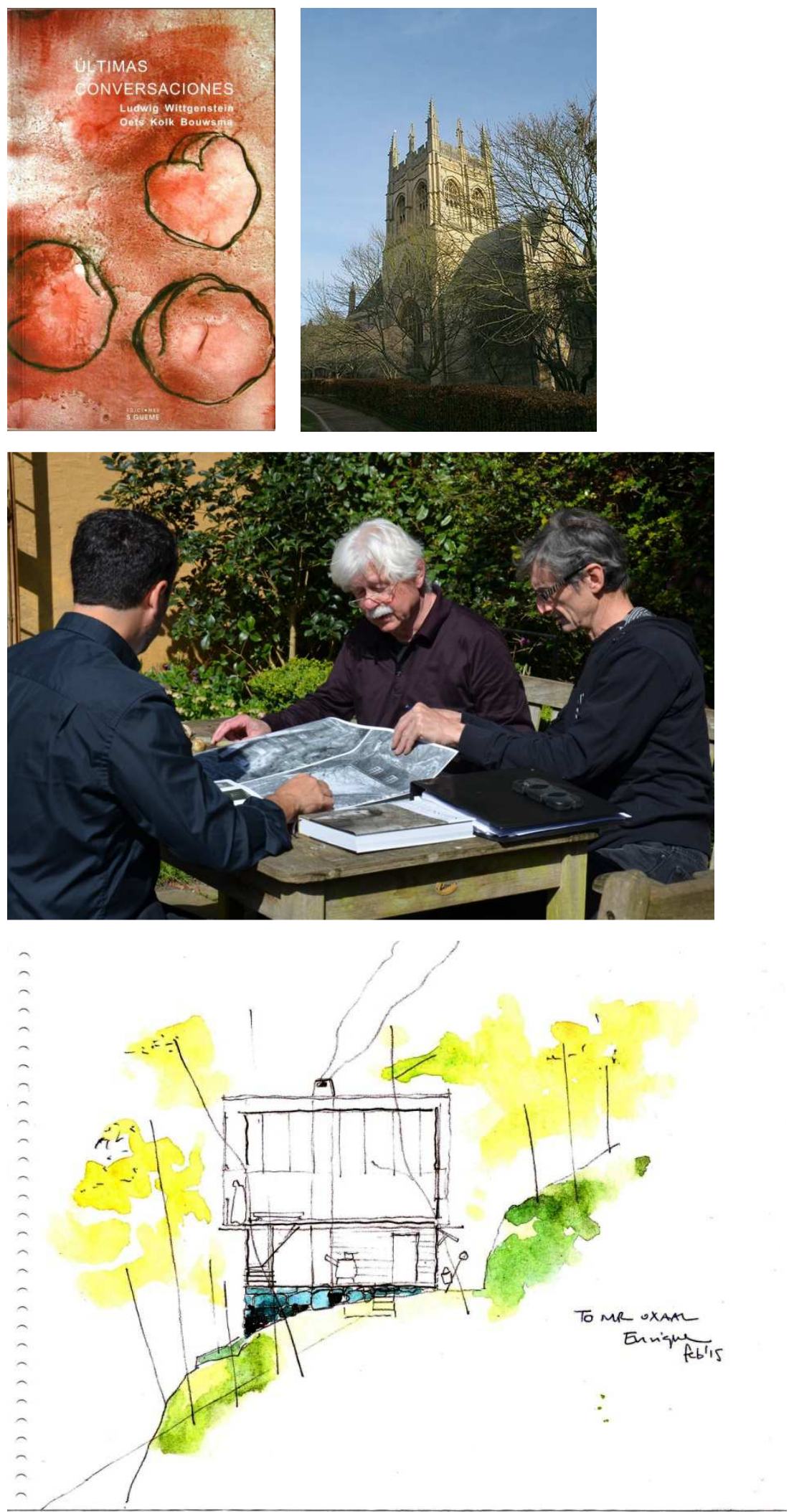

80. Wittgenstein \& Bouwsma, Últimas conversaciones | 81. Torre de Merton, Oxford

82. Conversación con Michael Nedo y David Connearn, Cambridge, abril 2015

83. Sección Casa de Wittgenstein. Work in progress, indecisiones respecto a la escalera 


\section{Referentes. Arquitectura vernácula y ética}

El 25 de septiembre de 1950, Wittgenstein pasea con Bouwsma por Oxford:

«Mientras pasábamos al lado de Merton estuvo admirando un pequeño árbol de hojas rojas; y nuevamente me llamó la atención sobre la torre de Merton y la edad de su capilla. Habían construido la estructura superior más tarde, se podía ver. "Austera, ¿no?" dijo, refiriéndose a la torre.»69

Las semblanzas y recuerdos que se han escrito sobre Wittgenstein abundan en referencias a la arquitectura, y desde luego a la música, a la literatura y en general a la estética. En sus recopilaciones de escritos aparecen en muchas ocasiones reflexiones independientes, a modo de aforismos -conviene recordar que no formaban parte de un texto con formato de libro preparado por Wittgenstein sino compilado por sus albaceas literarios- o alineados con conceptos filosóficos. Cuando nos enfrentamos a la obra de Wittgenstein, incluso a su vida, en su conjunto - creemos que no hay otra manera de hacerlo ${ }^{70}$ podemos ver que no hay una distinción clara entre sus reflexiones sobre la estética en cualquier campo y su propio sistema de hacer filosofía. Wittgenstein no pretendía, como se ha dicho en innumerables ocasiones destruir la metafísica, sino modificar la forma de enfrentarse a los problemas que ésta plantea en la filosofía. Una forma de hacerlo, su método fue el de decir/mostrar. Una forma de describirlo sería la metáfora. Hay una parte del lenguaje que nos permite expresar con claridad y significado las cosas y otra parte que es innecesaria y hemos de recurrir a mostrarlo en lugar de decirlo. Desde luego esto es lo que se expresa en el Tractatus aunque en las Investigaciones filosóficas esto es algo menos tajante. Este no es lugar para tales disquisiciones, pero baste decir que nos alineamos con la interpretación de que toda la producción filosófica de Wittgenstein se sostiene, evolucionando, en la clarificación.

\footnotetext{
${ }^{69}$ Bouwsma, 1986, op. cit. p. 87

${ }^{70}$ Michael Nedo en conversación en Cambridge, 20.04.2015: «Todos quieren escribir sobre aspectos parciales de Wittgenstein, qué leía, qué decía de esto o de lo otro...iqué más da eso y qué sabrán ellos de lo que Wittgenstein quería decir! Hay que leer al propio Wittgenstein para saber qué decía exactamente él mismo y dejar de hacer interpretaciones. Llevo años diciéndolo y publicando sus textos y ¿crees que lo lee alguien? iNo! Es más fácil coger un tema y hacer una conferencia iestoy harto de toda esa porquería!».
} 

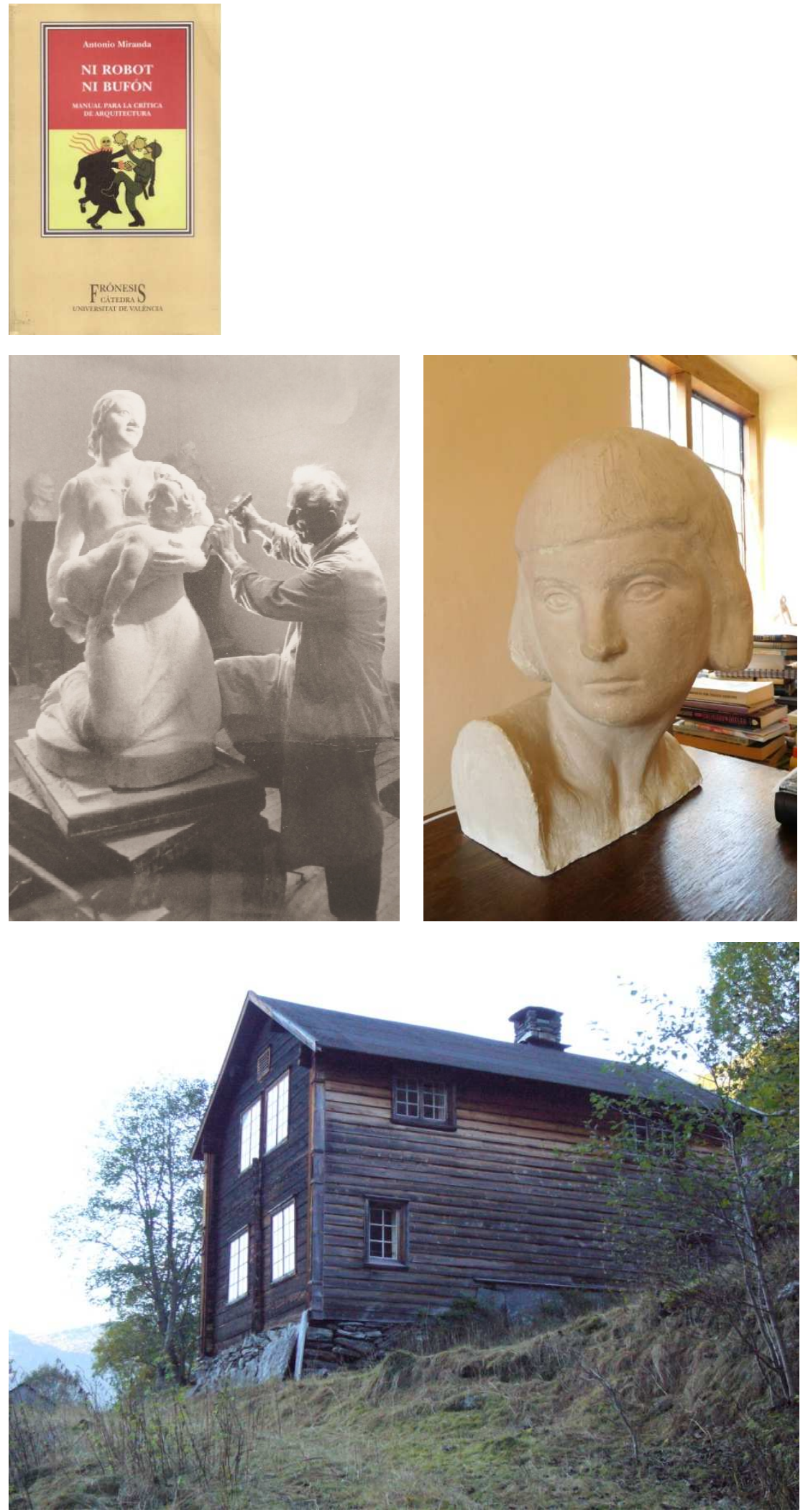

84. Antonio Miranda Regojo, Ni robot ni bufón, 1999: ¿Cuánta verdad hay en un proyecto de arquitectura?

85. El escultor Michael Drobil en su estudio, amigo de Wittgenstein | 86. L. Wittgenstein, busto (probablemente de M. Respinger), 1927 87. Casa de troncos tradicional noruega, Fortun, octubre 2013 
Ese ver con claridad o buscarla es trabajar los límites de la disciplina. En la Arquitectura, los límites los marcará la ética profesional. En cualquier disciplina es la ética, o menos genéricamente la honestidad, la que debe guiar cualquier actividad. Wittgenstein trataba todo y a todos con severidad, con la intención no de hacer daño sino de buscar lo verdadero. ¿Cuánta verdad hay en un proyecto de arquitectura? Resulta este argumento imposible de contestar aquí. Pero podemos aplicarlo como método para elucidar los problemas de la vida -del filosofar- con la formación de imágenes. Las reflexiones acerca de los límites son fundamentales:

«La arquitectura es un gesto. No todo el movimiento adecuado del cuerpo humano es un gesto. Como tampoco cualquier edificio adecuado es arquitectura.» ${ }^{71}$

No todo es arquitectura, ni escultura, ni música, ni filosofía, aunque hay cosas que se pueden parecer pero no soportan un juicio crítico profundo. Se ha dicho reiteradamente en las biografías de Wittgenstein que la casa de Viena para su hermana Gretl le hizo dar un giro a su visión significativa del mundo. Pero no estamos de acuerdo. Estamos convencidos que Wittgenstein mantuvo un juicio estético que forma parte del mismo sistema de juicio intelectual. Tras la lectura de numerosos textos y testimonios de personas que le conocieron es fácil darse cuenta de la dificultad que tenían muchas para relacionarse con el filósofo. No soportaba la superficialidad, pero no la superficialidad entendida como banalidad, sino la superficie de las cosas como fachada de ninguna estructura interna. En 1942 registra la anotación que hemos traído hace unas líneas, sobre el gesto en arquitectura. Entiende Wittgenstein que la arquitectura que no es mera apariencia, es una expresión del intelecto, sub specie aeternitatis ${ }^{72}$, en todo tiempo y momento, como ya escribía en 1916:

\footnotetext{
${ }^{71}$ Wittgenstein, Observaciones diversas. Cultura y Valor, §242. Ed. original Vermischte Bemerkungen, 1980

${ }^{72}$ Expresión de Baruch Spinoza recogida en Ética (Part V, Prop. XXIII, Scholium), 1677, que representa lo eterno, Io no contingente.
} 


\section{Everything is what it is and not another thing}

by David Connearn
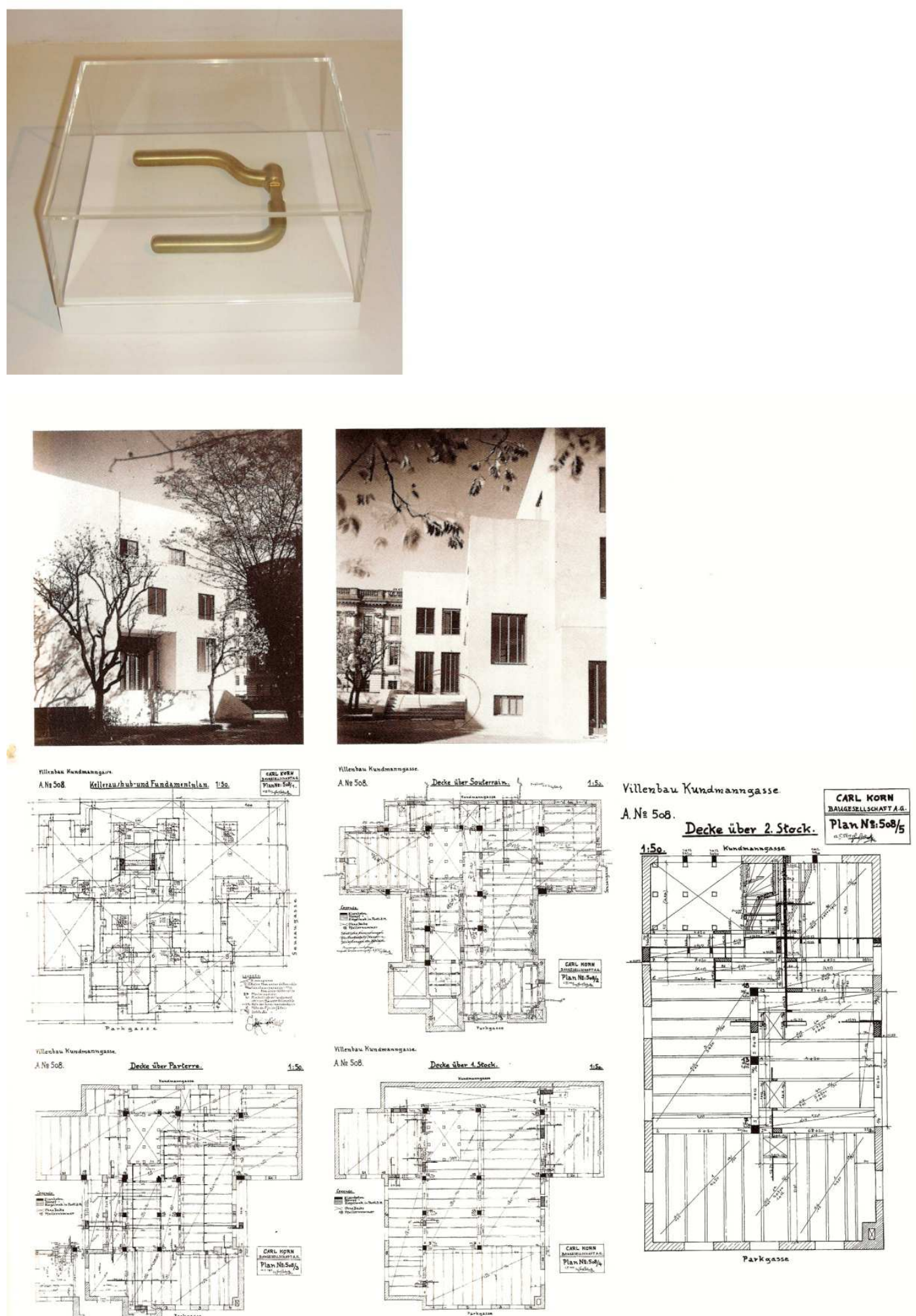

88. David Connearn, Reproducción a escala 1/12 de manilla de la Kundmanngasse 19

89. Fotografías de la Casa Wittgenstein, 1929 y planos de ejecución de 1926, en P. Wijdeveld (1993), p. 103 
«La obra de arte es el objeto visto sub specie aeternitatis; y la buena vida es el mundo visto sub specie aeternitatis. No otra es la conexión entre arte y ética.»73

Tan temprana conexión entre la ética y la estética fue una constante en la vida de Wittgenstein ${ }^{74}$. Parece más que probable, por los testimonios recogidos, sobre todo respecto a la exquisita sensibilidad para la música que mostraba Wittgenstein, que debía ser sinestésico, es decir, podía mezclar o compartir sentidos percibiendo colores en la música o tonos en las lecturas. La arquitectura no escaparía, por consiguiente, a su viveza sensitiva. En una conversación con Drury respecto al segundo movimiento de la Séptima Sinfonía de Beethoven:

«El acorde con el que se abre ese lento movimiento es del color de ese cielo [gris por el atardecer] (apuntando con su dedo a través de la ventana)».75

En 1930, Drury visita a Wittgenstein en sus habitaciones de Whewell's Court del Trinity College y se da cuenta que ha alterado las proporciones de las ventanas utilizando bandas de papel negro:

«Puede ver cuán diferente parece la habitación si las ventanas tienen la proporción adecuada. -Usted piensa que la filosofía es ya bastante difícil pero puedo decirle que no lo es en comparación con ser un buen arquitecto. Cuando estuve construyendo la casa de mi hermana en Viena quedaba tan completamente exhausto al cabo del día que todo lo que podía hacer era ir a ver una película cada noche.». ${ }^{76}$

¿Cómo aplicar la ética de Wittgenstein a la arquitectura? ¿Tenía Wittgenstein una teoría arquitectónica? La respuesta a esta última es negativa. La respuesta a la primera desarrollaría de alguna manera el razonamiento de la segunda. Es decir, Wittgenstein buscaba la estructura que vertebra las cosas. Ya se ha dicho líneas antes que su actividad como filósofo se entendía como método,

\footnotetext{
${ }^{73}$ Ludwig Wittgenstein, Diario filosófico (1914-1916), entrada de 07.10.1916, op. cit., p.110

${ }^{74}$ Wittgenstein decía ser probablemente el único profesor de filosofía que no había leído a los clásicos, aunque sabemos que exageraba 0 se refería por ejemplo a Aristóteles. Con Bouwsma (op. cit., p.70 et al.) discute lecturas de Platón y Epicuro; lo que nos Ilama la atención es la necesidad de Wittgenstein, casi presocrática, de buscar un origen único, aunque evidentemente no en el mismo plano ontológico, quizá en Wittgenstein todo lo gobierna la Ética, que Heráclito decía «Todo lo gobierna el rayo», en un constante hacerse y deshacerse.

${ }^{75}$ Rhees, op. cit., p. 130

${ }^{76}$ Rhees, op. cit., p.121-122
} 

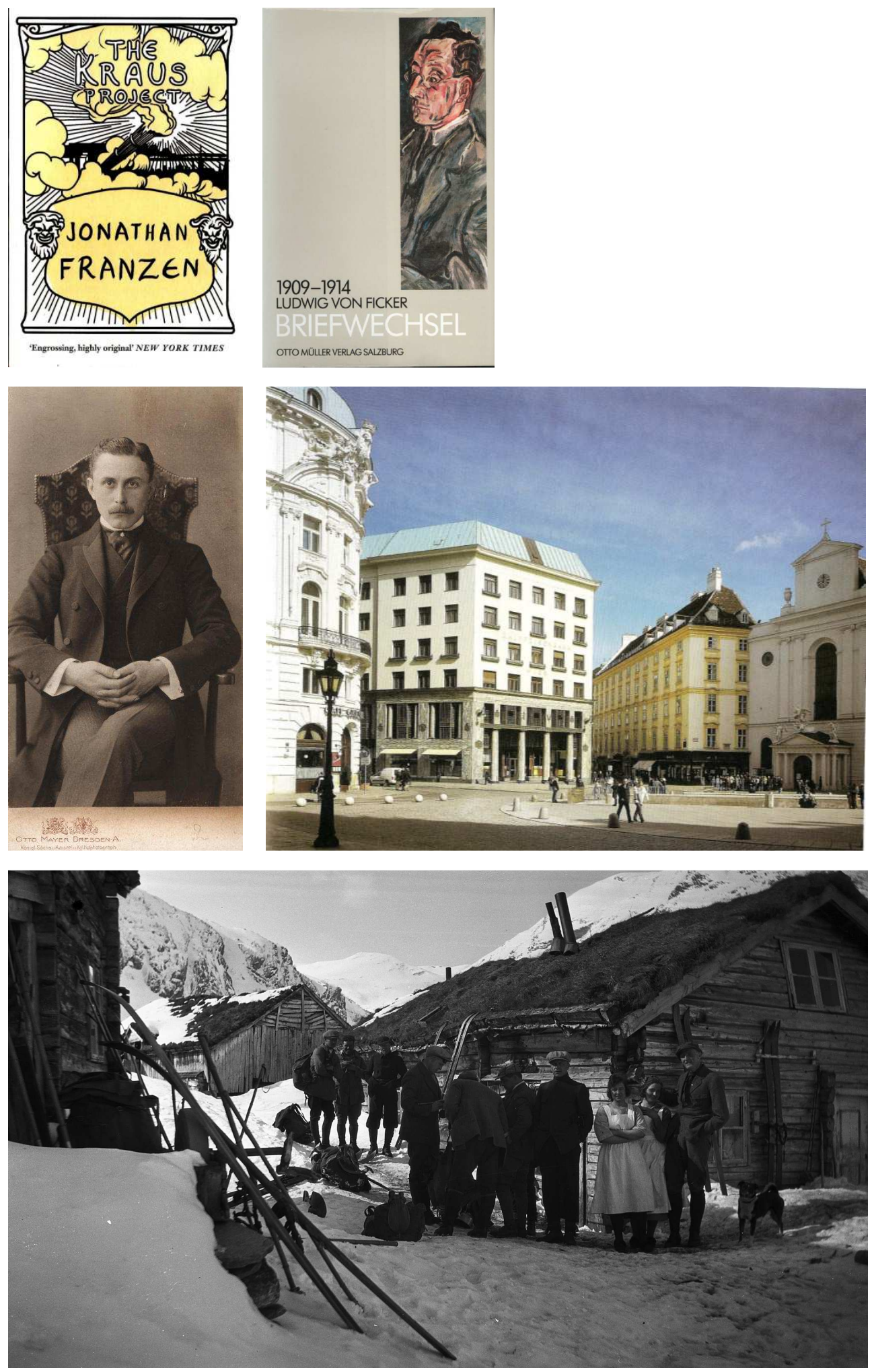

90. J. Franzen, The Kraus Project, 2013 | 91. Ludwig von Ficker, Briefwechsel

92. Adolf Loos, 1904 ｜ 93. Looshaus Michaelerplatz, 1909-1911

94. Cabañas tradicionales noruegas con tejado vegetal, 1910-1920 
y no como un objetivo en sí misma. La decencia es lo que encontró ejemplificada en el trabajo y las personalidades de Kraus y de Adolf Loos.

Café Imperial, Viena, domingo 26 de julio de 1914. Ludwig von Ficker ${ }^{77}$ y Ludwig Wittgenstein se encuentran con Adolf Loos. El mismo Wittgenstein había pedido a Ficker que le presentara al arquitecto: «¿Usted es Yo!», exclamó Loos durante la conversación. Wittgenstein tenía en alta consideración a Loos por lo que de él y sobre él había leído en Neue Freie Presse vienés de Adolf Werthner ${ }^{78}$ y en el Die Fackel del periodista satírico moralista Karl Kraus ${ }^{79}$. La lectura de estas revistas era habitual en la casa de los Wittgenstein de la Alleegasse y fue Margarethe -en opinión de McGuinness ${ }^{80}$ - quien ejercía de intelectual en la familia, y probablemente quien despertó en Wittgenstein el interés por ellas. De hecho sabemos que siguió recibiendo, al menos Der Brenner, durante sus exilios en Skjolden, aunque con el paso de los años, Wittgenstein acabara por no estar de acuerdo con todo lo publicado por Ficker. En 1921 escribe en una carta a Paul Engelmann desde Skjolden -en su primera visita a la casa desde su marcha en 1914:

«5.8.21. Skjolden i Sogn Noruega bei Herrn Drægni. Q.s.E.:

Estoy en Noruega, donde ya pasé un año entero antes de la guerra. El libro que me prometía no llegué a recibirlo. (Si por lo menos me hubiera dicho cuál era). Regreso los primeros días de septiembre y hasta que comience la escuela me quedaré en Viena. ¿Vendrá usted también en ese tiempo a Viena? ¡Sería muy bonito! Se ha amontonado mucho material de conversación, sin duda. Por cierto: Ficker sigue enviándome una y otra vez el Brenner, y una y otra vez me propongo escribirle para que deje de hacerlo, porque considero un desatino el Brenner (una revista cristiana es una estupidez); pero nunca acabo de escribir a Ficker al respecto, porque nunca encuentro la tranquilidad

\footnotetext{
${ }^{77}$ Ludwig von Ficker (1880-1967) editó en Innsbruck entre 1910 y 1954 la revista cultural de contenido literario, artístico y filosófico Der Brenner. A Wittgenstein le merecía gran respeto -al menos en aquel momento- pues Karl Kraus había escrito en Die Fackel que Ficker era el único editor que valía la pena leer en Austria. Wittgenstein comentó haberse sorprendido por las buenas ausencias que Ficker había hecho a su vez de Kraus en su revista y en la que encontró además artículos sobre su querido Dostoievski y las primeras traducciones al alemán de las obras de Kierkegaard. En McGuinness, op. cit. p. 205 y en Research Institute Brenner-Archives, Innsbruck University, 2013.

${ }^{78}$ Adolf Werthner publicó este periódico liberal entre 1864-1938. Fue objetivo reiterado de las sátiras de Kraus.

${ }^{79}$ Karl Kraus (1874-1936), «[...] fue un austríaco satírico y una figura central del fin de siècle vienés. Desde 1899 hasta su muerte, Kraus editó y publicó la influyente revista Die Fackel (La Antorcha); a partir de 1911, fue además el único autor de su revista. Aunque es probable que Kraus hubiera odiado los blogs, Die Fackel fue una especie de blog para la personas del mundo germanohablante, como Freud, Kafka o Walter Benjamin, que consideraban necesario leerlo y tener una opinión al respecto. [...]» (Franzen, J., The Kraus Project, London, 2014, p.4). Wittgenstein tuvo a Kraus como una de las nueve figuras que consideraba habían influido en su trabajo, según el listado que incluye en una anotación de 1931. (Wittgenstein, L. Observaciones diversas. Cultura y Valor, m. 101)

${ }^{80}$ Monk, op. cit. p.32
} 

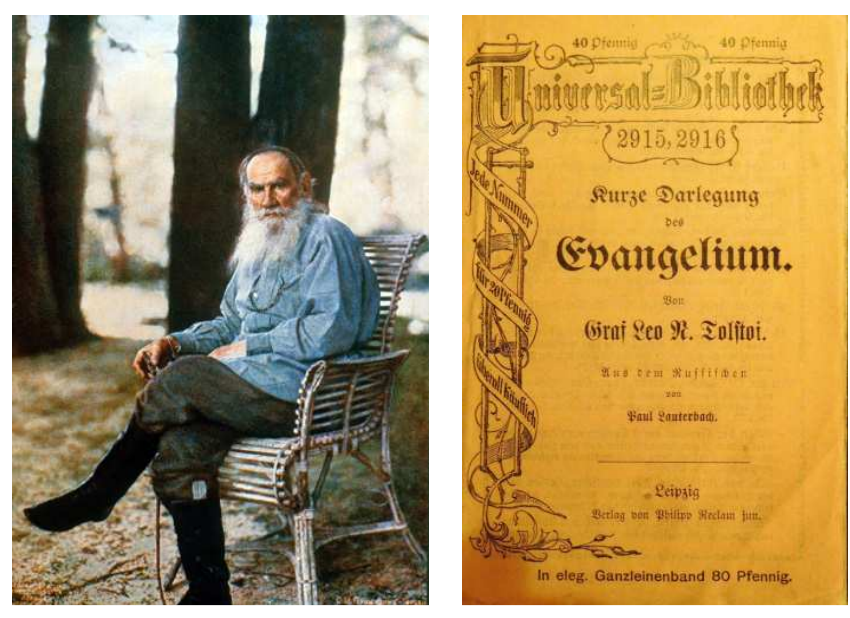

Tractatus

Logico-Philosophicus

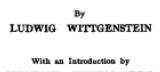

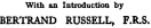

周

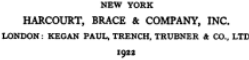

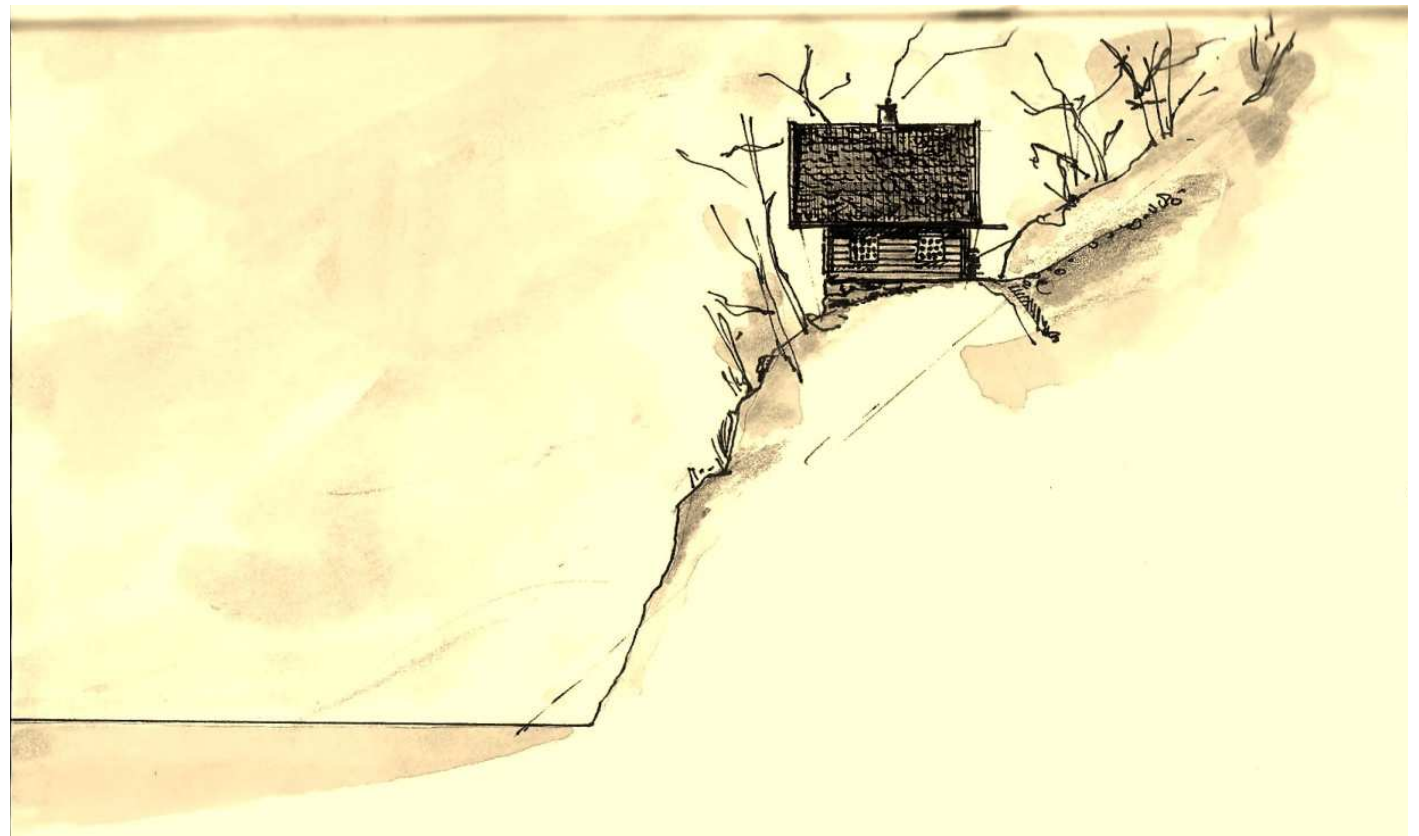

95. Leo Tolstoi, mayo 1908 ｜ 96. Leo Tolstoi, Evangelio abreviado. Marcó profundamente a Wittgenstein en 1914

97. Primera edición bilingüe del Tractatus, 1922

98. La casa tolstoiana de Wittgenstein en Skjolden 
para una explicación detallada. De ahí, por lo demás, puede deducir cómo me va. Hasta la vista.

Suyo.

Ludwig Wittgenstein.

Saludos de Arvid Sjögren, que está aquí conmigo.»

Es más que probable que Wittgenstein nunca superara la negativa de Ficker a publicar en 1919 su Tractatus. Era una persona que anteponía la moralidad y la ética personales a cualquier comportamiento en la vida con total independencia de las circunstancias. Russell comenta en su autobiografía que en 1922, en una época en la que Wittgenstein se mostró especialmente místico poco después de las tribulaciones sobre la publicación de su LogischPhilosophische Abhandlung en alemán en 1921 y en 1922 como Tractatus Logico-Philosophicus en su versión inglesa (bilingüe), y cuando se había convertido ya en profesor de escuela primaria en Trattenbach en pleno Tirol austríaco- que «he assured me with great earnestness that it is better to be good than clever» ${ }^{81}$. No es fácil comprender hasta qué punto los ideales éticos marcaron la vida del filósofo y de las personas con que se relacionó.

El primer contacto con Ficker se produjo en una carta de Wittgenstein, el 14 de julio de 1914, desde el Hochreith, en la que el filósofo, dispuesto ya a desprenderse -no lo consiguió totalmente y ante notario hasta 1919- de la inmensa fortuna heredada tras la muerte de su padre en 1913. En la misiva pedía ayuda a Ficker para repartir entre artistas austríacos necesitados 100000 coronas $^{82}$. Ficker, prudentemente, preguntó -en carta del 21.7.1914 al pintor Max von Esterle (1870-1947) - acerca de los Wittgenstein y de la insólita propuesta que había recibido. No le quedó duda de que la propuesta era coherente:

\footnotetext{
${ }^{81}$ Russell, B. The Autobiography of Bertrand Russell, vol. 2, 1914-1944, London, 1971, p.101: «me aseguró con absoluta seriedad que era mejor ser bueno que inteligente».

${ }^{82}$ Este episodio es bien conocido en la literatura biográfica sobre Wittgenstein. Por ejemplo McGuinness, 1988, op. cit. p.205 y ss. Resulta curioso que el propio Wittgenstein, patriota y pacifista -en opinión de Russell- hiciera una donación junto con su madre y hermanos de 1000 000 de coronas para la fabricación de un mortero de $30 \mathrm{~cm}$ de diámetro durante la Primera Guerra Mundial. «El arma nunca se fabricó y se destinó el dinero a un fondo de caridad que desapareció durante la inflación de la corona austríaca posterior a la guerra» en Hermine Wittgenstein, My Brother Ludwig, cfr. Rhees, R. 1988, op. cit., p.3 y ss. Las donaciones en tiempo de guerra se consideraban una obligación patriótica. Otras donaciones de la familia constan en la Austrian Newspapers Online: 250000 coronas (28.5.1915), 250000 coronas (7.5.1916), y más (cf. Nordic Wittgenstein Review 3 (№. 2) 2014).
} 

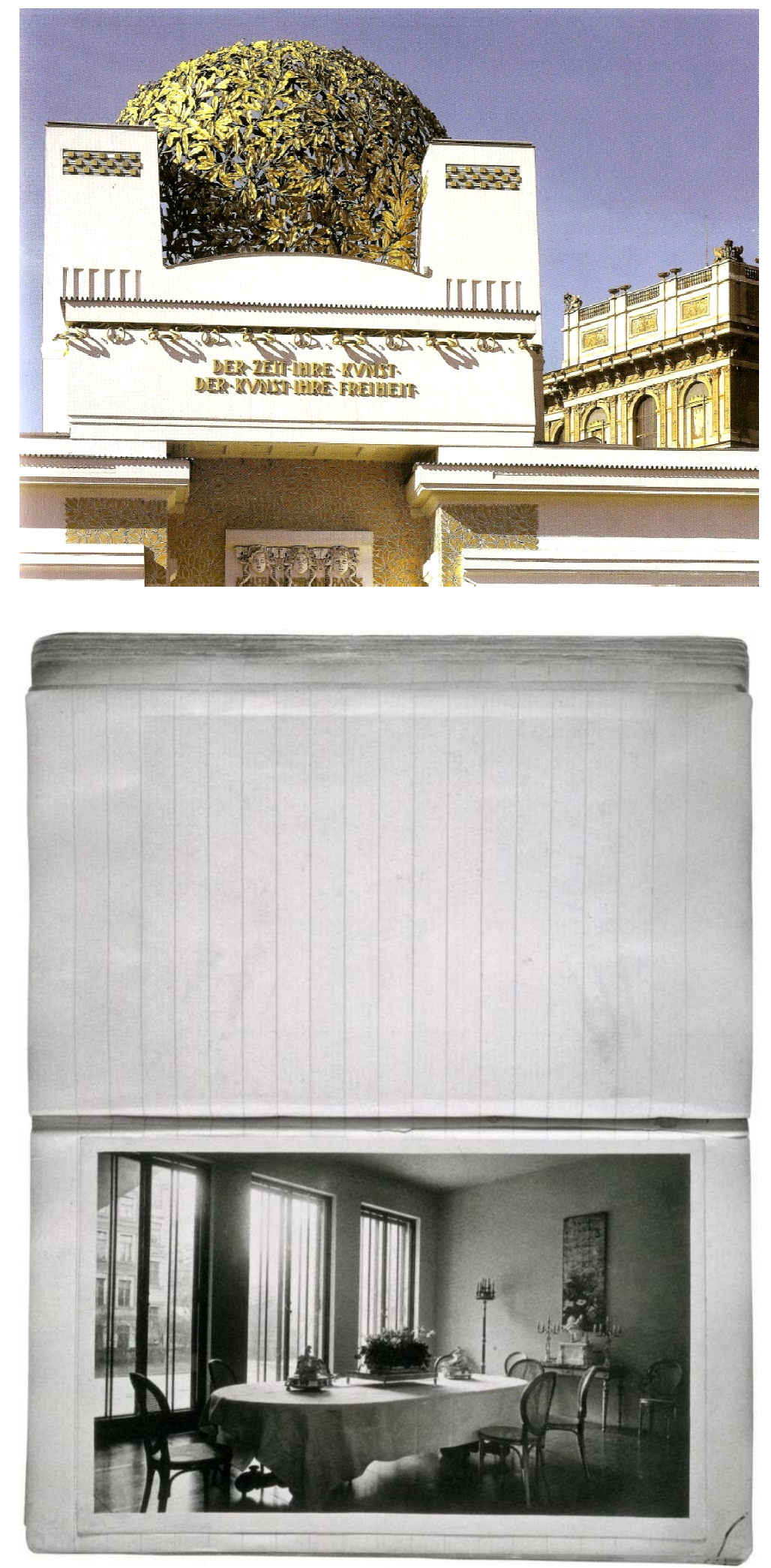

99. Joseph Maria Olbrich, Das Secessionsgebäude 1898. Subvencionado por Karl Wittgenstein

100. Comedor en la Casa Wittgenstein, Kundmanngasse 19, fotografía de 1929 (álbum personal de Wittgenstein) 
«Lavazé, 21.7.14

Estimado Sr. von Ficker,

Muchas gracias por su encargo en Der Brenner, y en particular por su estupenda carta.

Le voy a responder en el orden inverso al que Vd. plantea. El nombre de Wittgenstein lo conozco en cuanto a su relación con la Sezession de Viena. El padre falleció hace poco (aproximadamente 1 año) y tengo entendido que fue uno de los más ricos empresarios judíos del imperio y gran mecenas del arte. Parece que ha donado a la Sezession sumas importantes cada año, entre 20-40 000 coronas. Resulta del todo plausible que el hijo pretenda hacer algo similar y me parece claro que la petición que le hace es totalmente sincera. Podemos suponer que el hijo piense un poco diferente de su padre y que se decante por escritores más bien de la izquierda. Si Vd. tiene dudas respecto a qué se refiere con "artistas" quizá no sea sólo a artistas visuales por lo que podría preguntarle al señor W.[ittgenstein] y salir de dudas y hablarle de escritores como Dall.[ago] y Trakl. [...]»83

Uno de los diecisiete ${ }^{84}$ beneficiarios de la donación fue Adolf Loos, que recibió de a través de Ficker 2000 coronas $^{85}$. Loos era un personaje admirado y controvertido. Había publicado algunos de sus textos más polémicos en contra de las costumbres sociales, el arte y por supuesto la arquitectura historicista del viejo imperio austrohúngaro y construido algunas de las obras que le habían deparado popularidad e intensas críticas: la Villa Karma, la Casa Steiner, la Casa Scheu y sobre todo la Casa en Michaelerplatz de Viena en 1909-1911 que levantó ampollas entre los arquitectos y políticos vieneses y alcanzó niveles de crítica y de popularidad en la ciudad que hoy día se nos hacen difíciles de entender. Wittgenstein se mostró muy agradecido con Ficker por haberle presentado a Adolf Loos:

«1.08.14. [...] Gracias por su amable visita y por el hecho de que me haya presentado a Loos. Estoy muy contento de haberlo conocido, por fin. [...]»86

\footnotetext{
${ }^{83}$ Müller, 0., 1909-1914 Ludwig von Ficker Briefwechsel, Salzburg, 1986, p. 236. (En alemán en el original)

${ }^{84}$ El listado completo de cómo Ficker distribuyó la donación es el siguiente: Georg Trakl 20000 Kr, Rainer Maria Rilke $20000 \mathrm{Kr}$, Carl Dallago $20000 \mathrm{Kr}$, Redaktion Der Brenner $10000 \mathrm{Kr}$, Oskar Kokoschka 5000 Kr, Else Laster-Schüler $4000 \mathrm{Kr}$, Adolf Loos $2000 \mathrm{Kr}$, Karl Borromäus Heinrich $1000 \mathrm{Kr}$, Hermann Wagner $1000 \mathrm{Kr}$, Josef Georg Oberkofler 1000 Kr, Theodor Haecker 2000 Kr, Theodor Däubler 2000 Kr, Ludwig Erik Tesar 2000 Kr, Richard Weiss 2000 Kr, Karl Hauer 5000 Kr, Franz Kranewitter 2000 Kr, Hugo Neugebauer 1000 Kr. En McGuinness, 1988, op. cit. p. 207.

${ }^{85}$ El equivalente a $13000 €$ en 2015

${ }^{86}$ cfr. Briefwechsel, McGuinness, B., von Wright, G.H., 1980, p. 60. (En alemán en el original)
} 

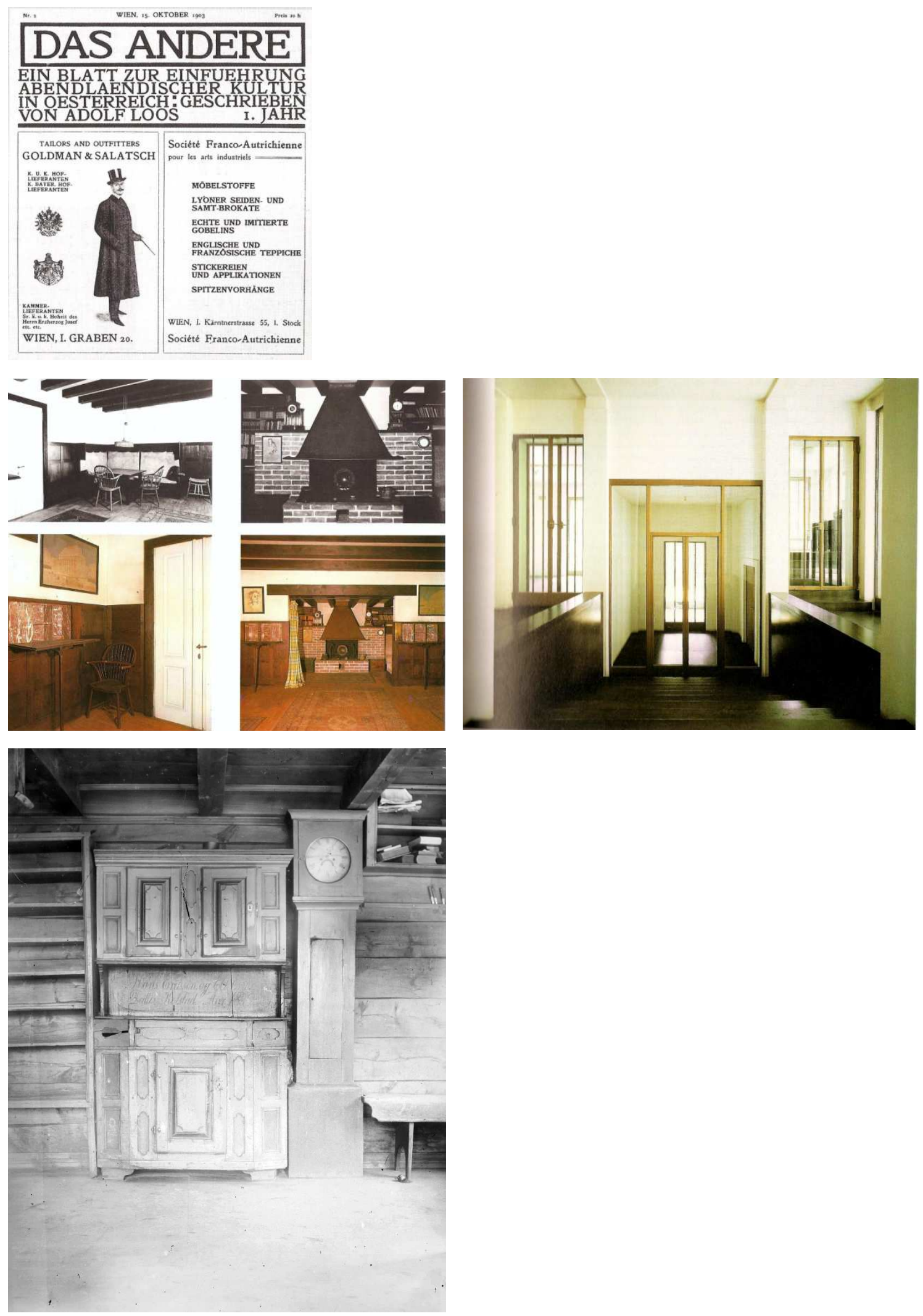

101. Revista Das Andere, (El otro) publicada por Loos en 1903

102. Interior del apartamento de Adolf Loos, 1903, publicado en la revista Kunst, Viena | 103. Interior del Hall de la Casa Wittgenstein, Kundmanngasse 19 104. Interior de casa tradicional noruega, 1910 
Es más que probable que Wittgenstein estuviera al tanto de la obra de Loos y es casi seguro que había leído sus artículos en Die Fackel. De ahí su interés por encontrarse con el arquitecto personalmente, pues debía parecerle que su obra era suficientemente ética.

¿Hasta qué punto podemos atribuir a Loos una influencia sobre el joven Ludwig Wittgenstein en su concepción de la arquitectura?

Es difícil responder a tal cuestión, porque como se ha dicho la identificación en cuanto a una estética ética fue mutua desde su primer encuentro. De hecho Nedo plantea que cuando Loos dedica su agradecimiento a Wittgenstein en el ejemplar que le dedica a este en 1924 de su Ins Leere Gesprochen ${ }^{87}$, lo que indica es lo que Wittgenstein influyó en Loos y no al contrario. ${ }^{88}$

En 1910 Loos había publicado su artículo Architektur en Der Sturm, que empieza con una reveladora imagen que bien podría ser una descripción del lago Eidsvatnet de Skjolden:

"¿Puedo conducirles a la orilla de un lago de montaña? El cielo es azul, el agua verde y todo descansa en profunda paz. Las montañas y las nubes se reflejan en el lago, y así las casas, caseríos y ermitas. No parecen creadas por mano humana. Están como salidas del taller de Dios, como las montañas y los árboles, las nubes y el cielo azul. Y todo respira belleza y silencio...» ${ }^{89}$

Es imposible no ver porqué Loos dijera a Wittgenstein que eran la misma persona. Wittgenstein había construido su casa en ese paraje y si explicó además a Loos sus planteamientos desde la ética, Loos debió quedar impactado ante tal fotografía mental.

\footnotetext{
${ }^{87}$ Adolf Loos, Ins Leere Gesrpochen, 1921. Edición consultada aquí: Adolf Loos, 1993, op. cit. p.185 y ss. La dedicatoria a Wittgenstein reza: «A Ludwig Wittgenstein, con gratitud y mucho afecto, gratitud por la inspiración y mucho afecto con la esperanza de que este sentimiento sea mutuo. Adolf Loos. Viena, agosto 1924.»

${ }^{88}$ En conversación con Michael Nedo, 20.04.2015, Cambridge.

${ }^{89}$ Adolf Loos, 1993, op. cit. p 23
} 

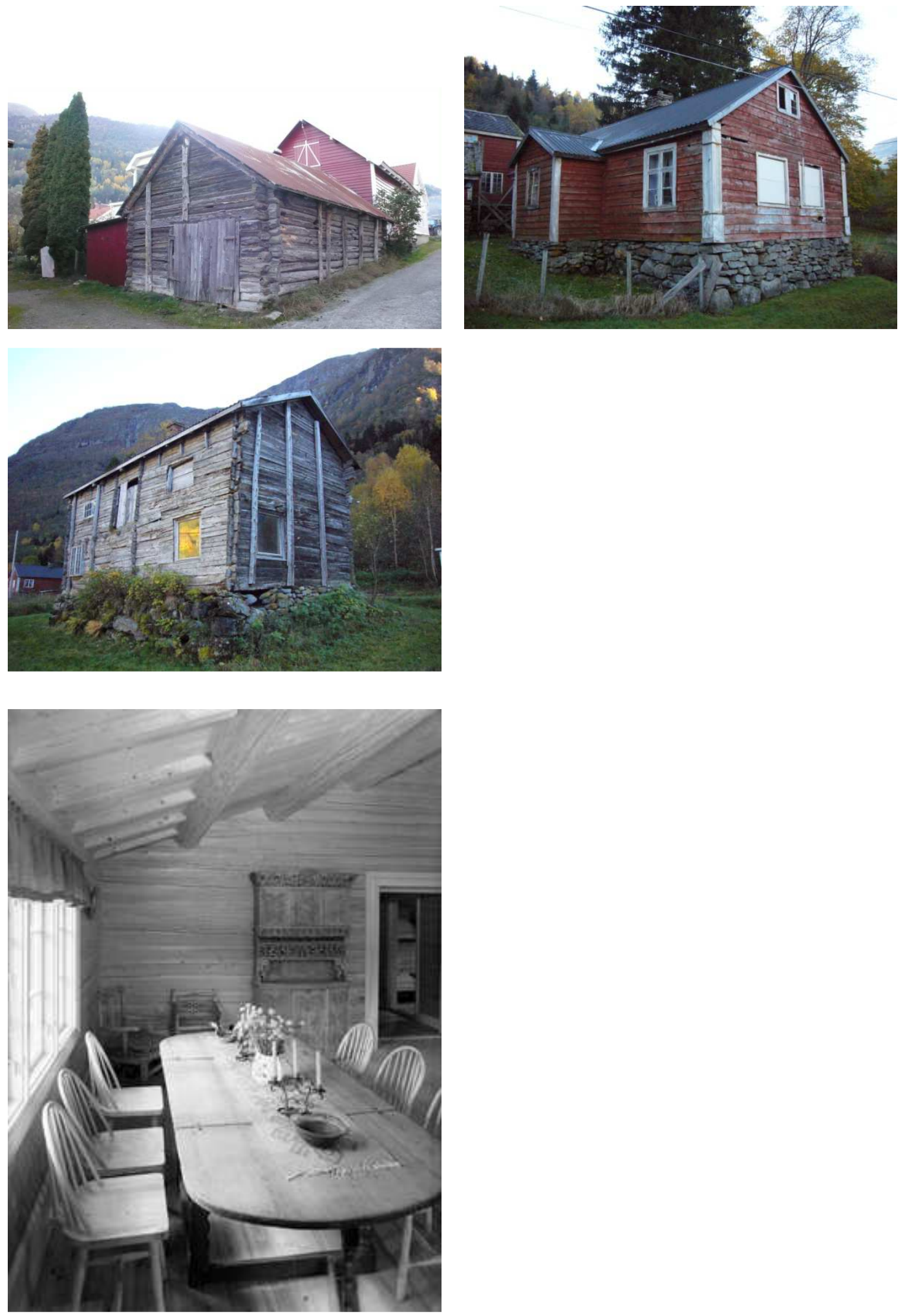

105. Construcción tradicional noruega, Solvorn, octubre 2013 106. Construcción tradicional noruega, Fortun, octubre 2013 107. Construcción tradicional noruega, Fortun, octubre 2013

108. Interior de casa noruega, 1939 
En Skjolden la casa de Wittgenstein no parecía noruega. Los responsables del área cultural del Luster la etiquetan como «tirolesa»" ${ }^{90}$. Desde el punto de vista de los referentes es inevitable pensar en las propuestas de Loos y el aparente fundamentado antiornamentalismo -como se ha definido a veces su práctica en la casa de Viena- y desde luego sus propias vivencias personales, como las residencias familiares del Hochreith. Allí, Wittgenstein solía ocupar parte de la vivienda del guarda de la finca y no la residencia de la familia.

Cuando Wittgenstein proyecta su casa en Skjolden, su formación es la de un ingeniero. Había recibido una instrucción técnica, tanto en Berlín como en Manchester.

$\mathrm{Su}$ infancia había transcurrido entre edificios suntuosos, el palacio familiar en Alleegasse 16 de Viena, la Neuwaldegg, residencia de entretiempo en la afueras de Viena y el palacio de verano de Hochreith. Aparte de las residencias del resto de la familia, la Villa Toscana de su hermana Margaret, etc. Arquitectos clasicistas, de otro tiempo y supuestamente modernos como Hoffmann habían trabajado en numerosas ocasiones para la familia.

Wittgenstein, por el contrario, quizá por oposición a la opresión paternal o por alineación con las opiniones vertidas en Die Fackel por Kraus y Loos había encontrado en el despojamiento del ornamento la estructura estética que le importaba. ${ }^{91}$

A su regreso de las vacaciones de Navidad de 1912 en Viena, Wittgenstein se traslada a Cambridge y puesto que no había habitaciones libres en el College, debe quedarse en una pensión en el n 4 de Rose Crescent.

\footnotetext{
${ }^{90}$ En conversación con Liv Ingrid Ostbye Roggen, 12.03.2015, Valencia.

${ }^{91}$ Si bien es cierto que años más tarde su opinión de Loos se vio modificada, creemos que por el mismo motivo que dejó de valorar a Russell 0 a Whitehead, y es que se habían relajado, por el contrario Hertz nunca se relajó y de él siempre fue devoto Wittgenstein. «2.9.19. Querido señor Engelmann. Muchas gracias por su carta. Por ahora no puedo ir a Olmütz. Mañana me voy al Hochreith para 8-10 días, a ver si es posible que me aclare un poco. iY después tomaré una profesión! ¿Cuál? Tiene tiempo para adivinar, hasta que venga a verme. Hace unos días visité a Loos. Me quedé horrorizado y me causó repugnancia. iSe ha idiotizado hasta un grado increíble! Me entregó un folleto sobre una "Institución artística" proyectada, donde habla del pecado contra el Espíritu Santo. iEs el colmo! Fui a verlo en un estado de ánimo muy abatido y eso era precisamente lo que me faltaba. Tendría que hablar con usted sobre muchas, muchas cosas. [...].» En Wittgenstein-Engelmann, op. cit. p. 63.
} 

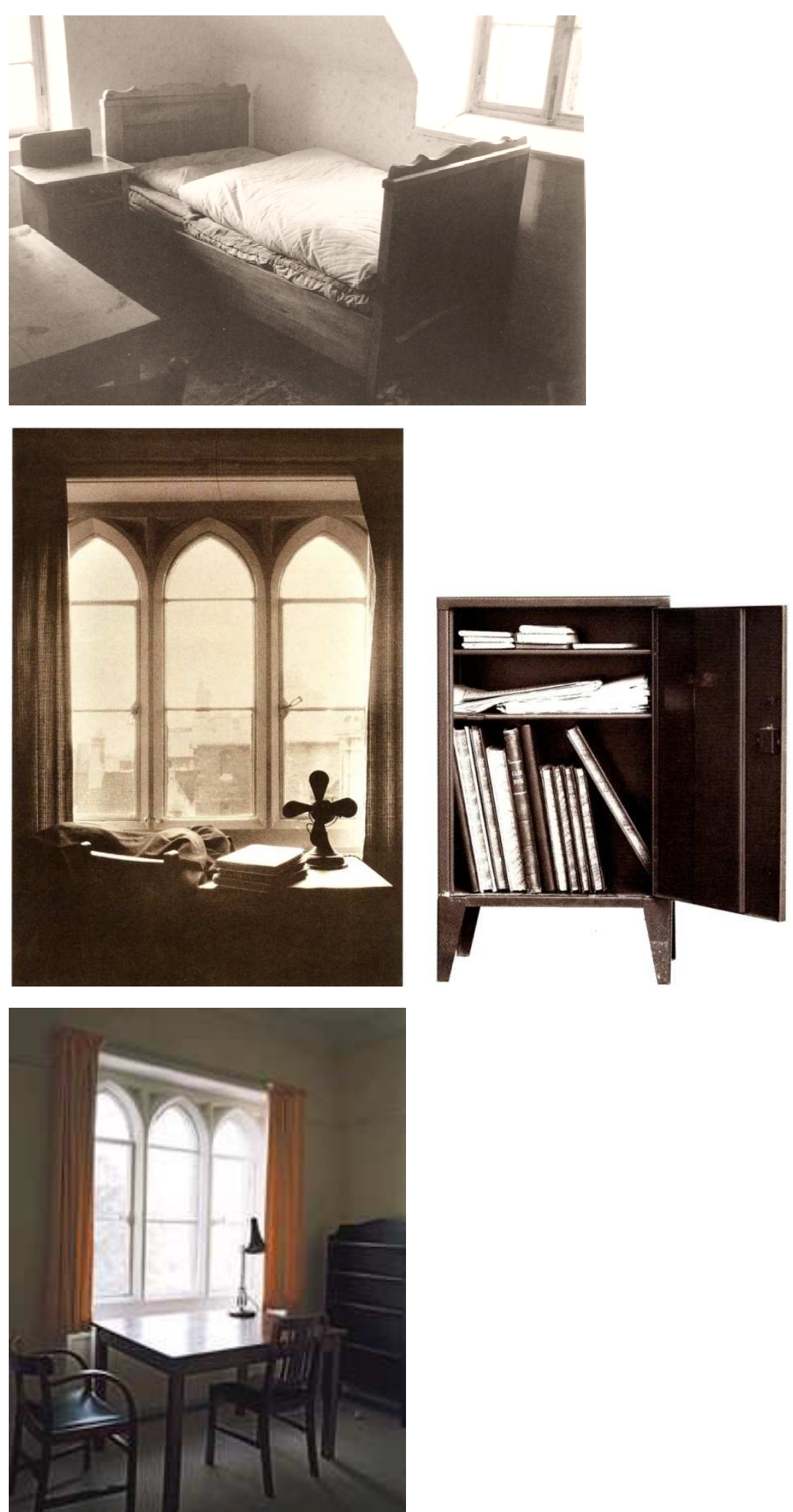

109. Muebles de Wittgenstein en la habitación de Trattenbach, donde fue profesor de escuela elemental

110. Armario metálico para los cuadernos de Wittgenstein | 111. Ventana y mesa de la habitación de Wittgenstein en Whewell's Court

112. La misma ventana en 2007 
El 12 de octubre de 1912 se instala en sus nuevas habitaciones de la residencia del Whewell's Court del Trinity College que ocupaban el piso más alto de la torre de la escalera G. ${ }^{92}$ Incluso muchos años después, puesto que mientras estuvo en Cambridge siempre ocupó esas estancias en la torre, Redpath, en 1936 recuerda que le impresionó la sencillez, pulcritud y limpieza de las habitaciones: «había en ellas algo de monástico, o quizá militar, o probablemente de ambas cosas en aquella atmósfera. En el dormitorio había una pequeña estantería repleta de libros.»193

Probablemente en los años treinta y cuarenta, la habitación de Wittgenstein en Cambridge fuera muy modesta, puesto que sus muebles y libros habían sido vendidos por menos de la mitad de su valor durante la guerra. ${ }^{94}$ Esos muebles muestran a un joven Ludwig preocupado por la pureza de líneas, por la autenticidad y calidad de los materiales. Cuando se va a trasladar al Trinity College pide a Pinsent que le acompañe a comprar nuevos muebles:

«Viernes, 12 de julio de 1912. A las 4.0 fui a tomar el té con Wittgenstein: después salimos y le ayudé a ver muchos muebles de varias tiendas: se va a trasladar al colegio el próximo trimestre. Resultó muy divertido: él es terriblemente fastidioso, y volvimos loco al dependiente con Wittgenstein exclamando “№ -Horrible!” ¡al 90 por ciento de lo que nos enseñó!»95

En tales disquisiciones participó Russell, quien se quejaba de que Wittgenstein era muy exigente: «Me dio una conferencia de cómo debían estar hechos los muebles: le desagrada toda la ornamentación que no forme parte de la construcción, y nunca es capaz de encontrar nada lo suficientemente sencillo.» Al final se hizo construir su propio mobiliario, de líneas sencillas y materiales de primera calidad.

\footnotetext{
92 Theodore Redpath, Ludwig Wittgenstein A Student's Memoir, London, 1990, p. 17. Monk (1990) dice que la escalera de las habitaciones de Wittgenstein era la 'K'. Redpath asistió a las clases del filósofo en los años 30.

${ }^{93}$ Redpath, 1990, op. cit. p.40

${ }^{94}$ Los compró Russell en 1919 al guardamuebles de Cambridge y con ellos amuebló su casa en Londres. «Jolley, en Cambridge, pide 80 libras esterlinas por tus muebles, incluidos los libros. Si vuelvo a Cambridge como parece probable, estaré encantado de quedarme tus muebles, 0 una parte de ellos. ¿Te parece bien si te pago 100 libras por los muebles y los libros (sin incluir algún libro en especial que quieras conservar)?» Carta de Russell a Wittgenstein, 24.11.1919, en McGuinness, 2012, op. cit. p. 109.

${ }^{95}$ David Pinsent, 1989, op. cit. p. 35
} 
$47^{*}$ Wittgenstein an Eccles $\quad$ [Juli 1914]

Lieber Eccles!

XVII Neuwaldeggerstr. 38 Wien

Wie Sie sehen, bin ich wieder in Wien, um Ferien zu machen. Danke für Ihren Brief, Ihre Entwürfe sind ausgezeichnet, soweit ich das beurteilen kann. Ich werde ein paar Bemerkungen machen: Zum Kleiderschrank: Warum ist die horizontale Querleiste an den Türen nicht in der Mitte (zwischen oberem und unterem Ende), so daß die oberen und unteren Türfüllungen gleich lang sind? - 2) Ich meine, es wäre vielleicht praktischer, den Kleiderschrank, wie in

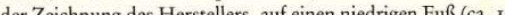
we öffnen.

ARZNEISCHRANK: Ausgezeichnet.

KOMMODE: Ausgezeichnet.

Ich sehe keine Zeichnung eines Betts, oder möchten Sie das nehmen, welches die Möbelhersteller angeboten haben? Wenn ja, so bestehen Sie unbedingt darauf, daß sie die abscheulichen Verzierungen absägen. Und weshalb sollte das Bett eigentlich auf Rollen stehen? Sie werden doch nicht damit in Ihrem Haus umberreisen!? Lasser Sie die anderen Dinge auf jeden Fall nach threm Entwurf Lassen Sie die anderen Dinge auf jeden Fall nach Ibrem Entwurf herstellen.

Der »kleine Fremdling ältt sich hoffentlich gut, und hoffentlich stellt sich heraus, daß er ein Junge ist.

Mitte August verreise ich und komme Sie um den 10. September besuchen. Empfehlen Sie mich Threr Frau und Threr Tante, und wenn ich Sie das nächste Mal sehe, habe ich eine Menge mit Ihnen zu bereden.

Immer Ihr L. W. auloinor al posingle

abscheuliche Verzierungen. - Wittgenstein zeichnete an dieser Stelle:

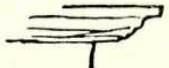

Mitte August verreise ich. - Wegen des Kriegsausbruchs fand diese Reise nicht statt. 19.) a midicdin

$5^{8}$
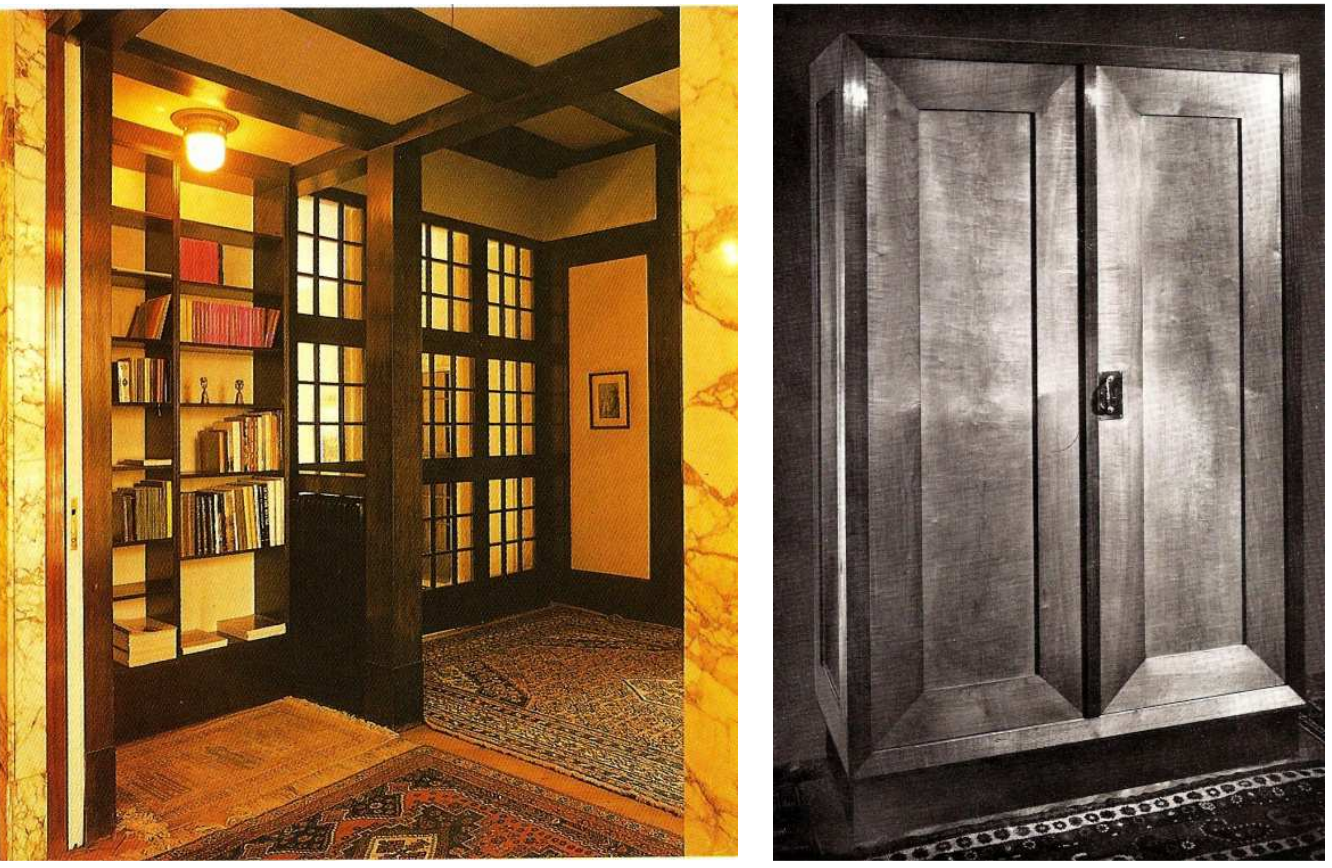

113. Carta de Wittgenstein a Eccles donde dibuja las «abominables molduras» que este debía evitar

114. Adolf Loos, interior de la casa Duschnitz, 1915-1916 | 115. Adolf Loos, armario del apartamento de Turnowsly, Viena 1900 
Wittgenstein utilizaba jarras de porcelana -del tipo de las utilizadas en laboratorio- para servir las bebidas, té, por ejemplo y Pinsent nos describe una visita a un marmolista de Euston, donde fueron juntos a ver cómo trabajaban, pulían y cincelaban la piedra. Wittgenstein había pedido una tabla especial de mármol negro para sustituir una de color blanco que tenía en su aparador de Cambridge. ${ }^{96}$

Apenas regresado a su casa de Neuwaldeggstrasse 38, Viena, desde Skjolden, en julio de 1914, recibe una carta de su amigo el ingeniero de Manchester, Eccles, en la que este le pide opinión - para Eccles Wittgenstein es un connoisseur- acerca de unos diseños de muebles que ha preparado para su nueva casa:

«Querido Eccles. Como observarás estoy en Viena de nuevo por vacaciones. Gracias por tu carta. Tus diseños son estupendos hasta donde soy capaz de juzgarlos. Y te haría algunas precisiones. El armario: ¿por qué no está la pieza horizontal que cruza las puertas justo en el medio (de arriba hasta abajo) dado que los dos paneles de arriba y abajo son de la misma longitud? 2) Creo que sería conveniente que el armario descansara sobre unas pequeñas patas (3 pulgadas) tal como aparece en el diseño del fabricante, en lugar de que las puertas abran directamente contra la alfombra.

BOTIQUÍN: estupendo.

TOCADOR: estupendo.

No veo ningún dibujo de la cama; ¿o es que vas a aceptar lo que quieran los fabricantes? Si es así, insiste en que corten todas esas abominables molduras. ¿Y por qué debería tener ruedas la cama? ¿Vas a circular con ella por la casa? ¡Por todos los medios has de conseguir que se hagan las demás cosas según TUS diseños! [...]L.W.»97

La decadencia de la cultura, pregonada por Kraus, explicitada por Spengler, se traduciría en arquitectura al rechazo del falso lujo. Como decía Loos, había que cambiar la forma de pensar. La diferencia fundamental entre Loos y Wittgenstein es la concepción propia de la arquitectura como disciplina que permite la felicidad del hombre, su comodidad. Para Loos es fundamental diferenciar entre arte y arquitectura precisamente por la necesidad. Su criterio

\footnotetext{
${ }^{96}$ David Pinsent, 1989, op. cit. p. 85

${ }^{97}$ Wittgenstein, Briefe, 1980 , op. cit. p.58
} 

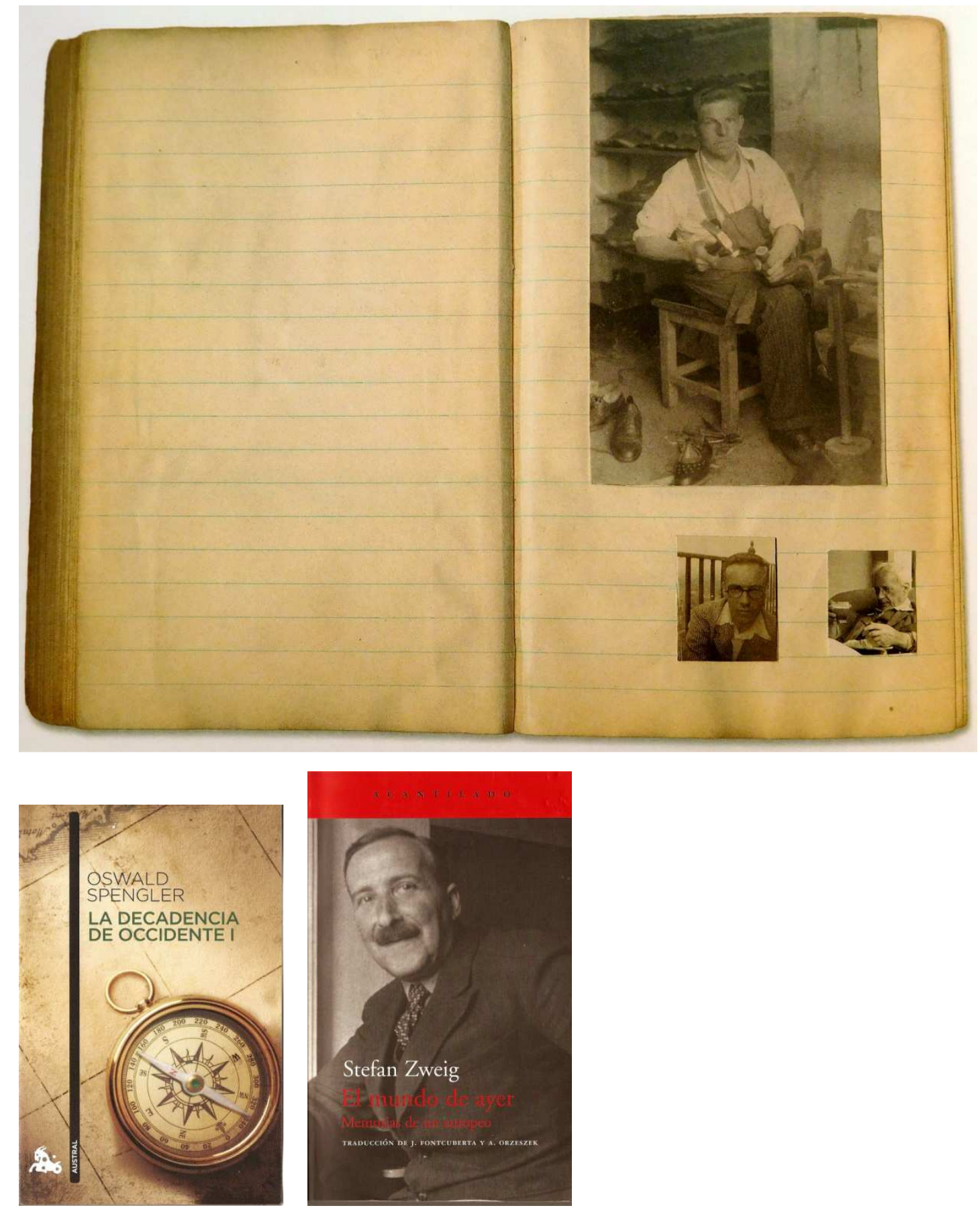

116. Álbum personal de Wittgenstein. Un alumno suyo de Trattenbach, zapatero, junto a Maurice O'Connor Drury, psiquiatra en Dublín y el filósofo G. E. Moore 117. La decadencia de Occidente que compartía Wittgenstein, «somos personas de otra época» | 118. Zweig describe también ese mundo. 
de que está al servicio del que habita se desalinea con la conceptualización del cobijo funcional que propone Wittgenstein.

Ambos vieron en el oficio, en el trabajo del artesano, el verdadero estilo de su tiempo. En su artículo Arte vernáculo de 1912 y Reglas para quien construya en las montañas de 1913, Loos nos habla de la construcción tradicional, no como algo a reproducir sino a comprender. «Construye lo mejor que puedas, no peor» dice Loos al arquitecto. Debemos volver a la tradición, no a la copia de lo pintoresco. La idea, que Wittgenstein asimila o comparte con Loos es que de la verdad interna se colige una estética ${ }^{98}$ correcta, por tanto coherente, honesta y ética. Siendo extremadamente reductivos el concepto es bien antiguo, griego.

Wittgenstein, que pasó gran parte de su vida como profesor disuadiendo a sus alumnos de estudiar filosofía y más aun de tener pretensiones académicas, defendía el trabajo manual, el oficio. El trabajo del artesano sólo se puede hacer, pero no mostrar. De alguna manera nos transporta de nuevo a la matriz indeleble de ética y estética: el carpintero, el albañil, el zapatero, pueden, a base de dedicación conseguir precisos trabajos manuales, de los que no sirve de nada hablar, siguen unas reglas que pueden ser mostradas pero no dichas, no forman un sistema ${ }^{99}$, puesto que el mero hecho de ser sabidas no presupone el mismo resultado. Es bello porque es útil, sirve a un fin específico, según Wittgenstein lo veraz se muestra por sí solo.

Wittgenstein decía que lo hermoso es lo que nos hace felices, pero también que un filósofo sólo debería hacerse preguntas, las respuestas son innecesarias.

\footnotetext{
${ }^{98}$ La estética y Wittgenstein o viceversa se desarrolla y expone con bastante claridad en Jacques Bouveresse, Wittgenstein y la estética (1993).

${ }^{99}$ En Wittgenstein, Philosophical Investigations, Part II, §227. Edición consultada aquí en castellano (Madrid: Editorial Gredos, 2009)
} 



\section{PROYECTO DE LA CASA DE WITTGENSTEIN EN SKJOLDEN}



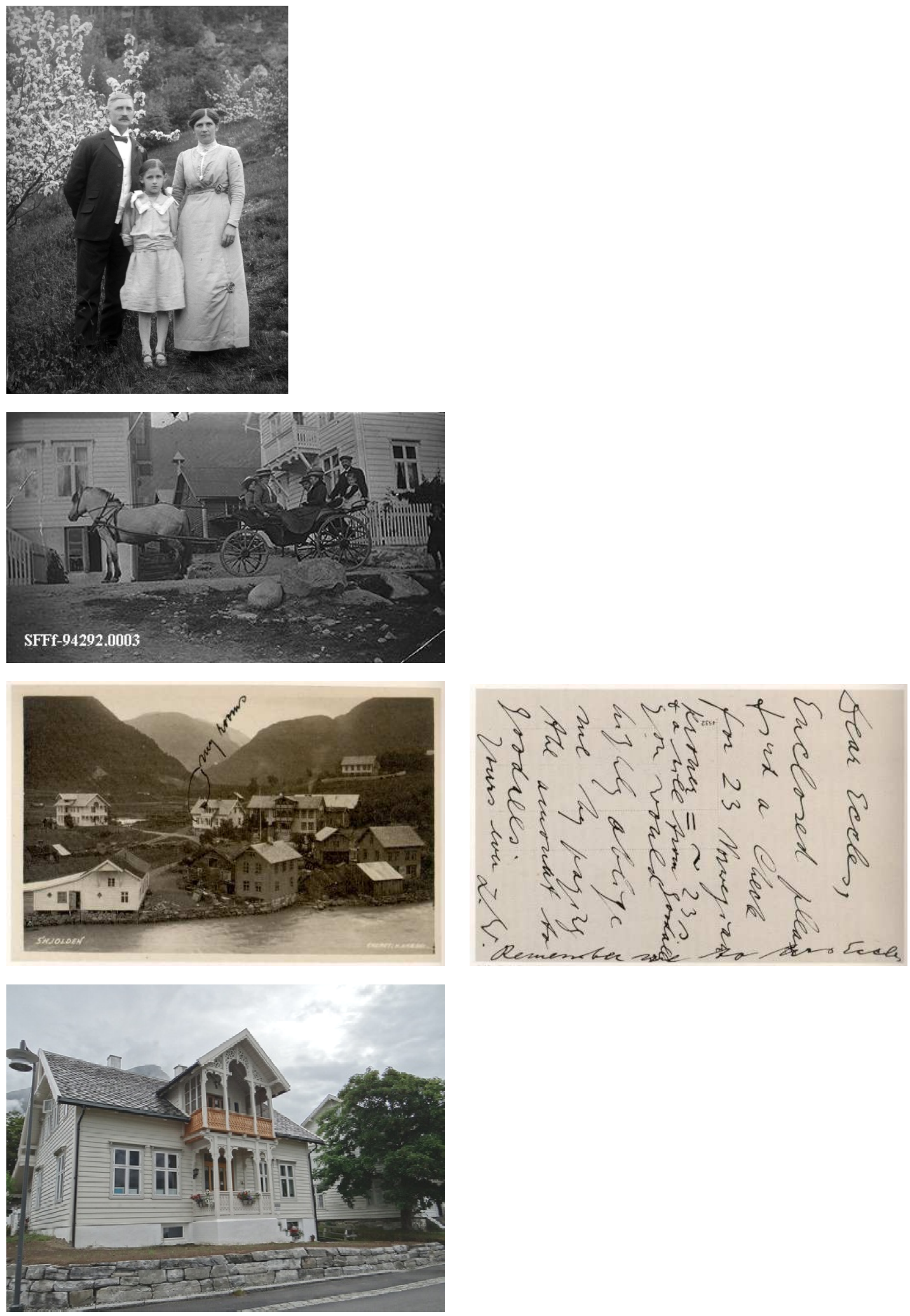

1. Hans, Sofie y Kari Klingenberg. Skjolden, 1915

2. Familia Klingerberg y familia Drægni. Skjolden, 1920-1922

3-4. Tarjeta postal de Wittgenstein a Eccles, 1914 donde señala sus habitaciones en la casa de Hans Klingenberg 5. Casa de la familia Klingenberg. Skjolden, 10.07.2012 
El proyecto de la casa en el lago responde a un emplazamiento muy concreto en Skjolden. Wittgenstein ocupaba dos habitaciones en la casa del cartero Klingenberg y su familia. La casa se encontraba junto al Hotel Skjolden, inaugurado en 1912. Como se ha dicho, la afluencia de turistas durante la temporada de verano era numerosa, incluso en 1914. Parece que Wittgenstein en ese paisaje costumbrista y de personajes tolstoianos ${ }^{1}$ que veía en Skjolden había encontrado un lugar suficientemente alejado del empalagoso Cambridge y la excesiva Viena.

Parece probado que antes del mes de marzo Wittgenstein estaba preparando la construcción de una casa en la zona para una estancia larga, quizá indefinida -aunque el plazo más prolongado que pasó en el mismo lugar desde que partiera de Viena fueron los tres años de estudios de ingeniería en Manchester-Glossop. Hoy en día, el viejo Skjolden Hotell de la familia Galde ${ }^{2}$ no existe, pero durante el tiempo que Wittgenstein ocupó las habitaciones en casa del cartero, debía sufrir el intenso ajetreo de visitantes, pues se encontraba junto a la casa de los Klingenberg.

Wittgenstein buscaba un mayor aislamiento. En aquel momento de su vida, era un joven muy rico, había llegado a Skjolden a propuesta del embajador austro-húngaro. Eso debió de marcar la relación de consideración y cierto recelo que se le profesaba en el pueblo. Estuvo consultando a sus amigos dónde poder construir una casa independiente, fuera del pueblo, alejado del bullicio.

\footnotetext{
${ }^{1}$ Las lecturas de la familia de Wittgenstein incluían a Dostoievski, Keller, Kierkegaard, Schopenhauer, etc., dice McGuinness (2011) que también a Tolstoi, sin embargo la primera referencia que tenemos de Wittgenstein y que fue una referencia indeleble el resto de su vida se inició con la lectura del Evangelio abreviado, en agosto de 1914 en plena guerra, cuando compra el único libro que encontró en una librería de Tarnów, en Galicia, donde estaba destinado en el barco Goplana. Los cuentos de Tolstoi, como Los tres ermitaños, fueron también muy queridos por Wittgenstein (Drury, en Rhees, 1984). Sin embargo lo que mejor representa la imagen que Wittgenstein debía tener de la naturaleza rural noruega sí la había encontrado en Brand de lbsen, lectura que compartió con David Pinsent en 1912-1913 según recogen los diarios de este. Los personajes de Brand se dice que se localizan precisamente en esa área de Noruega, y que Ibsen recogió tras sus viajes. La explicación viene al caso de que no sería cronológicamente correcto relacionar el escenario de Skjolden con Tolstoi en 1914. Sirva la enmienda como justificación del adjetivo.

2 Jon Olsson Galde (1889-1977) construyó el hotel en 1912, ampliándolo en 1918, 1937 y sucesivamente hasta que en 1976 fue construido uno nuevo. La familia Galde se ocupó del hotel hasta 2012. Jon era hijo de Ola Galde (1845-1940), sastre del pueblo y amigo de Wittgenstein; con quien solía pasear cada domingo.
} 

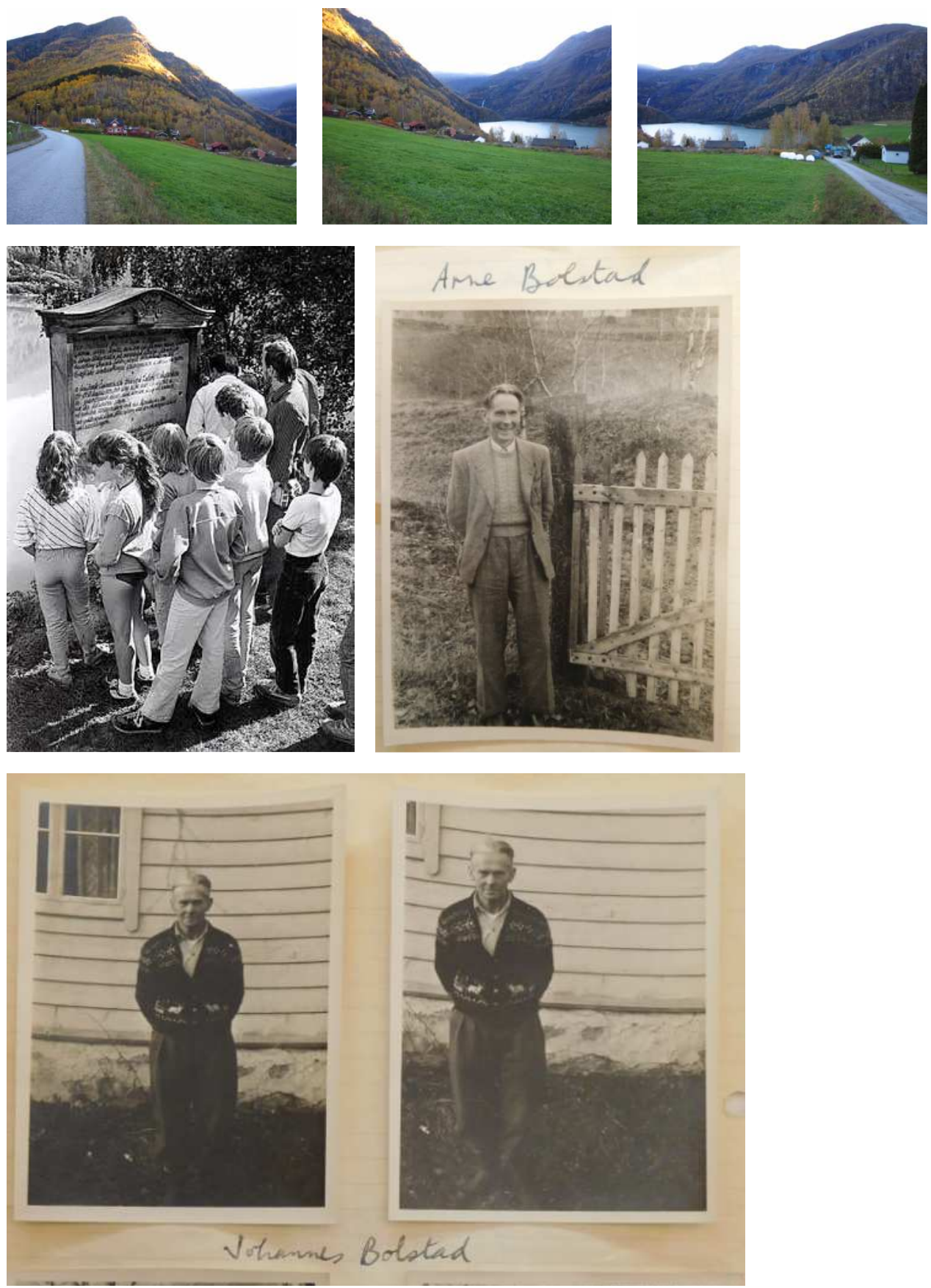

6-8. Lago Eidsvsatnet desde la carretera Bolstad, a la izquierda monte Hjerseggi, centro lago, derecha Fanaråken y granja Eide. Octubre, 2013 9. Colocación de la placa conmemorativa de la casa de Wittgenstein, agosto 1984 | 10. Arne Bolstad, 1950

11. Johannes J. Bolstad, padre de Arne y propietario del terreno donde se construyó la casa de Wittgenstein, 1950 
Al menos existe el testimonio de dos posibles localizaciones. Sin embargo en una apreció huellas en la nieve del paso de algún granjero. En la otra había un rebaño de cabras pasturando en los aledaños. Quizá incluso una tercera opción debió de ser la que indicara a Moore en su visita de marzo y abril de 1914, porque este se lo refiere en una carta desde Cambridge a Skjolden:

«[...]Recuerdo que me llevaste al lugar donde pretendías construir una casa: me parece que el sitio estaba muy bien. Pero creo que no sabía que realmente construiste una casa allí; o quizá no lo hiciste, o fue en otro lugar. Si no recuerdo mal el sitio que me llevaste no queda muy lejos de la postal, en el lado de la derecha, un buen trecho hacia arriba siguiendo el fiordo.[...]» $»^{3}$

Finalmente Johannes J. Bolstad (1843-1930) padre de un muchacho con el que había entablado cierta simpatía, Arne Bolstad (1899-1972) le cedió - no hay constancia de que llegaran a acuerdo económico alguno- un escarpado terreno, en la orilla este del lago Eidsvatnet. Sobre un berghylla -«estante o plataforma de roca» en noruego- que había en el escarpe de la falda sur del monte Hjerseggi, Wittgenstein decidió construir su casa.

En 1914, al lugar elegido se podía llegar sólo en barca o durante el invierno, cuando la capa de hielo sobre el agua del lago era lo suficientemente gruesa -en agua dulce esto ocurre al cabo de unos 4-5 días por debajo de $0^{\circ}-$, podía caminarse por encima del lago entre una orilla y la otra. ${ }^{4}$

La circunstancia no es anecdótica. Para Wittgenstein, el hecho de necesitar atravesar el lago en un bote, tendría un considerable valor lírico de lo iniciático. Paul Wijdeveld dice que durante el verano de 1921, Wittgenstein, junto a Paul Engelmann entre otros amigos y familiares, gustaban de reunirse a leer Walden o La vida en los bosques de Thoreau. ${ }^{5}$

\footnotetext{
${ }^{3}$ Wittgenstein, 1980, op.cit. p. 197. Carta de Moore a Wittgenstein, 30.09.1936.

${ }^{4}$ Skjolden se halla a $61^{\circ}$ de latitud norte, cercana a la del Círculo Polar Ártico, $65^{\circ} \mathrm{N}$. Sus condiciones geográficas hacen que el clima sea algo más benigno que otras áreas de latitud equivalente, como Alaska, Canadá o Siberia. La Corriente del Golfo que bloquea las aguas frías de las de Labrador y Groenlandia. Aun así de marzo a septiembre la temperatura media es positiva y negativa el resto del año. En 2014, las temperaturas extremas en 2014 fueron $20^{\circ} \mathrm{C}(23.07 .2014)$ y $-22.7^{\circ} \mathrm{C}$ (25.12.2014) Fuente: www.met.no/. Aunque refiere Vatne que en el invierno 2014-2015 han tenido unas nevadas excepcionales, la gráfica a largo plazo de temperatura media muestra una tendencia ascendente.

${ }^{5}$ En correspondencia electrónica de D. Connearn y P. Wijdeveld, 08.08.2012. Walden se publicó en 1884 en Inglaterra, y en los países germanófonos en 1897. Podemos suponer que Walden estaba en le biblioteca de los Wittgenstein, Karl Wittgenstein había vivido en Estados Unidos y admiraba el sentido empresarial y el modo de vida americano. Parece que tal referencia de las lecturas de Thoreau no es posible datarla, si bien el profesor Wijdeveld tuvo por fuente el testimonio del Mayor John J. Stonborough, hijo de Margaret y Jerome.
} 

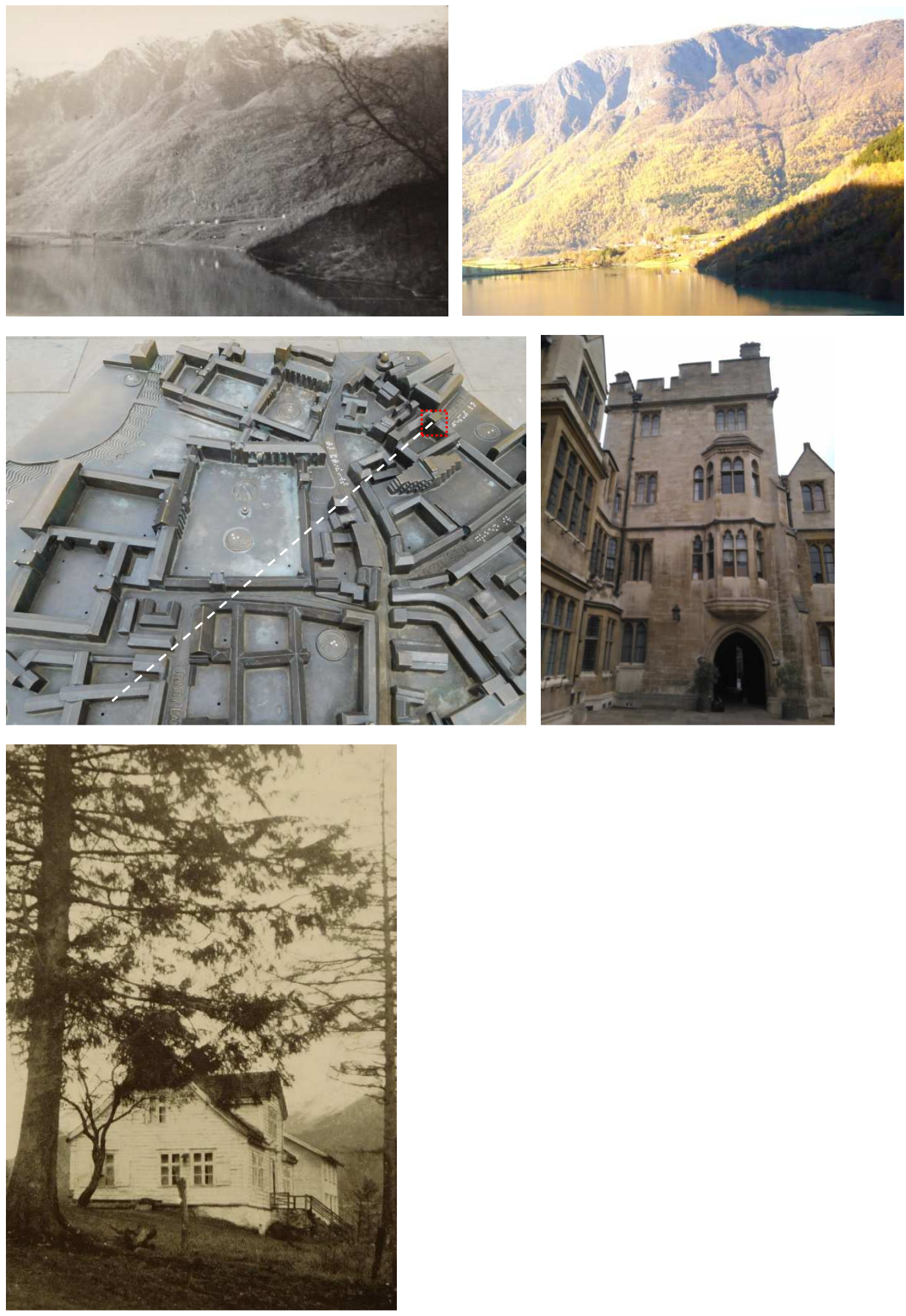

12. Vista desde la casa hacia Skjolden, octubre 1950 ｜ 13. Vista desde la casa hacia Skjolden, octubre 2013

14. Maqueta de Cambridge, situación Whewell's Court respecto ciudad, abril 2015 | 15. Ventanas (ático) de Wittgenstein en Whewell's Court, abril 2015 16. Granja Eide de Anna Rebni, 1950 
No podemos saber si Wittgenstein conocía ya en 1914 la obra de Thoreau, que desde su publicación había tenido una gran aceptación. Sin duda nos produce ciertas resonancias, que quizá en otro lugar y momento sea interesante investigar.

Cuando se visita el lugar donde se instalaba la casa, sobre el lago, la sensación es paradójica. Nos preguntamos por qué buscar un sitio aislado aunque no remoto, lejos del trasiego relativo de lugareños desde el cual sin embargo, el pueblo era perfectamente visible en la orilla opuesta del lago y por consiguiente, la casa y el filósofo podían ser observados.

La reflexión deriva hacia una concepción del paisaje como fondo. $\mathrm{Al}$ conseguir Wittgenstein alojamiento en el edificio de Whewell's Court, ocupó la parte más alta de una torre de escaleras del Trinity. De hecho eran las únicas habitaciones del Trinity College que le habrían permitido tener una visión panorámica de Cambridge hacia el norte de la ciudad por encima de los tejados:

«Wittgenstein needed open views to let his eyes to wonder.»"

Cuando se trasladaba a la casa de Hochreith se instalaba en la granja del guarda, que quedaba apartada del grupo de edificios de la residencia familiar. En tiempo de guerra, fue asignado a la escuela de artillería de Olomouc, en verano de 1917. Fue allí y entonces cuando conoció a Paul Engelmann, por recomendación de Adolf Loos. Inmediatamente Wittgenstein trató de alquilar un espacio en lo alto de la torre del reloj del ayuntamiento de la ciudad, pero el encargado del edificio se negó. Decían los lugareños de Skjolden que era habitual verlo asomado al balcón de su casa, al otro lado del lago, mirando hacia el fiordo.

Y del fondo necesario para la separación del mundo, a la asimilación de la pertenencia al mismo paisaje. La presente investigación, ha transcurrido desde la incredulidad, por lo innecesario, hacia el lugar escogido por Wittgenstein para construir su refugio hasta percibir una intención dramática y a la vez extremadamente ecológica en su emplazamiento.

${ }^{6}$ En conversación con Michael Nedo, Cambridge, 16.04.2015. 

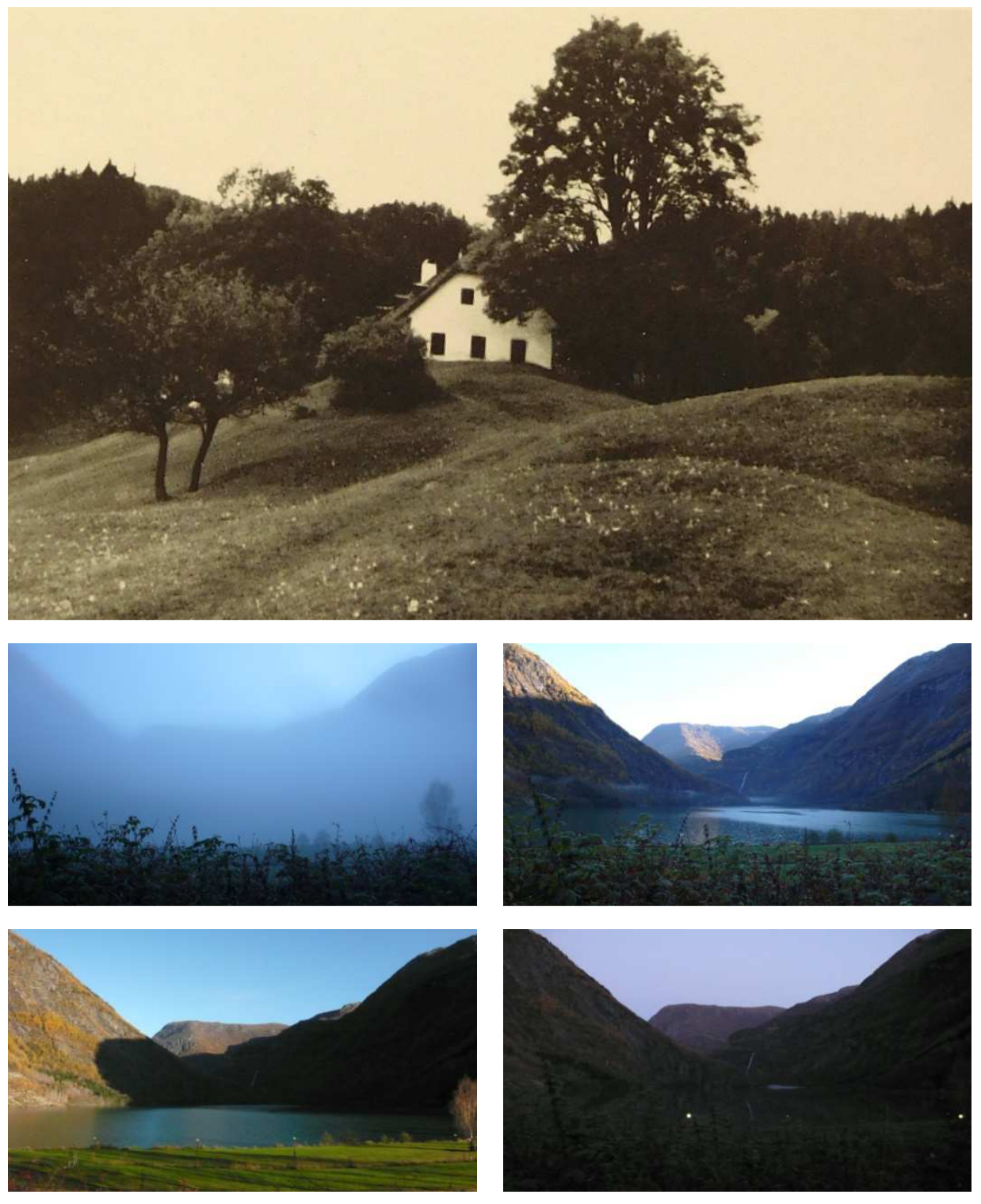

17. Casa del guarda de Hochreith, en la que Wittgenstein se alojaba

18. Eidsvatnet, $10: 48,12.10 .2013$ | 19. Eidsvatnet, 11:58, 12.10.2013

20. Eidsvatnet, $16: 18,12.10 .2013$ | 21. Eidsvatnet, 18:52, 12.10.2013 
Las imágenes que Wittgenstein conservó de la casa del lago tienen un discurso, que veremos más adelante. Podemos apreciar la crudeza del paisaje cortado, afilado de la ladera del Hjerseggi, y lo que parece una frágil construcción encaramada sobre un resalte de la montaña. Que sepamos, salvo una imagen tomada en octubre de 1950 por Ben Richards de la casa, a unos diez metros de distancia desde el lado sureste, las únicas fotografías que Wittgenstein tomó de su casa eran vistas lejanas7. La casa aparecía formando parte de un escenario natural, no era el objeto de la imagen sino un elemento asimilado por el paisaje. En esa línea de pensamiento, se expresaba Loos sobre la arquitectura vernácula y podemos establecer conexiones con el lugar-persona de Naess, la identificación con el sitio. De una manera o de otra, el paisaje era importante para Wittgenstein, cuando Skinner lo visita en septiembre de 1937, este le escribe a los pocos días desde Inglaterra:

"Con frecuencia pienso en lo bien que me sentía cuando estaba contigo y en lo maravilloso que era estar contigo y mirar el paisaje contigo.» ${ }^{8}$

Es imposible saber si el planteamiento de Wittgenstein era ético o pragmático, si perseguía un lugar trascendente en el que el esfuerzo físico le estimulara a olvidarse de todo menos de sí mismo. O quizá únicamente buscara el aislamiento físico, pero cuesta creerlo, el poliedro wittgensteiniano tenía muchas facetas, incluso siendo un joven estudiante de filosofía.

Sea cual fuere el motivo, el acceso no era obviamente cómodo. El lugar concreto escogido por Wittgenstein no era accesible a pie. En la actualidad sí es posible. En otoño de 1936 escribe, casi con vanidad:

«Querido Moore: Me alegró mucho recibir su carta. Mi casa no se halla en el sitio que usted cree. Este mapa le mostrará dónde está y por qué no puede ir a la villa como no sea a remo 9 ; pues la montaña es demasiado empinada para caminar por ella a lo largo del lago. [...] En las cuatro últimas semanas hemos tenido un tiempo maravilloso, aunque ya está haciendo un poco de frío. Las cascadas están totalmente congeladas y

\footnotetext{
${ }^{7}$ Por ejemplo las de la visita de Francis Skinner en septiembre de 1937.

${ }^{8}$ Carta de 14.10 .1937 de Francis Skinner a Wittgenstein, en Monk, op. cit. p. 348

${ }^{9}$ El lago Eidsvatnet tiene forma elíptica, con unos ejes máximos de 1.400-500 m y la distancia desde el embarcadero en el pueblo hasta la casa era aproximadamente de $1.200 \mathrm{~m}$, lo cual debía llevar cerca de una hora de ejercicio a una velocidad 1 nudo/hora.
} 

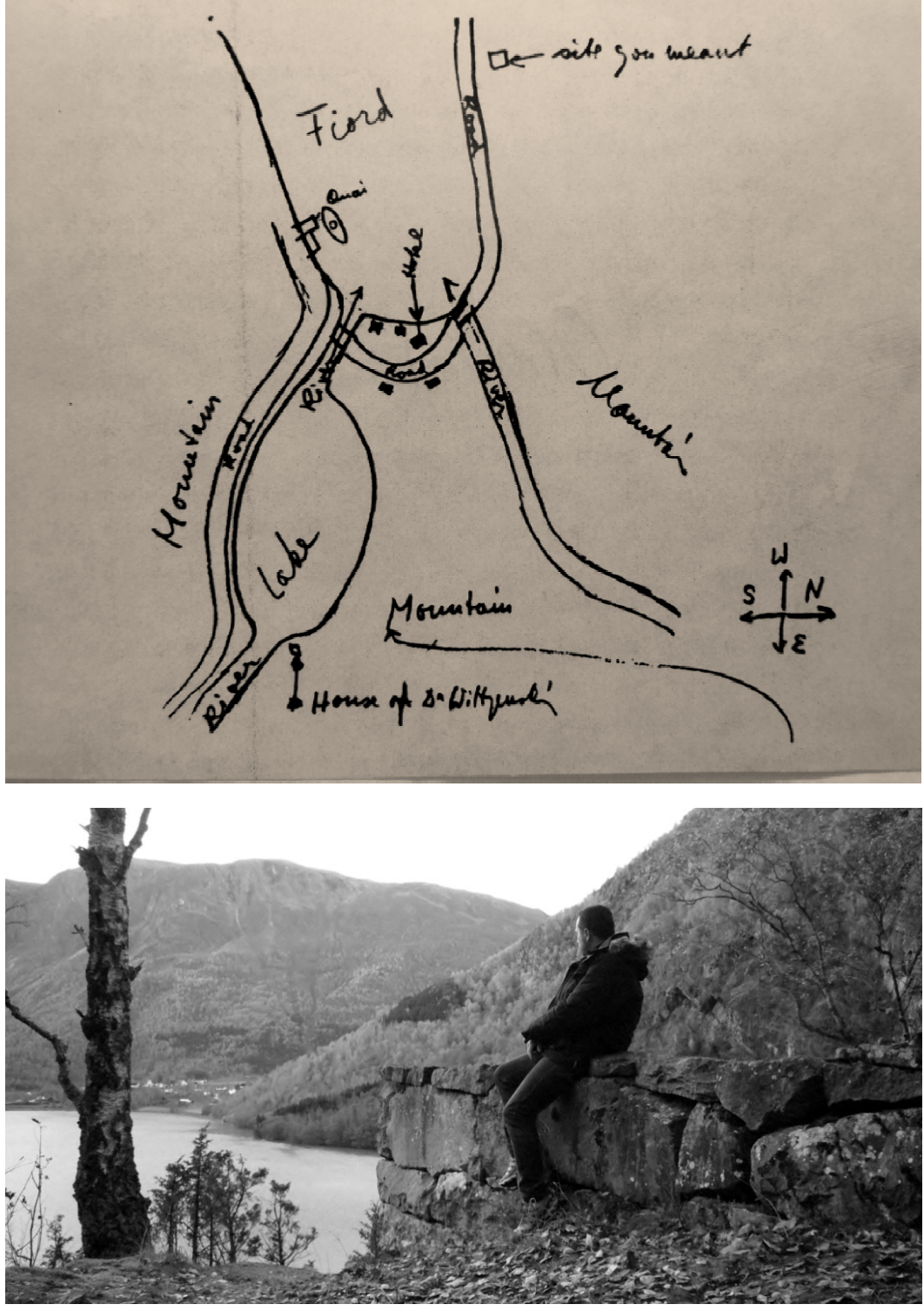

22. Plano de Wittgenstein de octubre de 1936 indicando la situación de su casa y del lugar que Moore había visto en abril de 1914. WAC, Cambridge, abril 2015 23. La casa de Wittgenstein en Skjolden, octubre 2013 
hacen unos $-3^{\circ} \mathrm{C}$ por las noches. Pero no sufro tanto del frío como en Inglaterra porque es seco. $^{10}$

Dice Åmås que el paisaje que se contempla desde la casa no es tan espectacular como relajante y tranquilo ${ }^{11}$. Puede que tampoco lo fuera para Wittgenstein, que se había criado en Austria. Probablemente su interés no fuera el paisaje-panorámico sino el paisaje-escenario.

«Jueves, 10.10.2013

[...]Plinto: 14:53. Se escucha el agua del río apenas, puede que sea la cascada de Vassbakken. Mucho silencio. Panorámica impactante. La pendiente de la montaña en el frente del lago, hacia el agua, es tremenda. No creo que pueda bajar por ahí a tomar fotos. En la otra orilla veo el pueblo, algunas luces ya encendidas. La mayor parte de las casas del centro quedan ocultas por el promontorio en la salida del río al fiordo. Pero sí se ve la parte del pueblo hacia el norte que sube por la carretera Bolstad. Todo es muy verde. Hay muchísima humedad y una cantidad enorme de hojarasca por el suelo. La mayor parte de los árboles son abedules, por lo menos en el entorno inmediato a la cabaña, pero por los tonos amarillentos de las laderas, debe predominar el abedul sobre el pino. No se oyen pájaros. Creo que puedo entender la sensación de soledad, pero sobre todo de tranquilidad. Llego muy agitado, porque hace años que esperaba venir a visitar Skjolden. Sin embargo todo me parece conocido. Sinceramente estoy emocionado pero no sorprendido.» ${ }^{12}$

La tesis doctoral de Raúl Martín Moreno tiene por motto: «A los paisajes fríos; a la intensidad de su luz y su silencio.» ${ }^{13}$ Wittgenstein le decía a Moore, en 1936: «No puedo imaginar que pudiera trabajar en ningún lugar como aquí. Es la tranquilidad, quizá, el maravilloso escenario; quiero decir, su tranquila seriedad.» ${ }^{14}$

\footnotetext{
${ }^{10}$ Wittgenstein, 1980, op.cit. p. 199

${ }^{11}$ Åmås, 1994:a, op.cit. p. 29

${ }^{12}$ Diario personal de viaje. Entrada (parcial) del 10.10.2013.
}

${ }^{13}$ El Dr. Raúl Martín Moreno nos permitió entender con su texto la geomorfología de Jotunheimen y por ende del Sognefjord. Tesis doctoral Estudio Comparativo de Formas y Procesos Glaciares y Periglaciares desde la Pequeña Edad del Hielo: Altas Latitudes Noruegas (Spitsbergen y Jotunheimen) y Altas Altitudes Españolas (Pirineos, Sistema Central y Teide), UAM 2006. En correspondencia electrónica de 13.03.2015.

${ }^{14}$ Wittgenstein, 1980, op.cit. p. 199. En noruego Det stille alvoret, que se traduce como la gravedad tranquila o la tranquila seriedad, es el título del libro de Åmås, 1994:a, del que tomamos reiteradas referencias. 


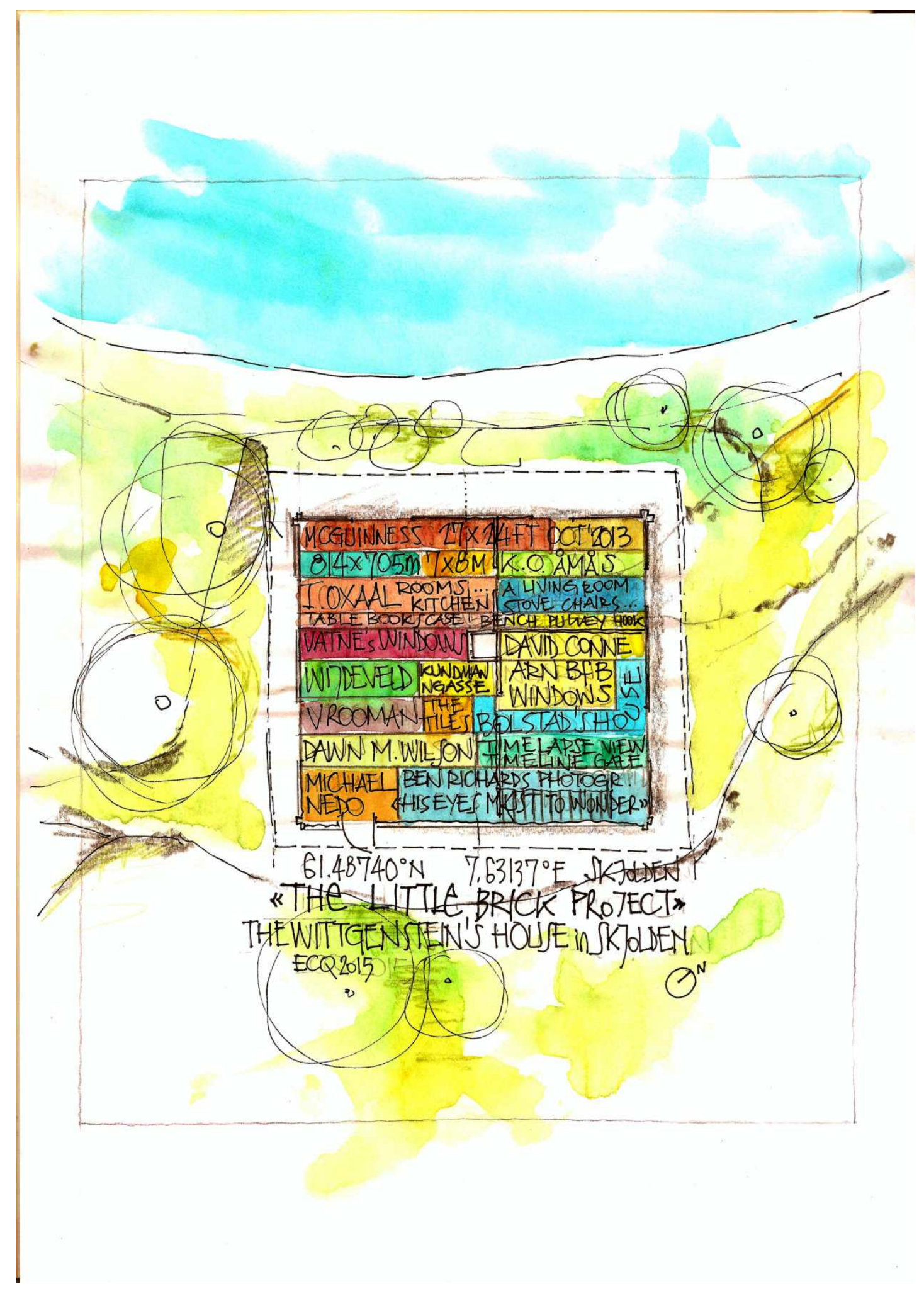

24. The Little Brick Project, Wittgenstein's House in Skjolden, 2015 
Hemos ido desgranando hasta ahora la información con la que contamos para contextualizar el proyecto de la casa de Wittgenstein. En el viaje propuesto se han ido sucediendo datos en los que nos hemos apoyado para completar la investigación. Hemos contextualizado ya el hombre y el lugar, pero ¿con qué substrato de información precisa y cierta contamos?

Avanzado el proceso de búsqueda de fuentes para la presente tesis, se fue conformando la imagen de un mosaico de datos, de teselas de información que sin embargo no nos permiten completar el conjunto. La cuestión del límite es muy importante en este proyecto, como se explicará en el epílogo, establecer claramente qué sabemos cómo fue y qué sabemos que estamos proyectando. Vamos a exponer estrictamente qué fuentes gráficas hemos utilizado en el proyecto de la casa de Wittgenstein. No nos referimos a comentarios acerca de la casa, puesto que la literatura sobre el filósofo abunda en menciones de la casa en Skjolden, meramente anecdóticos, sino datos concretos, constructivos, arquitectónicos, que aporten datos para su correcto entendimiento. Si no conocemos la estructura interna de la casa estaremos proyectando otra cosa. 

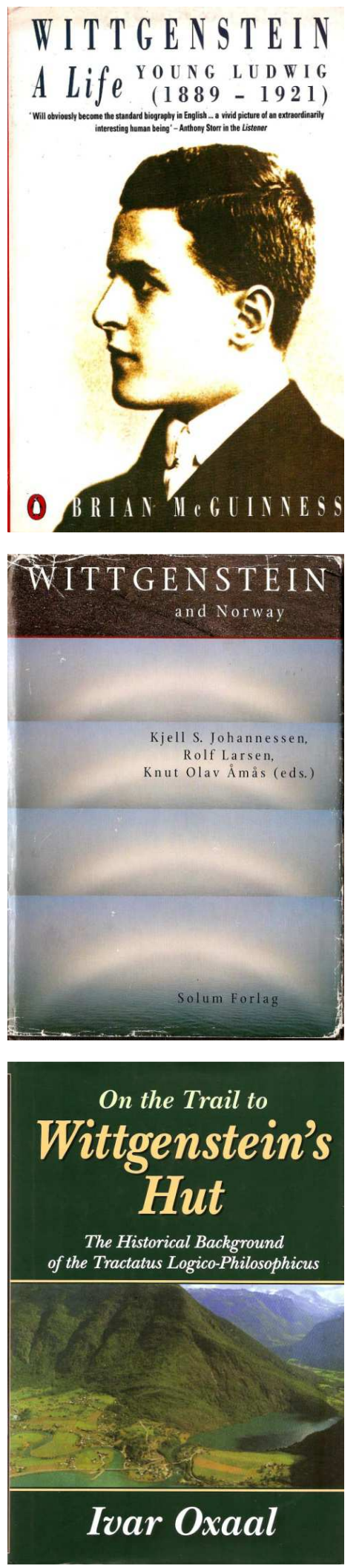

25. McGuinness, Wittgenstein A Life. Young Ludwig 1889-1921, 1988

26. Johannessen, Larsen y Åmås, Wittgenstein in Norway, 1994

27. Oxaal, Wittgenstein's Hut, 2011 


\section{Documentos escritos}

Brian McGuinness, Wittgenstein A Life. Young Ludwig 1889-1921 (London: Penguin, 1988), 202

«The house was of wood, 27 feet by 24 feet, a hundred yards from the lake. At some point (for he lived there later) Wittgenstein fixed up a rope-railway with pulleys to bring water and other supplies up to the house from the lake. The entrance was on the side away from the lake, under a gable, into the living-room; opening off this room on the right were a bedroom and a kitchen.»

Kjell S. Johannessen, Rolf Larsen, Knut Olav Åmås, ed., Wittgenstein and Norway (Oslo: Solum Forlag, 1994), 29

«The cottage might equally have been called a house. Wittgenstein himself referred to it sometimes as a "house" sometimes as a "cottage". Its dimensions were those of a typical Norwegian cotter's dwelling, with a $7 \times 8$ meter floor plan. The fact that the gable faced towards the village was peculiar in the area, as was the fact the porch was on the same side of the house, facing Lake Eidsvsatnet. At the back there was a small courtyard.»

Ivar Oxaal, On the Trail to Wittgenstein's Hut. The Historical Background of the Tractatus Logico-Philosophicus (New Brunswick, New Jersey: Transaction Publishers, 2011), 150

«Lars, as a boy in the 1930 s, visited the hut and remembered that it was furnished very simply: a table with some chairs, a stove, oil lamps, and loft for sleeping.» 

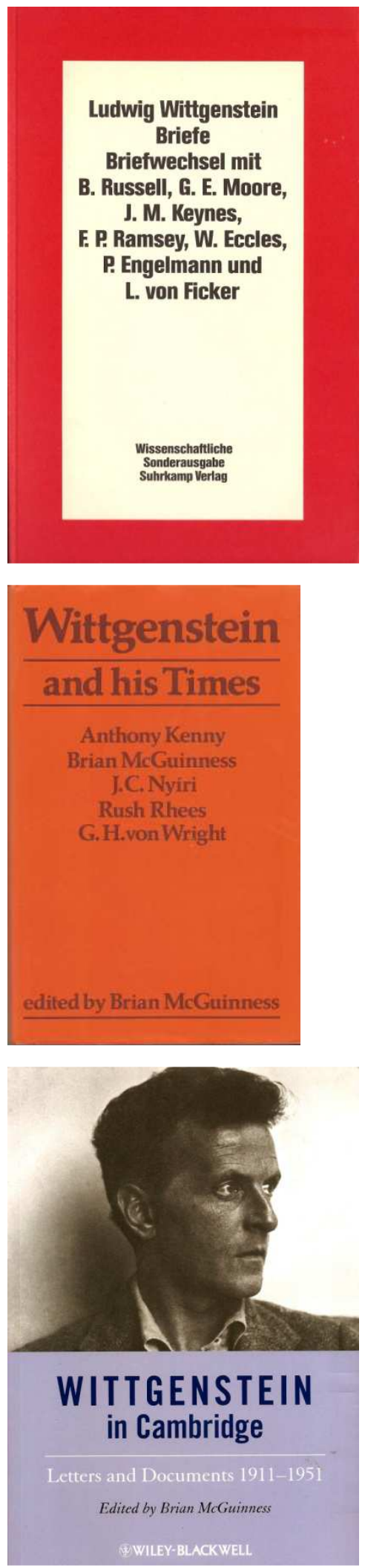

28. McGuinness (Ed.), 1980

29. McGuinness et alt., 198

30. McGuinness (Ed.), 2012 
Se ha dicho reiteradamente que la bibliografía secundaria de Wittgenstein es inmensa ${ }^{15}$. No deja de ser frustrante que estos tres escuetos fragmentos sean los únicos hasta la fecha ${ }^{16}$ que recogen información primaria de la casa en Skjolden. Sobre ellos y tal como se ha comentado más arriba en relación a las fuentes de la investigación, se procedió al contacto directo con los autores.

\section{McGuinness}

Brian McGuinness, es con Ray Monk y antes que este último, el biógrafo oficial de Ludwig Wittgenstein. McGuinness (1927) es un experto en la vida y obra de Wittgenstein. Su propia labor de publicación es inmensa, y tras ser fellow en la Universidad de Oxford durante 35 años y dar clases en Holanda, desde 1990 ha sido profesor en la Universidad de Siena y director de la Facultad de Filosofía en esa universidad, aunque en la actualidad se encuentre retirado. McGuinness no ha abandonado su labor como filósofo e investigador. Durante los veinte años que dedicó a la preparación de su libro sobre la primera mitad de la vida de Wittgenstein (su biografía abarca hasta la publicación de Tractatus en 1921-1922), y que firmó en el Queen's College de Oxford en julio de 1987, tuvo la oportunidad de conocer a gran parte de los compañeros, amigos y familiares vivos de Wittgenstein. Todos ellos le brindaron libre acceso a documentos, cartas, diarios, fotografías y testimonios directos sobre la vida del filósofo. En lo que respecta a la casa de Wittgenstein en Skjolden, la descripción ${ }^{17}$ constructiva que presenta McGuinness se puede colegir directamente de las fotografías de Ben Richards realizadas en 1950 y a las que probablemente tuvo acceso, pero no

\footnotetext{
${ }^{15}$ Existen miles de referencias bibliográficas sobre Wittgenstein. Es curioso y valeroso el documento compilado por Raimundo Drudis, Universidad de Castilla-La Mancha y que la revista Thémata. Revista de filosofía, publicó en su número 36, 2006 titulado Las ochocientas tesis y disertaciones sobre Ludwig Wittgenstein-Relación cronológica. La primera está fechada en 1933 y la última del listado en 2005, en total 826 elementos.

${ }^{16}$ El anunciado libro de Harald Vatne (pendiente de publicación desde 2012), profesor de historia jubilado, vecino de Skjolden y estudioso de todos los aspectos que relacionan a Wittgenstein con su villa, no ha sido publicado en el momento de redactar estas líneas. Es más que posible que Vatne cuente con información, que ha recopilado desde hace más de treinta años, desconocida hasta hoy por el resto de investigadores. Vatne tuvo la oportunidad de conocer personalmente a lugareños que frecuentaron la casa de Wittgenstein. El propio Vatne, siendo un colegial de 15 años ayudó en 1958 a la colocación del revestimiento de placas aislantes de la casa de Gunnar Bolstad. No hemos podido obtener sin embargo, ningún dato por su parte de la casa original.

${ }^{17}$ Las dimensiones del plinto de piedra sobre las que se apoyaba la casa las da McGuinness en unidades Imperiales, 27 × $24 \mathrm{ft}$. La conversión a metros dan 8,23 x 7,31 m, cerca de las reales tomadas in situ de 8,14 x 7,04 m.
} 


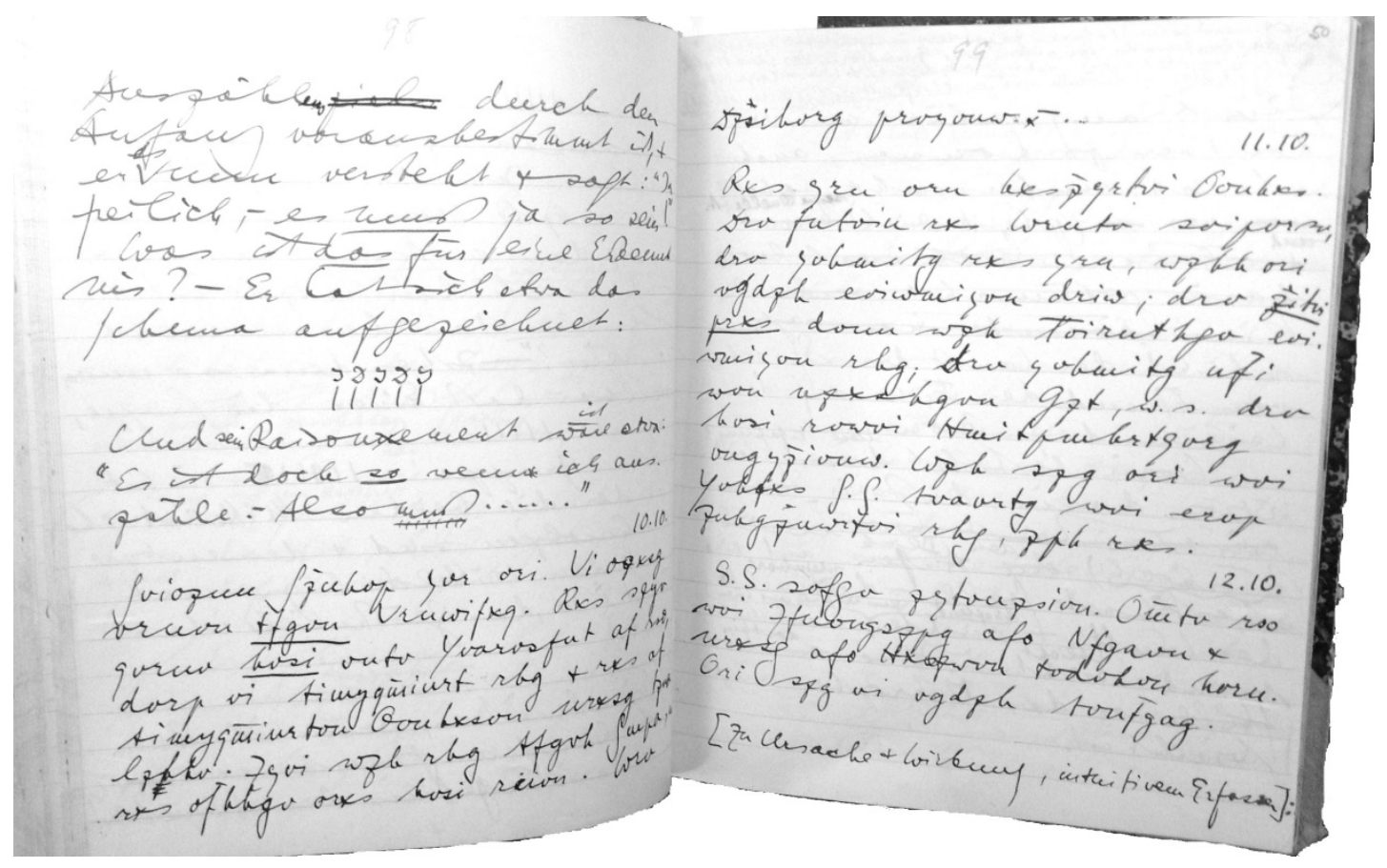

Ms-119,98[2]et99[1]; ...Hermann Hänsel bei mir. Er macht einen guten Eindruck. Ich habe keine sehr enge Beziehung zu ihm, weil er grobkörnig ist \& ich zu grobkörnigen Menschen nicht ganz passe. Aber das ist gutes Holz, oder ich müßte mich sehr irren. ... Die...... Wahrheit liebend-.

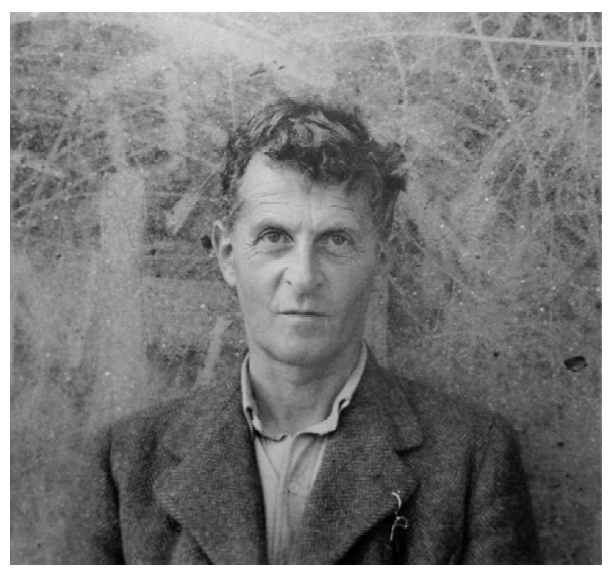

31. Manuscrito 10-12 octubre 1937. Hermann Hänsel visita a Wittgenstein en Skjolden, Wren Library, abril 2015

32. Wittgenstein en Swansea, Gales. Fotografiado por Ben Richards, 1947 
sabemos si la distribución que plantea es resultado de un testimonio de algún visitante de la casa o no -es la única referencia al espacio interior-, puesto que en el largo prefacio en que detalla las personas que han colaborado en su investigación y los lugares que ha visitado, no hay referencia alguna a Skjolden ni a Noruega. Podemos elucubrar si el testimonio fue recogido directamente por McGuinness en Skjolden. De las personas que sabemos que visitaron la casa con Wittgenstein, McGuinness pudo obtener información de Hermann Hänsel18, que pasó dos días con Wittgenstein en su casa del lago estando de viaje con su moto por Noruega, del 10-12 de octubre de 1937:

«...Hermann Hänsel conmigo. Me ha causado buena impresión. No tengo una relación muy estrecha con él porque es algo rudo y vigoroso. Pero parece buena persona o es que estoy muy equivocado...la verdad.[...] se muestra mucho más respetable que yo.»19

Ben Richards, que acompañó a Wittgenstein en octubre de 1950 a su casa de Skjolden no parece tener cabida en la investigación de McGuinness puesto que queda fuera de la cronología recogida en la misma (Wittgenstein y Richards se conocieron en Cambridge en 1946). Marguerite Respinger, que conoció a Wittgenstein en 1929 en Viena y que visitó Skjolden en 1931 no aparece referida en libro de McGuinness. Si este visitó Skjolden, no lo sabemos. El motivo es que no ha sido posible contactar al menos hasta la fecha con el profesor en Siena. Uno de los últimos intentos se remite a marzo de 2015, a través de un colega en la Universidad de Siena conseguimos contactar con el entorno cercano de Brian McGuinness con el siguiente balance:

«[...]Quanto all'altra cosa, pure capisco, e La ringrazio anche. Ma Lei deve comprendere che io non ho da anni (anche se l'anno scorso l'ho invitato ad una modesta cena qui a Siena con un collega di Oxford, cena che ho organizzato dopo un "evento" wittgensteiniano, ma cui io non ho potuto partecipare per motivi di salute) contatti personali con Brian. Brian è persona gentilissima e squisita, ma credo sia del 1926, quindi ha l'età che avrebbe mio padre, se fosse ancora in vita. Credo che stia bene, ma, come so purtroppo per esperienza diretta, star bene ed esser lucidissimi a un'età del genere significa esser pieni di acciacchi, piccoli o grandi.

\footnotetext{
${ }^{18}$ Hermann Hänsel (1918-2005), era hijo de Ludwig Hänsel (1886-1959), amigo de Wittgenstein desde el cautiverio italiano en Monte Cassino en el último año de la Primera Guerra Mundial.

${ }^{19}$ Wittgenstein, MS 119.98 [2] et 99 [1] y MS119.99 [2]. Anotaciones en el diario secreto, en clave, de Wittgenstein de 10.10 .1937 y 11.10.1937. La anotación en clave se ha traducido desde el alemán.
} 

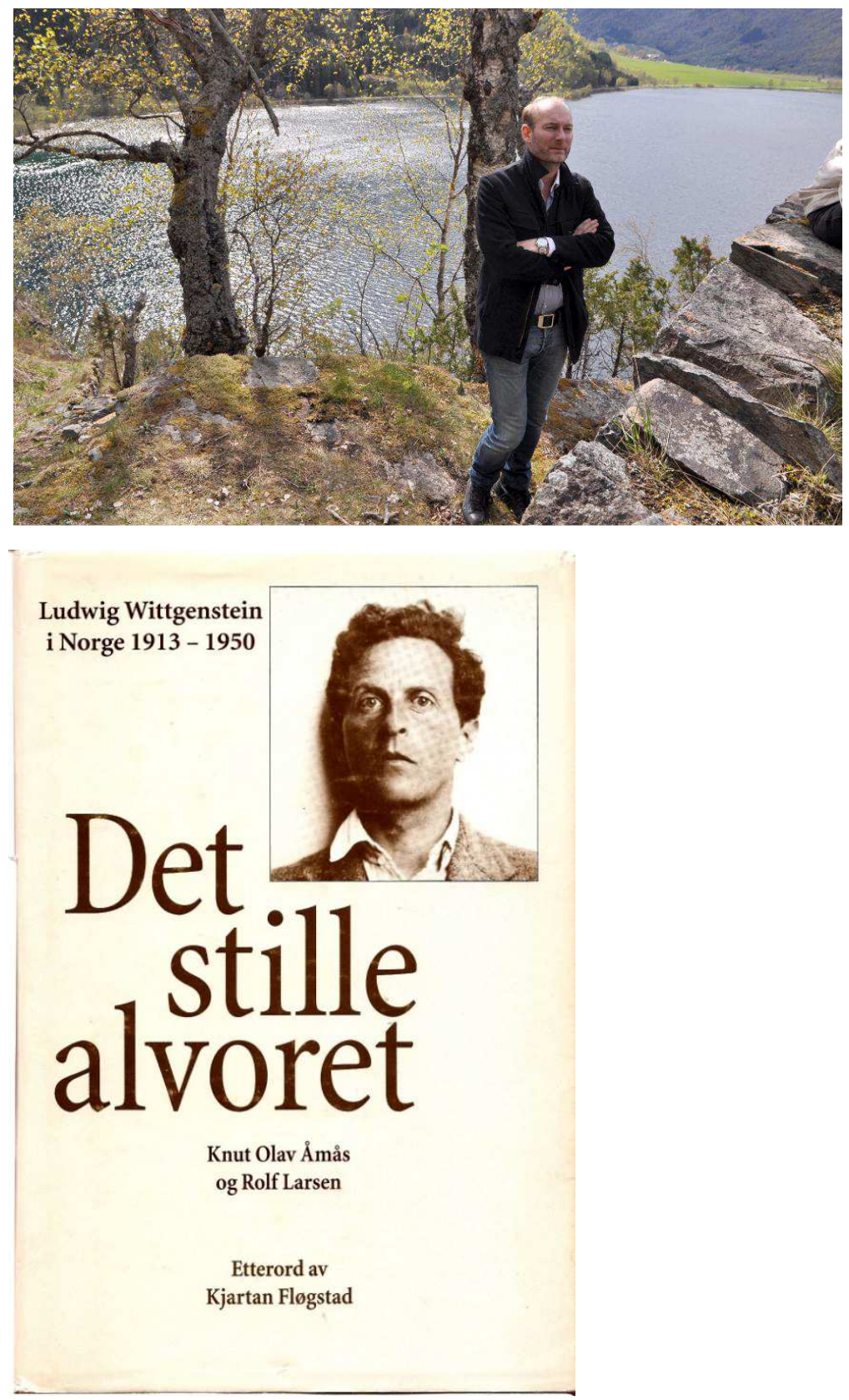

33. Knut Olav Åmås en los restos de la casa de Wittgenstein en Skjolden. Artículo en Sogn Avis 21.10.2013 34. Åmås y Larsen, Det stille alvoret, 1994 
Esito quindi (a parte il fatto che ho perso il suo cellulare) a metterla in contatto diretto. Io e chiunque di noi a Siena si augura che stia bene, e cerchiamo di avere sue notizie, tutto qui. [...]

Mi scuso, e La prego di salutarmeli tutti, e resto a Sua disposizione.

Suo,

Giuseppe Varnier» ${ }^{20}$

La propia naturaleza de una investigación queda a veces delimitada por el tiempo, el espacio y los recursos. Dawn Wilson, profesora de filosofía en la Universidad de Hull, y compañera en este viaje, es de la prudente opinión de tratar de contactar con Brian McGuinness, al que conoce personalmente, en otra ocasión, cuando se halle completamente recuperado.

\section{Åmås}

Knut Olav Åmås (1968) es filósofo, periodista y político. Se doctoró en filosofía en la Universidad de Bergen y allí desarrolló una investigación sobre Ludwig Wittgenstein que le llevó a escribir dos libros sobre la relación del filósofo con Noruega, uno con el escritor Rolf Larsen (1948-2002) y otro con el profesor de filosofía Kjell S. Johannessen (1936). Con el primero Det stille alvoret (1994) y con ambos, Wittgenstein and Norway (1994)21. Desde hace unos años está vinculado políticamente con el partido conservador noruego y ha sido fugazmente Secretario de Estado del Ministerio de Cultura de Noruega (16.10.2013-30.05.2014). Desde 2014 dirige la fundación Fritt Ord (Freedom of Expression Foundation), en Oslo.

Åmås es un personaje con gran presencia en el ámbito cultural y político de noruega. Mantiene fuertes vínculos con la Universidad de Bergen y dirige el Seminario Internacional Wittgenstein que convoca cada año en mayo o junio en Solvorn, un pequeño pueblo en el fiordo, a pocos kilómetros de Skjolden. Junto a

\footnotetext{
${ }^{20}$ En correspondencia electrónica, 10.03.2015. En resumen, el profesor Varnier no considera oportuno ponernos en contacto directo con Brian McGuinness por su avanzada edad y delicado estado de salud.

${ }^{21}$ Kjell S. Johannessen es profesor emérito en la Universidad de Bergen y tuvimos la fortuna de conocerlo y compartir la hora de comer junto a él, Alois Pichler y un pequeño grupo de investigadores en el Archivo de Wittgenstein en Bergen, 15.10.2013. Sus comentarios sobre el proyecto de reconstrucción de la casa de Wittgenstein en Skjolden no dejaban de ser mordaces.
} 

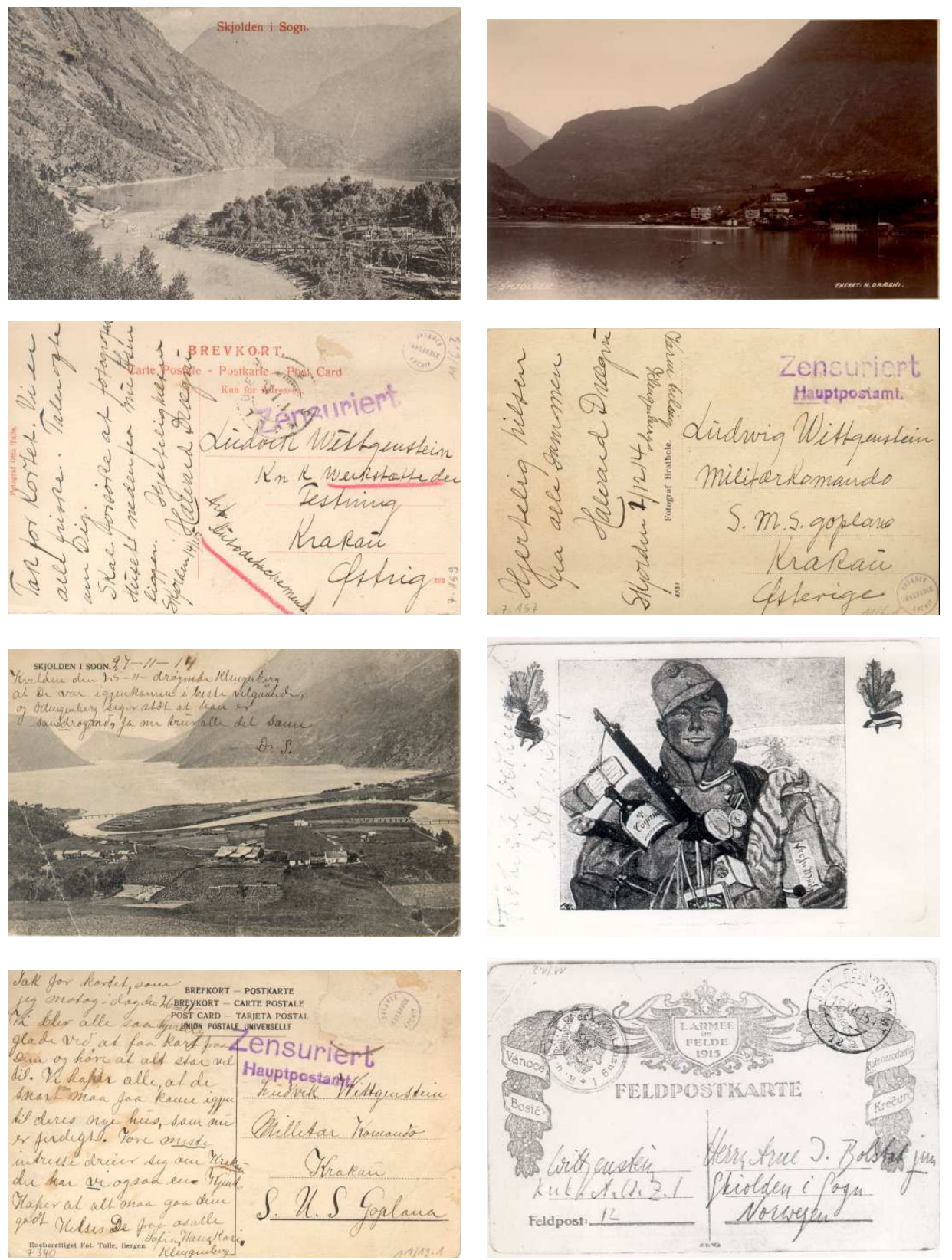
David Connearn y Dawn Wilson, apoyó una campaña de apoyo de intelectuales e instituciones de ámbito internacional en 2009, para la preservación del legado de Wittgenstein en Skjolden, frente la situación de abandono en que se encontraba la gestión de los restos por parte de las autoridades municipales (Lusterkommune), que apoyaron la iniciativa22, así como por el Riksantikvaren, The Directorate for Cultural Heritage, puesto que «is responsible for the management of all archaeological and architectural monuments and sites and cultural environments in accordance with relevant legislation. $»^{23}$

La información que aporta Åmås en sus libros de 1994 ha sido fundamental. La investigación sobre las circunstancias de la relación de Wittgenstein con Noruega fue meticulosa y envidiablemente amplia en recursos. Åmås tuvo oportunidad, de entrevistar a Ben Richards en su casa de Hemel Hempstead, Inglaterra, en marzo de 1993; en Sogndal, mayo de 1991, pudieron recabar documentos y recuerdos de Bjarne Drægni, hijo de Halvard, el empresario y alcalde de Luster que había sido amigo íntimo de Wittgenstein en Skjolden y al que éste encargó la supervisión de los trabajos de construcción de su casa; en mayo de 1991 y el 13.08.1994, Åmås se desplazó hasta Ginebra para entrevistar a Marguerite de Chambier (Respinger era su apellido familiar) ${ }^{24}$. El propio Georg von Wright, fiduciario del legado de Wittgenstein participó en la edición de las cartas recogidas en el libro de 1994, de su trabajo como custodio de tal legado, pudo conseguir 29 cartas y tarjetas postales en Viena, desde entonces en el Brenner Archives en Innsbruck University, Austria. Bjarne y Olav Drægni pusieron a disposición de Åmås, en agosto de 1993, ocho cartas y tarjetas postales que Wittgenstein había enviado a su padre Halvard, así como una de Arne Bolstad. En Skjolden, Tordis Hauge dio acceso a cinco cartas dirigidas a Anna Rebni. Siete cartas y tarjetas postales dirigidas a Arne Bolstad fueron aportadas por Olav Kjelsvik, en Voss. ${ }^{25}$

\footnotetext{
${ }^{22}$ Correo electrónico de D. Connearn: «l met the Kultursjef Erling Bjørnetun in 1999 and said that with his agreement I would have some letters sent to the Riksantikvaren, asking for input. He agreed».

${ }^{23} \mathrm{http}: / /$ www.riksantikvaren.no/en/About-Us

${ }^{24}$ Marguerite Respinger fue la prometida de Wittgenstein en 1931. Véase Contextualización, 1931.

${ }^{25}$ Johannessen, Larsen y Åmås, op. cit., 84-86.
} 


$$
16 \text { th Guly } 2012
$$

Dear Enrique,

$$
\text { Thank you for your }
$$

interest. I hope you get the

email If an sending today

and hope you find the

enclosed article useful.

$$
\begin{aligned}
& \text { Best wishes } \\
& \text { /var Oxaal } \\
& \text { ETC-ETC }
\end{aligned}
$$

$\frac{\text { P.S. } 18 \text { 'July }}{\text { since I woote this you should have }}$ received emails from Daun and

David. I am also sending photo-

uppies of the cellar and privy.
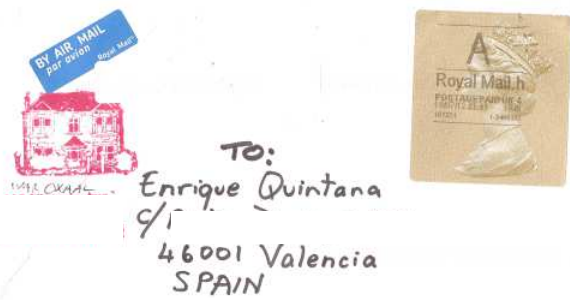

SPAIN

Wear Envique,

\section{England}

4 th March 2015

for sending a sketch of Wittgenstein's hut, in a design

ly you. Ion may or may not know that the boal

district has bought the site on the mountain, lnt the

old but is still in the village. I don't know what

they plan to do with it, but your new sketch is much

better! You have my permission to use the photcopies

of photographe taken on the site thent $g$ sent gou

of an foing to send wivi sketch to a lecturer

at to univessity here in Hull. She wrote a paper for

a German publication a few pears ojo obout the hut.

Her name and aldress.

Dr Dawn Wilson

Dept. of Philosophy

University of Hull

Cottingham Road

HULL

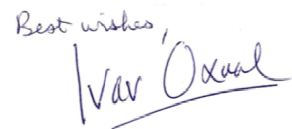

43-44. Correspondencia con Ivar Oxaal, 18.07.2012

45. Correspondencia con Ivar Oxaal, 04.03.2015 
El libro de Åmås no es un libro de arquitectura, sino biográfico. No contiene ningún documento gráfico, plano o fotografía en la edición en inglés, y sólo alguna fotografía en el libro en noruego, ambos de 1994. Algunas cuestiones que suscitaban duda fueron consultadas directamente con Åmås:

«[...] May I ask you what do you mean with "porch" (p. 29) that faced towards the lake? Do you mean the veranda upstairs?

YES

And the "courtyard" at the back, do you mean the entrance door with the wind-shield? YES

or was there some kind of wall outside the house?[...]

I've also try to get "Ludwig Wittgenstein i Skjolden" by Harald Vatne, that you name in your book, but It has not been possible either...I can't know if in that book there's further information about the house.

THIS IS ONLY A LEAFLET. THERE IS NO EXTRA INFO ABOUT THE HOUSE THERE. $[\ldots]\rangle^{26}$

El contacto con Åmås se ha mantenido y correspondido en el transcurso de esta investigación. Como se ha dicho en la introducción, en julio de 2011 nos puso en contacto con David Connearn. El hecho de haber sido catalizador de esta relación ha permitido que esta investigación haya llegado donde nos encontramos hoy.

\section{Oxaal}

Ivar Oxaal (1931) es profesor emérito de la Universidad de Hull27. Su descripción de algunos aspectos de la casa de Wittgenstein en su libro ${ }^{28}$ de 2011 es tangencial ya que el objetivo de su texto es antropológico, volcando sus esfuerzos en la relación de la obra de Wittgenstein, en concreto la escritura del Tractatus, con algunos aspectos socio-culturales de la época que le tocó vivir a Wittgenstein, como su origen judío -que ya hemos dicho más arriba- y sus observaciones sobre el pesimismo -ya hemos nombrado a Spengler y La

\footnotetext{
${ }^{26}$ Correspondencia electrónica de 23.08.2011. El libro de 1994, Wittgenstein in Norway no fue sencillo de localizar. En 2011 sólo una copia estaba disponible a la venta en Internet, localizada en una librería de segunda mano sueca. Aunque Åmås dijo haber enviado un ejemplar por correo postal, este nunca llegó. Pocas semanas antes del mensaje referido sucedieron los atentados de la Isla de Utøya. Åmås había escrito un artículo en el New Yorker: http://www.newyorker.com/online/blogs/newsdesk/2011/07/seven-days-in-oslo.html

${ }^{27}$ Ivar Oxaal reside en Hull, Inglaterra, aunque fue profesor en la Universidad de California, la Universidad de Guyana. Ha escrito numerosos libros de antropología, especialmente vinculados con el mundo judío.

${ }^{28}$ Oxaal, On the Trail...op. cit.
} 
decadencia de occidente- en Austria de los primeros años del s. XX y que Wittgenstein vivía desde la distancia en Cambridge y Noruega.

Decimos que la referencia a la casa de Wittgenstein no es directa porque aparece como un apéndice al texto. Oxaal es de origen noruego, nacido en Nordfjordeid, al norte de Skjolden, en la misma región de Sogn og Fjordane. Desde su ciudad natal, describe la visita que hizo a Skjolden en $1984 .{ }^{29}$ Allí llegó en autobús desde Nordfjordeid, por carretera, hacia el este pasando por Lom y en sentido descendente -atravesando el Parque Nacional de Jotunheimenhasta Skjolden ${ }^{30}$. Oxaal no tenía conocimiento de que la casa de Wittgenstein hubiera sido desmontada en 1957 por los Bolstad -hemos de tener en cuenta que el libro de McGuinness aún no había sido siquiera publicado- y trató en vano de localizarla entre los cobertizos en ruina del pueblo, lógicamente sin éxito. Herr Jon Galde -el director del Skjolden Hotell- le informó de la situación y tras visitar la casa de los Bolstad en el pueblo, Oxaal consiguió que dos miembros de los Bolstad le acompañaran hasta el lugar que ocupara la casa sobre el lago, donde Lars Bolstad refiere a Oxaal su recuerdo de la visita en los años 30. ¿No resulta una descripción quizá demasiado prototípica del interior de la casa de Wittgenstein? Tampoco dice que cuando la visitara se encontrara el filósofo en Skjolden, no olvidemos que Arne Bolstad -Lars y los Bolstad que compraron los materiales de la casa son parientes no directos, el apellido Bolstad es muy común en Skjolden- se ocupó de la casa a partir de 1919. El carácter huraño con que se desenvolvía Wittgenstein debía ser comentado entre los vecinos. Sabemos que visitó Skjolden en periodos bien alejados entre sí y con el objetivo de trabajar a solas en su casa, uno se cuestiona qué otra cosa podría recordar un visitante. Parece un escenario demasiado esperable.

Oxaal atendió siempre amablemente mis $\operatorname{consultas}^{31}$, alguna de ellas por correo electrónico, al que no es muy aficionado, y otras por carta:

${ }^{31}$ Ivar Oxaal ha dado además permiso para reproducir aquí las imágenes que remitió por carta en verano de 2012 de su viaje a Skjolden de 1984.
} 

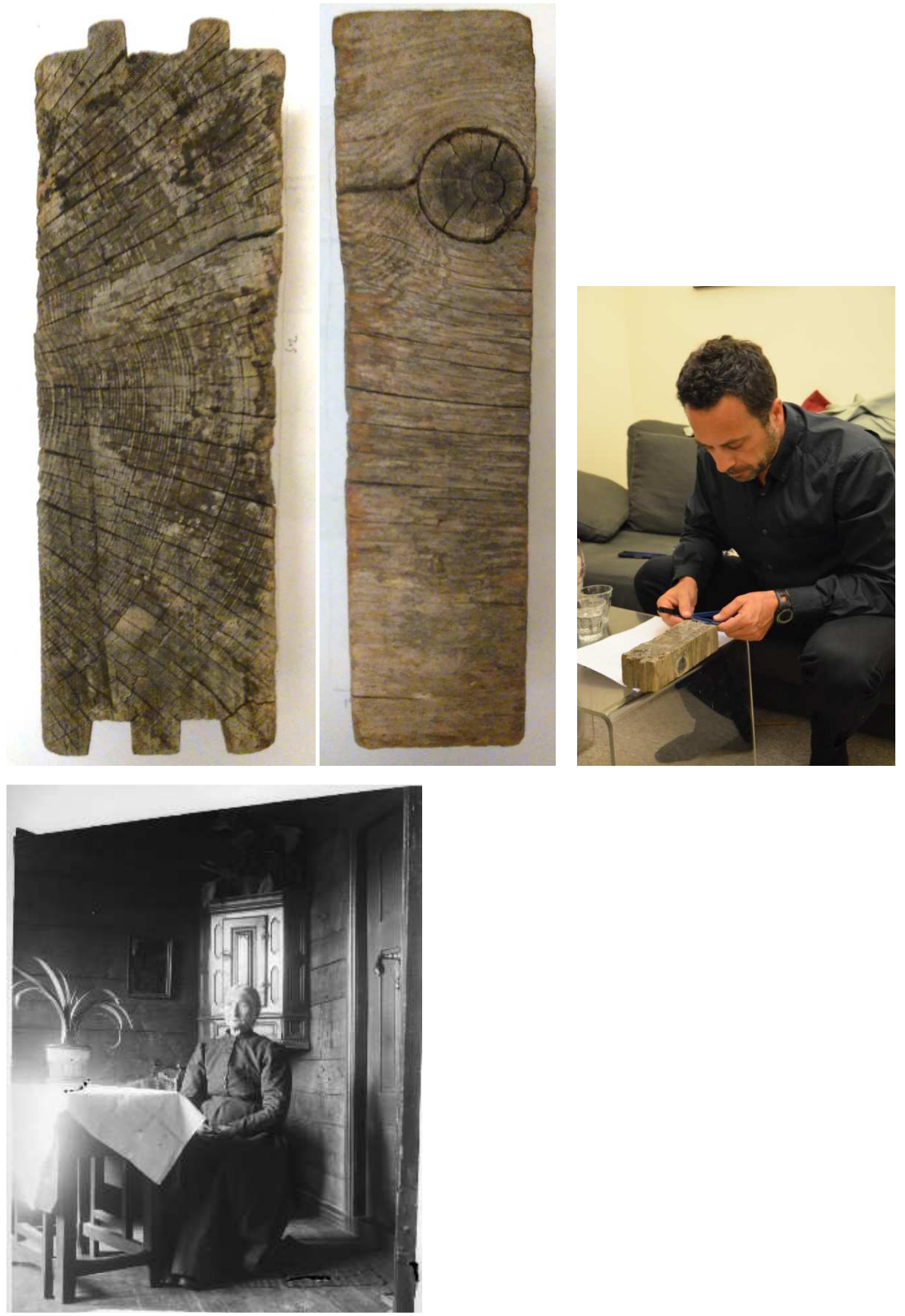

46-47. Sección de madera de la casa original, recogido en 1984 por Oxaal. Dimensiones 70x205 mm ～48. Toma de datos, Cambridge, 15.04.2015 49. Retrato de Eli Eriksdatter Kolstad, 1910-1914. Detrás de la señora apreciamos un tabique interior de construcción similar al que proyectamos aqui 
«Dear Enrique Clemente,

Many thanks for your interest and your questions. I cannot give you more details of the hut than those in my book. The only thing I can tell you is that the privy was about 20 metres from the hut. I mentioned that there was a line, at some point, near the hut to the water below. The photograph by Ben Richards -- in a new book titled Verortungen eines Genies, Ludwig Wittgenstein, publisher Junius Verlag 2011 -clearly shows the line.

(The photograph taken by a local photographer was too small and useless.) I am sending you the relevant article from this book by Dawn Phillips and David Connearn by postal mail today. I am sorry that the article is in German, but it is an important publication. The main person you must get in touch with is David Connearn.

Best wishes,

Ivar Oxaal»32

En diciembre de 2014, Dawn Wilson hizo una visita a Oxaal en Hull y este cedió a la profesora Wilson algunas piezas de madera y unos clavos que Oxaal encontró en su visita a los restos de la cabaña en 1984. Gracias a ellos hemos podido confirmar las dimensiones de algunos elementos importantes del proyecto, como las dimensiones de las escuadrías de madera de los tabiques interiores y de los troncos de las fachadas.

Tal como sin duda demostrará el libro de Harald Vatne cuando este sea finalmente publicado, así como la investigación que pueda hacerse de los archivos privados familiares de los Bolstad -tanto la rama de Arne Bolstad como la de Gunnar Bolstad-y de otros descendientes de conocidos y amigos de Wittgenstein, se encontrarán otros testimonios directos que permitirán conocer más datos de la casa en su construcción original. Sobre esto, hemos discutido extensamente durante los años de preparación de esta investigación. Alguna de las personas que se relacionaron directamente con Wittgenstein y que lo visitaron en su casa sobre el lago, debió atesorar recuerdos, quizá incluso por escrito, puesto que desde su primera visita en 1913, su presencia suscitó sin duda la curiosidad de los vecinos de Skjolden. No sabemos quién fue el carpintero encargado de la construcción de la casa del lago, aunque por Vatne sí

\footnotetext{
${ }^{32}$ Correspondencia electrónica de 16.07.2012. La fotografía que menciona Oxaal aparece referida, sin imagen en su libro (p. 151). No ha sido posible localizar al autor Magnus Haugh. En el archivo comarcal aparece un Magnus Hauge pero ningún Haugh, aunque tampoco consta que fuera fotógrafo sino que trabajaba en la tienda de Drægni. De la letrina que dice haber fotografiado Oxaal en 1984 en las cercanías de la casa del lago no conseguimos encontrar el más pequeño vestigio en 2013.
} 

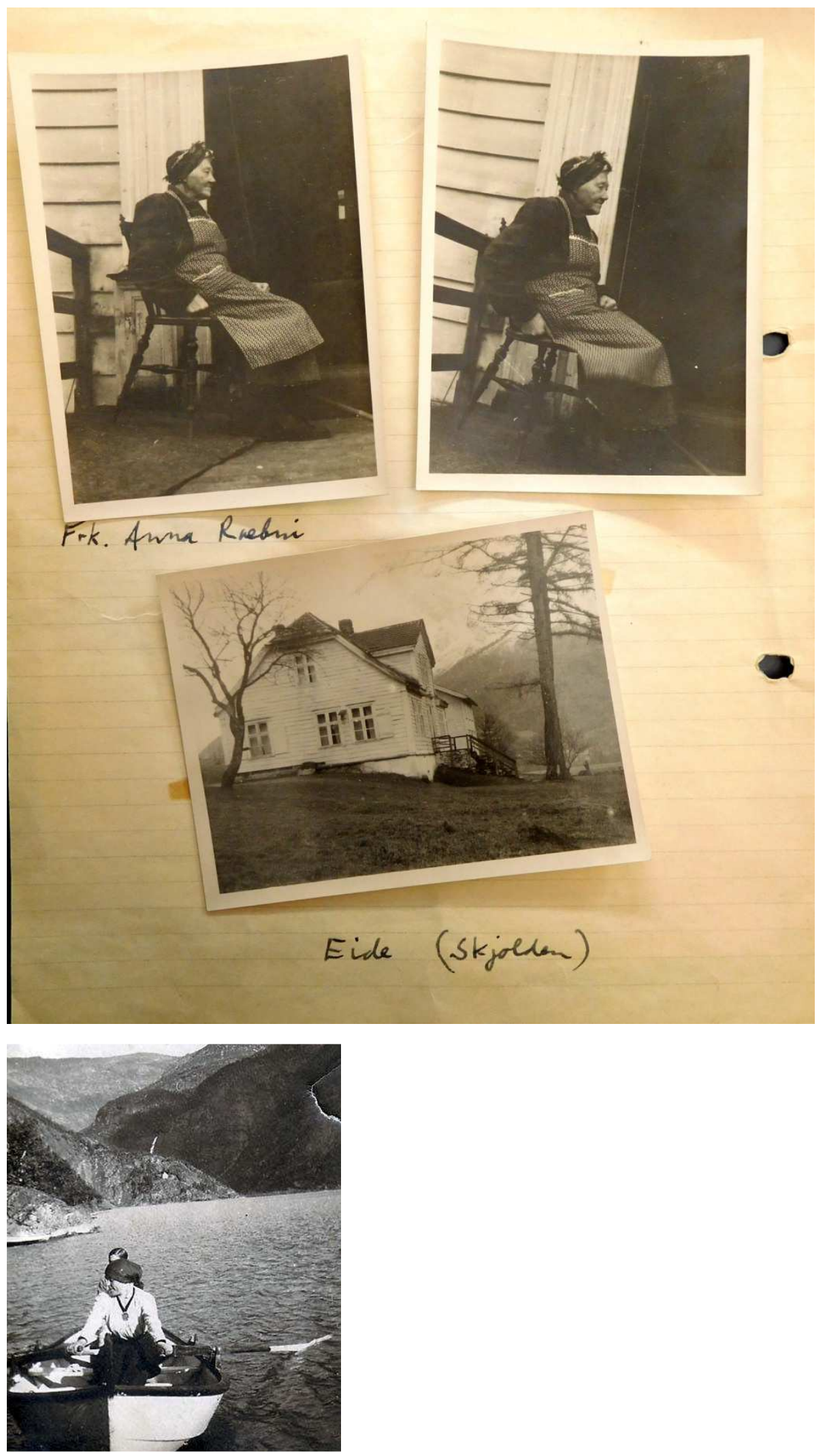

50. Álbum personal de Wittgenstein, fotografías de Anna Rebni ya con unos 80 años, en la granja Eide, octubre 1950

51. Dos mujeres reman en el lago Eidsvatnet. Al fondo se ve la casa de Wittgenstein. Fotografía de 1920-1930: ¿Son Anna Rebni y Anna Gutubø? 
sabemos que fue el mismo que realizó la casa de Halvard Drægni en Skjolden y la fábrica de zumos y conservas de fruta, en 1919, en Leikanger/Hermansverk, a $74 \mathrm{~km}$ de Skjolden hacia el sur por el fiordo.

Cabe la posibilidad de que en algún archivo haya documentación de la casa de Wittgenstein, planos, albaranes, quién sabe, por el momento qué podemos no conocer.

Durante la Segunda Guerra Mundial, la casa del lago fue visitada por grupos de Boy Scouts ${ }^{33}$, durante un tiempo en que reunirse estaba perseguido, los nazis prohibieron en Noruega el movimiento Scout en otoño de 1941. Vatne refiere estas visitas a Connearn en 2009. Por desgracia no ha habido éxito en encontrar a ninguno de aquellos visitantes a la casa de Wittgenstein:

«Vatne told me that during WW2 many people went to the house, including the boyscouts. You could talk there away from German ears.» ${ }^{34}$

Nadie parece, siquiera McGuinness, que entrevistara a Anna Rebni (18691970), antes de fallecer. Esta longeva profesora de inglés con la que Wittgenstein tuvo una amistad a veces más que tormentosa, fue un apoyo constante para el austríaco en sus visitas a Skjolden -también le proporcionaba leche y huevos de su granja-, quizá escribiera un diario. Su ayudante en la granja, Anna Gutubø (1920-2008? $)^{35}$, visitó la casa de Wittgenstein durante la estancia de 1936-1937 acompañando a Anna Rebni. En un artículo publicado en el suplemento cultural del periódico noruego Dagbladet, encontramos un testimonio de aquella visita:

«[...]At han kunne finne på å bygge der, nei, det er no heilt tullete, sukker Anna Gutubø (80). Hun var der på besøk - og fikk te og kjeks.

Vi var ikke sikre på om han var en tulling eller en skarping. Men ein ekte djuping, det var han, veit du.

Jeg husker en peis og et langbord, mange bøker og skrivesaker. Ingen visste hvor klok han var. Ikke før etterpå.[...]»36

\footnotetext{
${ }^{33}$ El movimiento Escolta en Noruega se fundó en 1911: http://www.slettebo.no/graphics/Scouting-Norway.pdf

${ }^{34}$ Correspondencia electrónica de D. Connearn, 21.03.2015

35 Parece que es la misma persona a la que D. Connearn hace referencia en correspondencia electrónica, 27.03.2015 «The manager of the hutcamping site told me that his grandmother used to help out Anna Rebni, and often went up to the W house. Maybe Anna R helped to make sure it was looked after. She died the year before he mentioned this (09).»

${ }^{36}$ Traducción del noruego: «El quiso encontrarla allí [la soledad], y no es del todo descabellado, asegura Anna Gutubø (80). Ella estuvo allí en una visita y tomó té y galletas. No estábamos seguros de si era un lunático o alguien muy listo. Pero era un filósofo, ya sabes. Me acuerdo de una chimenea y de una mesa larga, un montón de libros y papeles para escribir. Nadie sabía lo sabio que era. No hasta más tarde.» En Tone Rønning, Wittgenstein vare in djuping, Dagbladet, 09.08.2000, Kultur, http:// www.dagbladet.no/kultur/ 2000 /08 / 09 /214603.html
} 

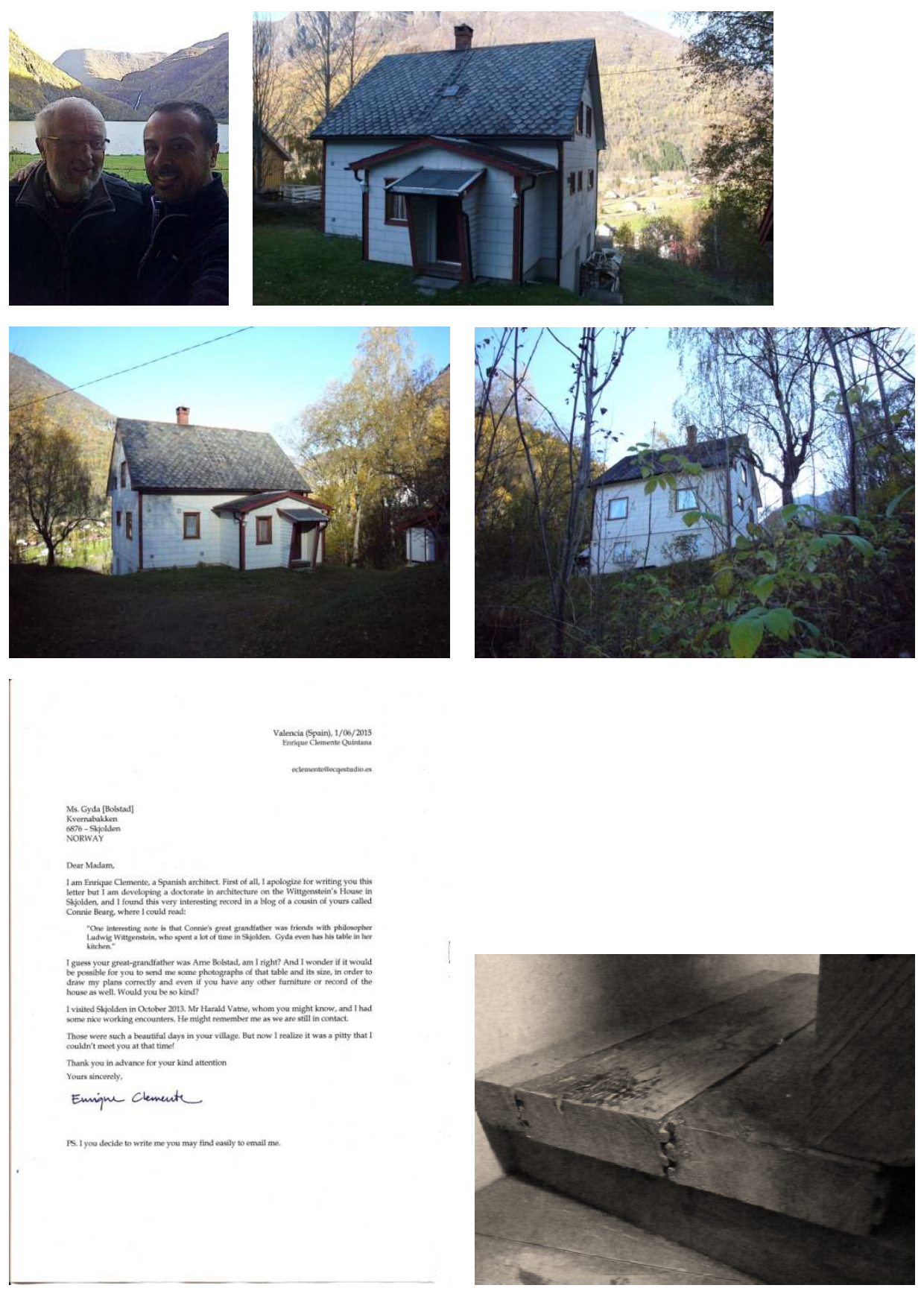

52. Conversación con Harald Vatne, Skjolden 10.10.2013 | 53. Casa de Gunnar Bolstad, Skjolden 12.10.2013

54-55. Casa de Gunnar Bolstad, Skjolden 12.10.2013

56. Carta a Gyda Bolstad, 01.06.2015, solicitando algún dato de la mesa original de Wittgenstein que conserva en su casa | 57 . Material original en el sótano de la casa de Gunnar Bolstad (madera reutilizada como peldañeado) 
Tenemos la absoluta certeza de que existe información a la que durante la fase de investigación de esta tesis no se ha tenido acceso. La principal, como se ha expuesto ya es la imposibilidad de tener libre acceso a la casa de Gunnar Bolstad, ni a las fotografías de familia ¿quién no fotografiaría la construcción de su propia casa? Multitud de datos quedan por ser esclarecidos pero como resulta evidente la limitación de este trabajo fijará sólo una parte del contenido. 


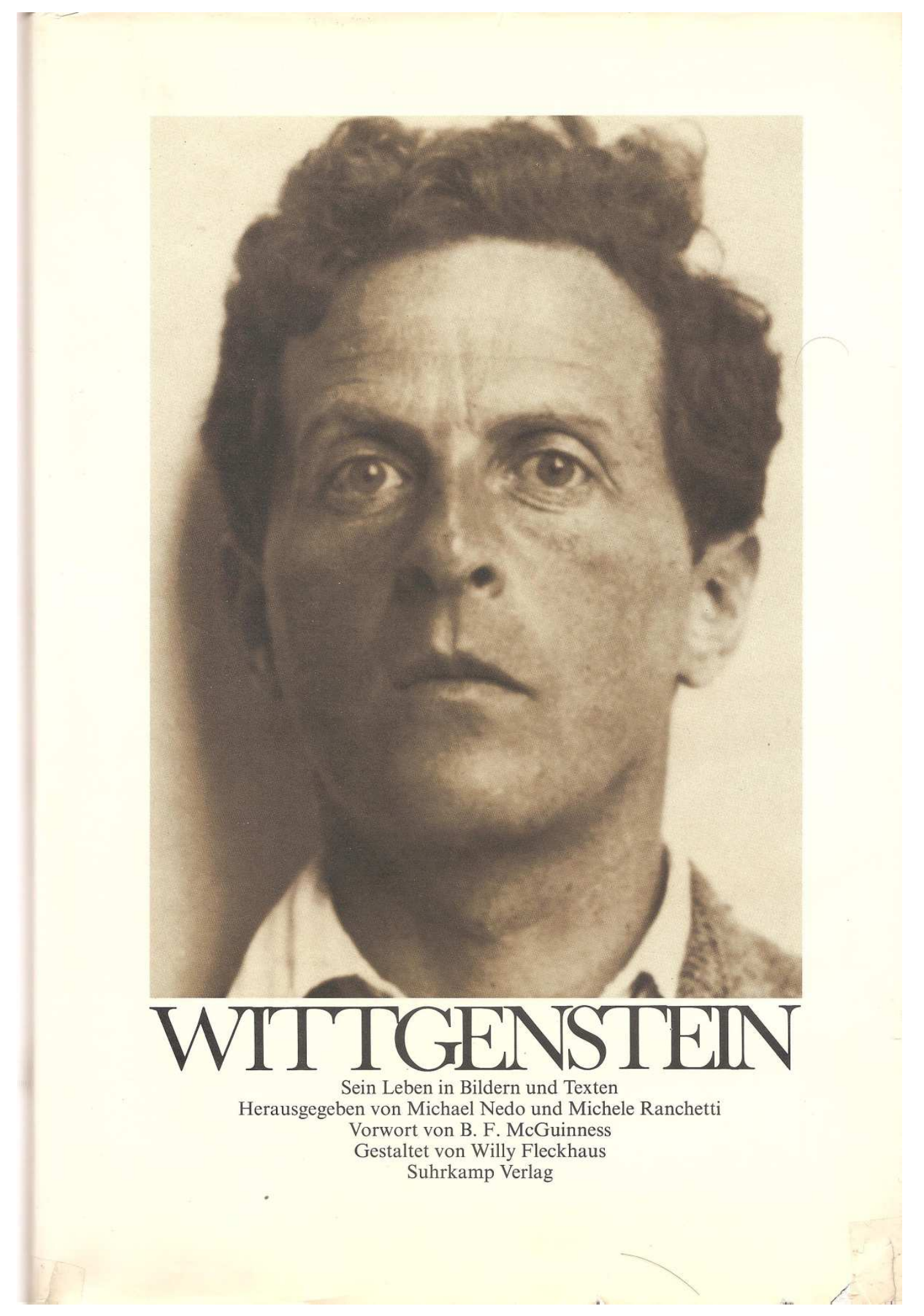

58. Michael Nedo \& Michele Ranchetti (Eds.), Wittgenstein, Sein Leben in Bildern und Texten, 1983. Ejemplar obtenido no sin dificultad en un anticuario de Munich 
Wittgenstein era un gran aficionado a la fotografía. Conservó durante toda su vida adulta la costumbre de coleccionar en cuadernos de bolsillo, de hojas rayadas, imágenes de lugares y sobre todo de personas, en la mayoría de los casos eran imágenes de muy pequeño tamaño, incluso del tamaño de los contactos de revelado. Lo hacía con un sistema compositivo propio, agrupando por familias de significado.

Wittgenstein mantuvo toda su vida una intensa e interesante relación con la fotografía. Cuando construyó para su hermana la casa de Viena, guardó una serie de fotografías en su cuaderno, tomadas en 1929. Para realizar esas imágenes recurrió a un artista y fotógrafo profesional, amigo de la familia, Moritz Nähr (1849-1945) que tuvo que soportar las meticulosas instrucciones que impuso Wittgenstein para cada una de las fotografías. ${ }^{37}$

La primera vez que se publicaron las -hoy ya ubicuas en Internetfotografías en blanco y negro de Ben Richards de 1950 fue en la extensa, meticulosa y costosa biografía en imágenes de Michael Nedo y Michele Ranchetti, Wittgenstein. Sein Leben in Bildern und Texten, publicada por Suhrkamp Verlag en Frankfurt am Main, 1983. Se trata de un volumen de $30 \mathrm{x}$ 21 x 4 cm y 394 páginas. La biografía gráfica se desarrolla en 490 imágenes, la mayor parte de ellas inéditas ${ }^{38}$ en aquella fecha, fruto de la labor compilatoria historiográfica de Nedo y Ranchetti, que más tarde formarían parte del Wittgenstein Archive Cambridge, dirigido por Nedo. Las fotografías no se describen sino que sirven, cronológicamente y agrupadas por parecidos de familia, como soporte de textos cortos, en general extractos de cartas o diarios.

\footnotetext{
${ }^{37}$ La relación de Wittgenstein con la fotografía supondría un extenso ensayo que no tiene cabida en este documento. Wittgenstein no sólo estaba interesado en la fotografía como documento gráfico sino como aplicación como método filosófico para encontrar la claridad expresando lo borroso con la fotografía: una fotografía es "una posibilidad" pero no "todas las posibilidades".

${ }^{38}$ En fechas recientes, Nedo ha publicado una especie de $2^{a}$ edición del mismo volumen con una calidad superior de impresión en un formato similar: «'ve just published a biography on Wittgenstein with some hitherto unknown information about Wittgenstein's house in Skjolden: "Wittgenstein - Ein biographisches Album", C. H. Beck Munich, it will come into the bookshops end of August». En correspondencia electrónica con M. Nedo, 01.08.2012
} 

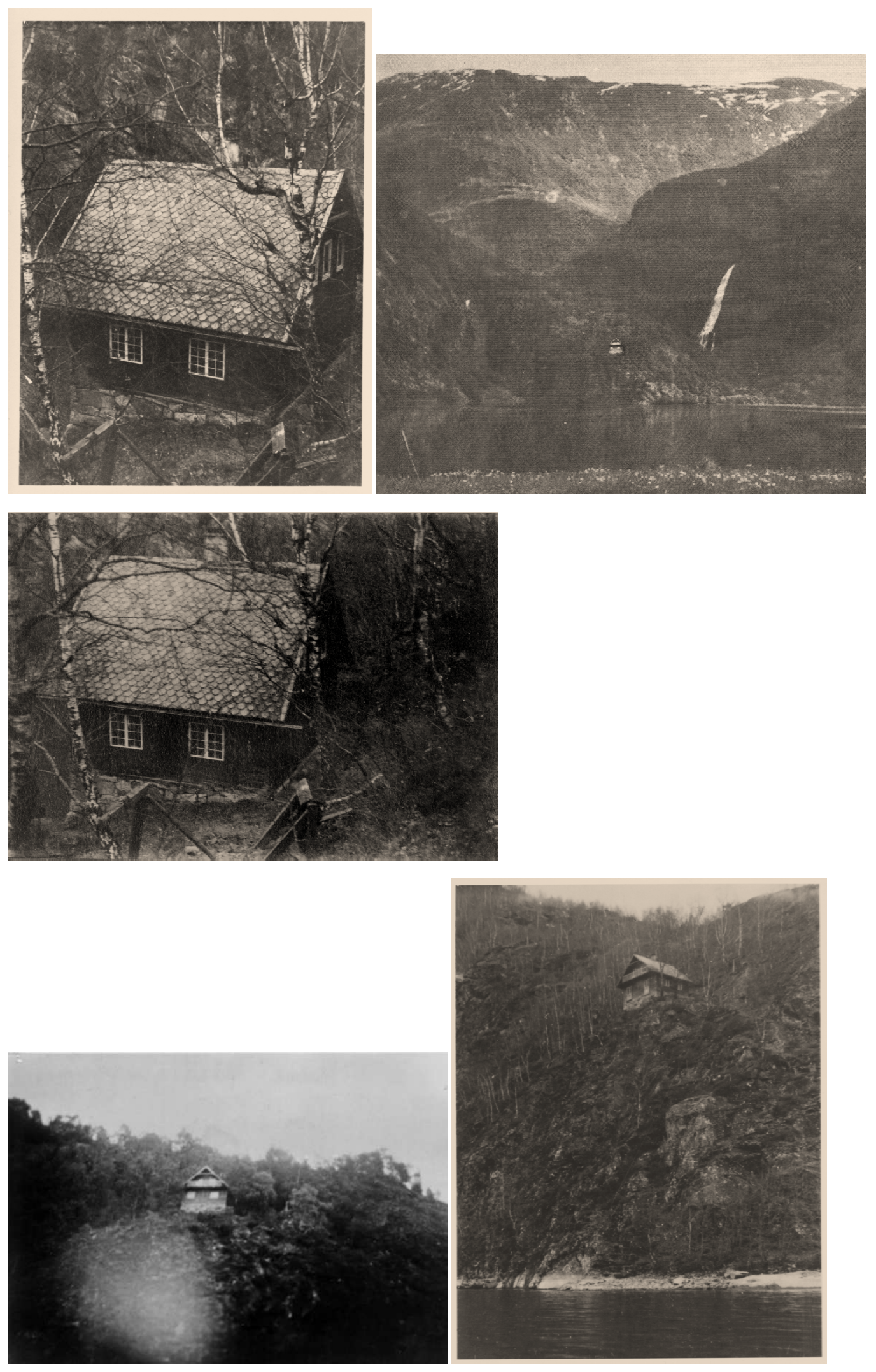

59-63. Fotografías Casa de Wittgenstein en Skjolden: $n^{0} 2152, n^{0} 787, n^{0} 514, n^{0} 656, n^{0} 519$ del Wittgenstein Archive Cambridge, Michael Nedo 
Las cuatro imágenes tomadas en octubre de 1950 y que son la base sobre la que se ha trazado toda la investigación y se ha desarrollado el proyecto son las siguientes:

Bildbuchnummer: 149/150 Wittgensteins Haus in Norwegen, p. 112-113

Bildbuchnummer: 151 Skizze zur Lage des Hauses in einem Brief an Moore vom Oktober 1936 p. 113

Bildbuchnummer: 402 Wittgensteins Haus in Norwegen, p. 285

Bildbuchnummer: 410 Wittgensteins Hütte, p. 290

Bildbuchnummer: 477 Wittgensteins Haus in Norwegen, p. 338

Debemos tener en cuenta que las imágenes numeradas como 149 y 402 son la misma toma con un ligero cambio de ángulo, la 149 en vertical y la 402 en horizontal. Además la imagen 151, el Skizze se refiere al boceto que Wittgenstein envió a Moore por carta desde Skjolden en 1936 para indicarle el emplazamiento correcto.

Por tanto, sólo disponemos de 2-3 imágenes que nos han podido aportar información constructiva sobre la casa de Wittgenstein, las numeradas como $149-402$ y 477.

El Dr. Michael Nedo puso amablemente, a disposición del que escribe, una copia escaneada de las imágenes en 2012 , con el fin de trabajar con ellas en esta investigación:

«Dear Enrique Clemente-Quintana,

As promised I attach the Ben Richard's photos of Wittgenstein's house in Skjolden, understanding that you will only use them for your $\mathrm{PhD}$-work.

Best wishes,

Michael Nedo

(Director of the Wittgenstein Archive Cambridge)»39

Las fotografías originales se han podido consultar posteriormente en el mismo Wittgenstein Archive Cambridge (WAC). Se trata de fotografías de reducido tamaño y baja calidad, realizadas probablemente con una cámara

${ }^{39}$ Correspondencia electrónica de M. Nedo, 01.08.2012 

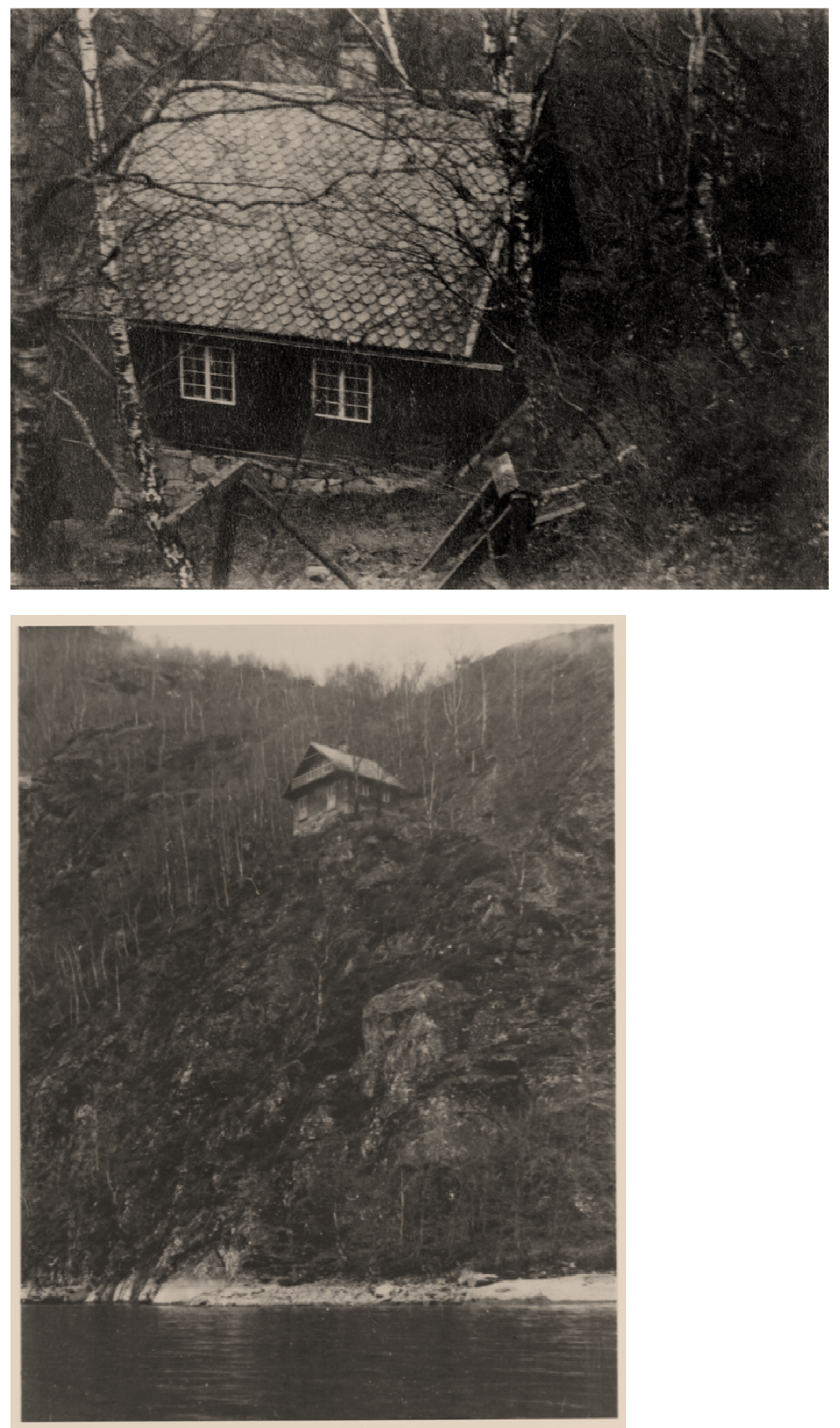

64. Fotografía n0 514 Wittgensteins Blockhaus in Norwegen, $95 \times 68$ mm, Wittgenstein Archive Cambridge. Escala 1:1 65. Fotografía n ${ }^{0} 519$ Wittgensteins Blockhaus in Norwegen, $68 \times 95$ mm. Wittgenstein Archive Cambridge. Escala 1:1 
fotográfica barata, similar a las que compraba Wittgenstein y rememora Fania Pascal en su semblanza sobre el filósofo en 1969:

«When we were eating the thick sandwiches Wittgenstein praised Woolworth's merchandise. He had bought a camera there in components each at $6 \mathrm{~d}$, total price two shillings -an excellent instrument!» ${ }^{40}$

El WAC dispone de un fondo documental de 2236 imágenes digitalizadas en alta calidad (600pp), fotografías y algún documento sobre Wittgenstein y su entorno familiar y de amistades. La codificación de las mismas será la numeración que vamos a seguir en adelante cuando hagamos referencia a alguna de las imágenes. Así, las tres fotografías que hemos utilizado como material de trabajo se nombran como sigue:

\section{4_Wittgensteins Blockhaus in Norwegen}

Corresponde a la vista lateral de la casa, en octubre de 1950. La fotografía se realizó en posición horizontal. Hay dos copias en dos hojas diferentes. Se han conservado sujetas con presillas de cinta adhesiva en un álbum propiedad de Ben Richards y cedidas a Michael Nedo por aquel. En la parte superior de la hoja aparece la inscripción «Norway, October 1950. Skjolden Sognefjord» y más abajo «L.W's house». El tamaño de la copia mayor es 68 x $95 \mathrm{~mm}$ y la menor 60 x $83 \mathrm{~mm}$. Esta última aparece en otra hoja del álbum de Richards, junto a una fotografía de la casa de Johannes Bolstad y una segunda copia de la fotografía 519.

\section{9_ Wittgensteins Blockhaus in Norwegen}

Corresponde a la vista desde el lago, cerca de la orilla, octubre 1950. La fotografía se realizó en posición vertical. Se han conservado dos copias, en hojas distintas. El tamaño de una de ellas es 68 x $95 \mathrm{~mm}$ y otra de 60 x $83 \mathrm{~mm}$.

Por supuesto, otras fotografías han formado parte de la investigación y han servido para documentar algún aspecto historiográfico. La mayor parte de ellas

\footnotetext{
${ }^{40}$ Rhees, op. cit., p. 42
} 

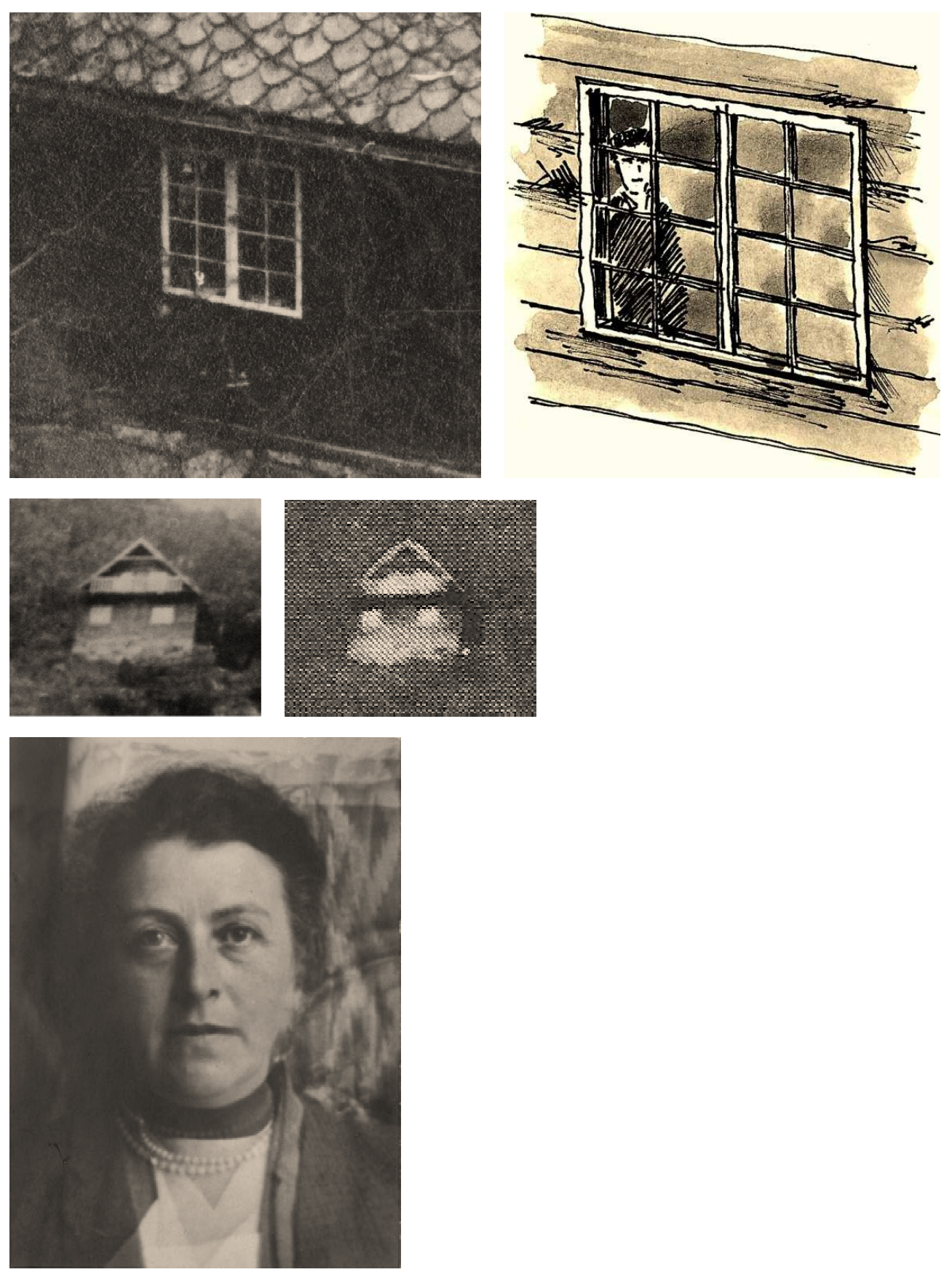

66-67. Wittgenstein en la ventana, detalle fotografía n² 2152, Ben Richards, octubre 1950 y cuaderno notas.

68. Detalle fotografía $n^{0} 656$, vista desde el lago de la casa | 69. Detalle muy ampliado de la fotografía $n^{0} 787$, se aprecia la manipulación de la imagen insertando la misma vista de la $n^{0} 656$. El motivo es que probablemente con la perspectiva natural en la que la casa se orienta hacia el nooeste, quedaría prácticamente oculta por los abedules laterales

70. Fotomontaje de Wittgenstein con la ayuda del fotógrafo Moritz Nähr, realizado en los años 20, superpone los retratos de sus tres hermanas: Helene, Hermine y Margaret y el suyo propio 
están catalogadas en el WAC, otras las hemos localizado en el Fylkesarkivet i Sogn og Fjordane en Leikanger, que siguen siendo inéditas y en el Norsk Folkemuseum de Bygdø en Oslo, en su sección digitalmuseum -se aportan como documentación anexa a la tesis-pero únicamente de aquellas 3 imágenes hemos podido obtener información sobre la construcción de la casa.

El trabajo dedicado al estudio minucioso de las imágenes ha sido de incontables horas. Se han estudiado las imágenes originales en Cambridge y se han utilizado herramientas informáticas de tratamiento de imagen sobre las fotografías escaneadas y refotografiadas. Se han modificado contrastes y brillos para tratar de obtener el mayor nivel de detalle. Sin embargo la calidad original de las imágenes y su reducido tamaño no han ofrecido más que información parcial, pero la recogida en este proyecto ha tratado de ser absolutamente rigurosa con los datos métricos y constructivos que de ellas se han derivado.

Tras estos tres años de observación minuciosa, milímetro a milímetro y sin que nadie antes hubiera reparado en ello, podemos tener la certeza de que las fotografías fueron realizadas por Ben Richards y que Wittgenstein no le acompañaba, al menos en una de ellas, pues hemos podido localizar su silueta tras el cristal de una de las ventanas de la fachada suroeste. Aunque esto no deje de ser una mera anécdota e interese -y sólo relativamente- a los estudiosos incondicionales de Wittgenstein, no deja de ser un hallazgo, una información inédita.

«I think he [Nedo] will be very surprised, and very pleased to see $\mathrm{W}$ in the window. Noone has ever mentioned this before. That is a scoop. Well done!

But why can't we see the bloody wall beams so clearly?! (Bloody was the favourite expletive)» 41

Además, la Bildbuchnummer 150 Wittgensteins Haus in Norwegen, p. 113, que se corresponde con el código 787 del WAC, está manipulada. Hemos podido comprobar que Wittgenstein utilizó la vista de la casa de la fotografía 656 (WAC). Esto no debe sorprendernos, pues ya en los años 20, Wittgenstein hizo

\footnotetext{
${ }^{41}$ Correspondencia electrónica de D. Connearn, 30.03.2015
} 

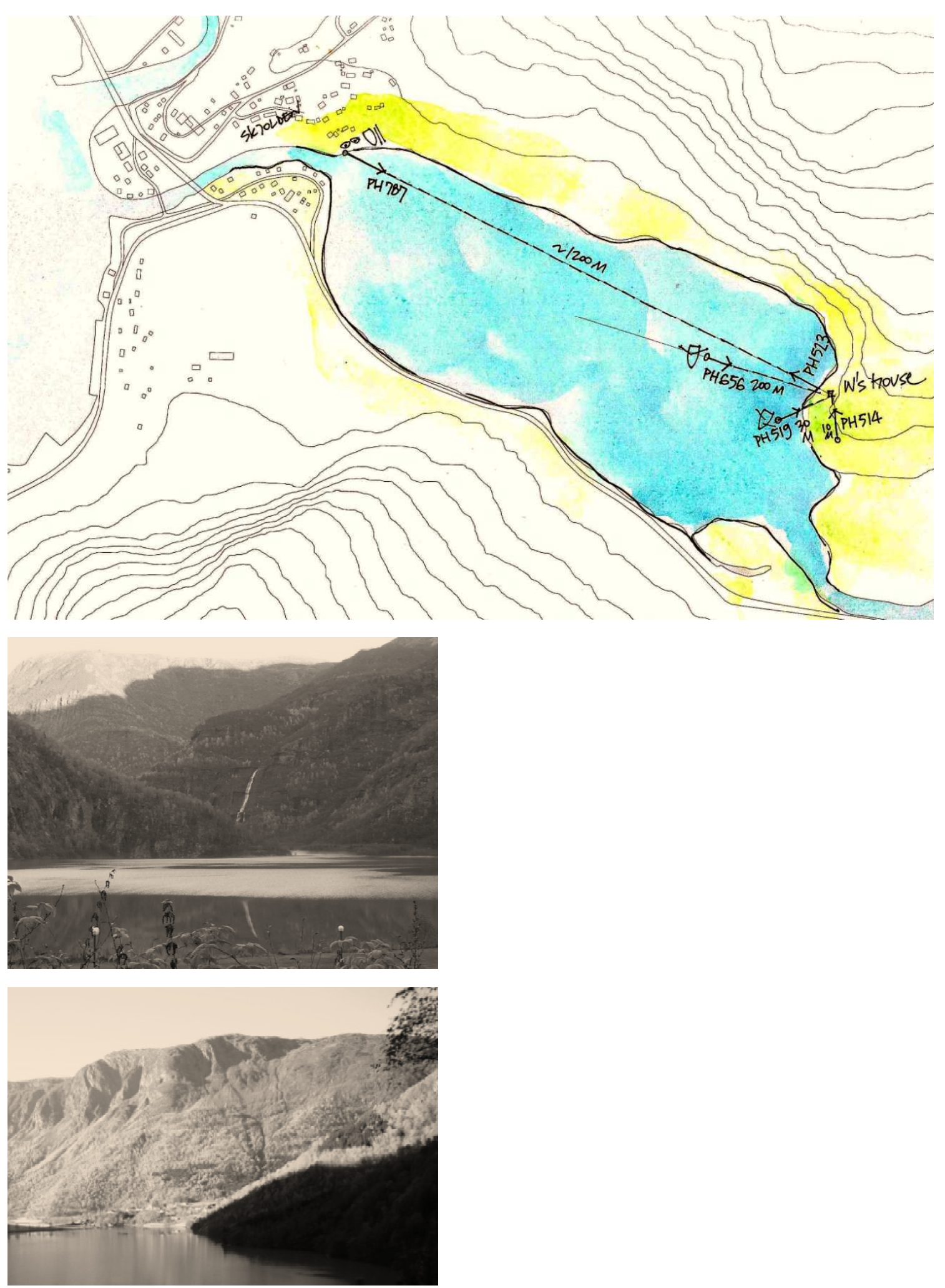

71. Trávelin de acercamiento dinámico a la casa de Wittgenstein: partiendo de la orilla opuesta del lago, dos imágenes intermedias a diferentes distancias de la casa y una finalmente desde la propia colina que alberga la construcción. Para terminar, la vista desde la casa hacia el pueblo.

72. Imagen equivalente a la $n^{0} 787$, tomada esta en octubre 2013

73. Imagen equivalente a la $n^{0} 523$ (cfr. Imagen $n^{0} 11$ de esta tesis), tomada esta en octubre 2013 
experimentos de composición de negativos con la ayuda de Moritz Nähr, siguiendo los trabajos del antropólogo y fundador del movimiento eugenésico Francis Galton. Wittgenstein compone un rostro con retratos de sus tres hermanas y el suyo propio. Así, la manipulación del negativo de Skjolden con el fin que hemos interpretado del recorrido, no es en absoluto descabellado. ${ }^{42}$

La serie completa de fotografías de 1950 siguen un discurso, una manera, como se ha dicho, de entender por Wittgenstein su casa y el paisaje. El criterio con que están hechas muestra sin duda los intereses en la imagen de Wittgenstein. La promenade dans le paysage se inicia en la orilla oeste del lago, donde se encuentran los embarcaderos de los botes de remos y termina con las vistas desde la propia casa hacia el pueblo y el fiordo:

1. Imagen 787. Vista de la casa desde la orilla del lago, se aprecia en la parte inferior la propia orilla. La distancia hasta la casa es de 1200 m. Esta aparece formando parte de la montaña, del paisaje.

2. Imagen 656. Desde el agua, fotografía tomada a bordo del un bote de remos. La distancia hasta la casa es de unos 100-200 m.

3. Imagen 519. Vista desde la barca. Cerca de la orilla, situándose probablemente en paralelo a la orilla. La distancia a la que está tomada la fotografía es de unos $40 \mathrm{~m}$ hasta las rocas. Se aprecia la posición casi dramática de la casa en un escarpe de la ladera.

4. Imagen 514. La fotografía se realiza desde la ladera donde se encuentra la polea que utilizaba Wittgenstein para izar agua desde el lago. Ese punto está a unos 10 $\mathrm{m}$ de altura respecto a la cota de acceso a la casa. La línea del horizonte se sitúa así prácticamente en la cumbrera de la casa. El fotógrafo está a unos $8 \mathrm{~m}$ de la casa. De las dos tomas existentes en una aparece el habitante de la casa, Wittgenstein, en la otra no.

5. Imagen 523. El recorrido visual termina en la casa, mirando hacia el fiordo. El escenario externo visto a través de los ojos -la cámara- de Wittgenstein. ${ }^{43}$

\footnotetext{
${ }^{42}$ Michael Nedo preparó en 2011 una exposición sobre la fotografía y Wittgenstein: «Wittgenstein's camera» en Cambridge.

${ }^{43}$ Aunque no vayamos a profundizar en ello, queremos puntualizar que las fotografías no fueron tomadas en una única sesión y probablemente en jornadas diferentes: las contraventanas de madera de planta baja están cerradas en las dos primeras imágenes y abatidas en la tercera, inevitablemente suponen al menos dos salidas con la barca. El hecho de haber «preparado» las fotografías refuerza su intencionalidad.
} 

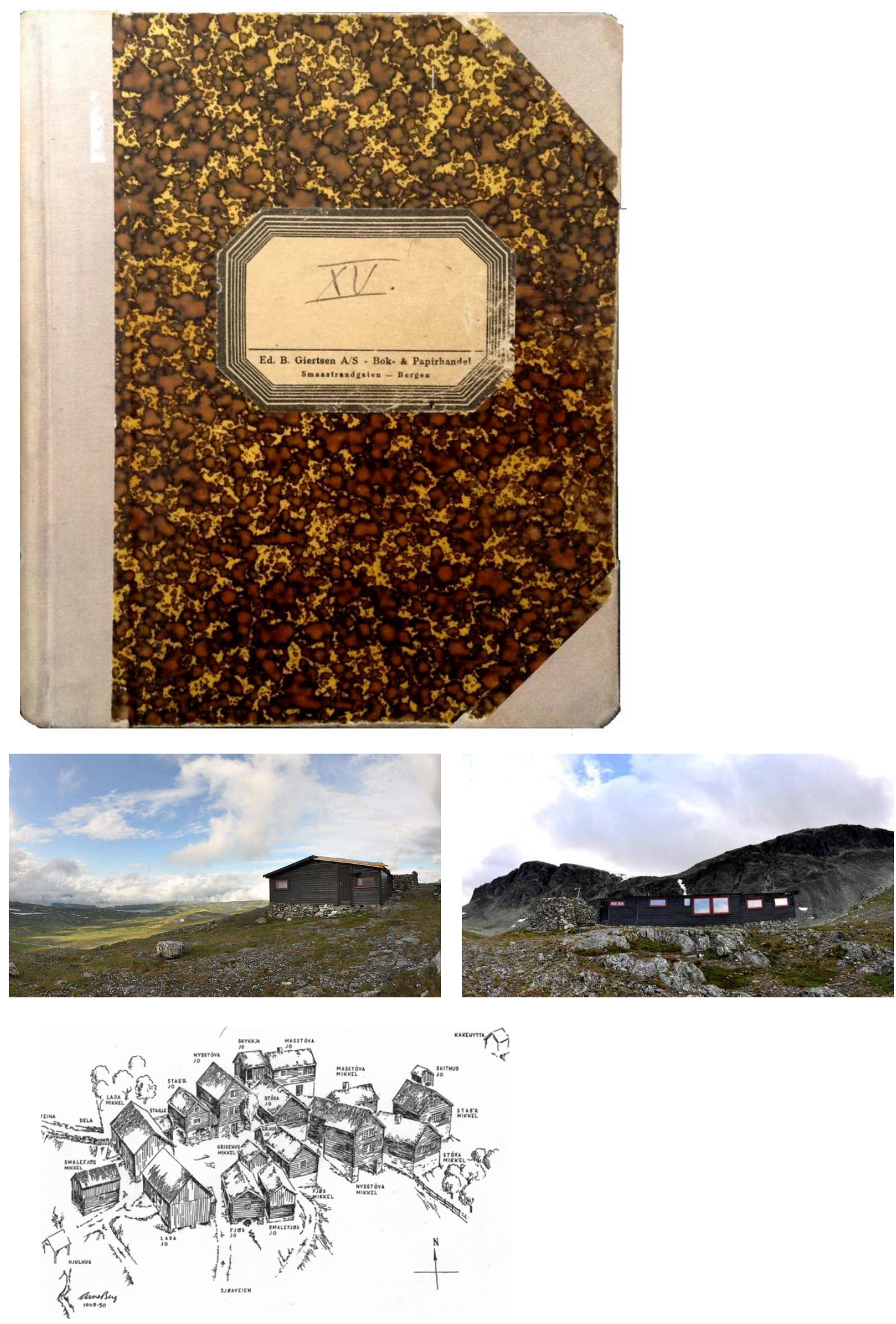

74. Cuaderno de manuscritos MS119, escrito en Noruega, $18 \times 22 \mathrm{~cm} 148$ hojas 24.09 .1937 al 19.11 1937. Wren Library. Cambridge, abril 2015 75-76. Cabaña de Arne Naess en Tvergastein

77. Granjas tradicionales en Sogn og Fjordane, región a la que pertenece Skjolden, en Arne Berg, Norske Gardstun, 1968 
El interés de esta investigación no es tratar de explorar gratuitamente las vivencias de Wittgenstein, sino entresacar pequeños paquetes de información que nos ayuden a proyectar su casa. Son muy pocos los testimonios que nos han llegado y quizá el entender cómo la ocupaba nos permitiría al menos pergeñar un programa de necesidades. La idea de desmenuzar los sentimientos de Wittgenstein, tan explícitamente expresados en sus diarios, ha sido siempre motivo de conflicto moral entre sus biógrafos. Cuando Paul Engelmann decide publicar las cartas que intercambió con el filósofo en 1965, muestra sus reticencias ante la imposibilidad de ser objetivo y en contestación a sus dudas, Elisabeth Anscombe - una de las fiduciarias del legado de Wittgenstein- le dice que efectivamente "si presionando un botón pudiera hacer que nadie se interesara por la vida personal de Wittgenstein, lo habría hecho».

Entre las más de 20000 páginas de los manuscritos del Nachlass de Ludwig Wittgenstein, no hay una sola descripción de su casa en la orilla del lago Eidsvatnet.

Así las cosas, un método de acercar los extremos del desconocimiento absoluto y el dibujo de nuestro proyecto puede ser, siguiendo a Monteys y Fuertes ${ }^{44}$, empezar por hacer vivienda en lugar de construirla. Esto lo haremos después. Mostrar el uso de la arquitectura es una forma previa de construirla, es la conversación que se da entre el arquitecto y el cliente.

Empezaremos por decir que en esta investigación hacemos uso reiterado y -salvo desliz o premeditación- exclusivamente de la palabra casa en lugar de cabaña. En castellano, la palabra cabaña adquiere connotaciones que no parecen concordar con el proyecto que aquí desarrollamos. El DRAE la define como «construcción rústica pequeña y tosca, de materiales pobres, generalmente palos entretejidos con cañas, y cubierta de ramas, destinada a refugio o vivienda de

${ }^{44}$ Xavier Monteys \& Pere Fuertes, Casa collage. Un ensayo sobre la arquitectura de la casa (Barcelona: Gustavo Gili, 2001) 


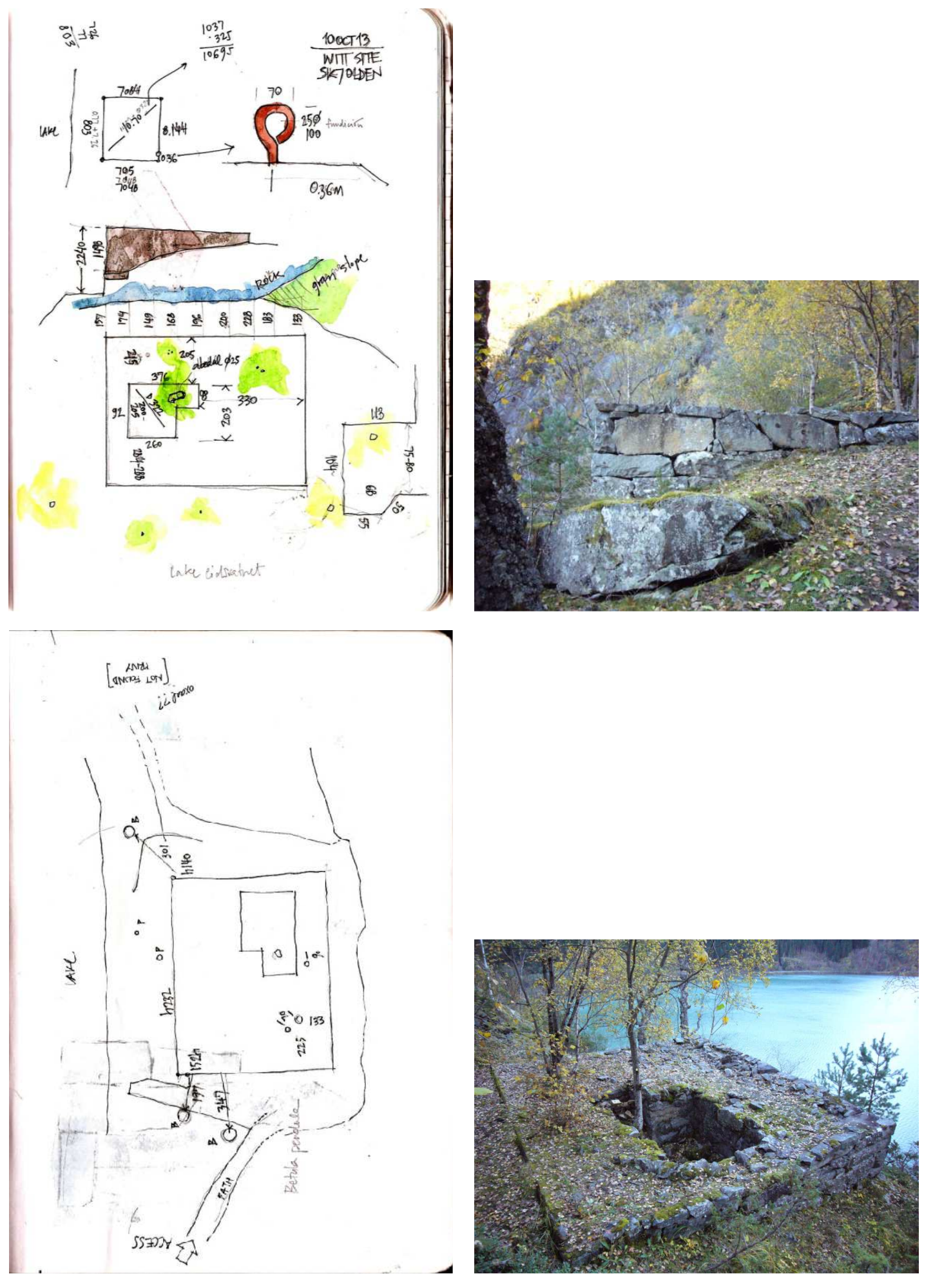

78. Toma de datos del plinto, 10.10.2013. Medidas generales | 79. Fotografía del plinto desde el sendero de acceso

80. Toma de datos del plinto, 10.10.2013. Situación del arbolado principal circundante | 81. Fotografía del plinto desde el norte 
pastores, pescadores y gente humilde. $\gg^{45}$ Ninguna de las cualidades intrínsecas a tal definición es aplicable a la casa de Wittgenstein en Skjolden. El propio Wittgenstein se refería a ella como house y Haus y no como hut. Y sin embargo el uso de la palabra cabaña sí parece que ha resultado significativo en toda la literatura secundaria sobre Wittgenstein. Los noruegos, prefieren la palabra hytte que precisamente traduciríamos al inglés como cottage o cabin y tampoco como hut, puesto que hut no recrea las connotaciones de nostalgia de lo auténtico que ellos aplican a sus refugios en la naturaleza.

La casa no era pequeña, Wittgenstein la define así, en carta a Russell, como se ha dicho unas líneas más arriba, salvo que Wittgenstein quisiera mostrar cierta afectación ante su mentor, abundando en la idea de refugio y exilio o quizá su concepción de escala se referenciaba a sus residencias familiares. Nos inclinamos a pensar lo primero, no tanto por la afectación, que sería contraria al ansia de honestidad que reguló la vida de Wittgenstein, pero sí por lo segundo, esto es el exilio de la vida cotidiana. Analizando reiteradamente las fotografías de la casa, la psicología de la percepción de la imagen de la casa, pertrechada en la escarpada ladera destila una fragilidad coherente con la escala de lo reducido. En cualquier caso, probablemente la literatura se haya ocupado de fijar como pequeña una casa que no lo era. La confusión con cabaña deriva de ello, sin duda.

El plinto sobre el que se apoyaba la casa ocupa 7,04 x $8,14 \mathrm{~m}$ y se distribuía en dos niveles, con una superficie útil total era de unos $102 \mathrm{~m}^{2}$.

La casa parecía proyectada para albergar cómodamente la vida de Wittgenstein y de algún invitado. Mientras planeaba su retiro intelectual en Noruega en la primavera de 1914 se encontraba en un estado de gran agitación nerviosa. Tenía la certeza de que iba a morir en pocos meses. Aunque con los años se moderó su carácter en ese sentido, siempre le acompañó la idea de la muerte, casi como si de un rasgo familiar se tratara. En este contexto mental, Wittgenstein nunca proyectó la casa para estar completamente a solas.

45 Diccionario de la Real Academia Española de la Lengua. (Avance de la $23^{\mathrm{a}} \mathrm{ed}$.) 

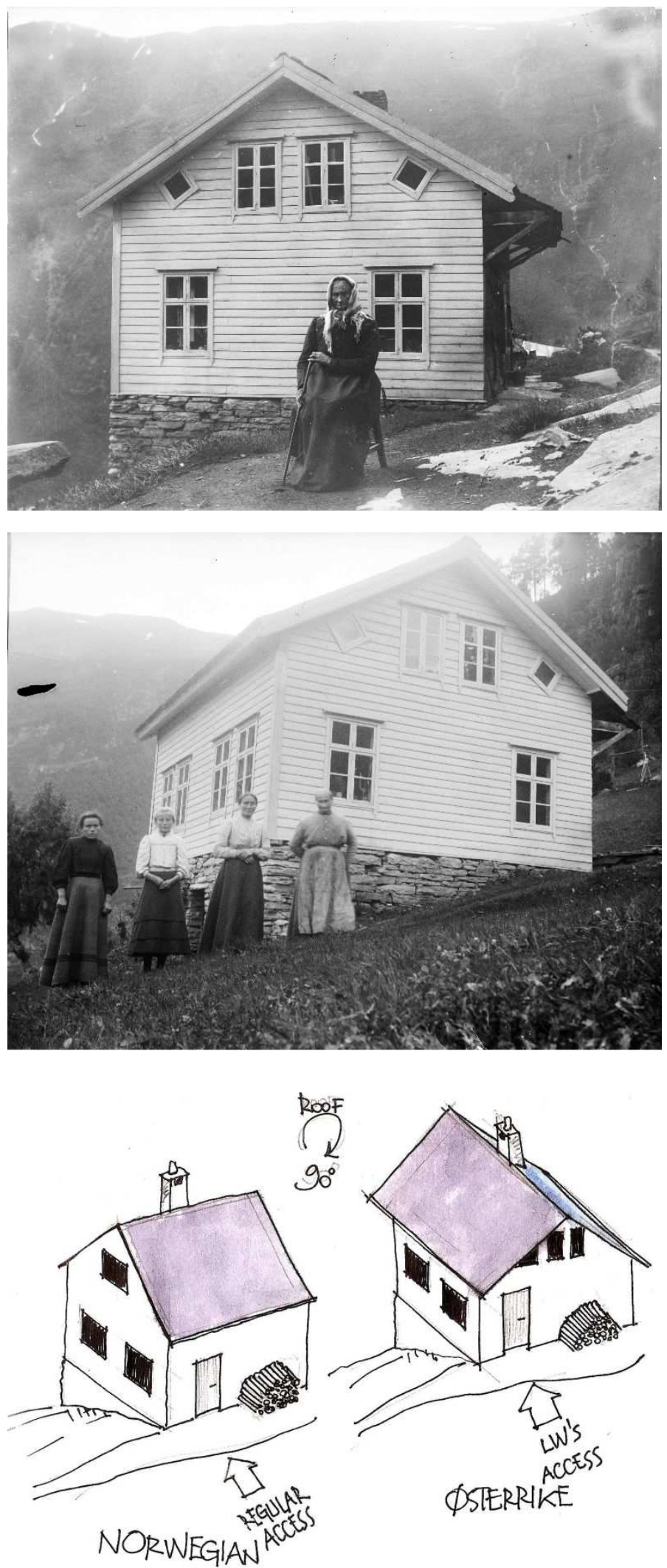

82-83. Casa de la familia Kolstad en Luster, 1910-1914. De volumetría similar a la de Witrtgenstein, servía a una familia completa. Obsérvese que el acceso y la orientación de la cubierta son exactamente opuestos a los de Wittgenstein.

84. Esquema de la diferencia entre la colocación tradicional noruega del acceso y la cubierta y la proyectada por Wittgenstein. 
En inglés existen dos palabras que se pueden traducir como soledad, solitude y loneliness. En Wittgenstein es difícil saber qué nivel de soledad pretendía, la primera, solitude define sin matices el estado de aislamiento hacia el exterior mientras que loneliness representa un conjunto de sentimientos rayanos en el abandono, premeditado o no, de los demás. Muchos creadores han buscado y disfrutado del romanticismo de Thoreau para sus retiros en el trabajo intelectual, pero Wittgenstein no podía pasar demasiado tiempo a solas, en muchas entradas de su diario personal, sobre todo durante los meses que pasó en Noruega en su casa entre 1936 y 1937, recoge su cobardía a estar solo en su casa, a su incapacidad de afrontar la loneliness.

Con esta premisa, el proyecto de Wittgenstein no lo planteó nunca como el refugio de un ermitaño. Las personas que le conocieron refieren que necesitaba constantemente un partner para escuchar. Aunque disfrutaba de la conversación, en muchas ocasiones simplemente requería la presencia del otro para hilvanar sus reflexiones ${ }^{46}$.

«Dear Mr Clemente,

I've just remembered that Mr Rudy Vrooman, who also provided me a number of important snapshot pictures of original details of the Wittgenstein House that were lost during its renovation, also traveled to Norway in his young years to find out about Wittgenstein's blockhouse (it was much larger than a cabin) in Skjolden and met the people W's left the house to. I suggest you to contact him as well.

His address is:

*

Bring him my cordial greetings,

Best regards,

Paul Wijdeveld

P.S.

The motto of my great-grand-uncle, H.Th. Wijdeveld, the Amsterdam School architect and friend of Frank Lloyd Wright, also was 'panta rhei'; the philosophy I am working on presently, based on the recent findings of neurocognitive science, can also be characterized by 'panta rhei' in the purest Heracleitian sense.. ${ }^{47}$

Tanto el profesor Wijdeveld como Michael Nedo utilizan la palabra blockhouse, Nedo en las fichas del catálogo del WAC, coinciden en juzgar la casa de Wittgenstein como algo más que una cabaña. Cuando, en contra de su propia

\footnotetext{
${ }^{46}$ En su primer año en Cambridge visitaba a Russell a cualquier hora de la tarde hasta bien entrada la noche. Muchos años después, ya en los años treinta a Fania Pascal o como recuerda en los cincuenta Oets Kolk Bouwsma refieren visitas intempestivas de Wittgenstein.

${ }^{47}$ Correspondencia electrónica de P. Wijdeveld, 11.09.2011.
} 

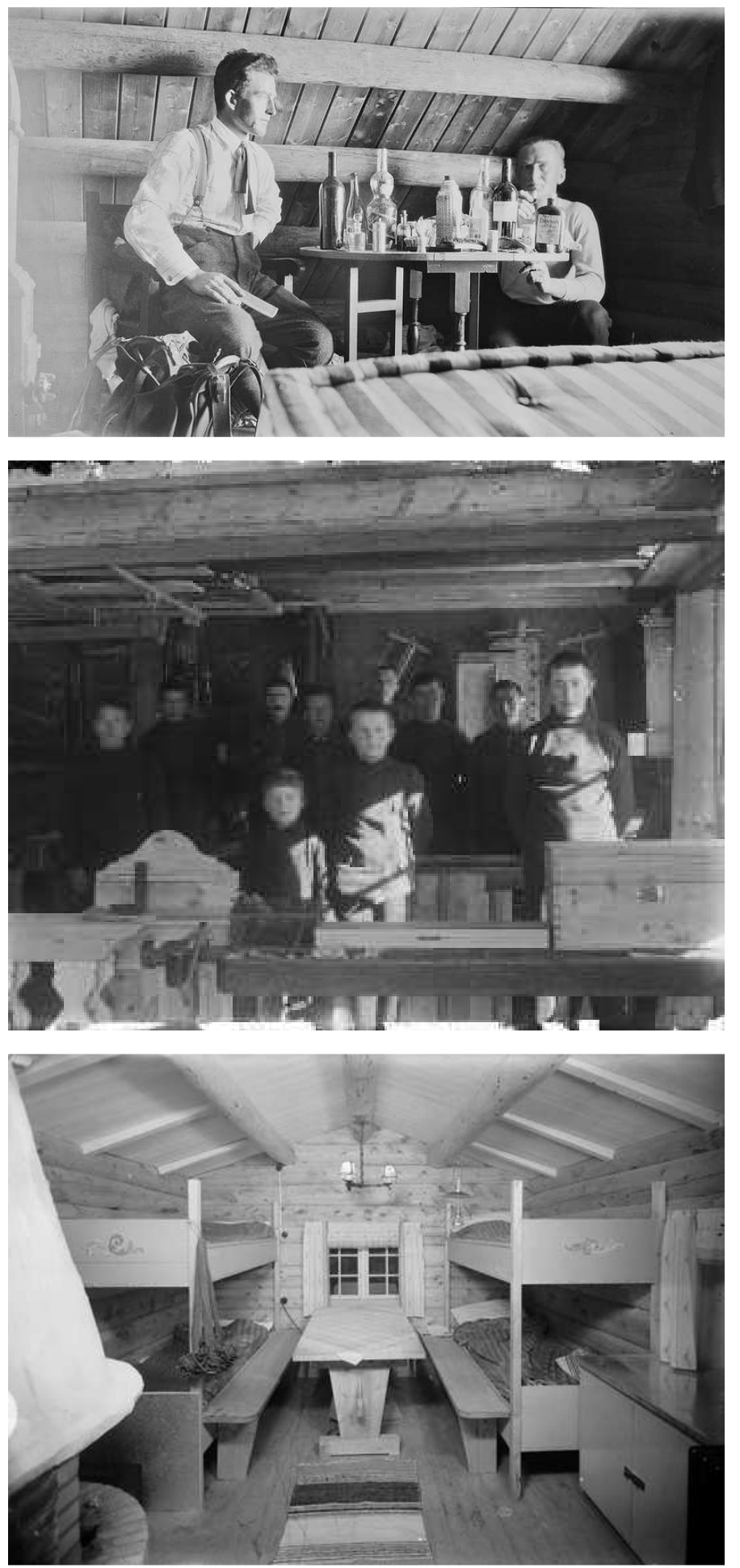

85. Interior de un ático bajo cubierta en noruega, 1910. Obsérvese la cubierta de correas Iongitudinales 86. Carpintería en Luster, 1912

87. Interior de un dormitorio vivienda tradicional noruega, 1939. Obsérvese la cubierta de correas Iongitudinales 
decisión de no volver a Noruega, visitó por primera vez su casa en el lago en agosto de 1921, lo hizo en compañía de Arvid Sjögren48; en la visita de 1931, con Marguerite Respinger y Gilbert Pattison; en 1936-37 recibió la visita de Francis Skinner y Hermann Hänsel y pasó una parte de su estancia en casa de Anna Rebni en la granja Eide, incapaz de vivir a solas en su propia casa. Finalmente, en 1950 visitó Skjolden con Ben Richards, pero al estar este aquejado de una bronquitis se alojaron en la granja Eide de Anna Rebni.

Cuando Wittgenstein partió hacia Austria a finales de junio de 1914, pretendía instalarse definitivamente en su casa del lago tras la pausa estival. McGuinness refiere ${ }^{49}$ que en su viaje de regreso a Noruega había planeado comprar los muebles para su casa en Kristiania -nombre de Oslo hasta 1925.

Sin embargo ya sabemos que Wittgenstein renunció a su casa en 1919, pensó en no volver jamás a Skjolden. Cedió la casa, terminada pero sin haberla podido ocupar ni amueblar a Arne Bolstad:

Arne Bolstad a Wittgenstein

Tarjeta postal

Skjolden, sin fecha [invierno 1914-1915]

«Thank you very much for the card you sent me. I am doing fine at present. The boat is is good order. Your house is now finished, and I wish you were now in Norway rather than in Austria.[...]»50

Bolstad utilizó la casa durante algunas temporadas en verano ${ }^{51}$ aunque parece que mantuvo siempre la sensación -así lo traslucen sus cartas a Wittgenstein -52 de que éste podría volver en cualquier momento a reclamar su casa. De las visitas que el filósofo realizó no se conserva ninguna comunicación sobre esta circunstancia, aunque en ese sentido Wittgenstein diera en más de

\footnotetext{
${ }^{48}$ Arvid era uno de los tres hijos de Mima Sjögren, de origen sueco y viuda de un ingeniero que había trabajado en la fábrica de Karl Wittgenstein. Con los Sjögren residió en Viena durante unos meses durante sus estudios para formarse como profesor en 1919. Wittgenstein encontró en Arvid un alma cándida pero con cualidades intelectuales y Arvid tuvo al filósofo como maestro y guía moral durante gran parte de su vida. Wittgenstein convenció a Arvid de no ir a la universidad y en lugar de convertirse en ingeniero se dedicó a la mecánica.

${ }^{49}$ McGuinness, op. cit., p. 203

50 Åmås, op. cit., p. 89

51 Åmås, op. cit., p. 41

52 Åmås, op. cit., p. 83 y ss.
} 

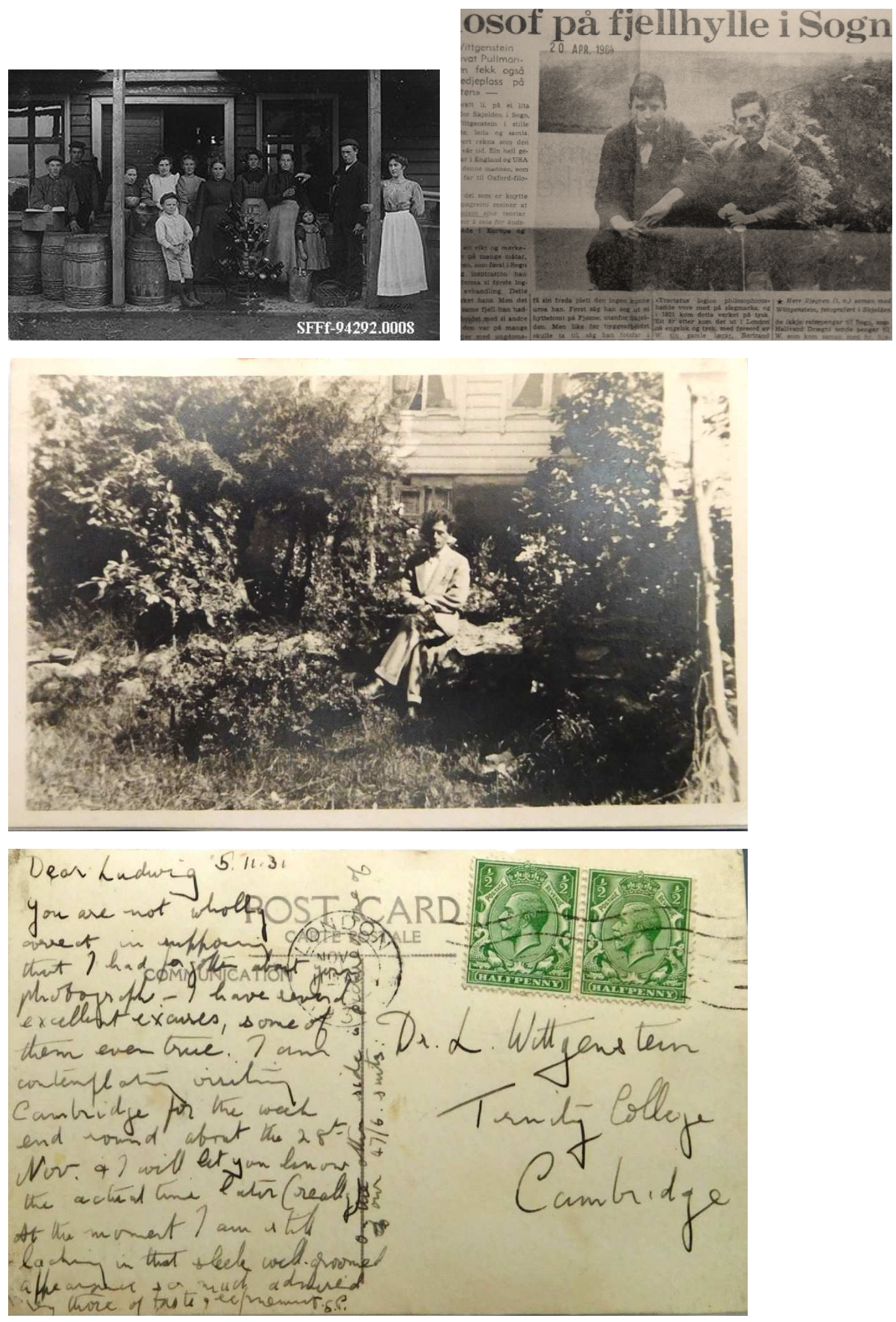

88. La fábrica de zumos y conservas de fruta de Halvard Dræani en 1907-1908 | 89. Wittgenstein y Arvid Sjögren en Skjolden, 192

90. Tarjeta postal de Gilbert Pattison a Wittgenstein. Imagen tomada en agosto 1931, Noruega, anverso. Enviada 05.11.1931. WAC, Cambridge, 04.2015 91. Idem. Reverso 
una ocasión impresión de no pensar en las deferencias que los demás pudieran tener con él. ${ }^{53}$

De las estancias previas a 1936 no nos consta ningún dato escrito, ni en cartas ni en diarios de las vivencias de Wittgenstein en su casa del lago. Del año 1921 sólo sabemos que trabajó junto a Arvid en la carpintería de la fábrica de Drægni y encontró cierta paz mental, tras los tiempos de guerra. Si como parece se instalaron en la casa del lago, debían cruzarlo a remo al menos dos veces al día, durante dos meses.

En 1931, dejó a Marguerite Respinger en casa de Anna Rebni y se dedicó a rezar en su casa, no a escribir, como hemos dicho que refirió a Drury en Cambridge tiempo más tarde. Meses antes Wittgenstein ya intuía el desenlace:

«07.03.1931. Estoy cansado por el trabajo de los últimos meses \& completamente hecho polvo por la tortura del asunto con Marguerite. Preveo ahí una tragedia. Y sin embargo sólo hay una cosa: obrar lo mejor que uno pueda \& seguir trabajando.» ${ }^{54}$

En agosto de 1936 los diarios de Wittgenstein empiezan a reflejar sus sensaciones respecto a la estancia en soledad en Skjolden. La casa se convierte así en lugar, se vive y se pertenece mutuamente, como un contrario al no-lugar de Marc Augé. Somos seres simbólicos, necesitamos el anclaje a lo social para darle sentido a la vida. En la ausencia de compañía, Wittgenstein se centró sobre todo en el paisaje, en el tiempo y en sí mismo. Alineados con el pensamiento de Augé, la casa del filósofo sólo existe mientras él la ocupara. Somos las personas las que creamos el paisaje, al interpretarlo, porque el paisaje es intransferible. La casa de Wittgenstein, aunque planteada en otros términos, seguro que más pragmáticos, pertenece sin querer, al imperio colectivo de la heterotopía ${ }^{55}$, donde podía tomar distancia de su propia vida y analizarse a sí mismo con mayor profundidad.

\footnotetext{
${ }^{53}$ Wittgenstein había renunciado a su parte de la riqueza familiar, pero parece que no a disfrutar de ciertos privilegios de la de sus hermanos. Así se sobreentiende de los comentarios de Ramsey a Russell, tras visitarlo en Trattenbach.

${ }^{54}$ Ludwig Wittgenstein, Movimientos del pensar. Diarios (Madrid: Gredos, 2009), p. 226. Entre la anotación del diario del 05.05 .1931 y la de 12.10.1931 no hay información. Tampoco las cartas arrojan luz sobre su estancia en Skjolden.

${ }^{55}$ Las heterotopías de Michael Foucault y los lugares/no-lugares de Marc Augé en relación con Wittgenstein desbordan esta investigación, si bien resultan de extremo interés.
} 

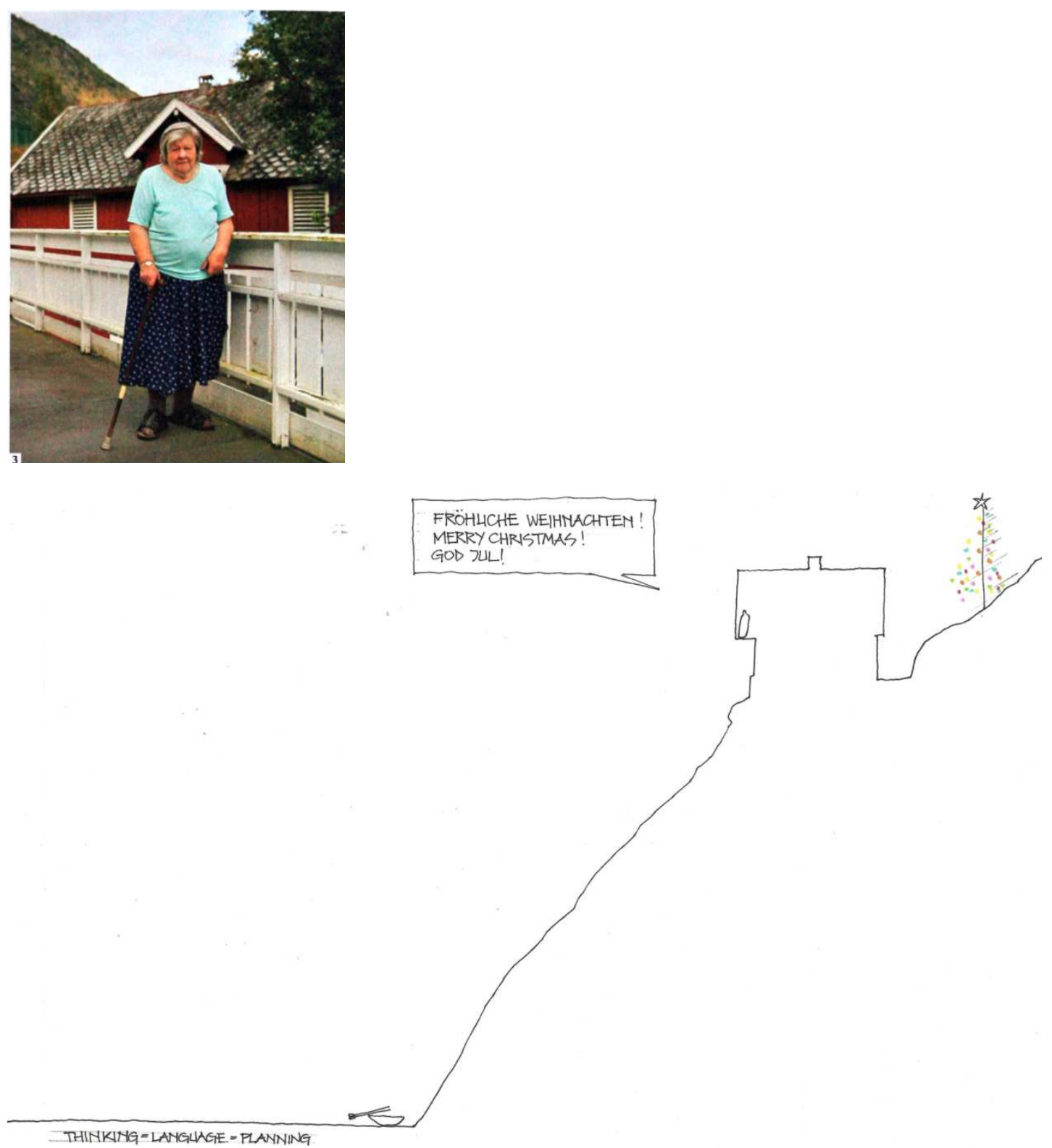

92. Alvhild Rebni (84) husker at Wittgenstein var en litt skremmende figure, og at han var «stri i øynene», en Dagens Næringsliv, 11.10.2013 [Alvhild Rebni (84) recuerda que Wittgenstein era una figura intimidante y que tenía una «mirada dura»]

93. Dibujo para felicitación de la Navidad 2013, 24.12.2013. "Wittgenstein en el balcón, mirando hacia el Sognefjord" 
«30.11.1936. Arrecia el temporal y no puedo coordinar mis pensamientos. $»^{56}$

Wittgenstein llevaba un diario desde muy joven, como aprendió de Keller, pero en Skjolden se convierte en una manera de hablar consigo mismo ${ }^{57}$. En él muestra sus debilidades, que considera necesario expiar sacándolas fuera de sí mismo a través de la escritura y en las confesiones. Dice que confesar es dar comienzo a una vida nueva. Su intención, al marchar a Noruega era preparar una versión definitiva del Cuaderno marrón, aunque abandonó tal proyecto de revisión y se dedicó a lo que más tarde compondrían los párrafos §1-188 de sus Investigaciones Filosóficas, publicadas póstumamente en 1953.

La vida en la casa del lago no debía ser cómoda. Dice Auster que quizá no haya que disponer de demasiadas comodidades, por miedo a que se contagien al espíritu. ${ }^{58}$ Pero tenemos que analizar, así lo haremos en breve, el proyecto de la casa del lago Eidsvatnet sincrónicamente. Los estándares de vida debían ser los habituales. Es algo reduccionista decir que era incómodo ir a por agua al lago. Es cierto que la pendiente resulta muy pronunciada y Wittgenstein hizo instalar una polea desde la ladera cercana a la casa (hacia el sur y encaramándose unos metros en un gran resalte rocoso) que llevaba un cable hasta el agua y le permitía llenar cubos que podía izar desde arriba, así como ser suministrado con compras y correo desde el agua sin necesidad de relacionarse con los recaderos, aunque parece que gustaba de dar largos paseos y muchos de ellos los dedicaba a visitar a Anna Rebni o en el pueblo para aprovisionarse.

Wittgenstein era visto regularmente en su balcón mirando hacia el pueblo y se veía la luz en el interior de la casa de las lámparas de parafina, desde el pueblo, por las noches, aunque se retiraba temprano a descansar. ${ }^{59}$

\footnotetext{
${ }^{56}$ Ludwig Wittgenstein, Movimientos del pensar. Diarios (Madrid: Gredos, 2009), p. 260.

57 «Exiliado de la estupidez humana, al amparo del aire espontáneo de su refugio noruego, junto al fiordo de Sogne, abrió con sus actitudes hacia la filosofía un camino: trató de comprender, no de juzgar; trató de convencer, no de demostrar». Enrique Vila-Matas, Café Perec, Lugares para pensar, El País, 04.10.2011

${ }^{58}$ Gérard de Cortanze, Dossier Paul Auster (Barcelona: Anagrama, 1996), p. 157. Y añade «En cuanto empiezo a escribir, ya no existe más que el trabajo. El entorno desaparece. Carece de importancia. El lugar en el que estoy es el cuaderno. El cuaderno es la habitación. Esto es la casa del cuaderno».

59 Åmås, op. cit., p. 46
} 

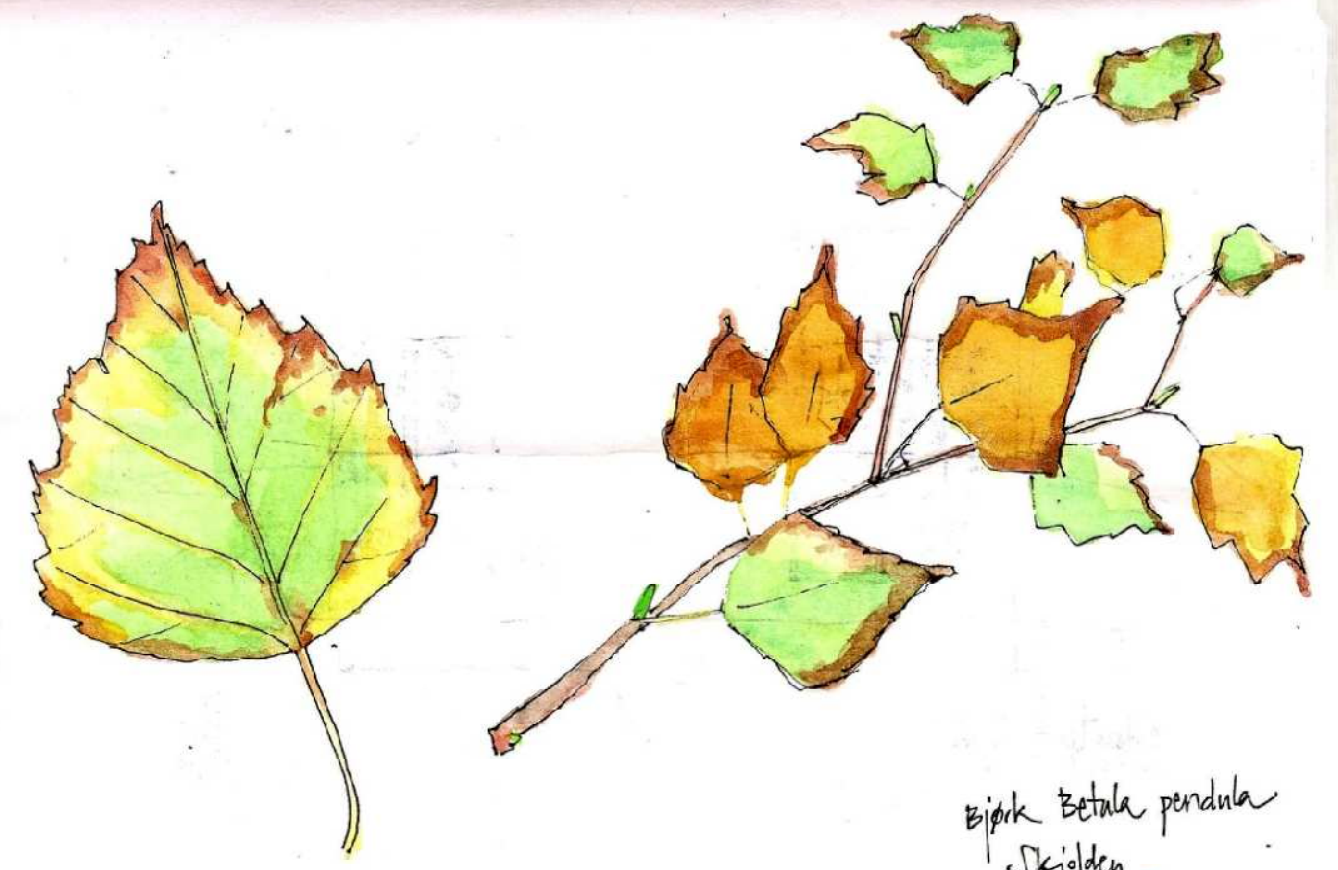

Biprk Betale pendula Skiolden.
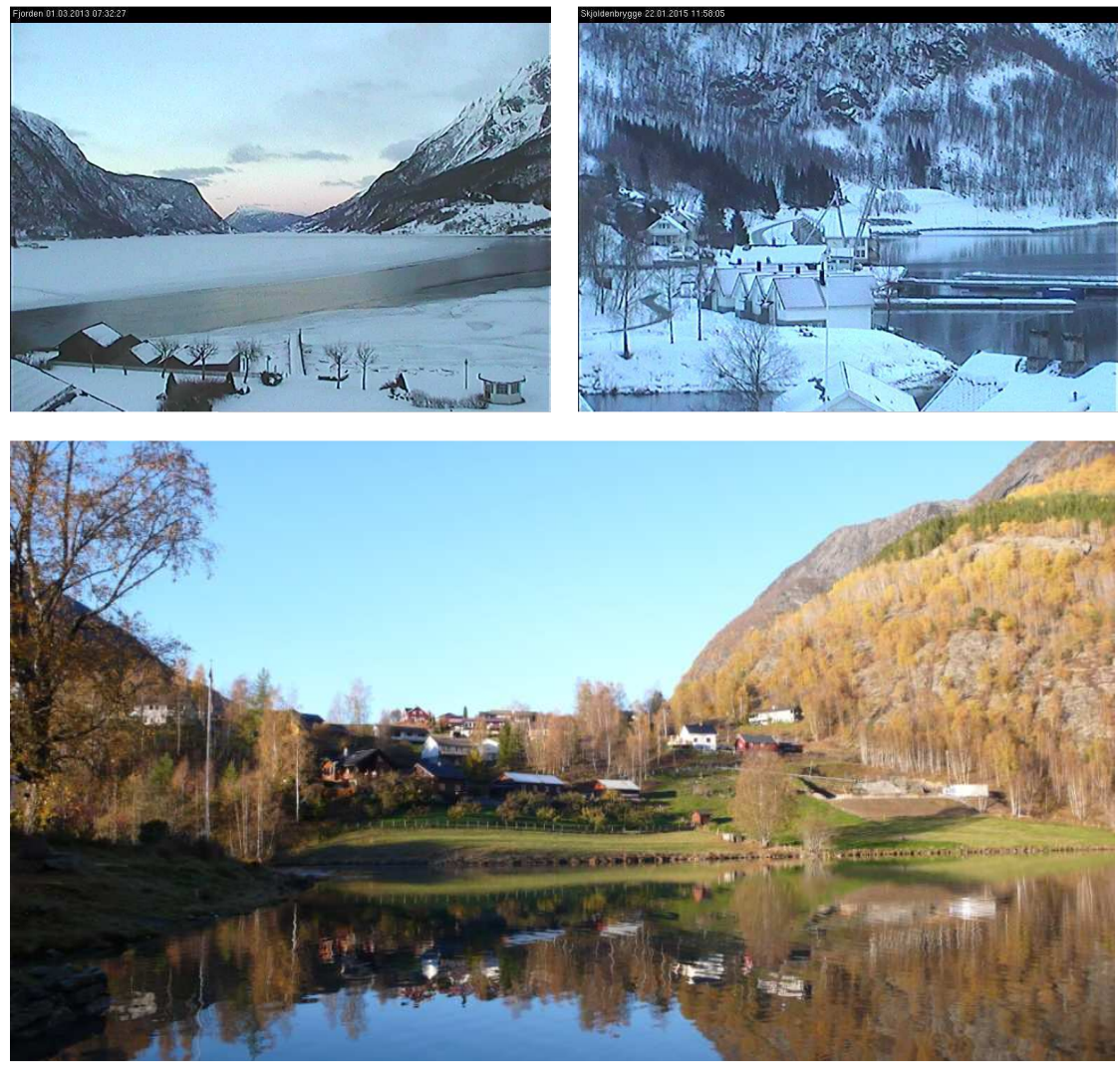

94. Dibujo de hojas de bjørk, abedul en noruego, Skjolden, 12.10.2013

95. Invierno en Skjolden, 22.01.2015, 11:58, Sognefjord | 96. Invierno en Skjolden, 01.03.2013, 7:32, Sognefjord 97. Otoño en Skjolden, 13.10.2013, 17:07, lago Eidsvatnet 
Contrasta ese testimonio con el de la abuela Fløde:

«La abuela de Tone Bolstad Fløde, cuenta a su nieta, su recuerdo de Wittgenstein de los años de treinta: "Al principio mi abuela no recordaba al filósofo. -No, ¡los filósofos no tienen nada que ver con Skjolden!...jOh, sí!, te refieres al austríaco, jasí que era filósofo! -Sí,...vino un tonto viajero desde Austria y se hizo una bonita casa al otro lado del lago, en un terreno escarpado allí, sobre la ladera. No había manera de llegar a pie, por lo que todo había que llevárselo en barca y la casa se hizo sobre una plataforma que tuvieron que hacerle. Obviamente era un solitario que no quería visitas. Era un poco raro. Nadie sabía porqué había venido al pueblo ni a qué se dedicaba. Pero tenía un montón de correo. Como estaba tan lejos se lo llevaban los sábados pero vino hasta la oficina de Correos para exigir que le fuera llevado inmediatamente. Y realmente tenía mucho correo; ese idiota del austríaco recibía constantemente pesados paquetes que le enviaban desde el extranjero y que había que llevarle enseguida en barca y después subirlos hasta la casa. Decían que se veía luz en las ventanas hasta bien entrada la noche, de madrugada, cuando toda la gente decente que tenía que madrugar y trabajar al día siguiente estaba durmiendo. No, no era demasiado sensato.» ${ }^{60}$

La mayor parte de las personas que trató en Skjolden en los años treinta tenían el recuerdo de que era una persona malhumorada y reservada. Sakkarias Bolstad, decidió en una ocasión cruzar el lago y subir por la colina a unos metros de la casa de Wittgenstein. Este, salió de su casa increpando al granjero por haberle hecho perder la concentración: «iAhora necesitaré dos semanas para volver a estar en el punto en el que estaba cuando usted me ha interrumpido!»61

Wittgenstein mantuvo un constante conflicto con su trabajo en soledad. Escribía cartas sin cesar a sus amigos y añoraba la presencia de una cara amiga, pero necesitaba una quietud absoluta y un entorno de procesos regulares a su alrededor para ser capaz de concentrarse. Probablemente, sea este último el motivo por el que recogía los cambios sucesivos en el paisaje. Su pugna constante, a veces física, con la soledad no era una forma de castigo, como no lo eran las confesiones, sino su interpretación de la honestidad, del camino para hacerse mejor persona:

«16.04.1937. Desde ayer los abedules tienen pequeñas yemas verdes.» ${ }^{62}$

«26.04.1937. Tiempo magnífico. Los abedules ya cubiertos de hojas.» ${ }^{63}$

\footnotetext{
${ }^{60}$ Correspondencia electrónica, 07.2011. Tone Bolstad es actriz. Natural de Skjolden, aunque no reside allí desde su juventud.

${ }^{61}$ Knut Olav Åmås \& Rolf Larsen, Ludwig Wittgenstein i Norge 1913-1950. Det stille alvoret, (Oslo: Det Norske Samlaget, 1994), p. 17. (En noruego en el original)

${ }^{62}$ Wittgenstein, 2009, op. cit., p. 303

${ }^{63}$ Ibídem, p. 305
} 


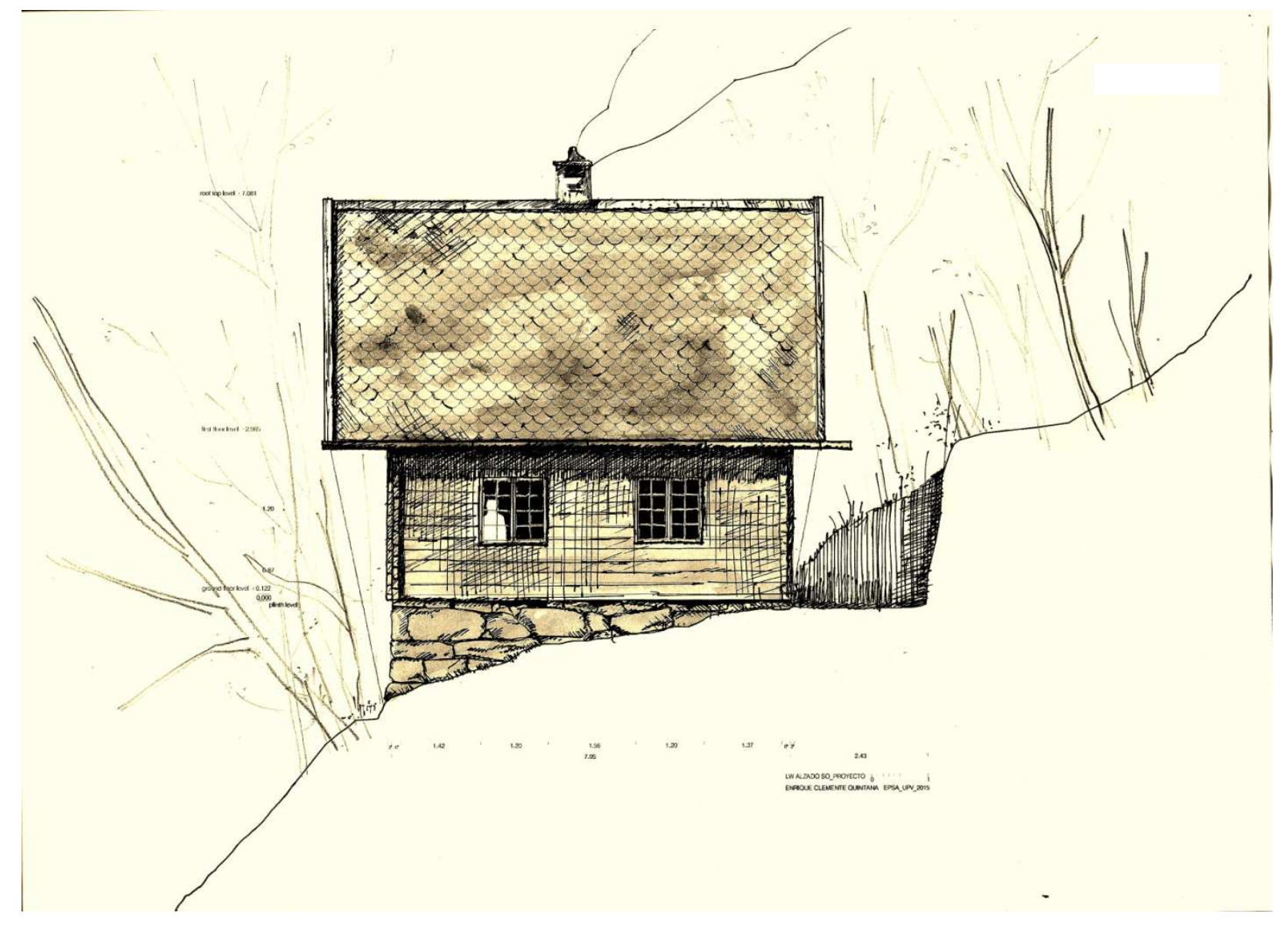

98. Alzado suroeste del proyecto de la Casa de Wittgenstein, dibujo de mayo 2015 


\section{Elementos de composición}

La arquitectura vernácula responde a las necesidades específicas de un lugar, con los recursos tanto materiales como técnicos disponibles en el mismo. Es por tanto, una arquitectura integrada en un ecosistema cultural que interacciona con un medio físico. En Noruega, únicamente un 2,7 \% de su suelo es cultivable. ${ }^{64} \mathrm{El}$ resto de sus $385252 \mathrm{Km}^{2}$ están ocupados por bosques, montañas, praderas boreales y hielo.

En Noruega, la arquitectura construida con madera responde a esos enormes recursos forestales de que dispone, resolviendo a través del conocimiento acumulado la adaptación al medio. La respuesta tradicional al mismo se conforma con el lugar, pero no trata conscientemente de integrarse en el paisaje, sino del cobijo. Wittgenstein sí pretendió instalarse de una determinada manera en la montaña, no era sólo casa y refugio, sino también proyecto.

La arquitectura vernácula parte de la inconsciencia de lo aprendido, Loos defendía que la Naturaleza sólo se vincula con la verdad:

«Observemos al campesino en su trabajo. Estaca el suelo sobre el que deberá levantarse su casa, y cava los cimientos. El albañil coloca ladrillo sobre ladrillo y, mientras, el carpintero ha instalado su taller al lado. Construye el tejado. ¿Un tejado bonito o feo? No lo sabe. ¡El tejado!» ${ }^{65}$

Pero Wittgenstein no sólo plantea su construcción desde lo artesano:

«Longfellow:

In the elder days of art,

Builders wrought with greatest care

Each minute and unseen part,

For the gods are everywhere.

(Podría servirme como un lema).»66

\footnotetext{
${ }^{64}$ Superficies cultivables en el mundo, por países: http://data.worldbank.org/indicator/AG.LND.AGRI.ZS. Por establecer una correspondencia, Noruega dispone de un $2,7 \%$ de superficie cultivable frente a un $54 \%$ de España.

${ }^{65}$ Loos, Heimatkunst, en Adolf Loos. Escritos II (Madrid: El Croquis, 1993), p. 65

${ }^{66}$ Ludwig Wittgenstein, Observaciones diversas. Cultura y valor (Madrid: Gredos, 2009), §177, p. 597. La anotación de 1938 de esta estrofa de Henry Wadsworth Longfellow corresponde al poema The Builders. ${ }^{6}$ Wittgenstein parece interesado en usarlo como lema del libro que había comenzado a preparar en Noruega durante su estancia de 1936-1937, Investigaciones filosóficas, que fue publicado póstumamente en 1953 por los fiduciarios de su legado.
} 


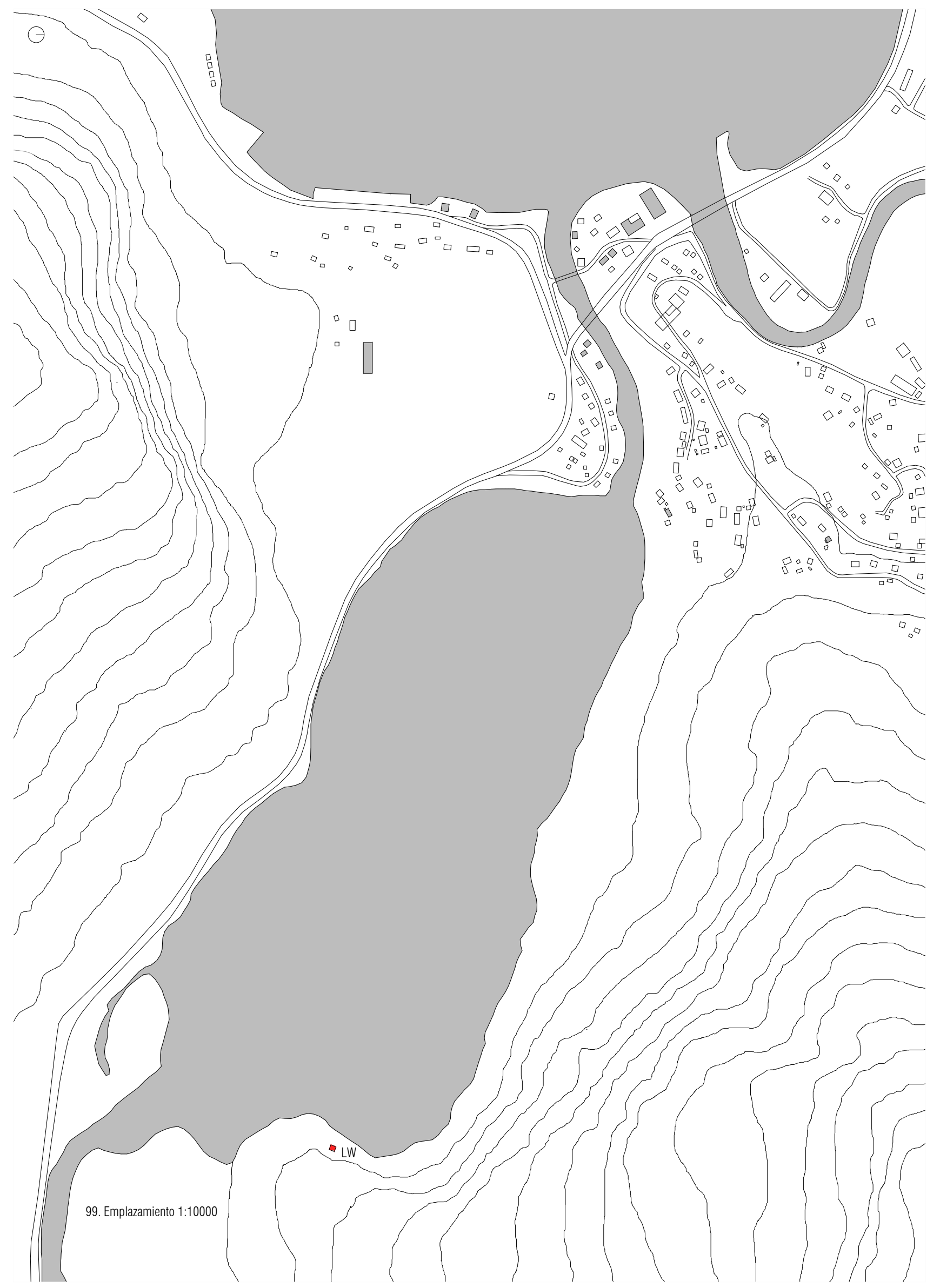


Porque Wittgenstein sí proyectó una composición arquitectónica para su casa. Utiliza las estructuras de lo vernáculo pero las adapta a una intención.

Insiste Wittgenstein a lo largo de su obra, que su búsqueda es la de un método: «No me interesa levantar una construcción, sino tener ante mí, transparentes, las bases de las construcciones posibles.» ${ }^{67}$ Es aquí, en la búsqueda de un sistema, de un andamiaje ético, donde encontramos lo vernáculo de la arquitectura de Wittgenstein. Cuando Loos se define como un artesano, la arquitectura no es un arte, se alinean ambos en una defensa del oficio, pero sobre todo de la ética. Pero no nos dejemos llevar, en palabras de Aldo Rossi, por el juego de intercambiar aforismos entre Loos, Wittgenstein y sus coetáneos. ${ }^{68}$

Ya hemos explicitado más arriba que Wittgenstein estimaba el oficio del artesano, su complicidad con el lenguaje de la verdad. Loos rompió con el artificismo de su tiempo tras sus viajes por América e Inglaterra, donde aprendió a valorar la relación entre forma y función, dejando sumariamente fuera del mundo de la arquitectura cualquier otra estética, por tanto el arte y sensu lato la contradicción que suponía para Loos el concepto de «artes aplicadas». Ni en Wittgenstein ni en Loos, la arquitectura es ética construida, porque ya sabemos por el primero que se muestra pero no se puede hablar de ella, y esto nos podría conducir a que tampoco se puede dibujar aunque sí construir. Cuando en los años treinta y cuarenta Wittgenstein desarrolla su concepto de los «juegos del lenguaje» no deja de sorprendernos la coherencia interna de su pensamiento, al establecer que las reglas que rigen el uso del lenguaje se definen precisamente por el uso, es decir, forman un sistema que se declara contingente. He aquí el plano de intersección de la crítica interna de la filosofía de Wittgenstein y la arquitectura de Loos: "como los romanos, el arquitecto utiliza las herramientas a su disposición únicamente con la lógica y el sentimiento.» ${ }^{69}$

\footnotetext{
${ }^{67}$ Ibidem, $\$ 30$

${ }^{68}$ Aldo Rossi, Preface en Benedetto Gravagnuolo, Adolf Loos. Theory and Works, (Milano: Rizzoli International Publications, 1982), p. 13

${ }^{69}$ Ibídem, p. 15
} 

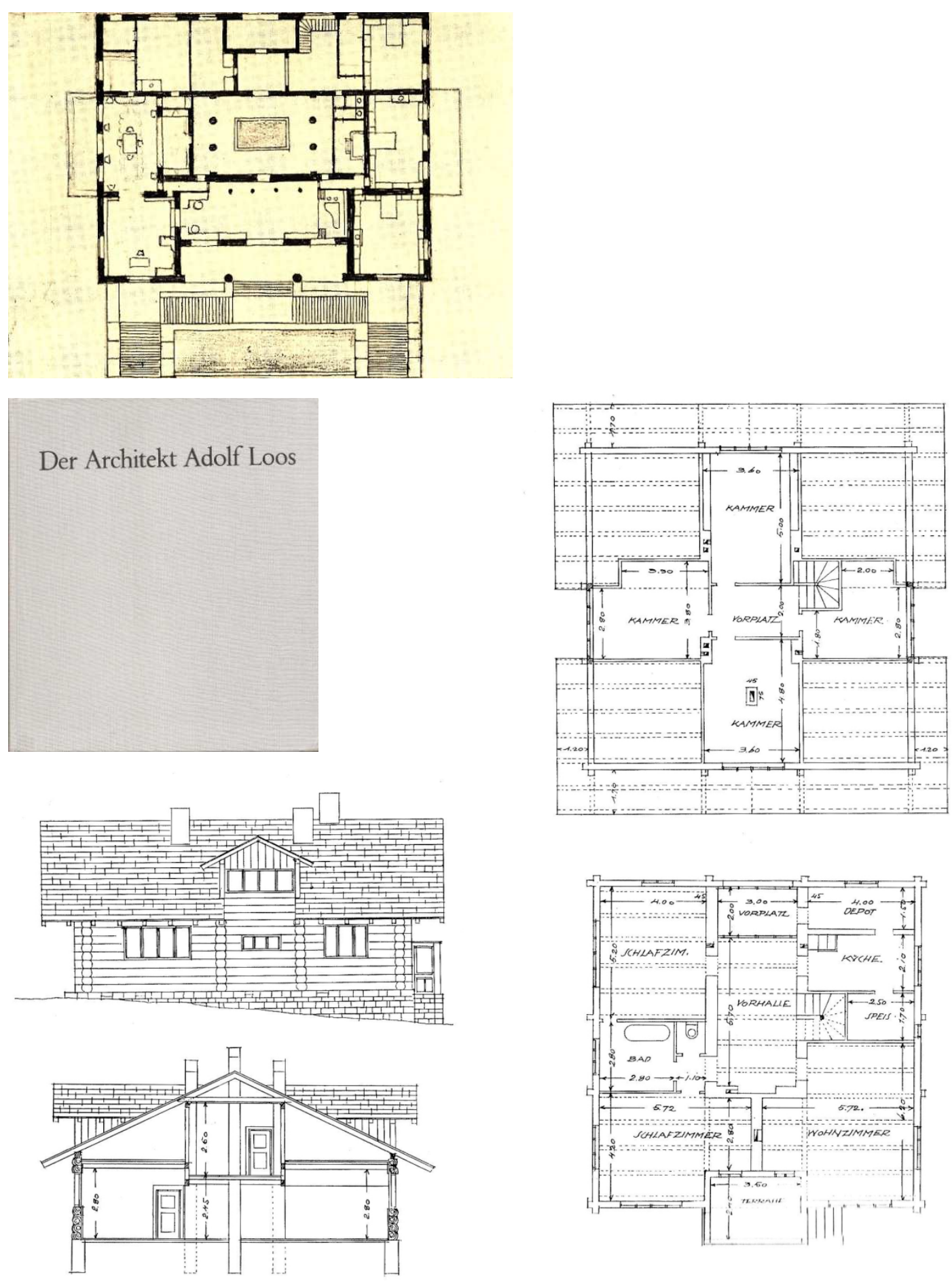

100. Adolf Loos. Proyecto de viviendas con atrio, 1912. Aplicación de Raumplanung

101. Monografía de Münz, Der Arkitekt Adolf Loos (Viena: Verlag Anton Schroll, 1964)

102-103. Alzado, sección y plantas de la Casa del Guarda en la Escuela Schwarzwald, Semmering (Austria), 1913 [proyecto no construido] 
El concepto de vernáculo en Wittgenstein se debe a una intencionalidad de la casa proyectada desde el interior hacia el exterior. La planificación espacial o Raumplan no sólo determina desde el punto de vista loosiano las distintas percepciones de los espacios, sino que se puede extender a la expresión del interior en el exterior, si bien Loos no muestra así la función. Es este un concepto que emana probablemente de la tradición, las cámaras -donde se dormía- debían tener el techo de menor altura para poder ser caldeadas más fácilmente, los espacios de paso, cobertizos, espacios para el ganado o almacenaje tampoco requerían altura excesiva y proporcionaban ventajas de economía material adicionales. La sala podía tener más altura y era casi necesario por contener el espacio del fuego y el humo debía poder disiparse hacia arriba. El concepto de Raumplanung en Loos tiene origen en la psicología de la percepción ${ }^{70}$-es difícil entender el criterio de economía, como el propio Loos la define en Mein Haus am Michaelerplatz ${ }^{71}$.

Sea como fuere el planteamiento de Wittgenstein en la casa del lago tiene una intención evidente, que se muestra en las imágenes que se conservan de Ben Richards y que hemos podido analizar métricamente. Las fachadas son aparentemente simétricas, sin embargo, un estudio más atento nos permite comprobar una fuerte asimetría en las composiciones de los huecos de las fachadas de los testeros.

En la fachada noroeste, recayente al lago esto es muy visible. Las dimensiones de la fachada en planta baja responden a un esquema $a / b / c / b / d$, 0,89/1,20/2,92/1,20/1,52. Esto significa que Wittgenstein colocó las ventanas con alguna intención en la fachada, quizá reflejando la distribución interior en el exterior. Cuando estudiamos las posibles soluciones de la planta baja y sus distribuciones siguiendo el programa descrito por McGuinness (1988), todo pareció encajar con la situación en esa fachada de dos salas de diferente tamaño,

\footnotetext{
${ }^{70}$ August Schmarsow introdujo la teoría de Raumgestaltung en 1896, Über den Wert der Dimensionen in menschilchen Raumgebilde. Quizá el propio Wittgenstein hubiera leído a Schmarsow, no lo sabemos, pero este formaba parte del contexto cultural germánico y no es improbable que pudiera encontrarse la biblioteca familiar.

71 «[...], en mi opinión, el arquitecto debe pensar en el espacio, en el cubo. Por ello yo ya iba con ventaja, pensando en la economía espacial. Un cuarto de baño no necesita ser tan alto como una sala. Si a cada espacio se le da sólo la altura que, por su naturaleza, le corresponda, puede construirse más económicamente.», Mein Haus am Michaelerplatz, Conferencia, 11 de Diciembre de 1911. Loos, op.cit. p. 44.
} 


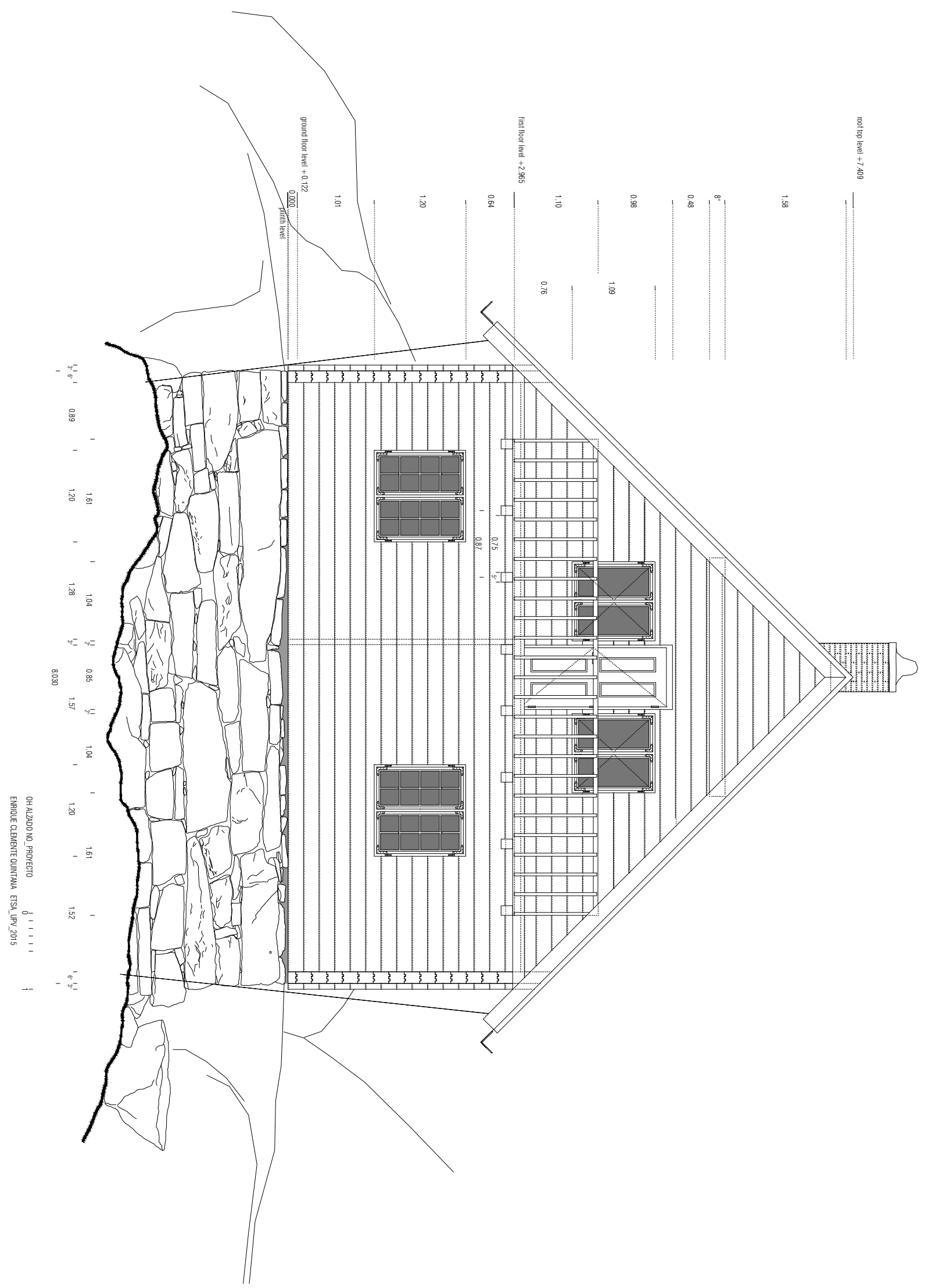

104. Alzado noroeste, recayente al lago Eidsvatnet, proyecto de la Casa de Wittgenstein, 1:75, mayo 2015

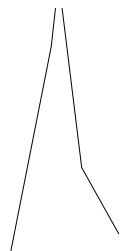


la sala principal, a la que se accedía directamente desde el exterior y un pequeño dormitorio. En la planta ático, aparece el reconocible balcón, por el que los lugareños decían que la casa era de tipo suizo. En la fachada vemos dos huecos simétricamente colocados alrededor de una puerta de acceso a la veranda.

En el frente sureste, en planta baja sólo sabemos que había una puerta (McGuinness, 1988) pero como se verá, el resto de la fachada junto a la puerta lo debía ocupar la escalera interior que impedía la colocación de huecos y probablemente Wittgenstein utilizara por el exterior, como es costumbre en esas latitudes para apilar madera para las estufas y aumentar el aislamiento térmico del cerramiento. En planta ático, de nuevo los huecos van a responder a la distribución interior, una habitación y dos huecos que iluminan la escalera y el distribuidor al que da acceso. ${ }^{72}$

De las otras dos fachadas sólo tenemos la seguridad que la suroeste es simétrica, con un ligero desfase dimensional que más bien podríamos juzgar como un error de replanteo o un error acumulado en nuestra medición sobre el material gráfico, puesto que no parece plausible que ese espacio de la sala estuviera dividido transversalmente. Las dimensiones ideales hubieran sido a/b/a/b/a, aunque nuestra medición ha sido 1,42/1,20/1,56/1,20/1,37.73

El azar quiso que en $1913^{74}$, Loos presentara el proyecto de la casa del guarda en la Escuela Schwarzbald en Semmering, Austria. Los primeros estudiosos de la obra de Loos, Münz y Künstler, la describen como una de las primeras aplicaciones de los principios compositivos del Raumplan. ${ }^{75}$ Para mayor abundamiento, se trata de la casa del guarda, proyectada con troncos de madera y cubierta inclinada, al estilo tradicional. Las diferentes alturas de las habitaciones son variables y podemos ver que los espacios secundarios tienen una altura menor que los principales.

\footnotetext{
72 Las tipologías, dimensiones y materiales de las ventanas se describen en el capítulo correspondiente: "Huecos".

${ }^{73}$ Descrito así resulta extremadamente reductivo, porque el trabajo de medición y recálculo sobre el material gráfico ha llevado un incontable número de horas.

${ }^{74}$ En 1913 Wittgenstein estuvo en Cambridge y Noruega y un proyecto no publicado ni construido resulta prácticamente imposible que le fuera accesible. Tampoco había conocido personalmente a Loos, como se ha relatado, que ocurrió en julio de 1914.

${ }^{75}$ L. Münz y G. Künstler, Der Architekt Adolf Loos (Viena: 1964), p. 122
} 
Las primeras se condicionan a las diferentes alturas del tejado y los segundos aprovechan el desnivel de la sección del propio terreno.

Respecto a las fachadas hemos visto que, necesariamente hubo una reflexión proyectual. Pero es que un rasgo interesante de la composición volumétrica de la casa es tan evidente como que ninguna vivienda noruega contemporánea de la que proyectara Wittgenstein en 1914 tenía el acceso en su testero, sino siempre en las fachadas laterales -bajo el alero de cubierta y no bajo el aguilón del axial- y aunque la principal motivación, como creemos, de que Gunnar Bolstad cortara parte de las vigas de cubierta, fuera el mantenimiento por el deterioro de la madera, parece relevante que en la casa reconstruida en el pueblo, la cubierta se girara $90^{\circ}$, según el gusto noruego.

Hemos dicho que Åmås se refiere a la casa del lago, como de las proporciones típicas de una Norwegian cotter's $d w e l l i n g 76$. En la edición en noruego de Det stille alvoret utiliza el término husmannsstove, ${ }^{77}$ que responde a una tipología tradicional concreta de construcción noruega. Se trata de la casa en la que vive con su familia el aparcero, no es propietario de la granja pero obtiene beneficio del trabajo y alojamiento. Este tipo de casas, normalmente de pequeño tamaño -la generalización de Åmås de 7 x 8 m no ha sido posible confirmarla- responden a una distribución de dos espacios en planta baja, uno destinado a la sala común, con el espacio de la estufa y siempre una mesa grande, ${ }^{78}$ en la que se lee, come, conversa, y un espacio de cocina, normalmente con su propia estufa y una despensa. En un altillo, aprovechando el calor que emana la estufa desde la planta baja, se encuentra el espacio de dormir, llamado hems, que suele ocupar sólo una parte del ático, el resto queda libre para permitir la convección del aire caliente-frío en el interior de la casa. Si el hems ocupa sólo una parte, la escalera de acceso suele ser ligera, incluso de mano, apoyada en el borde del altillo. Si la casa es de mayor dimensión y superficie, la escalera es un elemento fijo, aunque en la casa tradicional noruega no juega un

\footnotetext{
${ }^{76}$ Åmås, op. cit, p. 29

77 Åmås, Det stille alvoret (Det Norske Samlaget: 0slo, 1994), p. 120

${ }^{78}$ Conversación con Liv Ingrid Ostbye Roggen, 04.02.2015, Valencia
} 


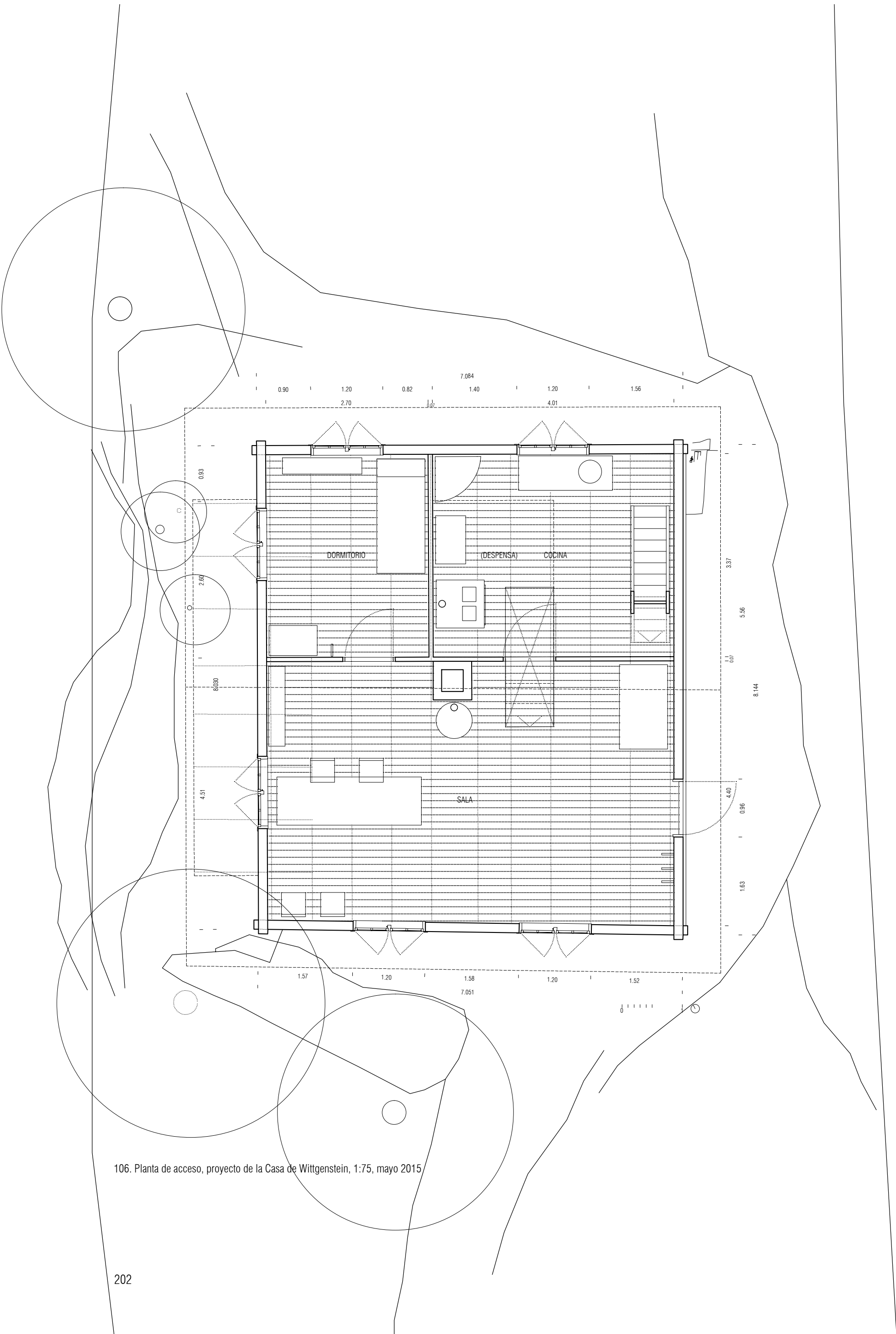


papel compositivo espacial, el hueco de la escalera se protege con una puerta o se instalan cortinas para evitar la pérdida de calor desde la planta baja.

En esa línea de composición, la casa de Wittgenstein sí responde a una distribución típica, esto es, en planta baja se compone de una sala principal de $6,68 \times 4,30 \mathrm{~m}$, una espacio de cocina (ya hemos dicho que Wittgenstein pensaba utilizar la casa como residencia más o menos prolongada), de 4,00 x 3,36 m y un espacio menor, en el frente del lago, en este caso utilizado como dormitorio, de 2,71 x 3,36 m. En un hueco dejado en el plinto y hasta una cota ligeramente por debajo de la natural de la pendiente del terreno proyectó un cellar, un espacio bajo el entablado de planta baja, a modo de despensa, de 2,60 x 2,05. El acceso se debía producir inevitablemente con portones de suelo, y la altura libre bajo él de 1,74 m no permitía erguirse completamente, por lo que las trampillas del suelo debían quedar abiertas cuando Wittgenstein cogía alguna provisión de la despensa.

La situación de la escalera ha supuesto un gran desafío en esta investigación. Los dos únicos testimonios con que contábamos (McGuinness y Oxaal) o incluso el recuerdo de Anna Gutubø de sus meriendas con Anna Rebni y Wittgenstein en 1937, no hacen ninguna referencia a la escalera.

La propia distribución, que ahora nos parece transparente, evidente, no lo fue tanto durante una larga fase de la investigación. La descripción de McGuinness, desde la mirada del arquitecto, la interpretamos dinámicamente, veamos la secuencia:

1 Se entraba directamente a la sala (desde el exterior, sin mediación por tanto de cortavientos, lo cual de por sí es extraño en esas latitudes) 79

2 A la derecha, dando a esta sala había un dormitorio y una cocina

\footnotetext{
79 «A veces el cortavientos es incluso de poner y quitar, en invierno es casi inexcusable para quitarte la ropa de estar fuera, el anorak, las botas que estarán llenas de nieve 0 de barro, etc. y porque a $20^{\circ}$ bajo cero, abrir directamente al espacio caldeado de la cabaña es una temeridad, todo el calor interior se escapa en cuestión de segundos.» En conversación con Liv Ingrid Ostbye Roggen, 04.02.2015, Valencia.
} 


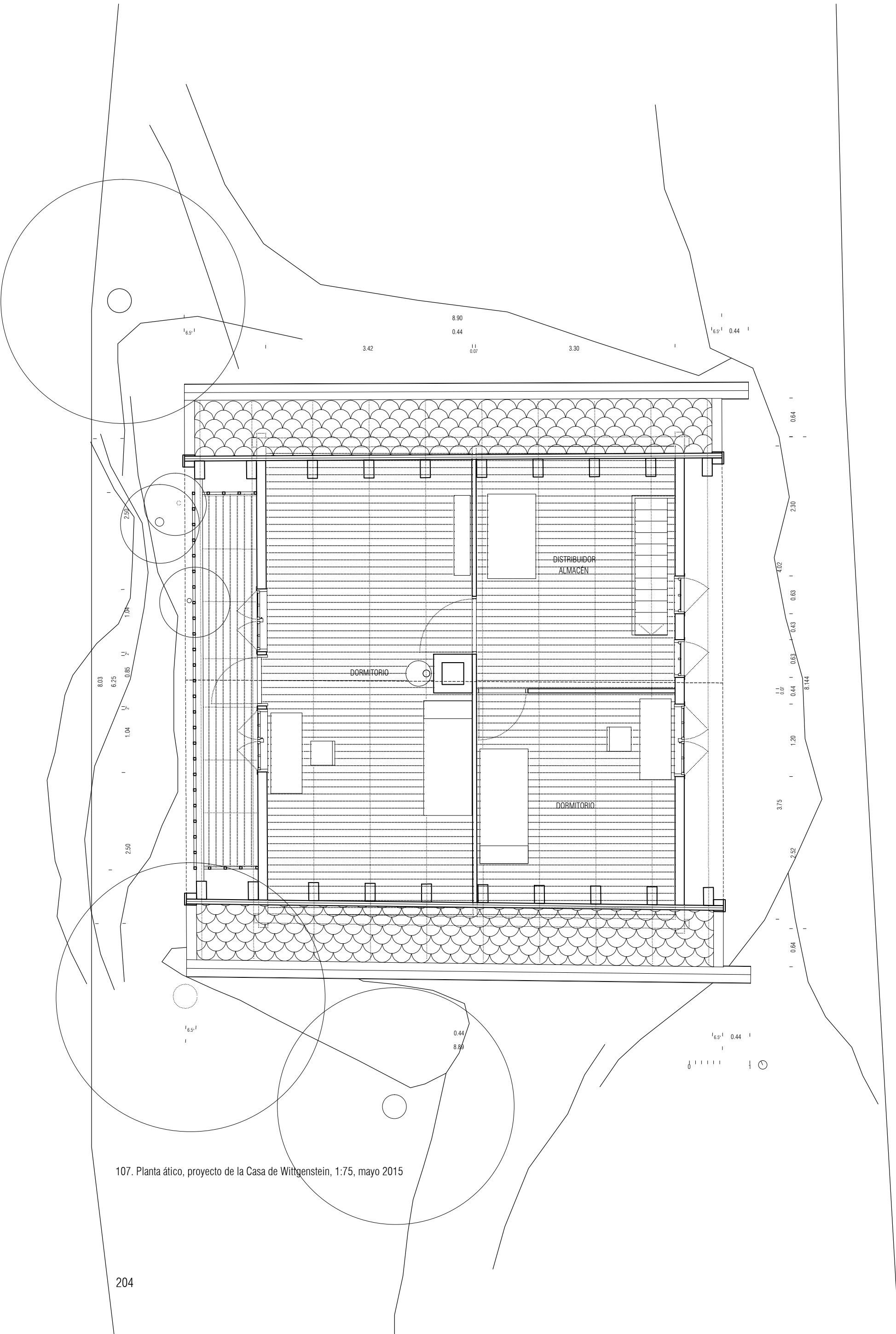


La secuencia describe la mirada del que entraba en la casa, llevando la descripción en sentido horario desde la sala. Entonces ¿dónde estaba la escalera? McGuinness ni siquiera nombra el espacio del ático y el balcón. ¿Significa eso que quien le diera el testimonio nos está diciendo que la escalera no era visible desde la sala?

A tal convencimiento hemos llegado tras numerosos intentos de componer la planta según un proyecto plausible, hasta llegar a ajustar dimensionalmente las piezas de planta baja y por fin, encontrar sentido a la asimetría de los huecos de la fachada del acceso y a la ausencia de ventanas junto a la puerta de acceso aunque las fotografías de esa fachada estén en total oscuridad, el contraste de los marcos blancos con los troncos de fachada debía al menos intuirse algún cambio en el tono de las sombras, y sin embargo en dicha área de la imagen no se aprecia elemento alguno.

Siguiendo la métrica de las estancias, los huecos de la fachada del lago se encuentran en el eje de simetría de los espacios a las que dan servicio, en la sala y en el dormitorio. Las ventanas de la fachada lateral también se sitúan simétricamente respecto al eje transversal de la sala.

¿Qué ocurre con los huecos de la puerta de acceso y con las ventanas del alzado noreste y del que no consta fotografía alguna? ${ }^{80}$

Como se expondrá más adelante en las cuestiones constructivas, la casa de Gunnar Bolstad, construida con los materiales de la casa de Wittgenstein en 1957, nos sirve parcialmente de modelo compositivo. En la reconstrucción, la casa sufrió importantes modificaciones, pero el estudio detallado de hasta qué punto se alteraró significativamente la composición de fachadas original no podemos saberlo. La familia Bosltad no permite el acceso a la casa salvo de manera restringida y no han autorizado catas en los cerramientos ni han aportado archivos familiares que nos hayan ayudado a entender de qué manera se realizó el montaje de la nueva casa.

\footnotetext{
${ }^{80}$ El lado noreste de la casa, sólo es visible desde la propia ladera de la montaña, aunque tras rebasar la casa, la senda se pierde al cabo de 6-8 metros y tiene sentido descendente, lo cual dificulta el punto de vista para tomar una fotografía. Desde el agua no es visible salvo llevando el bote hasta la misma orilla por el norte, desde donde la pared del escarpe es prácticamente vertical. No habiendo datos gráficos debemos estudiar la posición de los huecos desde la perspectiva de lo que nos ha llegado con la casa de Gunnar Bolstad.
} 

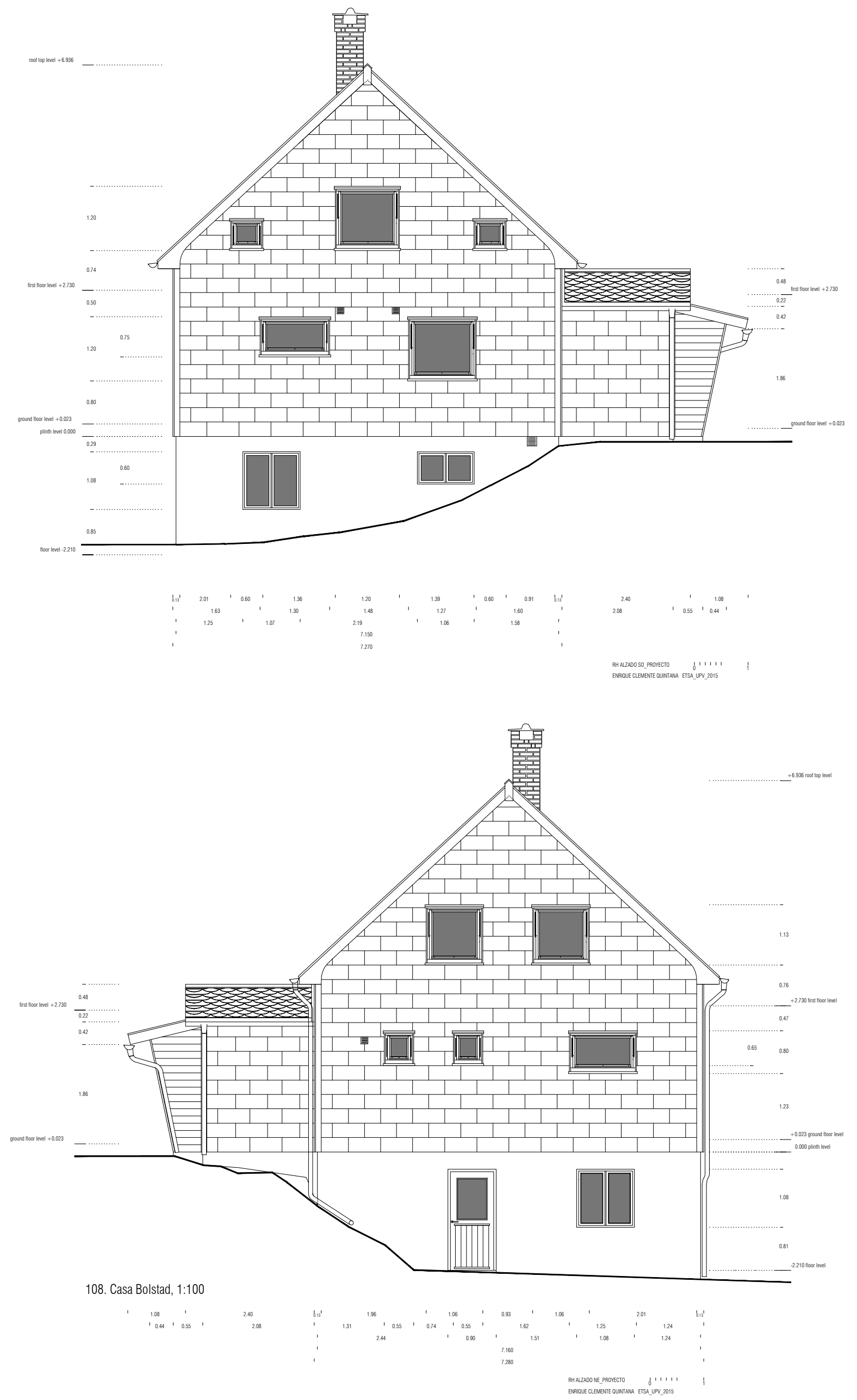
En 2010 o 2012 se desmontó el revestimiento de la casa, por razones de mantenimiento y no consta, sin embargo, que se tomaran fotografías del estado de la madera que suponemos es la original de la casa de $1914 .{ }^{81}$

Las fachadas de la casa Bolstad deberían responder compositivamente a la misma disposición de huecos que la original del lago, puesto que la lógica constructiva de una casa de troncos de madera supone la reutilización del material según la misma disposición. ${ }^{82}$

Pero sabemos que en la reconstrucción, Bolstad modificó sensiblemente dimensiones de cubierta y reutilizó el material de los testeros de $8 \mathrm{~m}$ de la casa original en los de $7 \mathrm{~m}$ de la casa reconstruida. Además, de la simple inspección visual se deduce que el número y disposición de los huecos no es el mismo que en las fotografías de Ben Richards de 1950 y Bolstad no dispuso de toda la madera original porque parcialmente se había deteriorado a causa de un escaso mantenimiento y desde luego por las condiciones de exposición a la intemperie de las fachadas. ${ }^{83}$

¿Con qué criterio utilizamos la composición de huecos de las fachadas de Bolstad? ¿Cómo discernir la situación original de una reformada?

Tras el análisis exhaustivo de la métrica de ambas casas y vista la intención de Wittgenstein en los huecos que sí conocemos por el material gráfico que se ha conservado, hemos observado que en dos de las fachadas Bolstad utilizó las fachadas reubicándolas simétricamente. Esto soluciona la probable situación del hueco de acceso si tomamos la fachada correspondiente girándola $180^{\circ}$. De igual manera, la fachada oculta a las imágenes, de orientación noreste, podría aportar un hueco de 48” a la iluminación de la cocina. Los dos pequeños huecos que vemos en la fachada de Bolstad no parecen tener correspondencia con la casa original, como veremos en el capítulo de «Huecos» de esta tesis.

\footnotetext{
${ }^{81}$ Tal situación nos traslada la negligencia 0 al menos la falta de interés con que se trata este asunto en Skjolden. Cuando Adam Sharr preparó su libro sobre la cabaña de Heidegger tampoco tuvo acceso al interior de la misma, la familia no lo permitió. «When I went in 2012, the asbestos cladding had been recently renewed (it still had pencil marks on it for cuts). I lamented that no one had been informed so that the original timber could have been viewed / measured / condition checked. In the circumstances, I take this to be either culpably stupid, or deliberately secretive.» Correspondencia electrónica, D. Connearn, 27.03.2015

${ }^{82}$ Esto quedará explicado con mayor extensión más adelante en el capítulo correspondiente: "Huecos".

${ }^{83} \mathrm{Al}$ menos 102 troncos en altura no pudieron utilizarse por estar demasiado deteriorados. Testimonio de Kåre Bolstad a D. Connearn en 2009.
} 

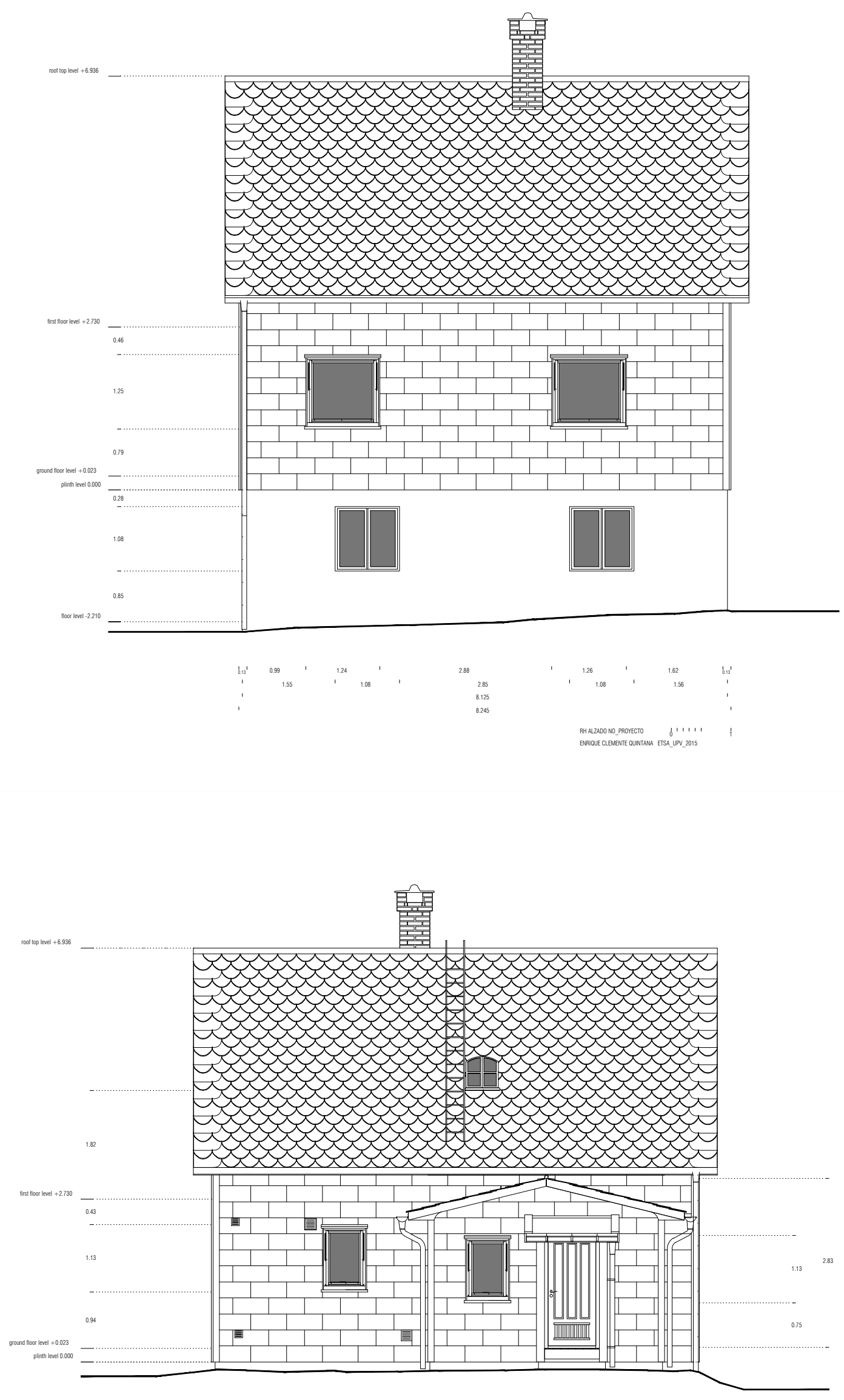

108. Casa Bolstad, 1:100

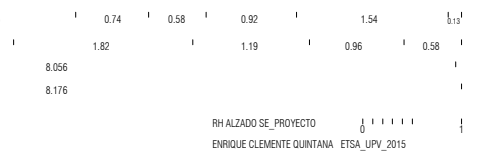


Con esta disposición, en planta baja, y teniendo en cuenta la intencionalidad de centrar los huecos en la fachada principal de la casa, hemos proyectado la fachada noreste de la que no tenemos ningún dato, con idéntico criterio, esto es aplicando huecos de 48" en posición simétrica respecto a las dimensiones interiores, y aunque no se corresponde exactamente en este caso con su colocación en la casa de Bolstad, entendemos que es suficiente el peso proyectual con que Wittgenstein interpretó un incipiente Raumplan en su casa como para defender tal modificación. Si esta operación se hizo y el hueco no estaba centrado en la cocina o en el dormitorio, o si como vemos hoy en día eran dos pequeños huecos de $60 \mathrm{~cm}$ o sólo uno, no lo sabremos hasta que tengamos acceso a las fachadas de la casa reconstruida, si es que esto llega a producirse:

«David,

Yes. I have been thinking so much time why on earth there were 42 " windows.

One of the problems for me was that the 48 " didn't fit well in the balcony gable. It is better to have there 42 " windows and so a stronger wall too.

If some 42 " windows came to the RH they had two window size models. A reason to make some more 42 " windows.

Regarding the windows of the hide side, I have tried both possibilities: heading directly "the axis of a $600 \mathrm{~mm}$ window" is internally symmetrical in the lake room. But then the kitchen windows are not. If I try to turn it $180^{\circ}$ the situation of the two $600 \mathrm{~mm}$ windows is perfectly symmetrical in the kitchen but the $48^{\prime \prime}$ window in the room (left side $108 \mathrm{~cm}$ right side $52 \mathrm{~cm}$ ) is not...

So still trying to fit something over there as I think like you the RH 7 m elevations must be almost similar to the $\mathrm{OH}$.

I'm working hard trying to close a table for a window proposal connecting RH-Vatne$\mathrm{OH}$. But each new decision like the 42" I wrote you makes me change all the drawings. Hope to send you it tonight.

Maybe 42" windows were 'standard' at that time (1957). The plinth windows have only a left opening part.

Perhaps those were ready made from a supplier. No idea.

Since we know more about the RH history I think we are digging the stone.» ${ }^{84}$

${ }^{84}$ Correspondencia electrónica E. Clemente a D. Connearn, 20.05.2015 

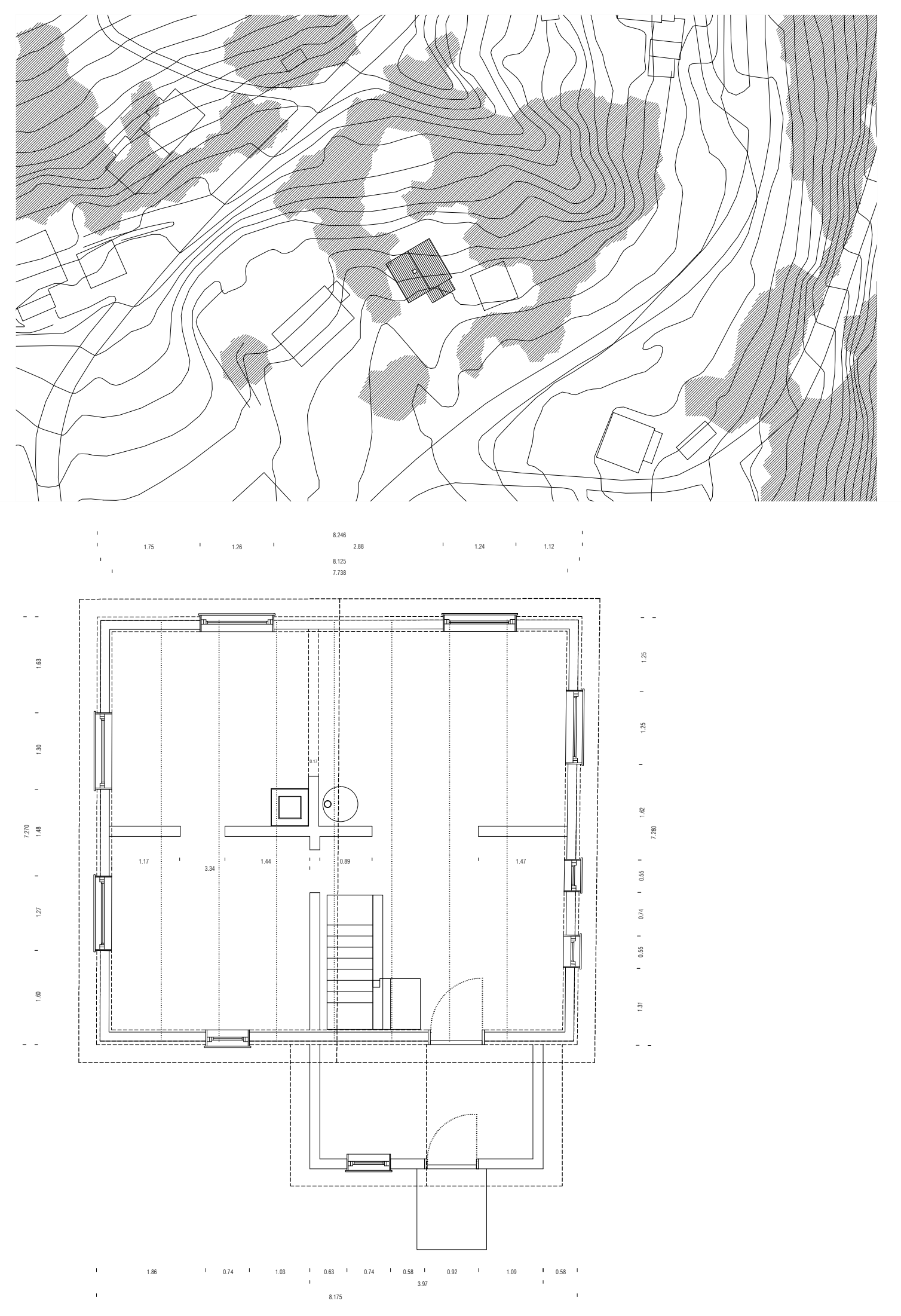

110. Casa Bolstad, emplazamiento

111. Casa Bolstad, planta de acceso (esquemática) 
Sí hemos podido comprobar en fotografías realizadas en 1993 de la casa Bolstad que los huecos no son idénticos a los que podemos ver en 2013. Además y pese a que sabemos que Bolstad no pudo reaprovechar la totalidad de los troncos de fachada, sin embargo, las superficies de ambas casas difieren sólo en $2,12 \mathrm{~m}^{2}$, con lo que es bien seguro que se incorporó material nuevo en el proceso de montaje de la nueva casa en el pueblo. Hemos reiterado la dificultad de contrastar nuestro proyecto con la realidad al menos de la casa de Bolstad, lo que nos ha obligado a deducir muchos elementos con un trabajo reiterado de ensayo gráfico y verificación sobre las fotografías sin saber cuán cerca estamos en realidad de la verdad.

En la planta ático, proyectamos una distribución en tres espacios independientes, el distribuidor/escalera, de 3,25 x 3,92 m y un dormitorio o sala de similar dimensión, al que le correspondería el hueco de doble hoja que describiremos más adelante. Las dimensiones de esta sala son de 3,25 x 3,77. La sala frontal al lago, con acceso a la veranda corrida en fachada es un único espacio -huecos simétricos- de 3,37 x 7,75 m. En estas tres piezas es evidente que una zona bajo la cubierta no es accesible en la franja en que no se tiene más de 1,20 m de altura. En la sala frontal la simetría es evidente, pero en el alzado de acceso, la ventana del dormitorio adicional y del distribuidor, no tienen una situación coherente con el esquema que sí hemos podido aplicar al resto de las fachadas. Con los datos de que disponemos en este momento, no encontramos explicación a tal variación, salvo que se tratara de una modificación por mantenimiento durante la vida útil de la casa aún en su emplazamiento original. De hecho, en una vista ampliada de ese tramo de fachada, pese a la difícil visibilidad, se aprecia un giro o deformación de la ventana más alejada. Quizá Arne Bolstad tuvo que sustituir algún elemento durante los 43 años que la casa estuvo sobre el lago. ${ }^{85}$

\footnotetext{
${ }^{85}$ No sabemos hasta qué punto la casa requirió mantenimiento, porque no queda constancia de ello, quizá alguna de las ventanas tuviera que ser sustituida antes de ser desmontada en 1957. Refiere Vatne que los últimos 15 años antes de 1957, la casa había sufrido serios desperfectos en la fachada del lago, el balcón y parte de la estructura interior, siendo este uno de los motivos por los que Bolstad decidió venderla. Cuando en 1950 la visitan Wittgenstein y Richards, la casa no estaba en buen estado. Un examen atento de la imagen de esas ventanas indica que la más alejada hacia la esquina noreste parece girada o deteriorada.
} 


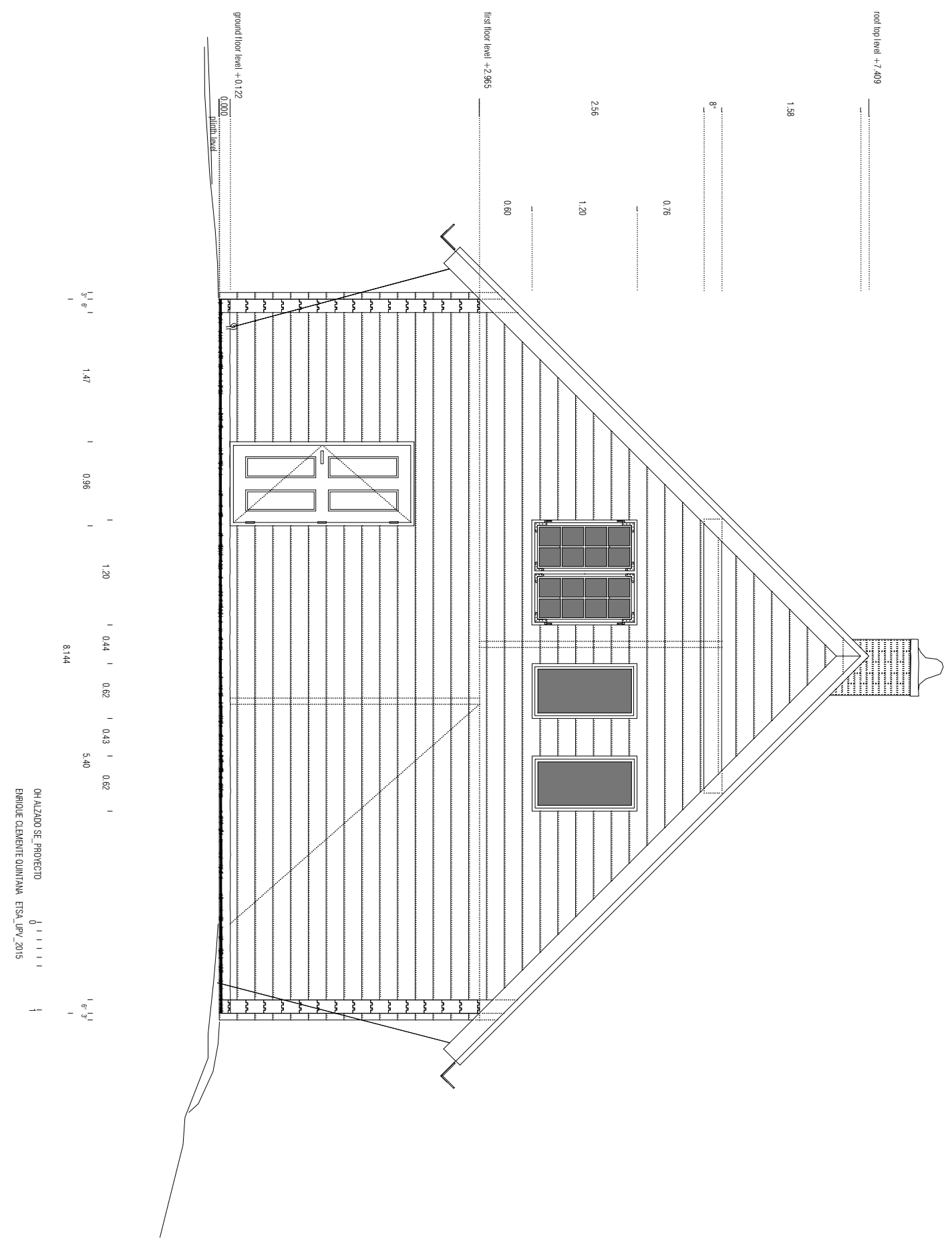

112. Alzado sureste, de acceso, proyecto de la Casa de Wittgenstein, 1:75, mayo 2015 
En conjunto la casa se concibe hacia el paisaje, aquí radica una diferencia fundamental con la concepción de lo vernáculo. El eje visual pretendido es el paisaje, es por ello que Wittgenstein proyecta un balcón, y con ello, buscando las mayores vistas en ambas plantas, la cubierta se alinea con ese eje. Los noruegos se defienden del clima, no lo introducen en sus casas.

No hay nada parecido a esta casa en su entorno, ni siquiera las casas de Klingenberg o Drægni, que tienen variaciones respecto a las casas convencionales de la zona, como los balcones en estilo «suizo» se le parecen. ${ }^{86}$

David Connearn aporta un matiz interesante, aunque no investigado todavía, como es que a principios del s. XX, fueron muchas las casas prefabricadas en Noruega que se enviaron a Islandia, donde escaseaban los recursos madereros -la casa vernácula islandesa es de turba y piedra. Docomomo Iceland indica que en 1912, en Reykjavik abundaba este tipo de casa traída desde Noruega, a veces incluso ya terminadas y transportadas en barco. En el viaje que Wittgenstein realizara con David Pinsent por Islandia en verano de 1912, es más que probable que vieran este tipo de construcciones:

"What interested me most about Iceland was this:

The kit houses that comprise Reykjavik are Norwegian. Some were actually floated over entire as shells. They are far closer to the design of the Wittgenstein Skjolden House than anything local to Skjolden.» ${ }^{87}$

Otros referentes los encontramos en la misma Austria. Ludwig pasó temporadas en casa de su tío Paul Wittgenstein (1842-1928) en Oberalm, a unos $450 \mathrm{~km}$ de Viena, cerca de Salzburgo. En Linz, ciudad situada entre una y otra encontramos ejemplos de arquitectura popular con un gran parecido de familia a la casa del lago Eidsvatnet (véase Epílogo de esta tesis).

Todo este esfuerzo proyectual no pudo deberse a simples instrucciones verbales ni a la iniciativa del carpintero o del propio Drægni. Sin embargo, Bjarne, su hijo, aún duda de que hubiera planos de proyecto:

\footnotetext{
${ }^{86}$ Nos referimos en su volumetría, veremos que la estructura sí tiene coincidencias aunque sean parciales.

${ }^{87}$ Correspondencia electrónica, D. Connearn 05.10.2013. Información suministrada a D. Connearn por integrantes de Docomomo Iceland en septiembre 2012
} 


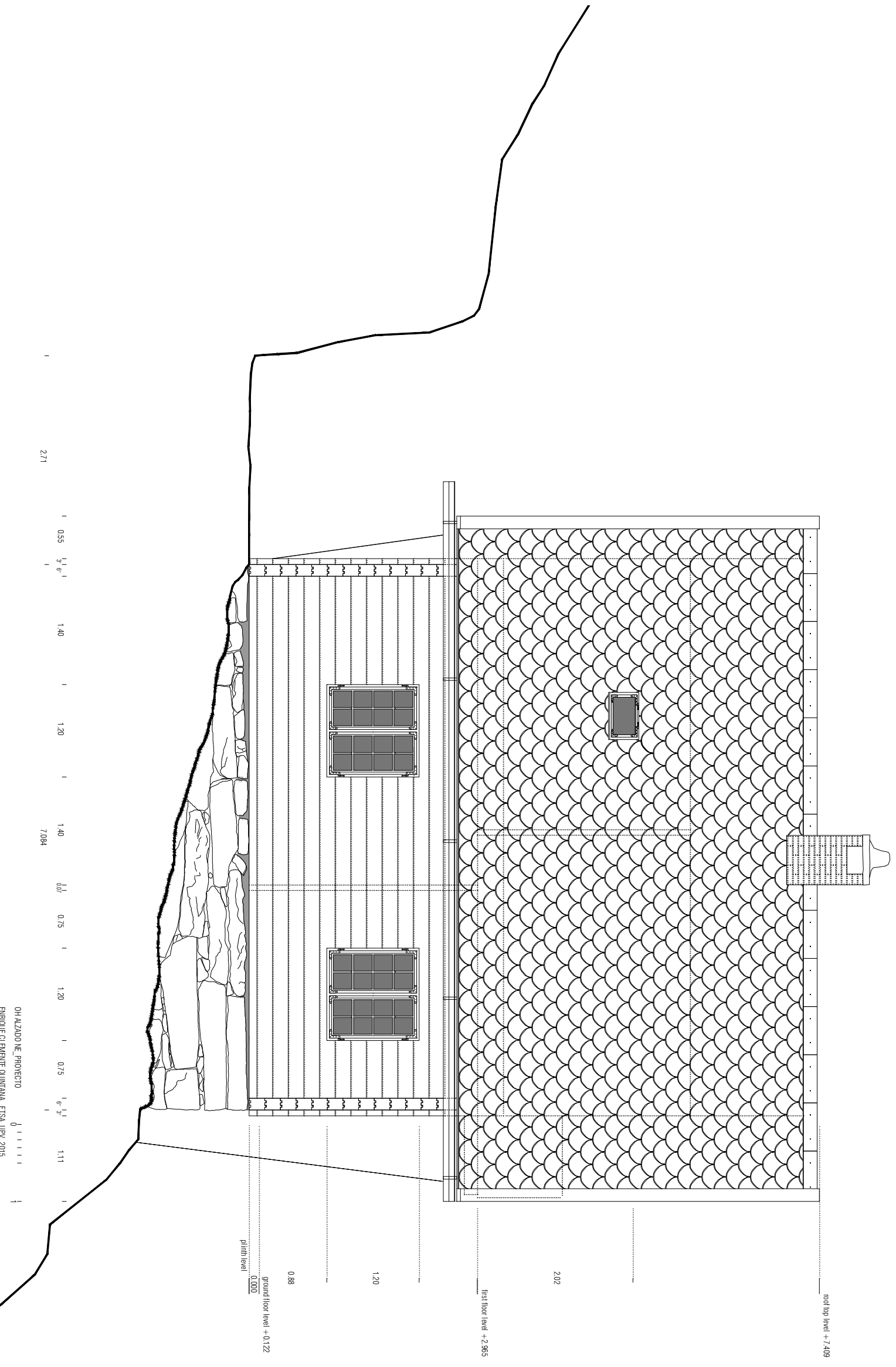

113. Alzado noreste, proyecto de la Casa de Wittgenstein, 1:75, mayo 2015 
«It was Halvard Drægni who coordinated the construction work in 1914. Whether or not it was based on architectural drawings we do not know for sure, but his son Bjarne, believes the answer to be negative. He considers it likely that a carpenter built it from a scratch.» 88

Estamos convencidos de que Wittgenstein detalló y dibujó planos de su casa. Durante su estancia en Manchester había demostrado su capacidad en los planos de aeronáutica que se conservan y los condicionantes de la casa eran tantos que no es creíble que sólo instruyera verbalmente a Drægni para obrar en su ausencia. Es cierto que no se ha conservado carta ni documento alguno que certifique esto. Harald Vatne ha referido denodados esfuerzos por localizar indicios de licencias de obras u otro tipo de documentos, sin éxito. ${ }^{89}$

El acceso a la casa, como se ha dicho y documentamos en el Anexo de esta tesis, sólo era posible a remo o sobre el hielo que cubría el lago. Desde hace unos años es posible realizar un recorrido de unos 30 minutos desde la carretera Rv55, a 2,5 km de Skjolden en dirección Fortun. Iniciando el paseo en el Vassbakken Kro \& Camping (el cartel de madera indica «Wittgenstein 45 minutos»), desde allí tomamos un camino carretero que cruza por un puente el río Fortun. Un poco más adelante el sendero se bifurca, a la derecha indica el camino que sube a la cima del Hjerseggi y a la izquierda indica «Wittgenstein».

Tras las unas sempiternas huellas de tractor, bordeamos una valla y alcanzamos una pradera abierta, propiedad de las granjas de Bolstad, llamada Vaiane. Siguiendo por el borde derecho, encontramos señales de madera con una O o una W rojas o WITTGENSTEIN. Llegamos por una senda hasta el nivel del agua y a partir de aquí compartimos el empinado y rocoso sendero que utilizaba Wittgenstein desde el amarre del bote hasta su casa. El camino gana altura rápidamente y nos lleva en pocos metros a la plataforma que ocupa el plinto. Es especialmente curioso que las indicaciones dirigen a «Wittgenstein», pero al final del sendero no encontramos ni al filósofo ni la casa, que ya no existen..$^{90}$

\footnotetext{
${ }^{88}$ Åmås, op.cit. p. 28. Bjarne dice que el constructor (carpintero) hizo la casa a partir de un boceto.

${ }^{89}$ Conversación con H. Vatne, 10.10.2013 en Skjolden.

${ }^{90}$ Con Foucault, una «heterotopía de la ilusión», que expone un lugar real a la creación de un lugar ilusorio. Como decíamos al principio, le ocurre al peregrino que busca a Wittgenstein y sólo encuentra una magnífica vista sobre el lago Eidsvatnet.
} 

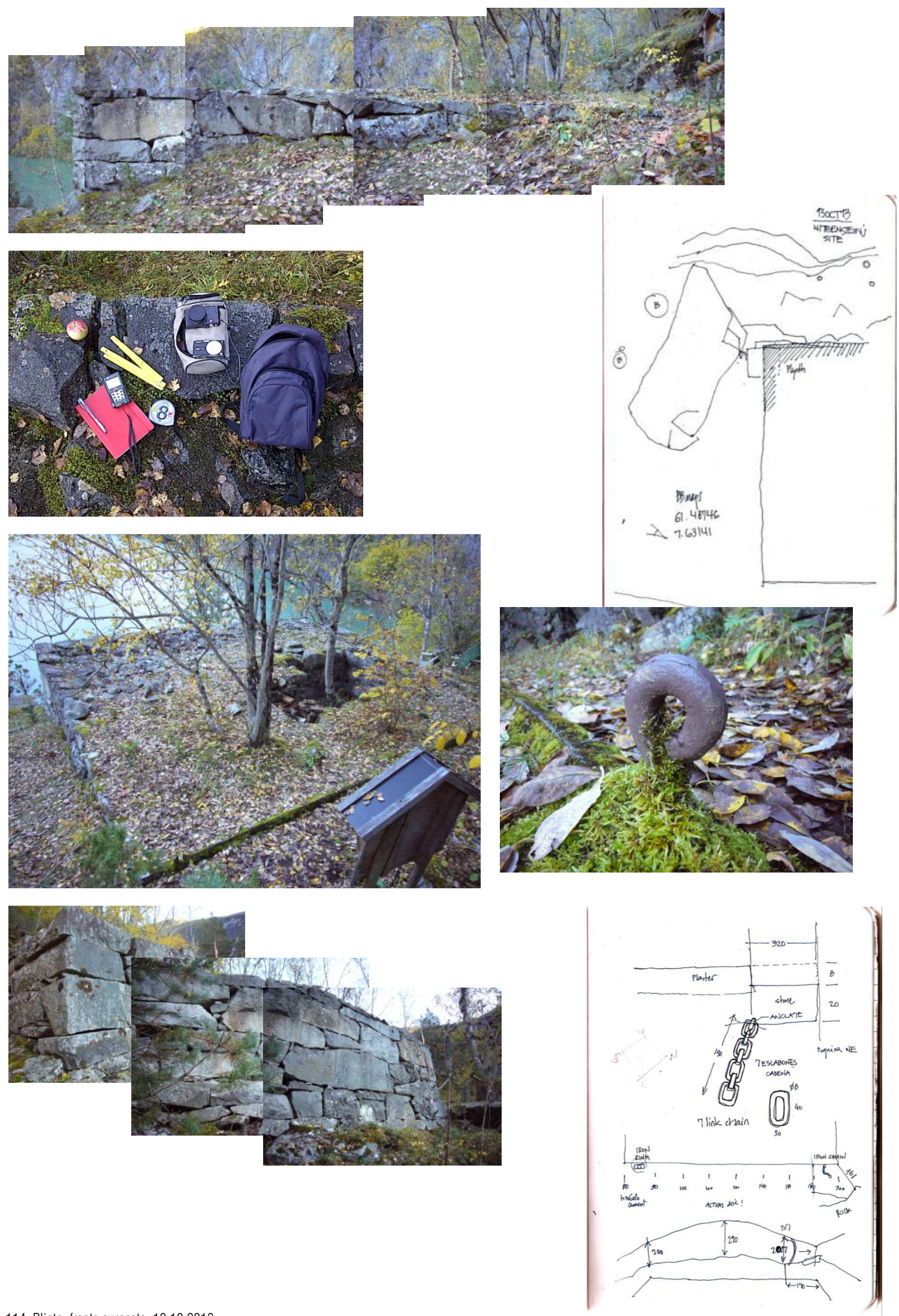

114. Plinto, frente suroeste, 10.10 .2013

115. Fotografiando el metro | 116. Toma de datos esquina oeste del plinto

117. Plinto desde la esquina sur | 118. Gancho de anclaje de la antigua cada, a $36 \mathrm{~cm}$ de esquina, sobre alambor de cemento

119. Plinto, frente noroeste, $10.10 .2013 \mid$ 120. Toma de datos del anclaje en esquina este y separación a corte del terreno respecto a la fachada sureste 


\section{Elementos de construcción}

\section{Plinto}

La geomorfología del área, a gran escala, responde a una estructura tectónica de rocas muy antiguas, paleozoicas, que sufrieron un metamorfismo en la Orogenia Caledoniana. Es la región denominada como Escandinavia Caledoniana se extiende de una forma más o menos continua en el $\mathrm{W}$ de la Península Escandinava a lo largo de una distancia de $1800 \mathrm{Km}$, desde los $58^{\circ}$ a $\operatorname{los} 71^{\circ} \mathrm{N}$. Predominan con variaciones los gneises, gabros y anortositas que se acabalgaron sobre rocas más jóvenes de filitas y micaesquistos. ${ }^{91}$

Los colores agrisados de las abruptas laderas del Sognefjord y del lago Eidsvatnet encajan con la clasificación que hemos realizado de la roca en la que se asentaba la casa de Wittgenstein. El gneis ${ }^{92}$ es una piedra metamórfica de gran densidad y por tanto peso por metro cúbico.

El plinto que Wittgenstein hizo construir para conseguir un rellano horizontal sobre el que apoyar la casa, debió ser un duro trabajo. La pendiente del terreno en el escalón donde se colocó la casa es cercana al 100\% y el espacio de trabajo una vez realizado el desmonte de parte de la ladera es de unos 12 x 9 $\mathrm{m}$. El gneis tiene una densidad de unos $3000 \mathrm{~kg} / \mathrm{m}^{3}$, lo que supone que algunos de los mampuestos que se utilizaron en el plinto deben pesar 600 o $700 \mathrm{~kg}$.

\footnotetext{
«"How were these massive boulders put into position? I asked. "Was it not dangerous for the labourers?" "Ja, particulary since Wittgenstein would not allow the use of dynamite." Lars thought that Sweden's Dynamite King, Alfred Nobel, was in Wittgenstein's bad books: Peace Prize or no, the invention could be a cause of war.

Whatever the method may have been used to set the foundation, it must have been a hell of job.» ${ }^{93}$
}

Los mampuestos están colocados en seco, aunque probablemente el plinto fuera construido como un muro de contención, esto es, con un frente en este caso

\footnotetext{
${ }^{91}$ Raúl Martín Moreno, op.cit.

${ }^{92}$ El Dr. Antonio Nadal Gisbert del Dpto. de Ingeniería Mecánica y de Materiales de la UPV, Campus de Alcoy, ha confirmado la clasificación.

${ }^{93}$ Oxaal, op. cit. p. 150
} 

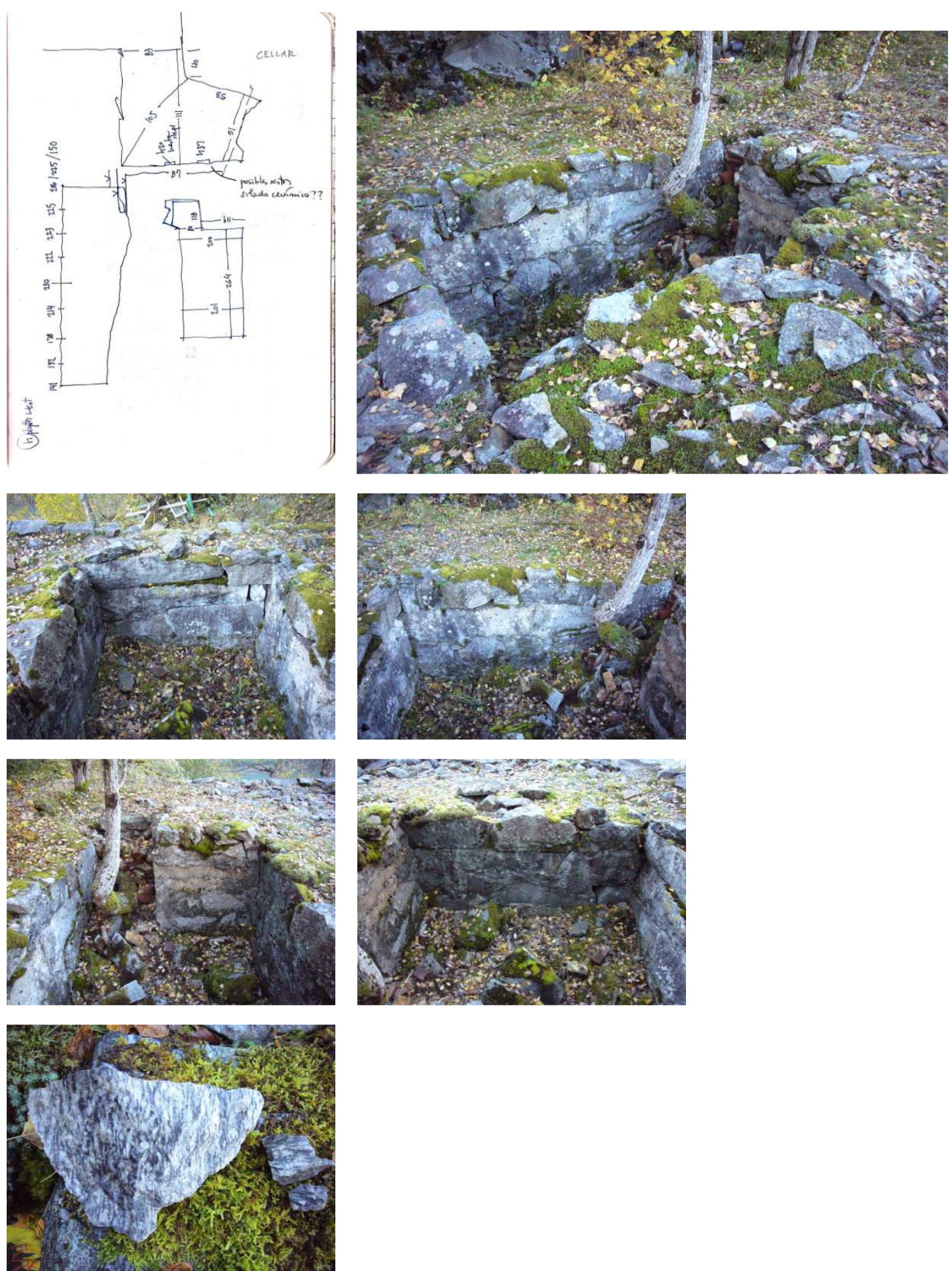

121. Toma de datos del hueco en el plinto [almacén/despensa] | 122. Hueco en el plinto, $260+116$ escalones x 205cm 123-126. Frentes interiores del hueco en el plinto 
con forma de «П» y un relleno de tierra por tongadas alternadas con mampuestos de menor tamaño, trabando el conjunto.

La plataforma se sitúa a $45 \mathrm{~m}$ de altura respecto al lago (medido sobre plano topográfico con curvas de nivel cada m). Las dimensiones, tal como se ha indicado ya, son prácticamente rectangulares, de $8,14 \mathrm{~m}$, el frente de acceso, 8,03 el recayente al lago, 7,05 el lado suroeste y 7,08 el noreste. El desnivel que salva, por el lado del escarpe, tomando como cota cero la superficie de la plataforma es de 2,24 m. En el frente del acceso se conserva un revoco de cal o cemento con forma de alambor de $8 \mathrm{~cm}$ de alto. En la plataforma se realizó un vaciado rectangular con una escalera de piedra, que confiere al hueco forma de L, de dimensiones $2,60 \times 2,05 \mathrm{~m}$ y escalera de 1,16 × 0,80 m. La escalera cuenta con 4 peldaños de piedra sin labrar. La altura hasta el borde de la plataforma es de 1,35 $\mathrm{m}$ pero debemos contar con la colmatación natural del fondo por el transcurso del tiempo.

El uso de una plataforma se justifica en Noruega por las condiciones climáticas - para separar la entrada de la considerable capa de nieve- y salvar en muchas ocasiones, como aquí, los acusados desniveles del terreno. En las granjas, el plinto sobre elevado se utilizaba para estabular el ganado y almacenar heno.

\section{Cerramientos}

La estructura de madera está vinculada con la tradición artesana de construcción de madera conocida desde centenares de años, pero Wittgenstein la aplica a su propio modelo, como ingeniero que es, está es su campo, el de las estructuras. En el área hemos podido comprobar que la casuística de modelos de construcción de casas de principios del s. XX es muy heterogénea. Básicamente se dan dos tipologías estructurales, la conocida como «log house» y la tipología de «stave construction». Ambas se han utilizado desde tiempos remotos (900 d.C.), y siguen siendo sistemas de construcción habituales. El primero responde a la formación de un espacio por mera superposición de troncos horizontalmente, 

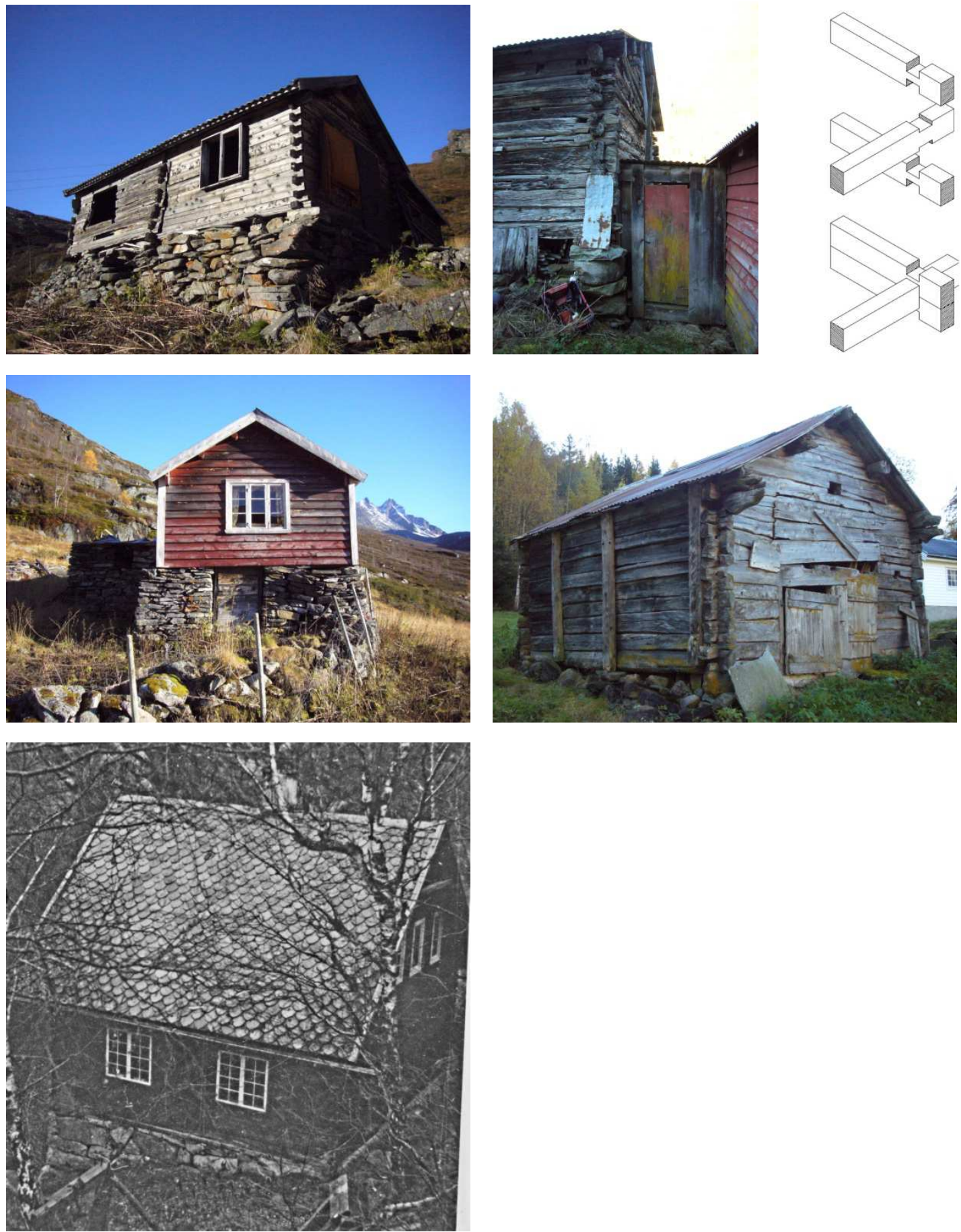

128-129. Antiguas Log constructions, Turtagrø y Fortun | 130 . Soluciones habituales de esquina 131-132. Antiguas Stave constructions, Turtagrø y Fortun

133. Fotografía obtenida por Andrew Penketh en abril de 2015 de la fotografía original de Ben Richards. El nuevo enfoque permite una mejor lectura de las aristas. Material inédito que ha permitido corroborar las dimensiones en altura de los troncos de fachada: 8" 
solucionando las esquinas a base de la intersección de los extremos de los troncos, con distintas técnicas. El segundo es el que construye un armazón de troncos o columnas -esta técnica se desarrolló especialmente en la construcción de iglesias en los siglos XII-XIV- que resuelve la estructura espacialmente, para después cerrar el conjunto con madera en posición vertical, como si de un panelado se tratase. Ambos sistemas son plenamente operativos e independientes y responden más a la tipología o a la necesidad que a un patrón concreto selectivo.

Las $\log$ constructions se utilizaban en general en los espacios habitables para las personas, mientras que las stave constructions se destinaban a graneros, almacenes pero también iglesias. Las primeras permitían un sencillo aislamiento, debido a la propia inercia térmica de la madera en espesor suficiente y por el contrario las segundas suponían una mayor economía material.

Wittgenstein eligió para su casa la robustez de la construcción de troncos horizontales. Implica esto que las cuatro fachadas forman una estructura autoestable, sobre la que deberán descargar las solicitaciones de la planta piso y de la cubierta. Del análisis de las fotografías de 1950 y con gran dificultad obtuvimos una primera medición de lo que parecían las dimensiones en alzado de las escuadrías de troncos utilizados por Wittgenstein en su casa. Así, en proporción a las dimensiones que sí conocíamos, como las ventanas de la fachada lateral y las dimensiones del plinto obtuvimos unas piezas de unos $20 \mathrm{~cm}$ de alto, lo cual encajaba con las observaciones de altura del antepecho de las ventanas de la fachada suroeste de cuatro troncos y medio hasta el alféizar de la ventana, medida que fijamos en 1,00 m. Puesto que en el interior el sistema de forjado descontará su espesor, medido sobre entablonado terminado es de 0,87 m, según se describe en planos:

«Enrique,

I think I am taking my hat off to you re 8".

I spent the evening with a photographer friend, coaxing the images.

The scans from MN have been filtered and probably contain more information if they can be rephotographed.» ${ }^{94}$

${ }^{94}$ Correspondencia electrónica de D. Connearn, 31.03.2015. Tras largos debates con Connearn conseguimos fijar la propuesta de troncos de 8" de las fachadas. 


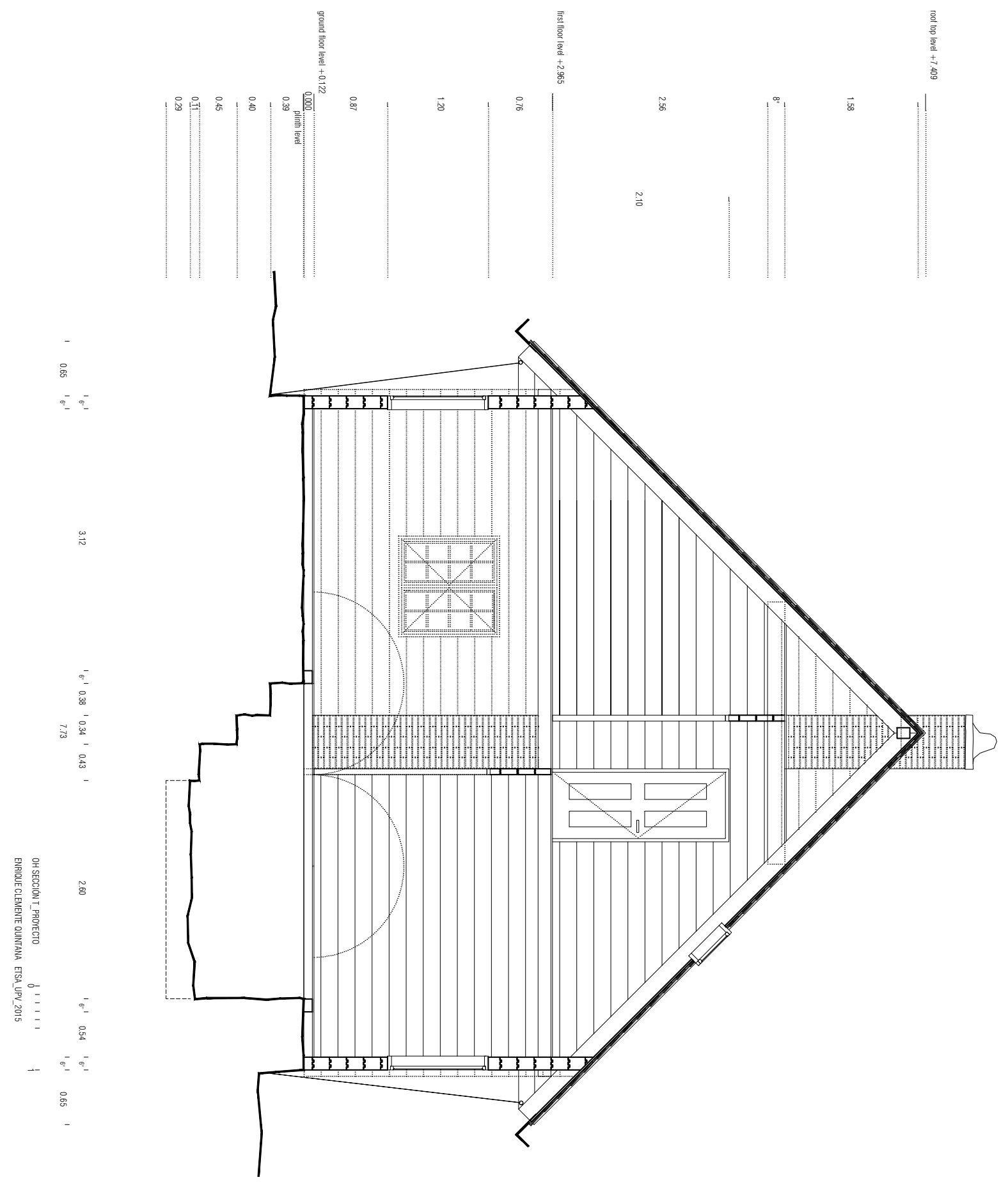

134. Sección transversal, proyecto de la Casa de Wittgenstein, 1:75, mayo 2015 
En Noruega, aunque se utiliza el sistema métrico, tradicionalmente en el ámbito de la construcción en madera se aplican medidas Imperiales, siendo habitual indicar las escuadrías de madera en tomme-pulgadas-y las longitudes en metros o en fot-pies. ${ }^{95}$

La medida obtenida cercana a $20 \mathrm{~cm}$ parecía encajar plenamente con una equivalencia de 8 " (20,32 cm). Tal dimensión se correspondía perfectamente con las proporciones del alzado de la casa, y nos permitió tener una referencia métrica muy importante para contar troncos en altura y determinar la altura de los testeros y por tanto de la casa en su conjunto, esto es, 15 troncos en planta baja, hasta nivel de forjado de ático y 34 troncos en total, lo cual nos daba unas dimensiones de 3,05 $\mathrm{m}$ a cara superior del forjado de planta ático y una altura de cumbrera de 6,90 m, al que habría que añadir el espesor de la propia solución de cubierta que se comentará más adelante.

No contábamos, sin embargo, con ninguna referencia de cuál podía ser las dimensión del espesor de los troncos que formaban los cerramientos estructurales, pero sí lo siguiente:

«iQuerido Sr. Drægni! Le agradezco mucho su carta y la fotografía que me envió en 23 de diciembre, 1914. He escrito a mi banco en Viena pidiendo que le transfieran mil coronas austríacas. Veo que mi casa costará más de lo esperado, y de lo que usted dijo que costaría. Cuando dejé Skjolden en julio, usted presumió haber recibido suficiente dinero por mi parte para completar la construcción. -En cualquier caso, no le enviaré más dinero hasta mi regreso a Skjolden. Saludos cordiales. Ludwig Wittgenstein.»96

Y la contestación un mes más tarde de Halvard Drægni:

«[...] Gracias por el dinero que he recibido. Cuando usted se fue, la idea era que usted pagaría a los trabajadores a su vuelta. Ahora he tenido que pagarles a todos ellos por usted. Llevo un cuidadoso listado de gastos para que usted pueda ver adónde va el

\footnotetext{
${ }^{95}$ El fot o pie como medida se toma en Noruega ya en tiempos modernos con los $30,38 \mathrm{~cm}$ del sistema anglosajón. La tomme 0 pulgada por tanto equivale a $1 / 12 \mathrm{f}$ es decir, $2,54 \mathrm{~cm}$ y el kvarter a $1 / 2 \mathrm{f}$, esto es, $15,24 \mathrm{~cm}$.

${ }^{96}$ Tarjeta postal de Wittgenstein a Drægni, 20.01.1915, en Åmås, op. cit., p. 99. Wittgenstein estaba en el frente de Cracovia.
} 


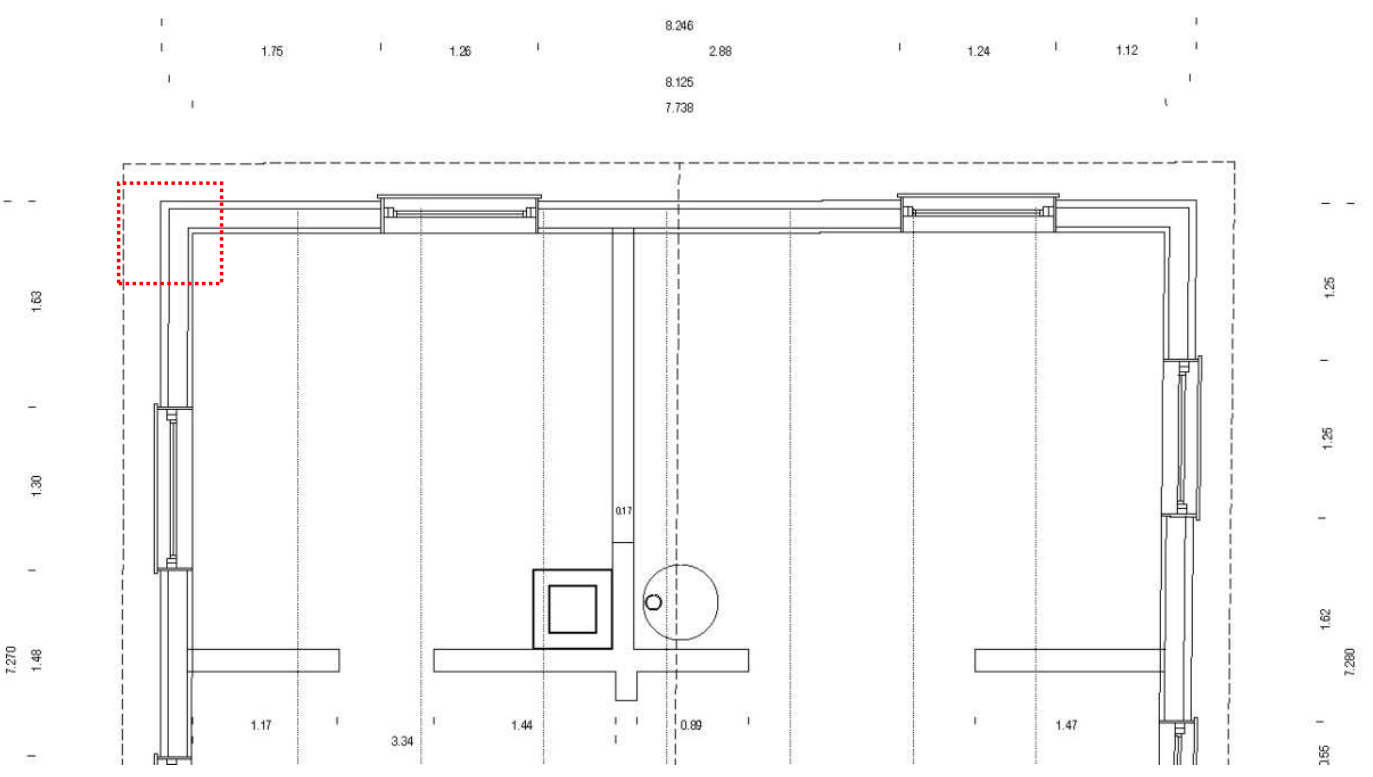

\section{LW's House 28th Mar 2015}

1) Wall timber. I have tried to fit some measurements with the first floor heigh.

I decided it was not possible to concur a bigger log section than $6 " 6,5^{\prime \prime} \times 8^{\prime \prime}$. Vatne's casements have about $16.5 \mathrm{~cm}$ so the walls must have similar dimension for construction reasons.

The number of logs we can -hardly- count in BR's photos are 4 below the window. I told you I found W behind the left window, so been tall 5 ft6" (Klagge) and arriving his head to the third pannel, I guess the logs had to be about 8 " $4 \times 8 "+1.5 \log$ (refers logs fitting) $=1.02 \mathrm{~m}$ (from stone plinth)
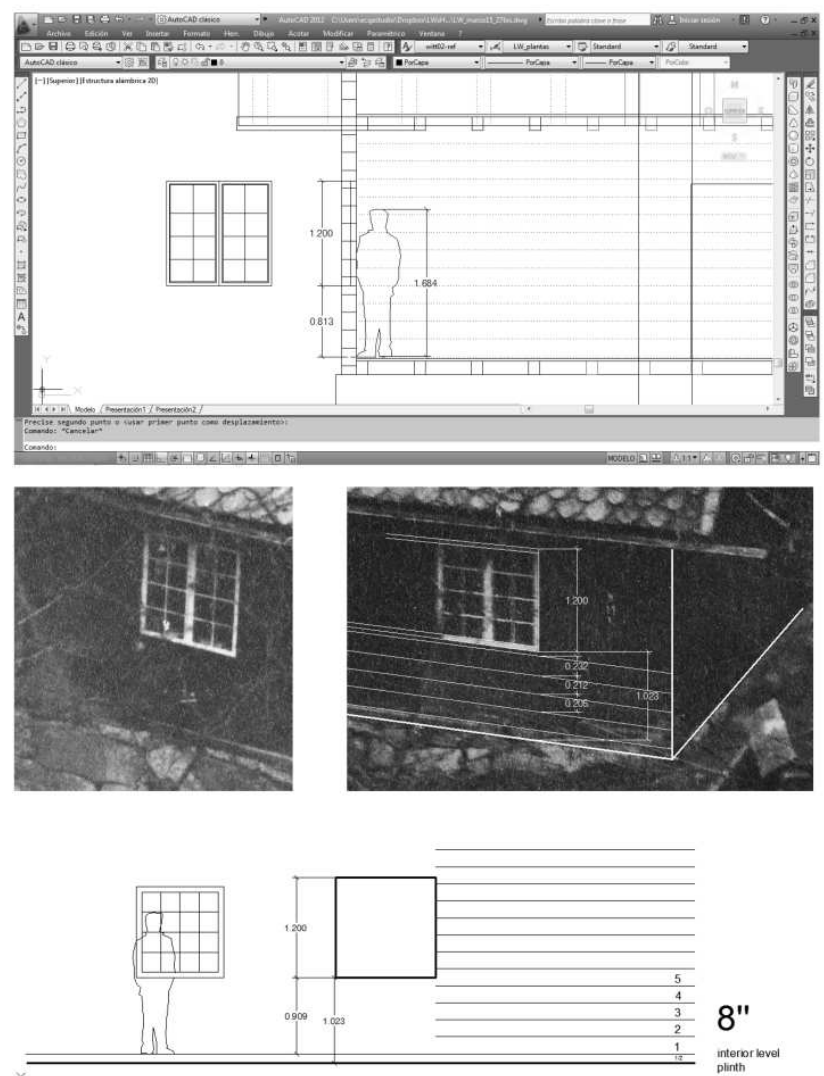

135. Estudio dimensional de la casa Bolstad, El notable esfuerzo por deducir una conclusión constructiva de una suposición constructiva se esclarecerá en el caso de que los Bolstad permitan la realización de catas en las fachadas

136. Estudios de las esquinas y del número de troncos en función de las alturas estimadas, octubre 2013 
dinero. Cuando uno construye con la solidez que usted lo ha hecho, siempre acaba

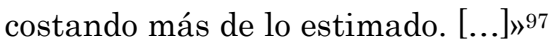

En conversación con Vatne y Kåre Bolstad, refieren que las paredes eran «bastante anchas, de 6" - 8”.» Este dato de momento lo consideramos de apoyo porque ya habíamos verificado en otras fases de la investigación que la memoria de las personas se recrea en cada ocasión en que se reconstruye el recuerdo. Pero el hecho de que Drægni dijera a Wittgenstein que su estructura era «sólida» era una referencia a tener en cuenta.

Hasta 2013 no pudimos resolver el enigma del espesor de los troncos, puesto que en las fotos de Ben Richards, pese a los denodados esfuerzos por ver más allá de lo posible, no tenían suficiente nitidez para apreciar los extremos de los troncos en las esquinas de las fachadas.

En la visita realizada en octubre de 2013 nos permitieron tomar algunas medidas del interior de la casa de Gunnar Bolstad, pudiendo así considerar la solución constructiva de los cerramientos. El análisis de los alzados y de las dimensiones y el dibujo arquitectónico preciso fueron herramientas necesarias para poder utilizar la casa de Bolstad como base de datos: cuanto más supiéramos de la casa reconstruida, más cerca estaríamos de la original. Desgraciadamente no nos han permitido analizar con mayor detenimiento el interior.

Aún así, teniendo en cuenta que tanto por dentro como por el exterior los muros de fachada están revestidos -un panelado de madera sobre rastreles, el tronco original y un revestimiento de fibrocemento por el exterior sobre un enrastrelado, pudimos tomar una medida del espacio interior que correspondía a la anchura de la fachada original recayente al lago de 7,738 m. Esa misma fachada, medida por el exterior es de 8,246 m. Hemos supuesto, que en lógica, Bolstad tuvo que aserrar las esquinas pasantes de los troncos originales para

\footnotetext{
${ }^{97}$ Tarjeta postal de Wittgenstein a Drægni, 04.02.1915, en Åmås, op. cit., p. 102. No sabemos cuáles fueron los acuerdos económicos entre ellos pero sí hemos localizado en el Fylkesarkivet documentos inéditos de los libros de cuentas de Drægni.
} 

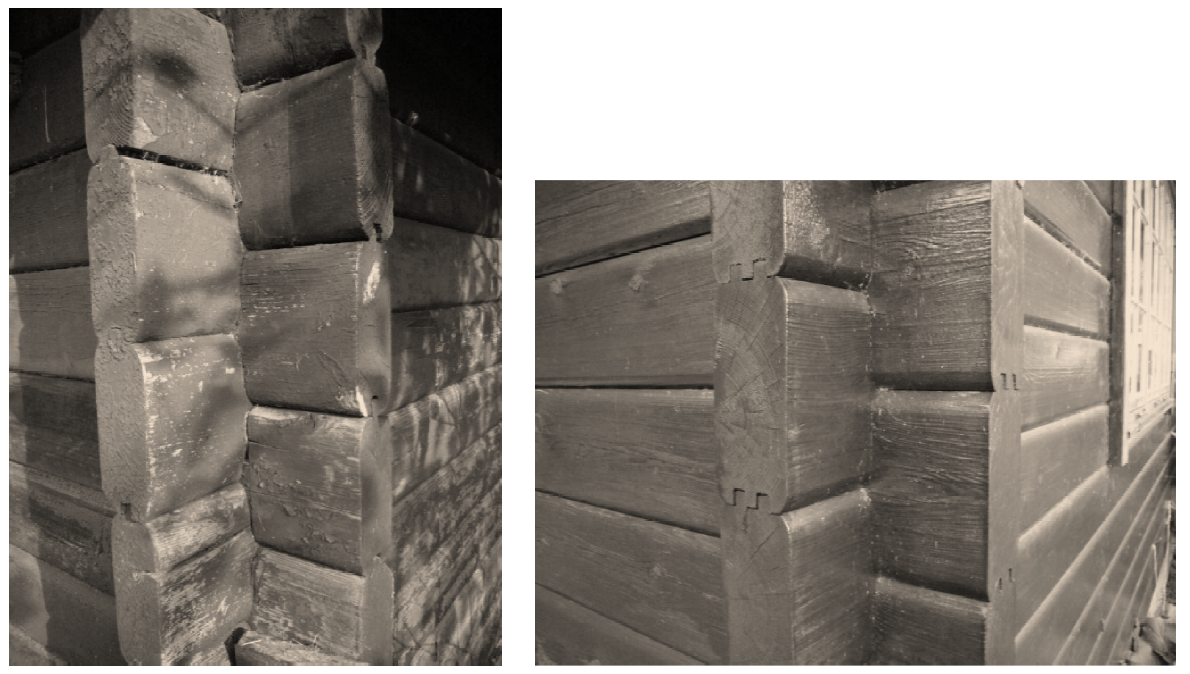

15 APQ 2015

CAMBRIDE

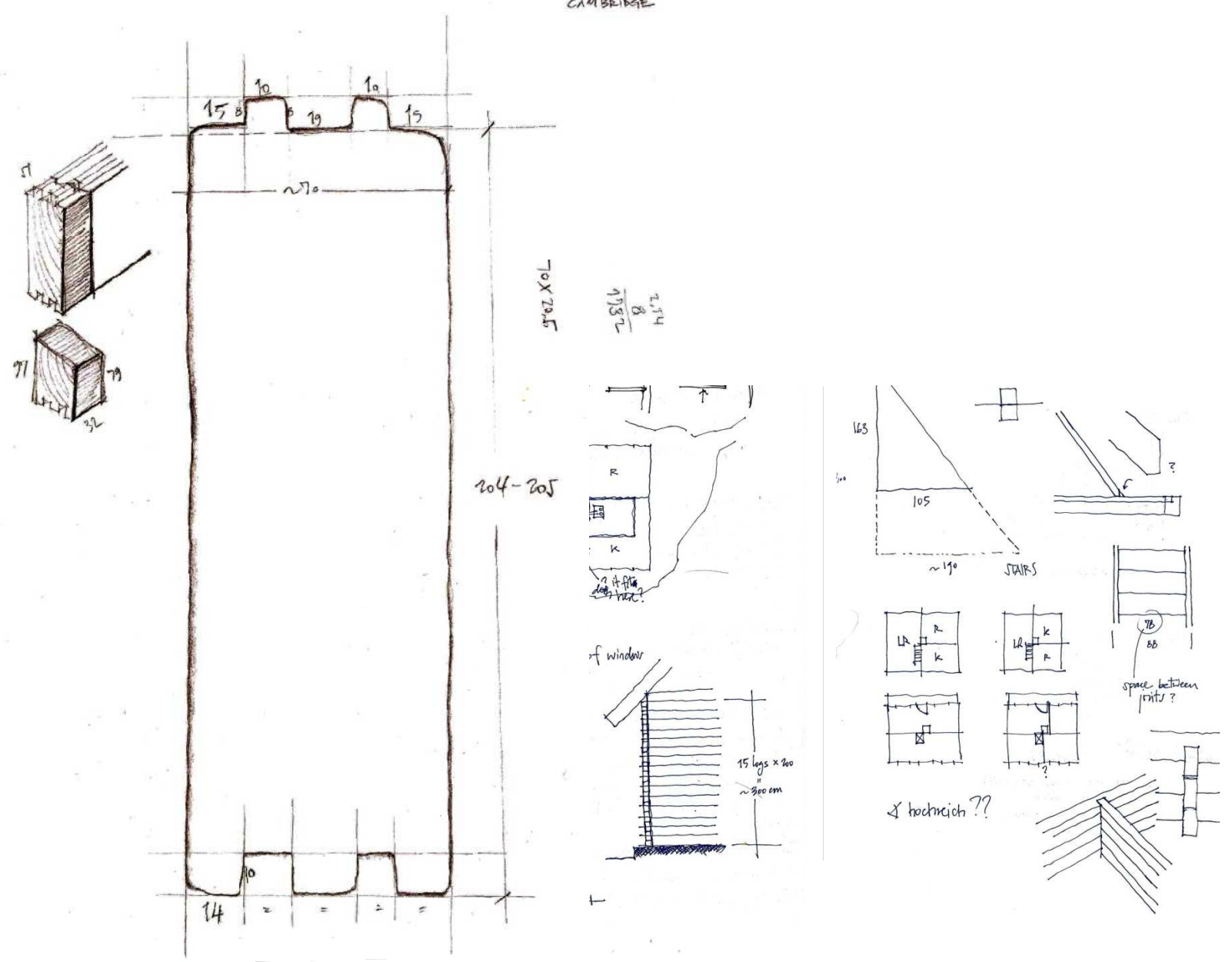

137. Esquina tipo crossing joint con troncos escuadrados y pestaña simple, cobertizo Bolstad ｜ 138. Mismo sistema, pestaña doble, cabaña Nymoen Leirplass 139. Silueta de la sección de tronco original de la tabiquería interior y estudios de posibles soluciones del número de troncos y ensambles 
volverlos a montar en su casa, sustituyendo el nudo por empotramiento entre la madera por un recio atornillado. Esto lo hemos deducido de contar con que el plinto de hormigón del semisótano de los Bolstad mide 8,12 m, tan cercano al original que debe sin duda reproducir la misma longitud de los troncos. Asumimos que el revestimiento externo supone el incremento de $6 \mathrm{~cm}$ por cada lado de la fachada.

Restando los vuelos del panelado exterior y la medida interior obtenemos una medida de $8,125-7,738=0,387 \mathrm{~m}$, esto es un espesor de cerramiento de $19,35 \mathrm{~cm}$. Al descontar un mínimo panelado interior con su rastrel, en torno a 4 $\mathrm{cm}$, vimos que la medida restante que debía corresponder al espesor del tronco original era de 15,35 cm, exactamente 6”. Debía ser correcta.

Fijamos en ese momento las medidas de los cerramientos en troncos de 6" $\mathrm{x}$ 8”, que se correspondían con los referidos por Kåre Bolstad de la casa de su hermano.

El sistema de montaje de troncos pasantes es sencillo, se arranca con medio tronco en dos fachadas opuestas y con tronco entero en las transversales, de forma que sucesivamente podamos encajar troncos completos en las esquinas, retallando sólo la mitad del tronco. El detalle exacto del encuentro es imposible de apreciar en las fotografías y no lo conoceremos con detalle hasta que se desmonte parcialmente para su estudio el revestimiento de las fachadas de Bolstad. Por ello y por ser una posibilidad plausible hemos supuesto que utilizaron «butt\&pass» o "crossing joints», como se conoce el sistema de encajar sencillamente medio tronco en otro medio, tal como todavía vemos hoy en construcciones de casas de madera contemporáneas en la misma zona.

Una aportación fundamental se produjo en diciembre de 2014, cuando Ivar Oxaal puso a disposición de Dawn Wilson en una visita a Hull algún pequeño material que Oxaal había recogido en su viaje a Skjolden en 1984. Se trataba de dos secciones de madera, una de ellas completa y otra parcial, así como dos o tres clavos de hierro. Lo importante del hallazgo fue poder determinar que las dimensiones de los troncos eran efectivamente de 8" de altura, confirmando nuestra propuesta y que debían de corresponder a tabiques interiores puesto que 

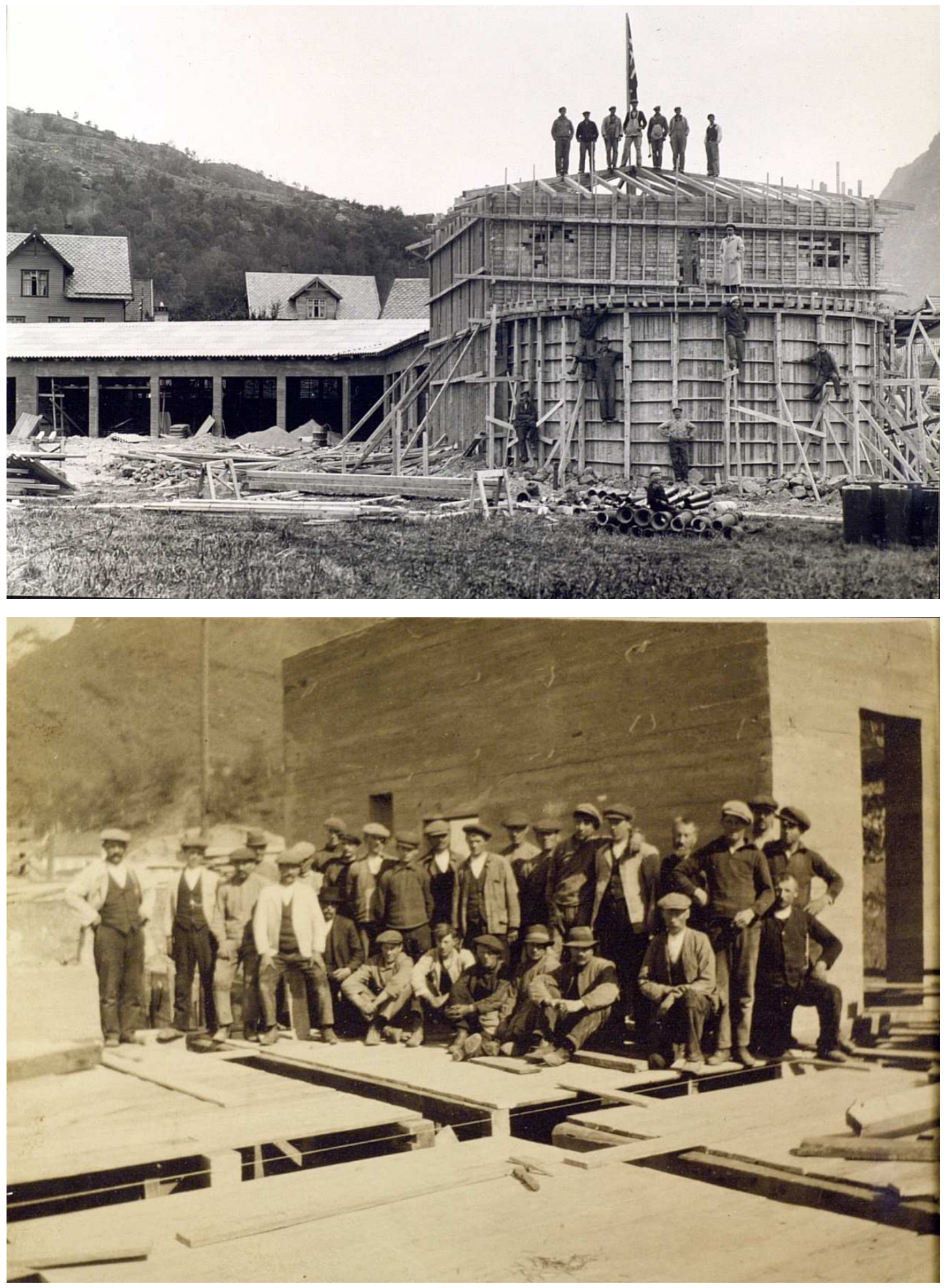

140. Construcción en madera, Luster, 1920. Archivo Halvard Drægni, Fylkesarkivet, octubre 2013 141. Construcción en madera, Luster, 1920. Archivo Halvard Drægni, Fylkesarkivet, octubre 2013. 
eran demasiado ligeros para ser exteriores y porque tenían $70 \mathrm{~mm}, 2$ "3/4, con lo que se reforzaba la idea de que los exteriores pudieran tener el doble de espesor, 6”. El material era de primera calidad, Wittgenstein parece que pidió a Drægni que su casa se construyera con madera proveniente de Frønningen, una pequeña localidad de apenas cien habitantes - un señorío en realidad- a unos ochenta kilómetros de Skjolden, en el Sognefjord, en la que desde el s. XVII se producía una de las mejores maderas del oeste del país, sus aserraderos eran famosos incluso entre los ricos de Bergen. ${ }^{98}$

Las principales especies maderables noruegas son el bjork, abedul blanco (Betula pendula) y furu, pino o abeto rojo (Pinus sylvestris var. lapponica). Ambas maderas tienen un peso específico y una tensión de trabajo a la flexión similares $\left(544 \mathrm{Kg} / \mathrm{m}^{3}\right.$ el abedul y $520 \mathrm{Kg} / \mathrm{m}^{3}$ el pino; ambos tienen una $\sigma_{\text {adm }} \approx 560$ $\mathrm{Kg} / \mathrm{cm}^{2}$ ). El abedul, por ser más putrescible se utiliza básicamente en solados y el pino sí se aplica en viguería y construcción de paredes.

De la inspección visual de los restos encontrados por Oxaal y en nuestra visita de 2013, se deduce que toda la estructura de la casa era de pino rojo. De la pieza de Oxaal hemos podido considerar que el sistema de apoyo de los troncos era elaborado, con una doble acanaladura, machihembrada, que en los tabiques interiores hemos podido constatar que era de 10 x $14 \mathrm{~mm}$ y hemos supuesto en proporción para los exteriores de 16 x $20 \mathrm{~mm}$. La acanaladura resuelve perfectamente el aislamiento al aire y al agua del exterior y pone de manifiesto la destreza de los aserraderos de Frønningen.

\section{Elementos horizontales}

El sistema estructural horizontal de la casa se ha planteado desde la lógica constructiva y la métrica. Sobre el plinto era necesario colocar un entramado de vigas para formar una superficie horizontal para el entablado del suelo. Sabemos que el suelo era de madera por Francis Skinner:

\footnotetext{
${ }^{98}$ Frønningen es la finca forestal más extensa del oeste de Noruega. De sus 65000 ha, 50000 están cubiertas de bosques. En http://www.nrk.no/sf/leksikon/index.php/Fr\%C3\%B8nningen
} 

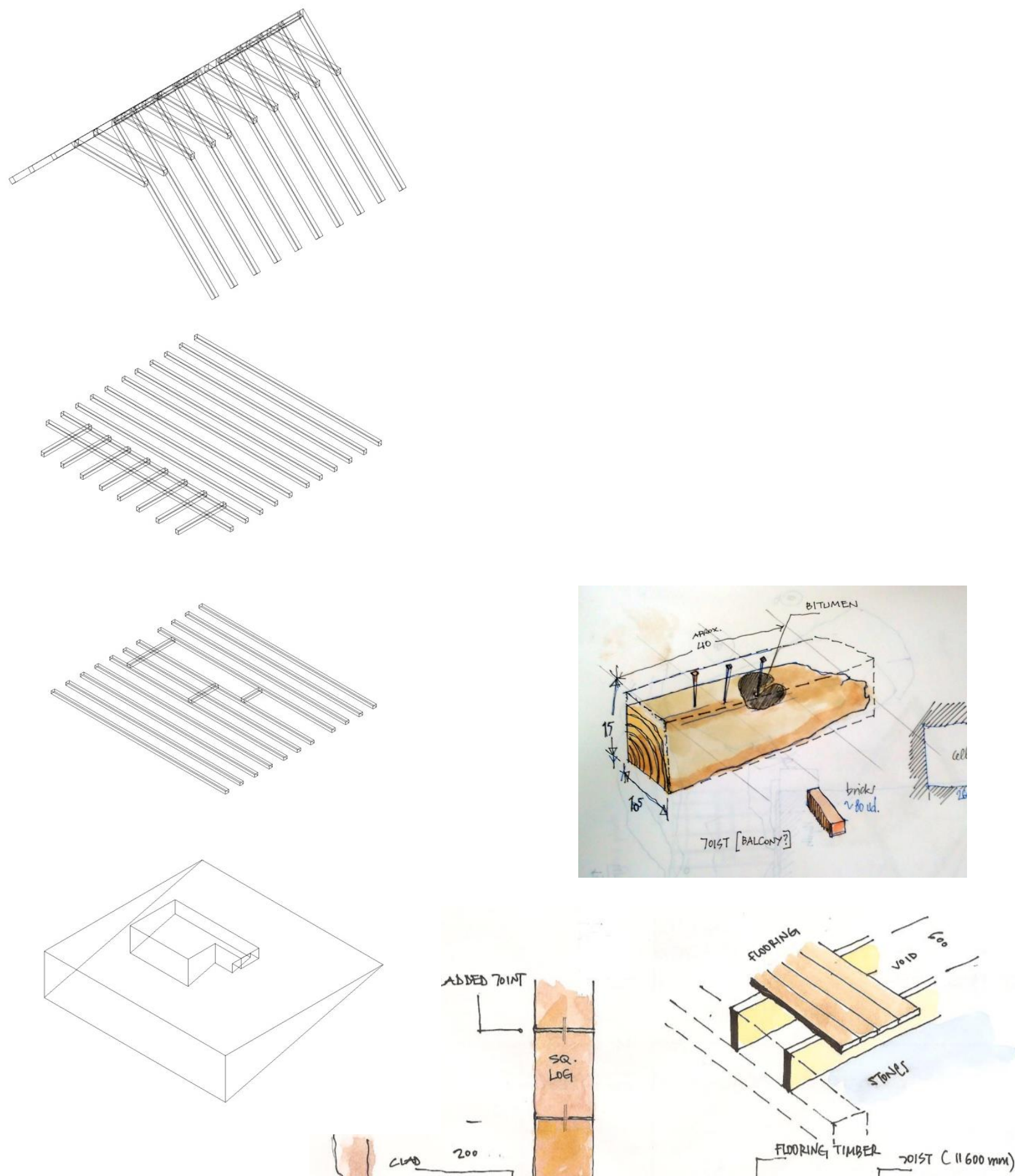

142. Esquema sistema horizontal de sustentación y cubierta

143. Resto de vigueta del balcón localizado en el lugar aproximadamente $11 \times 15 \mathrm{~cm}$ de sección

144. Apoyo viguetas en plinto 
«Pienso mucho en ti. También pienso en lo encantador que fue limpiar la habitación contigo. Cuando regresé decidí que no volvería a extender mi alfombra aunque hubiera sido sacudida, porque sé que no puedo limpiarla adecuadamente. Ahora tengo que barrer mi habitación. Me gusta hacerlo porque me recuerda los días que pasé contigo. Me alegra haber aprendido a hacerlo.. ${ }^{99}$

Se refiere Skinner a la costumbre -algo laboriosa- que tenía Wittgenstein de almacenar y más tarde utilizar las hojas húmedas del té, una vez desechadas, para extenderlas por el suelo y barrer, arrastrando con las hojas la suciedad que pudiera haber sobre las tablas de la tarima. Esta costumbre la mantuvo también cuando vivió algunos meses en la alquería del hermano de Drury en Rosroe, Irlanda. ${ }^{100}$

Como decíamos, sobre el plinto se colocó un número indeterminado de viguetas, probablemente calzadas con cuñas para poder asegurar la estabilidad del entablado interior y su planicidad. Hemos considerado que la separación media entre las viguetas, tanto en esta tarima de planta baja como en la del ático era de $60-70 \mathrm{~cm}$, lo cual hemos podido deducir por haber encontrado en la visita de octubre de 2013 algunos restos de madera originales de la casa. Se encontraban en un lugar de muy difícil acceso, en la ladera, a unos quince metros en dirección al lago. Con cierto riesgo los pudimos recuperar y tomar datos y fotografías. La tabla encontrada es un resto probablemente del solado del balcón, tiene unos 520 × 110 × $20 \mathrm{~cm}$ y un machihembrado longitudinal de 7 x $7 \mathrm{~mm}$. En la misma área de la ladera hallamos un resto de lo que sin duda fuera en su día una vigueta del balcón y por lógica constructiva del interior de la casa. Se trataba de un elemento de unos $200 \mathrm{~cm}$ y sección -muy deteriorada tras 99 años a la intemperie- de 150 x $130 \mathrm{~mm}$ aproximadamente. Se apreciaba una marca longitudinal a lo largo de la pieza y todavía conservaba uno o dos clavos sobre la marca, lo cual indicaría la situación de clavado de las piezas del entablado. Tal dimensionado respondería a una escuadría de 5" x 6" en sistema anglosajón, que hemos considerado adecuado para un entrevigado de $60-70 \mathrm{~cm}$.

\footnotetext{
${ }^{99}$ Francis Skinner en carta a Wittgenstein, octubre 1937. En Monk, op. cit. p. 349

100 Richard Wall, Wittgenstein in Ireland (London: Reaktion Books, 2000) p. 92. En realidad no hay demasiada diferencia con nuestra costumbre de utilizar el serrín de madera con idéntico fin.
} 

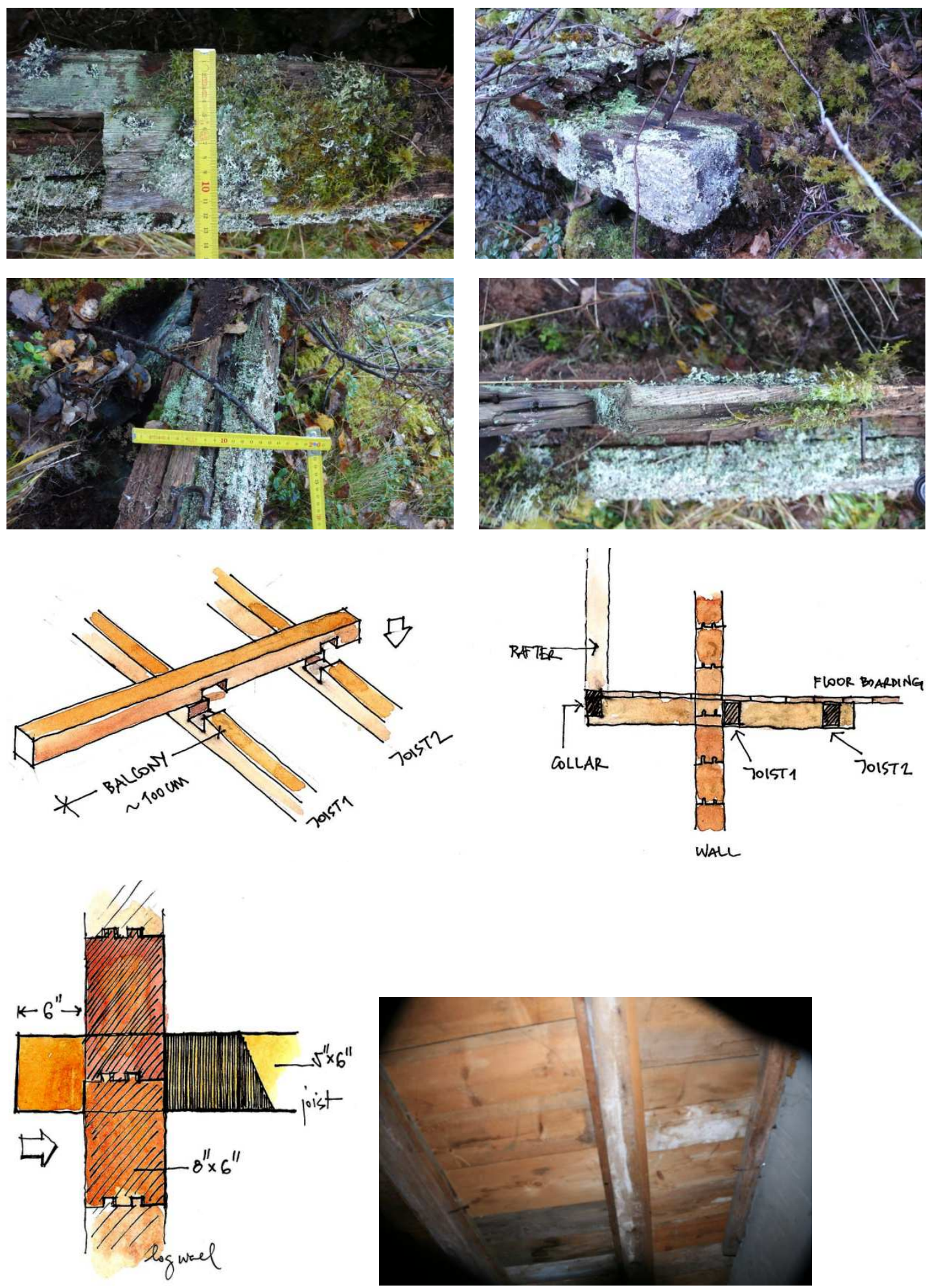

145-148. Restos de materiales localizados en el lugar

149. Solución de proyecto estructura del balcón

150. Sistema de atirantamiento de proyecto, viguetas de forjado encajadas en muros de cerramiento | 151. Fotografía forjado planta baja casa Bolstad 
Las viguetas se colocarían en paralelo a la fachada del lago, es decir en la dirección mayor, de unos $8 \mathrm{~m}$ de longitud. Tenemos que tener en cuenta que no suponen longitudes excepcionales en Noruega y contando con la máxima calidad exigida a la construcción por Wittgenstein son dimensiones plausibles. Tengamos en cuenta además que la luz de las viguetas quedaba interrumpida por la distribución transversal que separaba la cocina de la sala, por lo que la luz mayor a salvar con esa sección se reducía a 4,36 m.

Inevitablemente las viguetas deben asegurar el arriostramiento lateral del conjunto por lo que la solución tradicional es hacerlas proyectar hacia el exterior y mediante una mella en la vigueta, conformando un tirante entre ambos extremos de la casa.

De la fotografía desde el lago de Ben Richards hemos podido deducir que la estructura del balcón era perpendicular a la fachada, con ciertas dificultades hemos contado 8 viguetas; esto supone una estructura adicional que debe resolverse convenientemente con el entramado interior. El proyecto propone una solución que aprovecha el mismo detalle de las esquinas pasantes de los troncos de fachada, llevando las viguetas hasta la segunda línea de estructura por el interior y contar además con la compresión que produce el peso propio de la fachada desde la línea del balcón hasta el ápex del muro testero. La longitud del vuelo, obtenida del dibujo de restitución fotogramétrica, se ha fijado como de $1,05-1,10 \mathrm{~m}$.

En nuestra fugaz visita con Vatne y Kåre Bolstad del 14.10.2013 al interior de la casa familiar, pudimos verificar visualmente que las viguetas del suelo de planta baja tenían de una sección similar a la aportada aquí, pero no tuvimos oportunidad de medirla en condiciones y comprobarla. ${ }^{101}$

\footnotetext{
${ }^{101}$ La exhaustiva toma de datos del exterior de la casa Bolstad que ha permitido su dibujo pormenorizado, se realizó en dos jornadas, del 10.10.2013 y sobre todo del 12.10.2013, en la que se dedicaron unas 6 horas a medir, anotar y fotografiar la casa y el entorno con detalle. Nuestras fotografías en el interior de la casa, del 14.10.2013 fueron realizadas sin poder mediar reflexión, en menos de 15 minutos.
} 

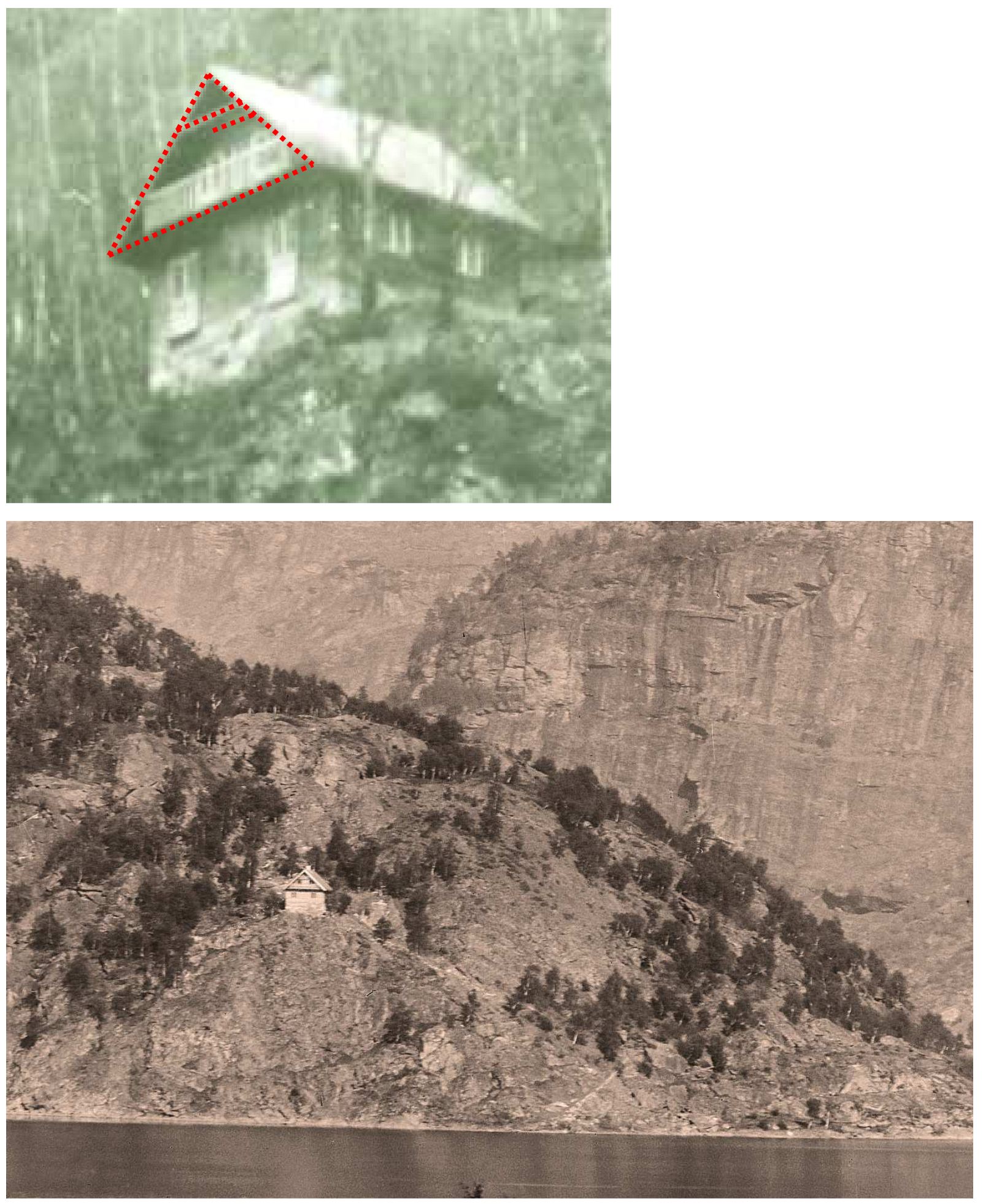

152. Imagen $n 0519$ Wittgenstein Archive Cambridge, detalle ampliado. Esquema de estructura de cubierta «visible»

153. Fotografía de Samson Brathole, fecha anterior a 1920, tamaño real $12 \times 16 \mathrm{~cm}$, Fylkesarkivet, Leikanger, 11.10.2013 


\section{Cubierta}

La estructura de la cubierta se ha podido re-proyectar, con bastante dificultad a partir de las fotografías de Ben Richards. De ellas se desprende, al menos de los elementos que quedan vistos, que está formada por un sistema de cerchas de tres elementos, dos inclinados y un tirante horizontal, un sistema de cercha de madera de par y nudillo.

La escasa nitidez de la fotografía, tanto en la vista desde el lago como en la vista lateral y su pequeño tamaño han dificultado enormemente la lectura y toma de decisiones respecto a estos elementos. Empezando a proyectar por lo que sí vemos, en la fotografía desde el lago se aprecian dos cerchas de cubierta, una en el mismo límite de los faldones de cubierta, en la que se ve claramente un tirante -nudillo- colocado a un tercio aproximadamente de la cúspide de la cercha. Además, entre las sombras de la fotografía y matizando el contraste y brillo con herramientas de tratamiento de imágenes hemos podido localizar un tirante a nivel del extremo de los pares de la cercha, que debía servir como apoyo adicional del conjunto del balcón lineal y que tiene sentido estructural sobre todo a efectos de empujes de viento, puesto que la fachada está muy expuesta en el borde de la montaña y con el condicionante añadido del vuelo de los faldones hacia el lago hacía necesario un elemento de estabilización horizontal a tracción.

Por el motivo contrario, en la foto lateral podemos ver en la fachada opuesta, donde deberíamos encontrar ese tirante, que este no aparece. Nos hace ver esto que Wittgenstein está en su territorio como ingeniero, no va a proyectar elementos innecesarios ni a forzar simetrías. En esta fachada únicamente podemos ver con claridad el nudillo superior que estabiliza los cabrios.

Volviendo a la imagen desde el lago, y gracias a las sombras, que produce el sol, como también lo podemos confirmar en la imagen tomada por Brathole hacia 1920, apreciamos una segunda cercha con su nudillo prácticamente sobre el plano de la fachada, esto implica que el sistema estructural de cubierta, que sin más datos podía ser de cabrios y correas o sólo de cabrios, según el esquema de par y nudillo, nos permite decidir que debía ser este último, una cercha por cada metro, aproximadamente, de longitud de cubierta. 

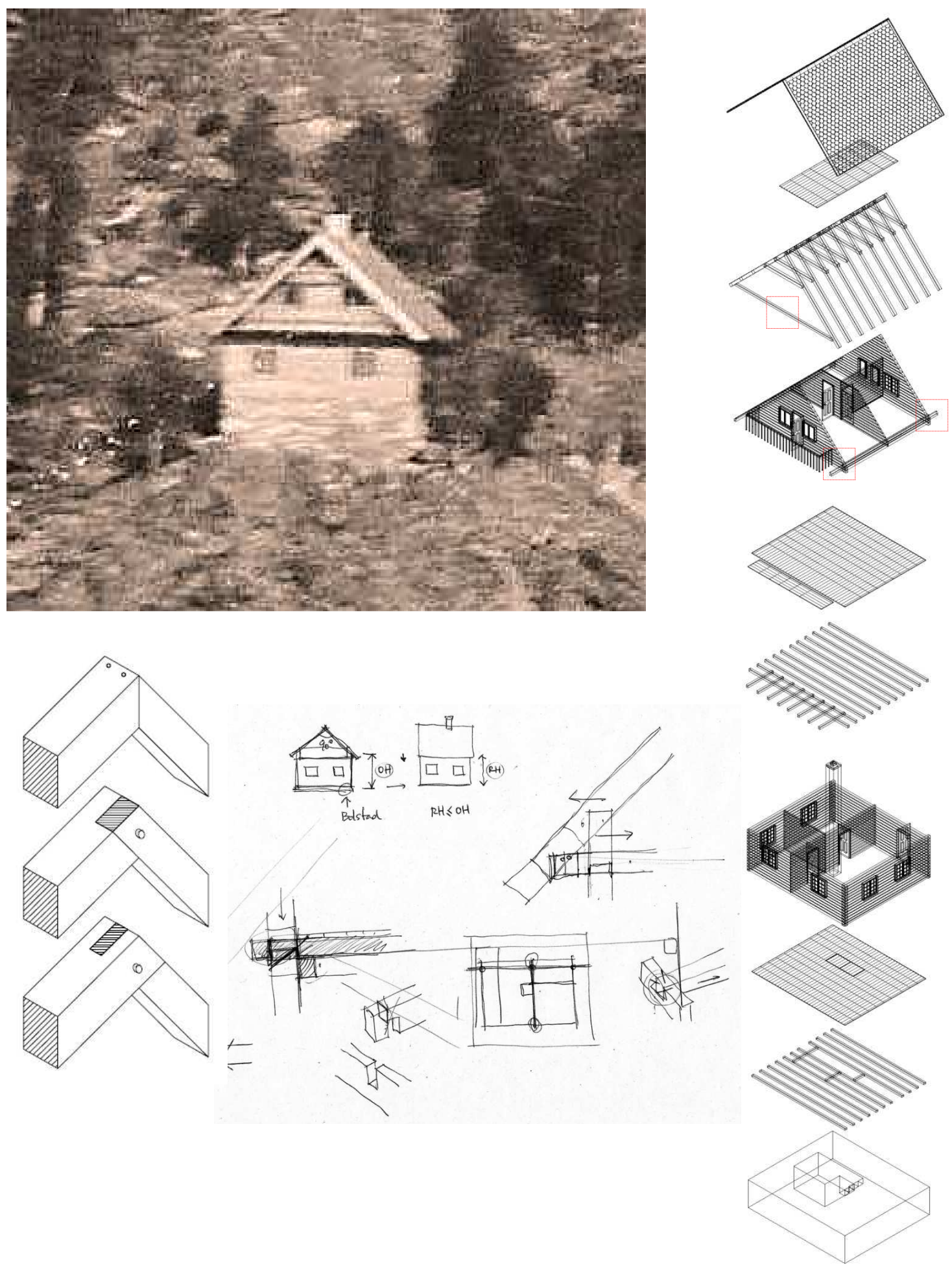

154. Detalle fotografía de Samson Brathole, muy ampliado. Podemos apreciar, pese a la distorsión del escaneado, las sombras arrojadas por la estructura de los nudillos sobre la fachada y con bastante claridad el tirante exterior:

155. Detalles de unión entre pares y anclaje de cubierta y tirantes de viguetas del forjado en los cerramientos laterales

156. Perspectiva del conjunto de elementos constructivos de la casa. Se aprecia que el último tronco de los cerramientos laterales sostiene en ménsula las cerchas de los extremos y el tirante entre los extremos de los pares recayentes al lago que servirá de apoyo adicional a las viguetas en voladizo del balcón 
El tejado con correas se suele utilizar en cubiertas en las que por economía de material o porque la propia dimensión de los elementos así lo requiera haya que unir las cerchas entre sí horizontalmente. Si Wittgenstein decidió utilizar un sistema de cercha cada metro es prácticamente seguro que no requiriera de correas laterales. Sí es necesario un apoyo horizontal a nivel de extremo del cabrio y que podía hacerse simplemente prolongando el tronco de las fachadas laterales a modo de ménsula. Esta solución la podemos ver en la casa de Halvard Drægni, que construyó el mismo carpintero. ${ }^{102}$

Tomando distintas referencias de proporción a partir del dibujo llegamos a la conclusión de que las secciones de madera debían ser de aproximadamente $6 \frac{1 / 2}{2}$ x 8 " y los nudillos de una sección parecida. En la fotografía lateral vemos que son bastante más gruesos que una simple plancha.

Puesto que se trata de una de las partes del edificio con mayor solicitación de carga, estática -el peso propio del tejado de pizarra es importante y no lo es menos la cantidad de nieve que se prevé se pueda acumular sobre él-y la dinámica -en esta área la exposición al viento es determinante-, decidimos hacer una verificación mediante cálculo de la estructura que planteábamos con las cargas «oficiales» propuestas por el Eurocódigo 1(UE).

El resultado fue alentador puesto que con separaciones entre ejes de aproximadamente $1 \mathrm{~m}$, concretamente de $0,93 \mathrm{~m}$, incluso con la carga de nieve de $2,5 \mathrm{kN} / \mathrm{m}^{2}$ y de peso propio de la cubierta de pizarra de $1,2 \mathrm{kN} / \mathrm{m}^{2}$, pudimos comprobar que la estructura era coherente desde el punto de vista del cálculo. ${ }^{103}$

En este caso, la casa de Bolstad no nos permitía establecer analogías puesto que en la reconstrucción, Gunnar decidió, como se ha dicho, girar la cubierta $90^{\circ}$, por lo que de los $8,90 \mathrm{~m}$ de longitud de cubierta de la casa original que mantenía hasta tres cerchas vistas, Bolstad reconstruyó una cubierta de $8,78 \mathrm{~m}$ de longitud sobre una fachada de longitud $8,20 \mathrm{~m}$, quedando pues ocultas desde el exterior cualquier información sobre sus dimensiones.

\footnotetext{
${ }^{102}$ Referido por Harald Vatne, en conversación personal, Skjolden, 10.10.2013. Pero no hemos podido saber quién pudo ser tal carpintero.

${ }^{103}$ Pese a que se ha dado el dato de la tensión admisible de la madera de $560 \mathrm{~kg} / \mathrm{cm}^{2}$, nos pareció excesiva a la hora de modelizar un cálculo estructural por lo que recurrimos a una madera C27, que supone un detrimento, del lado de la seguridad por tanto, de la resistencia hasta casi un $50 \%$ de la establecida genéricamente.
} 

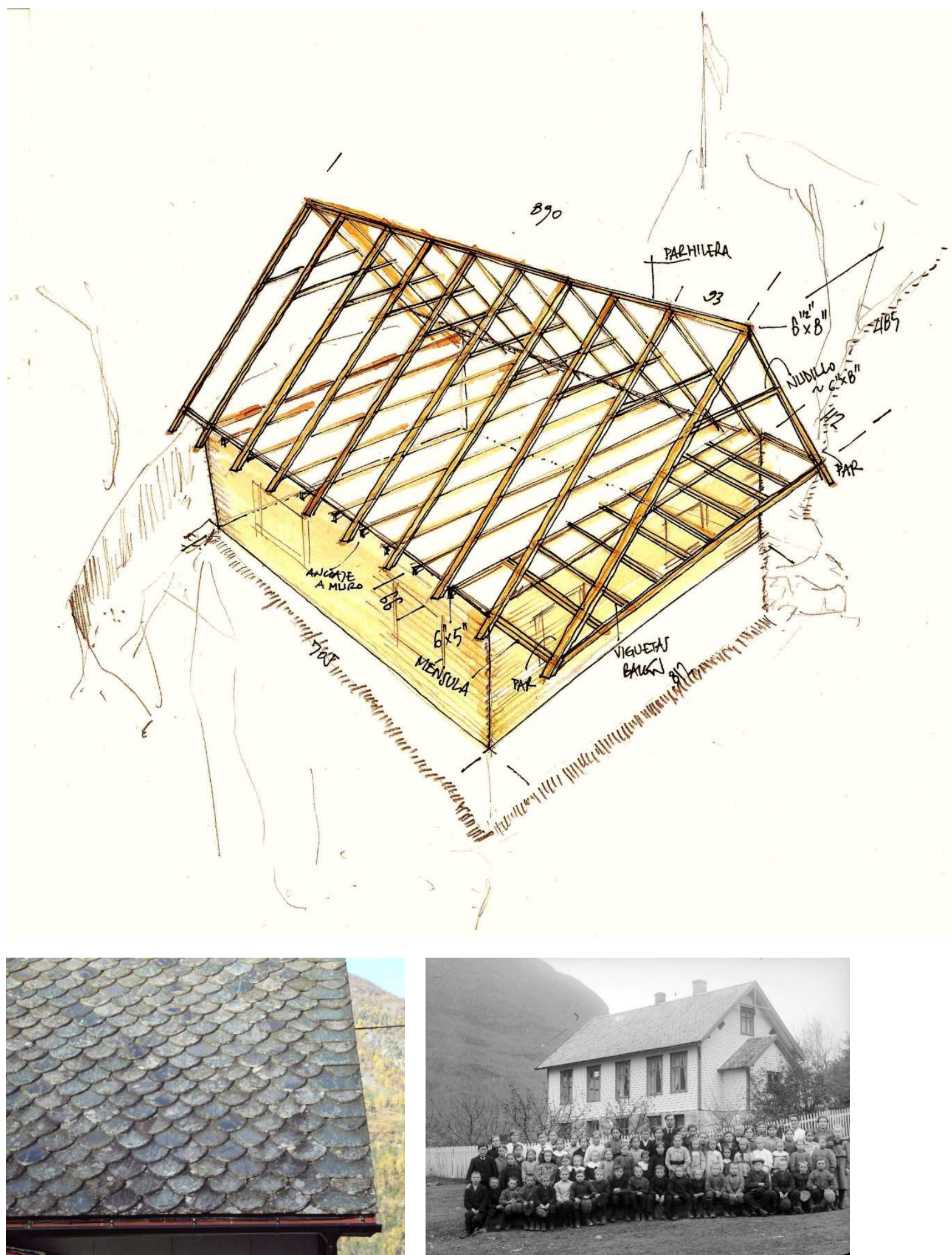

157. Esquema estructural de la cubierta y su interacción con el forjado de planta baja, el balcón y de este con los muros laterales 158. Tejado de pizarra en casa de los Bolstad | 159. Cubiertas de pizarra en la escuela de Skjolden, 1919 
El tejado se recuperó en su mayor parte para la reconstrucción de la nueva casa en el pueblo en 1957. Sin duda uno de los materiales más valiosos fueran las tejas de pizarra. Así lo refiere Rudy Vrooman en un testimonio que recogió en Skjolden en 1978:

«Dear Enrique,

What a wonderful but difficult idea. I am sorry to say I cannot help you very much.

In 1978 I visited Skjolden and I had contact with people who remembered Wittgenstein staying there. After W's death the house was inherited by Arne Bolstad who W knew as long as he had been coming to Norway. If I remember well Arne's father had helped to build the house. Arne looked after the house as well as he could in times W did not stay there. I was told that it was very popular by the youth in the later years as a love nest and for partying. Because it was made of first class material Arne broke the house down in the fifties to rebuild his own; especially for the roof. None can be found of the remains.

I met an alcoholic Norwegian journalist who had written some articles about W's stay in Skjolden. From people who had known $\mathrm{W}$ he had lent material which he never gave back to them. He showed me this. Some things where interesting for biographical reasons, but there was nothing about the house.

No photos, nothing...

So I am sorry I cannot help you more. There is one suggestion I can give you:

Try to get information at the council of Skjolden. Maybe their Land Registry has documentation or a building permission from the time it is built.

I wish you a lot of success and would be very greatful if you would keep me informed about this most interesting project.

Kind regards,

Rudy» ${ }^{104}$

El tejado de pizarra sin embargo, parece un elemento relativamente común, cuando menos en la actualidad en el área. Como se ha dicho, Luster pertenece a una región geológicamente compuesta por rocas metamórficas, por lo que la pizarra es un material de fácil acceso en toda la zona. Es cierto que el sistema tradicional de construcción noruego de cubiertas vegetales era también habitual en otras épocas, pero se destinaba más frecuentemente a cabañas y no a casas. Las fotografías históricas que hemos podido localizar de Skjolden muestran tejados en general de pizarra.

De hecho, con el fin de definir con precisión el proyecto se ha realizó un levantamiento gráfico del tejado de la casa de Bolstad y de la casa original para verificar -cualquier elemento sirve de referencia- las decisiones dimensionales que íbamos asumiendo en los planos.

${ }^{104}$ Correspondencia electrónica, 17.09.2011. Rudy Vrooman es un caricaturista y fotógrafo holandés. 

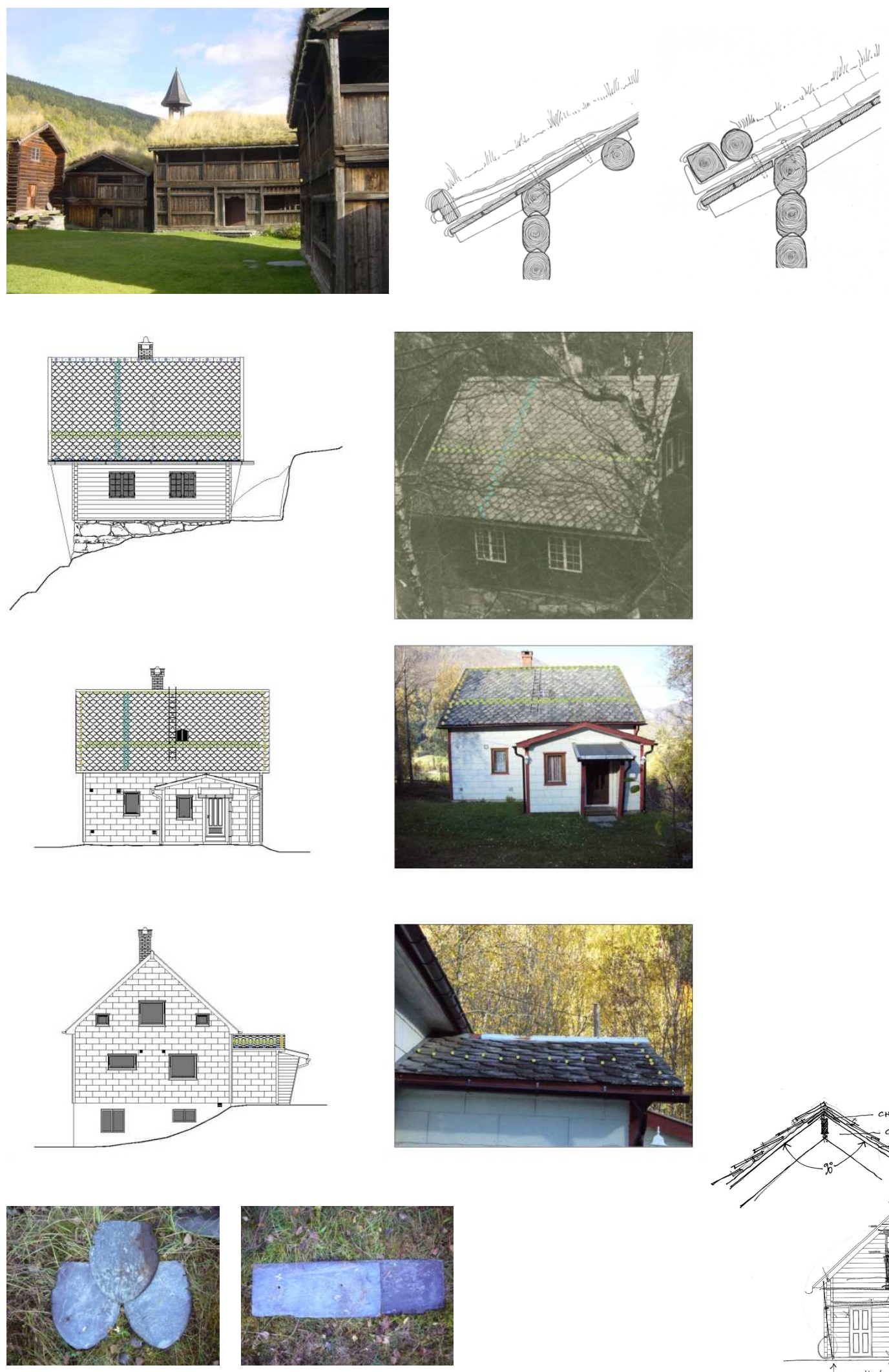

160. Cubierta vegetal tradicional nórdica | 161. Detalles constructivos de cubierta vegetal

162. Estudio de número y disposición de tejas en la Casa de Wittgenstein y en la Casa Bolstad

163. Tejas sobrantes en la Casa Bolstad | 164. Estudio de encuentro de cumbrera, probablemente el ángulo estuviera protegido interiormente con chapa de cinc

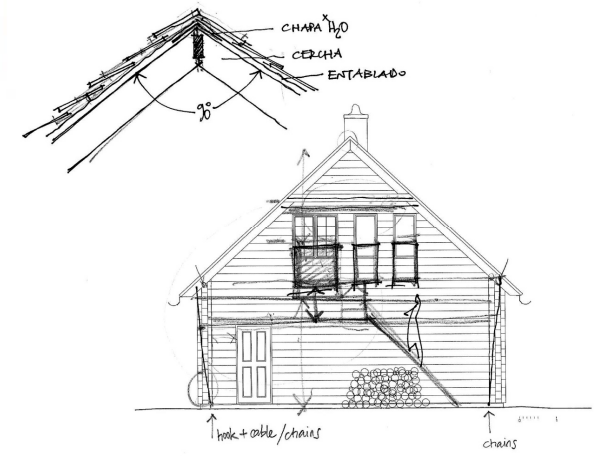


En la casa original hemos podido contar 29 filas de 27 tejas, esto es 783 piezas de forma lanceolada y dimensiones 380 × 310 × $10 \mathrm{~mm}$, dispuestas a tresbolillo, que se colocaban clavadas a rastreles sobre el entablado de cubierta. Todas las tejas parecen de idéntica factura salvo las de remate de la cumbrera y sobre el canalón, que son rectangulares, de 620 × 265 × $10 \mathrm{~mm}$, con un total de 28 piezas por cada faldón de ese otro tipo. El número total de lanchas de pizarra es de 1622 entre ambos faldones. El sistema lateral de cierre del tejado de la casa original, aunque no se puede apreciar su materialidad, debía ser de dos planchas de madera clavadas a los cabrios de la cercha la pieza frontal y a ella la superior, para proteger el lado libre de las lanchas de pizarra, tal como vemos en otras edificaciones locales, si bien en la actualidad se recurre a colocar un forro metálico en $\Gamma$ a tal fin.

Transportar, izar y colocar en 1914 -y en 1957 desmontar y devolver al pueblo- semejante cantidad de pizarra no debió ser trabajo fácil. Hemos calculado que la cantidad de piedra de pizarra instalada es de 3,15 t. ${ }^{105}$

En la solución de la cubierta es probable que utilizaran alguna plancha de zinc o alquitrán en la cumbrera para evitar la entrada de humedad, hay que contar con que en la zona, aparte de las intensas nevadas, la lluvia es un condicionante climático muy importante en esta zona. En Skjolden se recoge una media de $1950 \mathrm{l} / \mathrm{m}^{2}$ anuales. ${ }^{106}$

En la reconstrucción de la casa Bolstad hemos podido tomar datos del sistema y de las mismas piezas -algunas se apilan, en el suelo contra la fachada posterior del semisótano. Como era de esperar, el tejado, aunque reproduce el sistema de colocación, al tener menor recorrido -debieron eliminar por deterioro 1,00 o $1,20 \mathrm{~m}$ de longitud de las cerchas al girar la cubierta $90^{\circ}$ en su nueva situación- tuvo menor número de piezas, en total, puesto que son de diferente trazado, hemos podido contar 1538 piezas, incluyendo las que cubren el

\footnotetext{
${ }^{105}$ La superficie de pizarra del tejado es de $112,23 \mathrm{~m}^{2}$, realizada con piezas de $10 \mathrm{~mm}$ de espesor. Peso calculado para una densidad de 2700 $\mathrm{kg} / \mathrm{m}^{3}$. En 1914 se transportó todo el material en barca. En 1957 se utilizó la polea para llevarlo hasta el lago y desde allí, con un tractor se arrastró hasta el pueblo. Conversación con H. Vatne en Skjolden, 10.10.2013.

${ }^{106}$ Norks Meteorologisk Institutt. Compárese con los $1850 \mathrm{l} / \mathrm{m}^{2}$ año de media en Santiago de Compostela (España) (Fuente: Climatedata)
} 

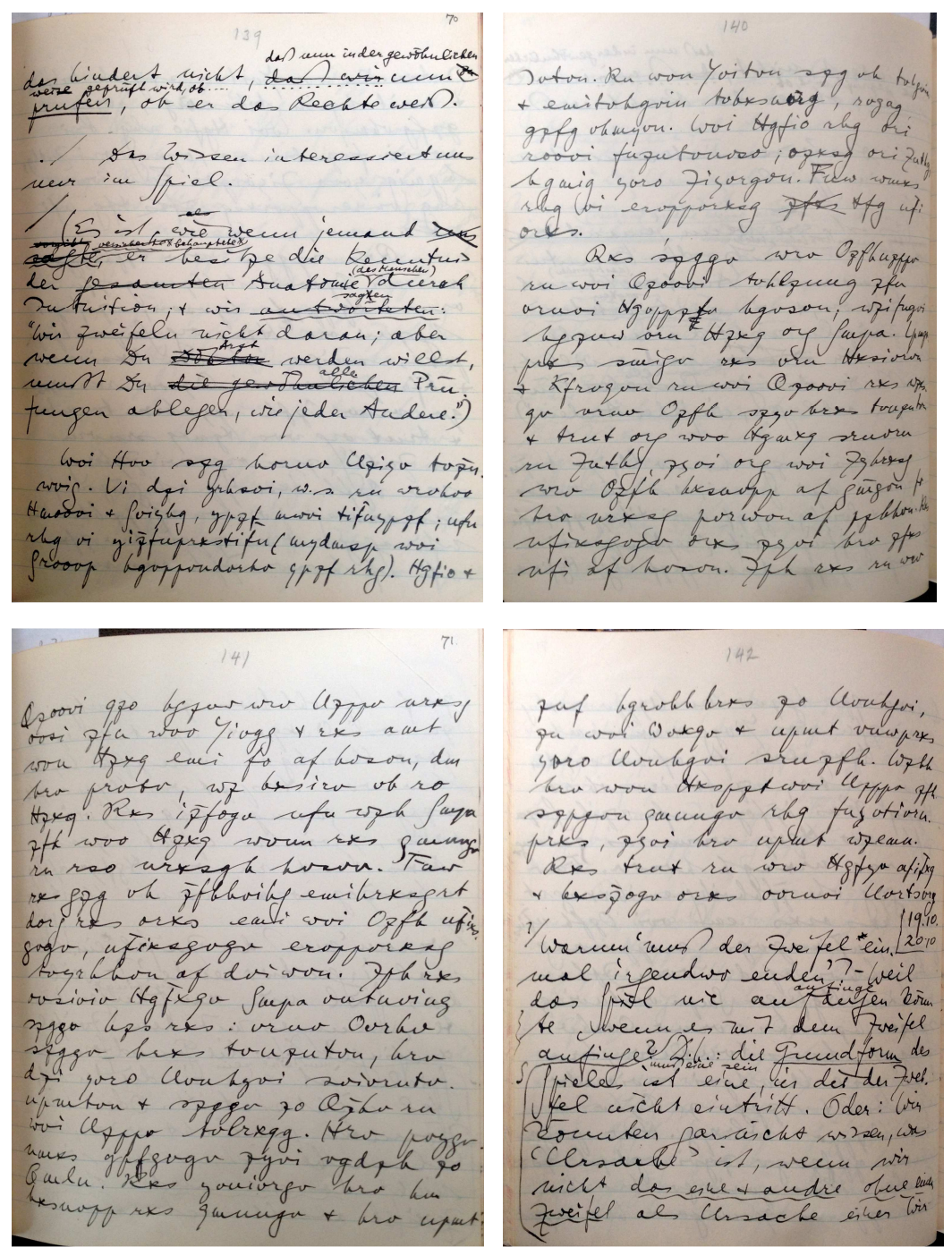

165-168. Diarios en clave, entrada del 18.10.1937 en MS119, «Diarios noruegos» Wren Library, Cambridge 
elemento cortavientos superpuesto a la fachada. Sin embargo vemos piezas diferentes en la casa reconstruida que no aparecen en la original, por tanto se aportó material nuevo en algún momento desde 1957.

\section{Espacio interior}

Unas líneas más arriba hemos dicho que Wittgenstein nunca escribió ni siquiera una línea en la que nos diera alguna pista de cómo era su casa. En realidad sí lo hizo, en una ocasión:

«Ms-119,139[4]et140[1]et141[1]et142[1]; ...Der See hat seine Farbe geändert. Er war bisher, d.h. in diesem Sommer \& Herbst, blau oder grünblau; nun ist er bräunlichgrün (obwohl der Himmel stellenweise blau ist). ... Sturm \&.......Regen. ...In den Bergen hat es gestern \& vorgestern geschneit, jetzt taut es oben. Der Sturm ist mir immer unangenehm; macht mir Angst, stört beim Arbeiten. Und doch ist es vielleicht gut für mich. Ich hatte die Mausfalle in der Kammer gespannt auf einer Stellage stehen; darunter stand ein Sack mit Holz. Plötzlich hörte ich ein Schreien \& Quieken in der Kammer ich dachte eine Maus habe sich gefangen \& ging mit dem Stock hinein in Angst, aber mit der Absicht die Maus schnell zu töten um sie nicht leiden zu lassen. Ich fürchtete mich aber sie auch nur zu sehen. ... Als ich in die......Kammer kam stand die Falle nicht mehr auf dem Brett \& ich zog den Sack vor um zu sehen, wo sie liege, da schrie es im Sack. ...Ich räumte nun das Holz aus dem Sack denn ich konnte in ihm nichts sehen. Und ich tat es äußerst vorsichtig weil ich mich vor der Maus fürchtete, fürchtete vielleicht gebissen zu werden. Als ich mehrere Stücke Holz entfernt hatte sah ich: eine Meise hatte sich gefangen, sie war beim Fenster hereingeflogen \& hatte am Käse in der Falle gepickt. Sie lebte noch blutete aber etwas am Kopf. ... Ich befreite sie so schnell ich konnte \& sie flog.......auf stieß sich am Fenster, an der Decke \& flog endlich beim Fenster heraus. ...Daß sie den Schlag der Falle aushalten konnte ist unbegreiflich, aber sie flog davon. Ich ging in die Stube zurück \& schämte mich meiner Feigheit.»107

La anotación corresponde a los diarios en clave, inéditos parcialmente, de Wittgenstein, en concreto a los llamados «diarios noruegos». Se trata de un episodio que nos relata el filósofo del 18.10.1937, en el que mientras está trabajando en su casa, escucha un ruido en la habitación, piensa que es un ratón, para el que había preparado una trampa -no mortal, Wittgenstein no podía soportar el daño a los animales- a base de una trozo de queso en el borde

${ }^{107}$ Ludwig Wittgenstein, MS119, p. 139-142, manuscrito en Wren Library Trinity College, Cambridge. 
Tejas de pizarra, $38 \times 32 \times 1 \mathrm{~cm}$

Ladrillos macizos,

$24 \times 12 \times 6 \mathrm{~cm}$

Tablero de madera, $\mathrm{e}=1^{\prime \prime}$

Cierre cubierta planchas madera, $6.5^{\prime \prime} \times 1 "$

Parhilera

Cerchas de madera de troncos escuadrados y nudillos,

$61 / 2^{\prime \prime} \times 8^{\prime \prime}$

Cerramiento de troncos

escuadrados y ranurados, 6" $\times 8$ "

Entablado madera cierre

cubierta, $\mathrm{e}=1^{\prime \prime}$

Nudillo cercha

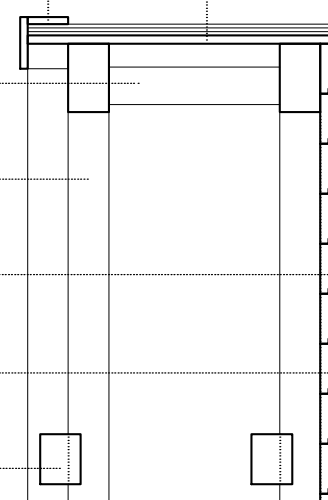

Puerta de madera abatible acceso a balcón

Pasamanos y barandales madera
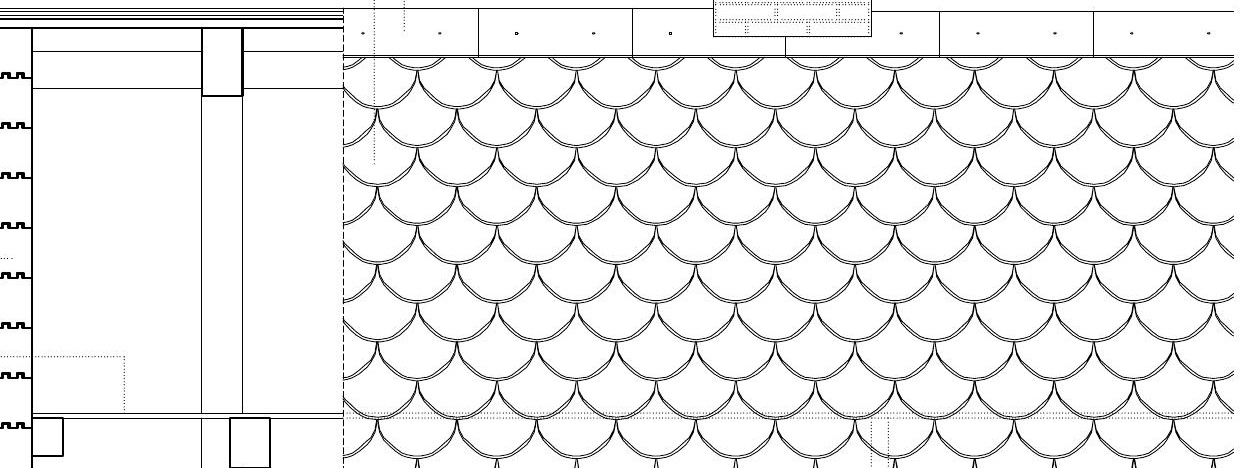

Tirante entre pares cercha, apoyo adicional balcón, $5^{\prime \prime} \times 6$

Viguetas en voladizo para sustentación del balcón, 5" × 6"

Ventana $120 \times 120 \mathrm{~cm}$ según planos, contraventana exterior madera

Cable anclaje a terreno

Entablado madera machihembrado, $\mathrm{e}=20 \mathrm{~mm}$

Viguetas separación plinto, 5" $\times$ 6"

Plinto de piedra

| | | | | | | | |
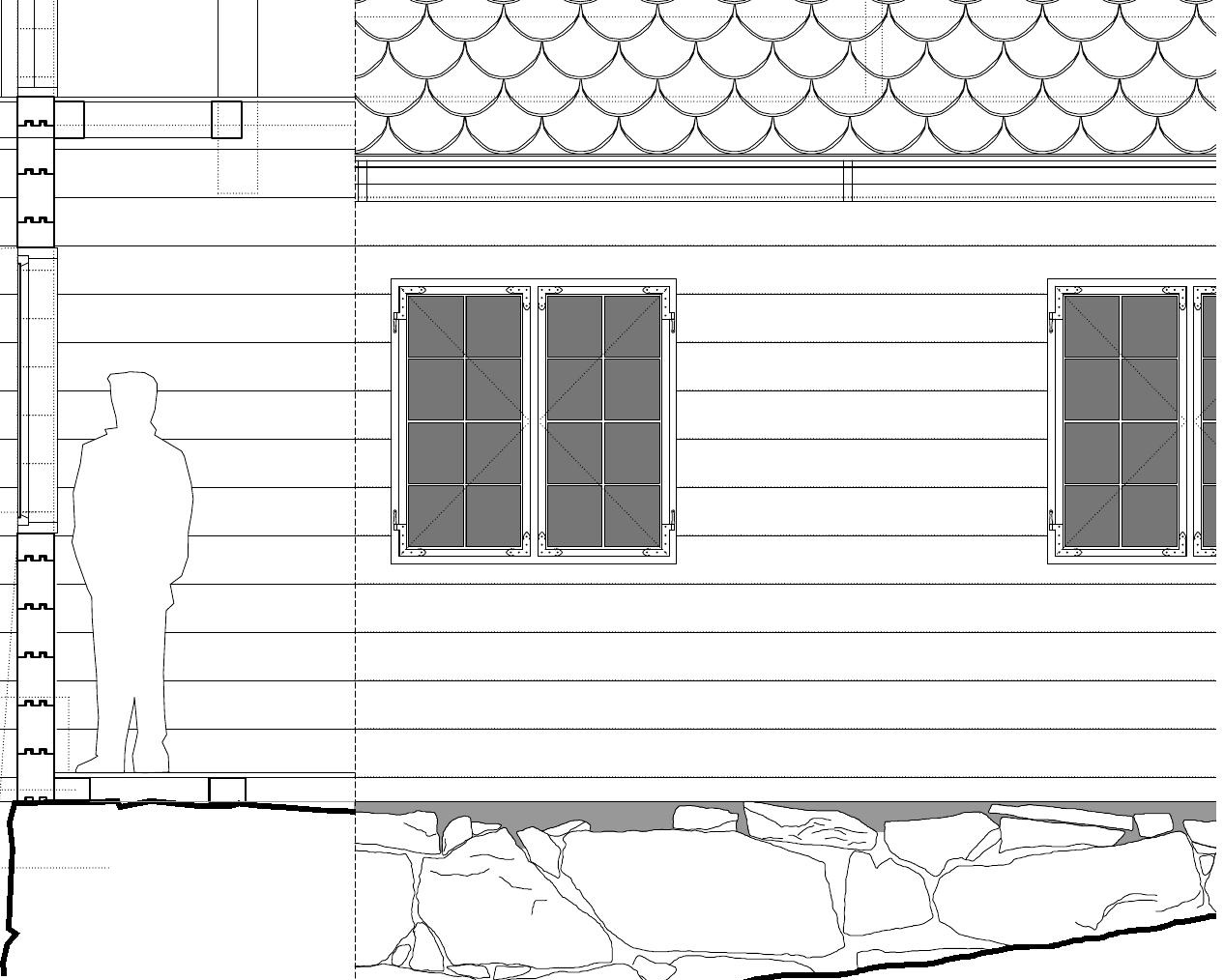
de una bolsa con virutas de madera colocada en un estante y un peso para que quedara atrapado ${ }^{108}$ y poderlo soltar vivo en el exterior de la casa.

Cuando Wittgenstein entra en la habitación encuentra un pequeño pájaro con el queso en el pico y parece herido, el pájaro vuela por la estancia chocando con el techo y la ventana y finalmente sale volando por la ventana.

La relevancia del pasaje se debe a que es la única ocasión en que Wittgenstein nos muestra parte del interior de su casa. Nos confirma al menos la propuesta de una sala en la que trabajaba y un dormitorio, con un estante, además de la despensa que había nombrado en el diario unos días antes y de ahí que preparara una trampa para un ratón. Parece evidente que Wittgenstein está hablando de la sala y dormitorio de la planta baja pero ¿en caso de que estuviera escribiendo en el ático podría haber dicho en su anotación que el pájaro salió volando por la ventana «del techo»?:

Correspondencia electrónica, Enrique Clemente/Alois Pichler:

«-Enrique: ... Ich befreite sie so schnell ich konnte \& sie flog......auf stieß sich am Fenster, an der Decke \& flog endlich beim Fenster heraus".

Does it mean that the titmouse mentioned some words above went away by a CEILING WINDOW?

-Alois: It could, but needn't. The question is: if the window wasn't a ceiling window, why would the bird hit the ceiling? I don't know about titmouses' behaviour when captured in a room - do they fly up to the ceiling if there isn't a window there? Maybe they do.

-E: Bird's behavior is always nervous, I mean that even if there was or not a roof ceiling or W was writing about a façade window he says that the bird was injured, isn't it? So perhaps he (the bird) was hitting the ceiling looking for an exit.

I guess if the 'comma' means exactly what I am trying to find: "sich am Fenster, an der Decke"="at/to the window, in/at/of the roof"...Does it have sense for you? Please let me know your opinion.

If the comma doesn't change the meaning of the phrase, W could be talking about the ground floor ceiling so the windows could be any of that floor, but if the comma means a ceiling/roof window, he could be working upstairs (as we know he loved to do) and then it could be a roof window anyway.

${ }^{108}$ Explica Wittgenstein que hay un ratón en su despensa unos días antes en MS119.130 [2] \& 131 [1] \& 132 [1], de 16.10 .1937 


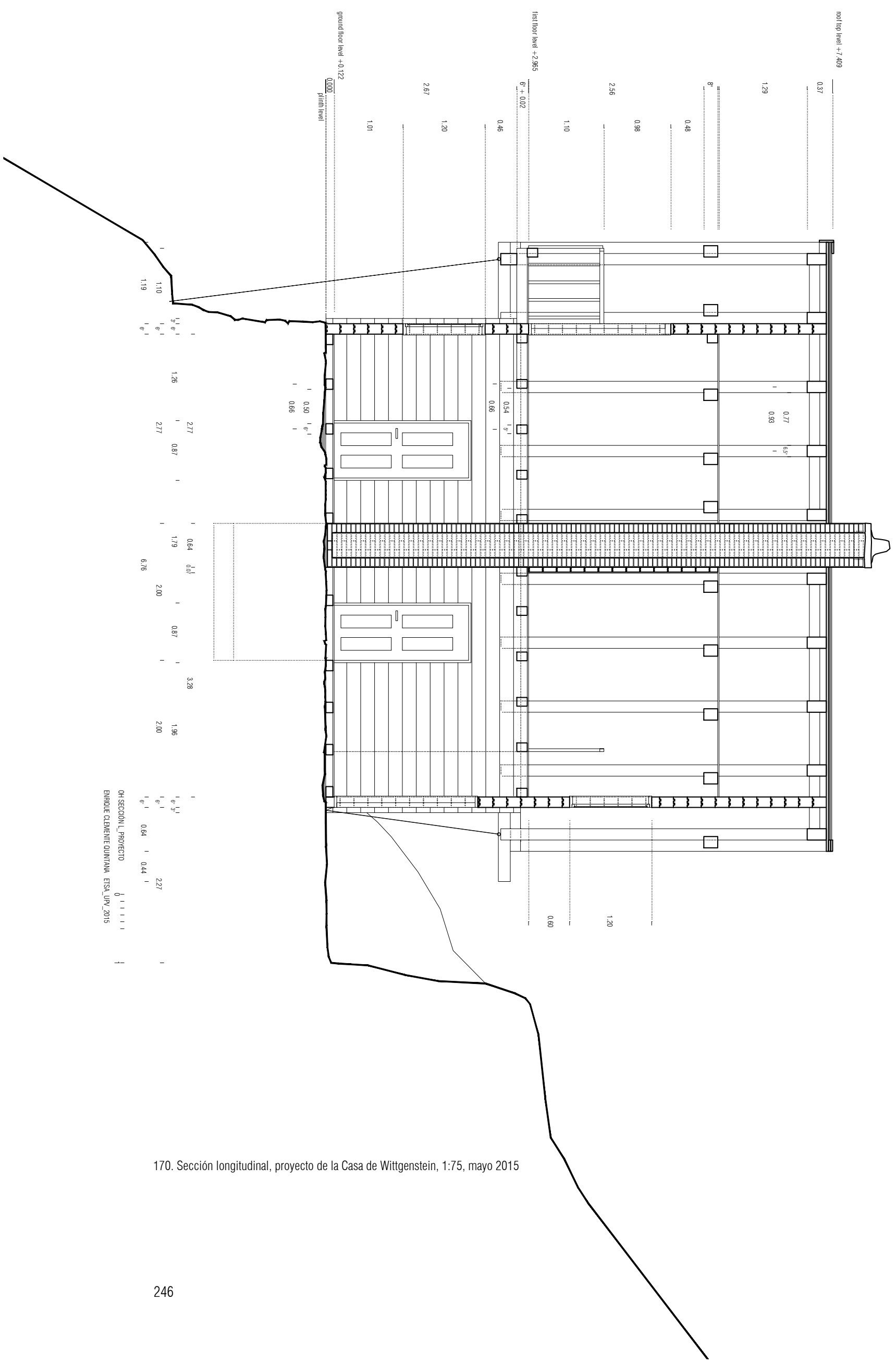


$-\mathrm{A}$ : This means: the bird hit itself at the window AND at the ceiling. If W had wanted to explicitly say: "am Fenster an der Decke" (= ceiling window), he would not have put the comma. But the way he put it, does *not* exclude that it was a ceiling window, either.

All best! Alois» 109

Es un elemento habitual en los tejados noruegos que haya un acceso a la cubierta con el fin de asegurar el mantenimiento de tejas tras las copiosas nevadas y lluvias que se registran. En nuestro proyecto hemos decidido colocar una en una situación equivalente a la de los Bolstad, accesible desde el interior del distribuidor de la escalera. Nos parecía coherente con el carácter de Wittgenstein y necesario para el trabajo a esa altura, teniendo en cuenta además que las pendientes laterales del terreno alrededor de la casa no permiten el acceso desde el exterior.

Son reiteradas las descripciones del gusto espartano de Wittgenstein para los interiores de los espacios que habitaba. Su vida fue un constante castigo autoimpuesto para intentar ser mejor persona, que le llevó a entender la ética como algo casi físico, que no podía dejar de aplicar a cualquier ámbito de su existencia. Cuando hemos analizado la concordancia de pensamiento de Wittgenstein con Loos hemos establecido una base ética que sin embargo les distancia en la pequeña escala, en el contacto directo con la realidad cotidiana inmediata. En 1917, Paul Engelmann, co-arquitecto en las primeras fases de construcción de la casa de Kunmanngasse 19 de Viena para su hermana, se encontraba haciendo una pequeña reforma en la casa familiar de Neuwaldegg, Wittgenstein le escribe desde Chernovtsy en el Frente Ruso de Ucrania:

«He oído con alegría que revuelve todo en Neuwaldegg. También mi querida madre está encantada con usted, lo cual entiendo perfectamente por lo demás. Trabajo bastante pero estoy intranquilo, sin embargo. Ojalá siga usted tan honesto como sería deseable.»110

\footnotetext{
${ }^{109}$ Correspondencia electrónica, Alois Pichler es Director del Wittgenstein Archives Bergen.

110 Wittgenstein-Engelmann, op. cit. p. 45
} 

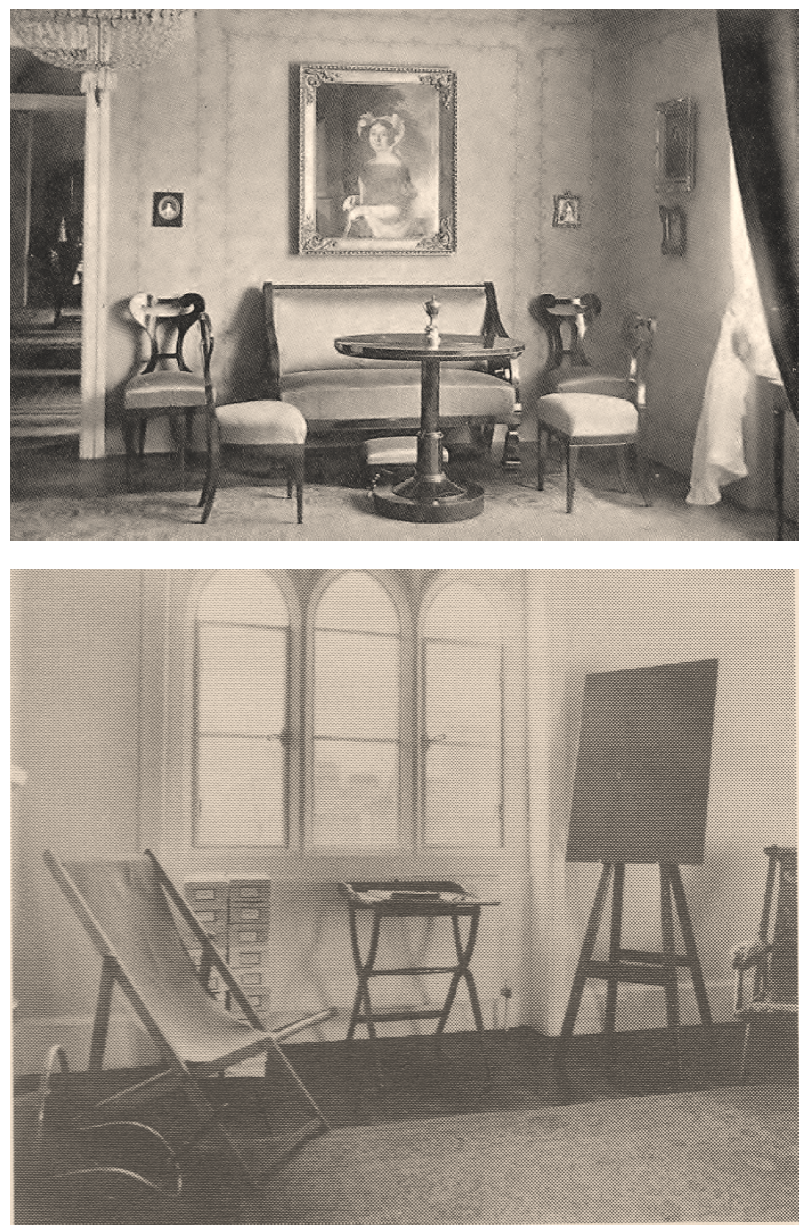

171. Interior de Neuwaldegg, Paul Engelmann, 1919

172. Interior habitación Wittgenstein en Whewell's Court 1940 c. 
Dos meses más tarde Engelmann le constesta que no cree haber dibujado nada deshonesto y que se ha esforzado lo más posible. Wittgenstein es implacable siempre. Ya en 1919, como hemos comentado, su amistad y respeto por Loos se deteriora como le expresa a Engelmann cuando aquel publica Directrices para una administración del arte. Pero Wittgenstein en realidad podía compartir determinados planteamientos con Loos si bien no creemos que fuera de su agrado la transposición física de sus ideas: la casa debía ser confortable para el habitante; lo placentero es el interior de las casas, «debe despertar sentimientos en el hombre» dice Loos en Arkitektur. ${ }^{111}$

Wittgenstein hacía, de sí mismo y de los interiores que habitaba experimentos de ascetismo, su habitación en Whewell's Court de Cambridge, la casa del guarda que ocupaba en la finca familiar de Hochreith, su dormitorio en Trattenbach, en la alquería de Rosroe de Irlanda y por supuesto en Skjolden:

«Tras remar y escalar hasta la cabaña lo primero que hicimos fue quitar las diversas banderas, etc., que Bolstad había colgado en las paredes de madera desnudas y barrer y limpiar el sitio. Compramos algunas provisiones.»112

Todo aquel que lo visitó, recuerda que la casa estaba prácticamente vacía, con algún mueble y poco más. La habitación que Wittgenstein ocupó en Trinity College aparece descrita en casi cada semblanza de sus alumnos de los años treinta y cuarenta en Cambridge modeliza su forma de entender el habitar:

«La habitación era cuadrada, con una ventana en el lado izquierdo que quedaba de frente a uno al entrar. Él se sentaba cerca de la ventana, con la luz sobre su hombro izquierdo, en una pequeña mesa plegable de cartas, sobre la que había un gran libro de contabilidad que utilizaba para escribir. Había una pizarra a la izquierda de W.»113

"Cuando entrabas en su habitación para una clase encontrabas quince o veinte sillas de madera y una de tijera frente a la chimenea, dentro de la que había una estufa de color negro antracita. A la derecha bajo la ventana había una mesa plegable con papeles. Sobre la repisa de la chimenea tenía una lámpara de bombilla de bajo voltaje en un retorcido soporte. Detrás de uno había una pequeña estantería con dos o tres libros.»114

\footnotetext{
${ }^{111}$ Loos, op. cit. p. 34

${ }^{112}$ Ben Richards, en Åmås, 1994, p.55 (en inglés en el original)

${ }^{113}$ Desmond Lee, Wittgenstein's Lectures Cambridge 1930-1932 (Totowa, New Jersey: Rowman and Littlefield, 1980), p. xiii-xiv

114 D.A.T. Gasking \& A. C. Jackson en K. T. Fann (ed.), Ludwig Wittgenstein: The Man and His Philosophy (New Jersey: Humanities Press, 1967), p. 50
} 

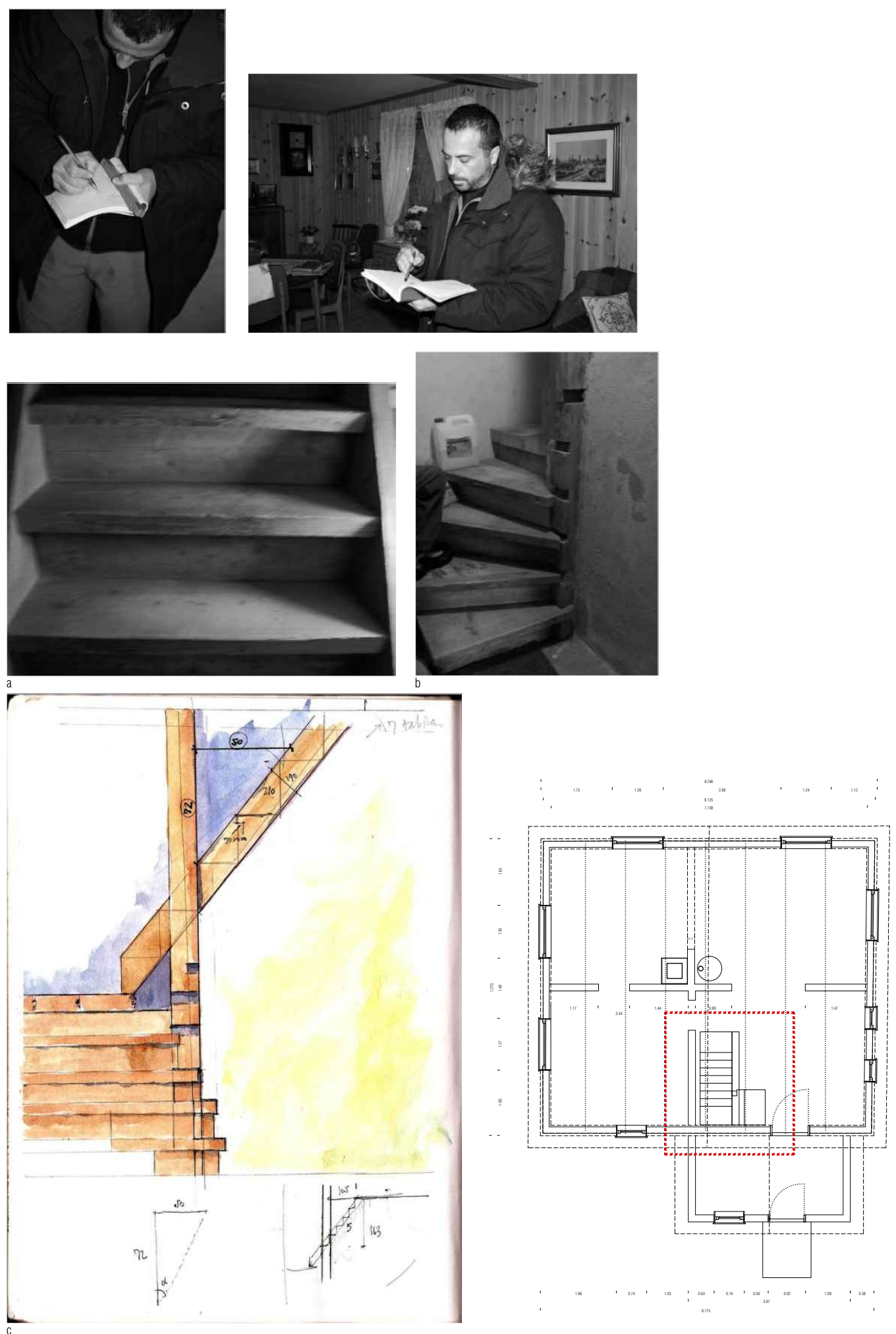

173-174. Toma de datos express en Casa Bolstad, 14.10.2013

175.a-b-c. Escalera de acceso al semisótano de casa de los Bolstad, 14.10.2013. Parte del material sí parece ser el original, pero reutilizado para la construcción de la escalera, no el trazado en sí mismo | 176. Situación de la escalera dibujada en la planta de la casa de los Bolstad. No hubo ocasión de tomar datos exhaustivos del interior 
«La habitación (su estudio) donde impartía las lecciones estaba escasamente amueblada, con una estufa negra cilíndrica en el centro de la que salía una chimenea hacia el techo. Debía haberla instalado él mismo; habiendo vivido en el Continente parece que no apreciaba la chimenea abierta inglesa. Durante las clases se sentaba cerca de la estufa en una silla plegable, a veces calentando una mano cerca de ella. Cerca de la ventana había un pequeño estante en el que pude ver, entre otras cosas, las obras de Hebbel, un libro de anatomía y algunas revistas del lejano oeste.»115

Aparte del gusto por lo sencillo como medida de penitencia decorativa, la casa del lago, como hemos dicho, quedó sin amueblar por Wittgenstein en 1914. Por tanto debió ser Arne Bolstad quien la utilizara en verano, desde 1919 cuando le fue cedida y 1921 cuando la visitó Wittgenstein por primera vez, y llevara algún enser para poder habitarla cómodamente, al menos lo imprescindible: cocina y estufa, cama, mesa y sillas, un arcón...no sabemos más que la segura existencia de una mesa grande, tal como recordaba Anna Gutubø y que debió conservar Arne Bolstad cuando desmantelaron la casa. Hoy tal mesa se conserva en Skjolden, en la cocina de Gyda Bolstad, como hemos sabido por azar a través del blog de su prima americana:

"One interesting note is that Connie's great grandfather was friends with philosopher Ludwig Wittgenstein, who spent a lot of time in Skjolden. Gyda even has his table in her kitchen."116

Hemos remitido una carta a la señora Bolstad solicitando alguna fotografía o descripción de la mesa de Wittgenstein pero no ha habido, por el momento, más correspondencia por su parte.

En la visita a la casa Bolstad de 14.10.2013, Kåre Bolstad, el más joven de los hermanos Bolstad señaló un mueble de esquina, a modo de aparador de $117 \times 65 \times 215 \mathrm{~cm}$, como original de la casa del lago. También indicó que la escalera que desciende al sótano era la original, a lo que Vatne matizó que «sí, pero cambiada de lugar en la casa». Hemos sido críticos con algunas de las informaciones obtenidas, puesto que muchas de ellas son simples convenios

\footnotetext{
115 Wolf Lays en Fann, op. cit, p. 79

${ }^{116}$ Carta a Gyda Bolstad, 01.06.2015
} 

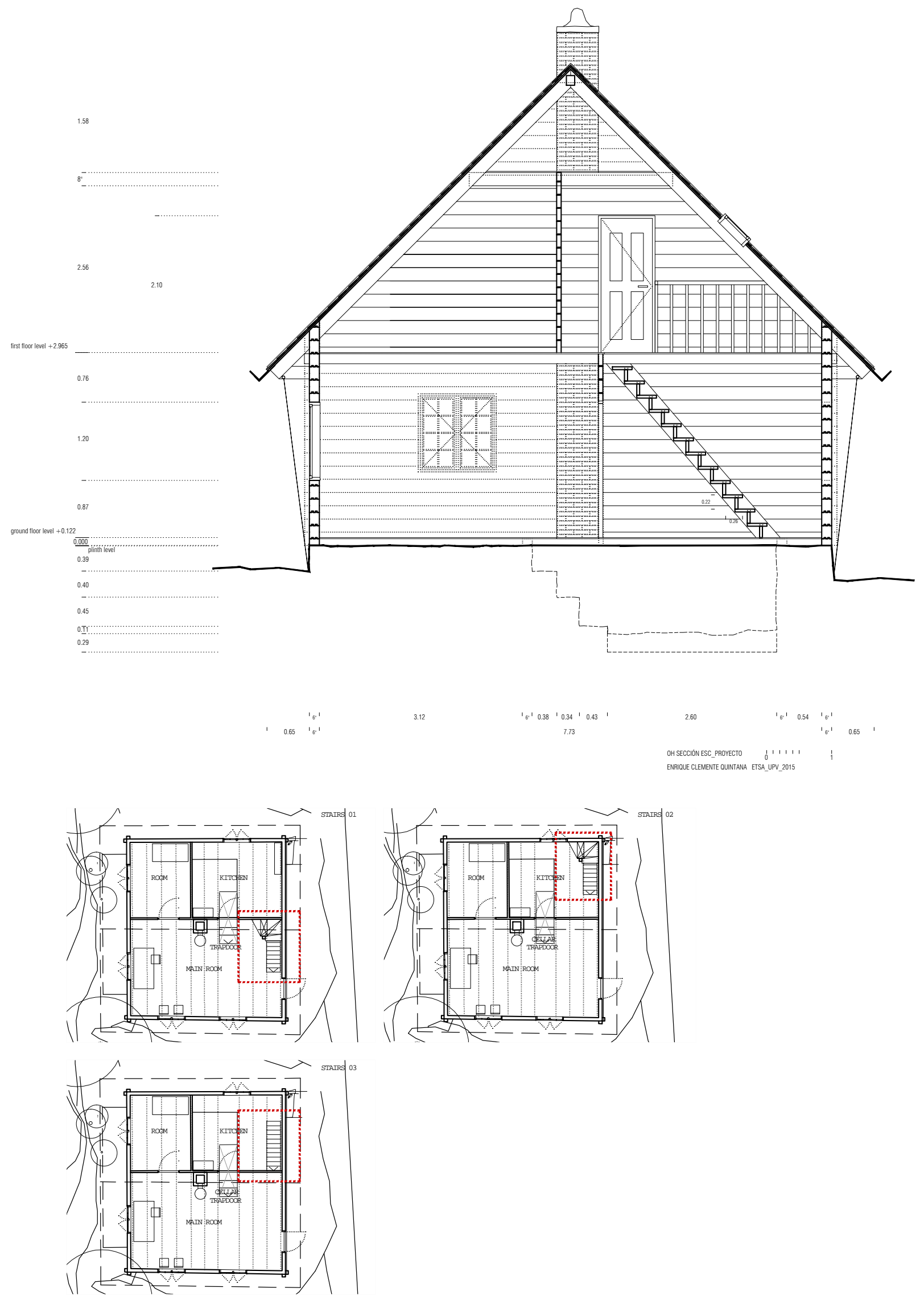

177. Sección por la escalera. Proyecto de la Casa de Wittgenstein, mayo 2015

178. Esquemas de ubicación de la escalera en la planta ST01, ST02 y ST03. Cfr. Comentarios p.253 
familiares, aparentes recuerdos que no responden en algunos casos a la realidad de la casa original. Tal escalera no hemos considerado que hubiera estado instalada en la casa del lago Eidsvatnet nunca, al menos con el trazado que presenta en la casa de Bolstad. Está construida con materiales de diversa procedencia e incluso hemos reconocido secciones de los troncos descritos antes como tabiques interiores (piezas de Oxaal), con los que construyeron el descansillo intermedio de la escalera. El mástil de apoyo del hueco, con diferentes mellas y señales de haber estado encajado con otros elementos lineales no responde tampoco a ninguna métrica racional de peldañeado. En definitiva, no es la escalera de Wittgenstein.

Disquisiciones acerca de la situación de la escalera han sido incontables, traemos aquí una de ellas, por su cercanía en el tiempo con la redacción de estas líneas:

«Hi friends!

Enrique: -Stairs. I am sending you drawings with some possibilities. Please let's discuss about them: ST01 \& ST02 reproduce the shape of the stairs in RH now (my watercolors drawing shows it)...there is a 'strange' slim column with some marks on it that seem to be places for steps but doesn't entirely fit with any logic distribution (turning to the right instead of to the left...) ST03 could be a quite 'architectural' \& rational solution for the blind wall. A trap door upstairs or at least a door for the kitchen is needed for heating reasons. The only two references of the $\mathrm{OH}$ interior (McGuinness p. 202 Penguin Ed. \& Oxaal p.150 Transaction Publ.) tell nothing about a staircase. My thought for this was from the first time that the stairs were not 'visible'/important', so was my first (2011) approach with a ladder and now inside the kitchen...but nothing to bear it against further information, opinions, etc etc.

D.Wilson: - Hi Enrique

What does the upper floor plan look like? I'm wondering where the stairs emerge upstairs. If there is more than one room upstairs it would make sense (sense to my way of thinking) if they emerge at a landing that is on the central axis, rather than emerge from a corner. Otherwise presumably it would be necessary to pass through one room to access other rooms.

I realise, in asking this, that this bears on your thinking about whether there is one room space or two behind the two balcony windows.

Best wishes, Dawn

E. - Hi Dawn, you are right.

If we emerge from the stairs by the wall side you must pass through one room to enter in the balcony room for example. I divided the space upstairs in two. But the asymmetry of the front windows (above the entrance door) is quite difficult to assume without more walls. Another possibility upstairs is to have a frontal room by the balcony, a room with the double multi-paneled window and a kind of landing-room where emerging the stairs with two single windows...but all of this sounds me messy. The great problem here is exactly that. The ground floor is more or less clear, but the 

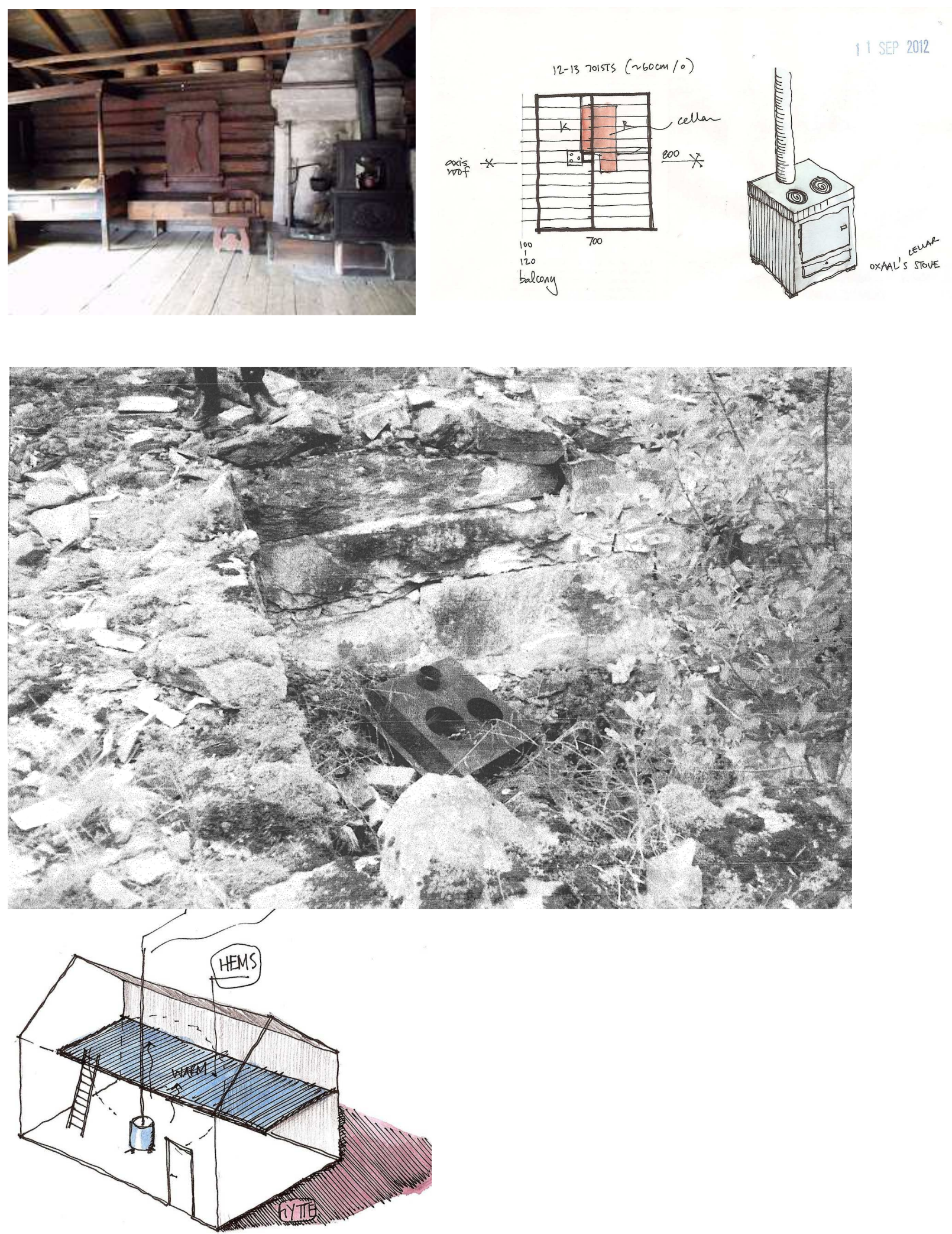

179. Imagen de interior de una granja del s. XVII, en Folkmuseum Oslo | 180. Dibujos preliminares de la situación de la cocina, nótese que la cocina y el dormitorio todavía aparecen intercambiados en planta

181. Restos de algún tipo de estufa en el hueco del almacén del plinto, 1984. Ivar Oxaa

182. Esquema tipo de vivienda tradicional noruega, con altillo (hems) ocupando sólo una parte del piso superior, aprovechando el calor de la estufa de planta baja 
situation of the stairs is absolutely unknown and even worse because it can be located in so many places and this is of course decisive in terms of upper level distribution.

If this was a Norwegian hut the purpose of the attic would have been a common space for sleeping, a ladder etc etc. But the 'style' here is different. Or seems to be. And if so there are only two possibilities as it was the whole upstairs surface occupied: 1 . $^{-}$To use a room as landing and passing through it to the balcony room (or rooms) or 2.- to have a more dense distribution and two or three spaces upstairs and in adding a landingdistributor.

Anyway, to use rooms for enter to other rooms is quite usual (my home for example).

So...

Transversal thinking is needed to untangle the walls ball.

E.

PS. When I told that the light through the windows upstairs was equal considering then that there must be a single space behind was a reflected proposal. But, what about if the equal surfaces were just closed shutters?

Still lots of work here my friends. What a trouble!» ${ }^{117}$

Un elemento importante sobre el que no hemos tratado es la chimenea. En el momento en que determinamos definitivamente las medidas del plinto y del hueco de la despensa en la plataforma, analizamos métricamente sobre la restitución gráfica la situación del tiro de la chimenea visible en las fotografías. Tal como parecía ser la costumbre también en los primeros años del siglo pasado, en las casas noruegas se prefiere el uso de la estufa antes que el hogar abierto. Este, se utiliza extensamente también, pero su aplicación parece relacionarse con el ámbito directamente rural, en granjas y cabañas:

«En el interior de la cabaña, se seguía el estilo del oeste noruego, con un gran hogar en esquina, el excepcional orden y la limpieza que caracteriza las cabañas en Gudbrandstal. Sobre altos estantes, los quesos se presentaban en hileras; más abajo, sartenes y ollas alineadas, y todas ellas -como las mesas y los bancos- brillaban de blancura.»118

En la visita de Ivar Oxaal de 1984, recuerda haber visto en el fondo del hueco del plinto los restos de una estufa. ${ }^{119}$ Kåre Bolstad y Harald Vatne aseguran que dos de las estufas almacenadas en el semisótano de los Bolstad fueron de Wittgenstein.

\footnotetext{
${ }^{117}$ Correspondencia electrónica E. Clemente/D. Connearn/D. Wilson, 11.05.2015

${ }^{118}$ Ellen Rees, Cabins in Modern Norwegian Literature. Negotiating Place and Identity (Lanham, Maryland: Fairleigh Dickinson University Press, 2014), p. 26

${ }^{119}$ Carta de Ivar Oxaal, 18.07.2012. Incluye dos fotografías inéditas.
} 

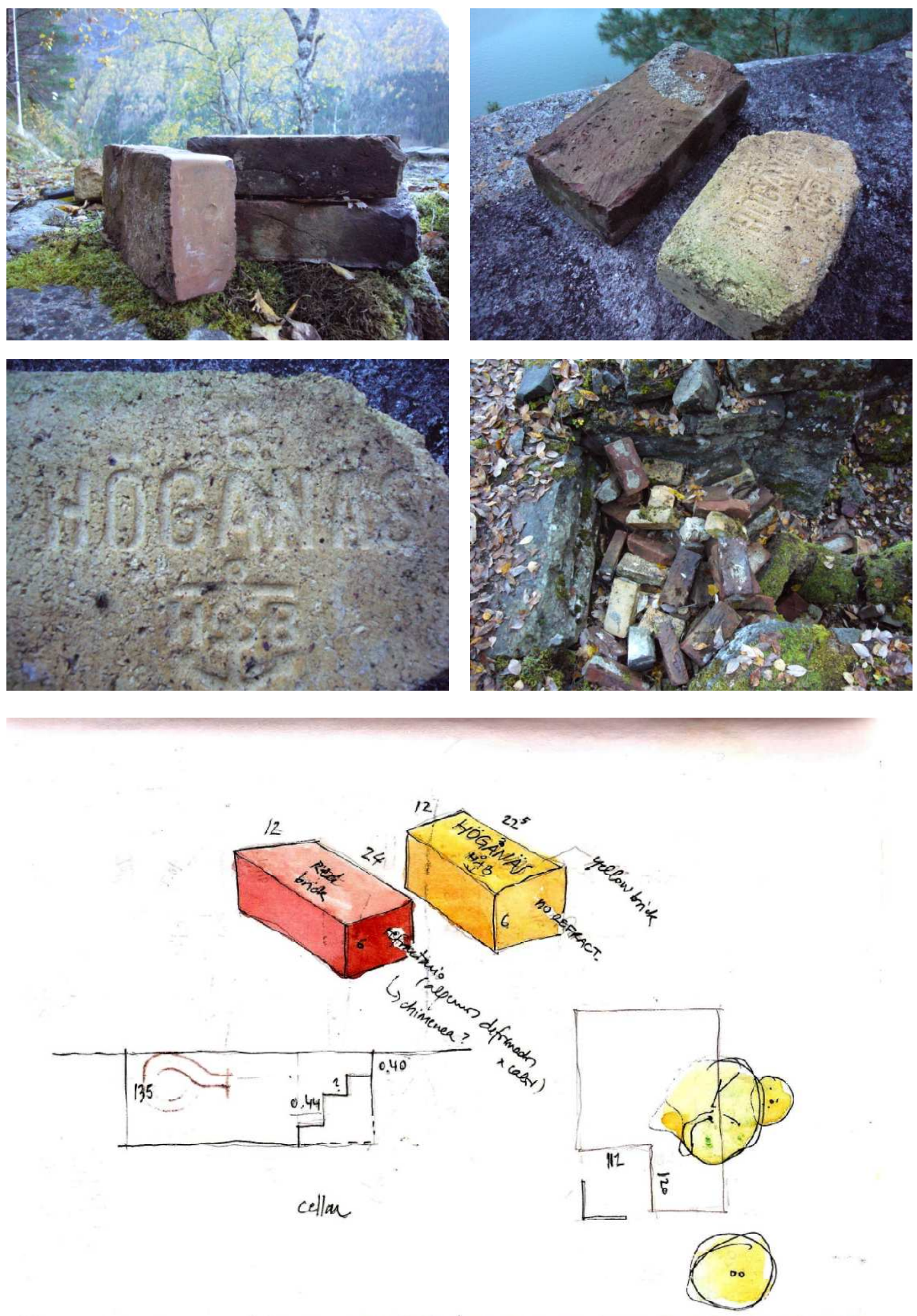

183. Ladrillos refractarios pesados de $24 \times 12 \times 6 \mathrm{~cm}$, oscurecidos por el humo $\mid$ 184. Dos tipos de ladrillo presentes en el plinto

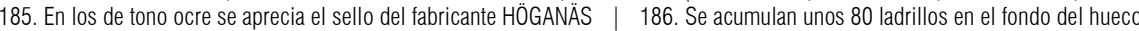
187. Toma de datos en Skjolden, 10.10.2013 
En la casa de Gunnar Bolstad vimos que el sistema que utilizan para calefactar el ambiente es una gran estufa de hierro cuyo conducto se enlaza con un tiro de ladrillo que lleva el humo hasta la cubierta. Entendemos que el mismo sistema se utilizó en la casa de Wittgenstein, el motivo adicional a las informaciones sobre estufas que pudieran pertenecer al filósofo, es que en el lugar todavía hoy queda un cierto número de ladrillos, contamos alrededor de ochenta, amontonados aquí y allá, casi todos en el fondo del hueco del plinto.

Observamos además que había dos tipos de ladrillo, ambos macizos. Unos rojos, pesados y probablemente refractarios, de dimensiones $24 \times 12 \times 6 \mathrm{~cm}$, algunos de ellos claramente deformados y por tanto casi con total seguridad provenientes de una chimenea. Otra serie de ladrillos eran más porosos, de color ocre claro y dimensiones $22^{5} \times 12 \times 6 \mathrm{~cm}$. En estos apreciamos lo que parecía un sello, que resultó ser el del fabricante sueco de productos cerámicos Höganäs, a los que cursamos petición de información:

«Dear Sirs.,

I'm a Spanish architect and I develop a researching work on the Wittgenstein's house in Skjolden, Norway (dated 1914). When visiting the remains, I found some old bricks made by your company, Höganäs. They were refractory (red) and regular (yellow) bricks. Is possible for you to give me further information about that bricks? composition, fabrication dates, distributors in Norway at that time...Do you have an archive of your company where I can contact to ask this kind of information? Many thanks in advance.

Enrique Clemente-Quintana»

Adrian Clayton, responsable de diseño de la empresa se puso en contacto inmediatamente:

«Dear Mr. Clemente-Quintana,

Thank you for your mail about the old Höganäs bricks you found in Norway. This is very interesting from a historical point of view for us as well.

To help us trace back in the archives is it possible you have some pictures of the bricks you can send to us? There should be a brand name and a production code stamped into the surface of the brick. If this information is there and still visible this will help us to trace the history.

We look forward to hear from you.» ${ }^{120}$

${ }^{120}$ Correspondencia electrónica, Adrian Clayton, Höganäs, 22.10.2013 

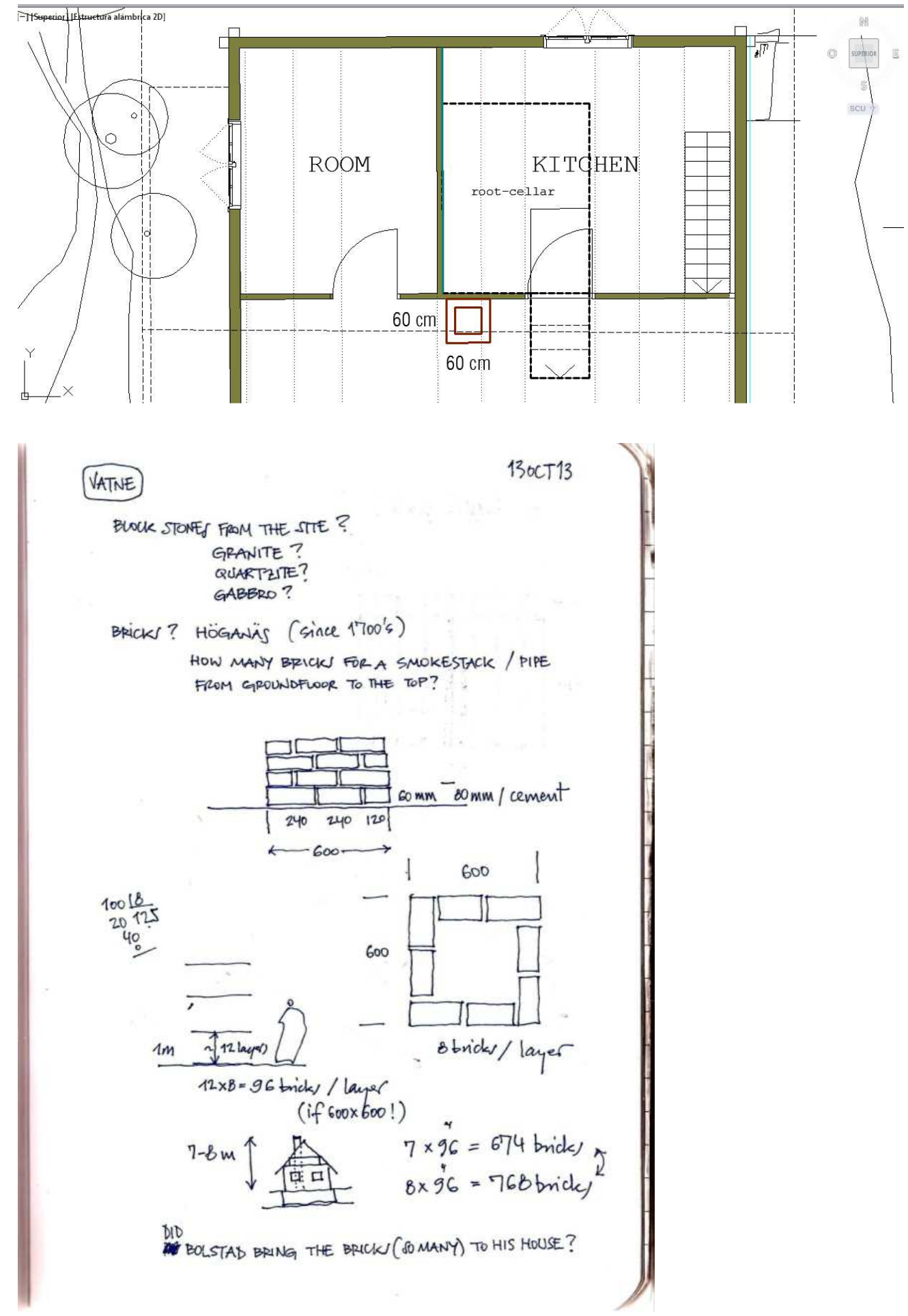

188. Plano de trabajo de ubicación de la chimenea, teniendo en cuenta el intereje de los cuchillos de cubierta y de las viguetas del forjado del ático. 189. Estudio del tiro de la chimenea original con los ladrillos encontrados en el lugar, Skjolden 13.10.2013 
Sin embargo, en sucesivos contactos y pese a la amable colaboración de la empresa, no consiguieron aportar datos adicionales del material cerámico:

«Dear Mr. Clemente-Quintana,

Yes, we got your photos, thank you.

I have forwarded them to our Director who was very interested in them, he is Norwegian. Hopefully I will see him later today. I will follow up on this for you.»121

«We are working on this, but it is proving to be a bit of a challenge. However as soon as I have some more information I will contact you.

Sorry for the time this is taking.»122

«Dear Mr. Clemente,

I have followed up on these bricks you asked about some time ago. As I wrote before this is a bit of a challenge, so much so that we have come a dead-end!

From the pictures we are sure they are some kind of firebrick and not a high grade bricks. However the only reference we can see is the Höganäs name and a logo. We produce and have produced a number of different brick qualities so it is difficult from the pictures to determine which one they are.

As to when they were produced, this is almost impossible to say when we do not know which quality they are.

Sorry we cannot be of more help with this at this time.

Med vänlig hälsning/Best regards/Mit freundlichen Grüssen.»123

Tomando como referencia las dimensiones de la chimenea de Bolstad y las obtenidas de la restitución gráfica obtuvimos unas medidas aproximadas de $60 \times 60 \mathrm{~cm}$, así, en el espacio macizo junto a escalera de la despensa, la cocina y casi en una posición central de la casa proyectamos un tiro de ladrillo que podía dar servicio a la sala en planta baja, a la cocina desde el interior de esta e incluso a una o dos estufas de menor tamaño en las estancias del ático. ${ }^{124} \mathrm{El}$ número de ladrillos necesario con un aparejo convencional para salvar una altura en el remate de 7-8 m era de 760 piezas. En la casa de Bolstad el tiro visible es algo más esbelto, de 50x50 cm, por lo que el descarte de un cierto número de ladrillos todavía hoy en el lugar original muestra posiblemente que no volvió al pueblo todo el material.

\footnotetext{
${ }^{121}$ Correspondencia electrónica, Adrian Clayton, Höganäs, 28.10.2013

${ }^{122}$ Correspondencia electrónica, Adrian Clayton, Höganäs, 18.12.2013

${ }^{123}$ Correspondencia electrónica, Adrian Clayton, Höganäs, 05.03.2014

${ }^{124}$ El tiro, como vemos en la casa de Bolstad, debía estar revestido para evitar fugas de monóxido de carbono o de humo en el interior de la casa. El tramo exterior, de muy difícil lectura en las fotografías parece revestido pero no es posible confirmarlo. En la casa reconstruida y en general en la zona, el tramo final no está revestido en la mayoría de los casos.
} 

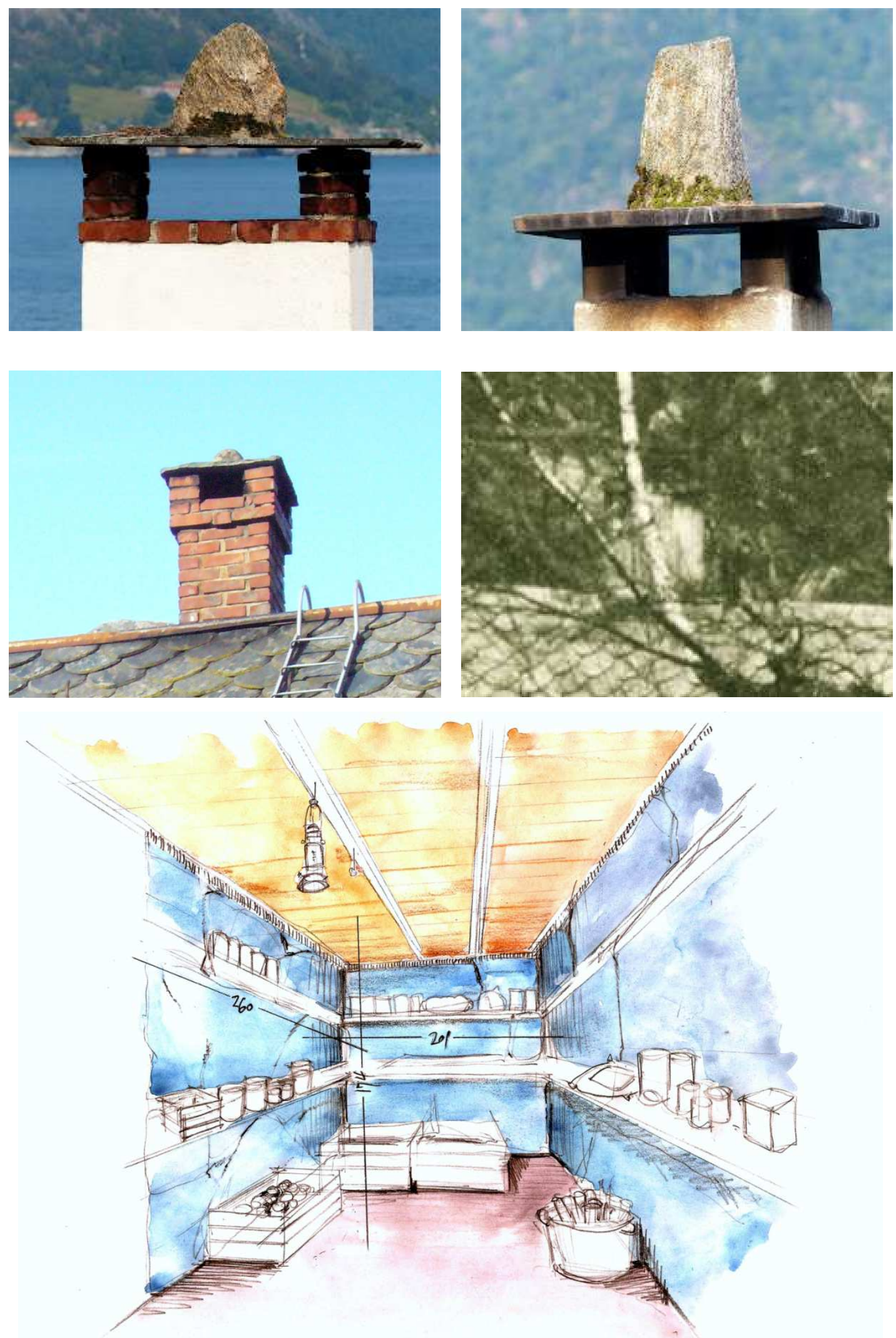

190-191. Remates típicos de chimeneas de ladrillo con piedras de pizarra en Skjolden, del blog de Connie Bearg, 2013

192. Remate de la chimenea de la casa de Gunnar Bolstad | 193. Remate de la Casa de Wittgenstein, apenas perceptible

194. Despensa bajo suelo, del tipo que debía tener Wittgenstein en su casa 
Si Wittgenstein tenía una estufa, dos o incluso tres en la casa, no lo sabemos. Su ascetismo vital se trasladaba también a sus gustos culinarios, por lo que no debía de cocinar demasiado. Como hemos dicho un poco más arriba, en su casa ofrecía a sus invitados galletas, té y alguna manzana. En la granja de Rebni se aprovisionaba de huevos y leche. De su estancia en la alquería de Rosroe en Irlanda en 1948, sabemos por Tom Mulkerrins que se alimentaba prácticamente de comida enlatada, que Tom debía traer desde Galway. Este, preocupado por tales hábitos alimenticios, como irlandés estaba acostumbrado a comer patatas y pescado fresco a diario:

«"La comida enlatada será la muerte para usted“, le advirtió Tom en una ocasión. "La gente vive demasiado tiempo de todas maneras", respondió Wittgenstein.»125

En su visita a Rosroe con Skinner en 1934, tras la comida ofrecida por la madre de Drury a los invitados - pollo asado, pastel de carne y dulces-, Wittgenstein insistió en dejar claro que la dieta para ellos sería en adelante gachas para el desayuno, verduras del huerto para comer y un huevo hervido como cena. ${ }^{126}$

En Noruega no quiso aplicar el derecho que le concedía vivir en el lago para la pesca de truchas, que sí aprovecharía Arne Bolstad en su ausencia. Si Wittgenstein cocinaba o no, y si disponía del equipamiento para hacerlo no es posible saberlo, aunque parece que no hubiera necesitado más que una palangana y cubos para el agua y algún cazo para hervir agua. En Noruega, tradicionalmente hay una gran cazuela en la estufa fundiendo constantemente nieve en invierno para tener agua líquida en la cocina y para el aseo personal. ${ }^{127}$

En una emotiva carta de despedida que envía Hans Klingenberg a Wittgenstein en las Navidades de 1919, al saber por Drægni que el filósofo ya no tenía intención de volver a Skjolden, incluyó un listado de efectos personales que permanecían en casa del cartero desde 1914:

\footnotetext{
${ }^{125}$ Richard Wall, op. cit. p. 89 y Monk, op. cit. p. 476

${ }^{126}$ Rhees, op. cit. p. 140

${ }^{127}$ En conversación con Liv Ingrid Ostbye Roggen, 04.02.2015, Valencia
} 


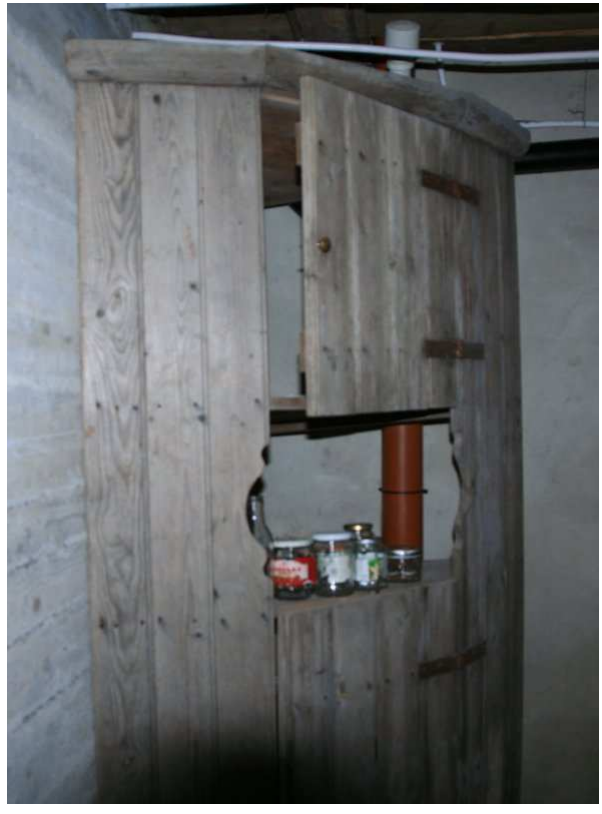

The Hut in 1984

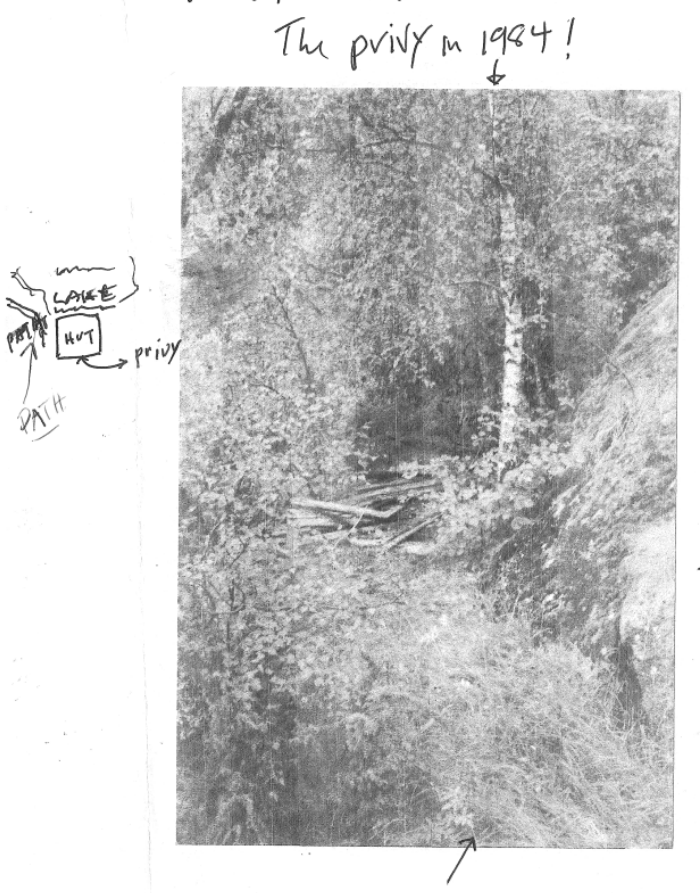

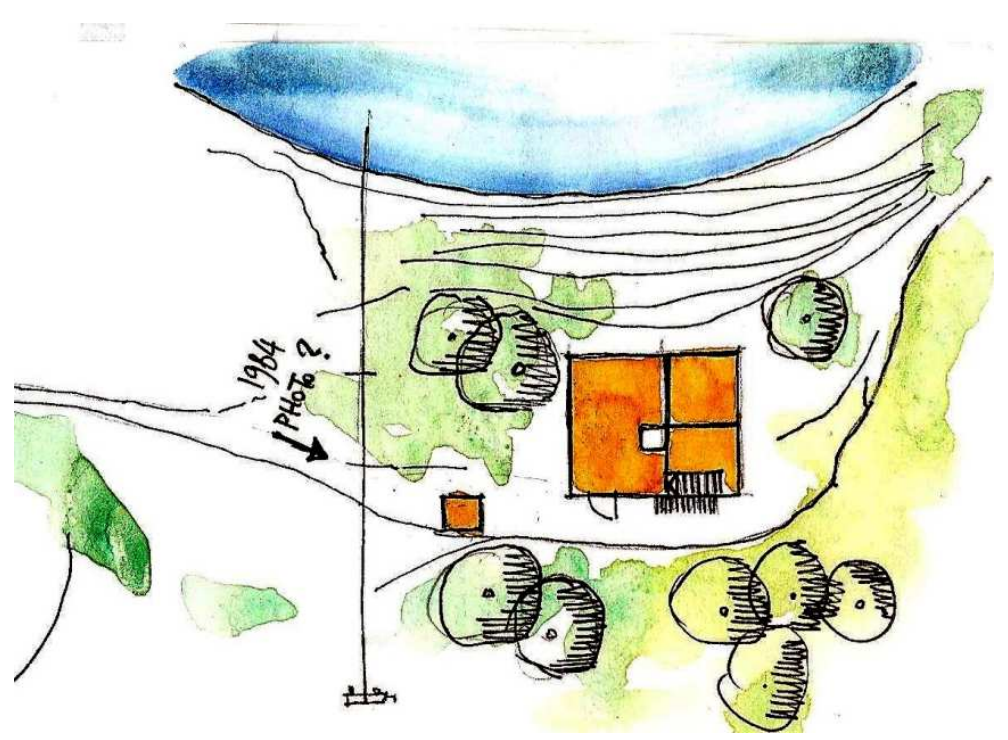

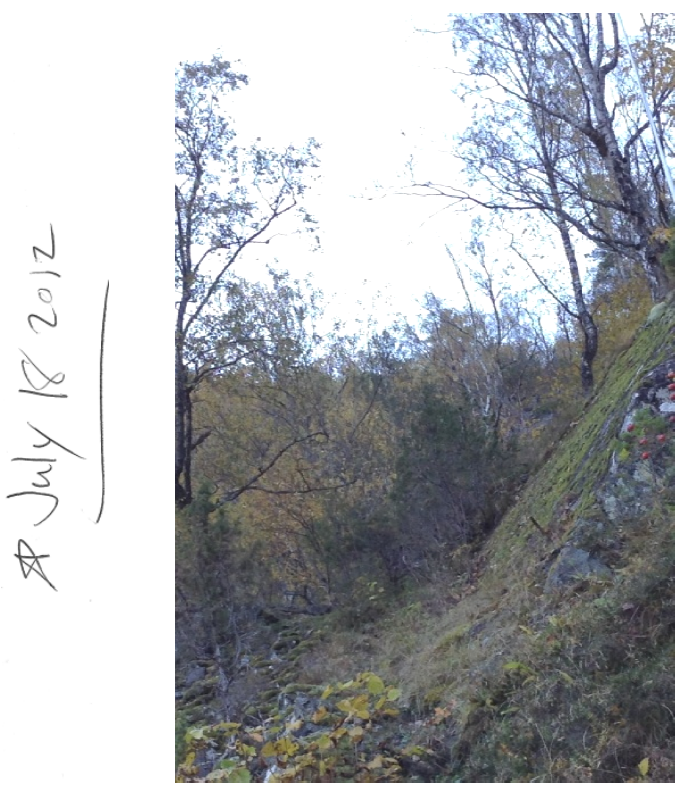

195. Armario rinconero de madera que Kåre Bolstad señaló como original en la visita a la casa familiar de 14.10.2013. Dimensiones 117x65x215. No parece del gusto de Wittgenstein pero quizá fuera Arne Bolstad quien lo llevara a la casa del lago | 196. Esquema de su posible situación teniendo en cuenta la losa de piedra que aparece en el lado derecho de la fotografía de Oxaal

197. Fotografía de los restos de una posible letrina en las cercanías de la casa de Wittgenstein y esquema de su localización, dibujado por Oxaal casi 30 años después de la visita al lugar | 198. El que podría ser un punto de vista similar al de Oxaal, unos metros hacia atrás en la senda, a unos quince metros del plinto 
«16 pares de calcetines usados, 3 mudas de ropa interior, 3 toallas de baño, 3 toallas de mano, 3 pares de botas, un par de botas de trabajo, 2 pares de polainas, un albornoz, un impermeable, una chaqueta cortavientos con capucha, dos bastones, un par de tirantes de pantalón, un chaleco gris, una funda de cuchillo, dos corbatas, una lámpara de mesa, una palangana, unos esquís y un bote de remos.»128

Quizá un arcón o algún mueble como el señalado por Kåre Bolstad sí podrían haber formado parte de la casa de Wittgenstein.

Sólo un elemento más de la casa requiere explicación en nuestro proyecto. Por la fecha en que se construyó y las técnicas constructivas utilizadas, sabemos que Wittgenstein no dispuso de instalación alguna en el interior de la casa, ni de retrete -como por ejemplo sí lo tuviera la cabaña de Martin Heidegger- ni instalación eléctrica ni de agua.

Wittgenstein era ciertamente maniático del aseo personal, siempre vestía de manera sencilla -tras su participación en la Primera Guerra Mundial, ya que anteriormente a 1914 vestía como un auténtico gentleman- pero limpia y él mismo siempre mostaba gran cuidado de su aspecto físico. Oxaal refiere que, en la visita de 1984 encontró cerca del lugar que ocupara la casa, los restos de lo que parecía haber sido una letrina exterior. Pese a que amablemente el profesor trató de indicar en un esquema la situación de tal construcción según su recuerdo, en 2013 y transcurridos 29 años no quedaba rastro alguno. Ciertamente el entorno inmediato de la casa no permite prácticamente ningún espacio horizontal para apoyar siquiera una pequeña construcción de madera para tal uso y hacia el norte la ladera imposibilita el paso sólo 5 o 6 metros más allá del plinto, como tampoco en el rellano de acceso parece que hubiera habido espacio suficiente. Tampoco se aprecia en ninguna de las fotos construcción anexa. Este y otros aspectos se podrán aclarar probablemente con testimonios que hasta la fecha no han sido accesibles.

128 Åmås, op. cit., p. 122 

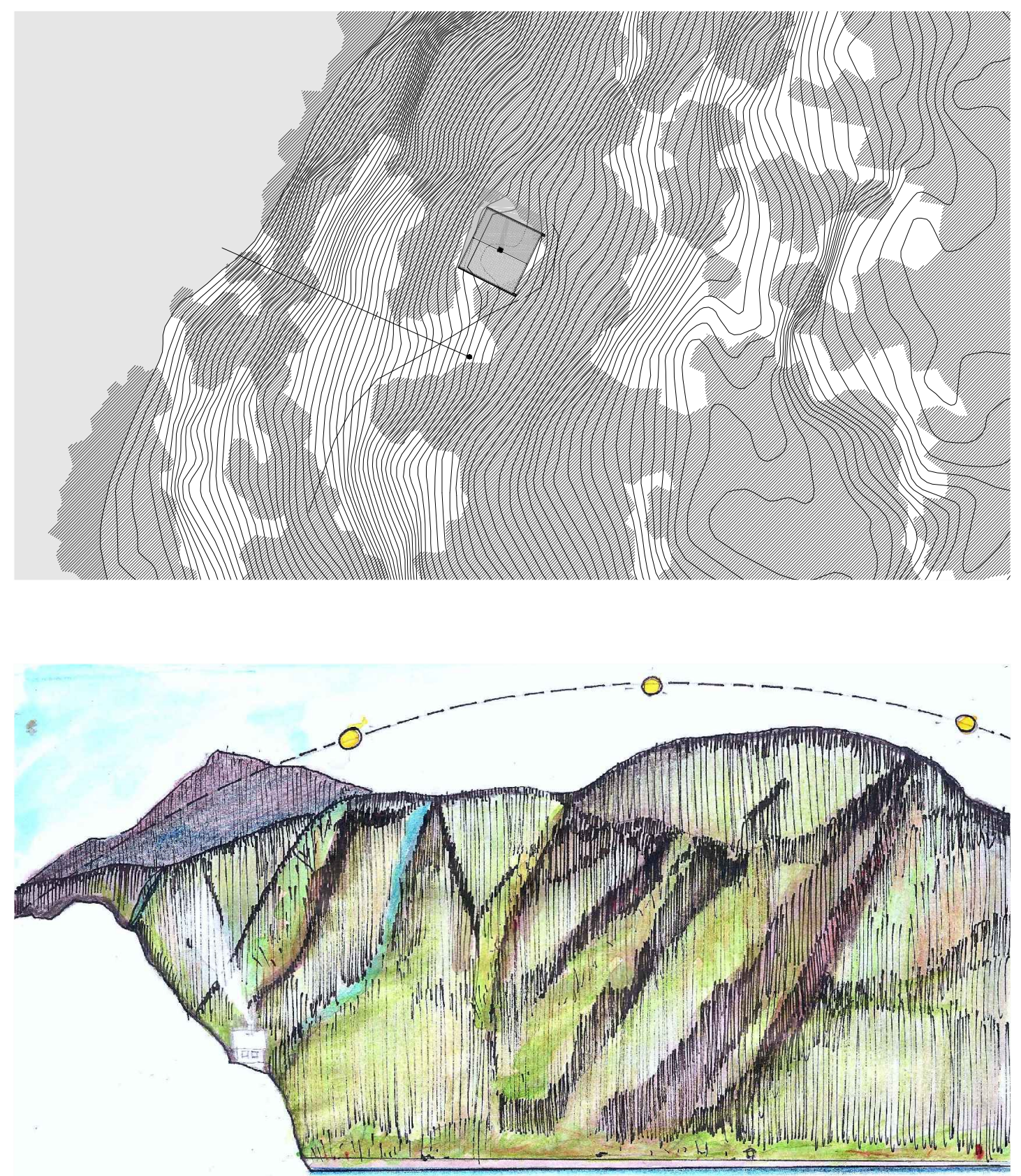

Latitud 61.487N Iongitud 7.631E Solsticio de verano (21.06) Azimut $168,48^{\circ}$ altura solar $51,58^{\circ}$

200. Sección del lago con la casa hacia el sur. Detrás vemos las crestas de Bjøkeskori, Tårnet, Ospenakken y Klepp. Al fondo Fanaråken. La cresta se mantiene a una cota casi constante de 800-1000 m de altura 


\section{Huecos}

El cielo noruego resulta bajo y gris. Las sombras que arroja el sol nórdico son alargadas y profundas. ${ }^{129}$

El emplazamiento de la casa sobre la orilla oeste del lago ofrecía una amplia panorámica del paisaje: las montañas que enmarcan el fiordo, el pueblo de Skjolden y tras un montículo en la desembocadura del Eidselvi, el inicio del fiordo de Luster.

En contrapartida, el punto exacto en el que se ubica la casa, pese a lo expuesto de su situación respecto al lago, queda condicionado por las fuertes pendientes y altitudes que alcanzan las cumbres que encierran tanto el curso del río Fortun como el lago Eidsvatnet. La orientación del eje mayor del lago y del cañón en ese tramo es prácticamente $\mathrm{SE}-\mathrm{NW}^{130}$, por lo que los frentes montañosos que lo flanquean por el Sur131 impedían que el sol alcanzara plenamente la casa. Sólo a partir del solsticio de primavera, entrado el mes de abril y a partir de las $13 \mathrm{~h}(\mathrm{GMT}+1)$, el sol podía bañar durante parte de la tarde la fachada del lago. El largo invierno noruego hizo mella en el espíritu de Wittgenstein tal como recogen sus anotaciones en el diario personal del año 1937132 (las cursivas, subrayados y el signo «\&» son del original):

«30/1/1937. Me encuentro mal físicamente; estoy extraordinariamente débil \& tengo una cierta sensación de mareo.»

«5/2/1937. Por algún motivo no puedo trabajar. Mis pensamientos no avanzan un paso \& estoy desconcertado, no sé qué he de hacer en esta situación. Me parece que aquí pierdo el tiempo inútilmente.»

\footnotetext{
${ }^{129}$ Sirva como referencia que la franja mediterránea cuenta con una media de 2600-3000 horas de sol anuales (fuente: Agencia Española de Meteorología) frente a las 1500-1700 en las latitudes nórdicas (fuente: Norks Meteorologisk Institutt). La altura solar en el solsticio de verano en el lugar exacto de la cabaña es de $51.58^{\circ}$ frente $73.95^{\circ}$ en la latitud y longitud de la ciudad de Valencia mientras que la correspondiente al solsticio de invierno es de $4.88^{\circ}$ frente a $25.55^{\circ}$ en nuestra ciudad. (En ausencia de una tabla gnomónica de Skjolden, se ha utilizado la herramienta disponible en línea: www.sunearthtools.com)

${ }^{130}$ El eje mayor del lago tomado desde la embocadura del Fortunselvi al Eidselvi está girado $54^{\circ}$ respecto al eje N-S. El eje central de la casa rectifica aún más este ángulo y se orienta a $70^{\circ}$ respecto al N-S.

${ }^{131}$ El flanco sur del lago, por el discurre la carretera RV55 - construida 1937-1938, y que coincidió parcialmente durante la más larga estancia Wittgenstein en Skjolden- asciende hacia la zona conocida como Tårnet con una pendiente media del 93\%. La línea de cresta a lo largo del lago, hasta el inicio propiamente del fiordo en el pueblo, alcanza cerca de $900 \mathrm{~m}$ de altitud a lo largo de algo más de $1 \mathrm{Km}$, manteniendo en sombra el lago y el área de la casa de Wittgenstein durante casi seis meses al año.

132 Ludwig Wittgenstein, Movimientos del pensar. Diarios (1930-1932/1936-1937), (Madrid: Gredos, 2009)
} 

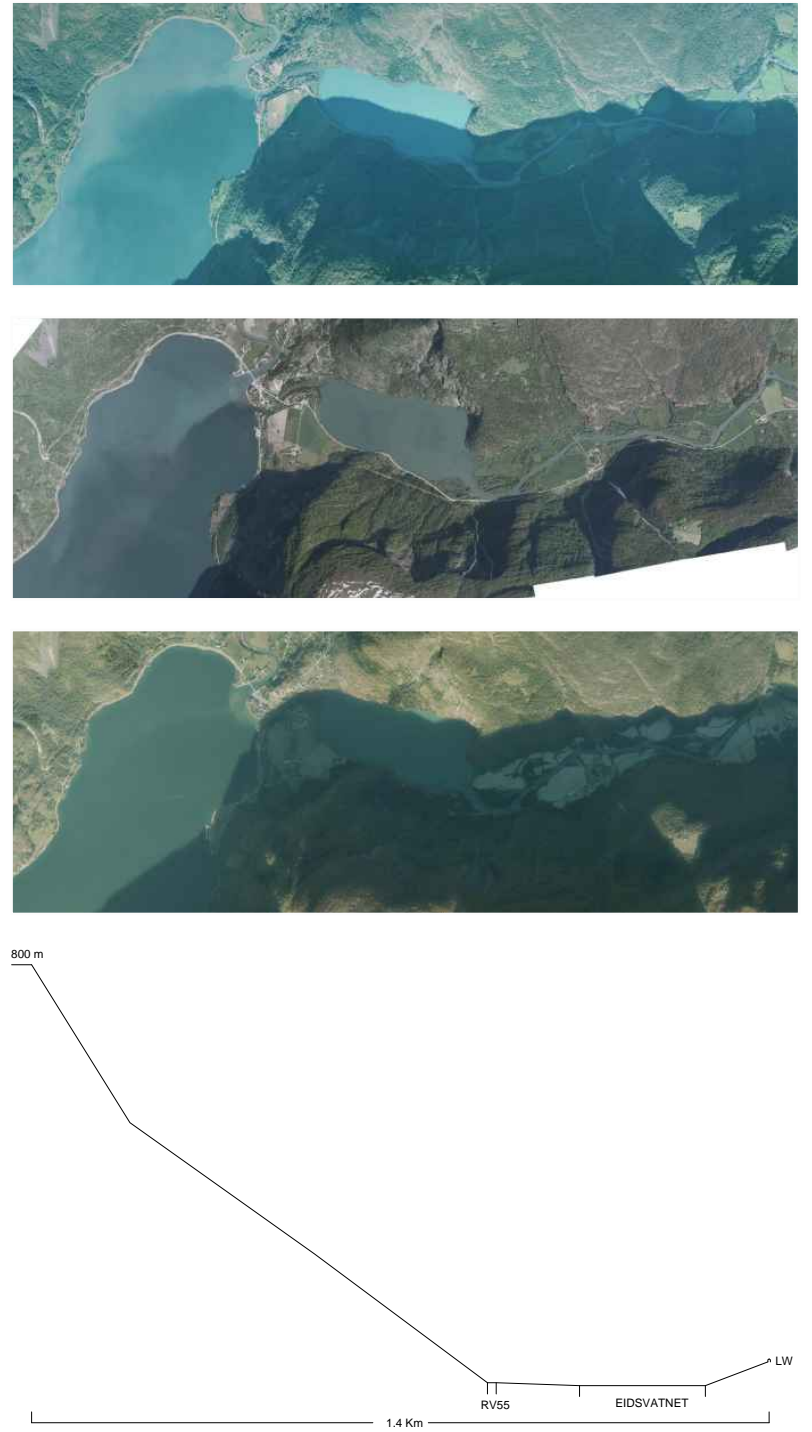

201-203. Fotografías satetilates, 2006-2007-2012. Sombra arrojada de Bjøkeskori, Tårnet, Ospenakken y Klepp sobre el lago. La mayor parte del pueblo queda siempre soleado cuando la altura solar lo permite

204. Sección norte-sur a escala desde la casa de Wittgenstein hasta la cota de la cresta de Tårnet, podemos intuir la dificultad de la localización respecto al soleamiento 
«20/2/1937. ;Doy gracias a Dios por haber venido a la soledad de Noruega.»

«4/3/1937. ¡El sol llega ahora muy cerca de mi casa \& me encuentro más alegre!»

«8/3/1937. Tengo mucha nostalgia de ver el sol desde mi casa \& hago cálculos diariamente de cuántos días faltarán todavía. Creo que no podré verlo antes de 10 días \& quizá no antes de 2 semanas, aunque me he dicho que lo veré ya en 4 días.»

«14/3/1937. Creo que hoy brillará el sol a través de mi ventana.»

«19/3/1937. Aproximadamente 20 min. Después de las 12 aparece ahora el borde del sol sobre el monte. Se mueve a lo largo del perfil del monte de modo que sólo se ve en parte, la mitad más o menos, o más. Sólo por pocos instantes pude verlo casi completo. Y esto quiere decir que fue ayer, si no hoy, la primera vez que superó el horizonte. A la 1 ya se había ocultado. Y vuelve todavía otra vez justo antes del ocaso.»

«22/3/1937. Hoy sale aquí el sol a las $12 \&$ ya aparece completo.»

Las entradas del diario durante el mes de marzo de 1937 siguen describiendo el recorrido del sol primaveral. Wittgenstein intercalaba entre sus reflexiones intelectuales y religiosas, breves descripciones de su estado de ánimo, que aparecen directamente relacionadas con la presencia del sol. Recoge casi cada día, a qué hora ve el sol tras las crestas de Bjørkeskori, Tårnet, Ospenakken y Klepp - en dirección y sentido este-oeste; Klepp ya sobre la granja Eide de Anna Rebni- cuándo lo ve brillar al fondo del lago sobre las casas del pueblo, cuándo vuelve a disfrutar de él, ya cerca del ocaso. Wittgenstein se empeñó en vivir casi siempre una vida de renuncias físicas, y en algunos periodos de estilita, pero la intensidad de su carácter, inestable y depresivo y su escasa resistencia física ${ }^{133}$ le tenían constantemente al borde del abandono:

«27/3/1937. A partir de hoy me llega el sol aquí dentro desde las 10:30 hasta las 5:30 ininterrumpidamente, \& hace un tiempo magnífico.

Había esperado que mi capacidad de trabajo se recuperaría cuando viera más el sol, pero no ha resultado así.»

${ }^{133}$ Wittgenstein sufriría en su casa de Noruega varios episodios de problemas estomacales, debilidad y fiebre. Lo recogen sus diarios reiteradamente. (Por ejemplo entrada en clave del diario del 22.08.37 «...ahora estoy realmente enfermo. Tengo fiebre y me duele el estómago.», MS 118, 9v[2]) 

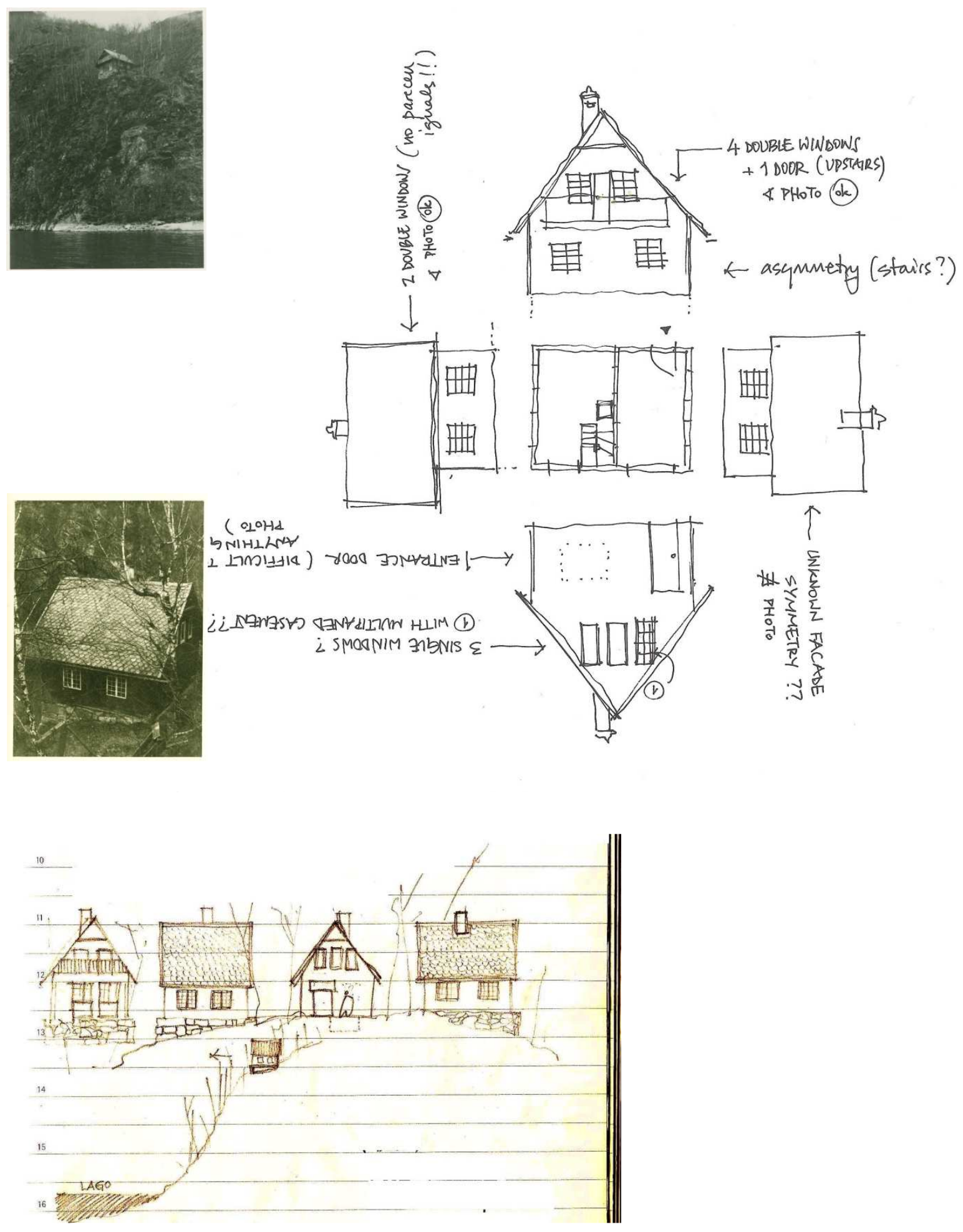

205. Estudio preliminar de los huecos, información directamente extraíble de las fotografías de Ben Richards de 1950 206. Estudio preliminar de los huecos. «Entendiendo las imágenes», 24.08.2011 
«5/4/1937. ¿Ha servido para lo que debía mi estancia en Noruega? Pues no puede estar bien que degenere en una especie de vida de ermitaño mitad cómoda, mitad incómoda. ¡Tiene que producir frutos!»

En el desarrollo del análisis del esquema compositivo de la casa hemos dicho que las dimensiones propuestas parten de la información que se ha podido obtener de un trabajo de dibujo de restitución fotogramétrica -manual- de la casa $^{134}$, a partir de una de las fotografías realizadas por Ben Richards en octubre de 1950 durante el viaje que ambos amigos realizaron por el fiordo y su estancia en Skjolden. La calidad de las imágenes fotográficas no es compatible con el análisis automático y la minuciosa labor de indagación sobre las mismas ha sido ímproba. De las cuatro fotografías de ese viaje y que nos permiten acercarnos a la imagen de la casa tal como la encontraron Wittgenstein y Richards en 1950, únicamente tres aportan información parcial pero cierta de la construcción, de su composición y materialidad: la realizada desde el lago, sobre el bote de remos que probablemente guiaba el propio Wittgenstein ${ }^{135}$, y sobre todo las dos imágenes cercanas, tomadas desde la pendiente de la colina, a unos diez metros de distancia de la casa. ${ }^{136}$

En lo referente a los huecos, y como se ha dicho ya por extenso, tenemos pocas más certezas ${ }^{137}$ sobre la composición original de la casa, que sí había dos huecos sensiblemente cuadrados, cerrados por ventanas de doble hoja, en cada una de las fachadas visibles del nivel de la planta de acceso; de otras dos ventanas, también cuadrangulares en la planta piso recayente al lago-fachada

\footnotetext{
${ }^{134}$ La imagen no tiene la calidad mínima adecuada para la obtención de un modelo informático fotogramétrico. Se han realizado intentos de ello en el Edinburgh Virtual Environment Centre -EdVEC: http://www.edvec.ed.ac.uk/- (D. Connearn en correo electrónico, 04.08.2012). Se desestimó por tanto esa vía -quizá sin haberla agotado. Sí se ha realizado una nueva serie de fotografías de las imágenes originales con el permiso de Michael Nedo en el mismo Wittgenstein Archive Cambridge, en abril de 2015, por el fotógrafo Andrew Penketh [www.andrewpenketh.com].

${ }^{135}$ Imagen n0 0519, «Wittgensteins Blockhaus in Norwegen, Oktober 1950», Ben Richards, Wittgenstein Archive Cambridge, Box 0045 Nr00 Art Repro positiv, Michael Nedo.

${ }^{136}$ Imagen $n^{0} 0514$, «Wittgensteins Blockhaus in Norwegen, Oktober 1950», Ben Richards, Wittgenstein Archive Cambridge, Box 0045 Nr00 Art Repro positiv Michael Nedo

${ }^{137}$ Término éste que en Wittgenstein es complejo y con él en el pensamiento resulta imposible aplicarla más que en un porcentaje menor de acercamiento a la realidad material de la casa tal como pudo ser.
} 


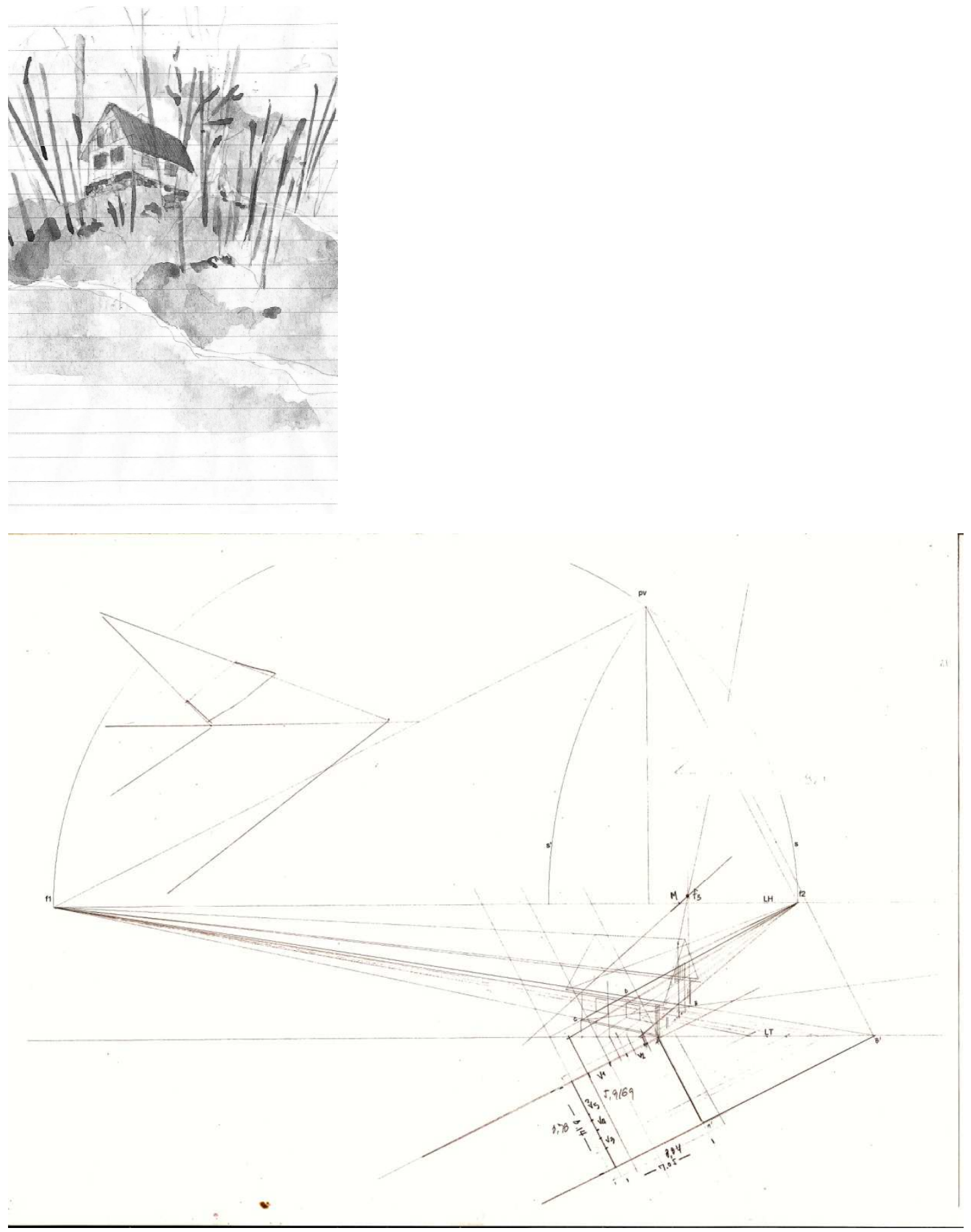

207. Analizando los huecos: «Redibujar las fotografías», 25.08.2011

208. Trabajos de fotogrametría para obtener dimensiones generales y situación de huecos, 12.08.2014 
oeste- y lo que parece una puerta colocada entre ellas, que daría acceso al balcón del testero noroeste. Además, al menos en las fotografías de 1950 podemos ver claramente dos contraventanas o protecciones exteriores apoyadas en la fachada ${ }^{138}$, bajo los huecos que recaen al lago, en planta de acceso. En la fachada este, fuertemente fugada y en sombra, oscurecida por la escasa luminosidad del cielo otoñal y la cercanía de la pendiente a la casa y en la que se encontraba la puerta de acceso, sólo podemos distinguir tres ventanas, en el ático. Los dos huecos más alejados son aparentemente idénticos, pero el hueco de ventana más cercano a la esquina sureste no puede apreciarse en su totalidad por quedar oculto parcialmente tras el tronco de un abedul. En las dos fotografías disponibles, que presentan un ligero cambio de vista, sí podemos ver que esa tercera ventana muestra un panelado de varillas que subdividen la hoja derecha, de aspecto por tanto similar a los huecos conocidos de las ventanas dobles de la fachada suroeste. De ello y de la circunstancia de que no se alcanza a apreciar el extremo izquierdo de la ventana -y que deberíamos poder ver si suponemos una dimensión igual a las dos sencillas a su derecha- se colige que, con toda probabilidad se trata de una ventana de doble hoja y dimensiones idénticas -lógica constructiva por otra parte- a las demás de planta baja. Por tanto ese alzado se compone asimétricamente con dos ventanas de una hoja y una de doble hoja, panelada en la planta del ático con separaciones a su vez diferentes entre ellas y un único hueco en planta baja que se corresponde con la puerta de la casa y que hemos situado teniendo en cuenta la aparición de un hueco en similar localización en la casa reconstruida por los Bolstad.

Para el estudio dimensional de los huecos se hizo una primera ${ }^{139}$ aproximación cuantitativa y cualitativa de las carpinterías de las fachadas

\footnotetext{
${ }^{138}$ En el resto de fotografías históricas localizadas durante la presente investigación no se alcanza a apreciar si las contraventanas estaban cerradas y cubrían el hueco y tampoco es posible saber en qué momento fueron instaladas. No hay referencia de si fue el propio Wittgenstein en los años treinta, Arne Bolstad u otra persona como Arne Drægni al cuidado de la casa, quien las colocara antes de 1950, probablemente por cuestiones de mantenimiento siendo la fachada más expuesta. En la foto de Brathole (1920) no se aprecian.

${ }^{139}$ Se refiere en realidad a las dimensiones obtenidas en una segunda fase de la investigación, posterior a 2012. La primera versión de los planos de la casa de Wittgenstein para este trabajo, fechados en 2011, partían de un supuesto absolutamente erróneo de las dimensiones de la base de la casa -el primer acercamiento al dibujo de la casa se realizó sin haber visitado el lugar- con la que se proporcionó el resto de los elementos, por lo que más allá del interés documental en el desarrollo de esta tesis no aportan información siquiera cercana a la realidad conocida tiempo más tarde. Sin embargo, el intento de encontrar la máxima precisión guiaba aquel fútil intento de igual manera como ha guiado la presente propuesta.
} 

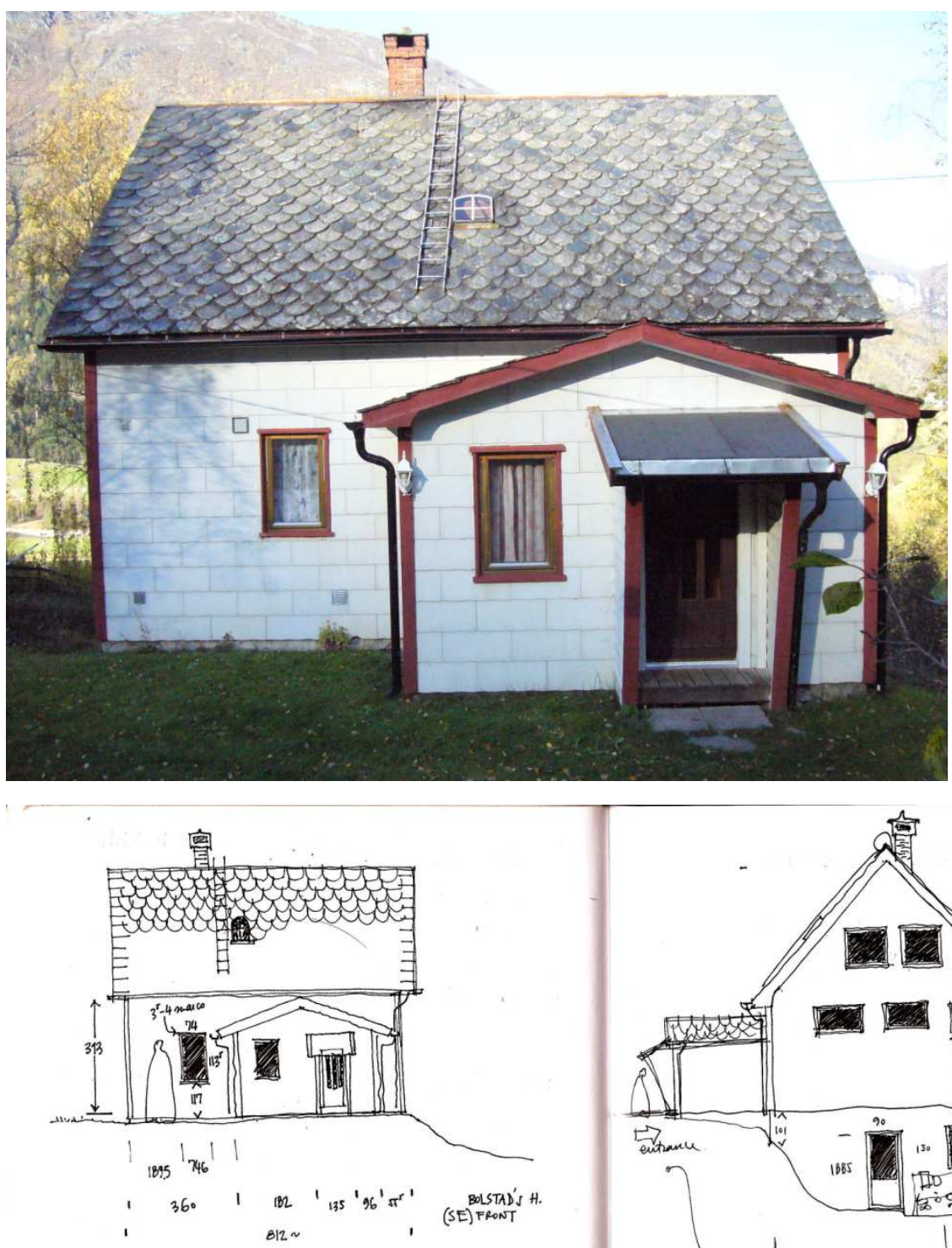

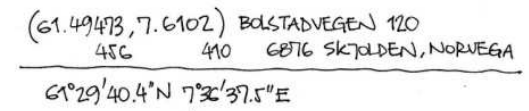
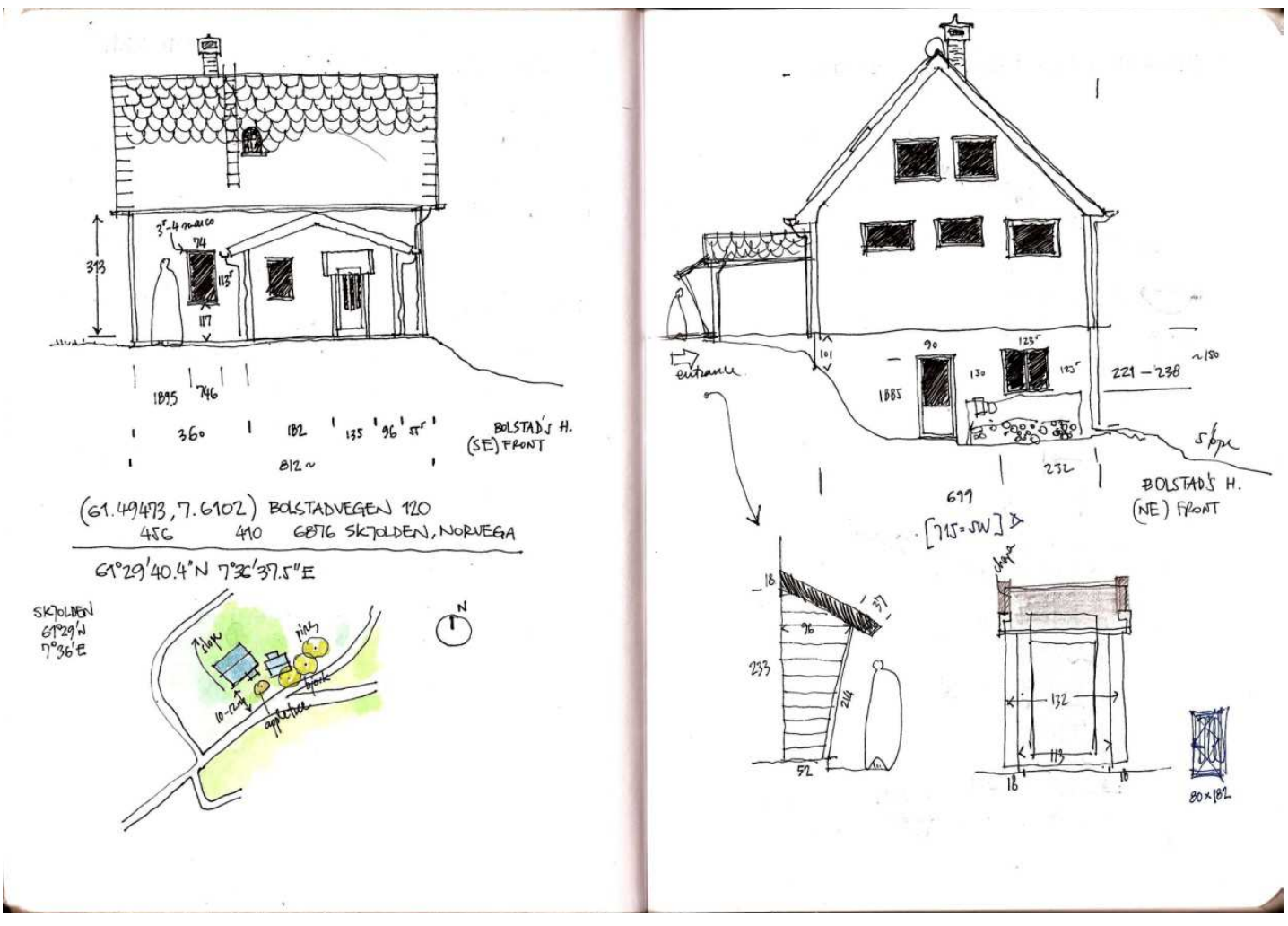

209. Casa de Gunnar Bolstad, fachada sureste. Skjolden, 12.10.2013 210. Toma de datos de las fachadas y detalles 
conocidas tomando las propias fotografías como patrón ${ }^{140}$. De ellas se obtuvo un plano de carpinterías que encajaba con las dimensiones obtenidas a partir del dibujo de reconstrucción fotogramétrica con el que se estaba trabajando. Las ventanas visibles se establecieron, con un error absoluto difícil de calcular, como sigue:

\begin{tabular}{llll} 
cód. & fachada & $\mathrm{mm}$ & tipo \\
\hline W01 & NO & $1200 \times 1200$ & doble hoja/panelada \\
W02 & NO & $1200 \times 1200$ & doble hoja/panelada \\
W03 & NO & $1200 \times 1200$ & doble hoja \\
W04 & NO & $1200 \times 1200$ & doble hoja \\
W05 & SO & $1050 \times 1100$ & doble hoja/panelada \\
W06 & SO & $1200 \times 1200$ & doble hoja/panelada \\
W07 & SE & $1200 \times 1200$ & doble hoja/panelada \\
W08 & SE & $600 \times 1200$ & hoja simple \\
W09 & SE & $600 \times 1200$ & hoja simple
\end{tabular}

Puesto que sólo nueve ventanas son visibles en las fotografías de Ben Richards de 1950 - y la W07 sólo parcialmente-, ha habido que recurrir a otras fuentes de información para poder avanzar en la investigación.

La principal base de datos para el proyecto original de la casa de Wittgenstein debía ser la casa reconstruida por Gunnar Bolstad en 1957 con el material llevado hasta el pueblo desde el lago para construir su propia vivienda. De igual manera las ventanas deberían haber sido reaprovechadas en su totalidad, siguiendo una lógica constructiva, la reconstrucción de la casa de madera debería haber reproducido la original: "una casa de madera es como un kit, el material lo debes recolocar de la misma manera para poder aprovecharlo al máximo» ${ }^{141}$. Sin embargo sabemos que únicamente la fachada noroeste de la

\footnotetext{
${ }^{140}$ Como se comprenderá, no es tarea fácil determinar los límites de los distintos elementos sobre una fotografía de tan pequeño formato, y lo que aquí se muestra como un resultado directo proviene de un trabajo reiterado de medición y aproximación hasta poder alcanzar un mínimo consenso. Por fortuna, como se verá, no ha sido el único medio disponible para este estudio, pero sí el primero y más obsesivo. Decenas de horas de trabajo han sido necesarias para obtener algunos resultados y quizá un par de hallazgos.

${ }^{141}$ Harald Vatne, en conversación personal. Skjolden 14.10.2013: «A log cabin is a kind of system, you must use the most possible quantity of material in the same position as it was in the original... if not, you must change too things, it's not practical».
} 

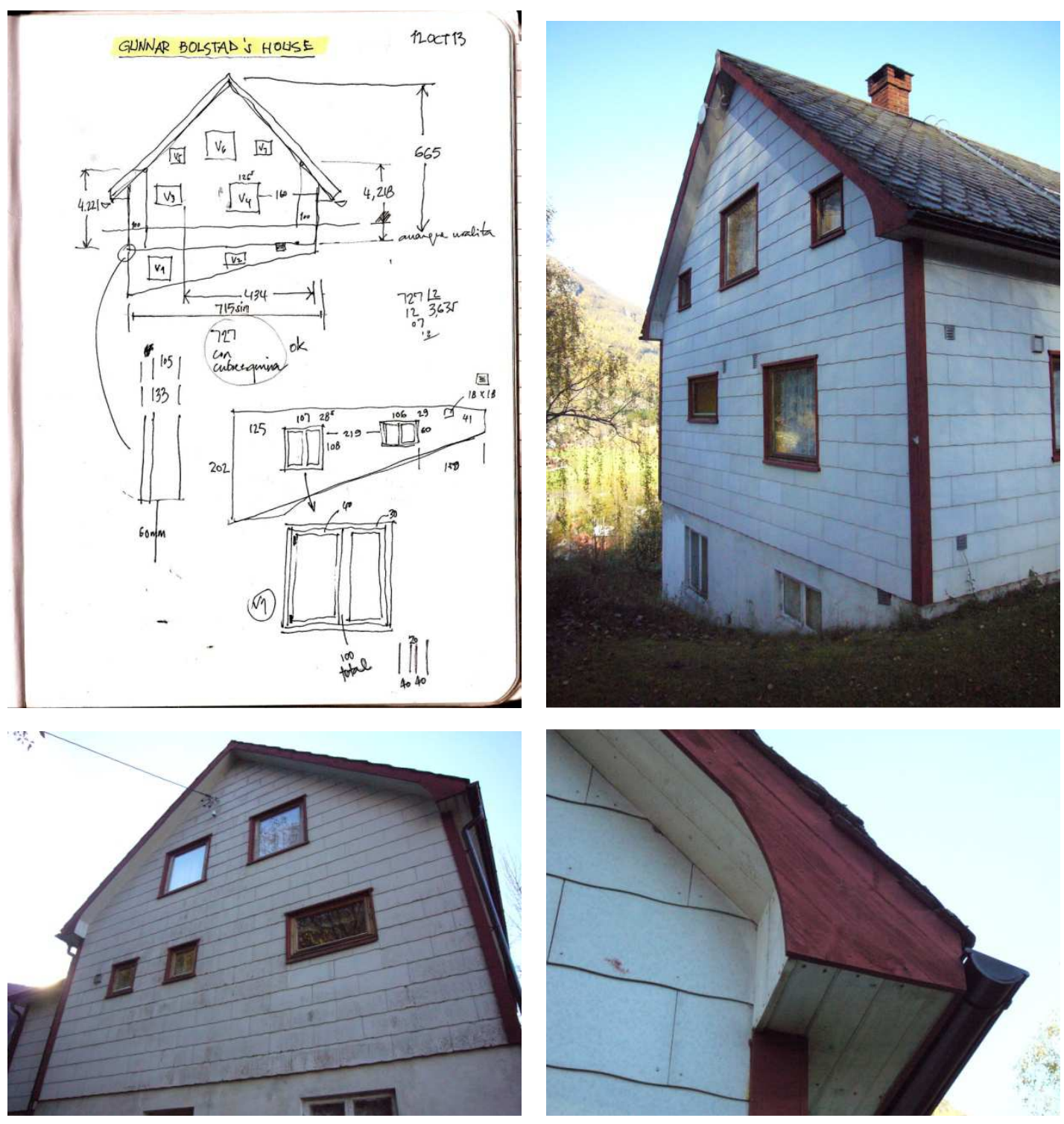

211. Toma de datos de las fachadas y detalles ～～212. Casa de Gunnar Bolstad, fachada suroeste. Skjolden, 12.10.2013

213. Casa de Gunnar Bolstad, fachada noreste. Skjolden, 12.10.2013 ｜ 214. Casa de Gunnar Bolstad, detalle esquina sur. Skjolden, 12.10 .2013 
casa reconstruida ha conservado la geometría original. Sobre esto hay consenso ${ }^{142}$.

La toma de datos in situ de la casa de Gunnar Bolstad nos proporciona una medida valiosa que es la del hueco de las ventanas de la fachada NO que, en la casa original recaía al lago, con similar orientación. Los datos obtenidos son de 1240x1250 mm para el hueco izquierdo y de 1255x1250 mm ${ }^{143}$ el derecho.

Por tanto, la lógica arquitectónica y constructiva indicaba que las ventanas del alzado correspondiente al lago en la casa original y las de la casa reconstruida por Bolstad en Skjolden debían corresponderse. El proceso de esta investigación fijó en este punto que las ventanas principales fueran cuadradas, de dimensiones razonadas de 1250x1250 mm. Como afirmaba Vatne, el hecho de reconstruir una casa de madera implicaba haber reutilizado las carpinterías puesto que son elementos especialmente costosos y que debían estar determinados por los huecos abiertos en las fachadas de la casa del lago. El conjunto de ventanas en la casa Bolstad se resume en la siguiente tabla:

$\begin{array}{llll}\text { cód. } & \text { fachada } & \text { mm } & \text { tipo } \\ \text { B01 } & \text { NO } & 1240 \times 1250 & \text { hoja simple } \\ \text { B02 } & \text { NO } & 1255 \times 1250 & \text { hoja simple } \\ \text { B03 } & \text { NO } & 1080 \times 1080 & \text { doble hoja } \\ \text { B04 } & \text { NO } & 1080 \times 1080 & \text { doble hoja } \\ \text { B05 } & \text { SO } & 600 \times 600 & \text { hoja simple } \\ \text { B06 } & \text { SO } & 1200 \times 1200 & \text { hoja simple } \\ \text { B07 } & \text { SO } & 600 \times 600 & \text { hoja simple } \\ \text { B08 } & \text { SO } & 1300 \times 750 & \text { hoja simple } \\ \text { B09 } & \text { SO } & 1260 \times 1200 & \text { hoja simple } \\ \text { B10 } & \text { SO } & 1070 \times 1080 & \text { hoja doble } \\ \text { B11 } & \text { SO } & 1060 \times 600 & \text { hoja doble } \\ \text { B12 } & \text { SE } & 740 \times 1100 & \text { hoja simple } \\ \text { B13 } & \text { SE } & 740 \times 1100 & \text { hoja simple } \\ \text { B14 } & \text { NE } & 1057 \times 1126 & \text { hoja simple }\end{array}$

\footnotetext{
${ }^{142}$ David Connearn y Dawn M. Wilson presentaron en 2011 con motivo de una exposición sobre el filósofo en el Schwules Museum Berlin, un artículo en esos términos.

${ }^{143}$ En general las medidas utilizadas en Noruega y más en construcción en madera aplicaban el sistema Imperial de medidas anglosajón. En determinadas partes de la investigación se utilizará este sistema. Estas ventanas se nombrarían como de 49 pulgadas.
} 

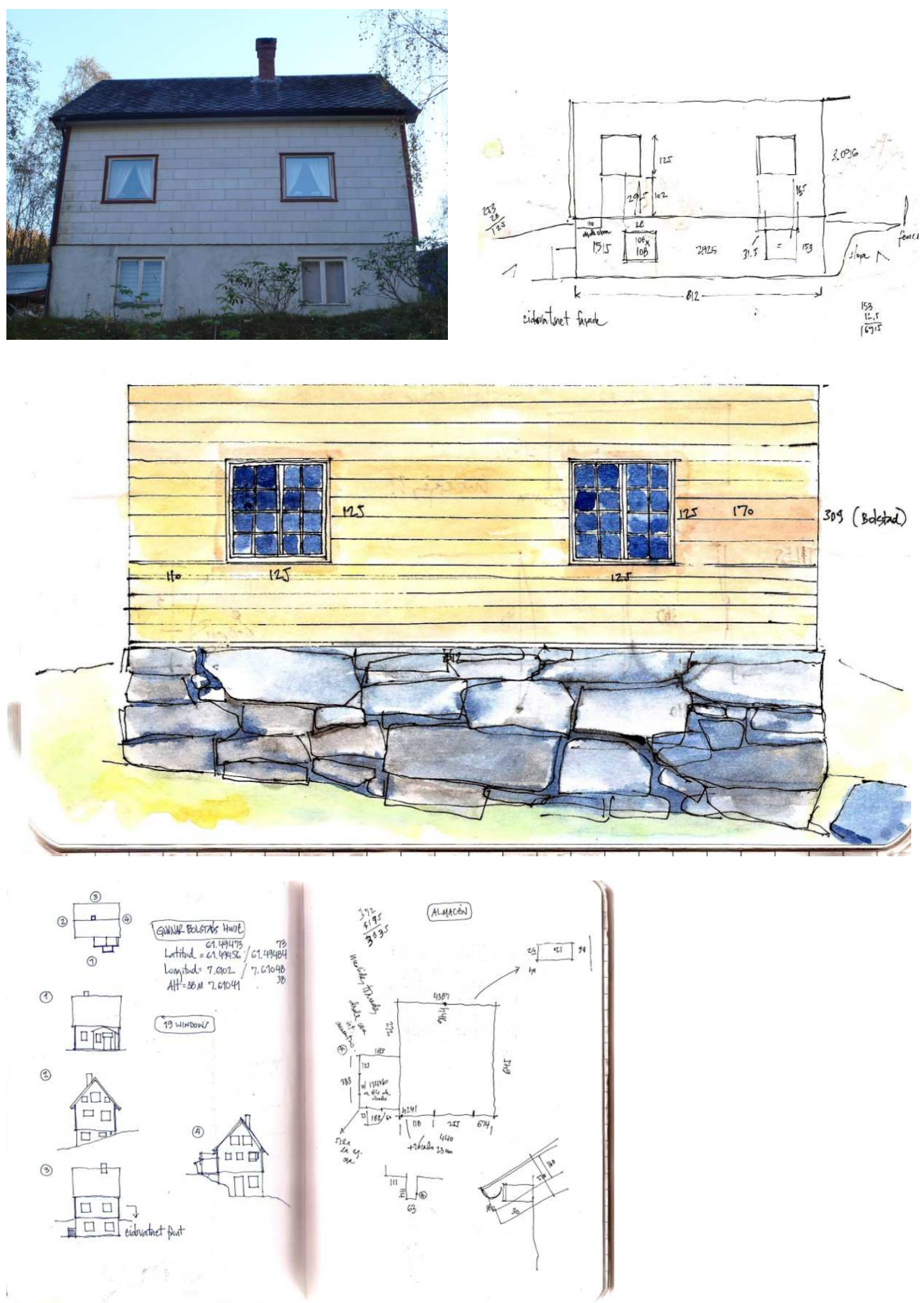

215. Fachada noroeste. Skjolden, 12.10.2013, corresponde con la fachada original recayente al lago Eidsvatnet | 216. Alzado noroeste, toma de datos, 12.10.2013

217. Dibujo de la fachada noroeste de la casa original a partir de las dimensiones de la casa Bolstad 218. Casa Bolstad y cobertizo exterior, 14.10 .2013 


$\begin{array}{llll}\text { B15 } & \text { NE } & 1057 \times 1126 & \text { hoja simple } \\ \text { B16 } & \text { NE } & 550 \times 652 & \text { hoja simple } \\ \text { B17 } & \text { NE } & 550 \times 652 & \text { hoja simple } \\ \text { B18 } & \text { NE } & 1250 \times 800 & \text { hoja simple } \\ \text { B19 } & \text { NE } & 1080 \times 1080 & \text { hoja doble }\end{array}$

Del estudio comparativo de la casa de Bolstad y las imágenes existentes de la casa de Wittgenstein, podemos extraer algunas conclusiones, en principio compositivas y como se verá más adelante también constructivas.

En la casa reconstruida contamos diecinueve huecos de ventana y dos puertas de acceso desde el exterior, una de ellas protegida por un elemento cortaviento adosado al volumen principal, característico en las construcciones nórdicas.

Observamos cierta convergencia en las medidas de los huecos cuadrados, tanto en la casa existente como en el estudio métrico de la original, predominando las medidas de $1250 \times 1250$ aproximadamente. Pero el criterio compositivo no arroja demasiadas respuestas. En un análisis de ambas casas, teniendo en cuenta las dimensiones principales de cada fachada y fijando la de orientación NO coincidente en ambas, únicamente podemos apreciar cierto parentesco entre la composición del alzado de planta baja SO de la casa Bolstad y el de la casa original, con la peculiaridad de que, el encaje es más preciso si aplicamos una simetría a la fachada reconstruida, como si en el proceso de recolocación de las fachadas, los Bolstad hubieran decidido utilizar los troncos de los cerramientos girados $180^{\circ}$. La fachada SE, con la puerta de acceso situada a la derecha en la actualidad, necesitaría una operación similar que permitiera situar el hueco en la casa original en la zona que se presume correcto, a la izquierda. Respecto a la fachada NE, puesto que no existen evidencias gráficos históricas de los huecos de fachada, podemos proyectar uno o dos huecos en una situación coherente a la prevista en esta investigación.

Los hastiales de las fachadas, teniendo en cuenta como se ha dicho que en la casa reconstruida se modificó la orientación de la cubierta, girándola $90^{\circ}$, tienen diferente anchura. Aún así encontramos que el hueco W07 del alzado SE 

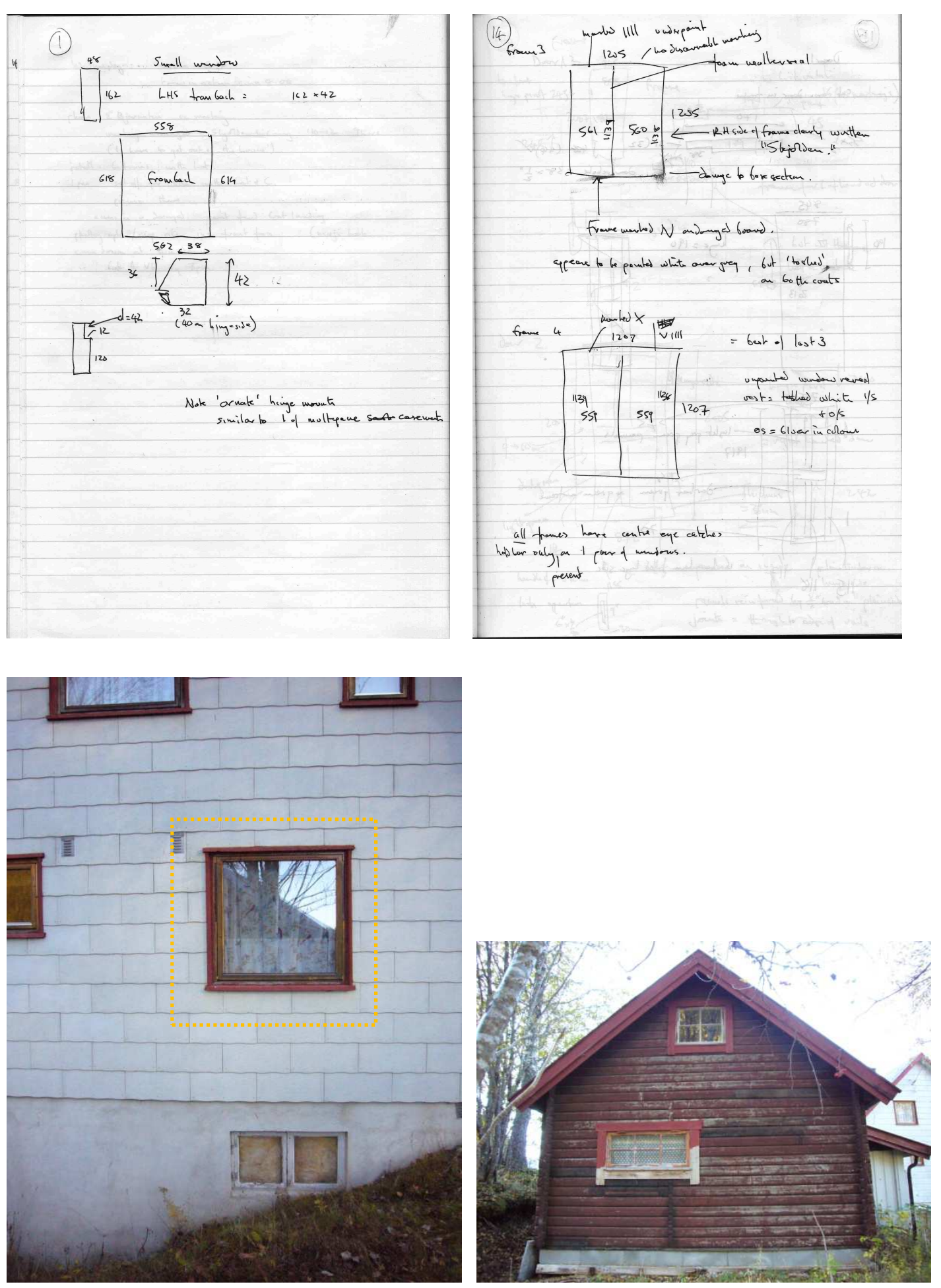

219-220. Cuaderno de D. Connearn con anotación de las ventanas de Vatne, julio 2009

221. Ventana de dimensiones $125 \times 126 \mathrm{~cm}$ en fachada suroeste, Casa Bolstad, 12.10.2013 | 222. Garaje exterior Casa Bolstad. Hasta la visita de octubre de 2013 se consideraba construido con madera procedente de la casa original (tabiquería interior). Kåre Bolstad desmintió tal información, 14.10.2013 
de la casa en el lago es coincidente en cuanto a situación y dimensiones con el hueco B14. No ocurre lo mismo con los huecos del hastial SO, puesto que la composición original muestra dos huecos laterales y una puerta centrada de acceso al balcón en la casa de Wittgenstein y no guarda relación con la distribución de huecos del alzado correspondiente en la actualidad.

Compositivamente hemos podido comprobar que hay elementos y razones geométricas que respaldan las decisiones tomadas en la investigación. Una vez analizadas las dimensiones reales de la casa de los Bolstad, se decide ajustar la situación y medida de los huecos del proyecto de la casa de Wittgenstein. Se produce, como en el resto de la investigación un proceso iterativo entre el análisis exhaustivo del -escaso- material gráfico, la toma de datos in situ y la racionalización del proyecto, compositiva y constructivamente.

No hemos hecho referencia a otros huecos que aparecen en ambas construcciones. En la casa de Bolstad, aparecen una serie de huecos de doble hoja y una puerta de acceso en el nivel del semisótano. Estos huecos parecen conservar carpinterías de cierta antigüedad. No sabemos en el momento de redactar estas líneas en qué año pueden fecharse pero como se verá después presentan un parecido razonable con la construcción de las carpinterías que presumimos pertenecieron a la casa de Wittgenstein. El resto de carpinterías presentes en la casa, en los pisos superiores son claramente de ejecución moderna, realizadas en madera barnizada, lisa, con herrajes de acero inoxidable y hojas sin particiones. Se desconoce la fecha en la que se instalaron las carpinterías que podemos observar en la actualidad.

Hasta el año 2012, todo el trabajo realizado sobre la casa del lago se había basado únicamente en el análisis de las imágenes y de la lógica arquitectónica propia de una edificación de esas características materiales, uso, localización y medios en el momento de su construcción.

Durante el verano de ese año, se consolida una relación de colaboración con el artista inglés David Connearn con el objetivo común ${ }^{144}$ de trabajar en el

\footnotetext{
${ }^{144} \mathrm{cfr}$. Introducción y estado de la cuestión del presente documento. Relación desde julio 2011.
} 


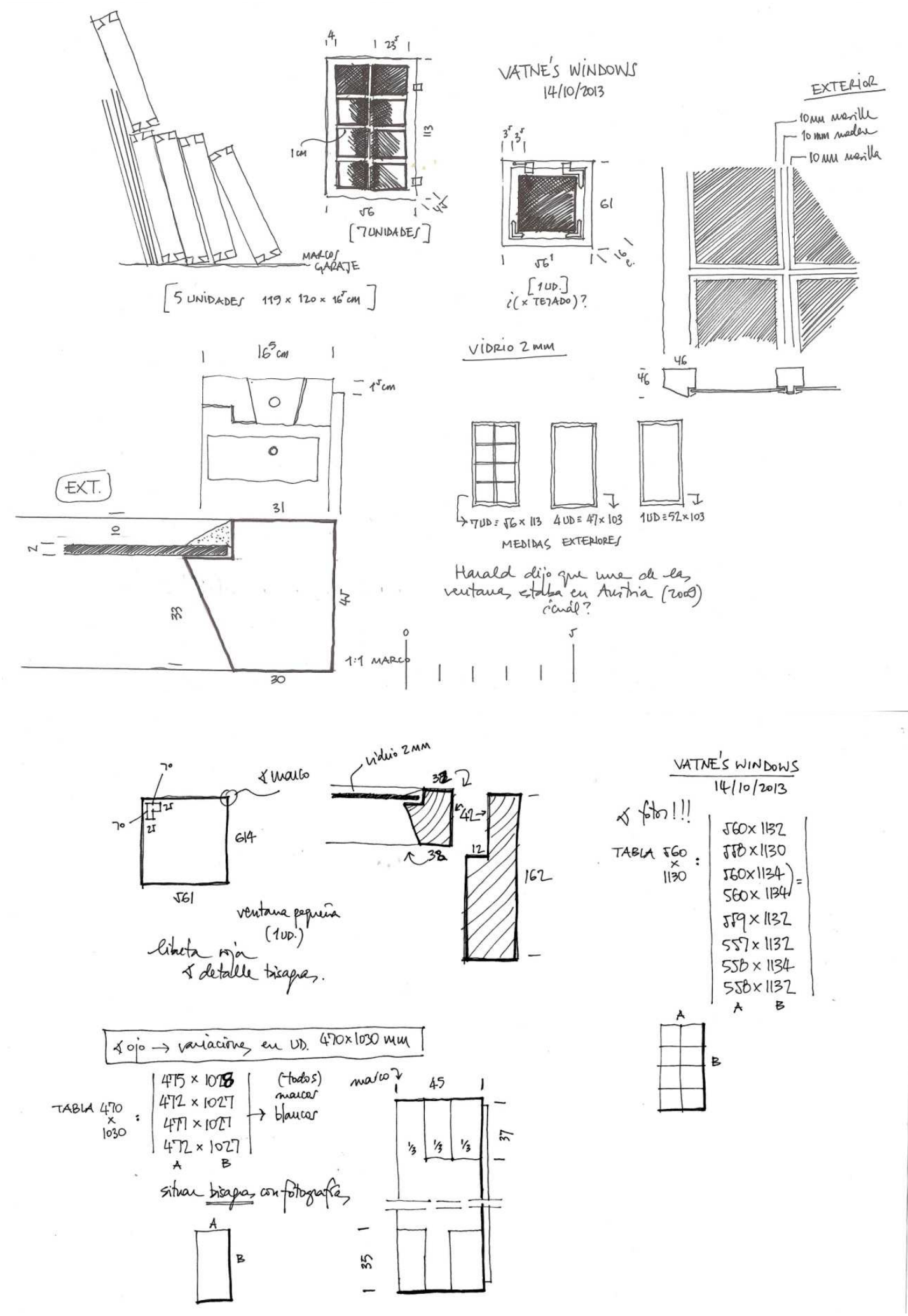

223. Toma de datos de las carpinterías originales que conserva Harald Vatne, 14.10.2013 224. Idem 
desarrollo de una propuesta descriptiva de la casa de Wittgenstein en Skjolden. La situación, inicialmente difusa y sin un esquema organizativo previo, cristaliza en agosto de 2012, cuando Connearn propone apoyar una ponencia a realizar en Islandia ${ }^{145}$ con la producción de nuevo material gráfico. Connearn revela que Harald Vatne, de Skjolden, había ido coleccionando durante años, algunos elementos supuestamente originales de la casa de Wittgenstein, cuando los Bolstad, por motivos de mantenimiento o actualización, habían decidido desechar parte del material original. Entre esos objetos, Vatne había adquirido una amplia colección de carpinterías de madera -ventanas, puertas y marcos. Esto podía suponer sin duda un cambio cualitativo en el acercamiento a una realidad constructiva que ya no existía y que hasta ese momento se había basado en estimaciones métricas.

En julio de 2009, tras casi diez años de contacto ${ }^{146}$, Vatne había accedido a que Connearn tuviera la oportunidad de analizar los objetos que aquel conservaba en el garaje de su casa. Connearn realiza en aquel momento una toma de datos de cada elemento que Vatne le muestra. Parte del material -todo el fotográfico- de aquella visita se perdió. Las anotaciones en un cuaderno personal, fueron puestas generosamente a nuestra disposición por Connearn. ${ }^{147}$

Una segunda propuesta de proyecto respecto a las ventanas se deriva de los datos de Connearn. La principal es que Vatne parece que conserva algunas de las ventanas, marcos y hojas de la casa original. Entre el material disponible relaciona un marco y su hoja, simple, de dimensiones 560x610 mm, cuatro hojas de ventana simples de 470x1027 mm, una unidad de 520x1030 mm y otra de 560x1130 mm, así como ocho hojas de 560x1130 mm paneladas. Además hay anotaciones de la existencia de cuatro marcos de ventana de 1200x1200 mm y

\footnotetext{
${ }^{145}$ Se trataba de la «International Conference "In Wittgenstein's Footsteps", Celebrating the 100th Anniversary of Ludwig Wittgenstein's Visit to Iceland, University of Iceland». David Connearn inauguró la conferencia con la ponencia titulada «Skjolden House Conservation Project: "Wittgenstein's Peregrinations and the Current Conservation of the Skjolden House"». Viernes 14.09.2012: Lögberg, Reykjavik.

${ }^{146}$ Conversación con D. Connearn: «[...] I corresponded with him in the 1990s but the first meeting was in 1999. Yes, slow to trust [...]». Fecha indeterminada.

${ }^{147}$ Correspondencia electrónica con D. Connearn de fecha 3.09.2012: «[...] I have measurements of all windows and their frames recovered from the reconstructed house by Harald Vatne, as they have been replaced. Also measurements of 2 doors and their frames. [...] I will put the appropriate notebook drawings, and photographs in Dropbox, Shared G-log for you now. [...]»
} 


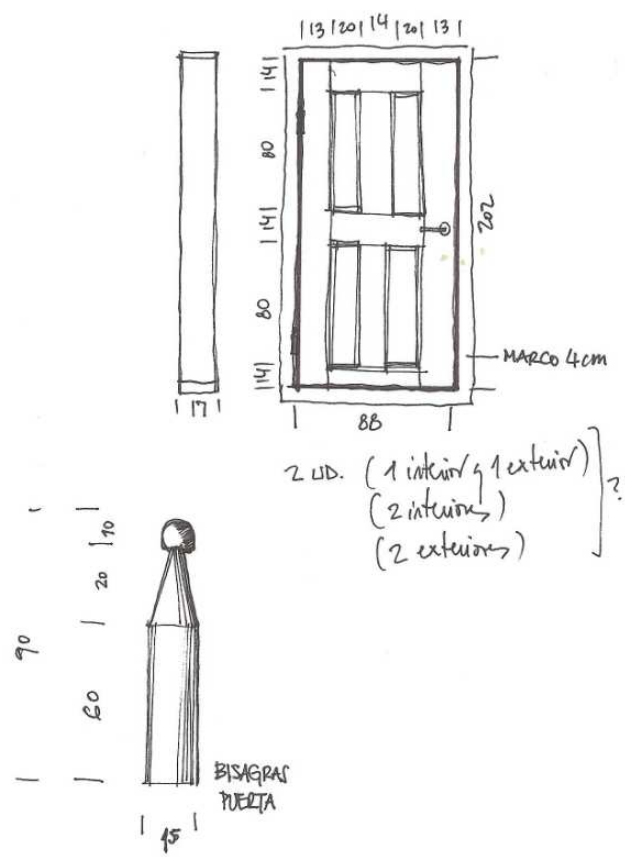

VATNE'S DOORS
$14 / 10 / 2013$
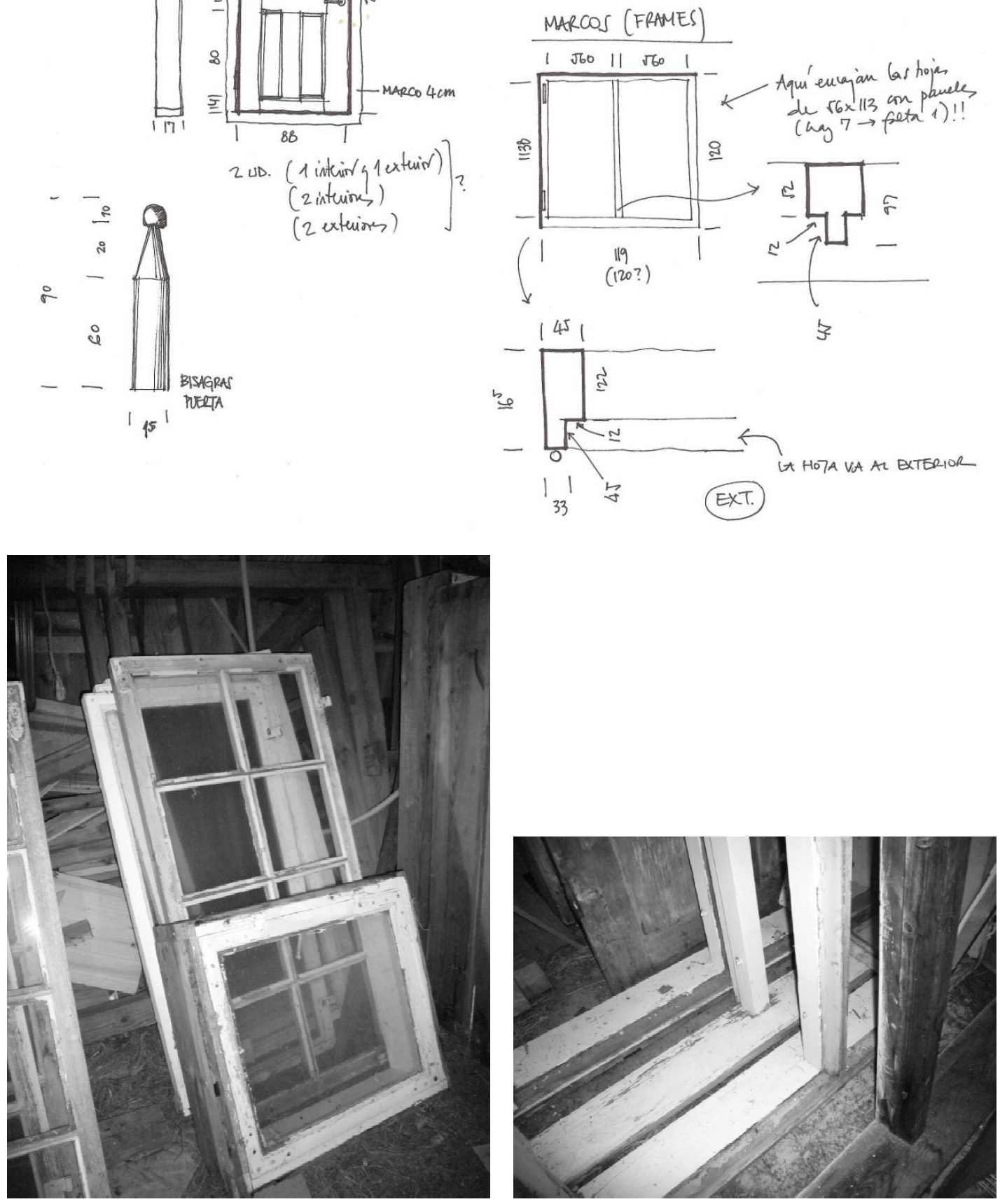

225. Toma de datos de las carpinterías originales que conserva Harald Vatne, 14.10.2013 226-227. Fotografías de elementos originales en garaje de Vatne, 14.10.2013 
uno de 1040x1090 mm. Las notas incluyen la referencia a dos hojas de puerta de dimensiones 2005x880 mm - una de ellas con marco- y una hoja de puerta de 1917x845 mm. Todos los marcos son algo mayores de $1200 \mathrm{~mm}$ en ambas direcciones apuntando a que parecen fabricados para ser instalados en un hueco de $48 "$

En definitiva, las medidas tomadas en proyecto sobre el material gráfico, las medidas in situ en la casa de los Bolstad y las tomadas sobre las supuestas ventanas originales parecían coherentes, al menos aquellas ventanas que sí podemos ver. El criterio seguido a partir de este momento fue fijar unas dimensiones de carpinterías para las ventanas dobles cuadradas de 48", unas paneladas -planta baja en el alzado del lago y alzado lateral- y de igual dimensión pero sin panelar en las correspondientes a la veranda.

Las dos ventanas simples, de una hoja, del alzado sureste encajarían con los huecos de 24"x48". Una reflexión más detallada se produjo durante la visita a Skjolden en octubre de 2013:

«Lunes, 14 de octubre de 2013. [...] Vatne ha estado fuera, en la montaña con la familia, todo el fin de semana. No he podido hablar con él desde el jueves, cuando nos reunimos en la cabaña y me acompañó cerca de "Østerrike". Conduce bastante deprisa por caminos tan embarrados. Llamada de Jani Fardal del Sogn Avis para decirme que había estado en USA y hasta hoy no había leído mi mensaje. Me ha preguntado si había descubierto algo y le he dicho que aún tenía que procesar la información recopilada. Ha tardado poco en colgar. A los pocos minutos ha llamado Vatne:

"-Hi Enrique, this is Harald. I am getting Skjolden in half an hour. I had my dentist today in Gaupne. I talked to Kåre Bolstad and if it is ok for you we can go there together and visit the house, he will open it to us. I have also some material from the Wittgenstein's House you might want to see." Ya no esperaba verlo antes de marcharme de aquí.[...]» 148

\footnotetext{
${ }^{148}$ Transcripción parcial del diario personal de viaje. Skjolden, 14.10.2013. Durante la tarde del día 14, se tuvo ocasión de visitar la casa de los Bolstad, en compañía de Harald Vatne, su esposa Olga y Kåre Bolstad, el más joven de los hermanos Bolstad. La visita realizada al interior de la casa de la casa familiar, permitió el acceso a determinados elementos que permanecían ocultos hasta ese momento a la investigación, y hasta ahora inéditos, tal como se ha expuesto en otras secciones del presente trabajo. Se realizó una sesión de fotografías con la intención de ser publicadas en Sogn Avis, a petición de J. Fardal, como testimonio del interés internacional en la casa de Wittgenstein. Tal reportaje nunca se publicó.
} 

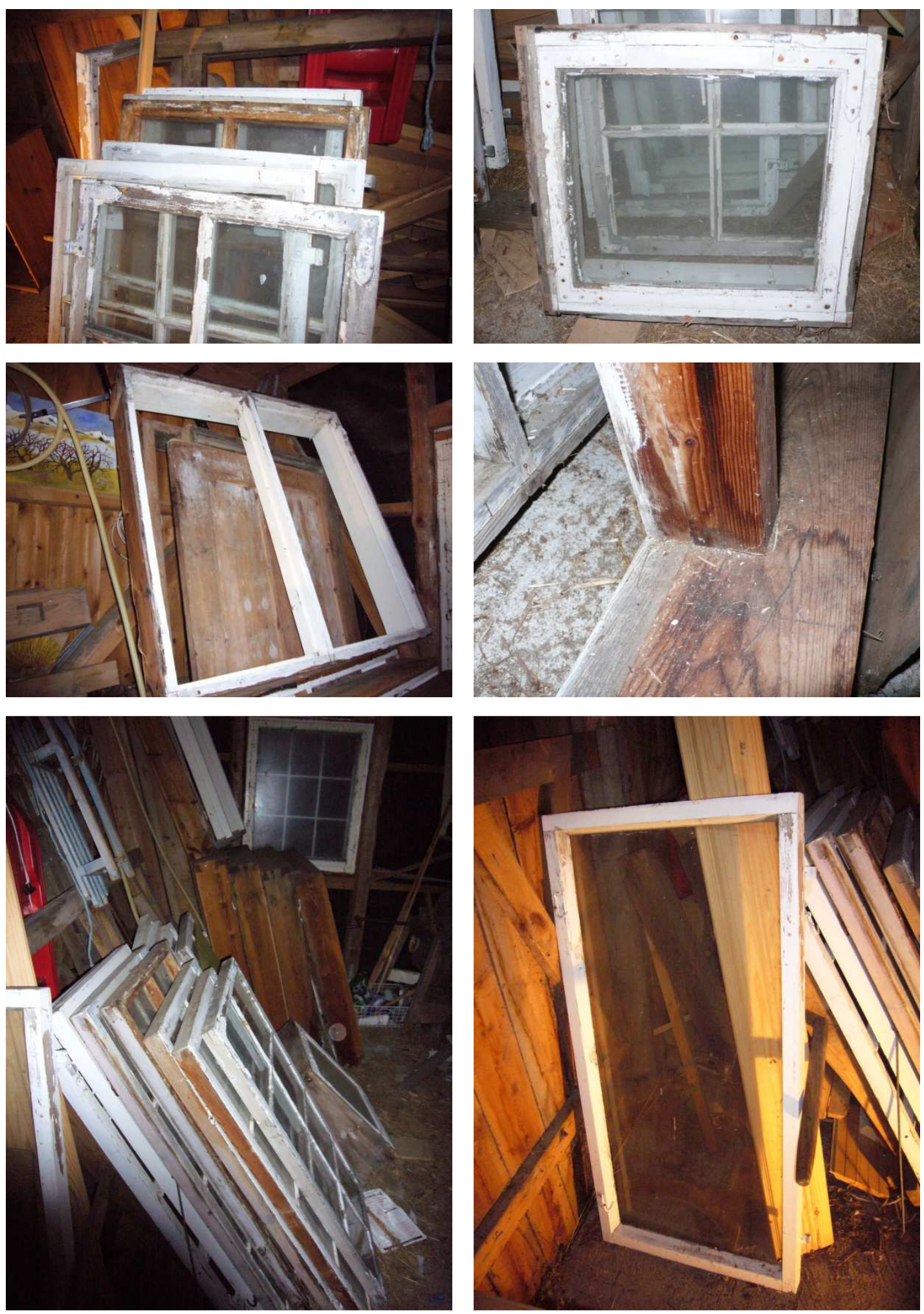
Harald Vatne conserva un total de veintidós elementos de carpintería que provienen de la casa de Gunnar Bolstad. Todos ellos son de madera de pino, de manufactura aparentemente similar, pero que acusan pequeñas y medianas variaciones. De la conversación mantenida durante la visita y la toma de datos en el garaje de Vatne, se deduce que este no había realizado ningún estudio sistemático de los elementos que adquiridos a los Bolstad. En una imagen de la casa Bolstad de 1994 se aprecian todavía las ventanas de madera originales ${ }^{149}$ y esto además nos permite confirmar que el trazado de los huecos originales no es en todos el que vemos en la actualidad sino que fue modificado al menos una vez a finales de los años noventa. Vatne presenta las carpinterías como provenientes de la casa de Wittgenstein de 1914. Las modificaciones en la casa Bolstad nos permiten proyectar que los huecos de la casa original eran coincidentes con los que habíamos obtenido del estudio fotogramétrico y que el sistema de modificación que hicieron los Bolstad recreciendo el antepecho de la ventana del salón en el alzado SO sobre la ventana original de 48" debería ser el mismo que el aplicado en el alzado NE, puesto que ambas ventanas tienen una situación claramente simétrica en el salón. Así, nuestra propuesta de tener al menos una ventana de 48" en el alzado oculto de la casa de Wittgenstein es coherente. Otra cuestión, que quedaría por debatir y que con los datos obtenidos hasta la fecha no podemos verificar, es la existencia o no de otro hueco de 48 " o de dos de 24 " tal como vemos en la Bolstad y que se muestra en los esquemas adjuntos.

El listado exhaustivo de las carpinterías, tal como se conservaban en octubre de 2013 es el siguiente:

- Una ventana de madera de pino, pintada en color blanco, de una hoja, dimensiones exteriores del marco 561x614x162 mm, marco interior de 35x45 $\mathrm{mm}$, vidrio de $2 \mathrm{~mm}$, bisagras y ángulos de refuerzo en esquinas de cinc. ${ }^{150}$

- Ocho hojas de ventana de madera de pino, pintadas en color blanco, dimensiones exteriores 560x1130 mm (560x1132, 558x1130, 560x1134,

\footnotetext{
${ }^{149}$ En ÅMÅS \& LARSEN, Det stille alvoret. Ludwig Wittgenstein I Norge 1913-1950, op.cit, p.118. Fotografía de Fredrik Wandrup. No ha podido confirmarse la fecha exacta de las imágenes al no haberse obtenido respuesta del autor.

${ }^{150} \mathrm{El}$ material gris opaco de los herrajes de todas las ventanas, no parece hierro puesto que no presenta corrosión. A falta de un estudio más detallado, apunta a que pueda ser cinc.
} 

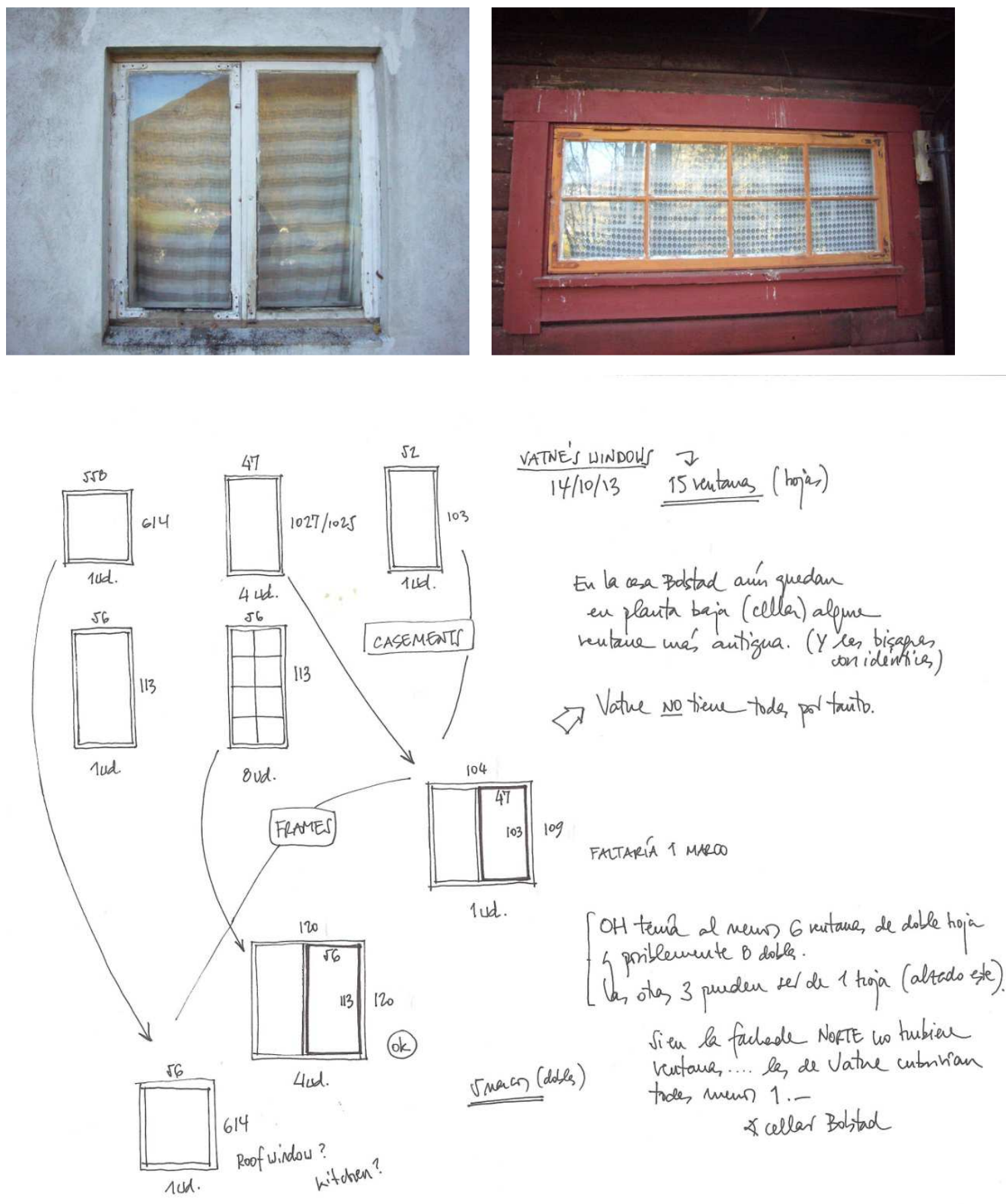

234. Ventana semisótano Casa Bolstad, $108 \times 108 \mathrm{~cm}$ ｜ 235. Ventana cobertizo exterior Casa Bolstad, $56 \times 113 \mathrm{~cm}$

236. Estudio de correspondencia entre las ventanas de Vatne y las de la Casa de Wittgenstein. La coincidencia no es plena, por lo que debe haber al menos dos series de carpinterías, unas originales de 1914 ( 0 al menos presentes en 1957 cuando se desmontó la casa) y otras fabricadas para la nueva casa ese mismo 
560x1134, 559x1132, 557x1132, 558x1134, 558x1132) 151, marco de 45x42 mm, vidrio de $2 \mathrm{~mm}$, bisagras y ángulos de refuerzo en esquinas de cinc. Las hojas están subdivididas en ocho paneles de vidrio separados por bastidores de $33 \times 30 \times 10 \mathrm{~mm}$.

- Cuatro hojas de ventana de madera de pino, pintadas en color blanco, dimensiones exteriores 470x1030 mm (475x1028, 472x1027, 477x1027, $474 \times 1027$ ), marco de $45 \times 45 \mathrm{~mm}$, vidrio de $2 \mathrm{~mm}$, bisagras y ángulos de refuerzo en esquinas de cinc. No están divididas en paneles de vidrio.

- Una hoja de ventana de madera de pino, pintadas en color blanco,

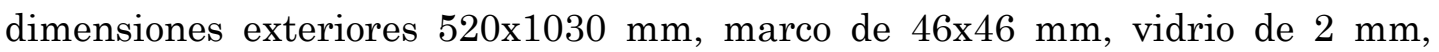
bisagras y ángulos de refuerzo en esquinas de cinc. No está dividida en paneles de vidrio.

- Un marco de madera de pino, de espesor $45 \mathrm{~mm}$ y dimensiones exteriores 1040x1090x170 mm. Doble hueco de 477x1030 mm y parteluz de 50x90 mm.

- Cuatro ${ }^{152}$ marcos de madera de pino, de espesor $45 \mathrm{~mm}$ y dimensiones exteriores 1200x1200x170 mm (1200x1208, 1208x1204, 1205x1205, 1207x1207). Doble hueco de 560x1138 mm (560x1138, 561x1140, 561x1138, 559x1138) y parteluz de 50x100 $\mathrm{mm}$.

- Dos puertas de madera de pino, de espesor $45 \mathrm{~mm}$ y dimensiones exteriores 2020x880 mm. Se conservan los marcos correspondientes de 2087x985x170 mm. Ambas presentan cuatro cuarterones, lisos. Sin pintar.

- Una puerta de madera de pino, de espesor $45 \mathrm{~mm}$ y dimensiones exteriores de $1917 \times 745 \mathrm{~mm}$. Se conserva un marco de $2077 \times 845 \times 170 \mathrm{~mm}$. La hoja está dividida en cuatro cuarterones. Sin pintar.

\footnotetext{
${ }^{151}$ Estas hojas tienen una marca o código escrito, lo cual hace suponer que fueron numeradas o nombradas para «volver» a ser instaladas en otro lugar. Probablemente desde la casa del lago hasta la casa de los Bolstad: las dos primeras del listado están marcadas como VII y VI, la segunda pareja como IIIIV y X, la tercera como III y IIII (N). No se aprecian marcas en el cuarto par. También podrían pertenecer al montaje original, no podemos saberlo.

152 En el lateral de uno de los marcos se lee «Skjolden».
} 


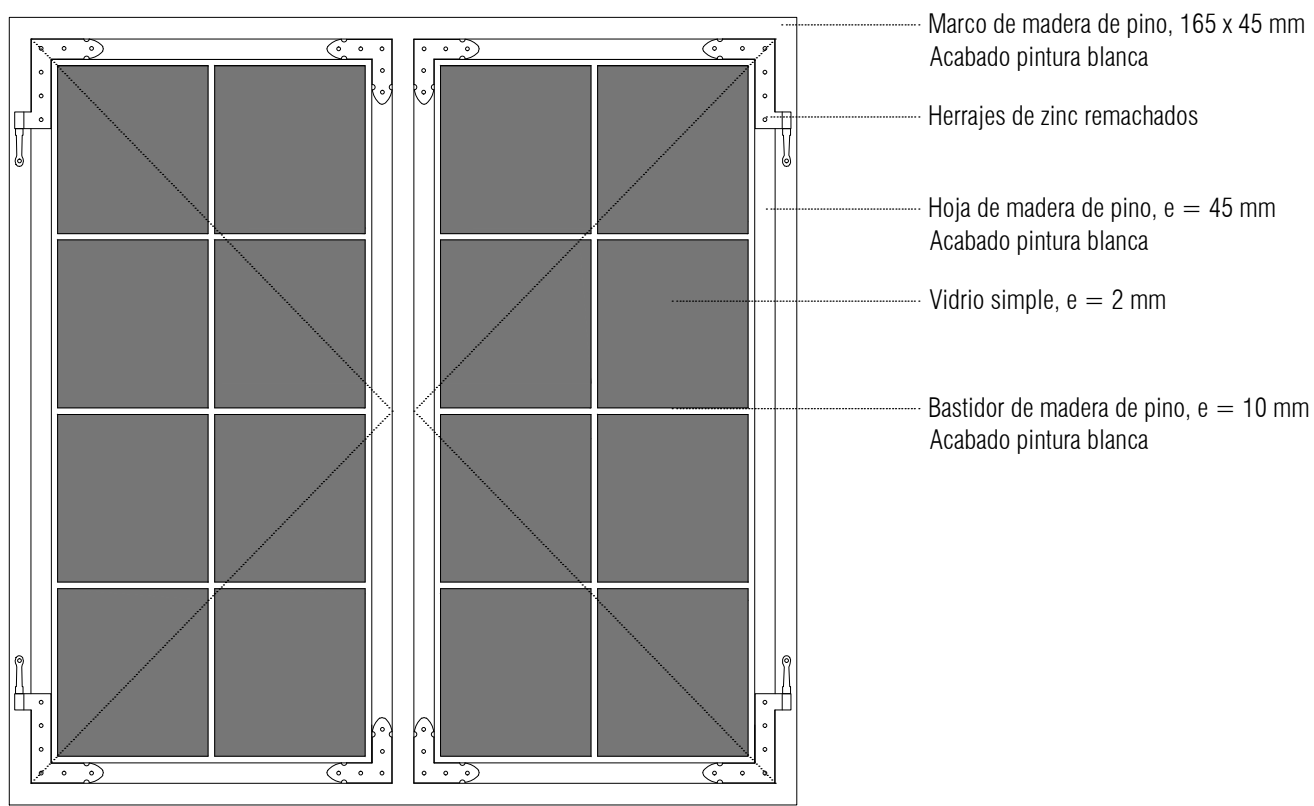

Gancho fijación hoja ventana, e = 2 mm

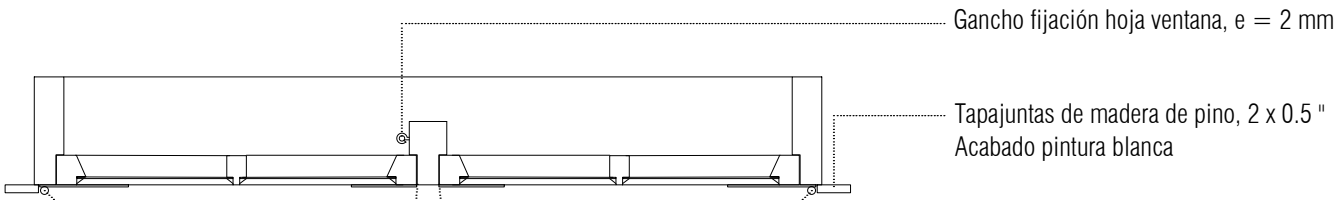


Además de la colección de Vatne, pudimos localizar otras ventanas que sospechamos pertenecen a la factura original. Se trata de una construcción anexa a la casa Bolstad, que se utiliza como garaje y caseta de aperos ${ }^{153}$. Esta construcción menor cuenta con cuatro ventanas, de las cuales al menos dos de ellas parecen idénticas a las hojas de 560x1130 mm de ocho paneles de vidrio. Las otras dos ventanas no responden a ninguno de los modelos de las que conserva Vatne, por lo que, de momento no se han considerado como originales.

En las fotografías históricas de 1950 hemos visto que las ventanas parecen pintadas en blanco. También las conservadas por Vatne tienen ese acabado. No sabemos si originalmente Wittgenstein decidió pintarlas o si fue una acción de mantenimiento. Tampoco si fue él mismo quien lo decidiera o Arne Bolstad, a quien el filósofo había cedido ${ }^{154}$ la casa en 1919. En la fotografía de Brathole de 1921, no se aprecia contraste de color entre las carpinterías en el alzado del lago y el color de la propia madera de las fachadas. La aplicación de brea o resina para la protección exterior de los troncos de las fachadas y el transcurso del tiempo habrían incrementado el efecto de contraste entre las carpinterías pintadas y el fondo de madera oscurecido, tal como vemos en las imágenes de la visita con Ben Richards. Entre los marcos de ventana conservados, dos presentan una capa de pintura y otros dos no estén pintados podría indicar que fueron reutilizados desde la casa del lago en la casa de los Bolstad o que fueron elaboradas en 1957 con un aspecto similar para la nueva residencia familiar. Las ventanas instaladas en el semisótano de los Bolstad en la actualidad -B03, B04, B10 y B11- no fueron sustituidas en el momento en que se desecharon las de las plantas superiores y podemos suponer que se colocaron en 1957. Las dimensiones de tres de ellas -la cuarta se modificó por la presencia del talud del terreno- son de 42" y aspecto similar a las que conserva Vatne, en cuanto a

\footnotetext{
${ }^{153}$ En 2009, un miembro de la familia Bolstad -quizá Vatne- indicó a D. Connearn que la madera con la que estaba construido el cobertizo anexo a la casa provenía de la casa original, en concreto de los muros de separación del interior de la casa de Wittgenstein. Así quedó recogido por ejemplo, en Connearn, D., Wilson, D. Wittgensteins Haus in Skjolden. Erhaltung und Interpretation en Ludwig Wittgenstein, Verortungen eines Genies, Berlín, 2011, p.36. En la visita realizada a la casa en octubre de 2013 y tal como sospechábamos a la vista de la mecanización de las escuadrías de madera, Kåre Bolstad negó este extremo. Se trataba de material adquirido con posterioridad a 1957. Sí son originales algunas de las ventanas instaladas.

154 Sabemos que Wittgenstein le cedió la casa a Arne Bolstad ante su decisión de no regresar a Noruega (carta a Draegni 30.10.1919 «Bolstad can have my house» y luego carta a A. Bolstad 01.03.1920 «My house belongs to you»), pero no consta que ello supusiera obstáculo para que el filósofo la utilizara en periodos incluso prolongados como el de 1936-1937 y en sus cartas y diarios la describiera como su casa. Por ejemplo en la carta de octubre 1936 a Moore con un croquis de la situación de la casa: «My house is not built on the site you mean.»
} 

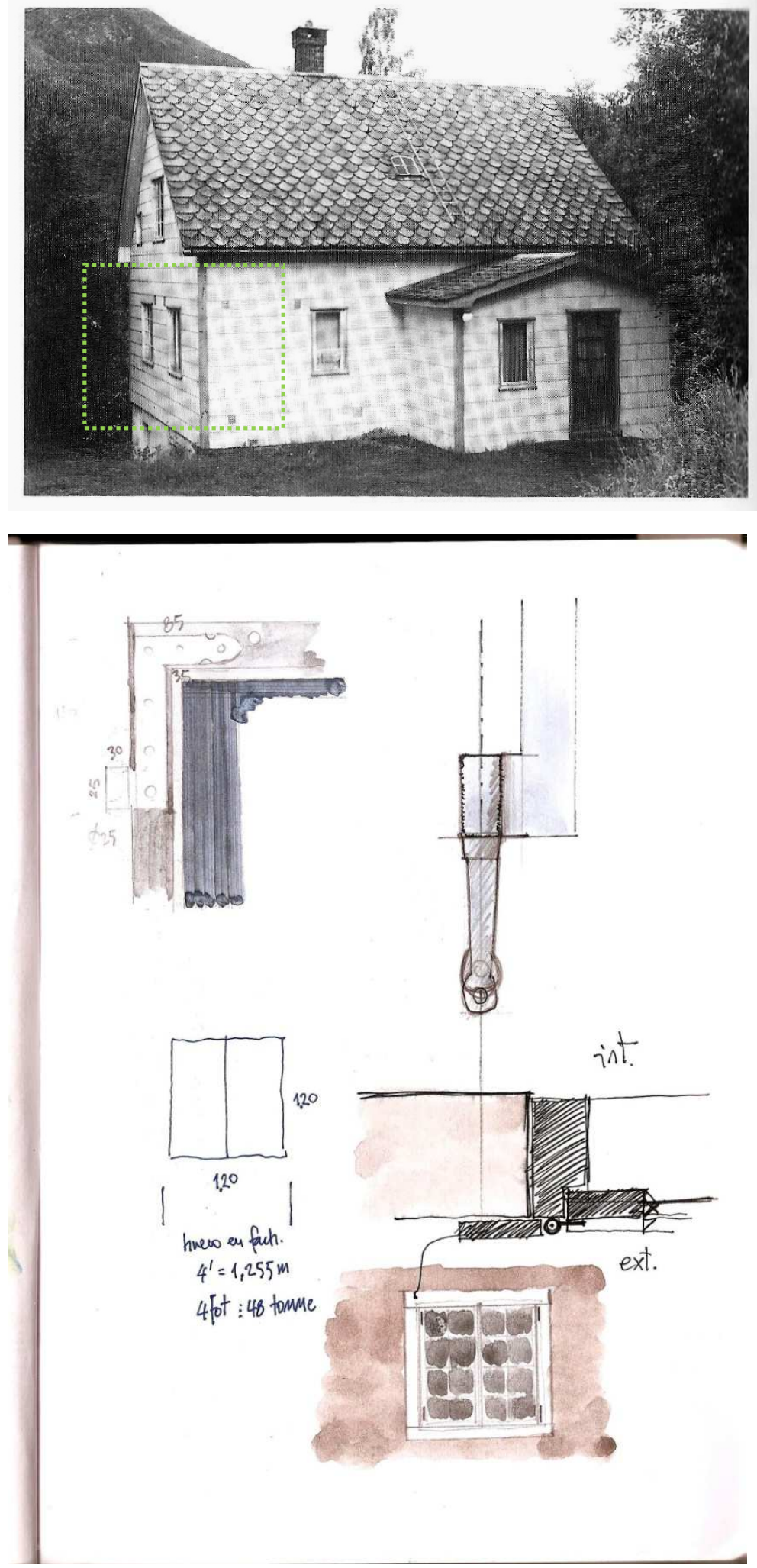

238. Fotografía de la Casa Bolstad anterior a 1994 firmada por Fredrik Wandrup, a la que hacíamos referencia en la página 285. Las ventanas del salón tienen aquí la altura de antepecho inalterada todavía y por tanto ambos huecos eran de $125 \times 125 \mathrm{~cm}$ 239. Estudio de los herrajes a partir de las fotografías 
secciones de marco y herrajes. Un detalle diferencial es que las cuatro tienen una única hoja móvil, la izquierda. Siendo un fijo la derecha. La reflexión aquí es que presenta serias dificultades el tratar de establecer si las ventanas que Vatne atesora como originales, lo son o fueron realizadas en 1957 cuando los Bolstad construyeron su casa en el pueblo.

Los herrajes son sencillos, comunes además en las carpinterías nórdicas. Las hojas abren hacia el exterior, y un simple gancho metálico, a veces corto y otras que permite la apertura completa de la hoja, se aloja para fijarla en un ojal o en un taladro en el propio marco de la ventana. Quizá Wittgenstein diera libertad al carpintero en la fabricación de estas piezas, sabemos que otras circunstancias se dieron en 1928 durante la construcción de la Kundmanngasse de Viena para su hermana Margaret:

«Ludwig diseñó cada ventana y cada puerta, cada cierre de ventana y cada radiador, con tal cuidado y atención al detalle que pudieren pasar como elementos de precisión, y a la vez de forma sumamente elegante. Y entonces, con su inagotable energía, se aseguraba que todo se realizara con el mismo y meticuloso cuidado.» ${ }^{155}$

En las fotografías de 1950 podemos ver unas persianas volteadas horizontalmente sobre la fachada, apoyadas parcialmente en el zócalo de piedra de la casa. En una de las imágenes aparecen cerradas y en la fotografía tomada desde el bote, algo más cercana las vemos ya abiertas. No se aprecia el mismo elemento en las ventanas de la balconada y tampoco en las del alzado lateral. Probablemente respondieran a la fachada más expuesta a las inclemencias meteorológicas. Wijdeveld va un poco más allá al considerar que algunas de las «ingeniosas» soluciones dadas en la casa de Skjolden, fueron precursoras de las que se aplicaron a la Kundmanngasse quince años más tarde. ${ }^{156}$

\footnotetext{
${ }^{155}$ Wittgenstein, H., My Brother Ludwig, en «Ludwig Wittgenstein. Personal Recollections», Rhees, R. (Ed.), New Jersey, 1981, p.7

${ }^{156}$ Wijdeveld, P. Ludwig Wittgenstein architetto: Milano, 2000, p.27. Nos parece poco verosímil como punto de partida, puesto que en la versión original de la casa no aparecen tales contraventanas -fotografía de 1921 de Brathole- y pudieron ser instaladas durante los años de cuidado por Arne Bolstad o por el propio Wittgenstein en su estancia de 1936-37 y por tanto posterior a la ejecución de la casa de Viena.
} 

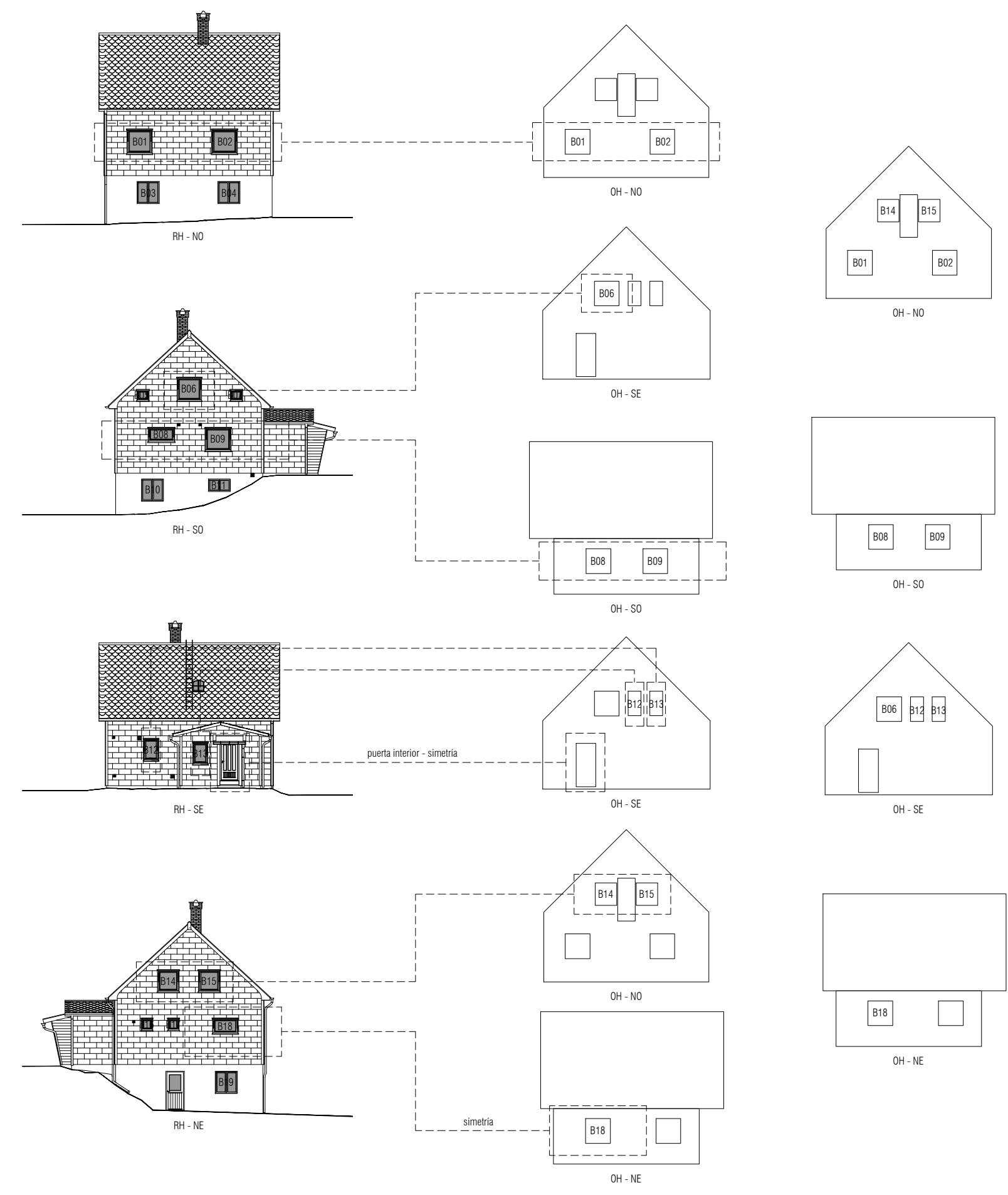

CABAÑA BOLSTAD

ESQUEMA DISTRIBUCIÓN DE HUECOS

ESQUEMA DE HUECOS POR FACHADA

RH = Rebuilt House/Casa de Bolstad

$\mathrm{OH}=$ Original House/Casa de Wittgenstein 
Este $\mathrm{y}$ otros aspectos ${ }^{157}$ nos obliga a tratar de establecer una correspondencia entre las carpinterías que deducimos de las fotografías de la casa de Wittgenstein, las dimensiones de los huecos de la casa de Gunnar Bolstad y las que guarda Harald Vatne. Al menos deberíamos poder establecer el criterio dimensional, si no ha sido posible hasta el momento, datar correctamente la madera de esos elementos. Puesto que la realidad construida está presente en la casa de Bolstad, partimos de ella como referencia:

\begin{tabular}{|c|c|c|c|}
\hline Bolstad & Vatne & \multicolumn{2}{|l|}{ Wittgenstein } \\
\hline B01 & $1240 \times 1250$ & $1200 \times 1200$ & NO 48” \\
\hline B02 & $1255 \times 1250$ & $1200 \times 1200$ & NO 48" \\
\hline B03 & $1080 \times 1080$ & & \\
\hline B04 & $1080 \times 1080$ & & \\
\hline B05 & $600 \times 600$ & & \\
\hline B06 & $1200 \times 1200$ & $1200 \times 1200$ & SE 48” \\
\hline B07 & $600 \times 600$ & & \\
\hline B08 & $1260 \times 750$ & lost & SO $48 "$ modif \\
\hline B09 & $1260 \times 1200$ & lost & SO $48 ”$ \\
\hline B10 & $1070 \times 1080$ & & \\
\hline B11 & $1060 \times 600$ & & \\
\hline B12 & $740 \times 1100$ & $56 \times 113$ & $\mathrm{SE}$ \\
\hline B13 & $740 \times 1100$ & $52 \times 103$ & $\mathrm{SE}$ \\
\hline B14 & $1057 \times 1126$ & 1040x1090 & NO $42 "$ \\
\hline B15 & $1057 \times 1126$ & $1040 \times 1090$ & NO $42 "$ \\
\hline B16 & $550 \times 652$ & $560 x 614$ & \\
\hline B17 & $550 \times 652$ & & \\
\hline B18 & $1250 \times 800$ & lost & NE 48 " modif \\
\hline B19 & $1080 \times 1080$ & & \\
\hline
\end{tabular}

Por tanto en nuestro proyecto podemos referenciar las ventanas de la casa de Bolstad. Vemos una correlación dimensional más que coherente entre las ventanas de 48", las que conserva Vatne y las que habíamos calculado a través del trabajo sobre las fotografías históricas -además la variación dimensional en su situación en los alzados ha sido en algunos de los huecos de 3-5 cm.

\footnotetext{
${ }^{157}$ Una inspección visual no es suficiente para determinar si todas las ventanas que conserva Vatne 0 alguna de ellas provienen de la casa originalmente construida por Wittgenstein. Ni siquiera podemos saber, por el momento, si las que se aprecian en las fotos de 1950 habían sufrido ya alguna tarea de mantenimiento 0 eran las instaladas en 1914. Si algunas -sabemos que todas es seguro que no lo son, ver tablatienen cien años, se han conservado en un estado excelente.
} 


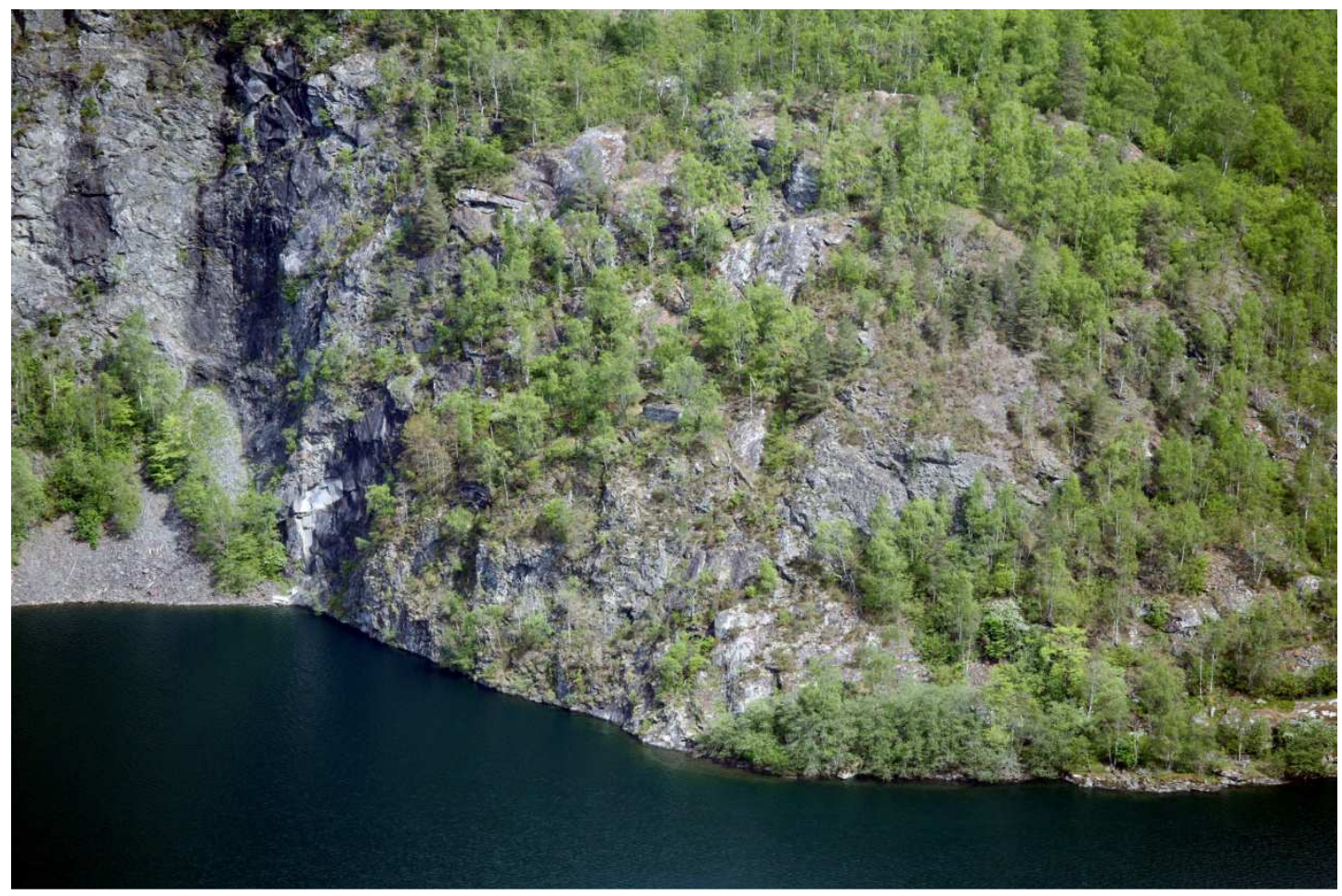

241. Los restos de la Casa de Wittgenstein en la ladera del Hjerseggi, Skjolden. Fotografía por cortesía de Harald Vatne, 14:44, 18.05.2008 
Es importante este estudio detallado porque de él se derivan otras relaciones dimensionales, nos permiten utilizar la proporción con mayor rigor para deducir elementos constructivos de la casa original -alturas, separación entre huecos, longitudes de cubierta, etc. Es por esto que usamos la casa de Bolstad como modelo, permitiendo un trabajo iterativo de verificación de las dimensiones, sin prejuzgarlas. Sabemos que la casa no se reconstruyó siguiendo el mismo trazado de la original, pero el material está ahí, tras un revestimiento de fibrocemento y se muestra en algunos elementos. En el momento de la redacción del presente texto no ha sido posible obtener nuevos datos dado que la familia Bolstad no permite el libre acceso a la casa ni ha autorizado la realización de catas ni estudios más precisos siquiera dimensionales. ${ }^{158}$

\footnotetext{
${ }^{158}$ La visita realizada el 14.10 .2013 a la casa Bolstad fue condicionada por Kåre Bolstad a no realizar fotografías de los espacios privados de la vivienda. No se permitió el acceso a la planta de dormitorios superior y los datos y las pocas fotografías tomadas se debieron hacer con premura ante la no disimulada presión de pasar el menor tiempo posible en el interior de la casa. Las fotografías que aquí se muestran no pueden ser publicadas por expreso deseo de la familia Bolstad y Harald Vatne.
} 



\section{4 ePílOGO}



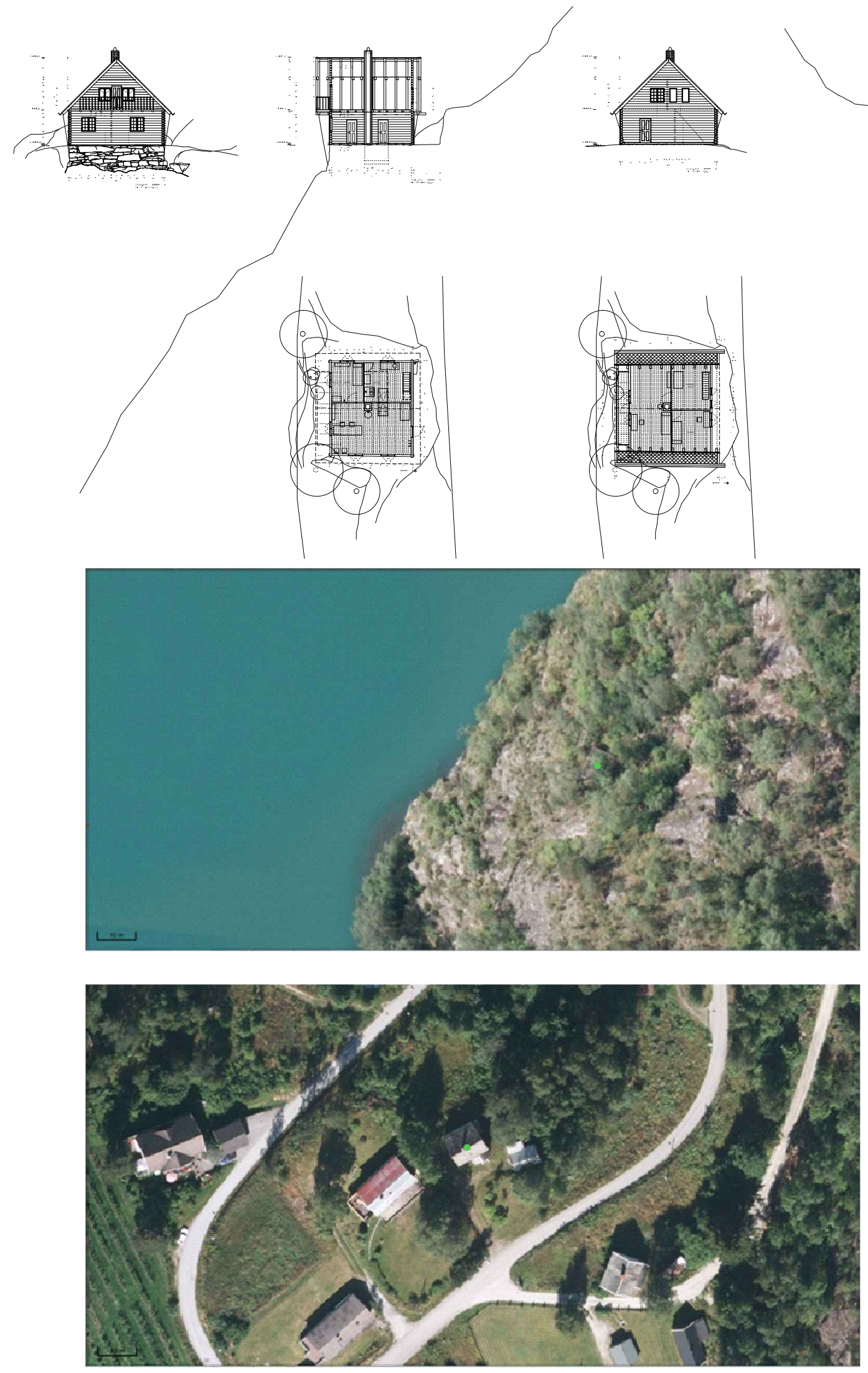

1. Planos del proyecto de la Casa de Wittgenstein en Skjolden, mayo 2015

2. Fotografía aérea del lugar que ocupaba la casa hasta 1957

3. Fotografía aérea de la casa de la familia Bolstad 


\section{A modo de cierre}

«...y todo lo que se sabe y no se ha oído meramente como rumor o murmullo, puede decirse en tres palabras.» Ferdinand Kürnberger ${ }^{1}$

Es esta una tesis sin conclusiones o quizá sea más acertado decir que es una tesis inconclusa. Es un proyecto de arquitectura y como tal tiene un final difuso. ${ }^{2}$ El proceso con sus necesarias renuncias, tomó sin embargo un camino paralelo cuando gran parte de la propuesta preliminar se había ya desarrollado. ${ }^{3}$ Tal fue, como se ha expuesto antes, entrar en contacto y tener conocimiento de un grupo de personas interesadas en reconstruir la casa de Wittgenstein en su localización original, sobre el lago Eidsvatnet.

El objetivo inicial de la tesis, este sí alcanzado, era poner orden en la escasa, imprecisa y casi siempre errónea información que existe publicada hasta la fecha en la literatura secundaria sobre la vida y obra de Wittgenstein y su refugio noruego. Hemos conseguido reunir en un único trabajo toda la información disponible públicamente y mucha que permanecía inédita. Algunos aspectos de la investigación no ha sido posible reproducirlos aquí por no contar con el permiso necesario, y elementos que serán definitivos para el conocimiento preciso de la casa original han quedado pendientes, porque como se ha reiterado a lo largo del texto, no ha sido posible tener acceso al estudio con detalle de la casa de la familia Bolstad, extremo que debemos respetar para no alterar la intimidad (y la integridad) de una propiedad privada. Difícil asumir que sin un exacto conocimiento de la casa Bolstad, no seremos capaces de alcanzar una mayor cantidad de verdad en nuestro proyecto.

\footnotetext{
${ }^{1}$ Lema utilizado por Wittgenstein en su Tractatus logico-philosophicus. F. Kürnberger (1821-1879) fue un crítico literario y escritor austríaco de ideología liberal.

${ }^{2}$ Aunque el objeto y la intención son diferentes, el planteamiento intelectual es común: en conversación con Nuria Ferriol Molina, en Valencia el 25.11.2010 y con motivo de la exposición «Colección particular», le pregunté: «-¿Cuándo decides que un cuadro está terminado?» a lo que respondió: «¿Terminado? En realidad sólo sucede cuando paso a otra cosa».

${ }^{3}$ El trabajo de investigación «La Casa de Ludwig Wittgenstein en Skjolden, Noruega» fue presentado en el Departamento de Proyectos Arquitectónicos de la ETSA a las 12:30 del 29.09.2011 para su evaluación, obteniendo la calificación de Sobresaliente el 10.10.2011.
} 

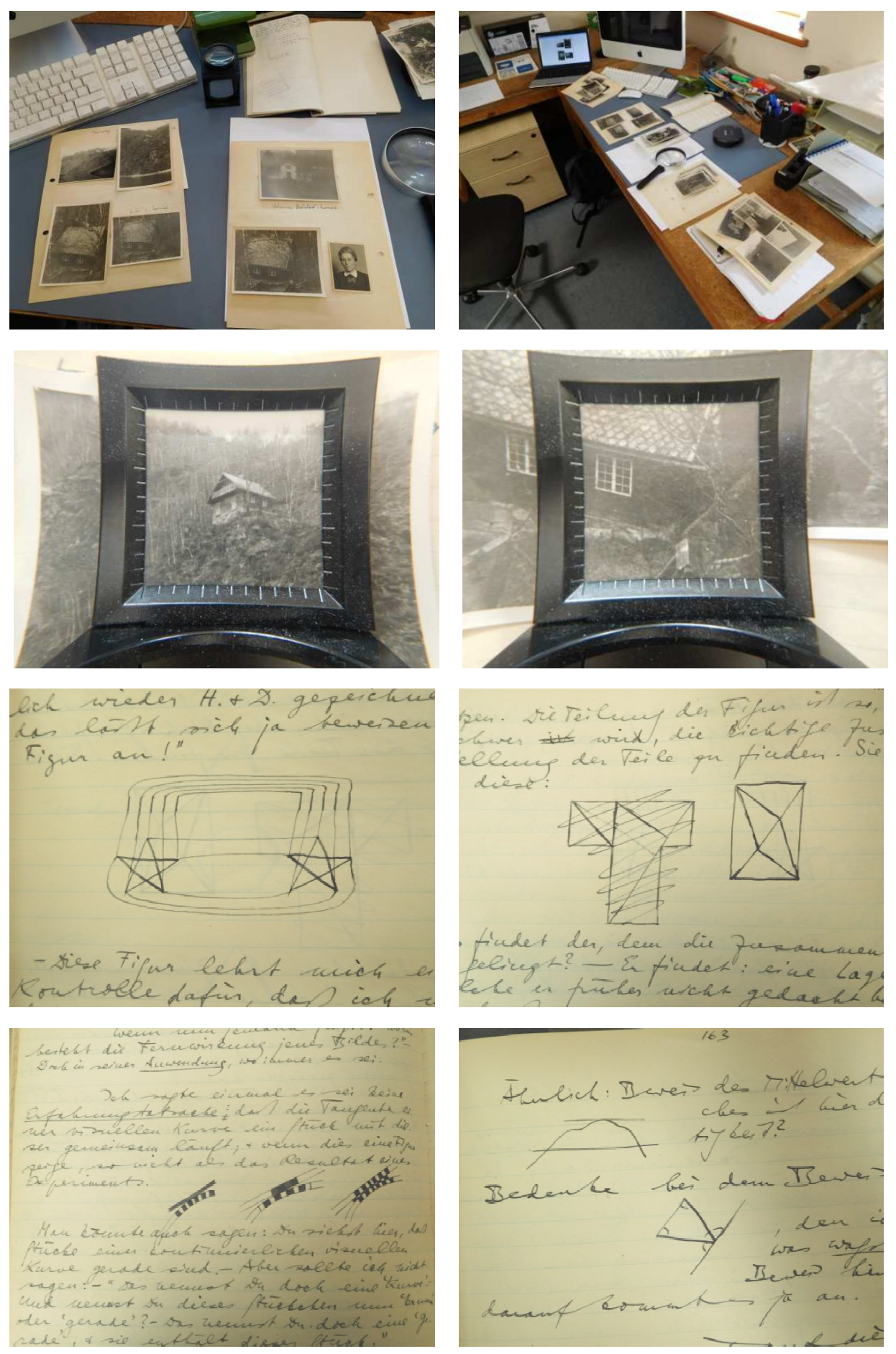

4. Hojas del álbum de Ben Richards en el Wittgenstein Archive Cambridge, 20.04.2015 ～5. Material original fotográfico en el WAC, 20.04.2015 6. Fotografía a través de lupa de imagen $n^{0} 519$ en el WAC, 20.04.2015 | 7. Fotografía a través de lupa de imagen $n^{0} 514$ en el WAC, 20.04.2015 8-11. Dibujos en las anotaciones de Wittgenstein, MS117. Vol. XIII: Philosophische Bemerkungen, 1937-1940 
Hasta donde los recursos han alcanzado, se ha dedicado el máximo esfuerzo, en primer lugar a recopilar cualquier rastro de información y más tarde interpretar los registros gráficos y proyectar la casa de Wittgenstein. El estudio de las fuentes y de los datos obtenidos in situ en Noruega e Inglaterra ha sido minucioso. Muchos aspectos han sido fundamentales para la redacción del proyecto, otros muchos puramente accidentales, anecdóticos y por tanto vitales. La casa es el lugar de la vida por excelencia, y la vida es una anécdota encadenada con la siguiente. Wittgenstein anotó el horario en que el sol entraba los primeros días de la primavera de 1937 en su casa, tras el sombrío invierno nórdico; relacionar las cartas aportadas por Tordis Hauge de Skjolden a Åmås para la redacción de su libro sobre Wittgenstein y encontrar que regentaba el Vassbakken Kro \& Camping, en el que en 2009 se alojara David Connearn y que este supiera por su hijo que su madre fallecida en 2008 hubiera sido la asistente de Anna Rebni, nos llevó a encontrar que Anna Gutubø, refería algún dato del interior de la casa del filósofo en las visitas que girara con Rebni en los años treinta. Entre la investigación arquitectónica y la detectivesca, ha sido este tipo de vivencias las que han desentrañado con notable esfuerzo el programa del proyecto aquí trazado.

No habrá pasado desapercibido que estas páginas se han escrito y dibujado también tal y como se han vivido, como si de un largo trávelin cinematográfico se tratase, ese ha sido el programa de esta tesis. Es por ello que hemos tenido que esperar hasta estos penúltimos párrafos para pedir disculpas al lector por la abundancia de cambios en el registro de la escritura, de la lengua utilizada castellano, inglés, noruego o italiano- ${ }^{4}$, pero el único objetivo de tan variopinta redacción responde precisamente a la honestidad con que nos hemos enfrentado a esta investigación, si es que cabe otra manera de acometer tal tarea. Es reconocible en el cuerpo de la tesis que, pese a tener la única autoría y responsabilidad del que escribe estas palabras, el desarrollo del proyecto se basa en un trabajo muchas veces colaborativo, de ahí la abundancia de referencias a

\footnotetext{
${ }^{4}$ Se ha confeccionado un anexo con las traducciones de los pasajes que no están traducidos en los pies de página del cuerpo principal del texto. Las traducciones son propias y por tanto libres, mejorables y sin duda criticables.
} 

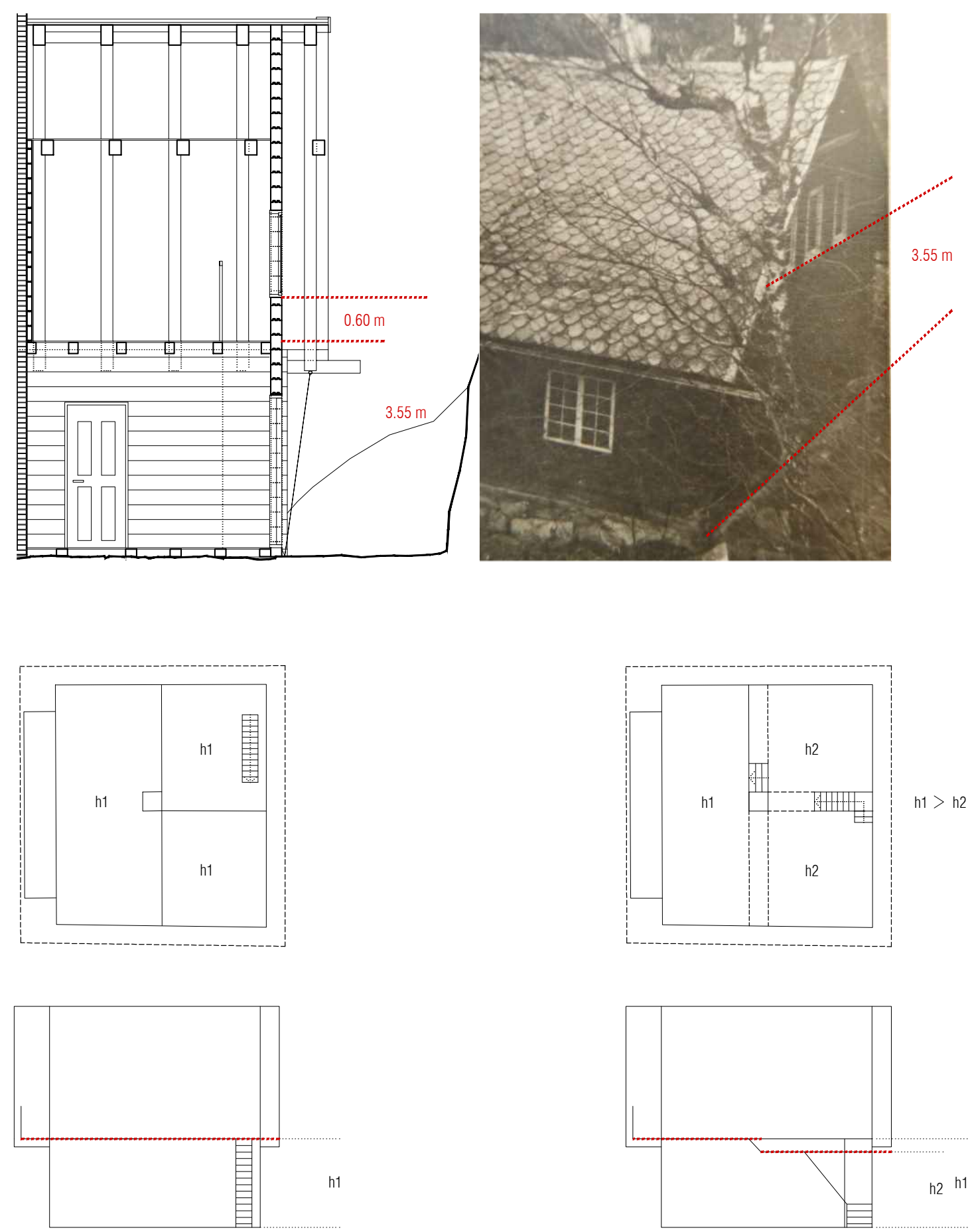

h2 h1

sección prevista en proyecto

sección modificada en dos alturas

12. Sección del alzado principal con indicación del antepecho de $60 \mathrm{~cm}$ en el dormitorio del ático | 13. En la fotografía vemos que las ventanas están sensiblemente más bajas de lo que corresponderían teniendo un forjado de $2.92 \mathrm{~m}$ de altura

14. Esquema de posible modificación de la sección que encajaría con una altura convencional de las ventanas, Raumplanung, (el acceso estaría delimitado en sección por una altura diferente) 
correspondencia, visitas y conversaciones. Ante la imposibilidad de reflejar cinco o seis años de trabajo con Wittgenstein, han quedado fuera de la presente tesis algunos aspectos que sin duda se acometerán en ulteriores estudios, en un ejercicio consciente de autolimitación: estudiar en profundidad los referentes de la arquitectura que interesara a Wittgenstein -su gusto por lo clásico en sentido amplio sí lo hemos comentado pero no nos hemos referido a construcciones que merecieran su aprobación y que sin embargo formaban parte de su bagaje intelectual $^{5}$ - o que formaran parte de su memoria visual, como el Hochreith, que era su casa familiar preferida, por su ubicación y recuerdos de una infancia feliz y relajada ${ }^{6}$, alejada del estricto ámbito cultural y formativo familiar de la Alleegasse de Viena.

La interrelación de Adolf Loos y Wittgenstein merecería un estudio completo aparte. Hemos clarificado que el proyecto de Wittgenstein es cuando menos contemporáneo a las propuestas espaciales de Loos y el Raumplanung. Al uso premeditado de la distribución de huecos relacionados con el uso de las estancias desde el interior y al concepto de exterior siguiendo tal distribución de la lógica interna, coherente con el funcionalismo y siempre desde una base ética, del oficio y de la verdad artesana. Más tarde Wittgenstein apreciaría cierta afectación en la forma de afrontar la arquitectura por parte de Loos y eso debió ser motivo suficiente para su desconsideración.

Abundando en la concepción espacial de Wittgenstein en su casa del lago, se ha dicho ya que la repercusión de la simetría de los huecos en los espacios interiores tiene su correspondencia intencionada en las fachadas. Pero nos obliga a hacer algunas reflexiones a partir ello. ¿Por qué los huecos de la planta ático de la fachada principal están a tan solo 0,60 m del entablado mientras que en la planta baja están correctamente colocadas a 1,00 de altura? Es claro que

\footnotetext{
${ }^{5}$ Por ejemplo valoraba enormemente la ingeniería de los puentes en su visita a Estados Unidos, como refería a Bouwsma en 1949 (op.cit.) 0 el Mausoleo a Lenin y la Catedral de San Basilio que visitara en Moscú en 1935.

${ }^{6}$ Michael Nedo propone un estudio en profundidad de la residencia de Hochreith que no ha sido posible realizar aquí. También la residencia de Hallein, cerca de Salzburgo de su tío Paul Wittgenstein y en la que en 1919 pasó unas semanas al volver de la guerra y terminó el manuscrito del Tractatus está siendo últimamente motivo de interés por parte de los historiadores y estudiosos de Wittgenstein. (Sobre la conservación de la casa de Paul Wittgenstein ver http://www.villa-wittgenstein.net/villa-in-not).
} 
then put forward. Some engines were tested on an unused railway line in the Manchester area, "which suggests a fair degree of development. We certainly meant to, and Russell, when he came to know him, occasionally referred to him as an aviator or aeronaut. It is entirely possible that he did: we should not necessarily have heard of it, for he was very selective in what he told his friends - he did not set out to give an account of his And, naturally, not all even of these have been recorded

And, naturally, not all wese in Manchester were work not for wecks but for years, and he did in fact spend three years there and planned to spend at least a fourth. He seemed an odd fish, Littlewood says. Bamber and Mason, then of the Engineering Department, both describe him as charming but as of nervous or excitable temperament. This indeed was his oddity to an English eye-the extreme formality and charming manners in everyday matters coupled with an intensy, a concentration, mattered to him. 'He was doing work' (Bamber says) 'on the combustion of gases and his nervous temperament made him the last person to tackle such research, for when things went wrong, which often occurred, he would throw his arms about, stamp around and swcar volubly in German.' He used to ignore the midday break and carry on till evening. In the autumn of 1909 Mason helped him to install some heavy apparatus of a heavy-duty compressor used in research into high-pressure gases. 'A charming, enthusiastic man, not then very well accustomed to the handling and assembling of engineering machinery,' says Mason. The qualification is important: Wittgenstein was a learner, by the time of the First War he made an workshop.

Wittgenstein himself took his 'nervous temperament' more seriously, his sister Hermine (de self that rankled with him, and 1ho8) he speaks firs of his work-how Lamb, the professor, 'doesn't know whether his equations are soluble by present methods' - and then goes on to the sort of personal problem typical of him. 'My evil spirits induce in me the most tiresome moods you can imagine.' After talking to Lamb he went into the drawing room and saw the assisanc, a drawing had been done. He got more and more excited he was upset that the assistant was so

indifferent-when fortunately the assistant was called away and Wittgenstein came to himself. It was a common pattern before the First War and later in his time as a teacher: some people were a danger to him because he was hypersensitive to them, he would react too violently and
betray himself. He wanted to be natural and spontaneous and yet in betray himself. He wanted to be natural and spontaneous and yet in
these cases his automatic reaction was a disproportionate one which he could only distike but could not correct. It added to the unpleasantness real falt the laziness, the Schlamperci, or the meanness that had evoled

Manchester University records show that Wittgenstein's registration as a research student in the Engineering Laboratory was renewed for 1909-1910, when, as we have seen, he was also the Voluntary Observer for the Kite Station. In 1 the Senate. The second year of this studentship he did not take up. It was a small honpur and an, indication that he, was, thep, as any rate.accented as a
serious student. Financially it meant little to him. He seems to have financed his own experiments with kites and combustion chambers, and to have had a shed built on the moor; and in general he lived not ostentatiously but the life of a rich man. Eccles estimated that he had an income of $f_{5}, 000$ a year, an 4.17770 .

enormous sum for those days. The episode of the proposed special train thas. .

where Wittgenstein's only pastime was to relax in a bath of very hot water where Wittgenstein's only pastime was to relax in a bath of very hot water
(there was more of his innocent boasting - this time about how hot the water was). His address in 1911 is known to have been 104 Palatine Rd (now 154); Palatine Rd was on the borders of Withington and West Didsbury-
Fallowfield adjoins and is perhaps a venial error of Bamber's. It is of some interest that the district was one of comfortable large houses, with a fair sprinkling of successful Jews and Armenians. 104 in particular was not a house that usually took in lodgers and there is an impression in Vienna that a friend of the family was found for him to stay with. At all events it was a austerity in his ways, apart from supporting the comparative rigours of the moor as well as the next man. He dressed carefully and apparently expensively. He took full advantage of the lively musical life of Manchester and every informant mentions visits to the Hallé concerts for more serious composers-Wagner, Beethoven, Brahms-and the concentration with which he would listen

Thout music.
Three years in Manchester: it was to be twenty years before Wittgenstein again spent so long in a single place. It is to be supposed that there-or between there and Charlottenburg - he learnt a lot; but these were not years in which he imposed himself or in which his powers
broke through. Charming, erratic in temper, able, eccentric-he might
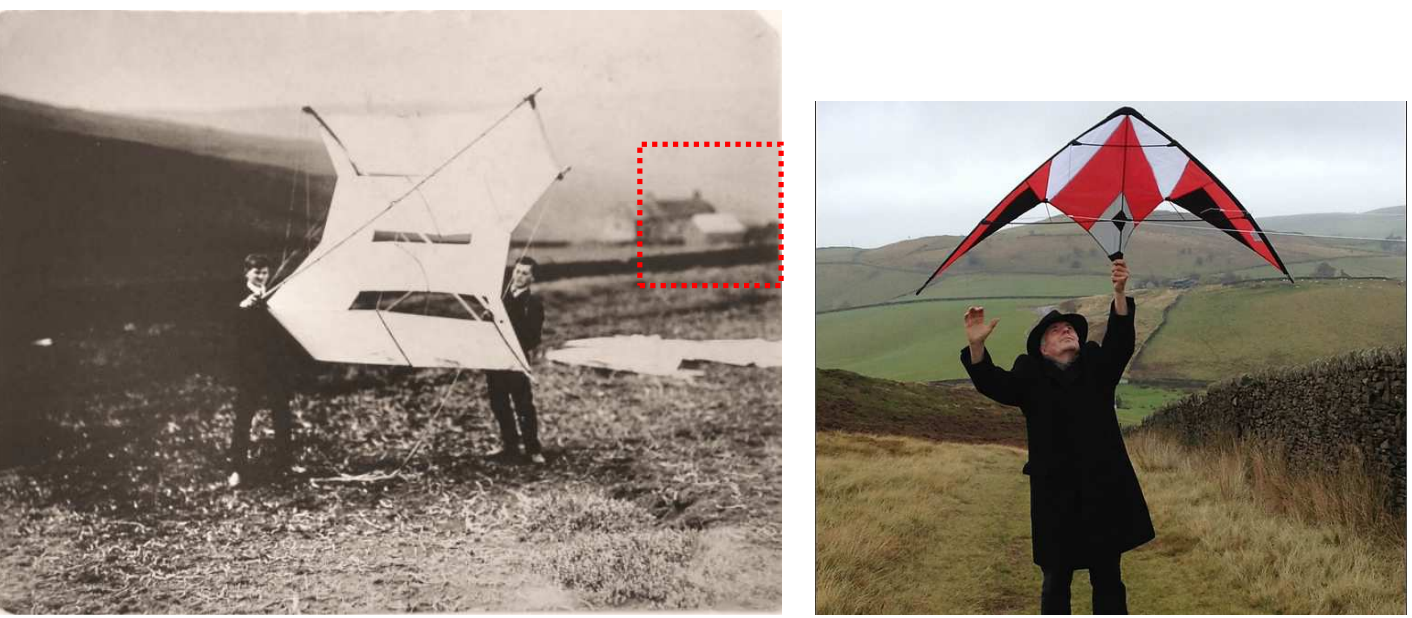

15. McGuinness, op. cit. p. 71: «La financiación no era un problema para él. Parece que se hizo cargo él mismo de sus experimentos con cometas y cámaras de combustión y se construyó un almacén en el páramo; y en general vivía sin ostentación pero la vida de un hombre rico. Eccles estimaba que tenía una renta de $£ 5000$ anuales, una cantidad enorme en aquellos tiempos.» [£5000 son más de $400000 €$ al cambio de 2015]

16. Fotografía de Eccles (izqda) y Wittgenstein en Glossop, 1908. Al fondo se ve el edificio de Grouse Inn y remarcado lo que debía ser el almacén al que hace referencia McGuinness, hoy desaparecido ｜ 17. Michael Howard volando una cometa en Glossop en el mismo páramo donde lo hiciera Wittgenstein 
podemos haber errado en las proporciones de determinados elementos, pero el trabajo de revisión y relación entre todos los elementos visibles y previsibles de la casa no deja dudas de que esos huecos no están a la misma altura que los de planta baja, respecto a la línea de cota del pavimento del balcón.

Entonces, ¿podría haber proyectado Wittgenstein dos alturas diferentes de forjado de la planta ático? Esto sería tan extraordinariamente coincidente con el planteamiento de Loos del Raumplanung que no podemos evitar al menos hacer la reflexión. En la citada casa del guarda de la Escuela Schwarzwald en Semmering, Loos plantea precisamente una diferenciación de las alturas de las estancias según su uso: espacios de paso de menor altura que las salas de uso diurno por ejemplo y diferente a su vez de los dormitorios de la planta superior. ¿Y si Wittgenstein planteó algo parecido? Si modificamos la sección longitudinal -véase esquema p. 302- el dormitorio de la planta superior podría tener la altura asignada al de planta baja y al mismo tiempo el acceso desde el exterior quedaría espacialmente diferenciado del resto de la sala principal. Sin embargo, con los datos de que disponemos no podemos sino elucubrar -en realidad lo que hacemos es proyectar- sobre una sección realmente moderna, compleja y reflexiva que Wittgenstein hubiera podido proponer para su casa en Noruega.

Pero es que la arquitectura formó parte de una manera inusualmente importante en la vida de Wittgenstein. Ha quedado demostrado que la casa de Skjolden representa la construcción de un artefacto premeditado, no sólo de un refugio meramente casual que pudiera utilizar en la vida de retiro intelectual que había previsto para su investigación en lógica matemática. No es metáfora construida del extrañamiento sino un proyecto de arquitectura de un no arquitecto, pero sí ingeniero.

Tal vinculación con la arquitectura merecería ser nuevamente revisada con detenimiento puesto que la casa de Skjolden no fue uno de los dos edificios proyectados por Wittgenstein sino que, el filósofo proyectó a lo largo de su vida cuatro construcciones, a saber y en orden cronológico: 

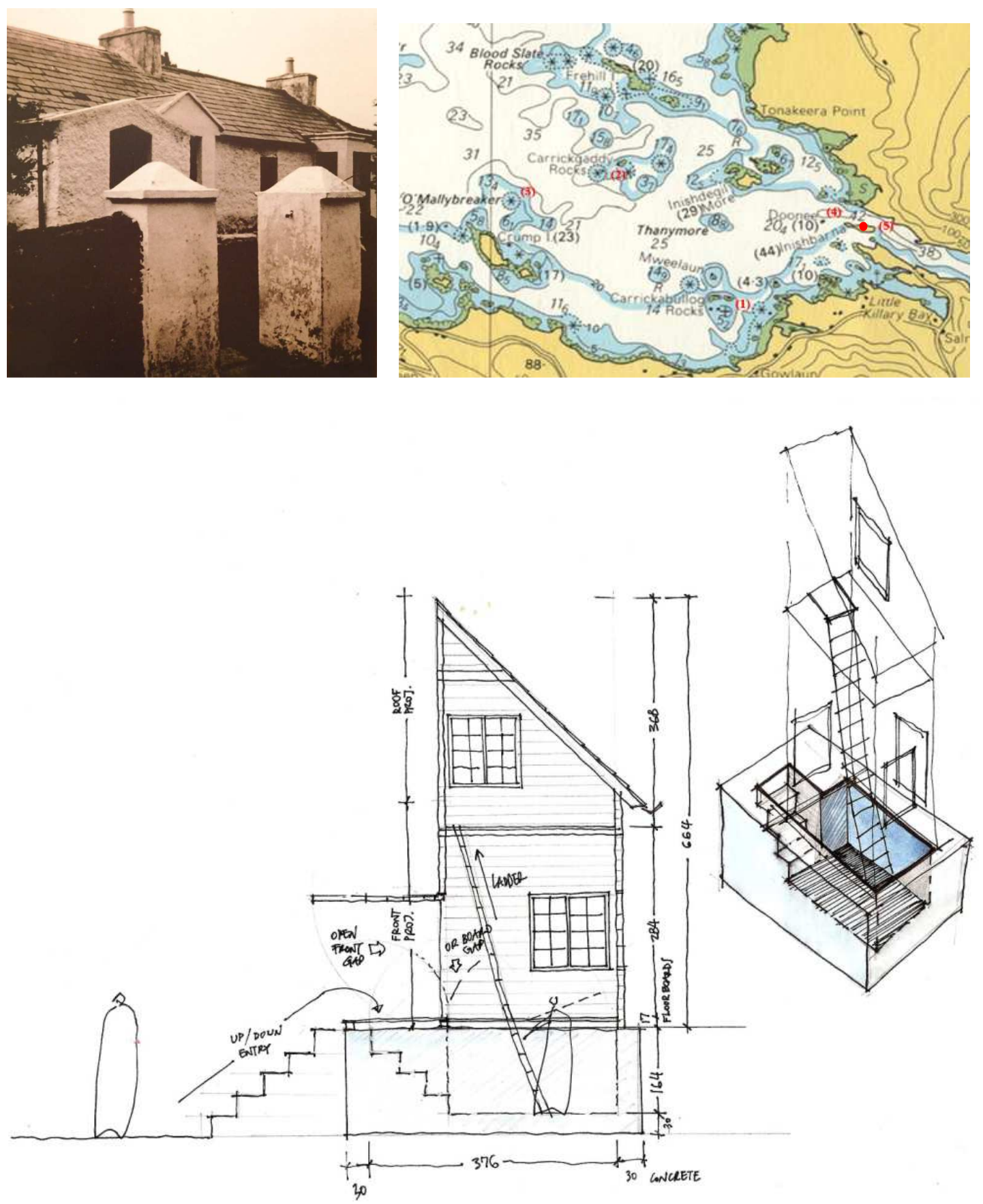

18. Rosro Cottage, Killary Harbour en Connemara (Irlanda). Wittgenstein pasó algunas semanas en 1934 con Francis Skinner y a solas en 1948, en circunstancias similares a las de su casa en Noruega | 19. Mapa de costa del fiordo de Rosro. Marcamos la isla de Inis Bearna en la que pretendía hacer un refugio para observar las aves

20. Provecto de colaboración con David Connearn para la construcción de una pieza artística que representa la casa de los pájaros nunca construida por Wittgenstein, partiendo del contorno del sótano de la casa de Skjolden y proyectándolo hasta interseccionar con la cubierta. En proceso, 2015. 
1. Una pequeña edificación para la construcción de cometas y la realización de sus propios ensayos de cámaras de combustión durante los estudios de aeronáutica en la Estación de Investigación de Glossop (Manchester), en 1910.7

2. La casa del lago Eidsvatnet en Skjolden, 1914.

3. Casa Wittgenstein o Kundmanngasse 19, en Viena, 1926-1929.

4. Proyecto de refugio para la observación de aves en la bahía de Galway, en la isla Inis Bearna, en 1948.

Los tres primeros edificios fueron construidos - dos de ellos desaparecidos y la casa de Viena estuvo a punto de ser demolida en 1970- y el refugio de observación nunca se construyó. ${ }^{8}$

Es por tanto importante y abre nuevas líneas de investigación el tratar de completar la biografía arquitectónica de Wittgenstein y analizar hasta qué punto nuestra disciplina tuvo un espacio en el desarrollo de su pensamiento.

«El trabajo filosófico -como en muchos aspectos sucede con la arquitectura-consiste, fundamentalmente, en trabajar sobre uno mismo. En la propia comprensión. En la manera de ver las cosas. (Y en lo que uno exige de ellas)...9

\footnotetext{
${ }^{7}$ Michael Howard hasta 2014 profesor en la School of Arts, Manchester y especialista en las investigaciones en aeronáutica que Wittgenstein desarrolló en la Glossop, desconocía sin embargo el edificio en cuestión. Sobre el motor de propulsión de Wittgenstein de 1910, hay una emisión en la BBC4 titulada «Wittgenstein's Jet» en $h$ ttp://www.bbc.co.uk/programmes/b04v3b9v. Correspondencia electrónica con D. Connearn, 27.04.2015

${ }^{8}$ Maurice 0'Connor Drury, amigo de Wittgenstein, prestó al filósofo en un par de ocasiones una vieja casa en Rosroe, Connemara (Irlanda). Tommy Mulkerrins, un granjero que vivía a unos kilómetros era el encargado de solucionar las cuestiones de intendencia de Wittgenstein. Fue Tommy quien, ante la idea de tener que construir el refugio, convenció al filósofo de que los temporales de invierno de la zona barrerían cualquier construcción sobre tan pequeña isla. (Sin embargo en ella vivió durante el s. XIX el escritor Seán Mac Conmar, hasta los 80 años, parece que sin mayores sobresaltos).

${ }^{9}$ Wittgenstein, Observaciones diversas. Cultura y valor, §84. Anotación de 1931.
} 

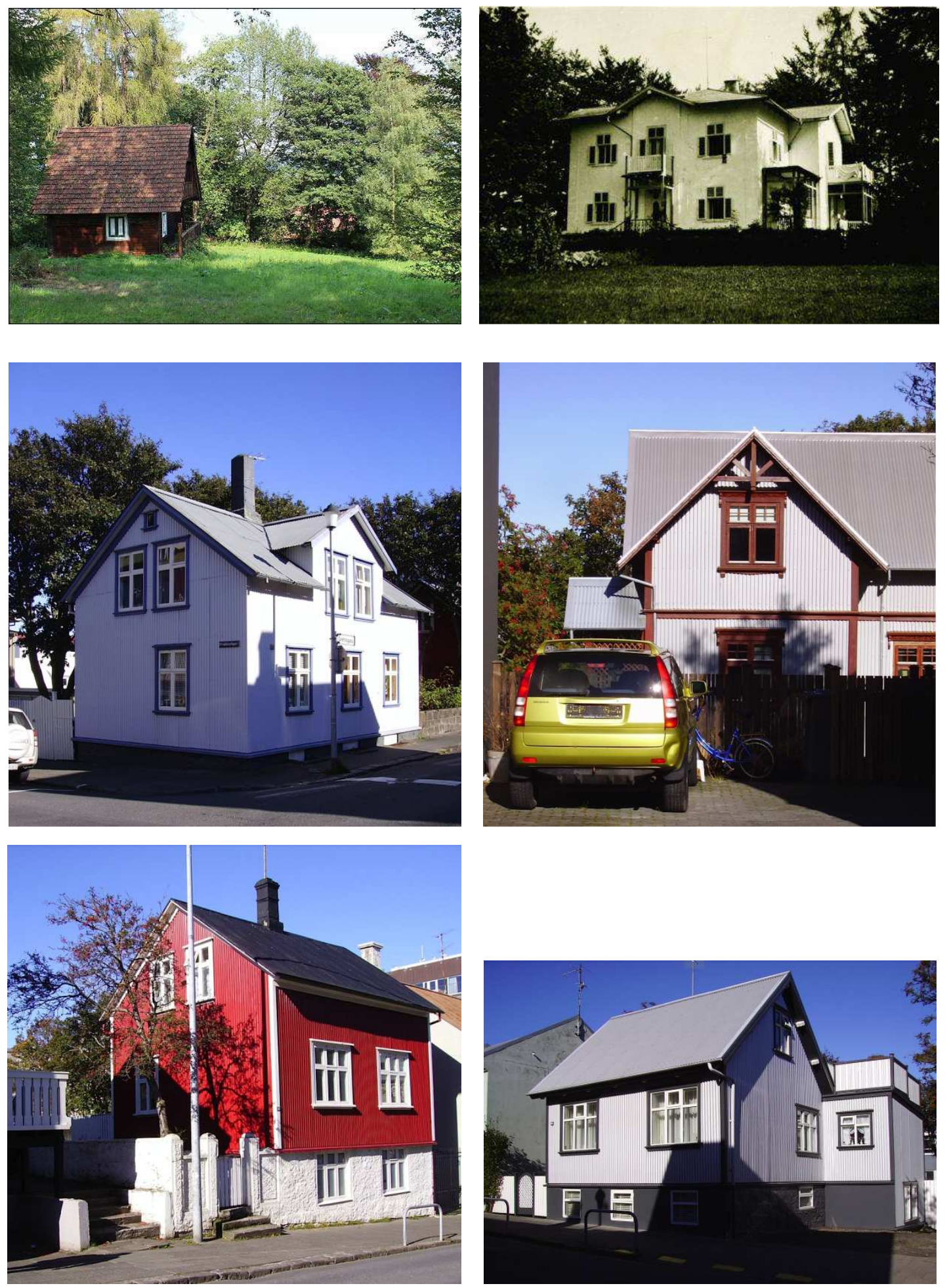

21. Casa de campo en Linz (Austria) ～22. Casa de Paul Wittgenstein (1842-1928) en Oberalm, Hallein, Salzburgo (Austria) 23-24. Casas noruegas de principios de $S$ XX en Reikiavik, septiembre 2012 25-26. Casas noruegas de principios de S XX en Reikiavik, septiembre 2012 


\section{Reconstruyendo Østerrike}

La reconstrucción de la casa de Wittgenstein en el lago Eidsvatnet es un asunto delicado. La cuestión previa es ¿por qué deberíamos siquiera plantear su reconstrucción? Evidentemente la respuesta correcta a tal pregunta, no existe. Es un asunto de dialéctica. Decía en 1984, Knut Eric Tranøy (1918-2012), filósofo de Oslo y estudiante con Wittgenstein en los años cuarenta en Cambridge, que este hubiera quedado «horrorizado por convertir su casa en un destino turístico.» ${ }^{10}$ En términos parecidos se expresaba Alois Pichler. ${ }^{11}$

Es evidente que el contenido del proyecto excedería en todo caso a la mera reconstrucción de la casa original sobre el lago. En términos puramente éticos, o si se nos permite la lítotes, románticos, nos inclinamos a pensar que no deberíamos reconstruir la casa de Wittgenstein. Hemos nombrado en este texto a Augé y el concepto del lugar y el no-lugar. Sin Wittgenstein, su casa no sería más que un escenario vacío, un espacio sin sentido o con sentido figurado, una recreación, teatro de la vida.

Pero el asunto es extremadamente complejo, teóricamente, la casa de Wittgenstein en Skjolden debería ser considerada, como ha sido reconocida la que construyó para su hermana en Viena, un artefacto intelectual, y por tanto al mismo nivel matérico incluso que sus miles de manuscritos, su obra escrita o la dibujada, pensada, proyectada, pertenecen al mismo intelecto. No estamos debatiendo sobre la conveniencia casi fetichista de un objeto personal de una celebridad sino de un constructo intelectual. David Connearn se preguntaba enfáticamente- en 2009 si nos estaríamos haciendo todas estas preguntas en caso de que la casa hubiera pertenecido a Platón. ${ }^{12}$

\footnotetext{
${ }^{10}$ Oxaal, op.cit., p. 152

11 Ya hemos comentado anteriormente aspectos de esa conversación mantenida en la sede del Archivo Wittgenstein de la Universidad de Bergen, 15.10.2013. Cfr. Introducción, p. 55 de esta tesis.

${ }^{12}$ David Connearn, seminario titulado «lf it were Plato's house... Wittgenstein and the other Buffalo Bill, precursors to the poker, Raumplanung, and the firewood», 14.10.2009, Millburn House, Warwick Graduate School.
} 


\section{The philosopher's home from home}

Ludwig Wittgenstein's Norwegian retreat nolonger exists, but his presence among the fjords is still felt 60 years after his death BY LESLEY CHAMBERLAIN
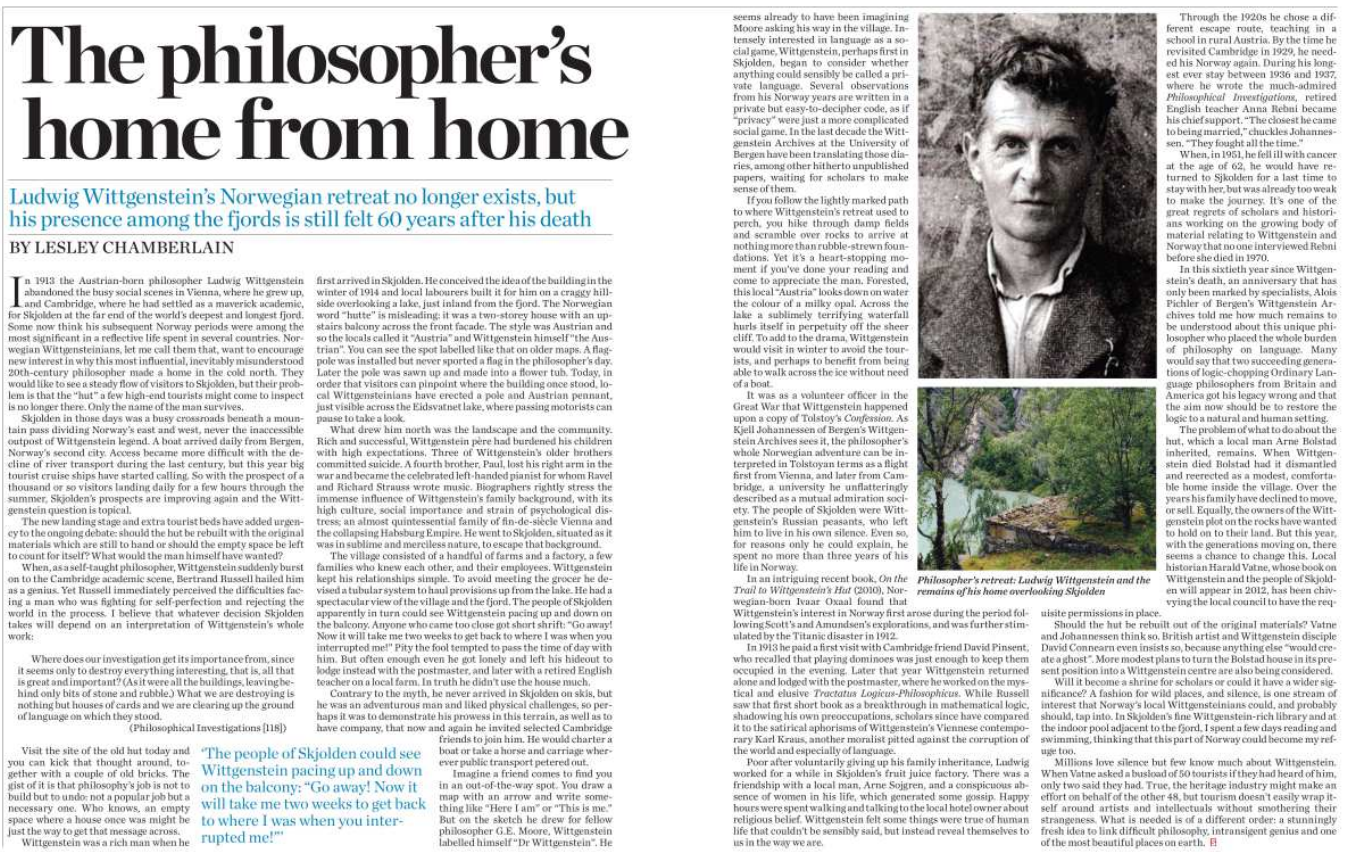

$+$

\section{IITK}

\section{NRK Sogn og Fjordane}

Dette er alt som står att etter den verdskjende filosofen
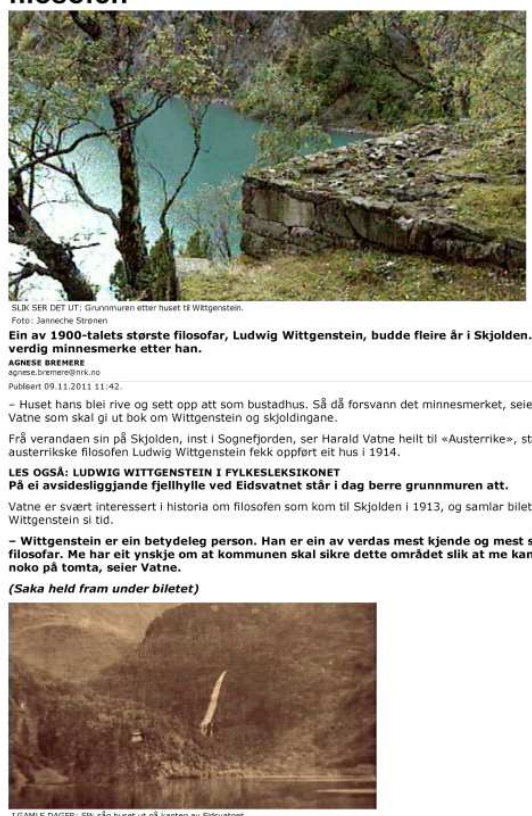

Vil ha tomta regulert
Vatne har klare vyar for korleis ein kan setje staden i stand att.

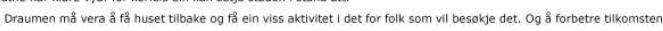

Comprehensive Conservation Planning is Essential for the Wittgenstein Legacy in Skjolden

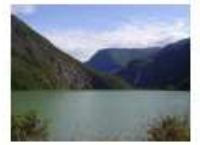
In 2009 the Kultunjef of Luter Kornmuns in Norway requoted that the intemutional communaty of Wittgenstein schalun should be infornod of devclopments tuking place in Skjolden - in particular, those which wout impact upon the Wittgentein legrey, and the conservation of the house the philasopher built there in 1913. The resalt was a collection of considered letters from sume 100 prominent Witterentecin scholats worldwide,
supported by Narweyian writer. These werc addressed to the Kommuns supported by Narweygian writen. These werc addressed to the Kommuno protect the Witugchstein house site and its asseciated fabros, and the

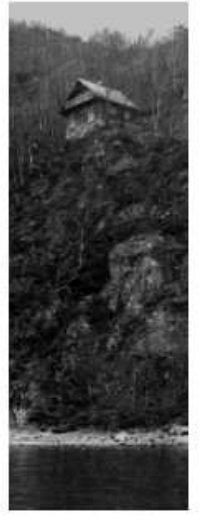
establishment of a process of Comprehensive Conservation Planning
commensurate with thair local, national and international significance. This initiative was widely reported in the Norweplan pross, and resulted in the

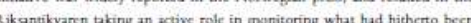
seen as a relatively minor ongaing hacal projece

secps are currently being akken at loal level to protect the Wittuenstein how:

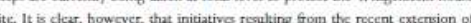

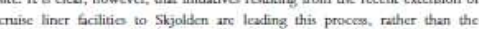

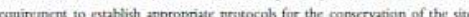

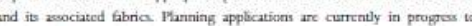
develop the shore of Eidvatnct, proximate to the site, a a tourist facility. Theo

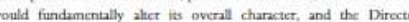
Riksanikvaren, Jom Holme, has cxpressed concem about the adequacy of the

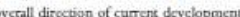

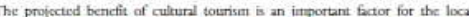
ccomonry, with the branding of Skjolden as a "Gatway' to the surnounding National Parks and Wordi Herituges site at Umes. The problems and opporannitices

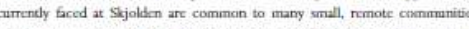
which atempt to manage and devclop tistoric sits of both local and intemational importance. Exxcllenty framed and intemationally rocognised consecvation

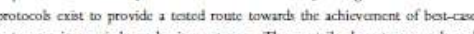

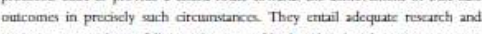
ascesenent procedura, full consideration of both cultural and ceonomic scupe.

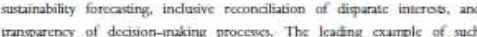

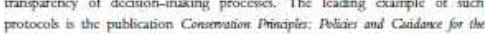

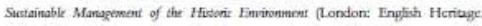
2018). The implenentation of such protocols to gruide the proceses of the

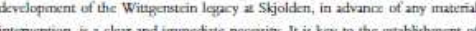

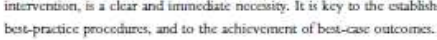

27. Lesley Chamberlain, The philosopher's home from home, en Standpoint, 10.2011

28. Agnese Bremere, Dette er alt som står att etter den verdskjende filosofen, en NRK Sog og Fjordane, 09.11.2011 | 29. David Connearn \& Dawn Wilson, Ludwig Wittgenstein - Verortungen eines Genies, Berlin, 03.07.2011 
Ese mismo año, Connearn inició con Dawn M. Wilson una campaña de cartas de apoyo a la conservación del lugar y protección de los restos de la casa de Wittgenstein en Skjolden. El objetivo principal era fijar la relevancia de la casa como elemento central en la producción filosófica de Wittgenstein y preservar la integridad de los elementos que se han conservado hasta la fecha negligentemente, en la ladera del escarpe donde estuviera construida la casa en su momento, abandonados a su suerte ante la climatología y el vandalismo de baja intensidad de los esporádicos visitantes desde 1957.

La campaña de apoyo, realizada en dos fases, 2009 y 2012, supuso una puesta en valor de la memoria de Wittgenstein en Skjolden y en paralelo el impulso final que se venía gestando desde las autoridades locales y regionales sobre la conservación de los restos todavía existentes y sobre un posible proyecto de reconstrucción. El interés por la conservación del legado noruego de Wittgenstein obtuvo el apoyo para iniciar algún tipo de procedimiento de protección por parte del responsable de cultura de Luster, Erling Bjørnetun, y del Riksantikvaren y por supuesto de Knut Olav Åmås, que como hemos comentado ya anteriormente es un referente en el mundo de la cultura en Noruega.

El éxito de la campaña entre los más prestigiosos investigadores, filósofos, artistas e intelectuales interesados en la figura de Wittgenstein y en la comprensión del papel que jugara la casa de Skjolden en su filosofía fue importante. Desde 2009, se han multiplicado los artículos en los medios de información acerca de este renovado interés por el lugar de retiro del filósofo.

En paralelo, la iniciativa local de desarrollo de algún tipo de proyecto de reconstrucción culminó en julio de 2014 con la creación de la «Foundation Wittgenstein in Skjolden», firmada simbólicamente en la granja Eide de Anna Rebni el año que se cumplía el centenario de la construcción de la casa de Wittgenstein. Tal grupo está formado por Harald Vatne, Jon Bolstad (Skjolden 


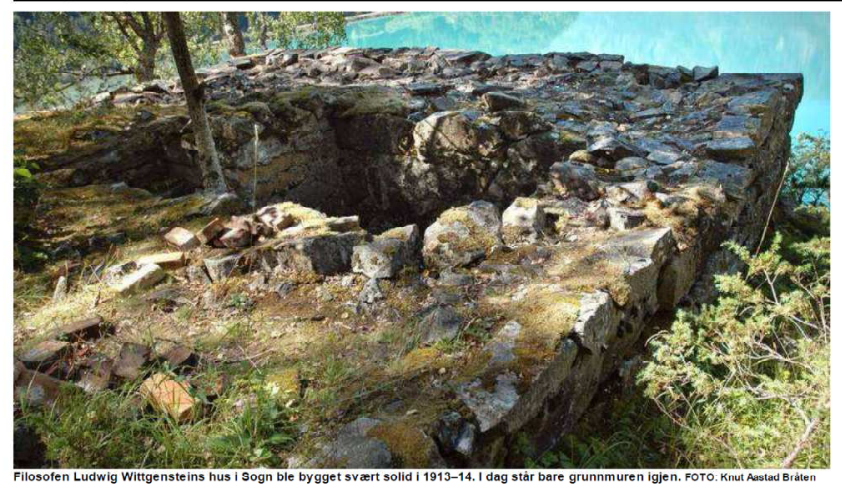

\section{Gjenreis filosofens norske hus!}

l et lite hus i Skjolden i Sogn satt filosofen Ludwig Wittgenstein og endret retningen pa det 20. arhundres filosofi. Ikke bare én, men to ganger. Nå er det pả tide å gjenreise huset.

\begin{tabular}{l} 
Knut Olav Amảs \\
Publisert: $29.1 \mathrm{j} .1201215 .47$ \\
\hline
\end{tabular}

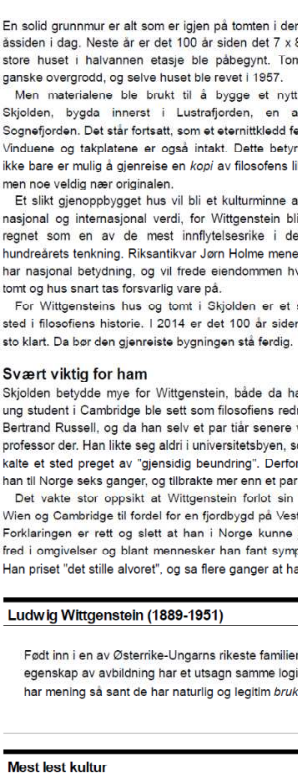

Wittgenstein's cabin in Skjolden to be rebuilt

The foundation 'Wittgenstein in Skjolden' has been established, with one of its intentions being to rebuild the cabin that wittgenstein erected in 1914 in the area known as "Austria" by the lake Eidsvatnet in Skjolden in the innermost part of the Sogne Fjord.

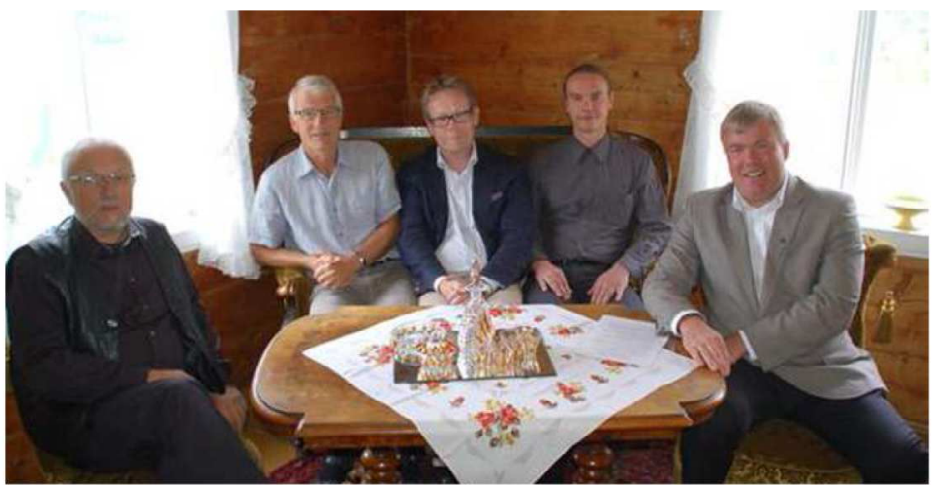

The board members seated In the Elde Gard, the house of Anna Ræbnl where Wittgensteln regularly stayed. L-r: local historlan Harald Vatne; engineer Trygve Marthinussen; director of Skjolden Aktiv, Jon Bolstad; assistant professor at the University of Bergen, Rune J. Falch; and mayor of the municipality of Luster and head of the board, Ivar Kvalen. Photo: Ering Bjornetur Copyright: Luster municipality

By Rune J. Falch (/en/persons/Rune.J...Falch) Created 02.07.2014-20.50 Last updated 22.07.2014 - 09.43

The foundation combines representatives of local authorities and organizations, as well as from the University of Bergen. The municipality of Luster published its press release (http:// www. Iuster.Kommune. no/stiftingawittgenstein-i-skjolden-er-skipa. 5574019-1574)6.html) on lune ?7 currently only available in Norwegian - watch this space for the forthcoming version in tnglısh.

30. Knut Olav Åmås, Gjenreis filosofens norkke hus!, en Aftenposten, 29.07.2012

31. Universidad de Bergen, Wittgenstein's cabin in Skjolden to be rebuilt, 02.072014 
Active), el ingeniero local Trygve Marthinussen, el profesor Rune J. Falch de la Universidad de Bergen y el alcalde del municipio de Luster, Ivar Kvalen.

Las noticias publicadas en periódicos regionales dirigen el interés del proyecto de reconstrucción al incentivo que podría obtener el municipio con la presencia de un objeto de importancia internacional. Se ha dicho anteriormente que Skjolden carece prácticamente de infraestructuras de desarrollo locales y las líneas de cruceros de grandes navíos trasladan hasta el puerto a miles de pasajeros que sin embargo parten hacia otros lugares sin detenerse apenas unas horas en el pueblo. Por tanto, de momento es desconocida la orientación de tal fundación, pero no es descabellado pensar que puedan primar intereses no puramente intelectuales o de memoria histórica, en un proyecto planteado desde un ámbito reducido como sería el del Luster. Desde su formación, las tareas emprendidas un año más tarde por el grupo de trabajo de Skjolden y que hemos podido consultar con Harald Vatne, parece que han tenido lento desarrollo.

Así la cosas, desde 2011, consideramos interesante -¿necesaria?- junto a David Connearn y Dawn Wilson la tarea de desarrollar el proyecto de la casa de Wittgenstein en Skjolden con la mayor precisión posible y con un criterio de protección no sólo de los restos existentes sino del paisaje en el que se enclavaba la casa. Un Plan Integral de Conservación debería ser redactado para asegurar que la recuperación del artefacto de Wittgenstein es adecuada en todos sus matices. Hay que tener en cuenta que, además, la normativa estatal de conservación de patrimonio noruega obvia las construcciones posteriores a 1900, con lo que el vacío legal existente deja abiertas puertas a intervenciones que pudieran ser no sólo dramáticas conceptual y paisajísticamente sino erróneas en el propio manejo del Nachlass construido de Wittgenstein. A tal efecto se pretende establecer unos criterios de intervención basados en estándares internacionales reconocidos -en ausencia, como se ha dicho de otros oficiales propios en Noruega- como los protocolos recogidos por la «English Heritage Conservation Principles, Policies and Guidance For the Sustainable Management of the Historic Environment». La búsqueda de precisión en el proyecto contrasta severamente con la actitud cercana a la desidia con la que 


\section{Viktig avklaring for Wittgensteins hus}

- Avtale underskriven a Stifting er formelt skipa

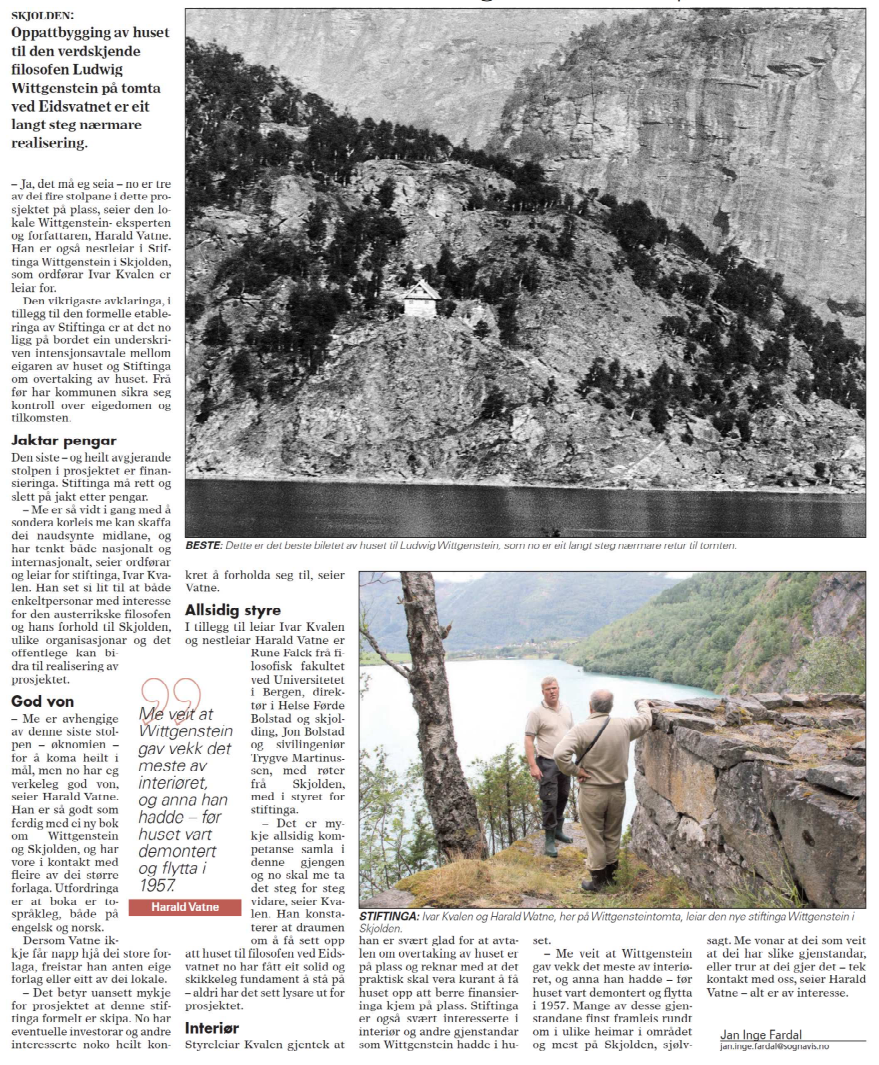

\section{AVTALE}

Mellom Luster kommune ved ordføraren (seinare kalla kjøpar) og Rune Fuglesteg frr. pnr. eigar av gnr. 20 bnr $10 \mathrm{i}$ Luster kommune (seinare kalla seljarar) er det inngătt fylgjande avtale:

1. Seljar overdreg til kjøpar den del av eigedomen gnr. 20 bnr. $10 \mathrm{i}$ Luster kommune som er vist på vedlagt kartskisse datert 18.03.2013

2. Det samla arealet som skal overdragast utgjer om lag $10.000 \mathrm{~m} 2$. Endeleg areal vert fastlagd etter oppmåling.

3. Kjøpesummen for det avstǻtte arealet er kr. 3,50 pr. kvm.

4. Kjøpesummen skal betalast kontant mot skøyte fritt for økonomiske hefte.

5. I tillegg betalar Luster kommune $\mathrm{kr}$. 185.000,- $\mathrm{i}$ affeksjonsverdi for kulturminna etter Ludwig Wittgenstein

6. Seljar beheld fiskerett og erstatning for tapt isveg.

7. Seljar søkjer om løyve til frådeling.

8. Kjøparen betalar alle kostnader med eigedomsoverdraginga.

9. Avtalen er underteikna i tre eksemplar, eit til kvar av partane samt eit eksemplar til tinglysingskontoret.

0.Avtalen er gjort med atterhald om godkjenning av Luster formannskap/kommunestyre.

11.Avtalen kan tinglysast som hefte på gnr. 20 bnr. $10 \mathrm{i}$ Luster kommune.

Gaupne den 20.03 .2013

Gaupne den 20.03.2013

Rune Fuglesteg

Ivar Kvalen

ordførar

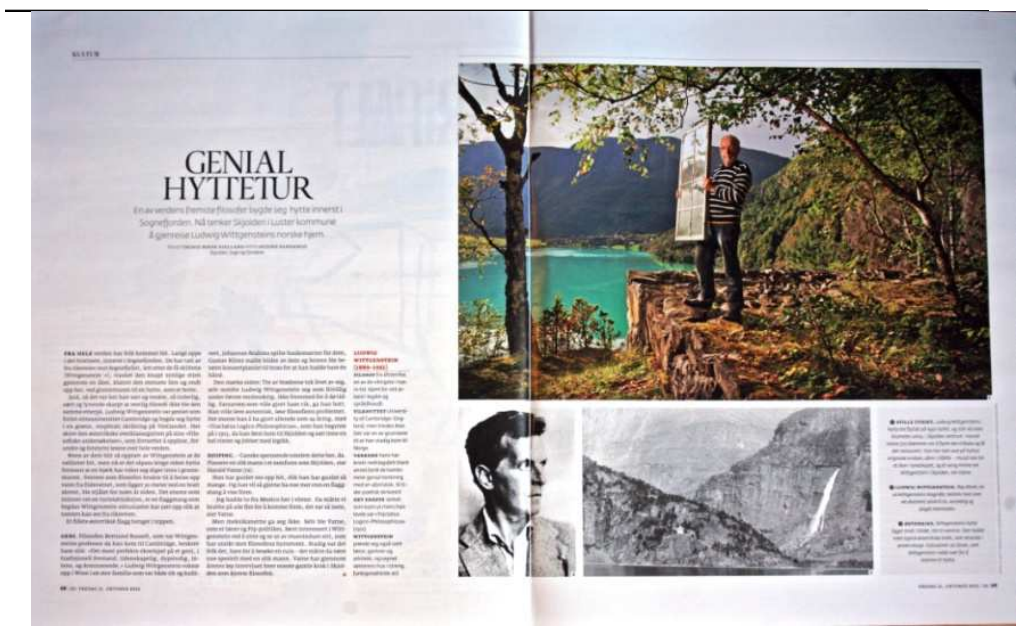

$$
\begin{aligned}
& \text { GUNNAR + } \\
& \text { SVERRE + } \\
& \text { KARE } \\
& \text { NILS } \\
& \text { GJELL }
\end{aligned}
$$

32. Jan Inge Fardal, Viktig avklaring for Wittgensteins hus, en Sogn Avis, 06.06.2015 | 33. Acuerdo de compra-venta del terreno del lago entre el propietario Rune Fuglesteg y el alcalde del municipio de Luster, Ivar Kvalen, 20.03.2013

34. Reportaje sobre la casa de Wittgenstein y Harald Vatne, 11.10.2013 ～35. Los hermanos Bolstad, nota manuscrita de Harald Vatne, 14.10.2013 
durante décadas se han tratado los asuntos relacionados con Wittgenstein en el mismo Skjolden, como muestra, sabemos que en varias ocasiones la casa de Bolstad ha sufrido tareas de mantenimiento de sustitución del recubrimiento de fibrocemento exterior, la última referida en 2010 , sin que conste que ninguna persona -siquiera Vatne- realizara un reportaje fotográfico del estado de la madera original que tales placas ocultan.

A nivel administrativo, parte del planeamiento de Luster afectaba, al menos todavía en 2012, al área de la orilla este del lago Eidsvatnet, proponiendo un nuevo acceso rodado, aparcamientos, etc. desde la carretera de Lom Rv55. En la actualidad y bajo la presión vigilante del ámbito académico internacional, podrían haberse modificado algunos criterios que desde el punto de vista de la conservación suponían una alteración definitiva del paisaje que hemos descrito para la casa de Wittgenstein, tan importante para él o quizá más que la propia edificación.

De igual manera, nuevas generaciones de los Bolstad parecen haber accedido a la venta de su casa -condicionada a elevadas compensaciones económicas- que durante décadas había supuesto el principal escollo para la recuperación de los materiales originales de la casa de Wittgenstein.

Importantes avances como la adquisición por el municipio de Luster del terreno en el que se asentaba la casa del lago se han producido ya, por lo que se aprecia un interés real por las administraciones interesadas en el desarrollo de un proyecto en torno a Wittgenstein en Skjolden. ${ }^{13}$

Traer a colación en esta tesis la situación de la realidad extraacadémica de la misma es especialmente interesante en una escuela de arquitectura. Un trabajo marcadamente teórico como esta investigación, de elucubración, de proyección de una casa que ya no existía, ha devenido en una posible colaboración en el futurible proyecto de reconstrucción de la casa de Wittgenstein en Skjolden. Las condiciones a cumplir por ese futuro todavía incierto dependerán de factores que en gran parte escapan a nuestro control.

${ }^{13}$ El contrato de adquisición del terreno se firmó el 15.07.2013, por valor de 185.000 kr. 


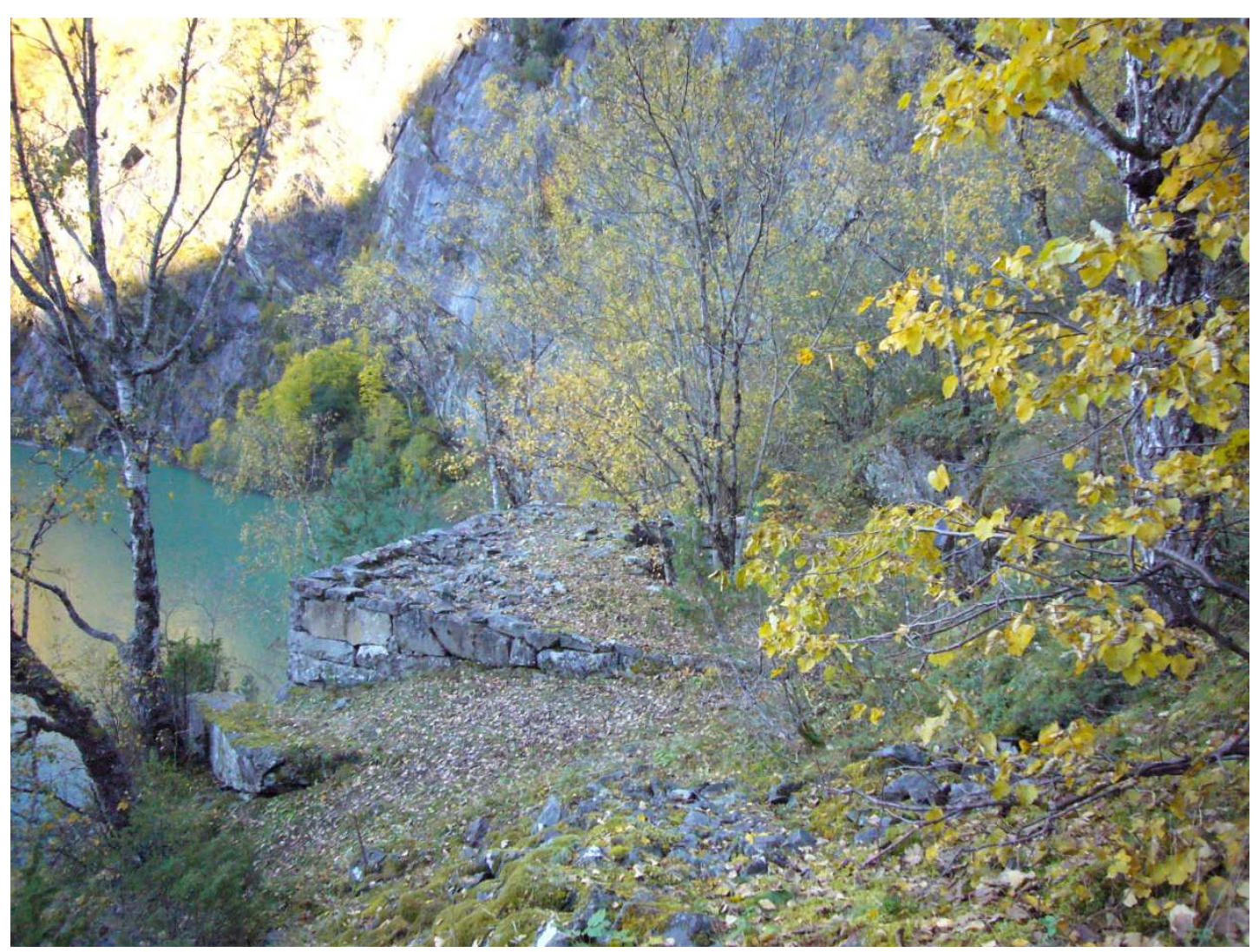

36. La tranquila seriedad, Skjolden, 13.10.2013 
La primera iniciativa para establecer definitivamente una línea de trabajo común será la presentación de los resultados de este proyecto en una página web, que tendrá acceso progresivo hasta hacerlo totalmente abierto, a lo largo del otoño de 2015. Se pretende que este sitio sea una plataforma de intercambio de información y de valoración del proyecto integral de conservación.

El proyecto considerado en esta tesis supone por lo tanto, la primera ocasión en la que la mirada del arquitecto se posa con intensidad en la casa de Wittgenstein de Skjolden. El sensible material sintáctico y pragmático inherente a este proyecto de arquitectura se ha desarrollado con honestidad, tratando de mantener a raya la invención, la ocurrencia, sin dejar empero de proyectar, de pensar como arquitecto en cada una de las horas dedicadas a tal empeño.

El proceso ha estado repleto de revelaciones, de arduas y sin embargo necesarias tareas de redibujo y elucidación; hemos dibujado apasionadamente, cada piedra, cada tronco, cada teja, sin manierismos, sin disfrazar la arquitectura de la casa detrás de trampantojos gráficos. Nuestro viaje sigue su curso, con la emocionante sensación de que, pese a lo mucho recorrido, el destino apenas se asoma entre abedules, más allá del fiordo, a cuarenta y cinco metros sobre el lago Eidsvatnet. 

05 ANEXOS 


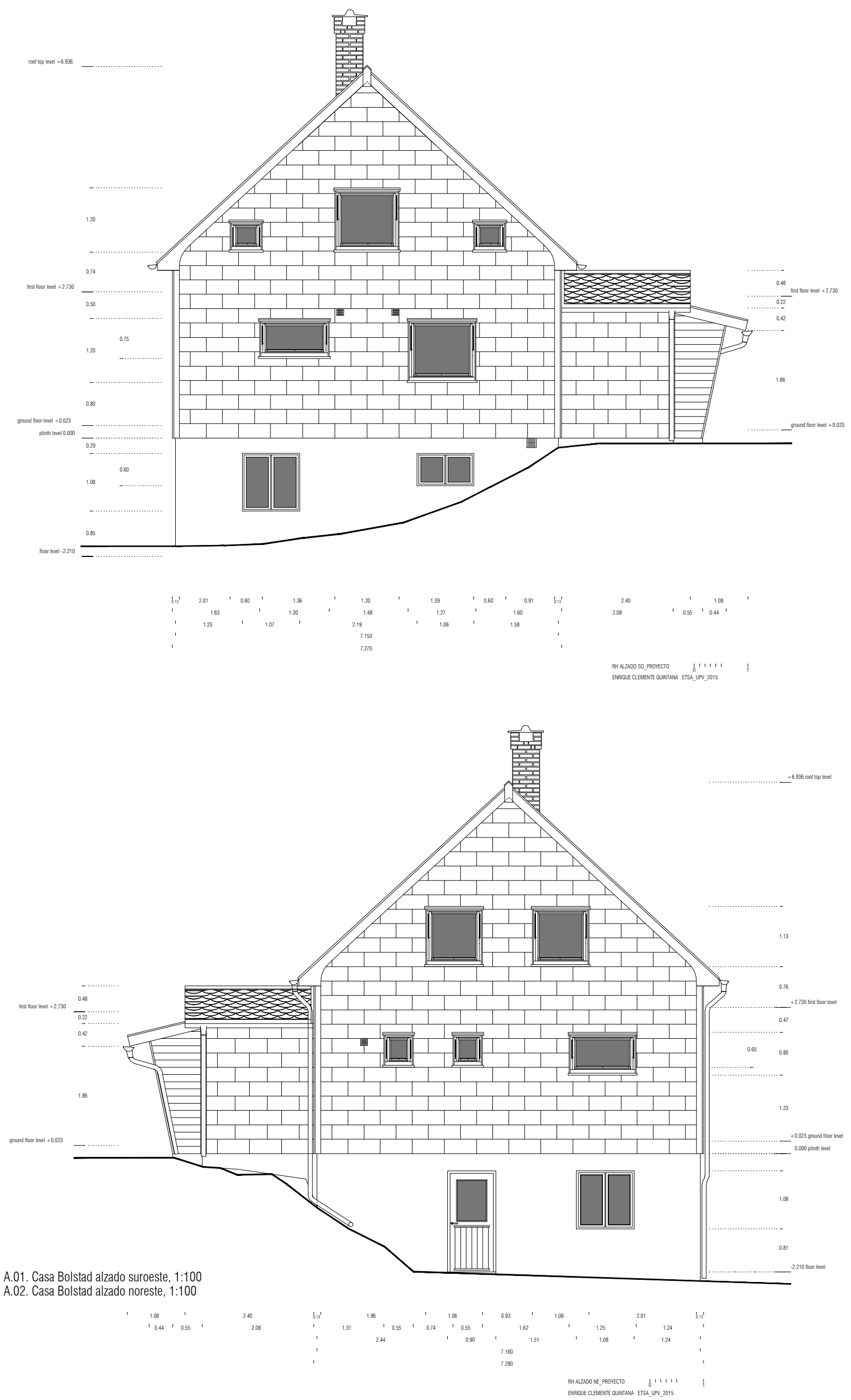

ANEXO 321 

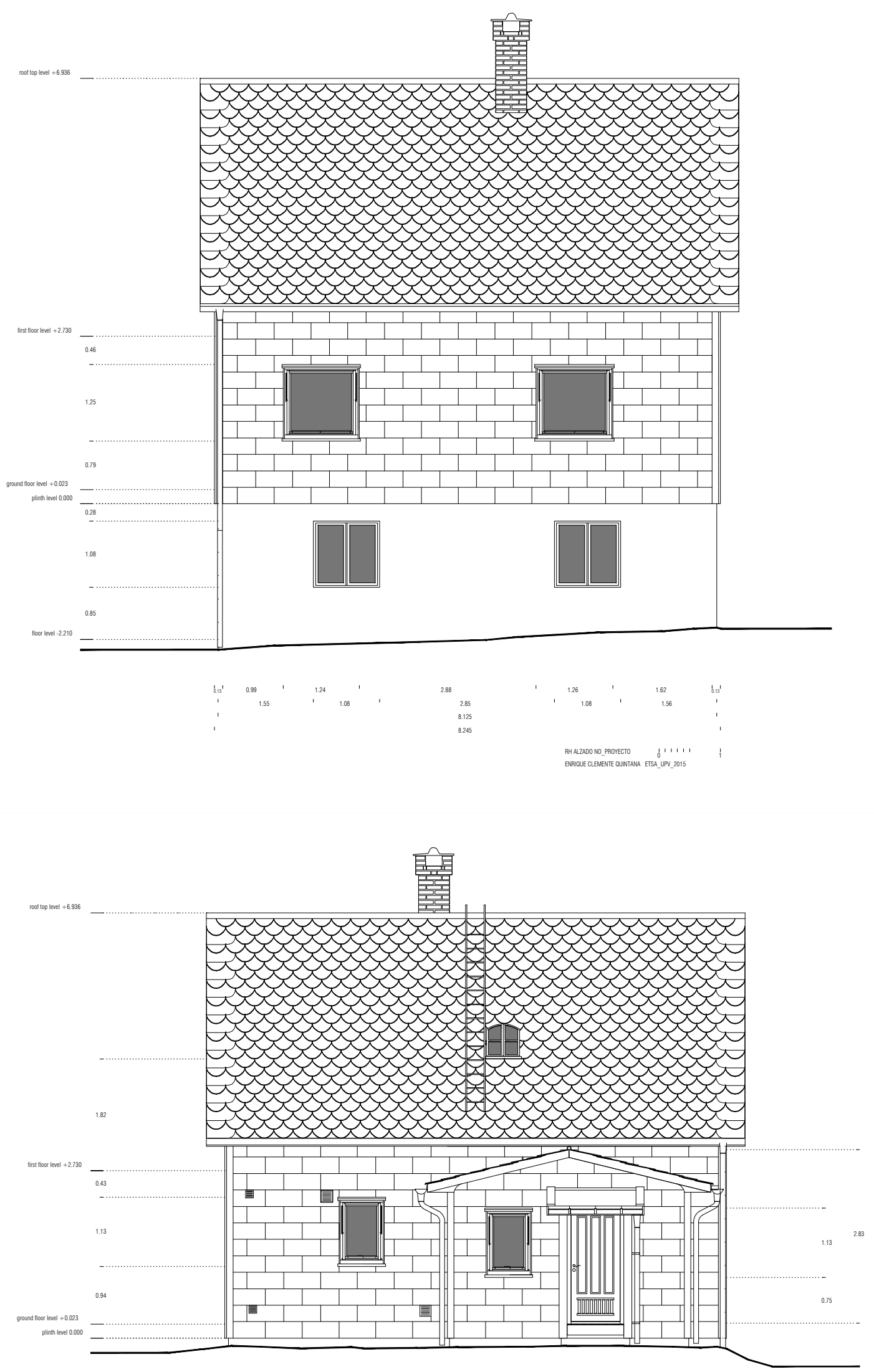


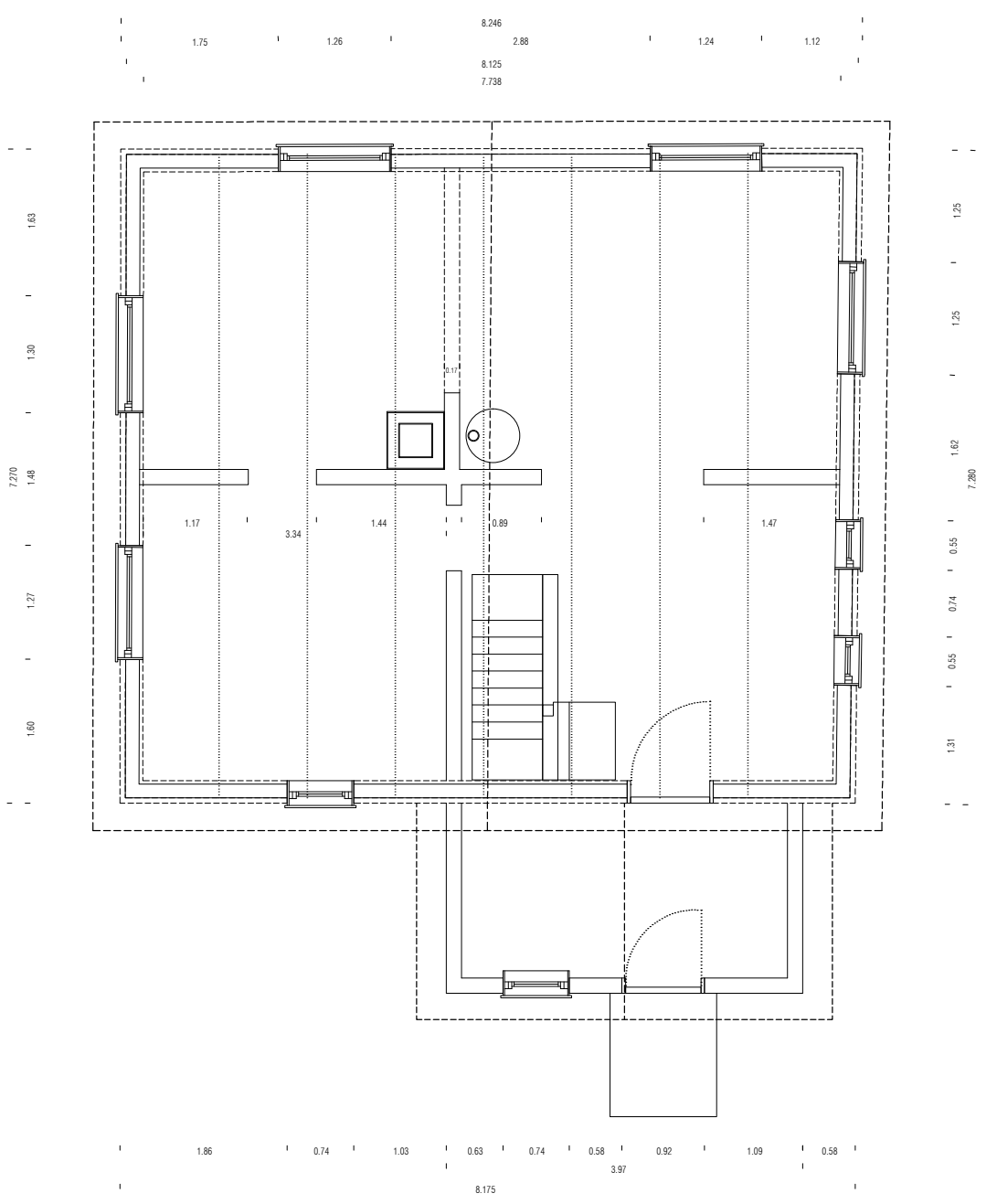

A.05. Casa Bolstad planta esquemática, 1:100 

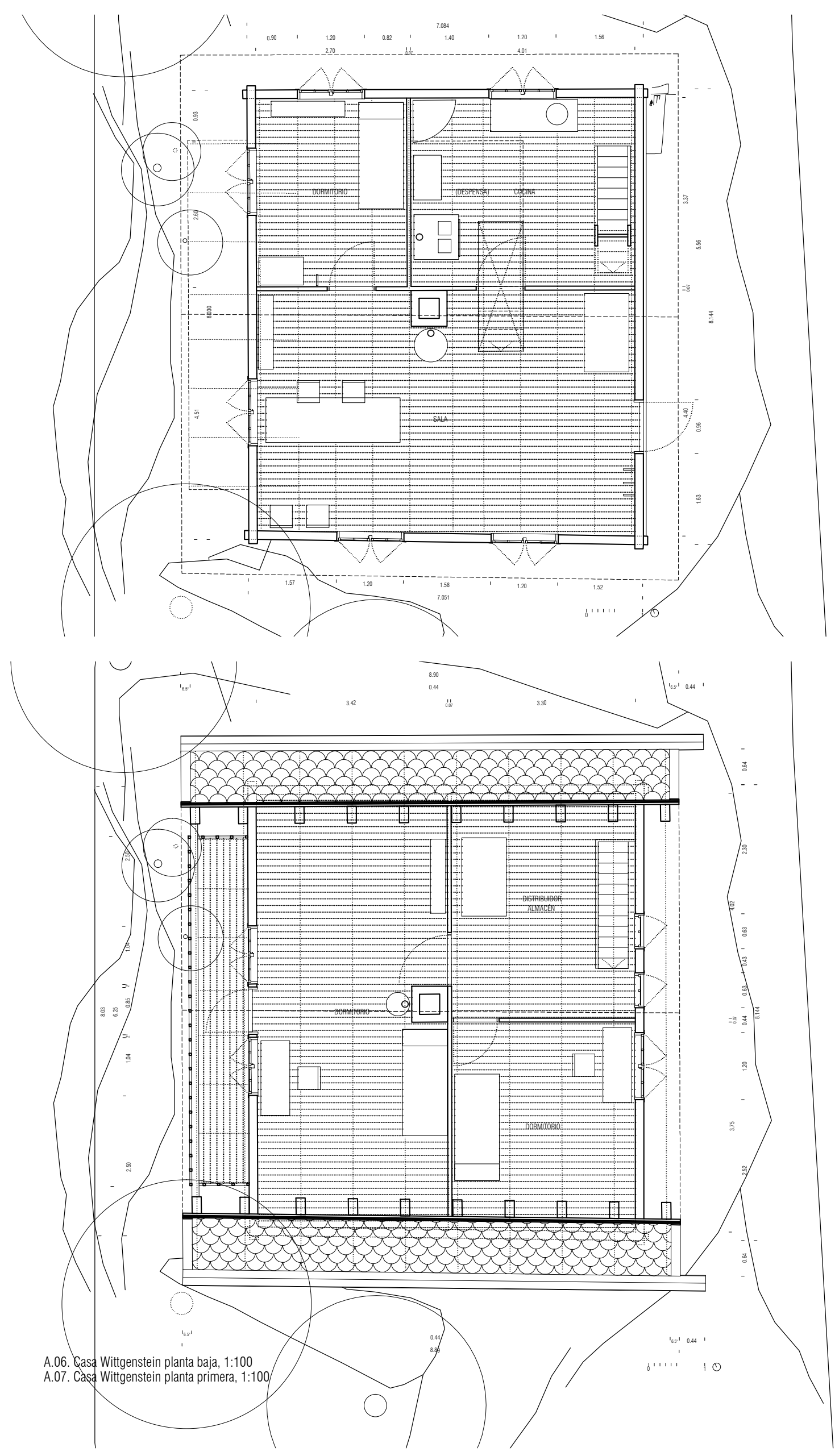

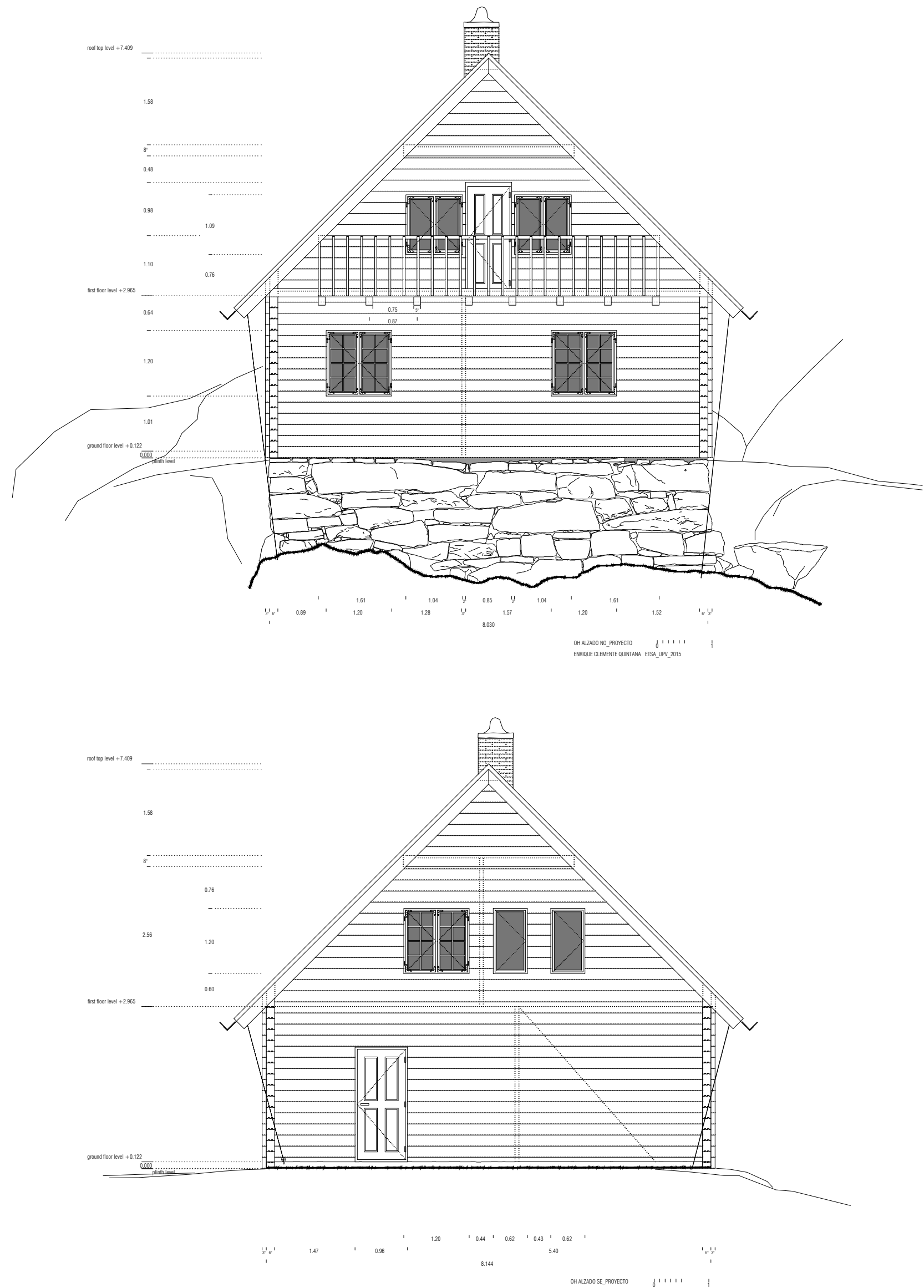

A.08. Casa Wittgenstein alzado noroeste, 1:100

A.09. Casa Wittgenstein alzado sureste, 1:100 


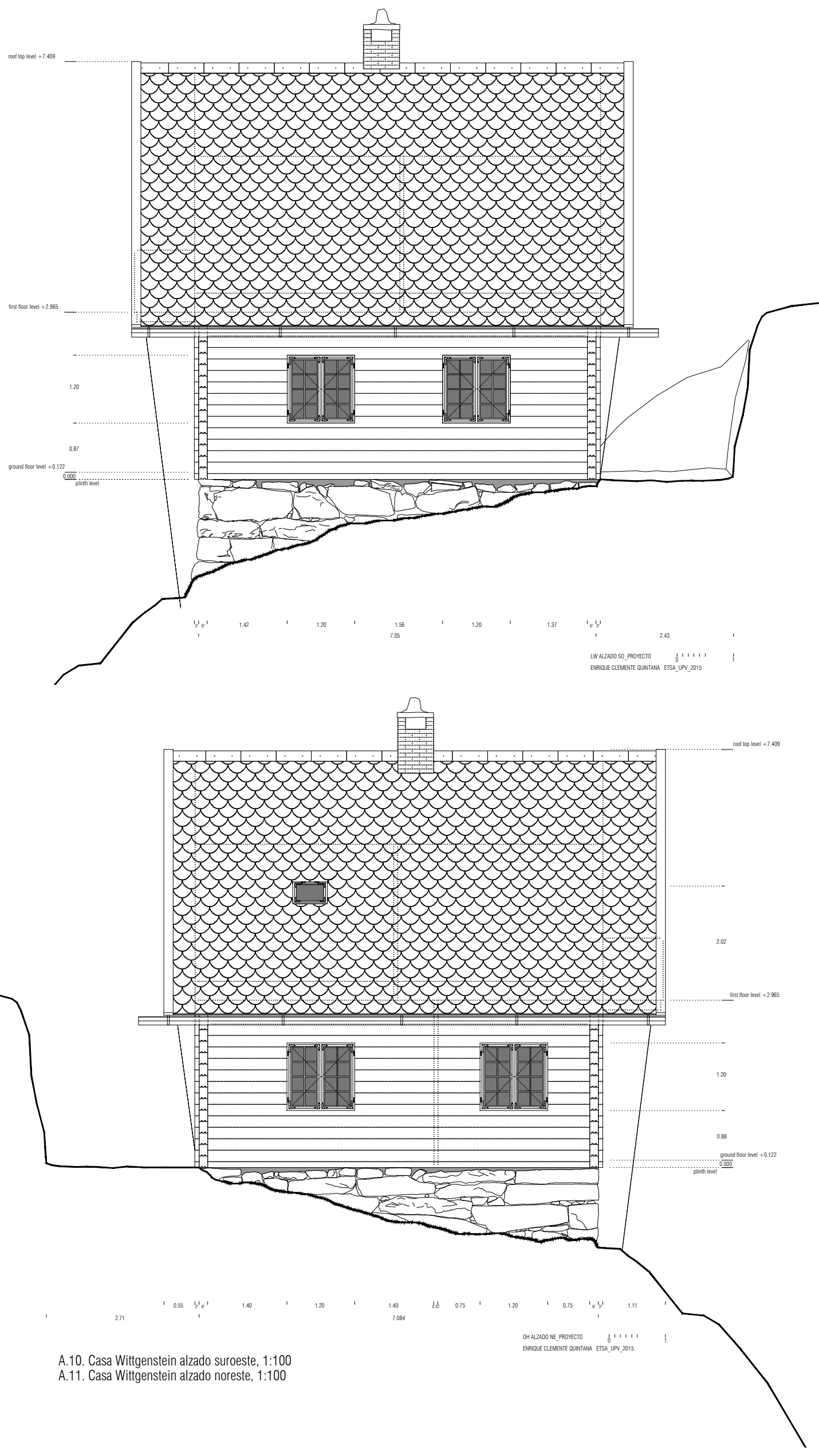



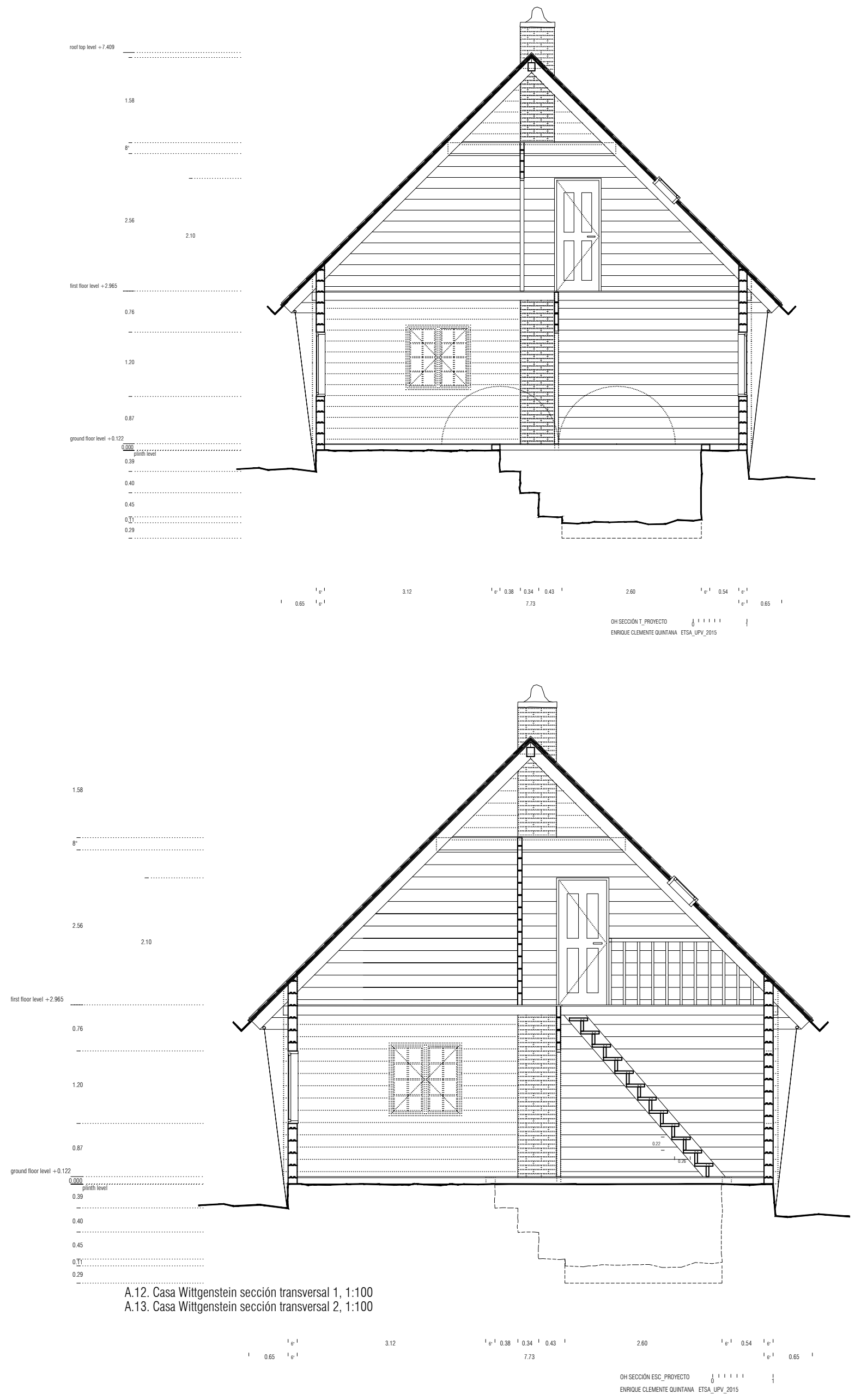


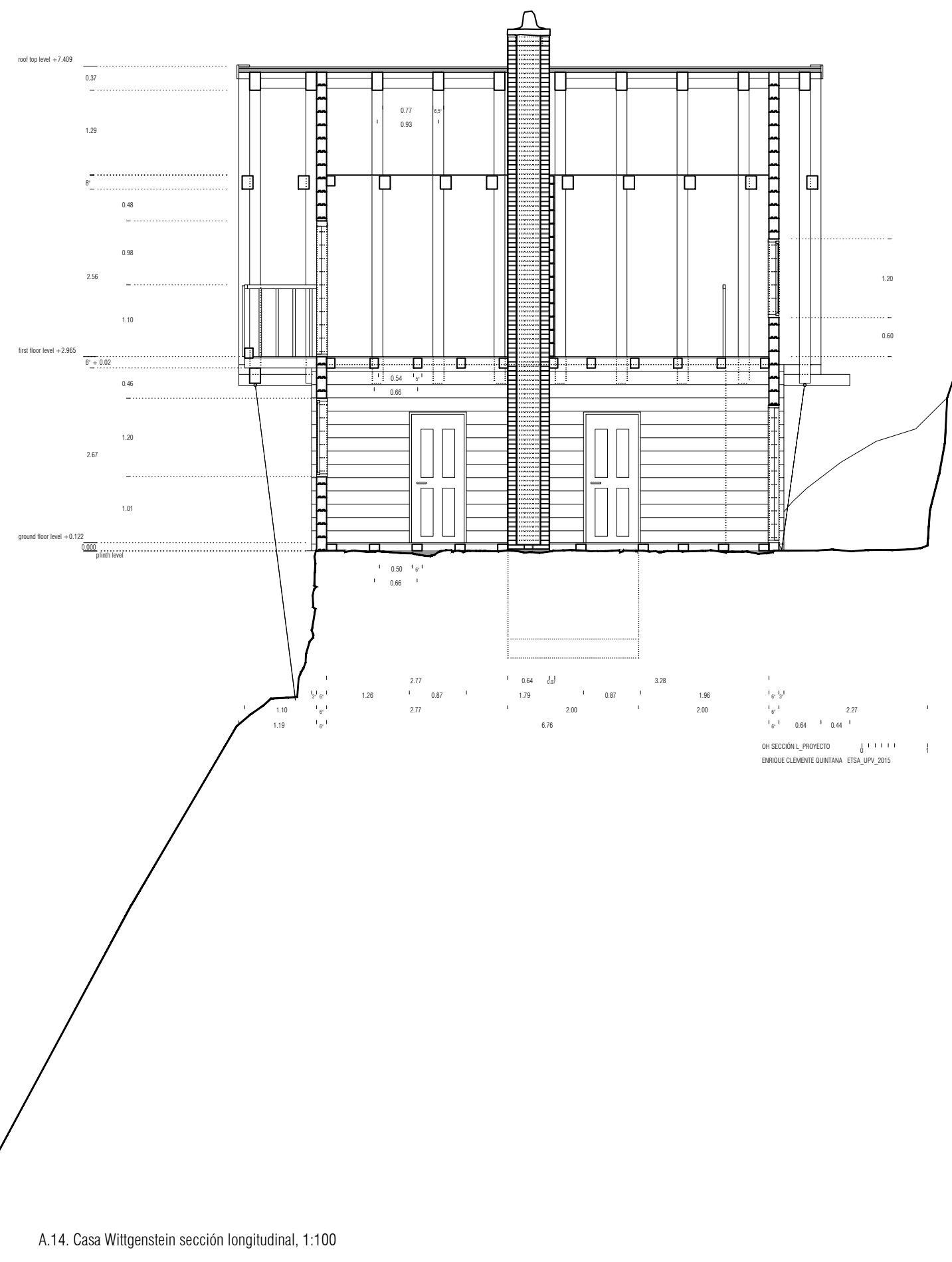




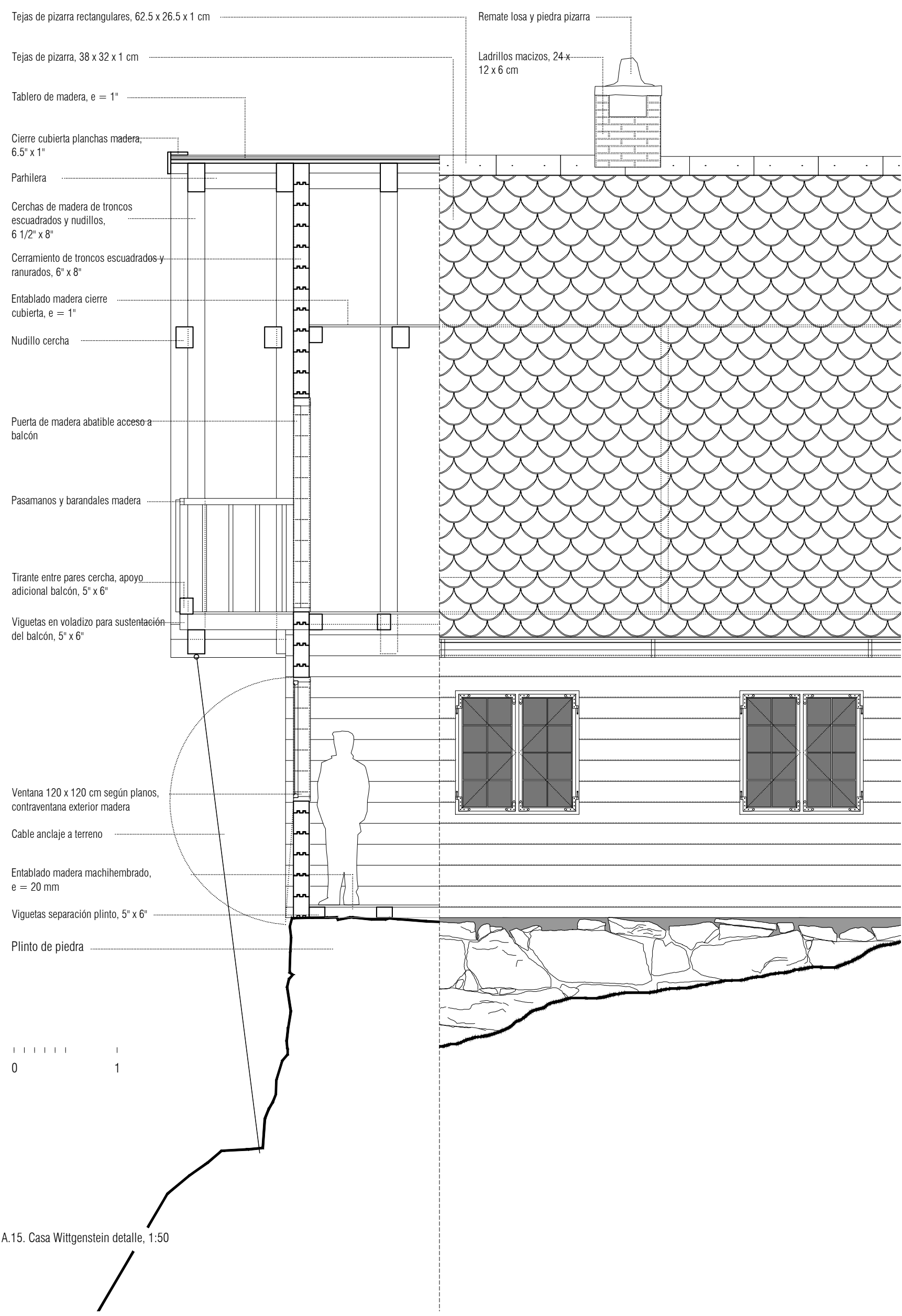




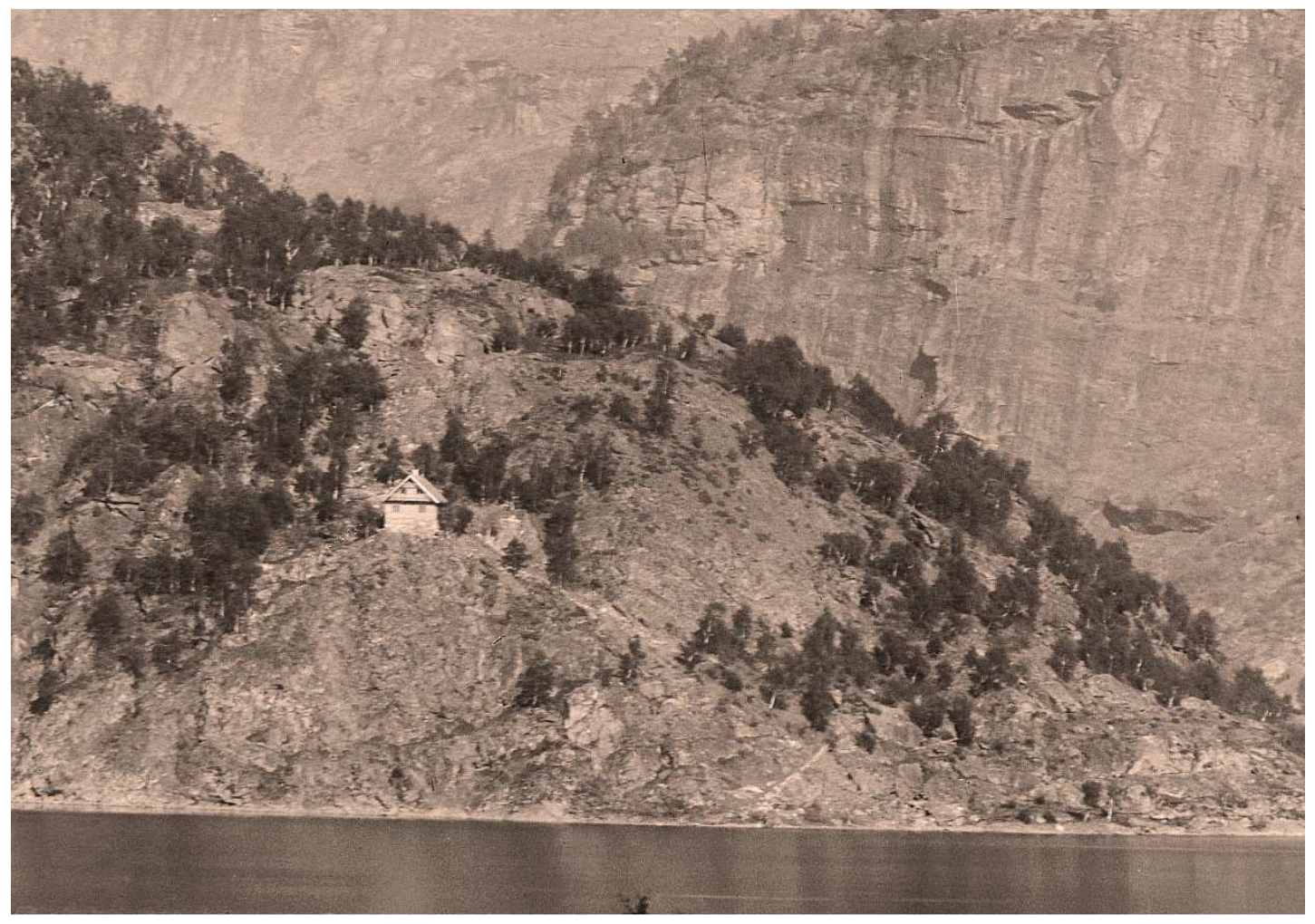

A.16. «Lago Eidsvatnet, Skjolden, Luster (Sogn)»; Samson Brathole; 1920 (Ant); $12 \times 16$ cm; Fylkesarkivet (Leikanger). 11.10.2013. Cód. SFFf-100114.119503 Imagen inédita hasta el mismo día en que se obtuvo del Fylkesakivet. Publicada por el Dagens Næringsliv en el suplemento de cultura D2, p.68-70 Entrevista a Harald Vatne (que proporcionó la fotografía de Brathole al rotativo) 


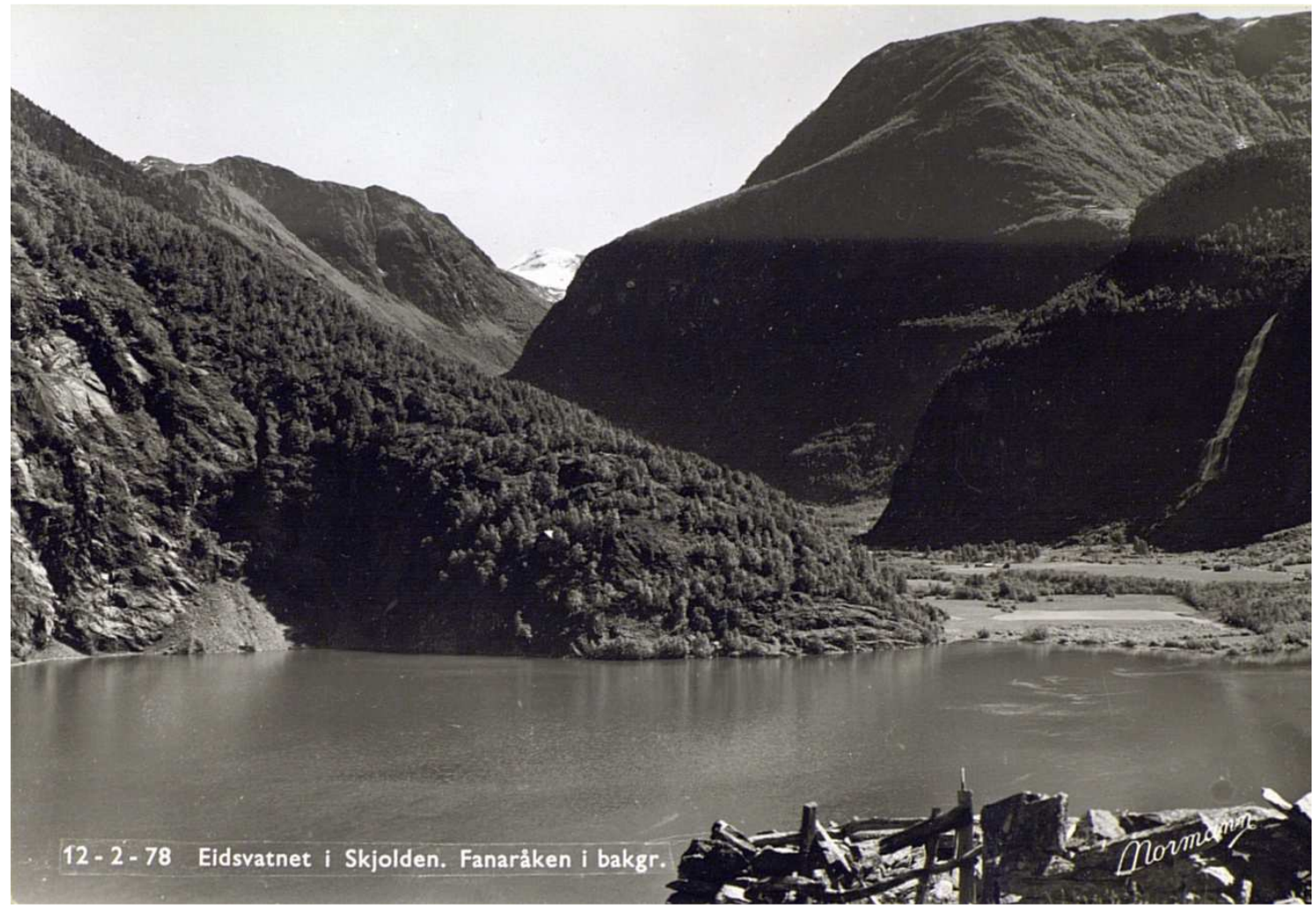

A.17. «12-2-78 Eidsvatnet i Skjolden. Fanaråken I bakgr. Normann»; Normann 1920-1940; 11 x15 cm; Fylkesarkivet (Leikanger). 11.10.2013. Cód. SFFf-1990069 Drægni, Dagfinn. La fecha de 1978 es una estampación de una serie de tarjetas postales sobre una foto de los años 30. 


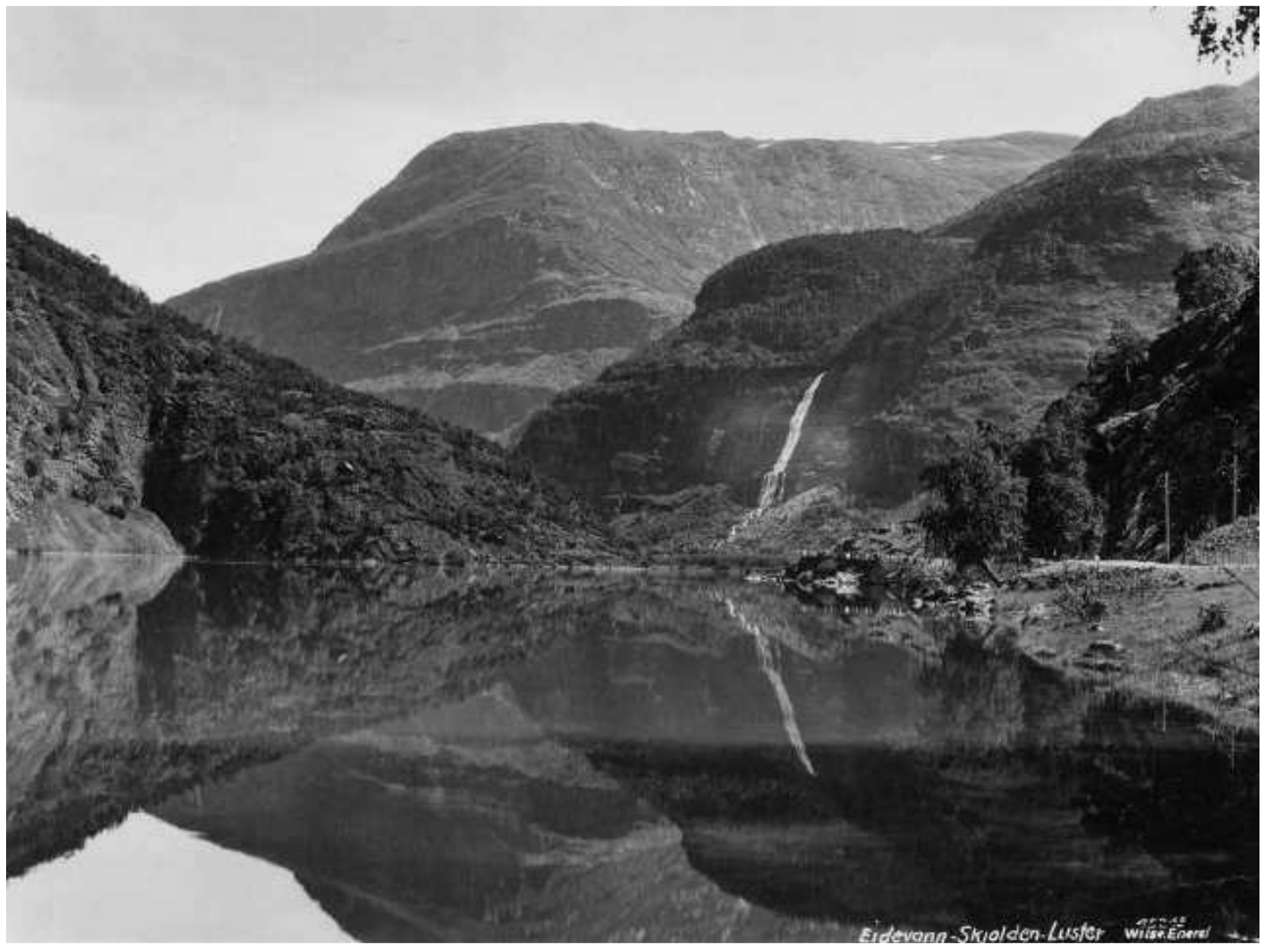

A.18. «Eidsvann-Skjolden-Luster. Wilse Anders»; Anders Beer Wilse; 1937; 640x479 pixels; Norsk Folkemuseum (Oslo). Cód. -7211 Material inédito 


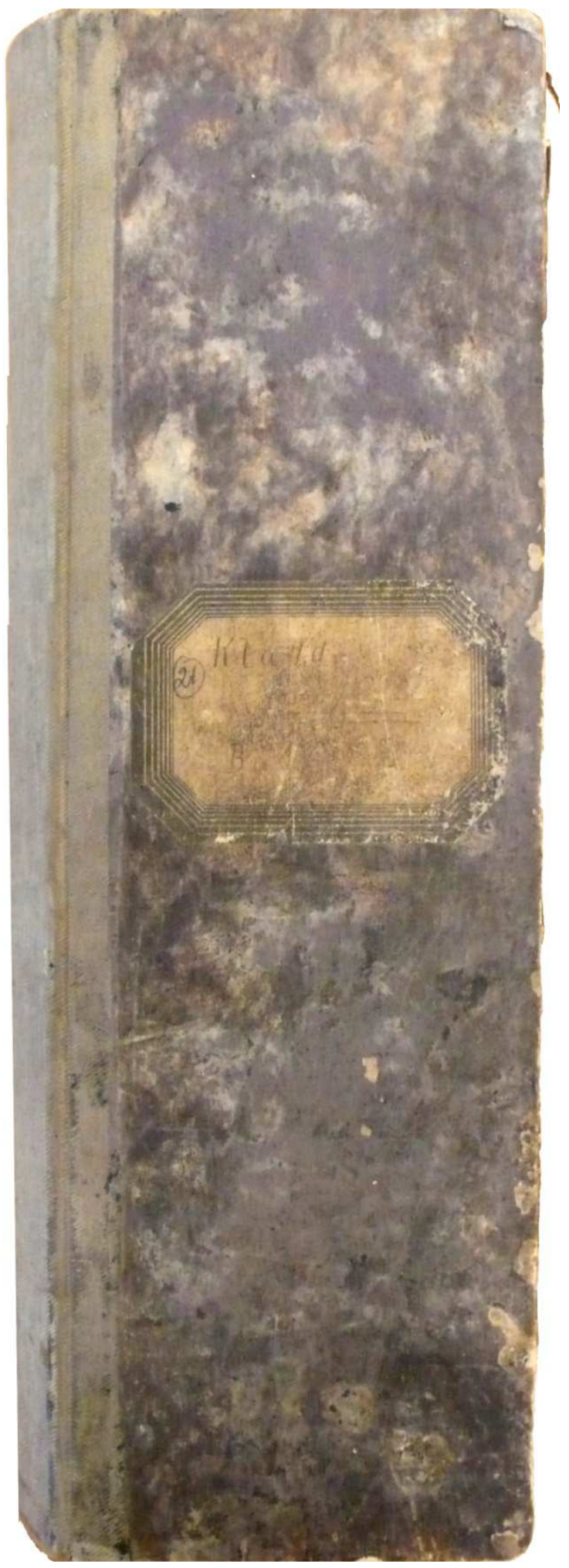

A.19. Libro de contabilidad manuscrito de Halvard Drægni, fechado en 1914; 32x12 cm, Fylkesarkivet (Leikanger). 11.10.2013. Cód. SFFf-1990069 Drægni, Dagfinn

Material inédito 


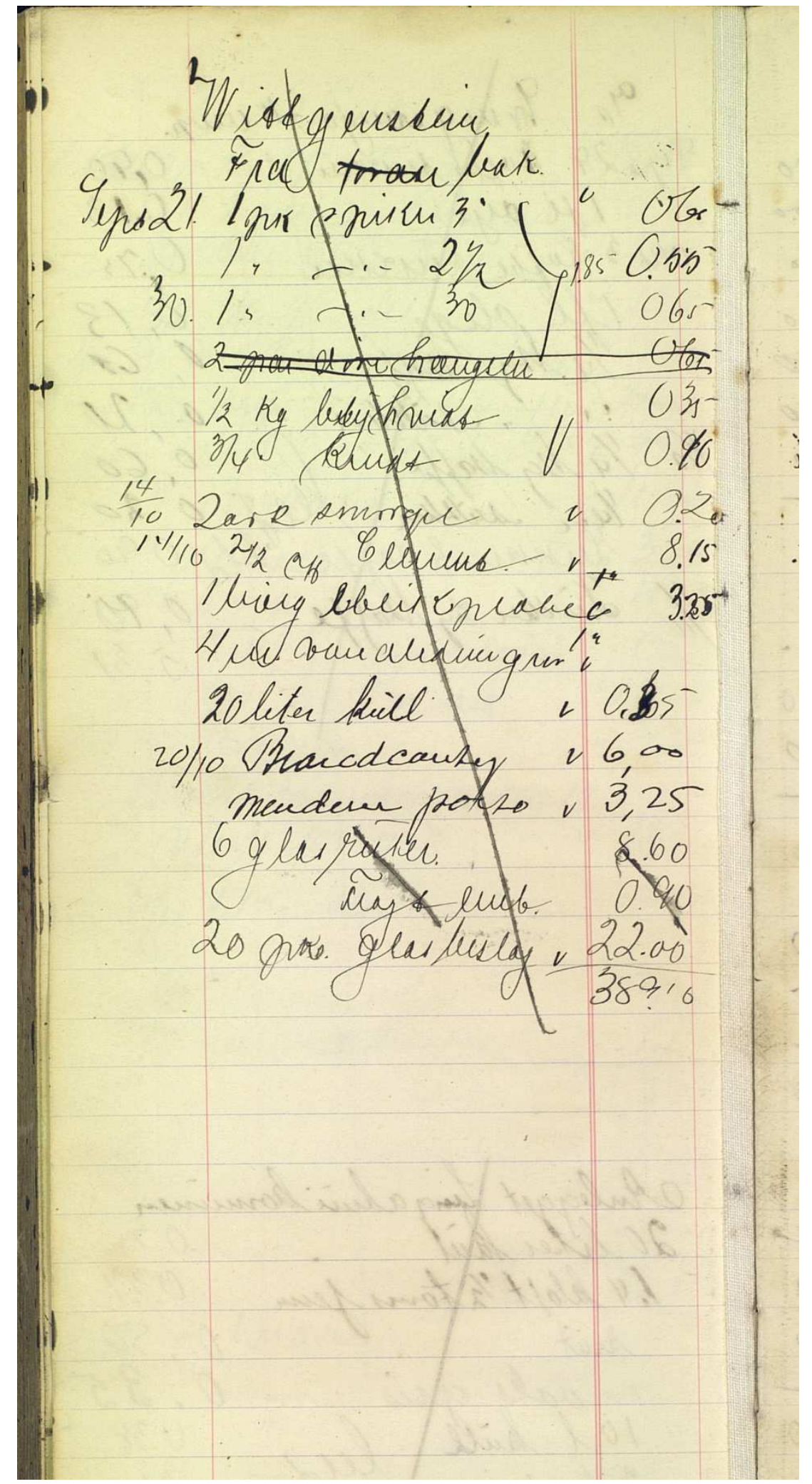

A.20. Anotaciones de gastos de la construcción de la casa de Wittgenstein, anotados por Halvard Drægni, fechadas en 1914; fragmento; Fylkesarkivet (Leikanger) 11.10.2013. Cód. SFFf-1990069 Drægni, Dagfinn Material inédito 


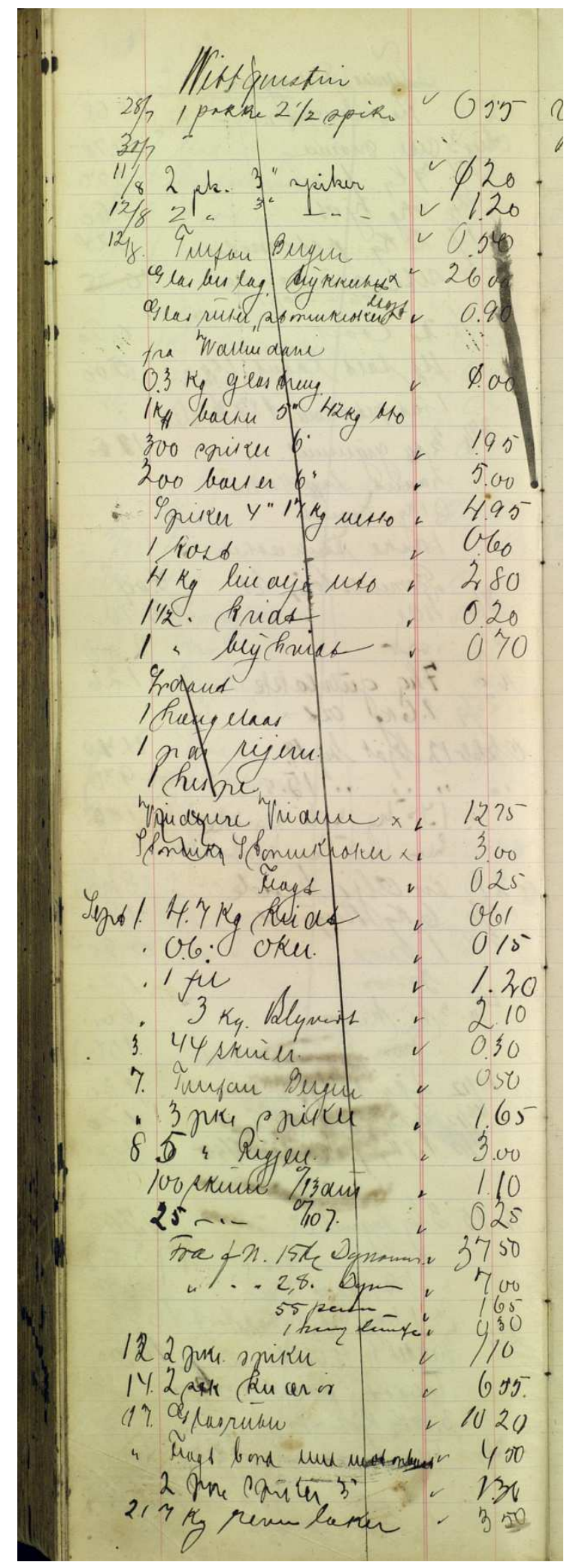

A.21. Anotaciones de gastos de la construcción de la casa de Wittgenstein, anotados por Halvard Drægni, fechadas en 1914; 30x12 cm; Fylkesarkivet (Leikanger). 11.10.2013. Cód. SFFf-1990069 Drægni, Dagfinn Material inédito 


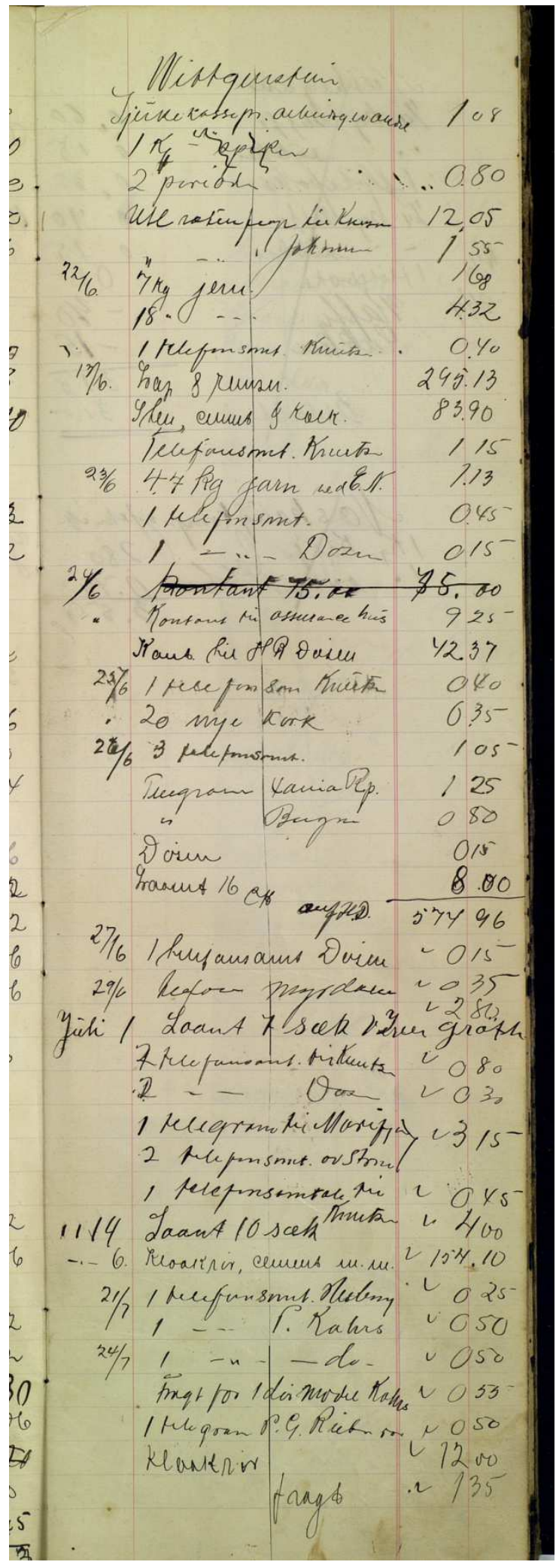

A.22. Anotaciones de gastos de la construcción de la casa de Wittgenstein, anotados por Halvard Drægni, fechadas en 1914; $30 x 12$ cm; Fylkesarkivet (Leikanger). 11.10.2013. Cód. SFFf-1990069 Drægni, Dagfinn Material inédito 


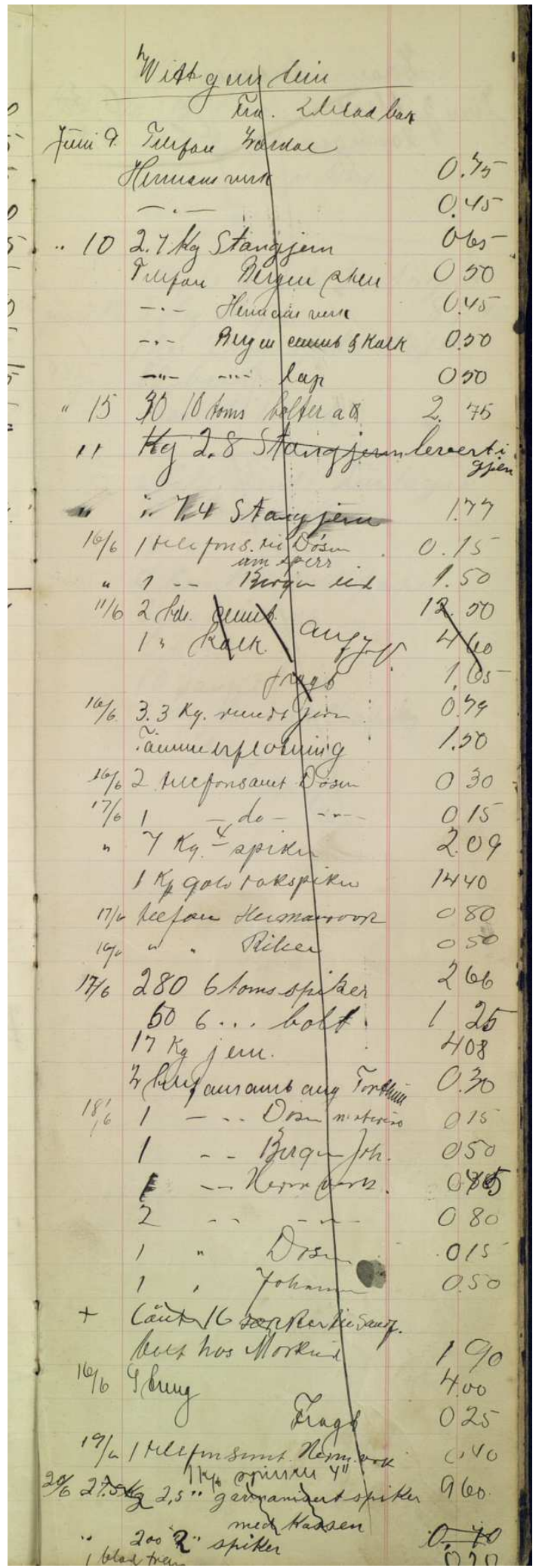

A.23. Anotaciones de gastos de la construcción de la casa de Wittgenstein, anotados por Halvard Drægni, fechadas en 1914; 30x12 cm; Fylkesarkivet (Leikanger). 11.10.2013. Cód. SFFf-1990069 Drægni, Dagfinn Material inédito 


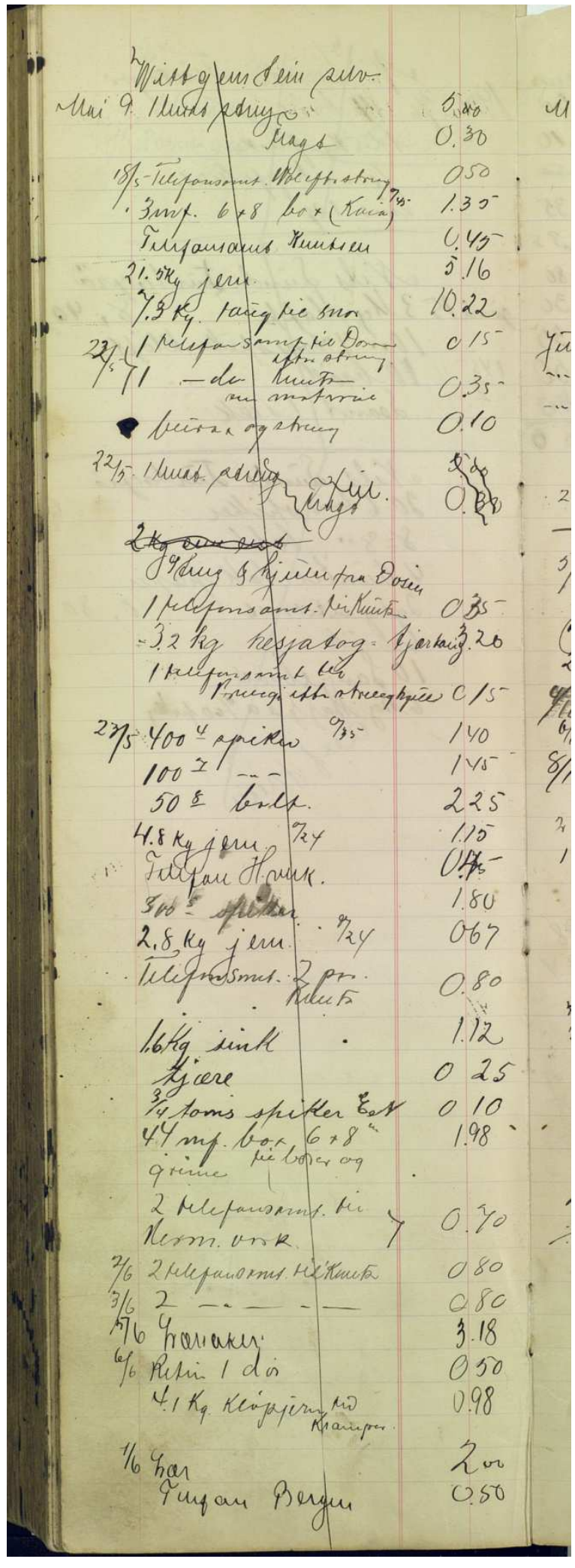

A.24. Anotaciones de gastos de la construcción de la casa de Wittgenstein, anotados por Halvard Drægni, fechadas en 1914; 30x12 cm; Fylkesarkivet (Leikanger). 11.10.2013. Cód. SFFf-1990069 Drægni, Dagfinn Material inédito 


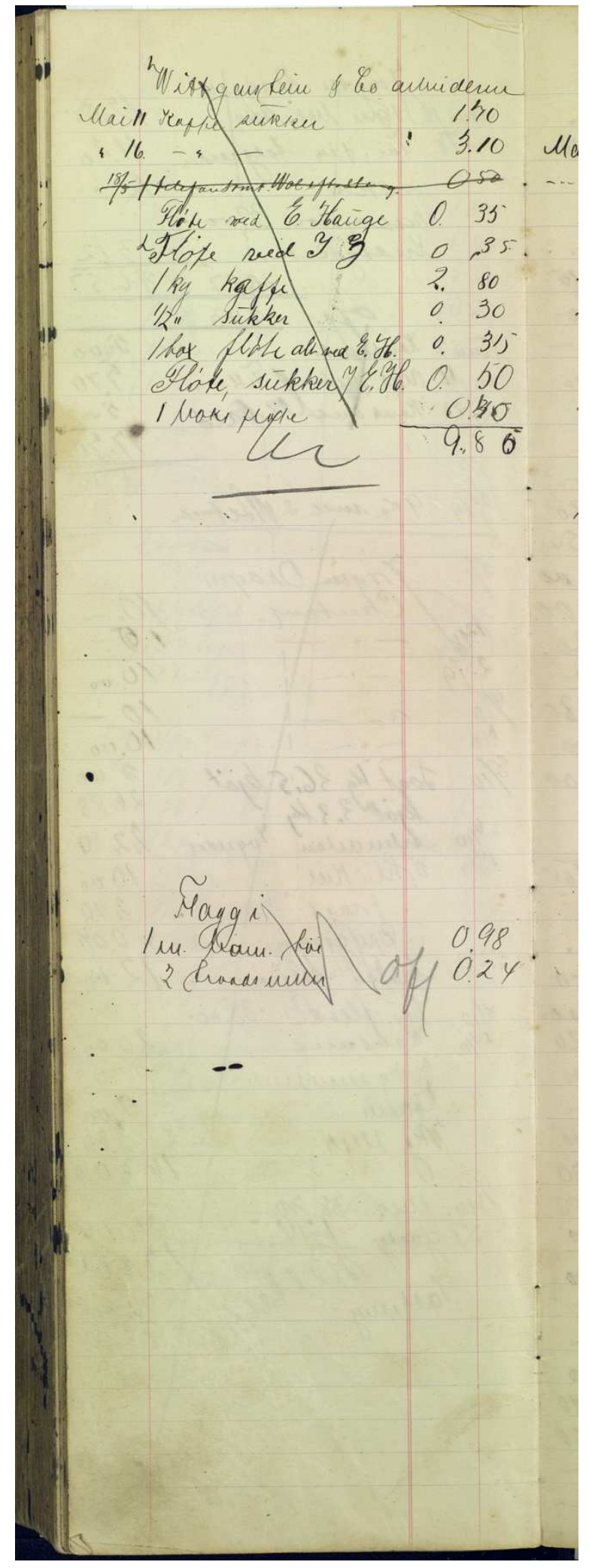

A.25. Anotaciones de gastos de la construcción de la casa de Wittgenstein, anotados por Halvard Drægni, fechadas en 1914; 30x12 cm; Fylkesarkivet (Leikanger). 11.10.2013. Cód. SFFf-1990069 Drægni, Dagfinn Material inédito 


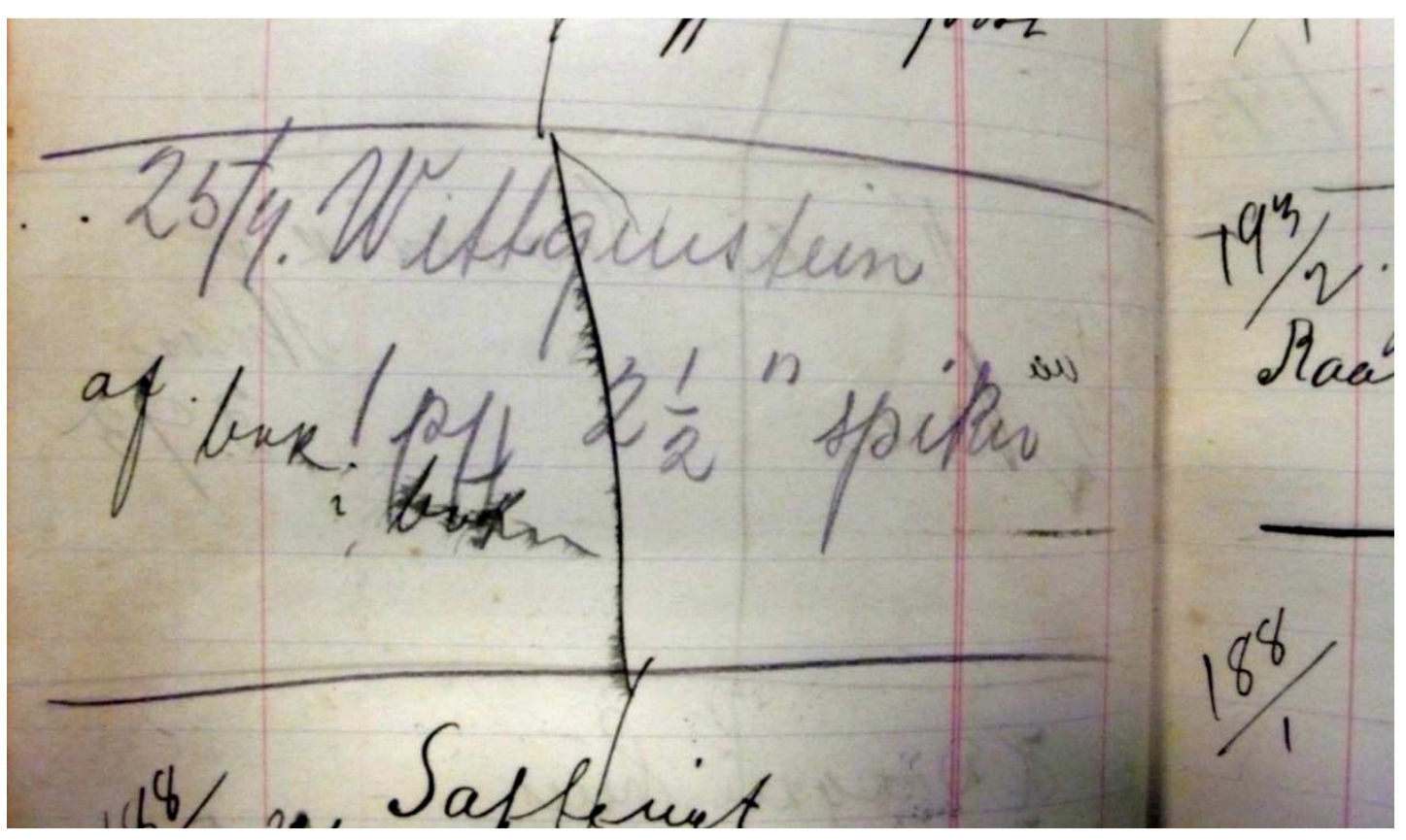

A.26. Anotaciones de gastos de la construcción de la casa de Wittgenstein, anotados por Halvard Drægni, fechadas en 1914; fragmento de una de las páginas: Fylkesarkivet (Leikanger). 11.10.2013. Cód. SFFf-1990069 Drægni, Dagfinn Material inédito 

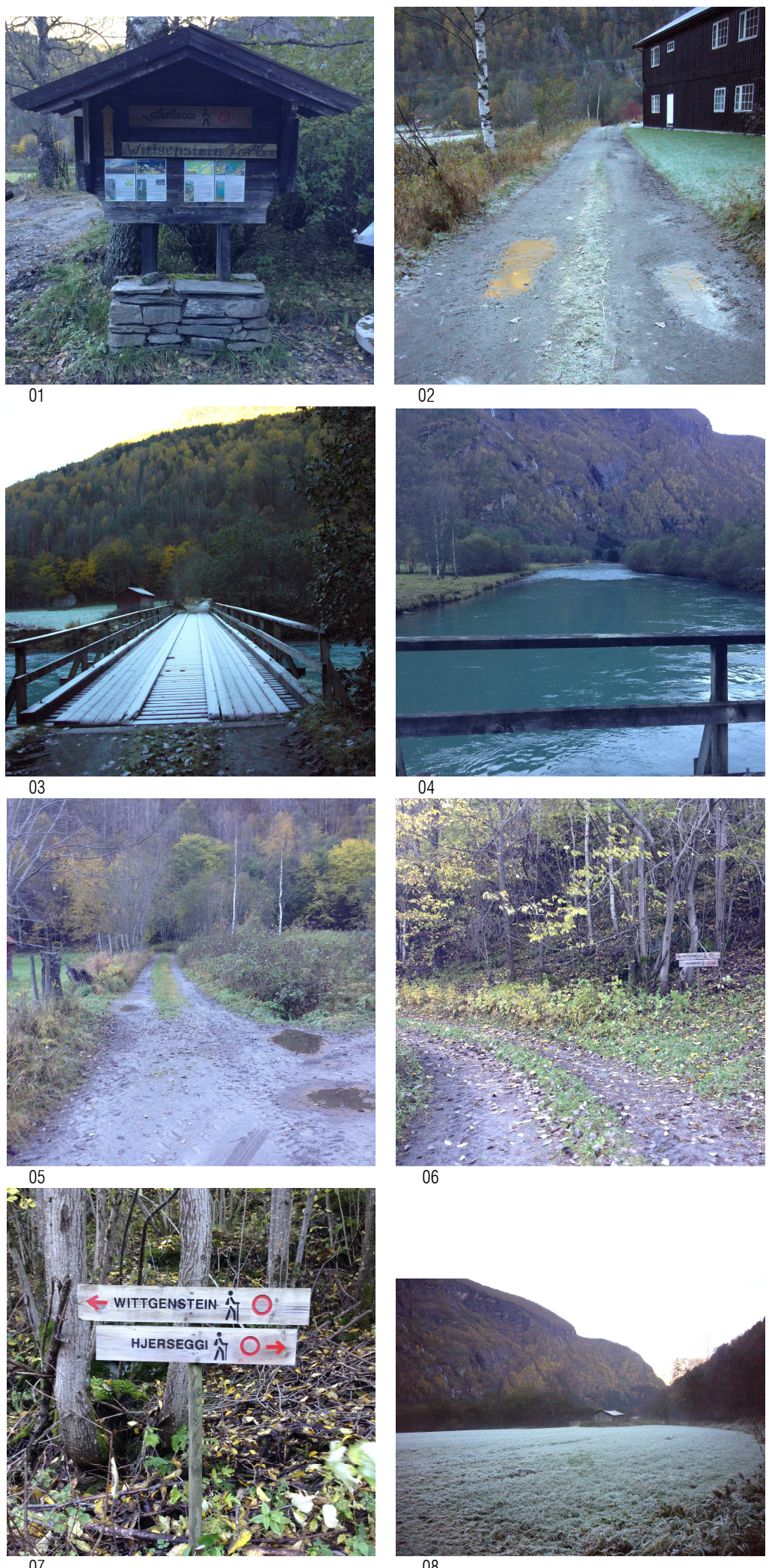

08

A.27. Secuencia del recorrido desde Camping Vassbakken en Rv55 hasta la Casa de Wittgenstein / sección 01 

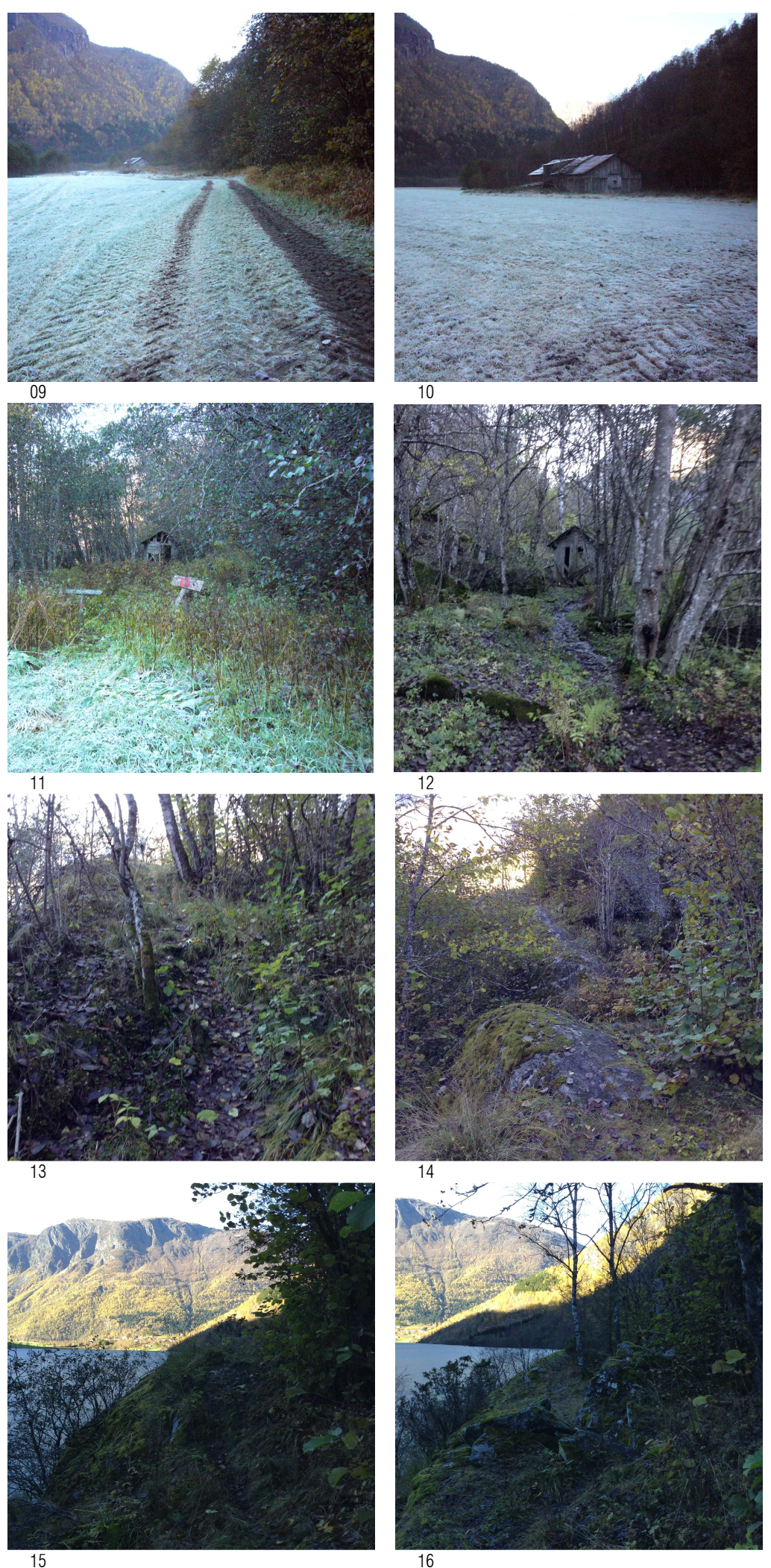

A.28. Secuencia del recorrido desde Camping Vassbakken en Ru55 hasta la Casa de Wittgenstein / sección 02 

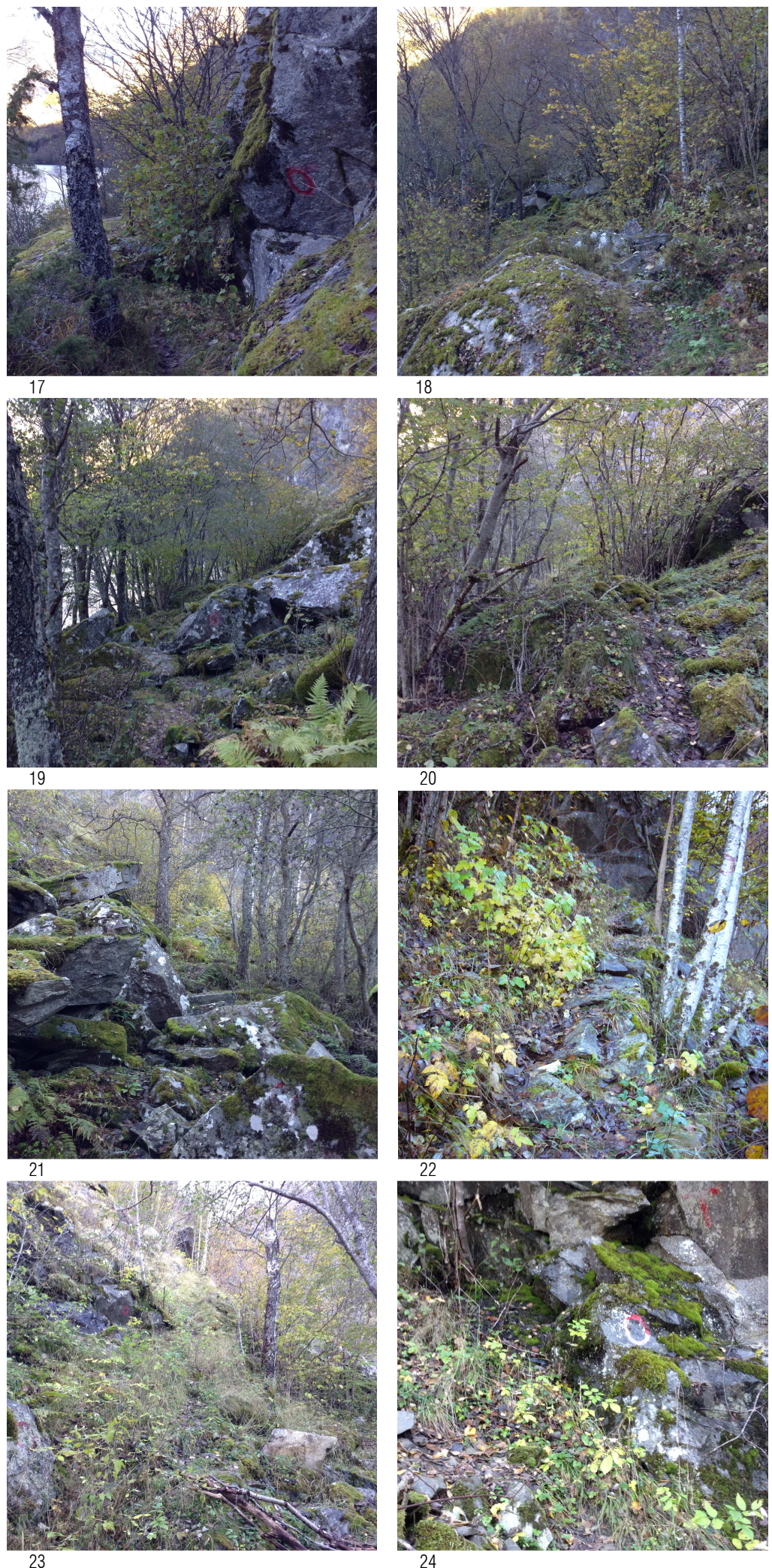

A.29. Secuencia del recorrido desde Camping Vassbakken en Rv55 hasta la Casa de Wittgenstein / sección 03 

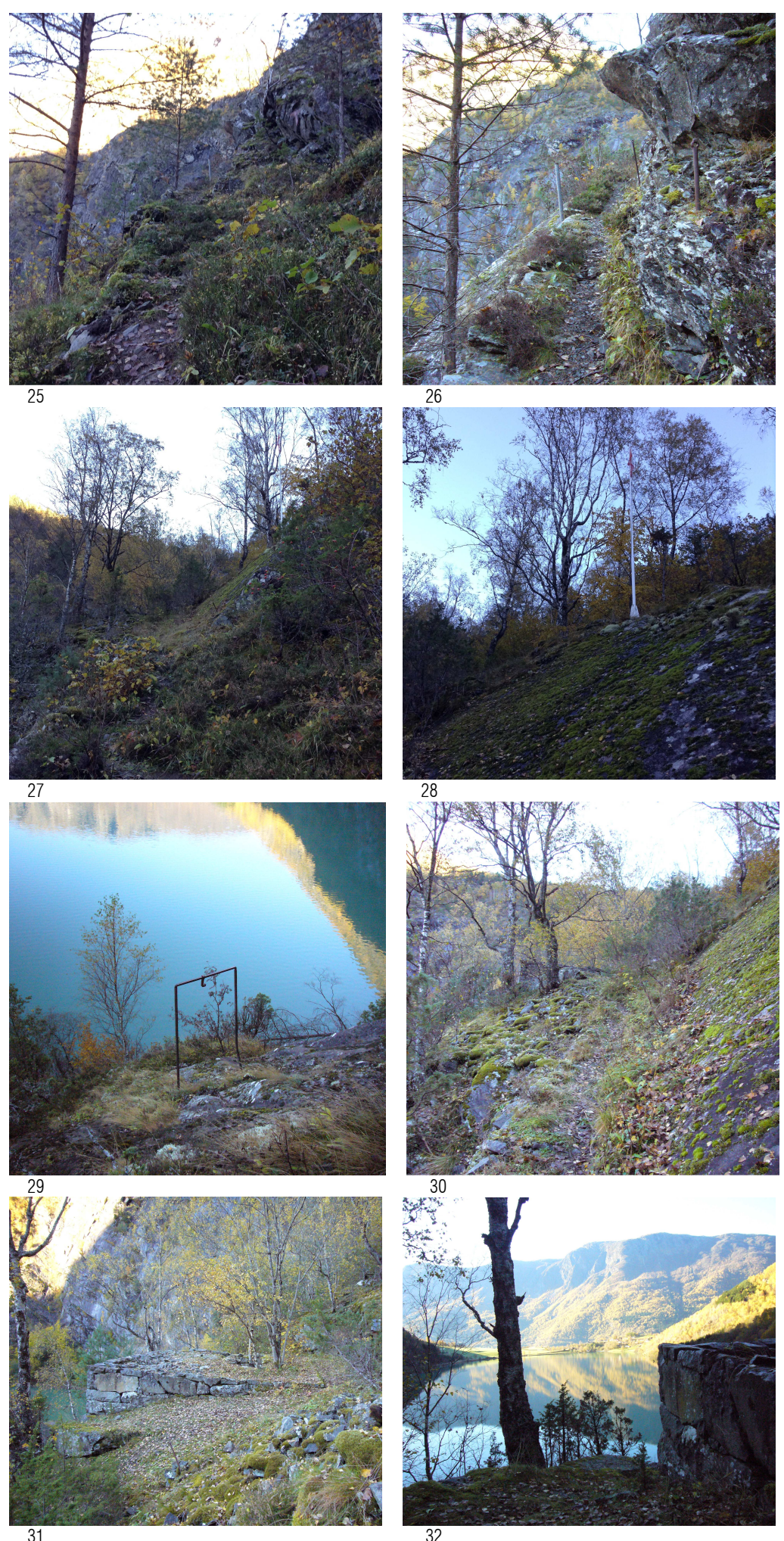

A.30. Secuencia del recorrido desde Camping Vassbakken en Rv55 hasta la Casa de Wittgenstein / sección 04 


\section{Bibliografía}

Es esta una lista temática de las referencias bibliográficas en distintos medios que han sido utilizadas directa 0 indirectamente a lo largo de la investigación y en la redacción de la presente tesis. No pretende ser una bibliografía exhaustiva de 0 sobre Wittgenstein. Las referencias citadas corresponden a las ediciones consultadas y en algunos casos se hace mención a la obra original y a su traducción al castellano, en caso de que haya sido utilizada aquí.

\section{Bibliografía fundamental arquitectura y pensamiento}

ÁBALOS, Iñaki, La buena vida. Visita guiada a las casas de la modernidad (Barcelona: Editorial Gustavo Gili, 2000). AMENDOLAGINE, Francesco y CACCIARI, Massimo, Oikos da Loos a Wittgenstein (Roma: Officina Edizioni, 1975). ANDERSON, Stanford et alt., Adolf Loos (Barcelona: Editorial Stylos, 1989).

ARENAS, Luis, Planos de [inter]sección. Materiales para un diálogo entre Filosofía y Arquitectura (Madrid: Lampreave, 2011).

AUGÉ, Marc, Los «no lugares». Espacios del anonimato. Una antropología de la sobremodernidad (Barcelona: Gedisa Editorial, 2000).

BACHELARD, Gaston, La poética del espacio (México: Fondo de Cultura Económica, 1975).

BAHAMÓN, Alejandro \& VICENS SOLER, Anna, Cabaña. De arquitectura vernácula a contemporánea (Barcelona: Parramón Ediciones, 2008).

BAYER, Raymond, Historia de la estética (México: Fondo de cultura económica, 2002).

BENJAMIN, Walter, La obra de arte en la época de la reproductibilidad técnica (México: Editorial Ítaca, 2003).

BERG, Arne, Norske Gardstun (with English Summary and Index) (Oslo: Universitetsforlaget, 1968).

BERGER, John, Algunos pasos hacia una pequeña teoría de lo visible (Madrid: Árdora Ediciones, 1997).

BERNHARD, Thomas, El sobrino de Wittgenstein (Barcelona: Anagrama, 1999).

—, Corrección (Madrid: Alianza Editorial, 2003).

BONNEFOY, Yves, Alberto Giacometti (Paris: Assouline, 1999).

BRENIFIER, Óscar, Aprendiendo a filosofar. 1. El arte y lo bello (Madrid: Ediciones del Laberinto, 2006). 
BUSTOS GUADAÑO, Eduardo De, Filosofía del Lenguaje (Madrid: UNED, 1999).

CACCIARI, Massimo, Soledad acogedora: De Leopardi a Celan (Madrid: Abada, 2004).

CALDUCH CERVERA, Juan, Temas de composición arquitectónica. Modernidad y arquitectura moderna. № 1 (Alicante: Editorial Club Universitario, 2002).

—, Temas de composición arquitectónica. Espacio y lugar. No 7 (Alicante: Editorial Club Universitario, 2001).

—, Temas de composición arquitectónica. Naturaleza y artefacto. No 9 (Alicante: Editorial Club Universitario, 2001).

—, Temas de composición arquitectónica. Memoria y tiempo. № 11 (Alicante: Editorial Club Universitario, 2002).

CALVINO, Italo, Seis propuestas para el próximo milenio (Madrid: Siruela, 1998).

CARNAP, Rudolf, Autobiografía intelectual (Barcelona: Paidós, 1992).

CARO BAROJA, Julio, Paisajes y ciudades (Madrid: Taurus, 1984).

CASADO DA ROCHA, Antonio, Thoreau. Biografía esencial (Madrid: Acuarela Libros, 2014).

CAVELL, Stanley, Los sentidos de Walden (Valencia: Pre-Textos 2011).

CLINE, Ann, A Hut of One's Own. Life Outside the Circle of Architecture (Cambridge (MA): The MIT Press, 1997).

COPLESTON, Frederick, Historia de la Filosofía. Vol. I. Grecia y Roma (Barcelona: Ariel, 1991).

CORTANZE, Gérard De, Dossier Paul Auster (Barcelona : Anagrama, 1999).

CRUZ RODRÍGUEZ, Manuel, Filosofía contemporánea (Madrid: Taurus-Santillana Ediciones Generales, 2002).

DE MICHELIS, Marco, Espressionismo e Nuova Oggettività. La Nuova Architettura Europea degli anni Venti (Milano: Electa, 1994).

DRURY, Maurice O'Connor, The Danger of Words (New York: Humanities Press, 1973).

FERGUSON, Robert, Enigma: The Life of Knut Hamsun (London: Hutchinson, 1987).

FERNÁNDEZ GÓMEZ, Margarita, Opiniones sobre arquitectura. La voz de los arquitectos (Valencia: Ediciones Generales de la Construcción, 2008).

FERNÁNDEZ-SAVATER MARTíN, Fernando, La aventura de pensar (Barcelona: Debate, 2008).

—, Invitación a la ética (Barcelona: Anagrama, 2008).

FERRATER MORA, José, Diccionario de Filosofía de bolsillo, 2 vols. (Madrid: Alianza Editorial, 1999).

—, "Filosofía y Arquitectura", en Cuestiones disputadas. Ensayos de filosofía (Madrid: Revista de Occidente, 1955), 43-59. 
FOUCAULT, Michel, "Des espaces autres", Conferencia dictada en el Cercle d'Études architecturales, 14 de marzo de 1967, publicada en Architecture, Mouvement, Continuité, n 5, octubre de 1984 (Trad. Castellano Luis Gayo Pérez Bueno, publicada en revista Astrágalo, nº 7, septiembre 1997), 46-49.

FRAMPTON, Kenneth, Historia crítica de la arquitectura moderna (Barcelona: ed. GG, 1996).

FRANZEN, Jonathan, How to Be Alone. Essays (New York: Farrar, Straus and Giroux, 2002).

_, Farther Away (Hammersmith, London: Forth Estate, 2012).

—, The Kraus Project (Hammersmith, London: Forth Estate, 2013).

FREGE, Gottlob, Estudios sobre semántica (Barcelona: Folio, 2002).

FUNDACIÓN LUIS SEOANE, Cabañas para pensar (Catálogo de la Exposición), Proyecto de Eduardo Outeiro Ferreño, Comisarios Alfredo Olmedo y Alberto Ruiz de Samaniego, Fundación Luis Seoane, A Coruña (Madrid: Maia Ediciones, 2011).

GARCÍA MORENTE, Manuel, Lecciones preliminares de filosofía (Buenos Aires: Losada, 1965).

GOETHE, VON, Johann Wolfgang, Goethe. Teoría de los colores (Valencia: Colegio de Arquitectos de Valencia, 1999).

GOLDSTEIN, Laurence, Clear and Queer Thinking (Boston: Rowman \& Littlefield, 1999).

GRAVAGNUOLO, Benedetto, Adolf Loos. Theory and Works (New York: Rizzoli, 1982).

GRIFFIN, Nicholas (Ed.), The Selected Letters of Bertrand Russell, the Public Years, 1914-1970 (New York: Routledge, 2002).

HARD, Roger, Construya su propia casa de madera. Colección Alternativas (Barcelona: Gustavo Gili, 1984).

HEGEL, Georg Wilhelm Friedrich, Lecciones sobre la Filosofía de La Historia Universal (Valencia: Universidad de Valencia, 1992).

HEIDEGGER, Martin, Arte y poesía (México: Fondo de Cultura Económica, 1999).

—, ¿Qué es la filosofía? (Barcelona: Herder, 2004).

_, Conferencias y artículos, $2^{\mathrm{a}}$ ed. rev. (Barcelona: Ediciones del Serbal, 2001).

—, "Paisaje creador: ¿Por qué permanecemos en la provincia?", en Cabañas para pensar (Madrid: Fundación Luis Seoane, 2011), 115-119.

IBSEN, Henrik, Brand (Madrid: Ediciones Encuentro, 2000).

JARAUTA MARIÓN, Francisco, Condiciones contemporáneas de la Arquitectura (Valencia: Ediciones Generales de la Construcción, 2003). 
LOOS, Adolf, Escritos / 1897-1909 (Madrid: El Croquis Editorial, 1993).

—, Escritos /l 1910-1932 (Madrid: El Croquis Editorial, 1993).

LUSTENBERGER, Kurt, Adolf Loos (Barcelona: Editorial Gustavo Gili, 1998).

MASHECK, Joseph, Adolf Loos. The Art of Architecture (New York: I.B. Tauris, 2013).

MARINO, Luigi, Il rilievo per il restauro (Milano: Hoepli, 1994).

MARTí ARIS, Carlos, La cimbra y el arco (Barcelona: Fundación Caja de Arquitectos, 2005).

MARTínEZ MARZOA, Felipe, Historia de la Filosofía I. Tomo I (Madrid: Akal, 2013).

—, Iniciación a la Filosofía (Madrid: Istmo, 1974).

MIRANDA REGOJO, Antonio, Ni robot ni bufón. Manual para la crítica de Arquitectura (Madrid: Cátedra Ediciones, 1999).

MONEO VALLÉS, José Rafael, Rafael Moneo (A Coruña: Fundación Barrié, 2013).

MONTEYS, Xavier, Casa collage. Un ensayo sobre la arquitectura de la casa (Barcelona: Gustavo Gili, 2003).

MORENO MANSILLA, Luis, Apuntes de viaje al interior del tiempo (Barcelona: Fundación Caja de Arquitectos, 2002).

MUNCH, Anders V., Der stillose Stil: Adolf Loos (München: Wilhelm Fink Verlag, 2005).

MüNZ, Ludwig, Der Architekt Adolf Loos (Wien: Verlag Anton Schroll, 1964).

NAESS, Arne, The Ecology of Wisdom. Writings by Arne Naess (Berkeley: Counterpoint, 2008).

NAZEER, Kamran, Send in the Idiots or How We Grew to Understand the World (London: Bloomsbury, 2006).

NIETZSCHE, Friedrich, Así habló Zaratustra (Madrid: Alianza, 2006).

OLIVER, Paul, Dwellings. The House across the World (Oxford: Phaidon, 1987).

PANOFSKY, Erwin, Idea. Contribución a la historia de la teoría del arte (Madrid: Cátedra Ediciones, 1998).

PAREYSON, Luigi, Conversaciones de estética (Madrid: Visor Libros, 1988).

PERAZA SÁNCHEZ, José Enrique, et. alt, Casas de madera. Sistemas constructivos a base de madera aplicados a viviendas unifamiliares (Madrid: Asociación de Investigación Técnica de las Industrias de la Madera y Corcho. AITIM, 1995).

REES, Ellen, Cabins in Modern Norwegian Literature (Lanham, Maryland: Fairleigh Dickinson University Press, 2014).

RISSELADA, Max, Raumplan versus Plan Libre. Adolf Loos / Le Corbusier (Rotterdam: 010 Publishers, 2008). 
ROCCHI, Giuseppe, Istituzioni di restauro dei beni architettonici e ambientali (Milano: Hoepli, 1994).

RODRÍGUEZ GENOVÉS, Fernando, Saber del ámbito. Sobre dominios y esferas en el orbe de la filosofía (Madrid: Editorial Síntesis, 2010).

RUIZ CABRERO, Gabriel, Una Tesis Dibujada (Madrid: Pronaos, 1993).

RUSSELL, Bertrand, The autobiography of Bertrand Russell (Vol. 1) 1872-1914 (London: George Allen \& Unwin LTD, 1971).

—, The autobiography of Bertrand Russell (Vol. 2) 1914-1944 (London: George Allen \& Unwin LTD, 1971).

—, The autobiography of Bertrand Russell (Vol. 3) 1944-1967 (London: George Allen \& Unwin LTD, 1971).

RYKWERT, Joseph, On Adam's House in Paradise. The Idea of the Primitive Hut in Architectural History. $2^{\text {nd }}$ Edition. (Cambridge (MA): The MIT Press, 1981).

SALVO (MANGIONE, Salvatore), De la pintura en el estilo de Wittgenstein (Valencia: Pre-Textos, 1989).

SARNITZ, August, Loos (Colonia: Taschen, 2003).

SHARR, Adam, La cabaña de Heidegger. Un espacio para pensar (Barcelona: Editorial Gustavo Gili, 2009).

—, Heidegger for architects (New York: Roudledge, 2007).

SOLÀ-MORALES, Ignasi de, Intervenciones (Barcelona: Gustavo Gili, 2006).

—, Territorios (Barcelona: Gustavo Gili, 2002).

—, Inscripciones (Barcelona: Gustavo Gili, 2003).

SPENGLER, Oswald, La decadencia de Occidente I (Madrid: Austral, 2011).

—, La decadencia de Occidente II (Madrid: Austral, 2013).

STEINER, George, Lecciones de los Maestros (Madrid: Siruela, 2005).

THOREAU, Henry David, Walden or Life in the Woods (New York: Signet Classics, 1999).

_, Caminar (Madrid: Árdora Exprés, 2014).

TOLSTOI, Leon, El Evangelio abreviado (Oviedo: KRK Ediciones, 2006).

THUN-HOHENSTEIN, Christoph, BOECKL, Matthias, WITT-DÖRRING, Christian, Wege der Moderne. Josef Hoffmann, Adolf Loos und die Folgen (Basel: Birkhäuser Verlag, 2014). [Catálogo exposición en MAK. Wien, 17.12.2014-19.04.2015].

WAGENSBERG, Jorge, El gozo intelectual (Barcelona: Tusquets editores, 2008).

WASHSMANN, Konrad, Building the Wooden House. Technique and Design (Basilea: Birkhäuser Verlag, 1995). 
WEININGER, Otto, Sexo y carácter (Buenos Aires, Losada, 1959).

ZUMTHOR, Peter, Pensar la arquitectura (Barcelona: Editorial Gustavo Gili, 2004).

ZWEIG, Stefan, El mundo de ayer. Memorias de un europeo (Barcelona: El Acantilado, 2002).

\section{Ediciones de las obras de Wittgenstein}

Ludwig Wittgenstein: Wiener Ausgabe (hrsg. von Michael Nedo), (Wien/New York: Springer Verlag, 1993 y ss.).

Schriften, (8 vol.) (Frankfurt am Main: Suhrkamp Verlag, 1960-1982).

Werkausgabe in 8 Banden, (Frankfurt am Main: Suhrkamp Verlag, 1984 y ss.).

Wittgenstein's Nachlass, The Bergen Electronic Edition, (Oxford University Press/University of Bergen/The Wittgenstein Trustees, 2000).

\section{Obras de Wittgenstein}

WITTGENSTEIN, Ludwig, Tractatus Iogico-philosophicus, Investigaciones filosóficas, Sobre la certeza, Obras Completas, vol.I (Madrid: Editorial Gredos, 2009).

—, Diarios y Conferencias: Diario filosófico (1914-1916), Diarios Secretos, Movimientos del pensar. Diarios (1930-1932-1936-1937). Cartas a Russell, Keynes y Moore, Notas sobre lógica, Notas dictadas a G. E. Moore en Noruega, Conferencia sobre ética, Observaciones a «La Rama Dorada» de Frazer, Observaciones diversas. Cultura y valor, Lecciones y conversaciones sobre estética, psicología y creencia religiosa, Zettel, Observaciones sobre los colores, en Obras Completas, vol.Il: (Madrid: Editorial Gredos, 2009).

—, Tractatus logico-philosophicus, Traducción, Introducción y Notas de Luis M. Valdés Villanueva, $2^{\text {a }}$ ed. rev. (Madrid: Editorial Tecnos, 2003).

_, Investigaciones filosóficas (Barcelona: Altaya, 1999).

_, Fenomenología. Secciones 94-100 del Big Typescript (Oviedo: KRK Cuadernos del Pensamiento, 2009).

- Conferencia sobre ética. Con dos comentarios sobre la teoría del valor (Barcelona: Ediciones Paidós Ibérica, 1997).

—, Observaciones sobre los colores (Barcelona: Paidós, 1994). 
—, Luz y Sombra. Una vivencia (-sueño) nocturna y un fragmento epistolar (Valencia: Pre-Textos, 2006).

—, Observaciones a «La Rama Dorada de Frazer», $3^{\mathrm{a}}$ ed. (Madrid: Editorial Tecnos, 2008).

—, Los cuadernos azul y marrón, 3a ed. (Madrid: Editorial Tecnos, 1998).

—, Últimos escritos sobre Filosofía de la Psicología, vols. I y II (Madrid: Editorial Tecnos, 2008).

—, Aforismos. Cultura y Valor (Madrid: Espasa, 2013).

\section{Biografías, epistolarios y bibliografía sobre la obra de Wittgenstein}

ALONSO PUELLES, Andoni, El arte de lo indecible (Wittgenstein y las vanguardias) (Cáceres: Universidad de Extremadura, 2002).

ÅMÅS, Knut Olav, Det stille alvoret. Ludwig Wittgenstein i Norge 1913-1950 (Oslo: Norske Samlaget, 1994).

—, "Gjenreis filosofens norske hus!" en Aftenposten, 29.07.2012. Accesible en http://www.aftenposten .no/kultur/Gjenreis-filosofens-norske-hus-6953199.html

AMBROSE, Alice, Wittgenstein's Lectures. From the Notes of Alice Ambrose and Margaret Macdonald, Cambridge 1932-1935 (Oxford: Basil Blackwell, 1979).

ANSCOMBE, Gertrude Elizabeth Margaret, An Introduction to Wittgenstein's Tractatus, 2nd edition Revised (New York: Harper \& Row Publishers, 1959).

ARENAS, Luis, "La casa como gesto: La arquitectura en Wittgenstein y en el neopositivismo vienés", Seminario de Filosofía, (Universidad de Zaragoza, 2008) Acceso en línea en http://www.unizar.es/seminario/ archivos/luis arenas_la_casa_como_gesto.pdf

AYER, Alfred Jules, Wittgenstein (London: Weidenfeld and Nicolson, 1985), [Trad. Joaquim Sempere, Barcelona: Crítica, 1986].

AZÚA COMELLA, Félix De, Diccionario de las Artes (Barcelona: Anagrama, 2002).

BARTLEY, III, William Warren, Wittgenstein (Madrid: Cátedra Ediciones, 1982).

BAUM, Wilhelm, Ludwig Wittgenstein. Vida y Obra (Madrid: Alianza Editorial, 1988).

BAYÓN ÁLVAREZ, Mariano, "La casa de Ludwig Wittgenstein", en Dicho en el vacío, Revista Arquitectura 281 (Madrid: COAM), 24-37.

BLACK, Max, A Companion To Wittgenstein's 'Tractatus' (Ithaca, New York: Cornell University Press, 1964). 
BOLSTAD FLØDE, Tone, "Østerrikeren. Wittgenstein på bygdebesøk", en Fortell! (25.11.2009) Accesible en http://my.opera.com/Tonebt/blog/show.dml/4823121

BOUVERESSE, Jacques, Wittgenstein: la Rime et la Raison. Science, ethique et esthetique (Paris: Les Editions de Minuit, 1973).

—, Wittgenstein y la estética (Valencia: Universitat de València, Col·lecció Estètica \& Crítica, 1993).

—, "Wittgenstein", (voz) en Enciclopedia Gran Larousse Universal, Tomo 36, (Plaza \& Janés, 1995).

CHAMBERLAIN, Lesley, "The philosopher's home from home", en Standpoint, 10.2011. Accesible en http://standpointmag.co.uk/features-october-11-the-philosophers-home-from-home-lesley-chamberlain-ludwigwittgenstein-hut-norway-skjolden

COMETTI, Jean-Pierre, "Wittgenstein, el arte, la arquitectura y el paisaje", en Iluminaciones. Revista de arquitectura y pensamiento 01 (Madrid: 2010): 38-47.

CONNEARN, David, "Everything is what it is and not another thing" (Cambridge: British Wittgenstein Society, 2011) Acceso en línea en http://www.editor.net/BWS/competition/Everything_is.pdf

CONNEARN, David \& PHILLIPS, Dawn M., "Wittgenstein's Haus in Skjolden: Erhaltung und Interpretation", en Ludwig Wittgenstein-Verortungen eines Genies, editado por Jan Drehmel y Kristina Jaspers (Berlín: Junius-Verlag, 2011), 34-39.

DORFLES, Gillo, L'estetica del mito. Da Vico a Wittgenstein (Milano: Mursia, 1990).

DUFFY, Bruce, The World As I Found It: A novel (Boston: Houghton Mifflin, 1988).

EDMONDS, David. J. \& EIDINOW, John A., El atizador de Wittgenstein, una jugada incompleta (Barcelona: Atalaya, 2001).

EGGUN, Terje, "Viktig avklaring”, en Nyhende, Sogn Avis, 05.09.2012. Accesible en http://www.sognavis.no/ nyhende/viktig-avklaring/s/1-105-6221252

ESTEP, Jan, Searching for Ludwig Wittgenstein. Lake Eidsvatnet, Skjolden, Sogn, Norway (Illustrated map) (New York-University of Minnesota, Minneapolis: Printed Matter, 2007).

—, "Showing the way out of the fly bottle: searching for Wittgenstein in Norway", en Cultural Geographies 15 (UK: SAGE Editions, 2008), 255-260.

FALCH, RUNE J., "Wittgenstein's cabin in Skjolden to be rebuilt" en News, Department of Philosophy, Universitat Bergensis, 02.07.2014. Accesible en http://www.uib.no/en/fof/79512/wittgensteins-cabin-skjolden-be-rebuilt FANN, Kuang Tih, El concepto de Filosofía en Wittgenstein (Madrid: Tecnos-grupo Anaya, 2013).

_, (Ed.), Ludwig Wittgenstein: The Man and His Philosophy (New Jersey: Humanities Press, 1978). 
FARDAL, Jan Inge, "Viktig for Wittgenstein", en Sogn Avis. 17.04.2013. Accesible en http://www.sognavismeiner. origo.no/-/bulletin/show/793011_viktig-for-wittgenstein

_, "Viktig avklaring for Wittgensteins hus", en Nyhende, Sogn Avis. 06.06.2015.

FERNÁNDEZ-SAVATER MARTín, Fernando, Wittgenstein, La Aventura del pensamiento (documental), CAP. 16., 30'. FERRATER MORA, José, Las filosofías de Ludwig Wittgenstein (Barcelona: Oikos-Tau, 1966).

FINDLAY, John Niemeyer, Wittgenstein: a Critique (London: Routledge, 1984).

FINLAY, Alec, MORETON, Guy \& NEDO, Michael, Ludwig Wittgenstein. There Where You Are Not (London: Black Dog Publishing, 2005).

GALLARDO CABRERA, Salvador, "La casa de la hermana de Wittgenstein", en Fedro, Revista de Estética y Teoría de las Artes. Número 7, septiembre 2008, 51-58.

GARCÍA ALONSO, R., "Ludwig Wittgenstein y la casa transparente", en Revista El Urogallo (Madrid: abril 1991), 16-22.

GRAYLING, Anthony Clifford, Wittgenstein (Oxford: Oxford University Press, 1988).

HADOT, Pierre, Wittgenstein y los límites del lenguaje (Valencia: Pre-Textos, 2007).

HARTNACK, Justus, Wittgenstein y la filosofía contemporánea (Barcelona: Ediciones Ariel, 1972).

JANIK, Allan \& TOULMIN, Stephen, La Viena de Wittgenstein (Madrid: Taurus, 2001).

JANIK, Allan, Assembling Reminders (Stockholm: Santérus Academic Press Sweden, 2006).

JARMAN, Derek (dir.), Wittgenstein, (largometraje), Ali, T. (prod.), 68' (drama, biográfico, 1993).

JIMÉNEZ PERONA, Ángeles, Wittgenstein y la tradición clásica (Valencia: Pre-Textos, 2010).

JOHANNESSEN Kjell S., LARSEN, Rolf y ÅMÅS, Knut Olav, (Eds.), Wittgenstein and Norway (Oslo: Solum Forlag, 1994).

KANTERIAN, Edward, Ludwig Wittgenstein (London: Reaktion Books, 2007).

KLAGGE, James Carl, Wittgenstein in Exile (Cambridge (MA): The MIT Press, 2011).

LAST, Nana, Wittgenstein's House: language, space, and architecture (New York: Fordham University Press, 2008).

LEE, Desmond (Ed.), Wittgenstein's Lectures Cambridge 1930-1932. From the notes of John King and Desmond Lee (Totowa, New Jersey: Rowman and Littlefield: 1980).

LEITNER, Bernhard, Die Architektur von Ludwig Wittgenstein-Eine Dokumentation-Mit Auszügen aus den Familienerinnerungen von Hermine Wittgenstein (Halifax: N.S.-London, 1973).

—, The Wittgenstein House (New York: Princeton Architectural Press, 2003). 
MCGUINNESS, Brian Francis, Ludwig Wittgenstein Briefe Briefwechsel mit B. Russell, G.E. Moore, J. M. Keynes, F.P. Ramsey, W. Eccles, P. Engelmann und L. von Ficker (Frankfurt-am-Main: Suhrkamp Verlag, 1980).

—, Wittgenstein and His Times (Chicago: Basil Blackwell, 1982).

_, Wittgenstein a life. Young Ludwig (1889-1921) (London: Gerald Duckworth, 1988).

—, (Ed.), Wittgenstein in Cambridge: Letters and Documents 1911-1951 (London: Wiley-Blackwell, 2012).

MALCOLM, Norman, Ludwig Wittgenstein. A memoir (New York: Oxford University Press, 1977).

MARRADES MILLET, Julián, (Ed.), Wittgenstein. Arte y Filosofía (Madrid: Plaza \& Valdés, 2013).

MASHECK, Joseph, "Forma(lismo), funcion(alismo) y la casa Wittgenstein en la historia del arte", en Iluminaciones. Revista de arquitectura y pensamiento 01 (Madrid: 2010), 25-37.

MONK, Ray, Ludwig Wittgenstein. El deber de un genio (Barcelona: Editorial Anagrama, 2002).

MUÑOZ GUTIÉRREZ, Carlos, "Wittgenstein Arquitecto: El pensamiento como edificio", en A Parte Rei 16 (06.07.2001) Accesible en http://serbal.pntic.mec.es/AParteRei/

NEDO, Michael \& RANCHETTI, Michele, (Eds.) Wittgenstein: Sein Leben in Bildern und Texten, (Frankfurt-am-Main: Suhrkamp Verlag 1983).

NEDO, Michael, Ludwig Wittgenstein. Ein biographisches Album (München: C.H. Beck, 2012).

NOLL, Justus, Ludwig Wittgenstein y David Pinsent (Berlín: Muchnik Editores, 2001).

OXAAL, Ivar, On the Trail to Wittgenstein's Hut. The Historical Background of the Tractatus logico-philosophicus (New Jersey: Transaction Publishers, New Brunswick, 2011).

PADILLA GÁLVEZ, Jesús, Wittgenstein I. Lecturas tractarianas (Madrid: Plaza \& Valdés, 2009).

—, (Ed.) Antropología de Wittgenstein (Madrid: Plaza \& Valdés, 2011).

PERONA, Ángeles J., Wittgenstein y la tradición clásica. Los peldaños de una escalera (Valencia: Pre-Textos, 2010).

PETERS, Michael A.,"Wittgenstein as Exile: A philosophical topography", en Educational Philosophy and Theory Vol.40, Issue 5, 591-605, 22.08.2008.

PINSENT, David Hume, Reise mit Wittgenstein in der Norden (Wien, Bozen: Folio, 1994).

PISANI, Daniele, L'architettura è un gesto. Ludwig Wittgenstein architetto (Macerata: Quodlibet Studio, 2011).

POISSON, Céline (Ed.), Penser, Dessiner, Construire; Wittgenstein et l'Architecture (París : Éditions de l'Éclat, 2007).

REDPATH, Theodore, Ludwig Wittgenstein. A Student's Memoir (London: Duckworth, 1990).

REGUERA PÉREZ, Isidoro, La miseria de la razón. El primer Wittgenstein (Madrid: Taurus, 1980). 
—, Ludwig Wittgenstein (Madrid: Edaf, 2002).

RHEES, Rush, Ludwig Wittgenstein. Personal Recollections (Oxford: Basil Blackwell, 1981).

RUIZ DE SAMANIEGO, Alberto, "Ludwig Wittgenstein en su cabaña. El engaño y el estilo", en FronteraD. Accesible en http://www.fronterad.com/?q=ludwig-wittgenstein-en-su-cabana-engano-y-estilo

SARNITZ, August, Die Architektur Wittgensteins-Rekonstruktion einer gebauten Idee (Wien-Köln-Weimar: Böhlau Verlag, 2011).

SCHOKKING, Jacob F., Hütte \& Haus Wittgenstein: Daniel Libens \& Jacob F. Schokking / mit Texten von/with texts by: Frederik Stjernfelt, Harald Vatne (Copenhague: Holland House, 1995).

SCRUTON, Roger, Historia de la Filosofía Contemporánea. De Descartes a Wittgenstein (Barcelona: Ediciones Península, 1983).

SLUGA, Hans y STERN, David G., The Cambridge Companion to Wittgenstein (Cambridge: Cambridge University Press, 1997).

STERRET, Susan G., Wittgenstein Flies a Kite (New York: Pi Press, Pearson Education, 2005).

SVARTEFOSS, Sigrid, "Håpet er tent for Wittgenstein-huset" en Nyhende, Sogn Avis, 21.10.2013. Accesible en http://www.sognavis.no/nyhende/hapet-er-tent-for-wittgenstein-huset/s/1-105-6933470

TOPDAHL, R. C., "Vil redde filosof-hus", en Aftenposten (16.10.2011), Accesible en http://www.Aftenposten .no/kultur/Vil-redde-filosof-hus-5594117.html

TRANøY Knut Erik, "Wittgenstein and the relation between life and philosophy", en From ontos verlag: Publications of the Austrian Ludwig Wittgenstein Society - New Series, Vol.2.

TURNOVSKY, Jan, Architectural Words 3. The Poetics of a Wall Projection (London: Architectural Association, 2009).

VERDI, John, Fat Wednesday. Wittgenstein on Aspects (Philadelphia: Paul Dry Books, 2010).

VON SCHONFELD, et alt., "The vastness of all grown things: Martin Heidegger's cabin at Todtnauberg and Ludwig Wittgenstein's cabin at Skjolden", en Daidalos 32 (1989), 84-87.

VON WRIGHT, George Hendrik, A Portrait of Wittgenstein As a Young Man. From the Diary of David Hume Pinsent 1912-1914 (Oxford: Basil Blackwell, 1990). En castellano: Retrato del joven Wittgenstein (Madrid: Editorial Tecnos, 2007).

—, Wittgenstein (Oxford: Basil Blackwell, 1982).

WV.AA., El urogallo. Revista literaria y cultural. Abril 1991, nº 59 (Madrid: Prensa de la Ciudad, 1991).

WALL, Richard, Wittgenstein in Ireland (London: Reaktion Books, 2000). 
WAUGH, Alexander, La Familia Wittgenstein (Barcelona: Lumen, 2009).

WIJDEVELD, Paul, Ludwig Wittgenstein architetto (Milano: Electa Editrice, 2000) [v. en inglés en Amsterdam: The Pepin Press, 1993]

WITTGENSTEIN, Ludwig \& BOUWSMA, Oets Kolk, Últimas conversaciones (Salamanca: Ediciones Sígueme, 2004).

WITTGENSTEIN, Ludwig \& ENGELMANN, Paul, (SOMAVILLA, IIse (Ed.)), Cartas, Encuentros, Recuerdos (Valencia: Pre-Textos, 2009).

YTRE-ARNE, Kristin, "Reportasje om Wittgenstein og Skjolden frå 1995" en NRK. Accesible en http://www .nrk.no/video /PS*201005 


\section{Listado de imágenes, planos y esquemas}

\begin{tabular}{|c|c|c|}
\hline$n^{0}$ & imagen & origen \\
\hline & ÍNDICE & \\
\hline 1 & Primer dibujo en el cuaderno «proyecto Wittgenstein en Skjolden», 2010 & Autoría propia \\
\hline & 01 INTRODUCCIÓN & \\
\hline 2 & Voss, $18: 14,09.10 .2013$ & Autoría propia \\
\hline 3 & Skjolden 21:51, 09.10.2013 & Autoría propia \\
\hline 4 & Skjolden 07:48, 10.10.2013 & Autoría propia \\
\hline 5 & Skjolden 08:12, 10.10.2013 & Autoría propia \\
\hline 6 & Skjolden, lago Eidsvatnet 08:41, 10.10.2013 & Autoría propia \\
\hline 7 & Skjolden, Rv55 a Lom & Autoría propia \\
\hline 8 & Coordenadas Casa de Wittgenstein en Skjolden & Autoría propia \\
\hline 9 & Casa de Gunnar Bolstad, 1957 & Autoría propia \\
\hline 10 & Puente sobre río Eidselvi & Autoría propia \\
\hline 11 & Tarjeta postal de Halvard Drægni y la familia Klingenberg a Wittgenstein, 21.12.1914 & $\begin{array}{l}\text { http://wab.uib.no/sept1914/postcards/A09. } \\
\text { html }\end{array}$ \\
\hline 12 & Cuaderno notas, 17.12.2010 & Autoría propia \\
\hline 13 & Cuaderno notas, sin fecha & Autoría propia \\
\hline 14 & Visita virtual al lago Eidsvatnet con google earth, 2010 & google earth \\
\hline 15 & Casa de Ludwig Wittgenstein en Skjolden, fotografía de 1950. Álbum de Ben Richards & Nedo:1983 Cfr. Bibliografía \\
\hline 16 & Wittgenstein en 1926-1928. Álbum personal de Wittgenstein & Nedo:1983 Cfr. Bibliografía \\
\hline 17 & Kundmanngasse 19 , fotografía de 1928. Álbum personal de Wittgenstein & Nedo:1983 Cfr. Bibliografía \\
\hline 18 & Wittgenstein, Tractatus logico-philosophicus & Cfr. bibliografía \\
\hline 19 & Wittgenstein, Secciones 94-100 del Big Typescript & Cfr. bibliografía \\
\hline 20 & S. Cavell, Los sentidos de Walden & Cfr. bibliografía \\
\hline 21 & Entrada «Wittgenstein», Nueva Enciclopedia Larousse & Cfr. bibliografía \\
\hline 22 & Wittgenstein, Conferencia sobre ética & Cfr. bibliografía \\
\hline 23 & Paul Wijdeveld, Ludwig Wittgenstein architetto. Portada y página 27 & Cfr. bibliografía \\
\hline 24 & Paul Wijdeveld, Ludwig Wittgenstein architetto. Portada y página 27 & Cfr. bibliografía \\
\hline 25 & A. Janik \& S.Toulmin, La Viena de Wittgenstein & Cfr. bibliografía \\
\hline 26 & Libro de Bernhard Leitner sobre la casa de Wittgenstein en Viena & Cfr. bibliografía \\
\hline 27 & Biografía de Ray Monk, 1990 & Cfr. bibliografía \\
\hline 28 & Dibujo de asimilación de la casa, agosto 2011 & Autoría propia \\
\hline 29 & La casa en octubre de 1950 & Wittgenstein Archive Cambridge \\
\hline 30 & La casa en octubre de 2013 & Autoría propia \\
\hline 31 & Primer mensaje de P. Wijdeveld, 31.07.2011 & Correspondencia propia \\
\hline 32 & Lago Eidsvatnet, $18: 15,11.10 .2013$ & Autoría propia \\
\hline 33 & Lago Eidsvatnet, cartel conmemorativo en Rv55 & Autoría propia \\
\hline 34 & Tarjeta postal Skjolden, innerst i Lusterfjorden, Sogn & Normanns Kunstforlag. Art. Nr.: N-02-112 \\
\hline 35 & Skjolden, 1950 & $\begin{array}{l}\text { https://www.facebook.com/SkjoldenForOg } \\
\text { No }\end{array}$ \\
\hline 36 & Eduardo Outeiro, Cabañas para pensar, 2011 & Cfr. bibliografía \\
\hline 37 & Walden en exposición Cabañas para pensar, Granada, noviembre 2011 & Autoría propia \\
\hline 38 & McGuinness, Young Wittgenstein, 1988, párrafo descriptivo de la casa & Cfr. bibliografía \\
\hline 39 & $\begin{array}{l}\text { Eduardo Outeiro, Cabañas para pensar, «planos de la casa y embarcadero de Wittgenstein» en } \\
2011\end{array}$ & Cfr. bibliografía \\
\hline 40 & $\begin{array}{l}\text { Versión preliminar del presente proyecto de investigación, 2011. Abajo: el embarcadero } \\
\text { 10.10.2013 de un granjero de Hjerseggi, según testimonio de Vatne }\end{array}$ & Autoría propia \\
\hline 41 & Jan Turnovsky, The Poetics of a Wall Projection & Cfr. bibliografía \\
\hline 42 & Nana Last, Wittgenstein's House, 2008 & Cfr. bibliografía \\
\hline 43 & Daniele Pisani, L'architettura è un gesto. Ludwig Wittgenstein architetto, 2011 & Cfr. bibliografía \\
\hline 44 & Dibujos de la Wall Projection en la Kundmanngasse 19. Jan Turnovsky & Turnovsky:1985 Cfr. Bibliografía \\
\hline 45 & Skjolden, Sognefjord, lago Eidsvatnet y los ríos Mørkridselvi y Eidselvi & http://www.skjolden.com/nymoen/ \\
\hline 46 & Cartel conmemorativo de la casa de Wittgenstein & Autoría propia \\
\hline 47 & Plinto de la casa, octubre 2013 & Autoría propia \\
\hline 48 & Paul Wijdeveld & $\begin{array}{l}\text { http://wittgenstein-initiative.com/about- } \\
\text { us/international-advisory-board/ }\end{array}$ \\
\hline 49 & Brian McGuinness & $\begin{array}{l}\text { https://www.nias.knaw.nl/resources/fellow } \\
\text { s/nias-fellows-1989-90/b-f-mcguinness.jpg }\end{array}$ \\
\hline 50 & Knut Olav Åmås & http://www.haugesenteret.no/filestore/Olav \\
\hline
\end{tabular}


David Connearn

Ivar Oxaal

Michael Nedo abril 2015 animales

Otto Weininger
Skjolden. Wittgenstein's site

Gunnar's Bolstad House

Harald Vatne (izq) y el alcalde del municipio de Luster Ivar Kvalen

Fylkesarkivet Sogn og Fiordane, Leikanger

Fylkesarkivet Sogn og Fjordane, Leikanger

Norsk Folkemuseum

Wren Library del Trinity College, Cambridge

Cambridge University Library

Registro visitantes Wittgenstein Archive Bergen, 15.10.2013

Diario David Pinsent, 07.03.1913, Wren Library

Diario G.M. Moore, Cambridge University Library

Manuscrito de Wittgenstein, Wren Library

Ámbito propio de la tesis

Ámbito propio de la tesis

Ámbito propio de la tesis

Ámbito propio de la tesis

Ámbito propio de la tesis

Ámbito propio de la tesis

Perfil de facebook 2014 y página web en 2011 de Enok Kippersund (1936)

Perfil de facebook 2014 y página web en 2011 de Enok Kippersund (1936)

Perfil de facebook 2014 y página web en 2011 de Enok Kippersund (1936)

Correspondencia electrónica a Knut Olav Åmås, 04.07.2011

Imagen de «la mosca en la botella», metáfora de la filosofía para Wittgenstein en correspondencia electrónica de D. Connearn, 04.08.2012

David Connearn, Cambridge, 2013

Olivier Tonneau, Dawn M. Wilson, David Connearn, Maude y Enrique Clemente, Cambridge,

Wittgenstein Archive Cambridge, abril 2015

Proyecto de la Casa de Ludwig Wittgenstein, julio 2012

Lago Eidsvatnet, Skjolden, 12.05.1995

Kjell S. Johannessen en el plinto de la casa de Wittgenstein, 12.05.1995

Conversación con Michael Nedo y David Connearn en casa de Nedo, Cambridge, 15.04.2015

Manuscrito de Wittgenstein, Wren Library, Cambridge

Notas tomadas en reunión con Nedo, Connearn y Wilson, 15.04.2015, Cambridge

Cuaderno. Trabajos en verano de 1914

\section{CONTEXTUALIZACIÓN}

Palais Wittgenstein, Alleegasse 16, Viena

Paul y Ludwig Wittgenstein

Ludwig jugando con un pájaro. Uno de sus intereses adultos fue la observación de estos

Residencia estival de la familia Wittgenstein, Hochreith (Austria)

Karl Wittgenstein y Leopoldine Kalmus-Wittgenstein

Helene, Margaret y Hermine Wittgenstein en Hochreith...

Ludwig, Helene y Paul Wittgenstein en Hochreith, 1914

Biografía de Wittgenstein por N. Malcom, 1958

Maurice O'Connor Drury, The Danger of Words

Otto Weininger, Sexo y carácter

Skjolden, bandera de Austria junto al plinto de la casa de Wittgenstein

Escalera de acceso Alleegasse 16, Viena

Escalera acceso Kundmanngasse 19, Viena

Casa del Dr. Bevan, Storey's End 76, Cambridge

William Eccles y Ludwig Wittgenstein en Glossop
H_Hauge-senteret/Forsida/Folk/Knut-Olav$\bar{A} A$ maas.jpeg?size $=400 \times 0$ \&quality $=75$

Correspondencia propia

http://www.transactionpub.com/merchant2 /merchant.mvc?\&Screen=AUTHOR\&autho rid $=8390$

http://www.wien.gv.at/kultur/abteilung/vorle sungen/vortragende/images/nedo.jpg

Autoría propia

Autoría propia

http://www.sognavis.no/nyhende/vil-sikraseg-wittgenstein-tomta/s/1-105-6149346 http://www.fylkesarkiv.no/

Autoría propia

http://www.norskfolkemuseum.no/en/

Autoría propia

Autoría propia

http://wab.uib.no/wab_goingon.page

Autoría propia

Autoría propia

Autoría propia

Autoría propia

Autoría propia

Autoría propia

Autoría propia

Autoría propia

Autoría propia

https://nn-

no.facebook.com/enok.kippersund http://www.hugen.no/reisa/index.htm http://www.hugen.no/reisa/wittgenstein02.h tm

Correspondencia propia

Correspondencia propia

Autoría propia

Autoría propia

Autoría propia

Autoría propia

http://www.nrk.no/video/PS*201005

http://www.nrk.no/video/PS*201005

Dawn M. Wilson

Autoría propia

Autoría propia

Autoría propia

Nedo:1983 Cfr. Bibliografía Nedo:1983 Cfr. Bibliografía Nedo:1983 Cfr. Bibliografía

Nedo:1983 Cfr. Bibliografía Nedo:1983 Cfr. Bibliografía Nedo:1983 Cfr. Bibliografía Nedo:1983 Cfr. Bibliografía Cfr. bibliografía

Cfr. bibliografía Cfr. bibliografía

Autoría propia

Nedo:1983 Cfr. Bibliografía

Nedo:1983 Cfr. Bibliografía

https://upload.wikimedia.org/wikipedia/com mons/thumb/3/33/0ttoWeiningerspring190 3.jpg/220px-OttoWeiningerspring1903.jpg Autoría propia Nedo:1983 Cfr. Bibliografía 
Grouse Inn, Glossop, Manchester, 1910

Grouse Inn, Glossop, Manchester, 2012

Bertrand Russell, Autobiography 1872-1914

Rose Crescent, Cambridge

Trinity College, Cambridge

David Pinsent

G. von Wright, diario de David Pinsent

D. Pinsent, Reise mit Wittgenstein in den Norden

Monte Hekla, Islandia

Diario de David Pinsent, 1912-1913 Wren Library

Diario de David Pinsent, 1912-1913 Wren Library

Eskimo, barco en que viajaron a Noruega en 1913 Wittgenstein y Pinsent

Øystese, Noruega

Entrada diario Pinsent 02.10.1913, Wittgensteni decide ir a vivir a Noruega

David Pinsent

Skjolden, 1910

Skjolden, 1930

Inmediaciones de la casa de Wittgenstein en Skjolden

Dedicatoria del Tractatus logico-philosophicus: "Dedicac

Pinsent»

Halvard Drægni (1879-1950)

Drægni Hus, Skjolden, 1919

Skjolden 1930

Skjolden 2013

Ilshuset Company

Edificio de la Ishuset, fábrica de hielo, 1898

Tarjeta postal de Kari Klingenberg a Wittgenstein, 27.07.1914, anverso

Idem, reverso

Granja Eide, Anna Rebni

Referencias en Skjolden

Skjolden Hotell, donde se alojó G.E. Moore en 1914. Fotografía de 1950.

Nuevo Skjolden Hotell, 2013

«Estoy construyéndome aquí una pequeña casa», cuaderno

Carta de Wittgenstein a Halvard Drægni, 1921

Walden, que leía Wittgenstein con Arvid Sjögren y otros amigos en Hochreith

Wittgenstein remando en el lago Eidsvatnet, 1921

Arvid Sjögren, 1930. Fotografía de Moritz Nähr

Arne Bolstad (izqda) con Hans Kristian Tomasson Mørkrid, en Knivabakkli, cerca de Skjolden

Wittgenstein, autofotografías, 1922

55 Hjerseggi sobre el lago Eidsvatnet, «Nature is wonderful in all her moods.»

Granja Eide

Gilbert Pattison

Correspondencia Wittgenstein - Engelmann

Con Francis Skinner en Cambridge

Viaje con Gilbert Pattisson por Francia, 1936

Viaje de Skinner a Skjolden, septiembre 1937

Acceso a la casa de Wittgenstein en invierno, 07.11.2012

Casa de Elisabeth Anscombre, Oxford

Ben Richards en Swansea, 1946

Royal London School of Medicine and Dentistry
Nedo:1983 Cfr. Bibliografía

google earth

Cfr. bibliografía

Autoría propia

Autoría propia

http://s3.amazonaws.com/rapgenius/pinse

nt david 1909 sixth form.jpg

Cfr. bibliografía

Cfr. bibliografía

Puri Muñoz

Autoría propia

Autoría propia

http://www.heritage-ships.com/

google earth

Autoría propia

Nedo:1983 Cfr. Bibliografía

https://www.facebook.com/SkjoldenForOg No

https://www.facebook.com/SkjoldenForOg

Autoría propia

Autiografía

http://www.nrk.no/st/leksikon/index.php/Dr \%C3\%A6gni_AS

http://www.fylkesarkiv.no/

https://www.facebook.com/SkjoldenForOg No

Autoría propia

http://www.fylkesarkiv.no/

https://www.facebook.com/SkjoldenForOg No

http://wab.uib.no/sept1914/postcards/A03.

$\mathrm{html}$

http://wab.uib.no/sept1914/postcards/A03.

html

http://www.visitnorway.com/es/producto/? pid $=190311$

Autoría propia

https://www.facebook.com/SkjoldenForOg No

Autoría propia

Autoría propia

https://www.facebook.com/SkjoldenForOg No

Cfr. bibliografía

Autoría propia

Nedo:1983 Cfr. Bibliografía

https://www.facebook.com/SkjoldenForOg No

Nedo:1983 Cfr. Bibliografía

http://www.panoramio.com/photo/662170

50

http://www.visitnorway.com/es/producto/? pid $=190311$

Nedo:1983 Cfr. Bibliografía

Cfr. bibliografía

Nedo:1983 Cfr. Bibliografía

Nedo:1983 Cfr. Bibliografía

Autoría propia

https://einarlunga.wordpress.com/tag/wittg

enstein-i-norge/

Google maps

Nedo:1983 Cfr. Bibliografía

http://www.qmul.ac.uk/about/history/index. html

Autoría propia 

mediodía por su orientación este-oeste Actividades culturales en la fiesta del verano de Skjolden, «Kulturdagane Skjolden 2010»

Edificio comunitario, Fjordstova, octubre 2013

Bibiloteca en el Fjorstova

Estantería dedicada a Wittgenstein en la biblioteca (en noruego)

Fuera de la temporada de verano (mayo-septiembre) el Fjordstova sólo abre una tarde a la semana durante unas horas

Excursión por el lago Eidsvatnet, 1950

Actividad portuaria de transporte de hielo y mercancías en Skjolden, 1910

Ishuset junto al Sognefjord, 1900

Hotel Turtagrø, 1920

Crucero Independence of the Seas, Skjolden, 21.05.2013

\section{Conversación con Michael Nedo y David Connearn, Cambridge, abril 2015}

Sección Casa de Wittgenstein. Work in progress, indecisiones respecto a la escalera Antonio Miranda Regojo, Ni robot ni bufón, 1999: ¿Cuánta verdad hay en un proyecto de arquitectura?

El escultor Michael Drobil en su estudio, amigo de Wittgenstein

L. Wittgenstein, busto (probablemente de M. Respinger), 1927

Casa de troncos tradicional noruega, Fortun, 2013

David Connearn, Reproducción a escala 1/12 de manillón de Kundmanngasse 19

Fotografías de la Casa Wittgenstein,1929 y planos de ejecución de 1926, en P. Wijdeveld, p. 103

J. Franzen, The Kraus Project, 2013

Ludwig von Ficker, Briefwechsel

Adolf Loos, 1904

Looshaus Michaelerplatz, 1909-1911

Cabañas tradicionales noruegas con tejado vegetal, 1910-1920

Leo Tolstoy, mayo 1908

Leo Tolstoy, Evangelio abreviado. Marcó profundamente a Wittgenstein en 1914

Primera edición bilingüe del Tractatus, 1922

La casa tolstoiana de Wittgenstein en Skjolden

Joseph Maria Olbrich, Das Secessionsgebäude 1898. Subvencionado por Karl Wittgenstein

Comedor en la Casa Wittgenstein, Kundmanngasse 19, fotografía 1929

Revista Das Andere, (El otro) publicada por Loos en 1903

Interior del apartamento de Adolf Loos, 1903, publicado en la revista Kunst, Viena

Interior del Hall de la Casa Wittgenstein, Kundmanngasse 19

Interior de casa tradicional noruega, 1910

Construcción tradicional noruega, Solvorn, 2013

Construcción tradicional noruega, Fortun, 2013

Construcción tradicional noruega, Fortun, 2013

Interior de casa noruega, 1939

Muebles de Wittgenstein en la habitación de Trattenbach, donde fue profesor de escuela elemental

Armario metálico para los cuadernos de Wittgenstein

111 Ventana y mesa de la habitación de Wittgenstein en Whewell's Court

112 La misma ventana en 2007

113 Carta de Wittgenstein a Eccles donde dibuja las «abominables molduras» que aquel debía evitar

Elaboración propia desde Atlas Nueva

Larousse

http://www.lib.utexas.edu/maps/ams/norwa y/txu-pclmaps-oclc-6498109-fortun-

d30.jpg

Google Earth

https://www.facebook.com/SkjoldenForOg

No

Autoría propia

Autoría propia

Autoría propia

Autoría propia

https://www.facebook.com/SkjoldenForOg

No

https://www.facebook.com/SkjoldenForOg

No

https://www.facebook.com/SkjoldenForOg

No

http://www.turtagro.no/?page id =132

https://www.facebook.com/SkjoldenForOg No

Cfr. bibliografía

http://www.picturesofengland.com/img/X/1

032367.jpg

Dawn M. Wilson

Autoría propia

Autoría propia

Nedo:1983 Cfr. Bibliografía

Autoría propia

Autoría propia

David Connearn

Cfr. bibliografía

Cfr. bibliografía

Cfr. bibliografía

https://upload.wikimedia.org/wikipedia/com mons/6/6a/Adolfloos.2.jpg

Munch:2005 Cfr. Bibliografía

http://www.fylkesarkiv.no/

http://prokudin-

gorsky.org/arcs.php?lang=ru\&photos_id=

818\&type $=1$

Nedo:1983 Cfr. Bibliografía

Cfr. bibliografía

Autoría propia

Munch:2005 Cfr. Bibliografía

Nedo:1983 Cfr. Bibliografía

Munch:2005 Cfr. Bibliografía

Gravagnuolo:1982 Cfr. Bibliografía

Leitner:2000 Cfr. Bibliografía

http://www.fylkesarkiv.no/

Autoría propia

Autoría propia

Autoría propia

http://www.fylkesarkiv.no/

Nedo:1983 Cfr. Bibliografía

Nedo:1983 Cfr. Bibliografía

Nedo:1983 Cfr. Bibliografía

https://www.pinterest.com/pin/347410558

728236822/

McGuinness:1980 Cfr. Bibliografía 
Adolf Loos, interior de la casa Duschnitz, 1915-1916

Adolf Loos, armario del apartamento de Turnowsly, Viena 1900

Álbum personal de Wittgenstein. Un alumno suyo de Trattenbach junto a Maurice 0'Connor Drury, psiquiatra en Dublín y el filósofo G. E. Moore

La decadencia de Occidente que compartía Wittgenstein, | somos personas de otra época» Zweig describe ese mismo mundo

\section{O3 PROYECTO}

Hans, Sofie y Kari Klingenberg. Skjolden, 1915

Familia Klingerberg y familia Drægni. Skjolden, 1920-1922

Tarjeta postal de Wittgenstein a Eccles, 1914 donde señala sus habitaciones en la casa de Hans Klingenberg

Tarjeta postal de Wittgenstein a Eccles, 1914 donde señala sus habitaciones en la casa de Hans Klingenberg

Casa de la familia Klingenberg. Skjolden, 10.07.2012

Lago Eidsvsatnet desde la carretera Bolstad, a la izquierda monte Hjerseggi, centro lago, derecha Fanaråken y granja Eide. Octubre, 2013

Lago Eidsvsatnet desde la carretera Bolstad, a la izquierda monte Hjerseggi, centro lago, derecha Fanaråken y granja Eide. Octubre, 2013

Lago Eidsvsatnet desde la carretera Bolstad, a la izquierda monte Hjerseggi, centro lago, derecha Fanaråken y granja Eide. Octubre, 2013

Colocación de la placa conmemorativa de la casa de Wittgenstein, agosto 1984 Arne Bolstad, 1950

Johannes J. Bolstad, padre de Arne y propietario del terreno donde se construyó la casa de Wittgenstein., 1950

Vista desde la casa hacia Skjolden, octubre 1950

Vista desde la casa hacia Skjolden, octubre 2013

Maqueta de Cambridge, situación Whewell's Court respecto ciudad, abril 2015

Ventanas (ático) de Wittgenstein en Whewell's Court, abril 2015

Granja Eide de Anna Rebni, 1950

Casa del guarda de Hochreith, en la que Wittgenstein se alojaba

Eidsvatnet, 10:48, 12.10.2013

Eidsvatnet, 11:58, 12.10.2013

Eidsvatnet, $16: 18,12.10 .2013$

Eidsvatnet, 18:52, 12.10.2013

Plano de Wittgenstein de octubre de 1936 indicando la situación de su casa y del lugar que Moore había visto en abril de 1914. WAC, Cambridge, abril 2015

La casa de Wittgenstein en Skjolden, octubre 2013

The Little Brick Project, Wittgenstein's House in Skjolden, 2015

McGuinness, Wittgenstein A Life. Young Ludwig 1889-1921, 1988

Johannessen, Larsen y Åmås, Wittgenstein in Norway, 1994

Oxaal, Wittgenstein's Hut, 2011

McGuinness (Ed.), 1980

McGuinness et alt., 1981

McGuinness (Ed.), 2012

Manuscrito 10-12 octubre 1937. Hermann Hänsel visita a Wittgenstein en Skjolden, Wren Library, abril 2015

Wittgenstein en Swansea, Gales. Fotografiado por Ben Richards, 1947

21.10.2013

\section{Åmås y Larsen, Det stille alvoret, 1994}

Correspondencia de Wittgenstein con Arne Bolstad, Halvard Drægni y la familia Klinglenberg en 1914-1915. Archivo audiovisual Universidad de Bergen

Correspondencia de Wittgenstein con Arne Bolstad, Halvard Drægni y la familia Klinglenberg en 1914-1915. Archivo audiovisual Universidad de Bergen

Correspondencia de Wittgenstein con Arne Bolstad, Halvard Drægni y la familia Klinglenberg en 1914-1915. Archivo audiovisual Universidad de Bergen

Correspondencia de Wittgenstein con Arne Bolstad, Halvard Drægni y la familia Klinglenberg en 1914-1915. Archivo audiovisual Universidad de Bergen

Correspondencia de Wittgenstein con Arne Bolstad, Halvard Drægni y la familia Klinglenberg en 1914-1915. Archivo audiovisual Universidad de Bergen

Correspondencia de Wittgenstein con Arne Bolstad, Halvard Drægni y la familia Klinglenberg en 1914-1915. Archivo audiovisual Universidad de Bergen

Correspondencia de Wittgenstein con Arne Bolstad, Halvard Drægni y la familia Klinglenberg en 1914-1915. Archivo audiovisual Universidad de Bergen
Gravagnuolo:1982 Cfr. Bibliografía

Münz:1964 Cfr. Bibliografía

Nedo:1983 Cfr. Bibliografía

Cfr. bibliografía

Cfr. bibliografía

http://www.fylkesarkiv.no/ http://www.fylkesarkiv.no/ Nedo:1983 Cfr. Bibliografía

\section{Nedo:1983 Cfr. Bibliografía}

https://www.flickr.com/photos/tipsfortravell ers/7610848882/in/photostream/

Autoría propia

Autoría propia

Autoría propia

http://www.fylkesarkiv.no/

Autoría propia

Autoría propia

Nedo:1983 Cfr. Bibliografía

Autoría propia

Autoría propia

Autoría propia

Autoría propia

Nedo:1983 Cfr. Bibliografía

Autoría propia

Autoría propia

Autoría propia

Autoría propia

Autoría propia

Autoría propia

Autoría propia

Cfr. bibliografía

Cfr. bibliografía

Cfr. bibliografía

Cfr. bibliografía

Cfr. bibliografía

Cfr. bibliografía

Autoría propia

Nedo:1983 Cfr. Bibliografía

http://www.sognavis.no/nyhende/hapet-ertent-for-wittgenstein-huset/s/1-105-

6933470

Cfr. bibliografía

http://wab.uib.no/sept1914/postcards/A11. html

http://wab.uib.no/sept1914/postcards/A08. html

http://wab.uib.no/sept1914/postcards/A11. html

http://wab.uib.no/sept1914/postcards/A08. $\mathrm{html}$

http://wab.uib.no/sept1914/postcards/A06. html

http://wab.uib.no/sept1914/postcards/A18. $\mathrm{html}$

http://wab.uib.no/sept1914/postcards/A06. $\mathrm{html}$ 
Correspondencia de Wittgenstein con Arne Bolstad, Halvard Drægni y la familia Klinglenberg en 1914-1915. Archivo audiovisual Universidad de Bergen

Correspondencia con Ivar Oxaal, 18.07.2012

Correspondencia con Ivar Oxaal, 18.07.2012

Correspondencia con Ivar Oxaal, 04.03.2015

Sección de madera de la casa original, recogido

Sección de madera de la casa original, recogido en 198

Toma de datos, Cambridge, 15.04.2015

Retrato de Eli Eriksdatter Kolstad, 1910-1914. Detrás de la señora apreciamos un tabique

interior de construcción similar al que proyectamos aquí

Álbum personal de Wittgenstein, fotografías de Anna Rebni ya con unos 80 años, en la granja Autoría propia

Eide, octubre 1950

Dos mujeres reman en el lago Eidsvatnet. Al fondo se ve la casa de Wittgenstein. Fotografía de

Conversación con Harald Vatne, Skjolden 10.10.2013

Casa de Gunnar Bolstad, Skjolden 12.10.2013

Casa de Gunnar Bolstad, Skjolden 12.10.2013

Casa de Gunnar Bolstad, Skjolden 12.10.2013

Carta a Gyda Bolstad, 01.06.2015, solicitando algún dato de la mesa original de Wittgenstein que conserva en su casa

Material original en el sótano de la casa de Gunnar Bolstad (madera reutilizado como peldañeado)

Michael Nedo \& Michele Ranchetti (Eds.), Wittgenstein, Sein Leben in Bildern und Texten, 1983. Ejemplar obtenido no sin dificultad en un anticuario de Munich

Fotografías Casa de Wittgenstein en Skjolden:

$n^{0} 2152, n^{0} 787, n^{0} 514, n^{0} 656, n^{0} 519$ del Wittgenstein Archive Cambridge, Michael Nedo Fotografías Casa de Wittgenstein en Skjolden:

$n^{0} 2152, n^{0} 787, n^{0} 514, n^{0} 656, n^{0} 519$ del Wittgenstein Archive Cambridge, Michael Nedo Fotografías Casa de Wittgenstein en Skjolden: $n^{0} 2152, n^{0} 787, n^{0} 514, n^{0} 656, n^{0} 519$ del Wittgenstein Archive Cambridge, Michael Nedo Fotografías Casa de Wittgenstein en Skjolden: $n^{0} 2152, n^{0} 787, n^{0} 514, n^{0} 656, n^{0} 519$ del Wittgenstein Archive Cambridge, Michael Nedo Fotografías Casa de Wittgenstein en Skjolden: $n^{0} 2152, n^{0} 787, n^{0} 514, n^{0} 656, n^{0} 519$ del Wittgenstein Archive Cambridge, Michael Nedo Fotografía $n^{0} 514$ Wittgensteins Blockhaus in Norwegen, 95x68 mm, Wittgenstein Archive Cambridge. Escala 1:1

Fotografía $n^{0} 519$ Wittgensteins Blockhaus in Norwegen, 68x95 mm, Wittgenstein Archive Cambridge. Escala 1:1

Wittgenstein en la ventana, detalle fotografía n² 2152, Ben Richards, octubre 1950 y cuaderno Autoría propia notas.

Wittgenstein en la ventana, detalle fotografía n² 2152, Ben Richards, octubre 1950 y cuaderno Autoría propia notas

Detalle fotografía $n^{0} 656$, vista desde el lago de la casa

Autoría propia

Detalle muy ampliado de la fotografía $n^{0} 787$, se aprecia la manipulación de la imagen insertando la misma vista de la $n^{0} 656$. El motivo es que probablemente con la perspectiva natural en la que la casa se orienta hacia el noroeste, quedaría prácticamente oculta por los abedules laterales

Fotomontaje de Wittgenstein con la ayuda del fotógrafo Moritz Nähr, realizado en los años 20, Nedo:1983 Cfr. Bibliografía superpone los retratos de sus hermanas: Helene, Hermine y Margaret y el suyo propio

Travelín de acercamiento dinámico a la casa de Wittgenstein: partiendo de la orilla opuesta del Autoría propia lago, dos imágenes intermedias a diferentes distancias de la casa y una finalmente desde la propia colina que aloja la construcción. Para terminas con la vista desde la casa hacia el pueblo. Imagen equivalente a la $\mathrm{n}^{0} 787$, octubre 2013

Imagen equivalente a la $n^{0} 523$ (cfr. Imagen $n^{0} 12$ de esta tesis), octubre 2013

Cuaderno de manuscritos MS119, escrito en Noruega, 18x22 cm 148 hojas 24.09.1937 al

19.11 1937. Wren Library, Cambridge, abril 2015

Cabaña de Arne Naess en Tvergastein

Cabaña de Arne Naess en Tvergastein

Granjas tradicionales en Sogn og Fjordane, región a la que pertenece Skjolden, en Arne Berg Norske Gardstun, 1968

Toma de datos del plinto, 10.10.2013. Medidas generales

Fotografía del plinto desde el sendero de acceso

Toma de datos del plinto, 10.10.2013. Situación del arbolado principal circundante

Fotografía del plinto desde el norte
Autoría propia

Autoría propia

Autoría propia

http://www.tu.no/bygg/bygg/2012/04/01/u sikker-fremtid-for-arne-nass-hytta http://www.tu.no/bygg/bygg/2012/04/01/u sikker-fremtid-for-arne-nass-hytta

Cfr. bibliografía

Autoría propia

Autoría propia

Autoría propia

Autoría propia 
Casa de la familia Kolstad en Luster, 1910-1914. De volumetría similar a la de Witrtgenstein, http://www.fylkesarkiv.no/ servía a una familia completa. Obsérvese que el accesoy la

orientación de la cubierta es exactamente la opuesta a la de Wittgenstein.

Casa de la familia Kolstad en Luster, 1910-1914. De volumetría similar a la de Witrtgenstein, http://www.fylkesarkiv.no/ servía a una familia completa. Obsérvese que el accesoy la

orientación de la cubierta es exactamente la opuesta a la de Wittgenstein.

84 proyectada por Wittgenstein.

85

86

87

88 Carpintería en Luster, 1912 Iongitudinales

Idem. Reverso hacia el Sognefjord

Emplazamiento 1:10000 mayo 2015

Casa Bolstad, 1:100

Casa Bolstad, 1:100

Casa Bolstad, emplazamiento

Fotografiando el metro

Plinto desde la esquina sur fachada sureste

Gneis
Interior ático bajo cubierta en noruega, 1910. Obsérvese la cubierta de correas Iongitudinales

La fábrica de zumos y conservas de fruta de Halvard Drægni en 1907-1908

Wittgenstein y Arvid Sjögren en el periódico regional en 1931

Tarjeta postal de Gilbert Pattison a Wittgenstein. Imagen tomada en agosto 1931, Noruega, anverso. Enviada 05.11.1931. WAC, Cambridge, 04.2015

Alvhild Rebni (84) husker at Wittgenstein var en litt skremmende figure, og at han var «stri i øynene», en Dagens Næringsliv, 11.10.2013 [Alvhild Rebni (84)

recuerda que Wittgenstein era una figura intimidante y que tenía una «mirada dura»]

Dibujo para felicitación de la Navidad 2013, 24.12.2013. Wittgenstein en el balcón, mirando

Dibujo de hojas de bjørk, abedul en noruego, Skjolden, 12.10.2013

Invierno en Skjolden, 22.01.2015, 11:58, Sognefjord

Invierno en Skjolden, 01.03.2013, 7:32, Sognefjord

Otoño en Skjolden, 13.10.2013, 17:07, lago Eidsvatnet

Alzado suroeste del proyecto de la Casa de Wittgenstein, mayo 2015

Adolf Loos. Proyecto de viviendas con atrio, 1912 Aplicación de Raumplanung

Monografía de Münz, Der Arkitekt Adolf Loos (Viena: Verlag Anton Schroll, 1964)

Alzado, sección y plantas de la Casa del Guarda en la Escuela Schwarzwald, Semmering (Austria), 1913 [proyecto no construido]

Alzado, sección y plantas de la Casa del Guarda en la Escuela Schwarzwald, Semmering (Austria), 1913 [proyecto no construido]

Alzado noroeste, recayente al lago Eidsvatnet, proyecto de la Casa de Wittgenstein, 1:75,

Alzado suroeste, proyecto de la Casa de Wittgenstein, 1:75, mayo 2015

Planta de acceso, proyecto de la Casa de Wittgenstein, 1:75, mayo 2015

Planta ático, proyecto de la Casa de Wittgenstein, 1:75, mayo 2015

Casa Bolstad, planta de acceso (esquemática)

Alzado sureste, de acceso, proyecto de la Casa de Wittgenstein, 1:75, mayo 2015

Alzado noroeste, proyecto de la Casa de Wittgenstein, 1:75, mayo 2015

Plinto, frente suroeste, 10.10.2013

Toma de datos esquina oeste del plinto

Gancho de anclaje de la antigua cada, a $36 \mathrm{~cm}$ de esquina, sobre alambor de cemento

Plinto, frente noroeste, 10.10.2013

Toma de datos del anclaje en esquina este y separación a corte del terreno respecto a la

Toma de datos del hueco en el plinto [almacén/despensa]

Hueco en el plinto, $260+116$ escalones $\times 205 \mathrm{~cm}$

Frentes interiores del hueco en el plinto

Frentes interiores del hueco en el plinto

Frentes interiores del hueco en el plinto

Frentes interiores del hueco en el plinto

Antiguas Log constructions, Turtagrø y Fortun

Antiguas Log constructions, Turtagrø y Fortun

Soluciones habituales de esquina

Antiguas Stave constructions, Turtagrø y Fortun

Antiguas Stave constructions, Turtagrø y Fortun

Fotografía obtenida por Andrew Penketh en abril de 2015 de la fotografía original de Ben Richards. El nuevo enfoque permite una mejor lectura de las aristas.
Autoría propia

http://www.fylkesarkiv.no/ http://www.fylkesarkiv.no/ http://www.fylkesarkiv.no/

http://www.fylkesarkiv.no/ Nedo:1983 Cfr. Bibliografía Nedo:1983 Cfr. Bibliografía

Nedo:1983 Cfr. Bibliografía Cfr. bibliografía

Autoría propia

Autoría propia

http://es.webcams.travel/search/Skjolden http://es.webcams.travel/search/Skjolden Autoría propia

Autoría propia

Autoría propia

Münz:1964 Cfr. Bibliografía

Cfr. bibliografía

Münz:1964 Cfr. Bibliografía

Münz:1964 Cfr. Bibliografía

Autoría propia

Autoría propia

Autoría propia

Autoría propia

Autoría propia

Autoría propia

Autoría propia

Autoría propia

Autoría propia

Autoría propia

Autoría propia

Autoría propia

Autoría propia

Autoría propia

Autoría propia

Autoría propia

Autoría propia

Autoría propia

Autoría propia

Autoría propia

Autoría propia

Autoría propia

Autoría propia

Autoría propia

Autoría propia

Autoría propia

AITIM

Autoría propia

Autoría propia

Andrew Penketh 
Material inédito que ha permitido corroborar las dimensiones en altura de los troncos de fachada: 8"

134 Sección transversal del proyecto de la Casa de Wittgenstein, mayo 2015

135 Estudio dimensional de la casa Bolstad, El notable esfuerzo por deducir una conclusión

Autoría propia constructiva de una suposición constructiva se esclarecerá en el caso

de que los Bolstad permitan la realización de catas en las fachadas

2013

Esquina tipo crossing joint con troncos escuadrados y pestaña simple, cobertizo Bolstad

Mismo sistema, pestaña doble, cabaña Nymoen Leirplass

139 Silueta de la sección de tronco original de la tabiquería interior y estudios de posibles soluciones del número de troncos y ensambles

Construcción en madera, Luster, 1920. Archivo Halvard Drægni, Fylkesarkivet, octubre 2013.

Esquema sistema horizontal de sustentación y cubierta

Resto de vigueta del balcón localizado en el lugar aproximadamente $11 \times 15 \mathrm{~cm}$ de sección

Apoyo viguetas en plinto

Restos de materiales localizados en el lugar

Restos de materiales localizados en el lugar

Restos de materiales localizados en el lugar

Restos de materiales localizados en el lugar

Solución de proyecto estructura del balcón

Sistema de atirantamiento de proyecto, viguetas de forjado encajadas en muros de cerramiento

151 Fotografía forjado planta baja casa Bolstad

152 Imagen n 519 Wittgenstein Archive Cambridge, detalle ampliado. Esquema de estructura de cubierta «visible»

153 Fotografía de Samson Brathole, fecha anterior a 1920, tamaño real $12 \times 16 \mathrm{~cm}$, Fylkesarkivet, Leikanger, 11.10.2013

154 Detalle fotografía de Samson Brathole, muy ampliado. Podemos apreciar, pese a la distorsión del escaneado, las sombras arrojadas por la estructura de los nudillos sobre la fachada y con bastante claridad el tirante exterior.

155 Detalles de unión entre pares y anclaje de cubierta y tirantes de viguetas del forjado en los cerramientos laterales

156 Perspectiva del conjunto de elementos constructivos de la casa. Se aprecia que el último tronco de los cerramientos laterales sostiene en ménsula las cerchas de los extremos y el tirante entre los extremos de los pares recayentes al lago que servirá de apoyo adicional a las viguetas en voladizo del balcón

157 Esquema estructural de la cubierta y su interacción con el forjado de planta baja, el balcón y de este con los muros laterales

158 Tejado de pizarra en casa de los Bolstad

159 Cubiertas de pizarra en la escuela de Skjolden, 1919

$160 \quad$ Cubierta vegetal tradicional nórdica

161 Detalles constructivos de cubierta vegetal

162 Estudio de número y disposición de tejas en la Casa de Wittgenstein y en la Casa Bolstad

Tejas sobrantes en la Casa Bolstad

Autoría propia

164 Estudio de encuentro de cumbrera, probablemente el ángulo estuviera protegido interiormente con chapa de cinc

Diarios en clave, entrada del 18.10.1937 en MS119, «Diarios noruegos» Wren Library, Cambridge, 17.04.2015

Diarios en clave, entrada del 18.10.1937 en MS119, «Diarios noruegos» Wren Library, Cambridge, 17.04.2015

Diarios en clave, entrada del 18.10.1937 en MS119, «Diarios noruegos» Wren Library, Cambridge, 17.04.2015

168 Diarios en clave, entrada del 18.10.1937 en MS119, «Diarios noruegos» Wren Library, Cambridge, 17.04.2015

169 Sección constructiva. Proyecto de la Casa de Wittgenstein, mayo 2015

170 Sección longitudinal. Proyecto de la Casa de Wittgenstein, mayo 2015

171 Interior de Neuwaldegg, Paul Engelmann, 1919

172 Interior habitación Wittgenstein en Whewell's Court 1940 c.

173 Toma de datos express en Casa Bolstad, 14.10.2013

174 Toma de datos express en Casa Bolstad, 14.10.2013

175 Escalera de acceso al semisótano de casa de los Bolstad, 14.10.2013. Parte del material sí parece ser el original, pero reutilizado para la construcción de la escalera, no el trazado en sí mismo

176 Situación de la escalera dibujada en la planta de la casa de los Bolstad. No hubo ocasión de tomas datos exhaustivos del interior

Autoría propia

Autoría propia

Autoría propia

http://www.fylkesarkiv.no/ http://www.fylkesarkiv.no/ Autoría propia

Autoría propia

Autoría propia

Autoría propia

Autoría propia

Autoría propia

Autoría propia

Autoría propia

Autoría propia

Autoría propia

Autoría propia

http://www.fylkesarkiv.no/ http://www.fylkesarkiv.no/

AITIM

Autoría propia

Autoría propia

Autoría propia

http://www.fylkesarkiv.no/ http://www.fylkesarkiv.no/

Autoría propia

Autoría propia

Autoría propia

Autoría propia

Autoría propia

Autoría propia

Autoría propia

Autoría propia

Autoría propia

Wijdeveld:2000 Cfr. Bibliografía

Nedo:1983 Cfr. Bibliografía

Harald Vatne

Autoría propia

Autoría propia

Autoría propia 
Sección por la escalera. Proyecto de la Casa de Wittgenstein, mayo 2015

Autoría propia Esquemas de ubicación de la escalera en la planta_ST01, ST02 y ST03. Cfr. Comentarios p. Autoría propia 253

Imagen de interior de una granja del s. XVII, en Folkmuseum Oslo

http://www.norskfolkemuseum.no/en/

Dibujos preliminares de la situación de la cocina, nótese que la cocina y el dormitorio todavía aparecen intercambiados en planta

Restos de algún tipo de estufa en el hueco del almacén del plinto, 1984. Ivar Oxaal

Autoría propia

Ivar Oxaal

Esquema tipo de vivienda tradicional noruega, con altillo (hems) ocupando sólo una parte del Autoría propia piso superior, aprovechando el calor de la estufa de planta baja

Ladrillos refractarios pesados de $24 \times 12 \times 6 \mathrm{~cm}$, oscurecidos por el humo

Dos tipos de ladrillo presentes en el plinto

En los de tono ocre se aprecia el sello del fabricante HÖGANÄS

Se acumulan unos 80 ladrillos en el fondo del hueco

Toma de datos en Skjolden, 10.10.2013

Plano de trabajo de ubicación de la chimenea, teniendo en cuenta el intereje de los cuchillos de cubierta y de las viguetas del forjado del ático.

Estudio del tiro de la chimenea original con los ladrillos encontrados en el lugar, Skjolden 13.10.2013

Remates típicos de chimeneas de ladrillo con piedras de pizarra en Skjolden, del blog de Connie Bearg, 2013

Remates típicos de chimeneas de ladrillo con piedras de pizarra en Skjolden, del blog de Connie Bearg, 2013

Remate de la chimenea de la casa de Gunnar Bolstad

Remate de la Casa de Wittgenstein, apenas perceptible

Despensa bajo suelo, del tipo que debía tener Wittgenstein en su casa

Armario rinconero de madera que Kåre Bolstad señaló como original en la visita a la casa

familiar de 14.10.2013. Dimensiones $117 \times 65 \times 215$. No parece del gusto de Wittgenstein pero

quizá fuera Arne Bolstad quien lo llevara a la casa del lago

Esquema de su posible situación teniendo en cuenta la losa de piedra que aparece en el lado derecho de la fotografía de Oxaal

Fotografía de los restos de una posible letrina en las cercanías de la casa de Wittgenstein y esquema de su localización, dibujado por Oxaal casi 30 años después de la visita al lugar

Lo que parece ser un punto de vista similar al de Oxaal unos metros hacia atrás en la senda, a Autoría propia unos quince metros del plinto

Emplazamiento en Hiserggi

Sección del lago con la casa hacia el sur. Detrás vemos las crestas de Bjøkeskori, Tårnet, Ospenakken y Klepp. Al fondo Fanaråken. La cresta se mantiene a una cota casi constante de 800-1000 m de altura

Fotografías satetilates, 2006-2007-2012. Sombra arrojada de Bjøkeskori, Tårnet, Ospenakken http://www.1881.no/Kart/?p=\{61.543530 y Klepp sobre el lago. La mayor parte del pueblo queda siempre soleado cuando la altura solar $8|7.7336065|$ Fortun\}\# lo permite

Fotografías satetilates, 2006-2007-2012. Sombra arrojada de Bjøkeskori, Tårnet, Ospenakken http://www.1881.no/Kart/?p=\{61.543530 y Klepp sobre el lago. La mayor parte del pueblo queda siempre soleado cuando la altura solar $8|7.7336065|$ Fortun\}\# lo permite

Fotografías satetilates, 2006-2007-2012. Sombra arrojada de Bjøkeskori, Tårnet, Ospenakken http://www.1881.no/Kart/?p=\{61.543530 y Klepp sobre el lago. La mayor parte del pueblo queda siempre soleado cuando la altura solar 8|7.7336065|Fortun\}\# lo permite

Sección norte-sur a escala desde la casa de Wittgenstein hasta la cota de la cresta de Tårnet, Autoría propia podemos intuir la dificultad de la localización respecto al soleamiento

Estudio preliminar de los huecos, información directamente extraíble de las fotografías de Ben Autoría propia Richards de 1950

Estudio preliminar de los huecos. Entendiendo las imágenes, 24.08.2011

Analizando los huecos. Redibujar las fotografías, 25.08.2011

Trabajos de fotogrametría para obtener dimensiones generales y situación de huecos, 12.08.2014

Casa de Gunnar Bolstad, fachada sureste. Skjolden, 12.10.2013

Toma de datos de las fachadas y detalles

Toma de datos de las fachadas y detalles

Casa de Gunnar Bolstad, fachada suroeste. Skjolden, 12.10.2013

Casa de Gunnar Bolstad, fachada noreste. Skjolden, 12.10.2013

Casa de Gunnar Bolstad, detalle esquina sur. Skjolden, 12.10.2013

Fachada noroeste. Skjolden, 12.10.2013, corresponde con la fachada original recayente al lago Eidsvatnet

Alzado noroeste, toma de datos, 12.10 .2013

Dibujo de la fachada noroeste de la casa original a partir de las dimensiones de la casa Bolstad

Casa Bolstad y cobertizo exterior, 14.10.2013
Autoría propia

Autoría propia

Autoría propia

Autoría propia

Autoría propia

Autoría propia

Autoría propia

Autoría propia

Autoría propia

Autoría propia

Autoría propia

Autoría propia

Autoría propia 


\section{Fotografía aérea de la casa de la familia Bolstad}

Hojas del álbum de Ben Richards en el Wittgenstein Archive Cambridge, 20.04.2015

Material original fotográfico en el WAC, 20.04.2015

Fotografía a través de lupa de imagen $\mathrm{n}^{0} 519$ en el WAC, 20.04.2015

Fotografía a través de lupa de imagen $n^{0} 514$ en el WAC, 20.04.2015

Dibujos en las anotaciones de Wittgenstein, MS117. Vol. XIII: Philosophische Bemerkungen, 1937-1940

Dibujos en las anotaciones de Wittgenstein, MS117. Vol. XIII: Philosophische Bemerkungen, 1937-1942

Dibujos en las anotaciones de Wittgenstein, MS117. Vol. XIII: Philosophische Bemerkungen, 1937-1943
Sección del alzado principal con indicación del antepecho de $60 \mathrm{~cm}$ en el dormitorio del ático En la fotografía vemos que las ventanas están sensiblemente más bajas de lo que corresponderían teniendo un forjado de $2.92 \mathrm{~m}$ de altura

Esquema de posible modificación de la sección que encajaría con una altura convencional de las ventanas, Raumplanung, (el acceso estaría delimitado en sección por una altura diferente) McGuinness, op. cit. p. 71: «La financiación no era un problema para él. Parece que se hizo cargo él mismo de sus experimentos con cometas y cámaras de combustión y se construyó un almacén en el páramo; y en general vivía sin ostentación pero la vida de un hombre rico. Eccles estimaba que tenía una renta de $£ 5.000$ anuales, una cantidad enorme en aquellos tiempos.» [£5.000 son más de $400000 €$ al cambio de 2015]

Fotografía de Eccles (izqda) y Wittgenstein en Glossop, 1908. Al fondo se ve el edificio de Grouse Inn y remarcado lo que debía ser el almacén al que hace referencia McGuinness, hoy desaparecido
Autoría propia

Autoría propia

Autoría propia

Autoría propia

Autoría propia

Autoría propia

Autoría propia

Autoría propia

Autoría propia

Autoría propia

Autoría propia

Autoría propia

Autoría propia

Autoría propia

Autoría propia

Autoría propia

Autoría propia

Autoría propia

Autoría propia Autoría propia

Autoría propia

Autoría propia
Autoría propia

http://www.norgeskart.no/?_ga $=1.575672$ 3.145659876.1423060734\#14/107882/6 839449

http://www.norgeskart.no/? ga $=1.575672$

$3.145659876 .1423060734 \# 14 / 107882 / 6$ 839449

Autoría propia

Autoría propia

Autoría propia

Autoría propia

Autoría propia

Autoría propia

Autoría propia

Autoría propia

Autoría propia

Autoría propia

Autoría propia

Autoría propia

Nedo:1983 Cfr. Bibliografía 
Rosro Cottage, Killary Harbour en Connemara (Irlanda). Wittgenstein pasó algunas semanas en 1934 con Francis Skinner y a solas en 1948, en circunstancias similares a las de su casa en Noruega

Mapa de costa del fiordo de Rosro. Marcamos la isla de Inis Bearna en la que pretendía hacer un refugio para observar las aves

Proyecto de colaboración con David Connearn para la construcción de una pieza artística que representa la casa de los pájaros nunca construida por Wittgenstein, partiendo de la silueta del sótano de la casa de Skjolden proyectándola hasta la cubierta. En proceso, 2015. Casa de campo en Linz (Austria)

Casa de Paul Wittgenstein (1842-1928) en Oberalm, Hallein, Salzburgo (Austria)

Casas noruegas de principios de s XX en Reikiavik, septiembre 2012

Casas noruegas de principios de s XX en Reikiavik, septiembre 2013

Casas noruegas de principios de s XX en Reikiavik, septiembre 2014

Casas noruegas de principios de $s$ XX en Reikiavik, septiembre 2015

Lesley Chamberlain, The philosopher's home from home, en Standpoint, 10.2011

Agnese Bremere, Dette er alt som står att etter den verdskjende filosofen, en NRK Sog og

Fjordane, 09.11.2011

David Connearn \& Dawn Wilson,

Ludwig Wittgenstein - Verortungen eines Genies , Berlín, 03.07.2011

Knut Olav Åmås, Gjenreis filosofens norske hus!, en Aftenposten, 29.07.2012

Universidad de Bergen, Wittgenstein's cabin in Skjolden to be rebuilt, 02.07.2014

Jan Inge Fardal, Viktig avklaring for Wittgensteins hus, en Sogn Avis, 06.06.2015

Acuerdo de compra-venta del terreno del lago entre el propietario Rune Fuglesteg y el alcalde del municipio de Luster, Ivar Kvalen, 20.03.2013

Reportaje sobre la casa de Wittgenstein y Harald Vatne, 11.10.2013

Los hermanos Bolstad, nota manuscrita de Harald Vatne, 14.10.2013

La tranquila seriedad, Skjolden, 13.10.2013

\section{ANEXOS}

A.01 Casa Bolstad alzado suroeste, 1:100

A.02 Casa Bolstad alzado noreste, 1:100

A.03 Casa Bolstad alzado noroeste, 1:100

A.04 Casa Bolstad alzado sureste, 1:100

A.05 Casa Bolstad planta esquemática, 1:100

A.06 Casa Wittgenstein planta baja, 1:100

A.07 Casa Wittgenstein planta ático, 1:100

A.08 Casa Wittgenstein alzado noroeste, 1:100

A.09 Casa Wittgenstein alzado sureste, 1:100

A.10 Casa Wittgenstein alzado suroeste, 1:100

A.11 Casa Wittgenstein alzado noreste, 1:100

A.12 Casa Wittgenstein sección transversal 1, 1:100

A.13 Casa Wittgenstein sección transversal 2, 1:100

A.14 Casa Wittgenstein sección longitudinal, 1:100

A.15 Casa Wittgenstein detalle, 1:50

A.16 «Lago Eidsvatnet, Skjolden, Luster (Sogn)»; Samson Brathole; 1920 (Ant); 12x16 cm; Fylkesarkivet (Leikanger). 11.10.2013. Cód. SFFf-100114.119503

Imagen inédita hasta el mismo día en que se obtuvo del Fylkesakivet. Publicada por el Dagens Næringsliv en el suplemento de cultura D2, p.68-70 Entrevista a Harald Vatne (que proporcionó la fotografía de Brathole al rotativo)

A.17 «12-2-78 Eidsvatnet i Skjolden. Fanaråken I bakgr. Normann»; Normann 1920-1940; 11x15 cm; Fylkesarkivet (Leikanger). 11.10.2013. Cód. SFFf-1990069 Drægni, Dagfinn. La fecha de 1978 es una estampación de una serie de tarjetas postales sobre una foto de los años 30.

A.18 «Eidsvann-Skjolden-Luster. Wilse Anders»; Anders Beer Wilse; 1937; 640x479 pixels; Norsk Folkemuseum (Oslo). Cód. -7211

Material inédito

A.19 Libro de contabilidad manuscrito de Halvard Drægni, fechado en 1914; 32×12 cm, Fylkesarkivet (Leikanger). 11.10.2013. Cód. SFFf-1990069 Drægni, Dagfinn Material inédito

A.20 Anotaciones de gastos de la construcción de la casa de Wittgenstein, anotados por Halvard Drægni, fechadas en 1914; fragmento; Fylkesarkivet (Leikanger). 11.10.2013. Cód. SFFf1990069 Drægni, Dagfinn

Material inédito http://www.bbc.co.uk/programmes/p02g2c $\mathrm{pz} / \mathrm{p} 02 \mathrm{fby} 2 \mathrm{~h}$

Nedo:1983 Cfr. Bibliografía

http://www.kildare.ie/nsac/images/Killary\% 20DiveSite.jpg

Autoría propia

http://immorial.at/wpcontent/uploads/2015/06/62.jpg http://www.villa-wittgenstein.net/villa-in-not David Connearn

David Connearn

David Connearn

David Connearn

Cfr. Bibliografía

Cfr. Bibliografía

Cfr. Bibliografía

Cfr. Bibliografía

Cfr. Bibliografía

Cfr. Bibliografía

http://luster.custompublish.com/cpclass/ru n/cpesa62/file.php/def/13005688d130067 200a7a331/avtale-dat-20-03-13-med-runefuglesteg.pdf

Dagens Næringsliv:2013 Cfr. Bibliografía Harald Vatne

Autoría propia

Autoría propia

Autoría propia

Autoría propia

Autoría propia

Autoría propia

Autoría propia

Autoría propia

Autoría propia

Autoría propia

Autoría propia

Autoría propia

Autoría propia

Autoría propia

Autoría propia

Autoría propia

Fylkesarkivet

Fylkesarkivet

Norsk Folkemuseum

Autoría propia

Autoría propia 
A.21 Anotaciones de gastos de la construcción de la casa de Wittgenstein, anotados por Halvard Autoría propia Drægni, fechadas en 1914; 30x12 cm; Fylkesarkivet (Leikanger). 11.10.2013. Cód. SFFf-

1990069 Drægni, Dagfinn

Material inédito

A.22 Anotaciones de gastos de la construcción de la casa de Wittgenstein, anotados por Halvard Autoría propia Drægni, fechadas en 1914; 30x12 cm; Fylkesarkivet (Leikanger). 11.10.2013. Cód. SFFf-

1990069 Drægni, Dagfinn

Material inédito

A.23 Anotaciones de gastos de la construcción de la casa de Wittgenstein, anotados por Halvard Autoría propia Drægni, fechadas en 1914; 30x12 cm; Fylkesarkivet (Leikanger). 11.10.2013. Cód. SFFf-

1990069 Drægni, Dagfinn

Material inédito

A.24 Anotaciones de gastos de la construcción de la casa de Wittgenstein, anotados por Halvard Autoría propia Drægni, fechadas en 1914; 30x12 cm; Fylkesarkivet (Leikanger). 11.10.2013. Cód. SFFf-

1990069 Drægni, Dagfinn

Material inédito

A.25 Anotaciones de gastos de la construcción de la casa de Wittgenstein, anotados por Halvard Autoría propia Drægni, fechadas en 1914; 30x12 cm; Fylkesarkivet (Leikanger). 11.10.2013. Cód. SFFf-

1990069 Drægni, Dagfinn

Material inédito

A.26 Anotaciones de gastos de la construcción de la casa de Wittgenstein, anotados por Halvard Autoría propia Drægni, fechadas en 1914; fragmento de una de las páginas; Fylkesarkivet (Leikanger).

11.10.2013. Cód. SFFf-1990069 Drægni, Dagfinn

Material inédito

A.27 Secuencia del recorrido desde Camping Vassbakken en Rv55 hasta la Casa de Wittgenstein / Autoría propia sección 01

A.28 Secuencia del recorrido desde Camping Vassbakken en Rv55 hasta la Casa de Wittgenstein / Autoría propia sección 02

A.29 Secuencia del recorrido desde Camping Vassbakken en Rv55 hasta la Casa de Wittgenstein / Autoría propia sección 03

A.30 Secuencia del recorrido desde Camping Vassbakken en Rv55 hasta la Casa de Wittgenstein / Autoría propia sección 04 


\section{Textos traducidos}

01 INTRODUCCIÓN

p. 17 «[...] Cuando haya acabado con el mundo, habré creado una masa amorfa (transparente), y el mundo, con toda su complejidad, se quedará a un lado, como un cuarto trastero nada interesante.»

p. 21 «Estimado Enrique,

Tenían razón, toparse con Wittgenstein es peor que una dosis de Kant, es vírico.»

p. 27 «De Paul Wijdeveld, 31.07.2011

Estimado Sr. Clemente,

Me temo que ya no soy tal especialista, puesto que han pasado 17 años desde la publicación de mi libro...;-) Durante mi investigación, la 'cabaña' en Skjolden guardó en gran parte sus secretos y no pude encontrar mucho más. Profundizar en ello hubiera llevado mucho tiempo y decidí que aquello sería un proyecto separado para otra persona -Sólo utilicé los datos que tuve a mano en mi investigación. Por lo que sé, hasta 1993 no se había hecho ninguna investigación minuciosa y sistemática sobre la historia de la arquitectura de la casa. Los contactos que ha hecho en Noruega y en Cambridge sugieren que después ha habido un renovado interés, lo cual resulta muy interesante; su información es, seguro, más actualizada que la que aporté en mi libro.

Por lo que le deseo éxito, y si encuentra algo nuevo estoy muy interesado en saberlo (mi principal foco de interés actualmente es la formulación de la "geometría de la conciencia y la creatividad" basada en los actuales hallazgos en neurociencia; en los que la última filosofía de Wittgenstein juega un cierto -reducido- papel que es lo que queda de mi interés por su vida y obra).

Saludos cordiales,

Paul Wijdeveld.»

p. 33-35

«Hay casas hermosas,

y hay casas feas.

Hay casas banales,

Y hay casas con espíritu.

Pero en toda casa,

el espíritu sistemático yerra.

Es hermoso observar eso.»

p. 49 «Estimado Enok Kippersund,

He encontrado su sitio web buscando información sobre la cabaña que Wittgenstein construyó en Skjolden en 1913-14.

Soy un arquitecto español y estoy investigando acerca de casas de "grandes pensadores", como Wittgenstein, Jung, Woolf...me parece muy interesante la bibliografía que presenta en su página sobre "Wittgenstein en Noruega", porque no había oído hablar antes de los autores: Åmås y Larsen.

Usted dice en su blog que probablemente haya una versión en inglés de esos libros. He conseguido encontrar el segundo de ellos, titulado "Wittgenstein in Norway" aunque es imposible comprarlo porque está descatalogado. Pero no puedo encontrar "Det stille alvoret: Ludwig Wittgenstein i Norge 1913-1950" en inglés. ¿Sabe si existe versión inglesa de ese libro? ¿Sabe cómo/dónde localizarla? Estaría encantado si me pudiera dar alguna información sobre los libros o sobre la cabaña de Wittgenstein en Skjolden. Estoy tratando de dibujarla pero tengo demasiadas dudas de si voy por el buen camino. No estoy seguro de si realmente existe alguna información gráfica de la cabaña, es demasiado complicado para mí encontrar nada sobre ello aquí en España...

Gracias de antemano,

Enrique»

p. 50 «Estimado Olav Åmås,

Agradezco la información sobre su libro "Wittgenstein in Norway". He tratado de localizarlo en España pero es definitivamente imposible y tampoco he conseguido encontrarlo en venta por internet. Espero hacerme con una copia, porque estoy muy interesado en todo lo referente a la relación de Wittgenstein con Noruega para entender la tranquila gravedad que él necesitaba para trabajar, y el paralelismo entre esa necesidad y las de otros pensadores de la historia para producir su trabajo...pero siempre desde el punto de vista de un arquitecto (reflexión como refugio y el refugio para la reflexión).

También le agradezco mucho que haya informado a David Connearn de mi interés en la cabaña de Wittgenstein. Espero que el Sr. Connearn me pueda dar alguna información sobre el proyecto de reconstrucción de la cabaña.

Saludos cordiales,

Enrique Clemente 
eclemente@ecqestudio.es

[Pongo en copia del mensaje a Enok Kippersund]»

p. 51 «Estimado Enrique,

Tu correo ha sido una sorpresa, una agradable sorpresa.

Intentaré ponerte en contacto con Olav Åmås, que está al frente de la reconstrucción de la cabaña de Wittgenstein. Si lo consigo te enviaré la dirección de Åmås. Espero que sea mañana.

Mis mejores deseos,

Enrique Clemente

Enok»

p. 51 01.07.2011 A Enrique Clemente

«He reenviado su petición a David Connearn, que encabeza este asunto. Det stille alvoret es la historia completa de los años que Wittgenstein pasó en Noruega. Sólo algunas partes de ese libro fueron traducidas al inglés en Wittgenstein in Norway.

Knut Olav Åmås

Redactor de Cultura y Debate

Aftenposten»

\section{p. 51-53 20.07.2011 A Enrique Clemente}

«[...] Creo que tenemos el mismo deseo. Llevo trabajando en la conservación integral del lugar desde 1999, y el principal problema es que no hay otra información pública aparte de la que indicas en tu lista. Por supuesto eso es un deplorable estado de la cuestión, y es absolutamente necesario que se aporte una completa documentación del edificio para conseguir un completo y minucioso detalle de los logros arquitectónicos de Wittgenstein.

Sería necesario conseguir un apoyo internacional solicitando documentación de la casa como un estado preliminar del asesoramiento para la conservación. Si este fuera el caso, espero poder contar con tu apoyo.

Sigamos en contacto,

David»

\section{p. 53 10.07.2011 A Enrique Clemente}

«Estimado Enrique,

Muchas gracias por el interés en mi libro sobre Wittgenstein. Estaría encantado de ayudar y darte tanta información como disponga. En cualquier caso, no puedo hacerlo enseguida porque estoy esperando familiares que van a visitarme desde USA mañana durante una semana, pero te escribiré en unos días.

Mis mejores deseos,

Ivar»

p. 53-55 17.07.2011 A Enrique Clemente

«Gracias por su carta.

Formo parte del grupo que proyecta devolver la casa de Wittgenstein a su emplazamiento original. Le enviaré más información conforme el proyecto avance.

Harald Vatne» 


\section{CONTEXTUALIZACIÓN}

p. 65 «Creo que estuvo hablando durante un rato y seguro que dijo un montón de cosas que no recuerdo. En un momento dado le grité: “¿Qué ocurre? ¿Es que quieres ser perfecto?” Y él se levantó de un salto, gritando: "Por supuesto que quiero ser perfecto".»

p. 65 «iDígales que he tenido una vida maravillosa!»

p. 67 «Cuando tenía 8 o 9 años que si no fue decisiva para el resto de mi vida, sí fue típica del tipo de vida que llevaba entonces. Cómo ocurrió no lo recuerdo: Sólo me acuerdo de mí mismo en el umbral de la puerta de nuestra casa y pensando: ¿por qué decir la verdad si es mejor para uno decir una mentira? No pude encontrar nada en contra de ello.»

p. 69 «Me propuso leer Sexo y carácter diciéndome que era el trabajo de un genio considerable.»

p. 73 nota 20 «El hielo se asociaba con heroísmo, peligro y quizá pureza.»

p. 81 nota 28 «Él me resulta intelectualmente más cercano que nadie que haya conocido, pero aún así estaré agradecido de verlo marchar.»

p. 85 «Él está en este momento haciendo planes para construirse una pequeña casa allí.»

p. 85-87 «A G. E, Moore, 18.02.1914

[...] Debe venir en cuanto acabe el Trimestre y le recogeré en Bergen. ¡Estoy deseando que venga más de lo que puedo expresarle! Estoy preocupado por morir por culpa de la Lógica y otras cosas. Pero espero que no muera antes de que pueda usted venir porque en ese caso no habrá mucho de qué hablar.»

p. 89 «Era Kari quien llevaba el té de la tarde a Wittgenstein mientras planeaba su casa en la ladera de roca del lago Eids.»

p. 91 «Mi casa es tuya.»

p. 95 «La naturaleza es maravillosa en todos los sentidos.»

p. 107 nota64 «¡Hola! Ese artículo se lo podemos enviar como copia impresa. Pero el texto será sólo en noruego. El autor, Harald Vatne, está terminando un nuevo libro sobre L.W. en Skjolden en el que cuenta también la historia de la casa (o de la cabaña como muchos parroquianos la conocen). Por favor envíeme su dirección de correo. Le agradezco el interés por la historia de L.W. en Skjolden, Noruega. Saludos cordiales, Erling Bjørnetun, Jefe de Sección de Cultura.»

p. 111 nota68 «Crucero desde la costa, 66 millas hacia el interior hasta el pueblo de Skjolden, población 300. Cruzamos este maravilloso fiordo en el Emerald Princess con 3000 pasajeros y amarramos en un pequeño muelle. No hay mucho que hacer en Skjolden, excepto dar una vuelta por el pueblo y disfrutar de los maravillosos alrededores....” 


\section{PROYECTO}

p. 141 «Wittgenstein necesitaba vistas lejanas para dejar que sus ojos se preguntaran cosas.»

(N.B. La traducción de las palabras de Nedo les hace perder parte de su lirismo)

p. 149 «La casa era de madera, de 27 pies por 24 pies, a un centenar de yardas del lago. En algún momento (puesto que vivió allí después) Wittgenstein fijó un cable para traer agua y otras mercancías hasta la casa desde el lago. La entrada estaba en el lado opuesto al algo, bajo un alero, en la sala; abierta a ella a la derecha había un dormitorio y una cocina.»

"La cabaña también podía ser llamada casa. Wittgenstein se refería a ella a veces como "casa" y a veces como "cabaña". Sus dimensiones eran las típicas de un aparcero noruego, con 7 x 8 metros de planta. El hecho de que el hastial apuntara hacia el pueblo era peculiar en el área, como lo era el hecho de que hubiera un porche en el mismo lado, dando al lago Eids. En la parte posterior había un pequeño patio.»

«Lars, un niño en los años treinta, visitó la cabaña y recuerda que estaba amueblada con mucha sencillez; una mesa con algunas sillas, una estufa, lámparas de aceite y un altillo para dormir.»

p. 153-155 «Respecto al otro asunto, lo comprendo y se lo agradezco también. Pero usted debe entender que desde hace unos años (aunque el año pasado lo invité a una modesta cena en Siena con un colega de Oxford, cena que organicé después de un "evento" wittgensteiniano pero en el que no pude participar por motivos de salud) no tengo contacto personal con Brian. Brian es una persona amabilísima y exquisita, pero creo que nació en 1926, por tanto tendría la edad de mi padre, si este estuviera todavía vivo. Creo que se encuentra bien pero, como me temo por propia experiencia, encontrarse bien y estar lúcido a una edad por el estilo significa estar lleno de achaques, pequeños o grandes.

Me niego por tanto (aparte del hecho de que he perdido su número de teléfono móvil) a ponerle en contacto directo. Yo y cualquiera de nosotros en Siena le deseamos que esté bien e intentamos tener alguna noticia suya, eso es todo. [...]

Discúlpeme y le ruego salude a todos de mi parte, quedando a su disposición.

Suyo,

Giuseppe Varnier.»

p. 159 «[...] ¿Puedo preguntar a qué se refiere con el "porche”(p.29) que daba al lago? ¿Se refería a la balconada del piso superior?

SÍ

¿Y el "patio" en la parte posterior, se refiere a una puerta protegida con un cortavientos?

Sí

¿O había algún tipo de pared exterior a la casa?

He tratado también de conseguir "Ludwig Wittgenstein i Skjolden" de Harald Vatne, que usted nombra en su libro pero ha sido imposible..No sé si en ese libro hay más información sobre la casa.

ESO ES SÓLO UN FOLLETO. NO HAY INFORMACIÓN EXTRA SOBRE LA CASA EN ÉL. [...]»

p.161 «Estimado Enrique Clemente,

Muchas gracias por su interés y sus preguntas. No puedo darle más detalles de la cabaña de los que aparecen en mi libro. Lo único que puedo decirle es que la letrina estaba a unos 20 metros de la cabaña. Mencioné que había un cable, en algún lugar, cerca de la cabaña, hasta el agua. La fotografía de Ben Richards - en un nuevo libro titulado Verortungen eines Genies, Ludwig Wittgenstein, publicado por Junius Verlag 2011- muestra claramente la línea.

(La fotografía tomada por el fotógrafo local era demasiado pequeña e inútil). Le envío un artículo relevante de ese libro de Dawn Phillips y David Connearn por correo postal hoy mismo. Siento que el artículo está escrito en alemán, pero es una publicación importante. La persona con la que debe contactar principalmente es David Connearn.

Saludos cordiales,

Ivar Oxaal.»

p. 165 «Vatne me contó que durante la Segunda Guerra Mundial muchas personas acudían a la casa, incluyendo Boy-Scouts. Podías reunirte allí sin que te oyeran los alemanes.»

p. 169 nota 38 «Acabo de publicar una biografía sobre Wittgenstein con alguna información desconocida hasta la fecha sobre la casa de Wittgenstein en Skjolden: "Wittgenstein - Ein Biographisches Album", C. H. Beck, Múnich, que estará disponible en las librerías a finales de agosto.»

p. 171 «Estimado Enrique Clemente-Quintana,

Como le prometí, adjunto las fotos de Ben Richards de la casa de Wittgenstein en Skjolden, entendiendo que únicamente las utilizará para su trabajo de doctorado. 
Mis mejores deseos,

Michael Nedo

(Director del Wittgenstein Archive Cambridge)»

p. 173 «Mientras comíamos los finos bocadillos Wittgenstein alababa los productos de Woolworth’s. Él había comprado allí una cámara por piezas a 6 peniques la unidad, en total dos chelines -un instrumento excelente.»

p. 175 «Creo que [Nedo] se sorprenderá, y se alegrará de ver a W en la ventana. Nadie ha mencionado esto nunca antes. Es una primicia. ¡Buen trabajo!

Pero ¿por qué no podemos ver con la misma claridad los malditos troncos? (maldito es la palabrota preferida).»

p. 183 «Estimado Sr. Clemente,

Acabo de recordar que el Sr. Rudy Vrooman, que también me proporcionó cierto número de importantes fotos de detalles originales de la Casa Wittgenstein que se habían perdido durante la restauración, también viajó a Noruega en su juventud para buscar la casa de Wittgenstein (era mucho más grande que una cabaña) en Skjolden y conoció a las personas a las que W había dejado la casa. Le sugiero que contacte con él también. Su dirección es:

Dele recuerdos de mi parte,

Saludos cordiales,

Paul Wijdeveld.

P.S. El lema de mi bisabuelo H.Th. Wijdeveld, arquitecto de la Escuela de Ámsterdam y amigo de Frank Lloyd Wright, también era "panta rhei"; la filosofía en la que trabajo en este momento, basada en los más recientes descubrimientos en neurociencia, podrían también caracterizarse como "panta rhei" en el más puro sentido heraclitiano.»

p. 185 «Muchas gracias por la tarjeta que me envió. Estoy bien últimamente. El bote está en buen estado. Su casa está ya terminada, y desearía que estuviera aquí en Noruega en lugar de en Austria [...].»

p. 193

«Longfellow:

En los viejos tiempos del arte,

Los constructores trabajaban con gran esmero

Cada pequeño y oculto detalle,

Porque los dioses están por todas partes.»

p. 209 «David,

Sí. He pensado mucho por qué demonios había ventanas de 42 pulgadas.

Uno de los problemas para mí era que las de 48 pulgadas no encajaban bien en el hastial del balcón. Es mejor tener ahí ventanas de 42 pulgadas y así la pared también quedaría más fuerte.

$\mathrm{Si}$ alguna de las ventanas de 42 pulgadas fue a la casa reconstruida, tenían entonces dos medidas diferentes. Una razón adicional para fabricar más ventanas de 42 pulgadas.

Respecto a las ventanas de la fachada oculta, he probado ambas posibilidades: encajando directamente en el centro "el eje de una ventana de $600 \mathrm{~mm}$ " queda internamente simétrica la fachada recayente al lago. Pero entonces la cocina no. Si intento dar la vuelta $180^{\circ}$ a la situación de las dos ventanas de $600 \mathrm{~mm}$ entonces la fachada de la cocina es perfectamente simétrica, pero la ventana de 48 pulgadas no (lado izquierdo $108 \mathrm{~cm} \mathrm{y}$ derecho $52 \mathrm{~cm}$ ).

Así que todavía estoy intentando encajar algo por ahí puesto que como tú, opino que los alzados de $7 \mathrm{~m}$ de la casa reconstruida deben parecerse al menos a los originales.

Estoy trabajando duro probando a cerrar una tabla de correspondencia entre las ventanas de la Casa BolstadVatne-Casa original. Pero cada nueva decisión como la que te he comentado de las de 42 pulgadas me obliga a cambiar todos los dibujos. Espero enviártela esta noche.

Quizá las ventanas de 42 pulgadas fueran un estándar en aquel tiempo (1957). Las ventanas del semisótano tienen sólo el lado izquierdo móvil.

Quizá esas estaban disponibles en el almacenista. Ni idea.

Hasta que sepamos más de la historia de la casa reconstruida creo que seguiremos dándonos contra un muro.»

p. 213 «Lo que más me interesó de Islandia fue esto:

Las casas tipo kit que formaban Reikiavik son noruegas. Algunas fueron transportadas realmente flotando como cascarones. Están mucho más cerca del diseño de la casa de Wittgenstein en Skjolden que ninguna otra construcción local de Skjolden.»

p. 213 «Fue Halvard Drægni quien coordinó los trabajos de construcción en 1914. Si se basó o no en planos arquitectónicos no podemos estar seguros, pero su hijo Bjarne cree que la respuesta a ello es que no. Considera que el carpintero construyó la casa a partir de un boceto.» 
p. 217 «"¿Cómo se colocaron en su sitio esos grandes bloques? Pregunté. ¿No fue peligroso para los trabajadores?" "Sí, en especial porque Wittgenstein no permitió el uso de dinamita." Lars pensaba que el rey sueco de la dinamita, Alfred Nobel, estaba en la lista negra de Wittgenstein: Premio de la Paz o no, la invención de Nobel podía ser causa de una guerra. Fuera un método u otro el que usaron para construir la cimentación, debió ser un trabajo durísimo.»

p. 221 «Enrique,

Creo que me quito el sombrero ante ti con respecto a las 8 pulgadas.

He dedicado la noche con un amigo fotógrafo a manipular las imágenes.

Los escaneos de Michael Nedo están filtrados y probablemente podamos obtener más información si las refotografiamos.»

p. 239 «Estimado Enrique,

Que idea tan maravillosa y difícil. Siento decir que no te puedo ser de mucha utilidad.

En 1978 visité Skjolden y conocí a personas que recordaban a Wittgenstein cuando estuvo allí. Tras la muerte de W la casa pasó a manos de Arne Bolstad que había conocido a W desde que este llegara a Noruega. Si no recuerdo mal, el padre de Arne Bolstad ayudó en la construcción de la casa. Arne cuidó de la casa lo mejor que pudo en los periodos de ausencia de W. Me dijeron que era un lugar muy popular entre la juventud como nido de amor y para celebrar fiestas familiares. Puesto que estaba hecha con material de primera calidad Arne desmontó la casa en los años cincuenta para reconstruirla él mismo: especialmente por el tejado. Nada queda ya en el lugar original.

Conocí a un periodista noruego alcohólico que había escrito algunos artículos sobre la estancia de W en Skjolden. De las personas que habían conocido a $\mathrm{W}$ consiguió objetos que nunca devolvió. Me enseñó algunas cosas. Algunas eran interesantes desde el punto de vista biográfico, pero nada tenía que ver con la casa.

$\mathrm{Ni}$ fotos, ni nada...

Por tanto siento no poder ayudarte en nada más. Te puedo hacer una sugerencia:

Intenta conseguir información en el Ayuntamiento de Skjolden. Quizá en su Registro de la Propiedad hay documentación o un permiso de obras del tiempo en que se hizo.

Te deseo éxito y me encantaría que me tuvieras al tanto de este proyecto tan interesante.

Saludos cordiales,

Rudy.»

p. 243 «Ms 119.139 [4] et140 [1] et141 [1] et142 [1];...El lago ha cambiado su color. Hasta ahora, es decir, este verano y otoño, azul o azul-verde; Ahora es verde parduzco (aunque el cielo se ve azul algunas veces)...Tormentas y...lluvia... Estuve en las montañas ayer y nevó, ahora se descongela arriba. La tormenta es siempre desagradable para mí; me molesta porque me asusta cuando trabajo. Sin embargo, tal vez sea bueno para mí. Había una trampa para el ratón en la habitación, sobre un estante; Debajo había una bolsa de virutas de madera. De repente oí un gritito en la habitación, pensé que el ratón estaba atrapado y fui con un bastón, asustado, con la intención del matar rápidamente al ratón y no hacerlo sufrir. Tenía miedo, pero viéndolo. ... Cuando entré en la habitación......ya no estaba el queso en la tabla y fui a ver el saco antes, ya que gritó por ahí ... Vacié la madera fuera de la bolsa porque no podía ver nada en ella. Y lo hice con sumo cuidado porque tenía miedo del ratón, tal vez miedo de ser mordido. Cuando tenía varias piezas de madera fuera vi un pequeño pájaro que había entrado por la ventana y había recogido el queso en la trampa. Todavía estaba vivo pero sangraba un poco por la cabeza. ... Lo liberé tan rápido como pude y voló...... chocando contra la ventana, contra el techo y al final voló por la ventana hacia el exterior. ... Que pudiera soportar los golpes es incomprensible, pero se fue volando. Volví a la sala y me avergoncé por mi cobardía.»

p. 245 «-Enrique: ... Ich befreite sie so schnell ich konnte \& sie flog.......auf stieß sich am Fenster, an der Decke $\&$ flog endlich beim Fenster heraus".

¿Significa eso que el pajarillo mencionado unas palabras más arriba salió por una VENTANA EN EL TECHO?

-Alois: Podría, pero no necesariamente. La cuestión es: si la ventana no estaba en el techo, ¿por qué chocaría el pájaro contra el techo? No conozco el comportamiento de los pájaros cuando están atrapados en una habitación -¿vuelan hacia el techo si no hay una ventana allí? Quizá sí.

-E: El comportamiento de los pájaros es siempre nervioso. Quiero decir que incluso si había o no una ventana en el techo o si W está refiriéndose a una ventana de fachada, dice que el pájaro estaba herido, ¿no? Entonces quizá él (el pájaro) chocaba contra el techo buscando una salida.

Me pregunto si la coma significa exactamente lo que estoy buscando: sich am Fenster, an der Decke $=$ en/hacia la ventana, en/del techo....ंTe parece que tiene sentido esto? Por favor dame tu opinión.

Si la coma no cambia el sentido de la frase, W podría estar hablando de un falso techo en planta baja por tanto las ventanas serían las de ese nivel, pero si la coma significa una ventana en el tejado, podría haber estado trabajando en el altillo (como sabemos que le gustaba hacer) y entonces podría ser de nuevo una ventana en el tejado. 
-A: Eso significa: el pájaro se golpeó con la ventana Y contra el techo. Si W hubiera querido decir explícitamente am Fenster an der Decke (=ventana de techo), no habría puesto la coma. Pero el modo en que la puso, *no* excluye que hubiera una ventana en el tejado, tampoco.

¡Mis mejores deseos! Alois.»

p. 251 «Una anotación interesante es que el bisabuelo de Connie era amigo del filósofo Ludwig Wittgenstein, que pasó mucho tiempo en Skjolden. Gyda tiene incluso su mesa en la cocina.»

p. 253-255 «iHola amigos!

Enrique: -Escaleras. Os mando dibujos con algunas opciones. Por favor vamos a comentarlas: ST01 y ST02 reproducen la forma de la actual escalera de la Casa de Bolstad (la que describe mi acuarela)...hay una extraña columna estrecha con algunas marcas que parecen espacios para alojar peldaños pero no encaja por completo con una distribución lógica (puesto que gira hacia la derecha en lugar de hacia la izquierda...) ST03 podría ser una propuesta bastante arquitectónica y racional para la pared ciega. Una puerta tipo trampilla arriba o al menos una puerta en la cocina sería necesaria por motivos de calefacción. Las únicas dos referencias al espacio interior de la $\mathrm{OH}$ (McGuinness p. 202 Edición Penguin y Oxaal p. 150 de Transaction) no dicen nada sobre la escalera. Mi razonamiento desde el primer momento fue que la escalera no era visible/importante, por lo que mi primera (2011) aproximación fue colocar una escalera de mano y ahora una escalera dentro de la cocina...pero no es algo que soporte nuevos descubrimientos, opiniones, etc etc.

D. Wilson: -Hola Enrique,

¿Cómo es el espacio de arriba? Me pregunto adónde desembarca la escalera arriba. Si hay más de una habitación arriba tendría sentido (sentido según mi forma de pensar) si sale a un rellano que está en el eje central, más que en una esquina. En caso contrario sería necesario atravesar una habitación para acceder a las otras.

Caigo en la cuenta, preguntándome esto, que esto encaja con tu reflexión sobre si hay un único espacio o dos detrás de las dos ventanas del balcón.

Saludos, Dawn

E: Hola Dawn, tienes razón.

Si salimos de la escalera en la zona de la pared tienes que atravesar una habitación para entrar en la que da al balcón, por ejemplo. He dividido el espacio de arriba en dos. Pero la asimetría de las ventanas frontales (sobre la puerta de entrada) es difícil de encajar sin más paredes. Otra posibilidad para el ático es tener una habitación frontal dando al balcón, una habitación con la ventana doble panelada y una especie de rellanohabitación al que sube la escalera con dos ventanas individuales...pero todo suena un poco liado. El mayor problema es exactamente ese. La planta baja está más o menos clara, pero la situación de las escaleras es totalmente desconocida y aún peor porque podría estar en muchos lugares diferentes y eso obviamente afecta a la distribución del ático. Si esta fuera una casa noruega, el propósito del ático sería un espacio común para dormir, una escalera de mano, etc. Pero el 'estilo' aquí es distinto. O eso parece. Y si es así sólo hay dos posibilidades puesto que toda la superficie de arriba estaba construida: 1.- Usar una habitación como rellano y espacio de paso hacia la estancia del balcón (o estancias) o 2.- Tener una distribución más densa y dos o tres espacios arriba y además un rellano-distribuidor.

En cualquier caso usar unas habitaciones para pasar a otras es bastante usual (mi casa por ejemplo).

Así que...

Se requiere pensamiento transversal para desenredar todo este asunto de los tabiques.

E.

PS: Cuando os comenté que la luz que se veía a través de las dos ventanas del ático era idéntica, considerando esto como que debía haber un único espacio detrás de ellas era una propuesta reflexionada. Pero, ¿qué pensar si esas superficies idénticas lo que nos muestran en realidad son persianas cerradas?

Aún hay un montón de trabajo por resolver aquí, amigos. ¿Qué problema!.»

p. 257 «Estimados Srs.,

Soy un arquitecto español y desarrollo una investigación sobre la casa de Wittgenstein en Skjolden, Noruega (de 1914). Cuando visité el lugar y los restos, encontré algunos viejos ladrillos fabricados por su empresa, Höganäs. Había ladrillos refractarios (rojos) y normales (amarillos). ¿Sería posible para ustedes darme información adicional sobre ese material? Composición, fecha de fabricación, distribuidores en Noruega en aquellos años... ¿Tienen un archivo en su empresa donde me pueda dirigir para solicitar este tipo de información? Muchas gracias de antemano.

Enrique Clemente-Quintana.»

«Estimado Sr.Clemente-Quintana,

Gracias por su correo acerca de los viejos ladrillos Höganäs que encontró en Noruega. Esto es muy interesante desde el punto de vista histórico también para nosotros. 
Para ayudarnos en la búsqueda en los archivos ¿podría enviarnos algunas imágenes de los ladrillos? Deberían tener una marca con el nombre y el código de producción impresos en la superficie del ladrillo. Si esta información es todavía legible podríamos hacer un trazado de la historia del ladrillo.

Espero noticias suyas.»

p. 259 «Estimado Sr.Clemente-Quintana,

Sí, nos llegaron las fotografías, gracias.

Se las he reenviado a nuestro Director que estaba muy interesado en ellas, él es noruego. Espero verlo hoy un poco más tarde. Le haré un seguimiento de cómo va todo.»

«Estamos trabajando en ello, pero esto parece todo un desafío. Sin embargo tan pronto tenga más información me pondré en contacto con usted.

Disculpe por el tiempo que está llevando todo esto.»

«Estimado Sr. Clemente,

He estado llevando un seguimiento de esos ladrillos por los que preguntó hace algún tiempo. Como le escribí anteriormente es un auténtico desafío, itanto es así que tenemos que acabar de un modo u otro!

Por las imágenes estamos seguros de que eran algún tipo de ladrillos refractarios pero no de alto grado. En cualquier caso la única referencia que podemos ver es el nombre de Höganäs y el sello. Producimos y hemos producido muchas calidades de ladrillo diferentes por lo que es difícil a partir de las imágenes determinar cuáles son.

Sobre cuándo fueron fabricados, es casi imposible de saber si no conocemos el tipo de ladrillo de que se trata. Siento no poder darle más ayuda con esto por el momento.

Saludos cordiales.» 
«Tuve los mejores maestros de mi generación, y de todos aprendí algo: De Kraus, a no escribir; de Wittgenstein, a no hablar; de Loos, a no construir.»

(Paul Engelmann, en Jorge Riechmann, La habitación de Pascal (Barcelona: Los libros de la Catarata, 2009) 



\section{EL PROYECTO DE \\ LA CASA DE LUDWIG WITTGENSTEIN \\ EN SKJOLDEN, NORUEGA}

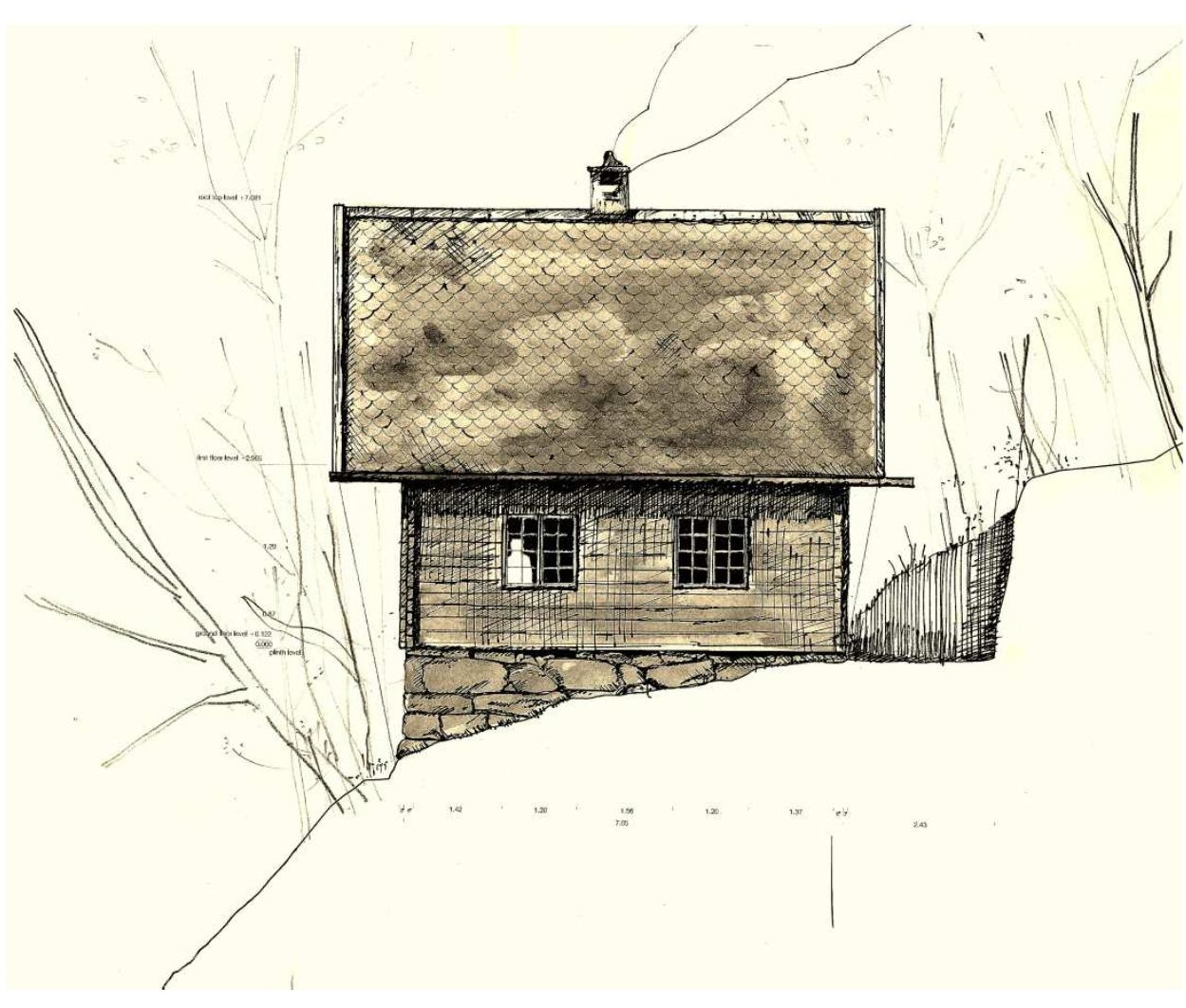


TESIS DOCTORAL

Enrique Clemente Quintana, arquitecto Universidad Politécnica de Valencia_09/15

En 1914, el filósofo Ludwig Wittgenstein (1889-1951) proyectó e inició la construcción de una casa de madera en la escarpada ladera del lago Eidsvatnet en Skjolden, Noruega. En esa pequeña villa, Wittgenstein había encontrado la tranquilidad necesaria para trabajar en lógica. Sin embargo sus planes de instalarse en Noruega se vieron truncados por el estallido de la Primera Guerra Mundial y sólo ocupó la casa en algunas visitas a lo largo de su vida, la última de ellas cinco meses antes de morir en Cambridge. Pese a ello, la casa de Skjolden fue central en el desarrollo del pensamiento de Wittgenstein y el único lugar en el que de verdad se sintió capaz de trabajar. Hasta hoy, la relación entre Wittgenstein y la arquitectura se había limitado a la casa de Viena que construyó para su hermana Margaret en 1929 en colaboración con el arquitecto Paul Engelmann. Esta tesis desarrolla por primera vez el proyecto de la única casa que el filósofo pensó y construyó para sí mismo, certifica su compromiso ético con la arquitectura, recalifica como hiciera Loos, la arquitectura vernácula y plantea elementos que anticipan soluciones que aplicaría años más tarde en la casa de Viena. 